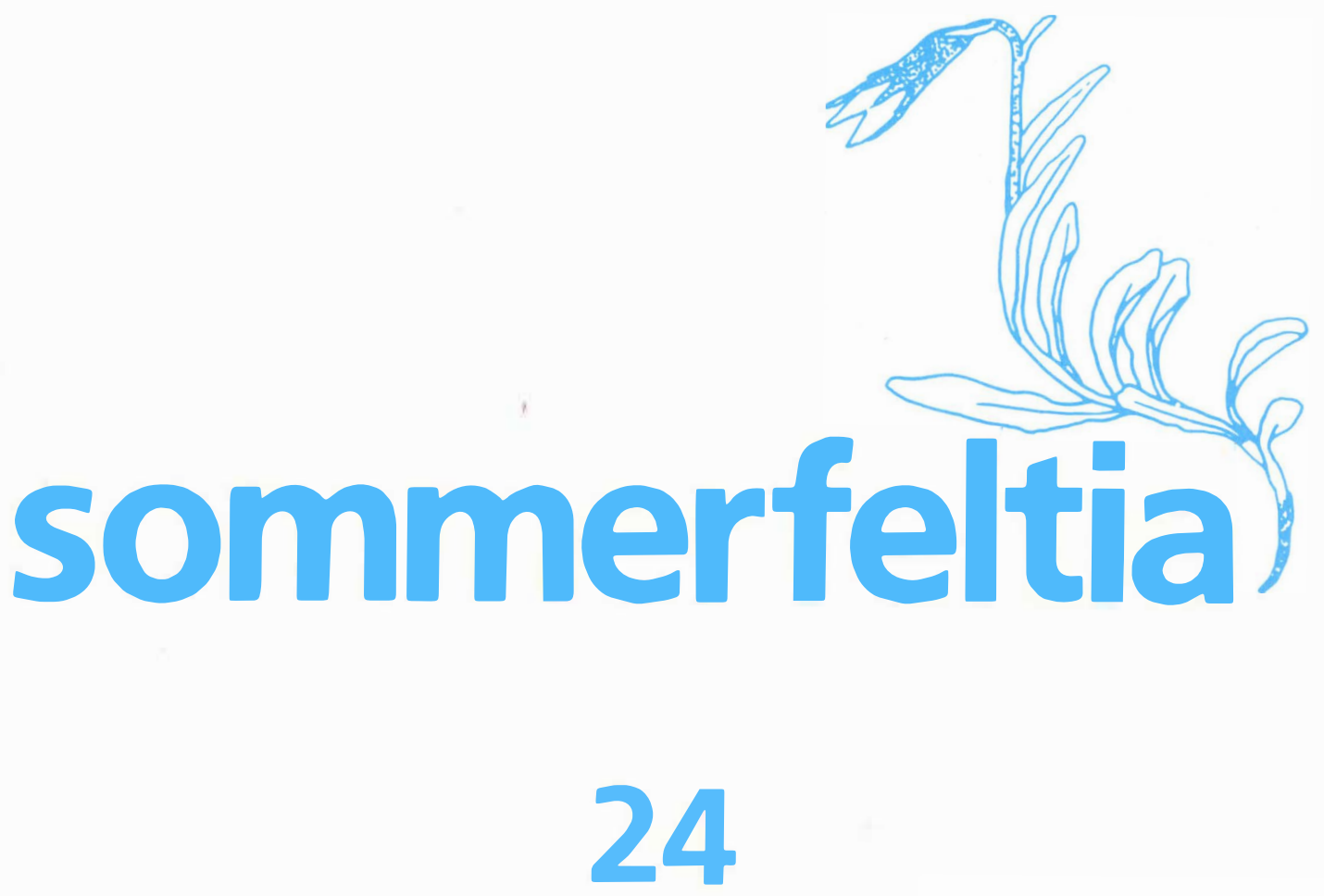

C. Brochmann, $\varnothing . H$. Rustan, W. Lobin \& N. Kilian

The endemic vascular plants of the Cape Verde Islands, W Africa

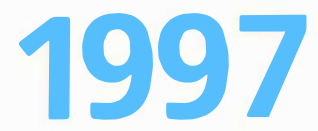




\section{sommerfeltia}

is owned and edited by the Botanical Garden and Museum, University of Oslo.

SOMMERFELTIA is named in honour of the eminent Norwegian botanist and clergyman Søren Christian Sommerfelt (1794-1838). The generic name Sommerfeltia has been used in (1) the lichens by Flörke 1827, now Solorina, (2) Fabaceae by Schumacher 1827, now Drepanocarpus, and (3) Asteraceae by Lessing 1832, nom. cons.

SOMMERFELTIA is a series of monographs in plant taxonomy, phytogeography, phytosociology, plant ecology, plant morphology, and evolutionary botany. Authors of Norwegian institutions other than the Botanical Garden and Museum in Oslo pay a page charge of NOK 30 , other authors pay NOK 100 per printed page.

SOMMERFELTIA appears at irregular intervals, normally one article per volume.

Editor: Rune Halvorsen Økland.

Editorial Board: Scientific staff of the Botanical Garden and Museum.

Address: SOMMERFELTIA, Botanical Garden and Museum, University of Oslo, Trondheimsveien 23B, N-0562 Oslo 5, Norway.

Order: On a standing order (payment on receipt of each volume) SOMMERFELTIA is supplied at $30 \%$ discount.

Separate volumes are supplied at the prices indicated on pages inserted before the back cover.

Copyright: The author(s) \& Botanical Garden and Museum, University of Oslo 


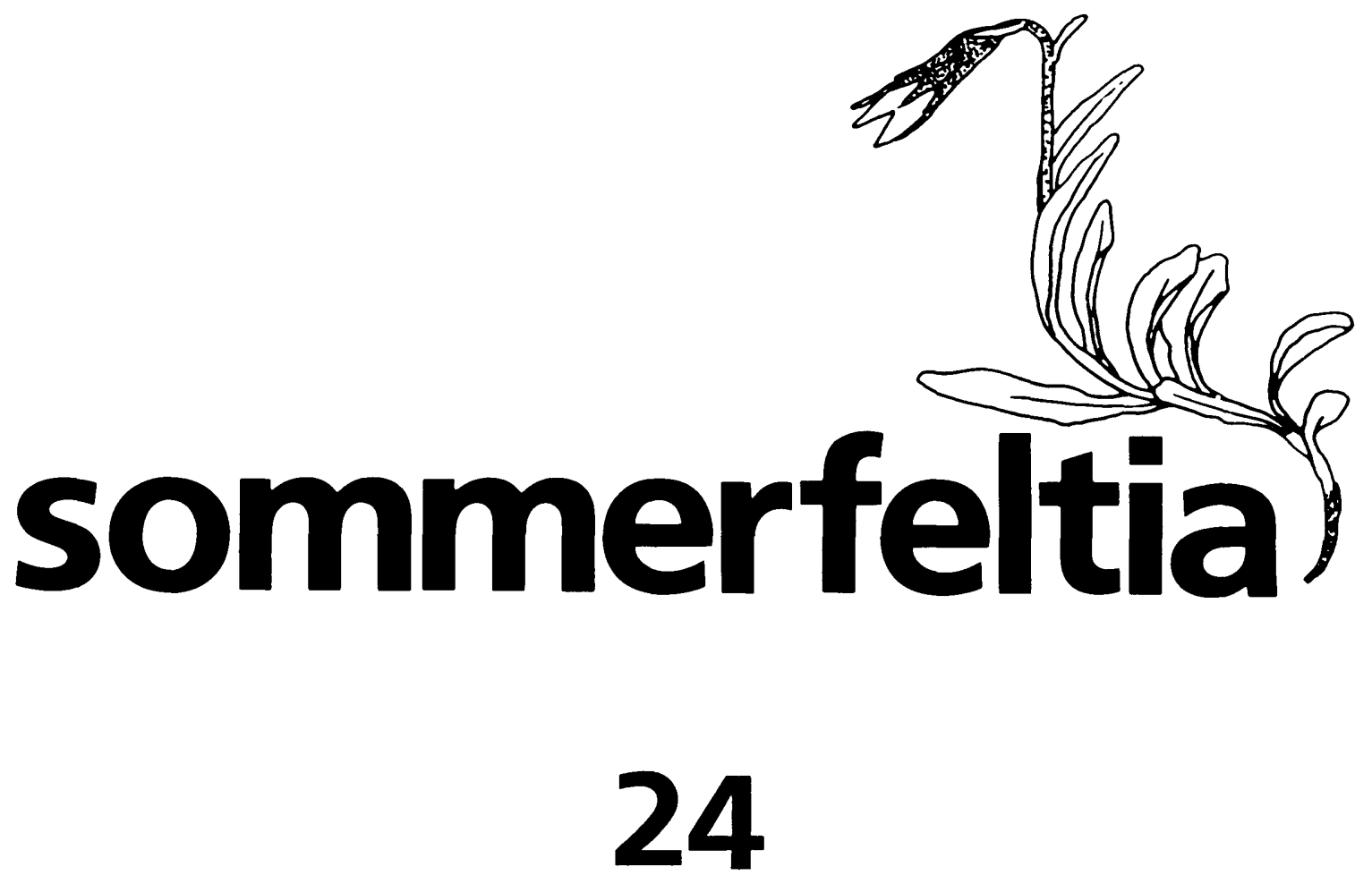

C. Brochmann, Ø.H. Rustan, W. Lobin \& N. Kilian

The endemic vascular plants of the Cape Verde Islands, W Africa

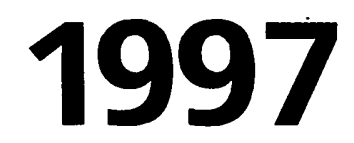


"Virtually all plant and animal species that have ever lived on the earth are extinct."

Raup, D. M. 1986. Biological extinctions in earth history.

- Science 231: 1528-1533.

ISBN 82-7420-033-0 
Brochmann, C., Rustan, Ø. H., Lobin, W. \& Kilian, N. 1997. The endemic vascular plants of the Cape Verde Islands, W Africa. - Sommerfeltia 24: 1-356. Oslo. ISBN 82-7420-033-0. ISSN 08006865 .

The archipelago of Cape Verde consists of nine main islands of oceanic origin situated $500 \mathrm{~km}$ west of the African mainland. The present study aims at increasing our knowledge of the endemic vascular flora and its origin and evolution, and at providing a scientific basis for its protection. One endemic genus (Tornabenea) and 82 endemic species and subspecies were accepted, including one new species in Tornabenea (T. humilis) and three new combinations in Campylanthus and Kickxia. Morphological descriptions, illustrations, typifications, chromosome numbers, phyto- and ecogeographic information, and conservation status, based on field-, herbarium-, garden-, and literary studies, are provided. The degree of endemism was $10.5 \%$ at the species level. The endemic flora had a mixture of holarctic (65\%, including $15 \%$ in a NW-Moroccan element) and tropic $(35 \%)$ affinities. Thirty-three Capeverdean endemics $(40 \%)$ were most closely related to taxa with a Canaro-Madeiran distribution. The endemic flora was divided into five distributional elements (northern, western, southern, eastern, and ubiquitous; with 26,21, 15,3, and 17 taxa, respectively) and three ecological elements (hygrophytic, mesophytic, and xerophytic; with 31, 34, and 17 taxa, respectively). Although distributional patterns corresponded closely to geographic positions of island groups, the patterns could be sufficiently explained by ecological factors. Endemic species richness was strongly correlated with humidity and maximum island altitude. The tropic proportion decreased with increasing altitude and humidity. More than half of the endemic flora is presently threatened (Red List taxa), and 16 single-island extinctions were recorded.

The proportion of polyploids was $27 \%$ based on $63 \%$ of the endemics, which is similar to the proportion in the endemic Canarian flora. Most taxa $(90 \%)$ were schizoendemic diploids or mesopolyploids, typically differentiated ecogeographically among islands and along humidity gradients. This pattern has frequently been complicated by parallel inter-island evolution along similar gradients, and many ecogeographically ubiquitous mesophytes showed large and complex interpopulational variation. In such cases, differentiation along continuous, steep, and tree-less coast-mountain gradients of humidity has resulted in eco-morphological clines of populations rather than classic adaptive radiation into distinct taxa.

Contrary to previous beliefs, we suggest that the present Capeverdean flora is very young, possibly only a few hundred thousand years old. It contains no palaeoendemics in the strict sense, only a single endemic genus, and most endemic taxa are only slightly differentiated morphologically from their sister groups. This conclusion is supported by recent geological, palaeontological, and molecular data. A possible scenario with origins and extinctions of successive Capeverdean floras is outlined, following the dramatic fluctuations between wet and dry climates in northern Africa during the Quaternary. The present flora was probably founded by two main waves of immigrants, both via dispersal from (north-)western Africa, but in different climatic periods.

Keywords: Cape Verde Islands, Taxonomy, Endemism, Conservation, Island evolution, Ecogeography.

Christian Brochmann and Øyvind H. Rustan, Botanical Garden and Museum, University of Oslo, Trondheimsveien 23 B, N-0562 Oslo, Norway. - Wolfram Lobin, Botanisches Institut und Botanischer Garten, Rheinische Friedrich-Wilhelms-Universität Bonn, Meckenheimer Allee 171, D53115 Bonn, Germany. - Norbert Kilian, Botanischer Garten und Botanisches Museum BerlinDahlem, Königin-Luise-Strasse 6-8, D-14191 Berlin, Germany. 


\section{CONTENTS}

INTRODUCTION 10

STUDY AREA 12

GEOGRAPHY AND GEOLOGY 12

CLIMATE AND ZONES OF HUMIDITY

$\begin{array}{ll}\text { VEGETATION } & 15\end{array}$

MATERIALS, METHODS, AND TERMINOLOGY …….............................. 19

MATERIALS 19

MORPHOLOGY AND TAXONOMY 19

PHYTOGEOGRAPHY 21

ECOLOGY AND ECOGEOGRAPHY 21

KARYOLOGY 25

CONSERVATION 26

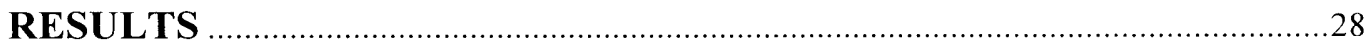

SYSTEMATIC OVERVIEW $\quad 28$

PHYTOGEOGRAPHY 28

DISTRIBUTIONAL PATTERNS $\quad 36$

Individual island floras, areas, and altitudes 36

Floristic similarity between islands $\quad 39$

Distributional elements $\quad 42$

ECOLOGY AND ECOGEOGRAPHY $\quad 44$

Humidity, altitude, and diversity $\quad 44$

Ecological groups $\quad 47$

Ecogeography 48

The northern element 49

The southern element $\quad 50$

The western element 50

The ubiquitous element $\quad 50$

The eastern element 51

RELATIONSHIPS BETWEEN PHYTOGEOGRAPHY AND ECOGEOGRAPHY 51

RELATIONSHIPS BETWEEN MORPHOLOGICAL AND ECOGEOGRAPHIC VARIATION $\quad 55$

KARYOLOGY

CONSERVATION

General conservation status $\quad 55$

Conservation status of individual island floras $\quad 59$

Conservation status and ecogeography 63

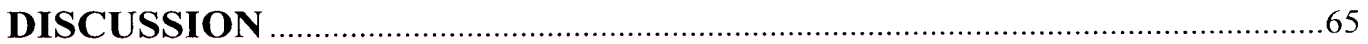

KARYOLOGY $\quad 65$ 
Proportion and types of polyploids $\quad 65$

Types of endemics $\quad 66$

$\begin{array}{ll}\text { Schizoendemics } & 66\end{array}$

$\begin{array}{ll}\text { Patro- and apoendemics } & 66\end{array}$

$\begin{array}{ll}\text { THE PRESENT FLORA IS PROBABLY YOUNG } & 67\end{array}$

The level of endemism is low: age or ecology? 68

The striking absence of palaeoendemics $\quad 69$

The low level of polyploidy gives no evidence of an ancient flora 70

Recent geological, palaeontological, and molecular data: further evidence of a $\begin{array}{ll}\text { young flora } & 71\end{array}$

Origins and extinctions of successive Capeverdean floras - a possible scenario 73

$\begin{array}{ll}\text { PATTERNS OF EVOLUTION } & 74\end{array}$

Relative importance of adaptive radiation, inter-island vicariance, polyploid evolution, and hybridization $\quad 74$

Adaptive radiation: typically clinal in widespread groups $\quad 76$

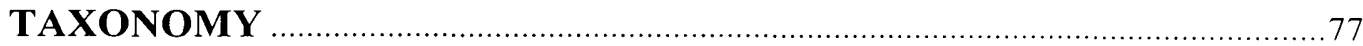

DICOTYLEDONEAE

$\begin{array}{ll}\text { APIACEAE } & 77\end{array}$

$\begin{array}{ll}\text { Tornabenea Parl. } & 77\end{array}$

Key to the genus Tornabenea 78

Tornabenea annua Bég. $\quad 78$

$\begin{array}{lr}\text { Tornabenea bischoffii J. A. Schmidt } & 81\end{array}$

Tornabenea humilis Lobin \& K. H. Schmidt $\quad 83$

Tornabenea insularis (Parl.) Parl. $\quad 86$

Tornabenea tenuissima (A. Chev.) A. Hansen \& Sunding 90

ASCLEPIADACEAE $\quad 91$

$\begin{array}{ll}\text { Periploca L. } & 91\end{array}$

Periploca laevigata Aiton $\quad 91$

Periploca laevigata Aiton ssp. chevalieri (Browicz) G. Kunkel 92

Sarcostemma R. Br. $\quad 95$

Sarcostemma daltonii Decne. $\quad 95$

$\begin{array}{ll}\text { ASTERACEAE } & 98\end{array}$

$\begin{array}{lr}\text { Artemisia L. } & 98\end{array}$

$\begin{array}{lr}\text { Artemisia gorgonum Webb } & 98\end{array}$

$\begin{array}{ll}\text { Conyza L. } & 101\end{array}$

Key to the genus Conyza 101

Conyza feae (Bég.) Wild 102

$\begin{array}{ll}\text { Conyza pannosa Webb } & 105\end{array}$

$\begin{array}{lr}\text { Conyza schlechtendalii Bolle } & 107\end{array}$

$\begin{array}{ll}\text { Conyza varia (Webb) Wild } & 110\end{array}$

\begin{tabular}{lr} 
Launaea Cass. & 112 \\
\hline & 112
\end{tabular}

Key to the genus Launaea 112

$\begin{array}{lr}\text { Launaea gorgadensis (Bolle) N. Kilian } & 113\end{array}$

$\begin{array}{ll}\text { Launaea picridioides (Webb) Engl. } & 116\end{array}$ 
Launaea thalassica N. Kilian, Brochmann \& Rustan 119

$\begin{array}{lr}\text { Nauplius (Cass.) Cass. } & 121\end{array}$

$\begin{array}{ll}\text { Key to the genus Nauplius } & 122\end{array}$

$\begin{array}{ll}\text { Nauplius daltonii (Webb) Wiklund } & 122\end{array}$

$\begin{array}{ll}\text { Nauplius daltonii (Webb) Wiklund ssp. daltonii } & 122\end{array}$

Nauplius daltonii (Webb) Wiklund ssp. vogelii (Webb) Wiklund 125

$\begin{array}{ll}\text { Nauplius smithii (Webb) Wiklund } & 128\end{array}$

$\begin{array}{lr}\text { Phagnalon Cass. } & 130\end{array}$

Phagnalon melanoleucum Webb 131

$\begin{array}{ll}\text { Pulicaria Gaertn. } & 131\end{array}$

Key to the genus Pulicaria $\quad 133$

$\begin{array}{ll}\text { Pulicaria burchardii Hutch. } & 134\end{array}$

Pulicaria burchardii Hutch. ssp. longifolia Gamal-Eldin 134

$\begin{array}{ll}\text { Pulicaria diffusa (Shuttlew.) Pett. } & 136\end{array}$

$\begin{array}{ll}\text { Sonchus L. } & 139\end{array}$

$\begin{array}{ll}\text { Sonchus daltonii Webb } & 139\end{array}$

$\begin{array}{lr}\text { Tolpis Adans. } & 142\end{array}$

Tolpis farinulosa (Webb) J. A. Schmidt 142

BORAGINACEAE $\quad 145$

$\begin{array}{ll}\text { Echium L. } & 145\end{array}$

Key to the genus Echium $\quad 145$

Echium hypertropicum Webb 146

$\begin{array}{ll}\text { Echium stenosiphon Webb } & 146\end{array}$

$\begin{array}{ll}\text { Echium stenosiphon Webb ssp. stenosiphon } & 149\end{array}$

Echium stenosiphon Webb ssp. lindbergii (Pett.) Bramwell 149

Echium vulcanorum A. Chev.

BRASSICACEAE $\quad 156$

Diplotaxis DC. $\quad 156$

Key to the genus Diplotaxis $\quad 157$

Diplotaxis antoniensis Rustan $\quad 158$

Diplotaxis glauca (J. A. Schmidt) O. E. Schulz 161

$\begin{array}{ll}\text { Diplotaxis gorgadensis Rustan } & 164\end{array}$

Diplotaxis gorgadensis Rustan ssp. gorgadensis 164

Diplotaxis gorgadensis Rustan ssp. brochmannii Rustan 167

$\begin{array}{ll}\text { Diplotaxis gracilis (Webb) O. E. Schulz } & 167\end{array}$

Diplotaxis hirta (A. Chev.) Rustan \& Borgen 172

$\begin{array}{ll}\text { Diplotaxis sundingii Rustan } & 175\end{array}$

$\begin{array}{lr}\text { Diplotaxis varia } \text { Rustan } & 178\end{array}$

$\begin{array}{ll}\text { Diplotaxis vogelii (Webb) Cout. } & 181\end{array}$

$\begin{array}{ll}\text { Erysimum L. } & 184\end{array}$

$\begin{array}{lr}\text { Erysimum caboverdeanum (A. Chev.) Sunding } & 184\end{array}$

$\begin{array}{ll}\text { Lobularia Desv. } & 184\end{array}$

$\begin{array}{ll}\text { Lobularia canariensis (DC.) Borgen } & 186\end{array}$

Key to the subspecies of Lobularia canariensis $\quad 187$

Lobularia canariensis (DC.) Borgen ssp. fruticosa (Webb) Borgen 187 
Lobularia canariensis (DC.) Borgen ssp. spathulata (J. A. Schmidt) Borgen

Campanula L.

Key to the genus Campanula

Campanula bravensis (Bolle) A. Chev.

Campanula jacobaea Webb

Paronychia Mill.

Paronychia illecebroides Webb

Polycarpaea Lam.

Key to the genus Polycarpaea

Polycarpaea gayi Webb

Helianthemum Mill.

Helianthemum gorgoneum Webb

Aeonium Webb \& Berth.

Umbilicus DC.

Umbilicus schmidtii Bolle $\quad 207$

EUPHORBIACEAE

Euphorbia L.

Euphorbia tuckeyana Webb

Lotus L.

Key to the genus Lotus

Lotus arborescens Lowe ex Cout.

Lotus brunneri Webb

Lotus jacobaeus L.

Lotus latifolius Brand

Lotus purpureus Webb

Frankenia ericifolia C. Sm. ex DC.

Frankenia ericifolia C. Sm. ex DC. ssp. caboverdeana Brochmann, Lobin \& Sunding

Frankenia ericifolia C. Sm. ex DC. ssp. montana Brochmann,

Lobin \& Sunding

Centaurium tenuiflorum (Hoffm. \& Link) Fritsch ssp. viridense (Bolle) 
$\begin{array}{ll}\text { GLOBULARIACEAE } & 240\end{array}$

Globularia L. $\quad 240$

LAMIACEAE

Globularia amygdalifolia Webb 240

Lavandula $L . \quad 243$

Key to the genus Lavandula 243

Lavandula rotundifolia Benth. $\quad 244$

$\begin{array}{ll}\text { Satureja L. } & 247\end{array}$

$\begin{array}{ll}\text { Satureja forbesii (Benth.) Briq. } & 247\end{array}$

PAPAVERACEAE 250

Papaver L. $\quad 250$

Papaver gorgoneum Cout. 250

Key to the subspecies of Papaver gorgoneum 252

Papaver gorgoneum Cout. ssp. gorgoneum 253

Papaver gorgoneum Cout. ssp. theresias Kadereit \& Lobin 254

PLUMBAGINACEAE 255

Limonium Mill. 256

Key to the genus Limonium 256

Limonium braunii (Bolle) A. Chev. 256

Limonium brunneri (Webb) Kuntze $\quad 259$

Limonium jovi-barba (Webb) Kuntze 261

Limonium lobinii N. Kilian \& Leyens 264

Limonium sundingii Leyens, Lobin, N. Kilian \& Erben 266

$\begin{array}{ll}\text { SAPOTACEAE } & 269\end{array}$

$\begin{array}{ll}\text { Sideroxylon L. } & 269\end{array}$

Sideroxylon marginata (Decne.) Cout. 269

SCROPHULARIACEAE 272

Campylanthus Roth $\quad 273$

Campylanth us glaber Benth. 273

Key to the subspecies of Campylanthus glaber 273

Campylanthus glaber Benth. ssp. glaber 275

Campylanthus glaber Benth. ssp. spathulatus (A. Chev.) Brochmann,

N. Kilian, Lobin \& Rustan $\quad 277$

$\begin{array}{ll}\text { Kickxia Dumort. } & 279\end{array}$

Kickxia elegans (G. Forst.) D. A. Sutton 279

Key to the subspecies of Kickxia elegans 280

Kickxia elegans (G. Forst.) D. A. Sutton ssp. elegans 280

Kickxia elegans (G. Forst.) D. A. Sutton ssp. dichondrifolia (Benth.)

Rustan \& Brochmann 284

Kickxia elegans (G. Forst.) D. A. Sutton ssp. webbiana (Sunding)
Rustan \& Brochmann

Verbascum L. $\quad 288$

Key to the genus Verbascum 288

Verbascum capitis-viridis Hub.-Mor. $\quad 288$

Verbascum cystolithicum (Pett.) Hub.-Mor. 291 
URTICACEAE 294

Forsskaolea L. $\quad 294$

Key to the genus Forsskaolea 294

Forsskaolea procridifolia Webb 294

MONOCOTYLEDONEAE $\quad 298$

ARECACEAE $\quad 298$

$\begin{array}{ll}\text { Phoenix L. } & 298\end{array}$

Provisional key to the genus Phoenix 298

Phoenix atlantidis A. Chev. $\quad 298$

ASPARAGACEAE 302

Asparagus L. $\quad 302$

Key to the genus Asparagus $\quad 302$

Asparagus squarrosus J. A. Schmidt $\quad 302$

CYPERACEAE 305

Carex L. $\quad 305$

Key to the genus Carex $\quad 305$

Carex antoniensis A. Chev. $\quad 305$

Carex paniculata Jusl. ex L. $\quad 307$

Carex paniculata Jusl. ex L. ssp. hansenii Lewej. \& Lobin 308

POACEAE $\quad 309$

$\begin{array}{ll}\text { Aristida L. } & 310\end{array}$

Key to the genus Aristida $\quad 310$

$\begin{array}{ll}\text { Aristida cardosoi Cout. } & 310\end{array}$

Brachiaria (Trin.) Griseb. $\quad 312$

$\begin{array}{ll}\text { Key to the genus Brachiaria } & 313\end{array}$

Brachiaria lata (Schumach.) C. E. Hubb. 313

Brachiaria lata (Schumach.) C. E. Hubb. ssp. caboverdiana Conert \&

C. Köhler 313

$\begin{array}{ll}\text { Eragrostis Wolf } & 316\end{array}$

Key to the genus Eragrostis $\quad 316$

$\begin{array}{ll}\text { Eragrostis conertii Lobin } & 317\end{array}$

$\begin{array}{ll}\text { Sporobolus R. Br. } & 319\end{array}$

Key to the genus Sporobolus $\quad 320$

Sporobolus minutus Link 320

Sporobolus minutus Link ssp. confertus (J. A. Schmidt) Lobin,
N. Kilian \& Leyens

$\begin{array}{ll}\text { EXCLUDED TAXA } & 324\end{array}$

ACKNOWLEDGEMENTS

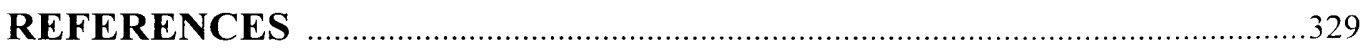

INDEX 


\section{INTRODUCTION}

Islands have always fascinated students of evolution because they represent natural biological laboratories where colonizing populations of organisms evolve in isolation from their continental relatives. Today, we also face the increasingly urgent issue of conserving what is left of the earth's biological diversity, and we need more information on how to protect small populations and very rare species. Insular ecosystems provide excellent study objects to increase our knowledge of theoretical and practical aspects of conservation. Insights derived from the study of small, isolated populations on islands are probably directly applicable to rare and endangered continental species as well (Bramwell 1990).

The vascular flora of the Cape Verde Islands is rather poor compared to the other MidAtlantic islands (Hansen \& Sunding 1993), comprising about 621 spontaneous species (Lobin \& Zizka 1990). A significant impact of human activities is evident in the composition of the flora. More than $50 \%$ of the flora (331 species) is probably introduced by man. In addition, 66 species cannot be classified with reasonable certainty as anthropochorous or idiochorous, and the indigenous flora may thus contain as few as 224 species (Lobin \& Zizka 1990). Lobin \& Zizka (1990) accepted 85 species as endemic to the archipelago, giving an endemism of $13.7 \%$ based on the entire spontaneous flora, or $37.9 \%$ based on the minimum estimate of the indigenous flora. The flora is composed of representatives of various flora elements, as can be expected from the geographic position of the islands (Sunding 1973b). The northern influence is most pronounced in humid, montane areas, where many of the Capeverdean species have their closest relatives in in the Mediterranean or the Canary Islands. Tropic elements dominate the lowland flora, but many of these species are of neotropic origin and have been introduced by man.

The Cape Verde Islands were uninhabited when Portuguese people colonized them about 1460. The first clear statement about a Capeverdean plant, Argemone mexicana, dates from 1636 (Lobin 1987). Interestingly, this species is a weed originating from Central America and represents a very early introduction by man to the archipelago. The endemic Lotus jacobacus was the first Capeverdean plant to be illustrated (Commelin \& Commelin 1701). The first collections of plants and animals for scientific purposes were made by the Portuguese J. da Silva Feijão. He lived for three years (1784-1787) in the archipelago and brought a rather voluminous herbarium back to Lisbon. When the French troops conquered Portugal, the well-known French scientist Geoffrey de St. Hillaire was ordered to visit Lisbon and transfer collections of natural history to Paris. Among the collections he selected was Feijão's herbarium, which later has been kept in Paris, labelled "Capvert. Herbier rapporté du Portugal en 1808 par M. Geoffrey St. Hilaire".

In 1849, P. Barker Webb wrote the first treatment of the flora of the Cape Verde Islands, publishing the collections of Feijão, C. Smith. J. Forbes, S. Brunner, J. D. Hooker and T. Vogel (Webb 1849). However, J. A. Schmidt was the first botanist who made thorough studies in the archipelago, not merely reporting findings from a temporary visit as the others before him. He published his results in 1852 (Schmidt 1852). In the following years, C. Bolle and R. T. Lowe made large plants collections. The Portuguese army pharmacologist $\mathbf{J}$. Cardoso Junior lived for 21 years on the islands and collected numerous plants, which he distributed to various herbaria. Unfortunately, his plants are often labelled without exact locality information (if any at all), and 
their scientific value is limited. Towards the end of the nineteenth century (1897-1898), the Italian naturalist L. Fea collected plants for almost a year in the archipelago.

In 1934, the French botanist A. Chevalier travelled for four months in the Cape Verde Islands and made extensive collections. His comprehensive account of the flora, published in 1935, is still one of the most important contributions, but for most species he did not provide descriptions (Chevalier 1935a). The Finnish naturalist H. Lindberg visited the archipelago from September 1953 until December 1954. He mainly made collections of animals, but also collected some plants. L. A. Grandvaux Barbosa stayed twice $(1956,1961)$ on the islands, and he also spent his old age there (until 1983). His plant collections are among the most important ones from the Cape Verde Islands.

The present epoch of botanical exploration in the Cape Verde Islands was initiated by $P$. Sunding from the University of Oslo, who visited the islands in 1972 and 1976. He published a first edition of a checklist of Capeverdean vascular plants in 1973 (Sunding 1973a). which later was revised and included in a checklist of Macaronesian vascular plants (Eriksson et al. 1974, 1979a, 1979b, Hansen \& Sunding 1985, 1993). A number of contributions to the knowledge of the Capeverdean flora have been published by various German, Norwegian, and Portuguese botanists in the 1980s and 1990s, but still no comprehensive, modern treatment of the endemic flora has been published

Many endemics are extremely rare today and threatened by various factors. Considering that the Republic of Cape Verde is one of the poorest countries in the world, suffering from drought, erosion, and desertification, it may seem inappropriate to worry about conservation of rare plant species. However, the self-reinforcing circle of poverty and over-exploitation of resources can only be broken by increased foreign aid aimed at restoring the water balance and buffering capacity of the native perennial vegetation, of which endemic species constitute a major component. Most areas are constantly being over-grazed by domestic animals, in particular goats. The people rely on a diet consisting mainly of maize and beans which require long cooking time, resulting in extensive collection of firewood in the shrublands. These factors, together with the fluctuating climate with long periods of drought, are major threats to plant life in the archipelago.

A prerequisite for conservation of rare and threatened species is a basic knowledge of the organisms that need conservation. The endemic plants of the Cape Verde Islands represent unique genetic resources, but the taxonomy, variation, ecology, distribution, and abundance are still poorly known for many of them. This work aimed at summarizing and increasing our knowledge of the endemic taxa to provide a scientific basis for political actions to protect Capeverdean biodiversity. We also wanted to synthesize and analyze the available data to increase our understanding of the origin and evolution of the flora and its phytogeographic relationships. 


\section{STUDY AREA}

\section{GEOGRAPHY AND GEOLOGY}

The Cape Verde Islands are situated in the Atlantic Ocean outside the westernmost cape of the African mainland (Cap Vert), about $500 \mathrm{~km}$ west of Dakar in Senegal and $1500 \mathrm{~km}$ south of the Canary Islands (Fig. 1). The archipelago consists of nine large, inhabited islands and six small, uninhabited islands and islets. The archipelago forms a horse-shoe with three island groups, each with three inhabited islands: a northern group with Santo Antão, São Vicente, and São Nicolau, an eastern group with Sal, Boa Vista, and Maio, and a southern group with Santiago, Fogo, and Brava. The total land area is $4033 \mathrm{~km}^{2}$. Santiago is the largest island $\left(991 \mathrm{~km}^{2}\right)$, followed by Santo Antão (779 km², Tab. 8; Westermann 1969).

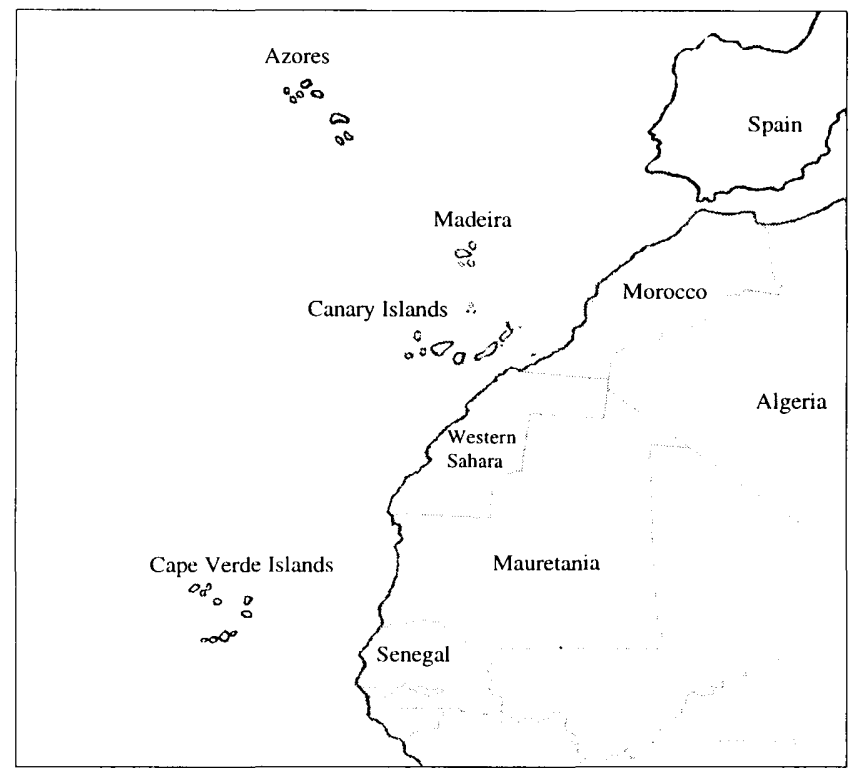

Fig. 1. Geographic position of the Cape Verde Islands.

All islands are oceanic, originated as submarine volcanoes (Mitchell-Thomé 1976, 1985, Rothe 1982, Gier \& Dahms 1987a, Boekschoten \& Manuputty 1993). The period of major volcanic activities dates back to the late Miocene and early Pliocene, but rocks of Upper Cretaceous (perhaps even Lower Jurassic) age have been found in Ribeira de Morro on Maio. These well-studied rocks in Ribeira de Morro were formed by marine sediments, and contain fossils of organisms which lived at depths of about $1000 \mathrm{~m}$. 
The three eastern islands are probably the oldest ones and therefore much more eroded, flat, and topographically monotonous than the western islands. The highest mountain on the eastern islands extends only to $436 \mathrm{~m}$ above sea-level (Maio). In contrast, the western islands (Santo Antão, São Vicente, São Nicolau, Santiago, Fogo, and Brava) are characterized by steep, high mountains and a rough topography with deep river valleys ("ribeiras"; Fig. 1). The highest mountain in the Cape Verde Islands is the central volcano on Fogo, which extends to $2829 \mathrm{~m}$ above sea-level. This volcano is still active, and had its latest eruptions in 1971 and 1995.

\section{CLIMATE AND ZONES OF HUMIDITY}

The archipelago is situated at the border of the North African arid and semiarid climatic regions (Teixeira \& Barbosa 1958, Good 1974) and has been heavily influenced by the drought periods of the Sahel zone during the latest decades. The climate is influenced by the cold Canary-current and by three main wind systems: the northeastern trade wind $(80 \%)$, the southwestern monsoon (5\%), and the eastern Harmattan (6\%; Gier \& Dahms 1987b). The temperature is balanced by the surrounding ocean, where the water temperature never falls below $20{ }^{\circ} \mathrm{C}$. January is the coldest month with an average lowland temperature of $22.0^{\circ} \mathrm{C}$, and July is the warmest month with an average lowland temperature of $25.8^{\circ} \mathrm{C}$ (Gier \& Dahms 1987b). In high mountain areas, the climate is less influenced by the ocean, and frost may occur in the coldest months.

The northeastern trade wind carries medium humidity, in particular in autumn and winter. This important wind system mainly affects mountains above $600 \mathrm{~m}$. It only results in insignificant amounts of rainfall, but often causes fogs which are of outmost importance for the supply of water to the natural vegetation and agricultural crops. The monsoon blows from August until October and is the main cause of the rain season, which is very irregular because the Cape Verde Islands are situated at the northern limit of influence from this wind system. The length of the Capeverdean rain season is very variable, and it may be entirely absent for several years, causing catastrophic drought periods. The Harmattan is a dry eastern wind which carries dust from the Sahara, even as far as South America. It mainly blows from October until June, after the rain season.

The close connection between the wind systems and humidity results in conspicuous ecological differences between the windward and leeward slopes of the mountains. In October 1979, for example, there was no precipitation at all on the leeward slopes of Fogo, whereas about $3000 \mathrm{~mm}$ of rainfall was measured on the windward slopes of this island (Monte Velha; Lobin 1982b). This difference also explains why the eastern islands are desert-like. They lack sufficiently high mountains.

Topography, aspect, and altitude are thus the main factors determining the amount and distribution of humidity in the archipelago. The islands were divided (Brochmann \& Rustan 1987) into five zones of humidity, extremely arid (H1), arid (H2), semiarid (H3), subhumid (H4), and humid (H5), simplified after the ecological maps of Teixeira \& Barbosa (1958). These maps were based on extensive field studies including examination of soil profiles, local topography, and local experience with crops cultivated without irrigation. 


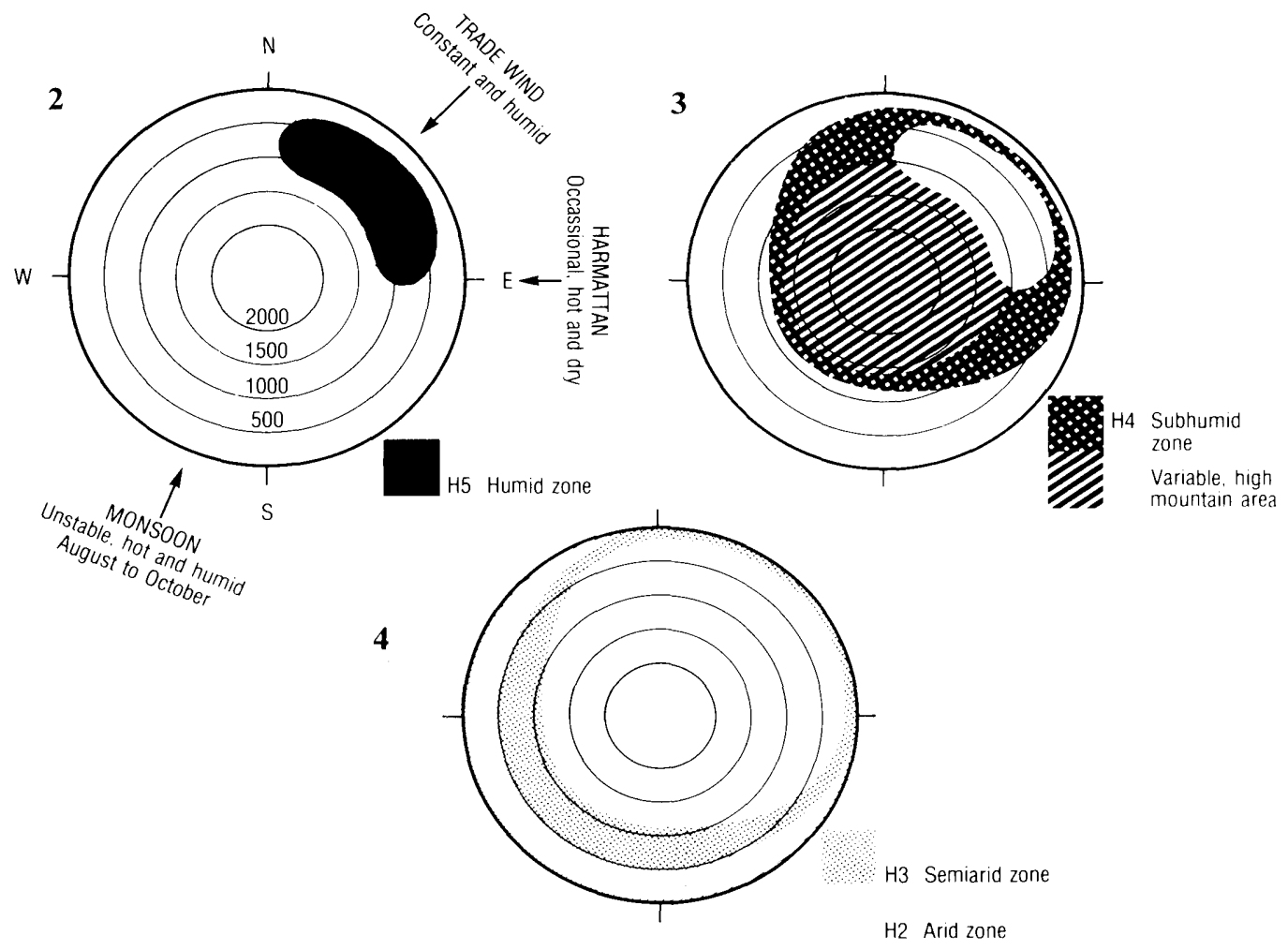

Figs 2-4. Conical island model of $2000 \mathrm{~m}$ altitude showing the relationship between prevailing wind systems and distribution of humidity in the Cape Verde Islands. Fig. 2. The humid zone and the wind systems. Fig. 3. The subhumid zone and the variable, high mountain area. Fig. 4. The semiarid and arid zones. The extremely arid zone (H1) does not occur on this type of island. Modified after Teixeira \& Barbosa (1958).

An island model (Figs 2-4) shows the distribution of the zones of humidity on a conical island of $2000 \mathrm{~m}$ altitude. The humid and subhumid zones are confined to elevated, northeastfacing slopes. The uppermost montane part of the island varies in humidity (semiarid to subhumid). The semiarid and arid zones are mainly found in southwest-exposed areas shaded from the trade wind. The approximate distribution of humidity on the islands is shown in Figs 5 7. Fogo is close to the island model, but the climate on the other islands is influenced by a mixture of topographical parameters such as mountain slope angle, orientation of mountain massifs, and mountain shading effects. The two most humid zones are absent from the low: eastern islands and reach their maximum extent on Santo Antão, Santiago, and Fogo. The semiarid zone is the most humid one on the eastern islands, where it is limited to small areas in the highest mountains. The extremely arid and arid zones have a wide distribution on most islands (Figs 5-7). 


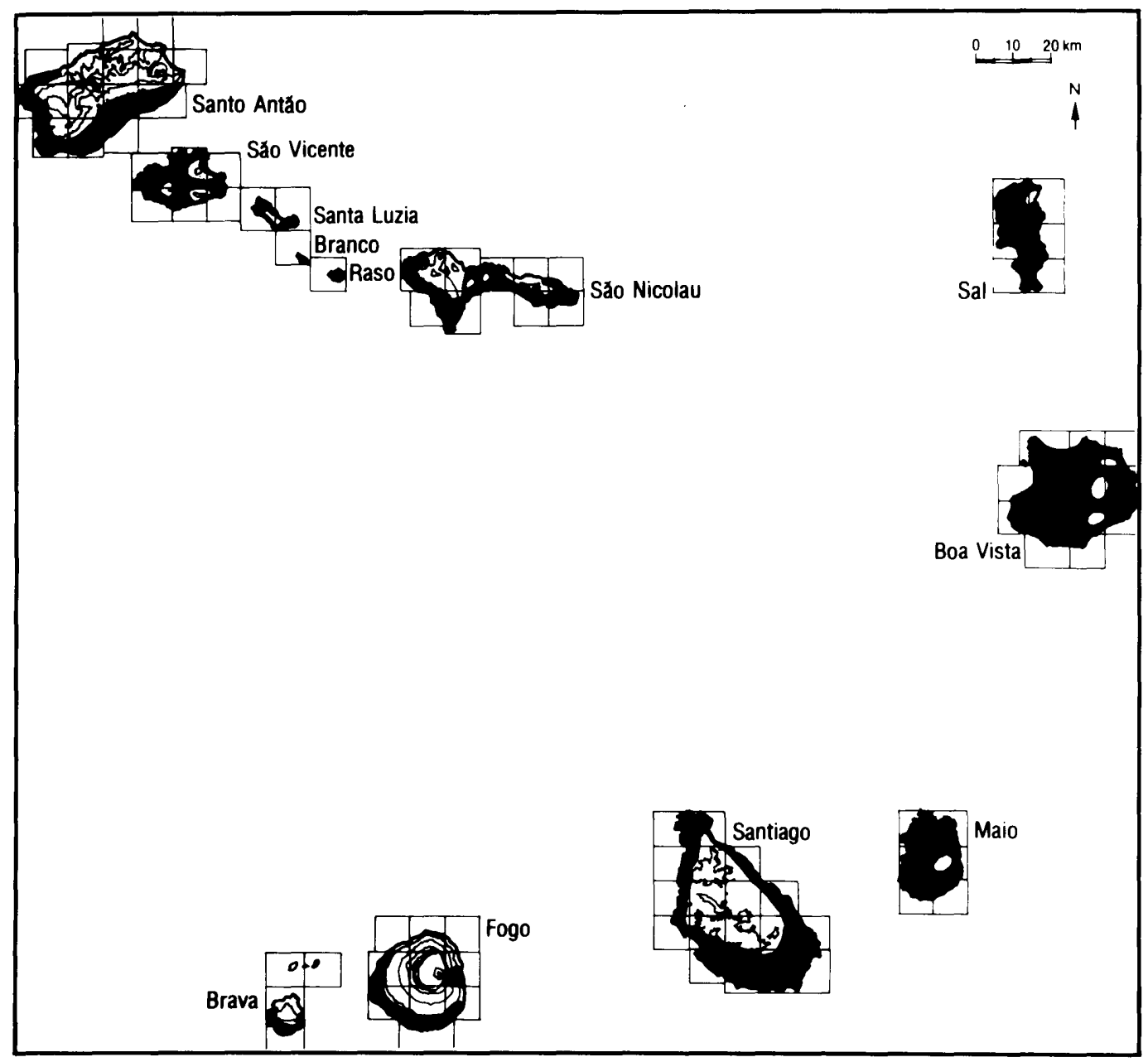

Fig. 5. Geographic distribution (shaded) of the arid (H2) and extremely arid (H1) zones in the Cape Verde Islands. Simplified after Teixeira \& Barbosa (1958).

\section{VEGETATION}

Large areas in the Cape Verde Islands are covered by open grassland and semidesert vegetation, and considerable parts of the eastern islands are almost naked deserts. The human impact on the natural vegetation has been considerable for more than 500 years, and most of the present 


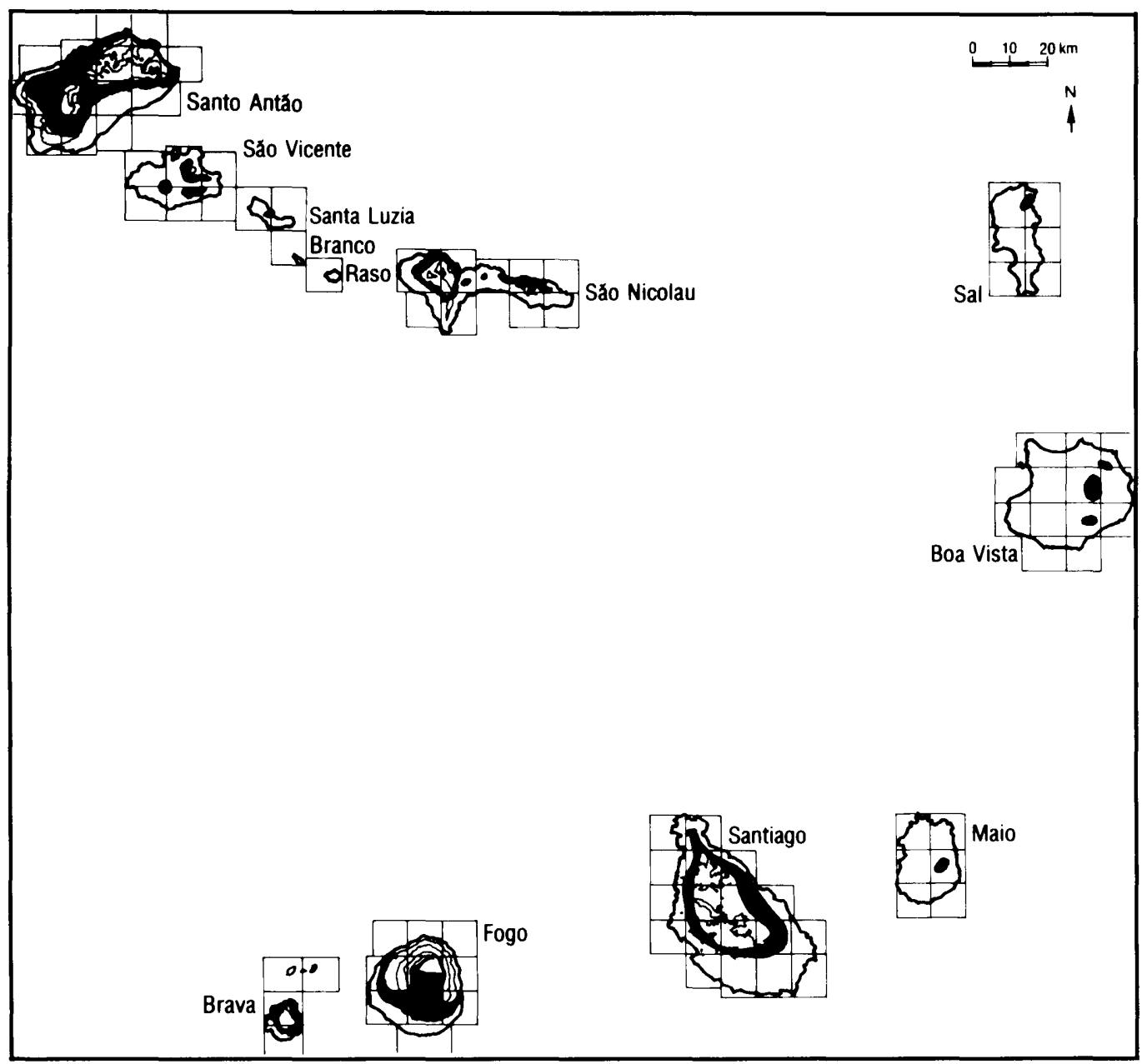

Fig. 6. Geographic distribution (shaded) of the semiarid (H3) zone in the Cape Verde Islands. Simplified after Teixeira \& Barbosa (1958).

vegetation is severely disturbed. Some introduced species, such as the South American Lantana camara and Furcraea foetida, have been completely naturalized and are quantitatively important in semi-natural vegetation types. The combination of harsh climate and human disturbance limits the regeneration potential of the vegetation. and only remnants of supposedly natural vegetation are left. The potential natural vegetation in the Cape Verde Islands was outlined by Lobin (1982c), Lobin \& Ohm (1987), and Leyens (1994).

The coastal habitats are among the least affected ones. The habitats vary depending on the local topography, and include sand dune systems, estuaries, gravelly or sandy plains and slopes, and up to $200 \mathrm{~m}$ high coastal cliffs falling steeply into the sea. Halophytic non-endemics such as 


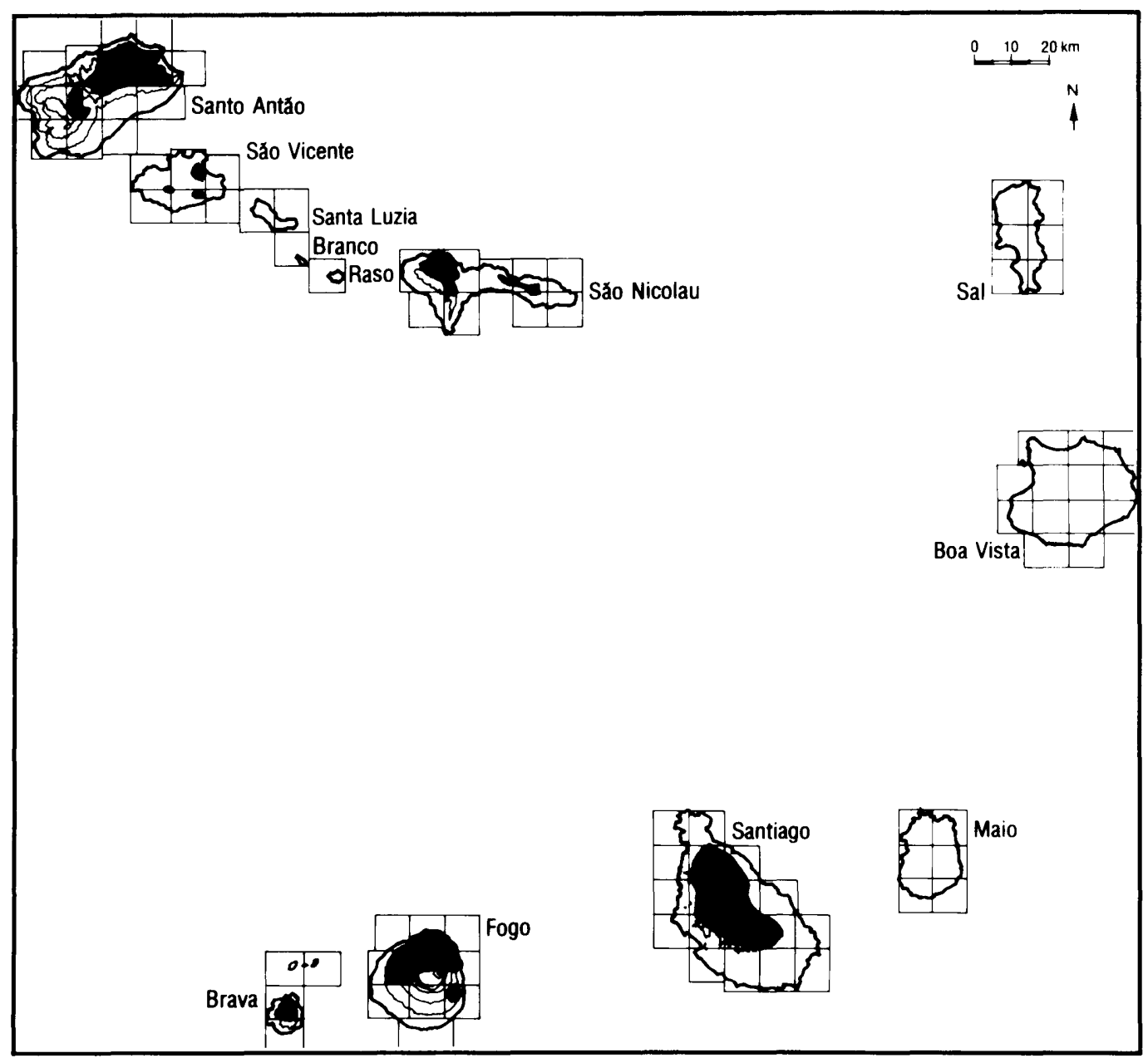

Fig. 7. Geographic distribution (shaded) of the humid (H5) and subhumid (H4) zones in the Cape Verde Islands. Simplified after Teixeira \& Barbosa (1958).

Suaeda spp., Zygophyllum spp., Sporobolus spicatus, S. robustus, and Convolvulus pes-caprae ssp. brasiliensis, as well as some littoral endemic species, e.g., Limonium braunii, L. brunneri, Campylanthus glaber ssp. spathulatus, Lotus brunieri, Pulicaria diffusa, and Diplotaxis glauca, are typical in these habitats, forming a mosaic of different vegetation types.

The vegetation in the colline and lower montane zone is almost completely changed by human activities, and the potential natural vegetation in this region is the most difficult one to reconstruct. Depending on exposition, substrate, and topography, a variety of different vegetation types probably covered these areas. Along the stream beds there may have been open "gallery forests" with Tamarix spp., or, along more favourable, non-saline streams similar 
woodland with Ficus sycomorus, or, in sand dune areas, open stands of Phoenix atlantidis. On the southern islands, grasslands and wooded grasslands with Acacia albida may have covered the foothills. Low-grown, cushion-like scrub vegetation types dominated by Nauplius daltonii ssp. vogelii probably played an important role in some areas. Rocky escarpments were, as they still are today, frequently covered with extensive mats of Sarcostemma daltonii.

Scrub vegetation of varying density, height, and species composition probably covered most of the highlands and the steepest slopes of the mountains (Lösch et al. 1990). This shrubland was most prominent in the humid, northeast-exposed slopes, where it probably was overtopped by scattered trees of Dracaena draco or Sideroxylon marginata. In many semiarid and subhumid areas, such vegetation was probably dominated by Periploca laevigata ssp. chevalieri. All scrub vegetation types are largely destroyed today, but a few, small remnants give an impression of their former importance. At the Monte Gordo mountain on São Nicolau, for example, Euphorbia tuckeyana and the local endemic Nauplius smithii still form dense shrubland of up to $2 \mathrm{~m}$ height. On the outer escarpments of the rim surrounding the caldeira of the main volcano of Fogo, there are remnants of an impressive scrub of Echium vulcanorum, Artemisia gorgonum, Erysimum caboverdeanum, and Verbascum cystolithicum.

The northeast-exposed cliffs in the mountains are humid because of fog and occasional rainfalls. These habitats, in particular inaccessible, steep cliff walls, are inhabited by a number of endemic plant species, e.g., Diplotaxis spp., Tolpis farinulosa, Sonchus daltonii, Limonium spp., and Aeonium gorgoneum.

Although some trees and large shrub species are indigenous, there has probably never been any forests in the Cape Verde Islands during the present climatic period (Kämmer 1982, Lobin 1982c, Lobin \& Ohm 1987). The indigenous trees (Acacia albida, Dracaena draco. Ficus sycomorus, Phoenix atlantidis, Sideroxylon marginata, and Tamarix spp.) are not able to form forests with a more or less continuous canopy of tree crowns. In the altitudinal sequence of the vegetation on other mid-atlantic islands such as the Canary Islands and Madeira, the forests are situated at elevations above the scrub vegetation (Lösch et al. 1990). Lösch et al. (1990) suggested that the uppermost, potential natural vegetation in the Cape Verde Islands under the present climate is scrubland. The mountains of the Cape Verde Islands are simply not high enough to facilitate development of forests. It is nevertheless possible that forests may have existed also in the Capeverdean archipelago in earlier climatic periods. In neighbouring West Africa and the Canary Islands, the forests could withdraw to higher elevations in the mountains when the climate became drier, whereas forests that may have been present in the Cape Verde Islands became extinct. 


\title{
MATERIALS, METHODS, AND TERMINOLOGY
}

\author{
MATERIALS
}

This study was based on several periods of field work in the Cape Verde Islands between 1979 and 1995. All inhabited islands were investigated. For morphological and taxonomic studies, 1-5 herbarium specimens were collected from populations selected to cover most parts of the distribution area of each endemic taxon. Ecological and distributional data were recorded on field-note registration forms (Rustan \& Brochmann 1981).

Our own material is deposited in $\mathrm{O}$ (coll. $\mathrm{CB}$ and $Ø \mathrm{HR}$ ), FR and herb. Lobin in BONN (coll. WL), and B, BONN, and FR (coll. NK). In addition, we studied the (apeverdean material, including the types of most names, deposited in $\mathrm{B}, \mathrm{BM}, \mathrm{CGE}, \mathrm{COI}, \mathrm{FI}-\mathrm{W}, \mathrm{FR}$. GOET, H, HBG, K, L, LISC, LISU, MB, O, P, W, and Z. Herbaria are abbreviated after Holmgren et al. (1990).

We also studied material of many taxa raised from field-collected seeds and cultivated in the Botanic Gardens in Berlin, Bonn, and Oslo. Several taxonomic groups and larger collections have been treated and published separately over the years (cf. Tab. 1), and extracts of information given in these studies, updated with more recent information, are included in this paper.

Literary records on distribution and ecology of Capeverdean endemics were systematically filed with reference to cited herbarium specimens. This literature search was initially based on the Capeverdean botanical bibliography of Sunding (1977) and later supplements (Nogueira \& Ormonde 1981, Hansen \& Sunding 1988), and updated with more recent papers. A total of 101 papers contained records of endemic taxa (Tab. 1). We later verified or redetermined much of the material cited in these studies. Some unconfirmed literary records that were considered doubtful and excluded are mentioned in the text.

\section{MORPHOLOGY AND TAXONOMY}

A catalogue of all taxa described on material collected in the Cape Verde Islands was provided by Lobin $(1986 \mathrm{~b}, 1988,1993)$. This catalogue lists a total of 238 vascular plant taxa, including one genus (Tornabenea) and a number of species, subspecies, and varieties, of which 112 taxa provisionally were accepted as endemic to the archipelago. In the present paper, all described taxa were re-evaluated based on new morphological and taxonomic studies. Percentages of endemism in the Capeverdean flora were calculated based on species numbers given by Lobin $\&$ Zizka (1990).

All accepted endemic taxa, excluded taxa, synonyms, and non-endemic taxa mentioned in the taxonomic part are included in the scientific index. Keys are provided for all genera with two or more taxa occurring in the Cape Verde Islands. Non-endemic taxa are included in the keys in 
Tab. 1. Literature used as sources for ecological and distributional data for endemic vascular plants in the Cape Verde Islands.

Barbosa 1961

Basto $1987 \mathrm{a}, 1987 \mathrm{~b}, 1988$

Basto \& Diniz 1993

Béguinot 1918

Betsche 1984

Bolle 1852, 1855, 1859a, 1859b, 1860a, 1860b, 1861

Borgen 1987

Boulos 1974

Bowdich 1825

Bramwell 1972

Brochmann \& Rustan 1988

Brochmann et al. 1995

Browicz 1966

Brunner 1840

Carter et al. 1984

Chaudhri 1968

Chaytor 1937

Chevalier 1935a, 1935b, 1946

Conert \& Köhler 1987

Conert \& Lobin 1985

Coutinho 1914, 1915

Eriksson et al. 1979a

Fernandes 1959

Forster 1789

Gamal-Eldin 1981

Gilli 1976

Gomes et al. 1995a

Halvorsen \& Borgen 1986

Hansen \& Sunding 1985, 1993

Heim 1984

Henriques 1896

Jarvis 1984

Kadereit \& Lobin 1990

Kilian 1988
Kilian \& Leyens 1994

Kilian et al. 1987

Köhler 1987, 1988

Köhler \& Lobin 1988

Krause 1892

Lewejohann \& Lobin 1981, 1987

Leyens \& Lobin 1995

Lobin 1982a, 1982b, 1982c, 1986a, 1986e

Lobin \& Porembski 1994

Lobin \& Roessler 1985

Lobin et al. 1988a, 1988b, 1995

Malato-Beliz 1970, 1971

Miller 1980

Nogueira 1975a, 1975b, 1976, 1977, 1979

Nogueira \& Ormonde 1981, 1985

Ormonde 1976, 1977, 1980

Ormonde \& Nogueira 1985

Paiva \& Nogueira 1974

Pérez de Paz 1978

Peters 1864

Pettersson 1960

Polatschek 1976

Rustan 1996

Rustan \& Brochmann 1985, 1988, 1993

Schlechtendal 1851

Schleich \& Wuttke 1983

Schmidt 1852

Soares 1961

Sunding 1973a, 1974, 1981, 1982

Sventenius 1971

Tuckey 1818

Valdés 1979

Webb 1849

Wild 1969 
brackets. Most keys were prepared particularly for this paper, and some of them were rewritten based on the literature cited. The morphological descriptions were based on field-collected material and field observations, in some cases supplemented with examination of cultivated material. The morphological variation within taxa was examined, described, and subjectively scored on a scale from 1 (no significant variation) to 4 (high degree of variation). The descriptive terminology mainly follows Stearn (1983).

Drawings are provided for all accepted taxa. The drawings were based on field-collected specimens if not otherwise stated. Fifty taxa were drawn particularly for the present paper. Previously published drawings of 32 taxa were reprinted with permission from the publishers (specified in the respective figure legends): Botanischer Garten und Botanisches Museum Berlin-Dahlem, Berlin (Willdenowia); Nordic Journal of Botany, Copenhagen (Nordic Journal of Botany, Opera Botanica); and Senckenbergmuseum, Frankfurt a. M. (Courier ForschungsInstitut Senckenberg, Senckenbergiana Biologica).

\section{PHYTOGEOGRAPHY}

The phytogeographic analyses were based on the present flora of the archipelago as well as the estimated minimum number of founder taxa. For classification into phytogeographic elements, it was necessary to identify the sister taxon of each endemic taxon (or group of endemic taxa) and the entire geographic distributions of the sister taxa. Taxonomic relationships were evaluated and discussed in the taxonomic part. A founder taxon analysis was included because the analysis of the present taxa leads to over-representation of groups showing extensive differentiation within the archipelago (e.g., Diplotaxis). Definitions of phytogeographic elements (Tab. 2) followed Wickens (1976) except that the NW Moroccan area was classified as a subregion of the Mediterranean region (Lobin 1982c).

\section{ECOLOGY AND ECOGEOGRAPHY}

Ecogeographic maps showing horizontal distribution, vertical distribution, and distribution in zones of humidity were constructed (Fig. 8). Each geographic site was referred to zone of humidity based on Teixeira \& Barbosa (1958). Different symbols were used for verified herbarium specimens, field registrations, and literary records. Occurrences in altitudinal zones and zones of humidity were summarized for the entire archipelago (Fig. 8, bottom left). The actually occurring combinations of humidity and altitude are shown in Fig. 8. For some records, only the geographic position could be given because the exact altitude and zone of humidity were unknown.

Available ecological and distributional data covered all islands and islets, most island squares, and most of the possible combinations of altitude and humidity zones (summarized in Fig. 9), and gave a reasonable basis for ecogeographic analysis. There was nevertheless large variation in exploration intensities among geographic areas and zones. The western islands 
Tab. 2. Definition of phytogeographic elements used in classification of the endemic vascular taxa of the Cape Verde Islands. Circumscription of phytogeographic units mainly after Wickens (1976).

\begin{tabular}{|c|c|c|c|}
\hline $\begin{array}{l}\text { Phytogeographic } \\
\text { element in the Cape } \\
\text { Verde Islands }\end{array}$ & Kingdom & Region/subregion & Geographic area \\
\hline Widely Holarctic & Holarctic & & $\begin{array}{l}\text { Northern hemisphere (Europe, N } \\
\text { Asia, N America) }\end{array}$ \\
\hline Mediterranean & Holarctic & Mediterranean & $\begin{array}{l}\text { Circum-Mediterranean parts of S } \\
\text { Europe, W Asia ( } \mathrm{N} \text { and } \mathrm{W} \text { Turkey, } \\
\mathrm{W} \text { parts of Near East), } \mathrm{N} \text { and } \mathrm{NW} \\
\text { Africa } \mathrm{N} \text { of Sahara }\end{array}$ \\
\hline Canaro-Madeiran & Holarctic & $\begin{array}{l}\text { Mediterranean/ } \\
\text { Canaro-Madeiran }\end{array}$ & The Canary Islands and Madeira \\
\hline NW-Moroccan & Holarctic & $\begin{array}{l}\text { Mediterranean/ } \\
\text { NW-Moroccan }\end{array}$ & NW part of Morocco \\
\hline Palaeotropic & Palaeotropic & & $\begin{array}{l}\text { Africa, S and SE Asia, N Australia, } \\
\text { New Guinea, Pacific Islands }\end{array}$ \\
\hline Saharo-Arabian & Palaeotropic & Saharo-Arabian & $\begin{array}{l}\text { Sahara and Arabian peninsula } \\
\text { (except southernmost parts of Jemen) }\end{array}$ \\
\hline $\begin{array}{l}\text { Sudano-Zambesian- } \\
\text { Sindian }\end{array}$ & Palaeotropic & $\begin{array}{l}\text { Sudano-Zambesian- } \\
\text { Sindian }\end{array}$ & $\begin{array}{l}\text { W to E Africa (except tropic Central } \\
\text { Africa), southwards to Karoo- } \\
\text { Namibia and the Cape Region, parts } \\
\text { of the Arabian peninsula (S Jemen) } \\
\text { and NW India (Sind) }\end{array}$ \\
\hline Afromontane & Palaeotropic & Afromontane & $\begin{array}{l}\text { Ericaceous and alpine vegetation of } \\
\text { mountains ( } 1000-2000 \mathrm{~m} \text { alt.) in } \\
\text { Cameroon, E Africa, Ethiopia }\end{array}$ \\
\hline
\end{tabular}

have been more thoroughly investigated than the eastern ones (especially Boa Vista and Maio), and the humid and subhumid zones have been more thoroughly investigated than the drier zones. There were also limited data from elevated arid areas such as the southwestern montane part of Santo Antão, and from the southern and southwestern mountain slopes and coasts of most islands. Santa Luzia with the neighboring islets Branco and Raso and the islets close to Brava were least explored among all areas.

The geographic distributions of the taxa were analyzed by calculation of floristic similarity between islands (i.e., shared endemic taxa). The Dice coefficient (Rohlf 1990) was selected because it disregards shared absences of taxa. Similarities between all pairs of islands were calculated from a presence-absence taxon $\times$ island matrix and subjected to UPGMA clustering and correspondence analysis (CA), which is based on Chi-squared distances (Rohlf 


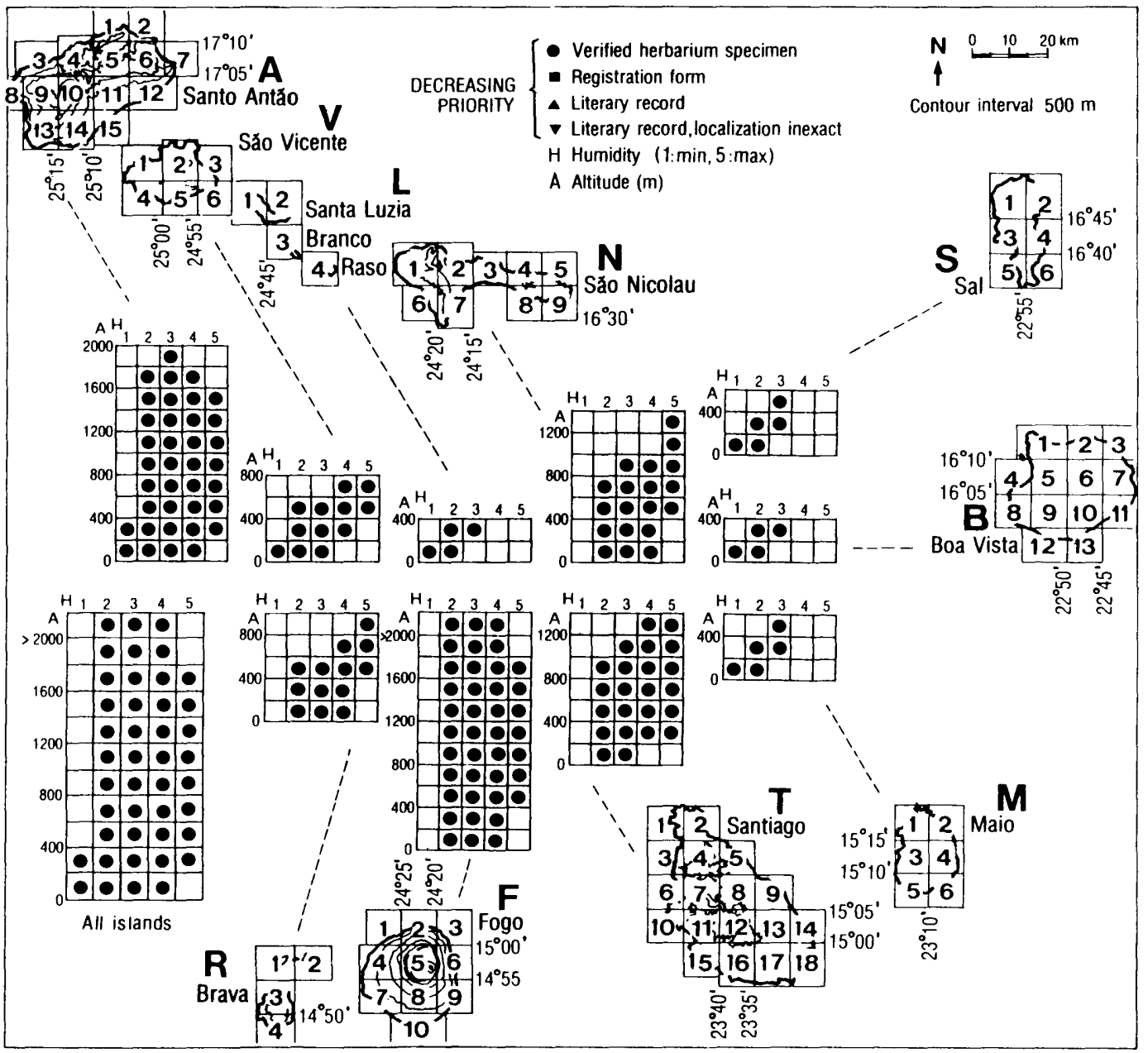

Fig. 8. Key to the ecogeographic distribution maps for the endemic taxa of the Cape Verde Islands showing combinations of altitude and humidity that actually occur on each island. $\mathrm{H} 1$ - the extremely arid zone; $\mathrm{H} 2$ - the arid zone; $\mathrm{H} 3$ - the semiarid zone; H4 - the subhumid zone; H5 - the humid zone.

1990). Minimum spanning trees (MSTs) were superimposed on the CA ordinations to reveal potential distortions. Calculations were carried out using NTSYS-pc (Rohlf 1990). The endemic taxa were classified into five within-archipelago distributional elements based on the results of these analyses. These elements were identical to those recognized in earlier analyses of the entire vascular flora of the archipelago (Brochmann \& Rustan 1987).

The abundance and main distribution with respect to altitude and humidity were determined for each taxon (cf. Tab. 4). The taxa were classified into three groups based on 


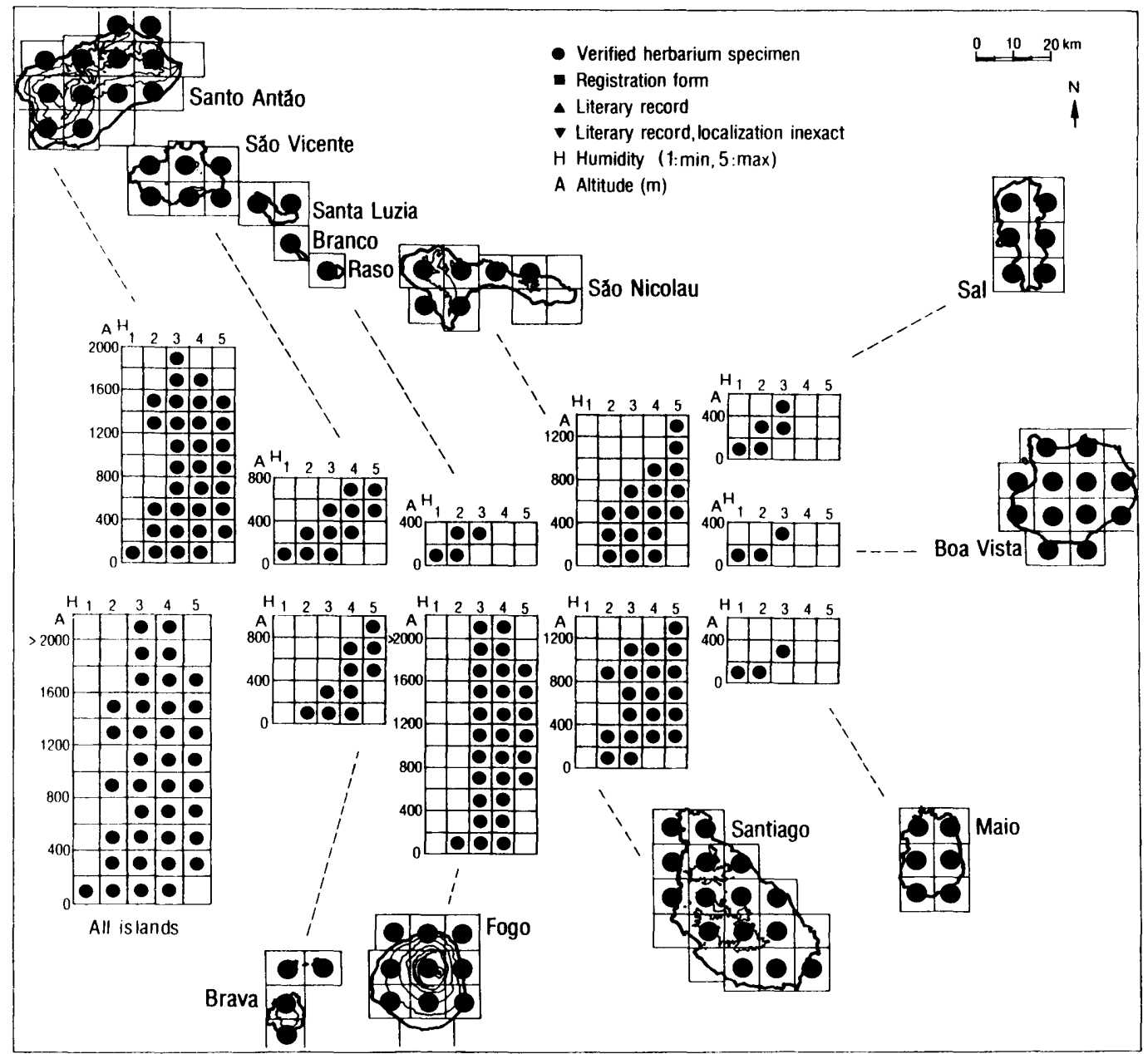

Fig. 9. Geographic areas and combinations of altitude and zone of humidity covered by the data recorded for the endemic taxa of the Cape Verde Islands. H1 - the extremely arid zone; H2 - the arid zone; H3 - the semiarid zone; H4 - the subhumid zone; H5 - the humid zone.

their occurrences in zones of humidity (xerophytes, mesophytes, and hygrophytes) and three groups based on their main altitudinal distribution (coastal taxa, altitudinally ubiquitous taxa. and montane taxa). Thus, we used the terms xerophyte, mesophyte, and hygrophyte, which usually refer to conditions of the local habitat, in a more general sense.

The degree of morphological variation within the endemic taxa (cf. Tab. 4) was compared to the following estimates of the geographic and ecological amplitude of the taxa: (1) size of geographic distribution (as number of islands); (2) amplitude with respect to humidity (as number of zones of humidity); (3) main altitudinal amplitude; and (4) amplitude 
with respect to a combination of humidity and altitude (as number of scores in the main table in the ecogeographic map).

\section{KARYOLOGY}

New chromosome counts were obtained from plants raised in Berlin. Root tips were pretreated with $0.002 \mathrm{M}$ hydroxyquinoline for $2-4 \mathrm{~h}$ at $5{ }^{\circ} \mathrm{C}$, fixed in $96 \%$ ethanol/glacial acetic acid (3:1), hydrolyzed in 1-2 N HCl for $10-15 \mathrm{~min}$ at $60^{\circ} \mathrm{C}$, stained in aceto-orcein and squashed (vouchers are deposited in B). All previously published chromosome numbers counted in Capeverdean endemics were compiled based on the literature cited in a checklist for Macaronesian plants (Borgen 1977) and more recent papers (see Tab. 12 for references). Chromosome numbers of the most closely related taxa of the Capeverdean endemics were extracted from various chromosome indices (Bolkhovskikh et al. 1969, Moore 1973, 1974, 1977, 1982, Goldblatt 1981, 1984, 1985, 1988, Goldblatt \& Johnson 1990, Ardévol González et al. 1993).

The system of Favarger \& Contandriopoulos (1961) was used for classification of the Capeverdean endemics based on their ploidal level. This system has earlier been applied to the Canarian (Bramwell et al. 1972, Borgen 1979) and the Madeiran flora (Dahlgaard 1994). Diploids and three types of polyploids were distinguished based on their putative differences in age (Favarger \& Contandriopoulos 1961; somewhat modified): (1) diploid - the taxon has the lowest chromosome number in its family (or subfamily or tribe), or the number do not have a simple polyploid relationship to an even lower number in the family; (2) palaeopolyploid - the taxon has the lowest chromosome number in its genus (or subgenus or section), and this number is polyploid relative to chromosome numbers found in other genera (or subgenera or sections) in the family (or subfamily or tribe); (3) mesopolyploid - the taxon is polyploid relative to other taxa belonging to the same genus (or subgenus or section), but not relative to the same species or group of very closely related species; (4) neopolyploid - the taxon (or population) is polyploid relative to other taxa (or populations) belonging to the same species or group of very closely related species. In practice, it may be difficult to distinguish between meso- and neopolyploids, and in this study, we restricted the category of neopolyploids to those polyploids which have related taxa at lower ploidal levels in the Capeverdean flora.

Four types of endemics were recognized based on the ploidal level of the endemic and that of its most closely related taxon: (1) palaeoendemic - the taxon is diploid or palaeopolyploid and belongs to a monotypic genus, subgenus, or section; (2) schizoendemic - the taxon is diploid or old-polyploid (palaeopolyploid or mesopolyploid) with closely related taxa at the same ploidal level; (3) patroendemic - the taxon is diploid or old-polyploid with closely related taxa at higher ploidal levels; the closely related taxa are young polyploids (meso- or neopolyploids); (4) apoendemic - the taxon is polyploid with closely related taxa at diploid or lower polyploid level; the endemic is a young polyploid (meso- or neopolyploid). 
Tab. 3. Definitions of conservation categories for the Cape Verde Islands (after Leyens \& Lobin 1996), somewhat modified from the latest IUCN categories (cf. Mace \& Stuart 1994).

$\begin{array}{ll}\text { EX } & \text { Extinct } \\ \text { PA } & \text { Prolonged Absence } \\ \text { CR } & \text { Critically Endan } \\ \text { EN } & \text { Endangered } \\ \text { VU } & \text { Vulnerable } \\ \text { I } & \text { Indeterminate } \\ & \\ \text { R } & \text { Rare } \\ & \\ \text { LR } & \text { Lower Risk } \\ \text { DD } & \text { Data Deficient }\end{array}$

A taxon is Extinct when there is no reasonable doubt that the last individual has died

A taxon is Prolonged Absence when it is likely that the last individual has died. The taxon has been searched for for decade(s), but too little time has passed to assume extinction with certainty

A taxon is Critically Endangered when it is facing an extremely high risk of extinction in the wild in the immediate future if the causal factors continue operating

A taxon is Endangered when its populations are significantly becoming smaller or already have disappeared on individual islands or in large areas. The taxon is thus facing a very high risk of extinction in the wild in the near future

A taxon is Vulnerable when its populations are becoming smaller or already have locally disappeared. The taxon is thus facing a high risk of extinction in the wild in medium-term future

A taxon is Indeterminate when it is assumed to belong to one of the categories $\mathrm{CR}, \mathrm{EN}$, or $\mathrm{VU}$, but more data are needed for final classification

A taxon is Rare when it always has been rare and/or occurs in a rare habitat only

A taxon is Lower Risk when it has been evaluated and does not satisfy the criteria for any of the above-listed categories

A taxon is Data Deficient when an assessment of its risk of extinction cannot be made because of inadequate information

\footnotetext{
${ }^{1}$ The Indeterminate category provides a useful tool in regions where data on the exact decline of taxa are missing, as is the case in many tropic and subtropic countries. Thus, although a taxon obviously is threatened, it is often not possible to distinguish between CR, EN, or VU. We therefore continue to use the Indeterminate category although it has been eliminated from the latest IUCN categories (Mace \& Stuart 1994).

${ }^{2}$ For island systems with their often naturally small, geographically restricted populations, a category is needed to call attention to taxa that not necessarily are threatened at the moment, but that may become extinct very rapidly in case of changing conditions. Thus, we continue to use the Rare category although it has been included in the Vulnerable category by the latest IUCN Species Survival Commission (Mace \& Stuart 1994).
}

\section{CONSERVATION}

The status of each endemic taxon was evaluated for individual islands and the entire archipelago based on its abundance, ecology, and distribution. This evaluation was also based on the frequency and dates of observations, number of populations on different islands, 
exploration intensity of different areas, population sizes and potential decline, and the extent and nature of human influence in various areas. Field work particularly aimed at evaluating the conservation status of the taxa and to recognize particular areas for conservation was carried out in cooperation with Capeverdean authorities in 1993, 1994, and 1995 by WL and NK together with T. Leyens, Bonn, who has contributed significantly to the final evaluation of the taxa (cf. Leyens 1994).

A project aimed at preparing an official Red Data List for Capeverdean plants and animals has lately been carried out in parallel to the work leading to the present publication, with WL and NK as two of the participants. This project amended the definitions of Red Data List categories given by IUCN (cf. Mace \& Stuart 1994) for use in the Cape Verde Islands. These definitions have also been adopted here (Tab. 3). The conclusions presented in the official Red Data List for the Cape Verde Islands (Leyens \& Lobin 1996) were based partly on data originally collected for the present publication as well as on data collected particularly for the Red Data List. 


\section{RESULTS}

\section{SYSTEMATIC OVERVIEW}

One genus, Tornabenea (Apiaceae), was accepted as endemic to the Cape Verde Islands. Eighty-two taxa were accepted as endemic at the specific or subspecific level (Tabs 4, 5). This number included 65 endemic species, of which six comprised 13 subspecies, and 10 subspecies of eight non-endemic species. A total of 138 taxa described based on Capeverdean material were not accepted: 82 of these taxa were considered non-endemic or of doubtful taxonomic significance (see list in the taxonomic part), and the 56 remaining taxa were considered synonymous to the accepted taxa. Although many of the accepted species and subspecies showed large morphological variation, this variation was in all cases considered too complex and unstructured geographically and/or ecologically to allow for recognition of taxa at the varietal level. When calculated based on the total vascular flora of the archipelago (621 species), the level of endemism at the species level in Cape Verde Islands was $10.5 \%$. The level of endemism based on the indigenous flora of the islands ( 224 species) was $29.0 \%$.

All of the 82 endemic taxa were angiosperms. The vast majority ( 74 taxa, 90\%) were dicots, belonging to 20 of the totally 24 families, and only eight taxa (10\%) were monocots (Tab. 5). The largest families were Asteraceae with 16 taxa and Brassicaceae with 12 taxa. Medium-sized families were Scrophulariaceae with seven taxa, Apiaceae, Fabaceae, and Plumbaginaceae, each with five taxa, and Boraginaceae and Poaceae, each with four taxa. One third of the families contained more than two thirds of the endemic taxa.

The 82 endemic taxa belonged to 42 genera, giving an average of 1.95 endemic species or subspecies per genus. Seventeen genera comprised more than one endemic taxon (Tab. 6, Fig. 10). The largest genera were Diplotaxis with nine taxa, Limonium, Lotus, and Tornabenea, each with five taxa, and Conyza and Echium, each with four taxa. Twenty-five genera only comprised a single endemic taxon (Fig. 10).

Most of the endemic taxa (67 taxa, $82 \%$ ) were woody perennials, mainly shrubs or subshrubs (Tab. 4). Only two taxa, Phoenix atlantidis and Sideroxylon marginata, were trees. In addition, Euphorbia tuckeyana was sometimes tree-formed. Fifteen taxa (18\%) were herbaceous, eight of them annuals or annuals-to-biennials, and seven of them perennials.

\section{PHYTOGEOGRAPHY}

The holarctic elements comprised almost twice as many endemic Capeverdean taxa as the tropic elements (53 versus 29 taxa, respectively; Tab. 7, Fig. 11). The Canaro-Madeiran element was by far the largest one with its 33 taxa, representing about $40 \%$ of the endemic flora. The next largest elements were the Saharo-Arabian element with 14 taxa, the NWMoroccan element with 12 taxa, and the Sudano-Zambesian-Sindian element with 12 taxa. 
Tab. 4. Synopsis of the endemic vascular flora of the Cape Verde Islands. Minimum altitude and minimum zone of humidity are given in parentheses if these records refer to occasional occurrences in locally particularly suitable sites or to secondary, ephemeral occurrences of the taxon. Phytogeographic elements: WID. HOLARCTIC - Widely holarctic, MEDITERR - Mediterranean, CANARO-MAD - Canaro-Madeiran, NW-MOROCCAN, PALAEOTROP - Palaeotropic, SAHARO-ARAB - Saharo-Arabian, SUDZAMB-SIND - Sudano-Zambesian-Sindian, AFROMONTANE. Ecogeographic elements: n - northern, s - southern, w - western, e eastern, $\mathrm{u}$ - ubiquitous; $\mathrm{x}$ - xerophytic, $\mathrm{m}$ - mesophytic, $\mathrm{h}$ - hygrophytic. Abbreviations of islands: A - Santo Antão, V - São Vicente, L Santa Luzia (incl. Branco and Raso), N - São Nicolau, S - Sal, B - Boa Vista, M - Maio, T - Santiago, F - Fogo, R - Brava (incl. two islets). Zones of humidity: 1 - extremely arid, 2 - arid, 3 - semiarid, 4 - subhumid, 5 - humid. Intra(sub)specific morphological variation: 1 - no significant variation, 2 - some variation, 3 - distinct variation, 4 - High degree of variation. Conservation categories: EX - Extinct, PA - Prolonged Absence, CR - Critically Endangered, EN - Endangered, VU - Vulnerable, I - Indeterminate (but probably CR, EN, or VU), R - Rare, LR - Lower Risk, DD - Data Deficient.

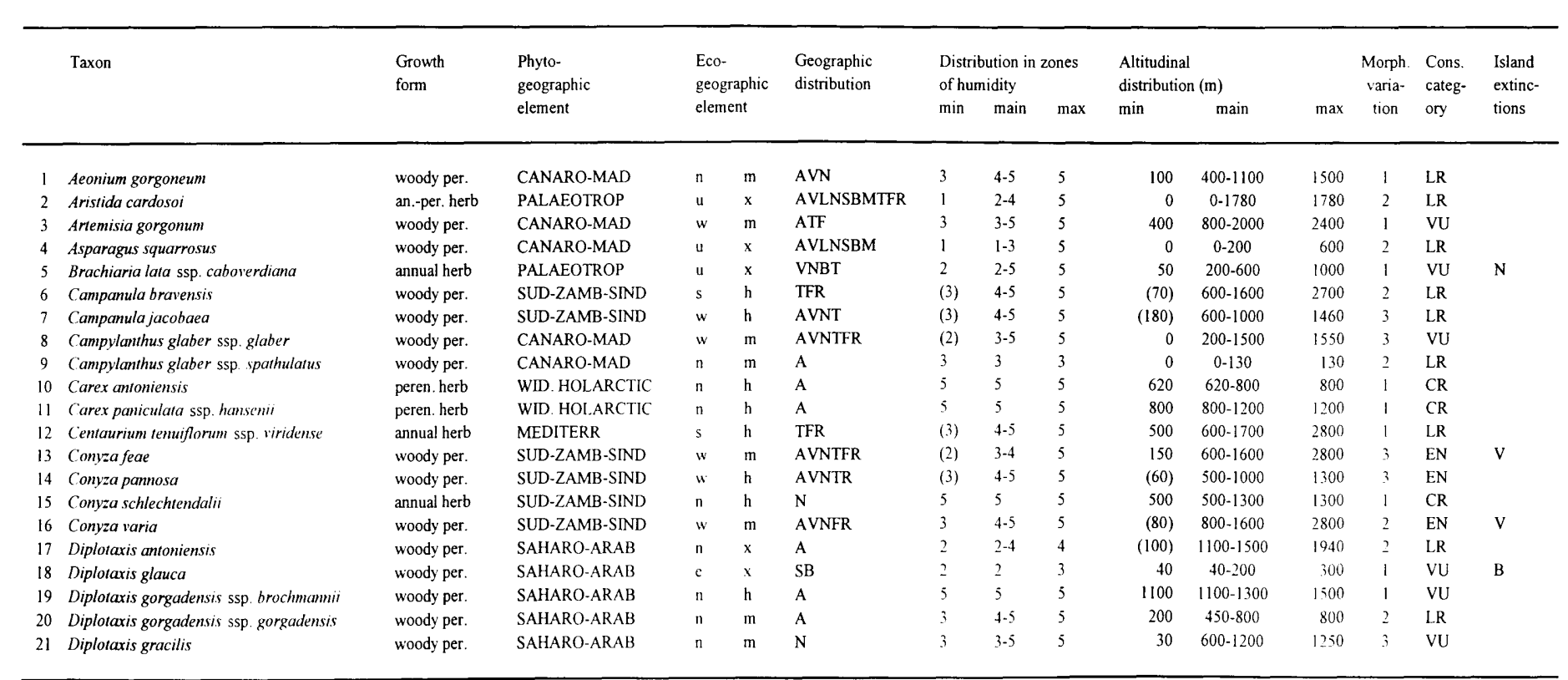


Tab. 4 (cont.)

\begin{tabular}{|c|c|c|c|c|c|c|c|c|c|c|c|c|c|c|c|}
\hline & \multirow[t]{2}{*}{ Taxon } & \multirow[t]{2}{*}{$\begin{array}{l}\text { Growth } \\
\text { form }\end{array}$} & \multirow{2}{*}{$\begin{array}{l}\text { Phyto- } \\
\text { geographic } \\
\text { element }\end{array}$} & \multirow{2}{*}{\multicolumn{2}{|c|}{$\begin{array}{l}\text { Eco- } \\
\text { geographic } \\
\text { element }\end{array}$}} & \multirow[t]{2}{*}{$\begin{array}{l}\text { Geographic } \\
\text { distribution }\end{array}$} & \multicolumn{3}{|c|}{$\begin{array}{l}\text { Distribution in zones } \\
\text { of humidity }\end{array}$} & \multicolumn{3}{|c|}{$\begin{array}{l}\text { Altitudinal } \\
\text { distribution (m) }\end{array}$} & \multirow{2}{*}{$\begin{array}{l}\text { Morph. } \\
\text { varia- } \\
\text { tion }\end{array}$} & \multirow{2}{*}{$\begin{array}{l}\text { Cons. } \\
\text { categ- } \\
\text { ory }\end{array}$} & \multirow{2}{*}{$\begin{array}{l}\text { Island } \\
\text { extinc } \\
\text { tions }\end{array}$} \\
\hline & & & & & & & $\min$ & main & $\max$ & $\min$ & main & $\max$ & & & \\
\hline 22 & Diplotaxis hirta & woody per. & SAHARO-ARAB & s & $\mathrm{m}$ & $\mathrm{F}$ & (2) & $3-4$ & 4 & $(30)$ & $800-2000$ & 2800 & 3 & LR & \\
\hline 23 & Diplotaxis sundingii & woody per. & SAHARO-ARAB & $n$ & $\mathrm{~h}$ & $\mathrm{~N}$ & 5 & 5 & 5 & (270) & $500-640$ & 640 & 1 & $\mathrm{R}$ & \\
\hline 24 & Diplotaris raria & woody per. & SAHARO-ARAB & $\mathrm{s}$ & $\mathrm{m}$ & TR & (2) & $4-5$ & 5 & 20 & $20-920$ & 920 & 3 & I & \\
\hline 25 & Diplotaxis rogelii & woody per. & SAHARO-ARAB & $\mathrm{n}$ & $\mathrm{m}$ & $\mathrm{v}$ & 3 & 3 & 3 & 100 & $100-300$ & 300 & 2 & I & \\
\hline 26 & Echium hypertropicum & woody per. & CANARO-MAD & $\mathrm{s}$ & h & TR & 4 & $4-5$ & 5 & (200) & $500-900$ & 1100 & 1 & EN & \\
\hline 27 & Echium stenosiphon ssp. lindbergii & woody per. & CANARO-MAD & n & h & A & 4 & $4-5$ & 5 & $(260)$ & $800-1400$ & 1470 & 2 & 1 & \\
\hline 28 & Echitum stenosiphon ssp. stenosiphon & woody per. & CANARO-MAD & $\mathrm{n}$ & $\mathrm{m}$ & AVLN & 3 & $3-5$ & 5 & 50 & $200-800$ & 1300 & 3 & LR & \\
\hline 29 & Echism vulcanorum & woody per. & CANARO-MAD & s & $\mathrm{m}$ & $\mathrm{F}$ & 3 & 3 & 3 & $(380)$ & $1200-2000$ & 2400 & 1 & EN & \\
\hline 30 & Eragrostis conertii & peren. herb & AFROMONTANE & w & $\mathrm{h}$ & AVNTF & 4 & 5 & 5 & 500 & $500-1250$ & 1250 & 2 & $\mathrm{R}$ & \\
\hline 31 & Erysinum caboverdeanum & woody per. & CANARO-MAD & s & m & $\mathrm{F}$ & 3 & 3 & 4 & 1550 & $1550-2000$ & 2400 & 1 & EN & \\
\hline 32 & Euphorbia huckeyana & woody per. & MEDITERR & u & $\mathrm{m}$ & AVLNSBTFR & (2) & $3-5$ & 5 & (0) & $300-2000$ & 2500 & 2 & VU & \\
\hline 33 & Forsskaolea procridifolia & woody per. & SUD-ZAMB-SIND & u & $\mathrm{x}$ & AVLNSMTFR & (1) & $2-4$ & 5 & 0 & $0-1700$ & 2700 & 4 & LR & \\
\hline 34 & Frankenia ericifolia ssp. caboverdeana & woody per. & NW-MOROCCAN & $\mathrm{n}$ & m & AVN & 3 & 3 & 5 & 0 & $0-120$ & $(800)$ & 3 & LR & \\
\hline 35 & Frankenia ericifolia ssp. montana & woody per. & NW-MOROCCAN & $\mathrm{n}$ & h & $\mathrm{N}$ & (3) & $4-5$ & 5 & $(70)$ & $300-640$ & 640 & 1 & $\mathrm{EN}$ & \\
\hline 36 & Globularia amygdalifolia & woody per. & CANARO-MAD & w & h & ANTFR & (2) & $4-5$ & 5 & $(100)$ & $400-2200$ & 2400 & 2 & vU & \\
\hline 37 & Helianthemum gorgoneum & woody per. & CANARO-MAD & w & $\mathrm{m}$ & ALFR & (2) & $3-4$ & 5 & 0 & $0-1800$ & 2200 & 3 & LR & \\
\hline 39 & Kickxia elegans ssp. eleganıs & woody per. & SAHARO-ARAB & u & $x$ & AVLNSBMTFR & (1) & $2-4$ & 5 & 0 & $0-600$ & 950 & 3 & LR & \\
\hline 40 & Kickxia elegans ssp. webbiana & woody per. & SAHARO-ARAB & $\mathrm{n}$ & $\mathrm{m}$ & A & 3 & $3-4$ & 4 & 200 & $200-550$ & 790 & 2 & LR & \\
\hline 41 & Lannaea gorgadensis & woody per. & SUD-ZAMB-SIND & $n$ & in & AVN & 3 & 3 & 5 & 20 & $100-450$ & 700 & 2 & LR & \\
\hline 42 & Launaea picridioides & woody per. & NW-MOROCCAN & $\mathrm{n}$ & in & AVLN & 3 & $3-4$ & 5 & 20 & $200-900$ & 1400 & 2 & LR & \\
\hline 43 & Lamaea thalassica & woody per. & SUD-ZAMB-SIND & s & $\mathrm{m}$ & $\mathrm{R}$ & 3 & $4-5$ & 5 & 50 & $300-500$ & 640 & 1 & $\mathrm{R}$ & \\
\hline 44 & Larandula rotundifolia & woody per. & SAHARO-ARAB & w & $\mathrm{m}$ & AVNTF & (2) & 3-4 & 5 & $(0)$ & $400-1500$ & 2400 & 3 & LR & \\
\hline 45 & I.monium braunii & peren. herb & CANARO-MAD & w & in & ANFR & (2) & 3 & 3 & 0 & $0-60$ & 100 & 2 & LR & \\
\hline 46 & L.monium brunneri & peren. herb & CANARO-MAD & u & $\mathrm{x}$ & VLS & 2 & 2 & 2 & 0 & 0.50 & 50 & 1 & LR & \\
\hline 47 & l.monium jovi-barba & woody per. & CANARO-MAD & $\mathrm{n}$ & $\mathrm{h}$ & $\mathrm{VN}$ & (3) & $4-5$ & 5 & $(50)$ & $200-600$ & 770 & 1 & $\mathrm{R}$ & \\
\hline 48 & Limonium lobinii & woody per. & CANARO-MAD & s & h & $\mathrm{T}$ & 5 & 5 & 5 & 550 & $550-800$ & 800 & 1 & $\mathrm{R}$ & \\
\hline 49 & L.monium sundingii & woody per. & CANARO-MAD & $n$ & h & $\mathrm{N}$ & 5 & 5 & 5 & 550 & $550-700$ & 700 & 1 & $\mathrm{R}$ & \\
\hline 50 & I.obularia canariensis ssp. fruticosa & woody per. & CANARO-MAD & w & $\mathrm{m}$ & ANTFR & 3 & $4-5$ & 5 & 100 & $400-1250$ & 1250 & 3 & I & $\mathrm{R}$ \\
\hline 51 & Lobularia canariensis ssp. spathulata & woody per. & CANARO-MAD & $n$ & $m$ & $\mathrm{VN}$ & 3 & $4-5$ & 5 & 300 & $450-700$ & 760 & 3 & 1 & \\
\hline 52 & Lotus arborescens & woody per. & NW-MOROCCAN & $n$ & h & $\mathrm{N}$ & 4 & $4-5$ & 5 & 600 & $600-1000$ & 1000 & 2 & $\mathrm{R}$ & \\
\hline 53 & I.otus brumeri & woody per. & NW-MOROCCAN & " & $\mathrm{x}$ & VSBM & 1 & $1-2$ & 3 & 0 & $0-80$ & 380 & 2 & LR & $\mathrm{v}$ \\
\hline 54 & Lotus jacobaeus & woody per. & NW-MOROCCAN & s & m & $\mathrm{TF}$ & 3 & $3-4$ & 5 & 330 & $600-2000$ & 2300 & 3 & LR & \\
\hline 55 & Lotus lanifolius & woody per. & NW-MOROCCAN & $n$ & $m$ & A & 3 & $3-5$ & 5 & $(200)$ & $600-1600$ & 1600 & 4 & LR & \\
\hline 56 & Ionus purpureus & woody per. & NW-MOROCCAN & u & $x$ & AVNBTFR & (1) & $2-4$ & 5 & 0 & $0-600$ & 1100 & 4 & LR & \\
\hline 57 & Namplius dalıonii ssp. dalionii & woody per. & CANARO-MAD & s & $\mathrm{h}$ & $\mathrm{T}$ & 4 & 5 & 5 & 640 & $800-1020$ & 1020 & 2 & EN & \\
\hline 58 & Vunplius daltonii ssp. vogelii & woody per. & CANARO-MAD & $u$ & $x$ & AVLNMTFR & 2 & $2-4$ & 5 & 0 & $0-800$ & 1940 & 3 & LR & \\
\hline 59 & Vusplius smithii & woody per. & CANARO-MAD & $n$ & h & $\mathrm{N}$ & 5 & 5 & 5 & 900 & $900-1300$ & 1300 & 1 & EN & \\
\hline
\end{tabular}


Tab. 4 (cont.)

\begin{tabular}{|c|c|c|c|c|c|c|c|c|c|c|c|c|c|c|c|}
\hline & \multirow[t]{2}{*}{ Taxon } & \multirow[t]{2}{*}{$\begin{array}{l}\text { Growth } \\
\text { form }\end{array}$} & \multirow{2}{*}{$\begin{array}{l}\text { Phyto- } \\
\text { geographic } \\
\text { element }\end{array}$} & \multirow{2}{*}{\multicolumn{2}{|c|}{$\begin{array}{l}\text { Eco- } \\
\text { geographic } \\
\text { element }\end{array}$}} & \multirow[t]{2}{*}{$\begin{array}{l}\text { Geographic } \\
\text { distribution }\end{array}$} & \multicolumn{3}{|c|}{$\begin{array}{l}\text { Distribution in zones } \\
\text { of humidity }\end{array}$} & \multicolumn{3}{|c|}{$\begin{array}{l}\text { Altitudinal } \\
\text { distribution (m) }\end{array}$} & \multirow{2}{*}{$\begin{array}{c}\text { Morph. } \\
\text { varia- } \\
\text { tion }\end{array}$} & \multirow{2}{*}{$\begin{array}{l}\text { Cons. } \\
\text { categ- } \\
\text { ory }\end{array}$} & \multirow{2}{*}{$\begin{array}{l}\text { Island } \\
\text { extinc } \\
\text { tions }\end{array}$} \\
\hline & & & & & & & $\min$ & main & $\max$ & $\min$ & main & $\max$ & & & \\
\hline 60 & Papaver gorgoneum ssp. gorgoneum & annual herb & MEDITERR & $w$ & h & NF & (3) & $4-5$ & 5 & 800 & $800-1700$ & 1900 & 2 & vU & \\
\hline 61 & Papaver gorgoneum ssp. theresias & peren. herb & MEDITERR & $\mathrm{n}$ & h & A & (3) & $4-5$ & 5 & 940 & $1200-1400$ & 1450 & 1 & LR & \\
\hline 62 & Paronychia illecebroides & woody per. & MEDITERR & u & $\mathrm{x}$ & AVLNBMTF & 2 & $2-5$ & 5 & 0 & $0-2800$ & 2800 & 4 & LR & \\
\hline 63 & Periploca laevigata ssp. chevalieri & woody per. & CANARO-MAD & w & $\mathrm{m}$ & ANTFR & (2) & $3-4$ & 5 & $(0)$ & $400-1800$ & 2800 & 2 & EN & \\
\hline 64 & Phagnalon melanoleucum & woody per. & CANARO-MAD & $\mathrm{w}$ & $\mathrm{h}$ & AVNTF & (3) & $4-5$ & 5 & 300 & $800-1800$ & 2800 & 2 & LR & \\
\hline 66 & Polycarpaea gayi & woody per. & NW-MOROCCAN & u & m & AVLNSTF & (2) & 3-4 & 5 & 0 & $0-1400$ & 2000 & 4 & LR & vs \\
\hline 67 & Pulicaria burchardii ssp. longifolia & woody per. & NW-MOROCCAN & $\mathrm{e}$ & $\mathrm{x}$ & $\mathrm{s}$ & 1 & 1 & 1 & 0 & $0-10$ & 10 & ? & $\mathrm{DD}$ & \\
\hline 68 & Pulicaria diffusa & woody per. & SUD-ZAMB-SIND & u & $\mathrm{x}$ & SBMTF & 1 & $1-2$ & 2 & 0 & $0-50$ & 370 & 2 & vU & MF \\
\hline 69 & Sarcostemma daltonii & woody per. & SUD-ZAMB-SIND & u & $x$ & AVNSBTFR & 2 & $2-4$ & 5 & 0 & $100-600$ & 1830 & 1 & LR & \\
\hline 70 & Satureja forbesii & woody per. & CANARO-MAD & w & $\mathrm{m}$ & ANTFR & 3 & $3-5$ & 5 & 500 & $800-1600$ & 2830 & 4 & I & \\
\hline 71 & Sideroxylon marginata & woody per. & CANARO-MAD & u & $\mathrm{m}$ & AVN(S)BTFR & (2) & $3-5$ & 5 & $(40)$ & $500-1200$ & 1400 & 3 & EN & $\mathrm{SB}$ \\
\hline 72 & Sonchus daltonii & woody per. & CANARO-MAD & $\mathrm{w}$ & $\mathrm{h}$ & AVNTF & 4 & $4-5$ & 5 & 450 & $800-1800$ & 2200 & 1 & I & \\
\hline 73 & Sporobolus minutus ssp. confertus & annual herb & SUD-ZAMB-SIND & e & $\mathrm{x}$ & SM & 1 & $1-2$ & 2 & 0 & $0-10$ & 10 & 1 & $\mathrm{R}$ & $\mathrm{s}$ \\
\hline 74 & Tolpis farinulosa & woody per. & CANARO-MAD & w & $\mathrm{h}$ & AVFR & 4 & $4-5$ & 5 & (250) & $800-1800$ & 2600 & 3 & I & \\
\hline 75 & Tomabenea аппиа & an.-bi. herb & CANARO-MAD & $\mathrm{s}$ & $\mathrm{h}$ & $\mathrm{T}$ & 4 & $4-5$ & 5 & 340 & $650-1000$ & 1050 & 2 & Vu & \\
\hline 77 & Tomabenea humilis & woody per. & CANARO-MAD & $\mathrm{s}$ & $\mathrm{m}$ & $\mathrm{F}$ & 3 & $3-4$ & 4 & 50 & $100-300$ & 480 & 3 & LR & \\
\hline 78 & Tomabenea insularis & woody per. & CANARO-MAD & $\mathrm{w}$ & $\mathrm{h}$ & VNR & 3 & $4-5$ & 5 & 70 & $600-1200$ & 1300 & 4 & LR & \\
\hline 79 & Tomabenea tenuissima & woody per. & CANARO-MAD & $\mathrm{s}$ & $\mathrm{h}$ & $\mathrm{F}$ & 4 & $4-5$ & 5 & 750 & $1200-1700$ & 1850 & 3 & $\mathrm{VU}$ & \\
\hline 80 & Umbilicus schmidtii & peren. herb & MEDITERR & $\mathrm{w}$ & $\mathrm{h}$ & ANTF & 4 & $4-5$ & 5 & 550 & $800-1600$ & 2000 & 1 & $\mathrm{R}$ & \\
\hline 81 & Verbascum capitis-viridis & an.-bi. herb & NW-MOROCCAN & $u$ & $\mathrm{~m}$ & AVNBMT & 3 & 3-5 & 5 & $(0)$ & $400-1400$ & 1600 & 4 & VU & VBM \\
\hline 82 & Verbascum cystolithicum & woody per. & NW-MOROCCAN & $\mathrm{s}$ & $\mathrm{m}$ & $\mathrm{F}$ & (2) & 3 & 4 & $(100)$ & $1300-2800$ & 2800 & 2 & LR & \\
\hline
\end{tabular}


Tab. 5. Systematic groups in the endemic vascular flora of the Cape Verde Islands. After the number of subspecies, the number of species they belong to is given in parenthesis.

\begin{tabular}{|c|c|c|c|c|c|c|c|c|}
\hline & Family & $\begin{array}{r}\text { No. of genera } \\
\text { with endemic } \\
\operatorname{taxa}\end{array}$ & $\begin{array}{r}\text { No. of } \\
\text { endemic } \\
\text { species }\end{array}$ & $\begin{array}{l}\text { No. of subspecies } \\
\text { of endemic species }\end{array}$ & $\begin{array}{r}\text { No. of endemic } \\
\text { subspecies of } \\
\text { non-endemic species }\end{array}$ & $\begin{array}{l}\text { Total no. of } \\
\text { endemic taxa }\end{array}$ & $\begin{array}{r}\% \text { of } \\
\text { endemic } \\
\text { flora }\end{array}$ & $\begin{array}{r}\text { No. of } \\
\text { endemic taxa } \\
\text { per genus }\end{array}$ \\
\hline \multirow[t]{18}{*}{ Dicots } & Apiaceae & 1 & 5 & & & 5 & 6.1 & 5.0 \\
\hline & Asclepiadaceae & 2 & 1 & & $1(1)$ & 2 & 2.4 & 1.0 \\
\hline & Boraginaceae & 1 & 3 & $2(1)$ & & 4 & 4.9 & 4.0 \\
\hline & Brassicaceae & 3 & 9 & $2(1)$ & $2(1)$ & 12 & 14.6 & 4.0 \\
\hline & Campanulaceae & 1 & 2 & & & 2 & 2.4 & 2.0 \\
\hline & Caryophyllaceae & 2 & 2 & & & 2 & 2.4 & 1.0 \\
\hline & Cistaceae & 1 & 1 & & & 1 & 1.2 & 1.0 \\
\hline & Crassulaceae & 2 & 2 & & & 2 & 2.4 & 1.0 \\
\hline & Euphorbiaceae & 1 & 1 & & & 1 & 1.2 & 1.0 \\
\hline & Fabaceae & 1 & 5 & & & 5 & 6.1 & 5.0 \\
\hline & Gentianaceae & 1 & 0 & & $1(1)$ & 1 & 1.2 & 1.0 \\
\hline & Globulariaceae & 1 & 1 & & & 1 & 1.2 & 1.0 \\
\hline & Lamiaceae & 2 & 2 & & & 2 & 2.4 & 1.0 \\
\hline & Papaveraceae & 1 & 1 & $2(1)$ & & 2 & 2.4 & 2.0 \\
\hline & Plumbaginaceae & 1 & 5 & & & 5 & 6.1 & 5.0 \\
\hline & Sapotaceae & 1 & 1 & & & 1 & 1.2 & 1.0 \\
\hline & Scrophulariaceae & 3 & 4 & $5(2)$ & & 7 & 8.5 & 2.3 \\
\hline & Urticaceae & 1 & 1 & & & 1 & 1.2 & 1.0 \\
\hline \multirow[t]{4}{*}{ Monocots } & Arecaceae & 1 & 1 & & & 1 & 1.2 & 1.0 \\
\hline & Asparagaceae & 1 & 1 & & & 1 & 1.2 & 1.0 \\
\hline & Cyperaceae & 1 & 1 & & $1(1)$ & 2 & 2.4 & 2.0 \\
\hline & Poaceae & 4 & 2 & & $2(2)$ & 4 & 4.9 & 1.0 \\
\hline Total & 24 & 42 & 65 & $13(6)$ & $10(8)$ & 82 & 100.0 & 1.95 \\
\hline
\end{tabular}


Tab. 6. Genera with more than one endemic taxon in the Cape Verde Islands.

\begin{tabular}{|c|c|c|c|c|c|}
\hline Genus & Family & $\begin{array}{l}\text { No. of } \\
\text { endemic } \\
\text { species }\end{array}$ & $\begin{array}{c}\text { No. of subspecies } \\
\text { of endemic } \\
\text { species }\end{array}$ & $\begin{array}{l}\text { No. of endemic sub- } \\
\text { species of non- } \\
\text { endemic species }\end{array}$ & $\begin{array}{l}\text { Total no. of } \\
\text { endemic } \\
\text { taxa }\end{array}$ \\
\hline Diplotaxis & Brassicaceae & 8 & 2 & & 9 \\
\hline Limonium & Plumbaginaceae & 5 & & & 5 \\
\hline Lotus & Fabaceae & 5 & & & 5 \\
\hline Tornabenea & Apiaceae & 5 & & & 5 \\
\hline Conyza & Asteraceae & 4 & & & 4 \\
\hline Echium & Boraginaceae & 3 & 2 & & 4 \\
\hline Kickxia & Scrophulariaceae & 1 & 3 & & 3 \\
\hline Launaea & Asteraceae & 3 & & & 3 \\
\hline Nauplius & Asteraceae & 2 & 2 & & 3 \\
\hline Campanula & Campanulaceae & 2 & & & 2 \\
\hline Campylanthus & Scrophulariaceae & 1 & 2 & & 2 \\
\hline Carex & Cyperaceae & 1 & & 1 & 2 \\
\hline Frankenia & Frankeniaceae & & & 2 & 2 \\
\hline Lobularia & Brassicaeae & & & 2 & 2 \\
\hline Papaver & Papaveraceae & 1 & 2 & & 2 \\
\hline Pulicaria & Asteraceae & 1 & & 1 & 2 \\
\hline Verbascum & Scrophulariaceae & 2 & & & 2 \\
\hline Total & & 44 & 13 & 6 & 57 \\
\hline
\end{tabular}

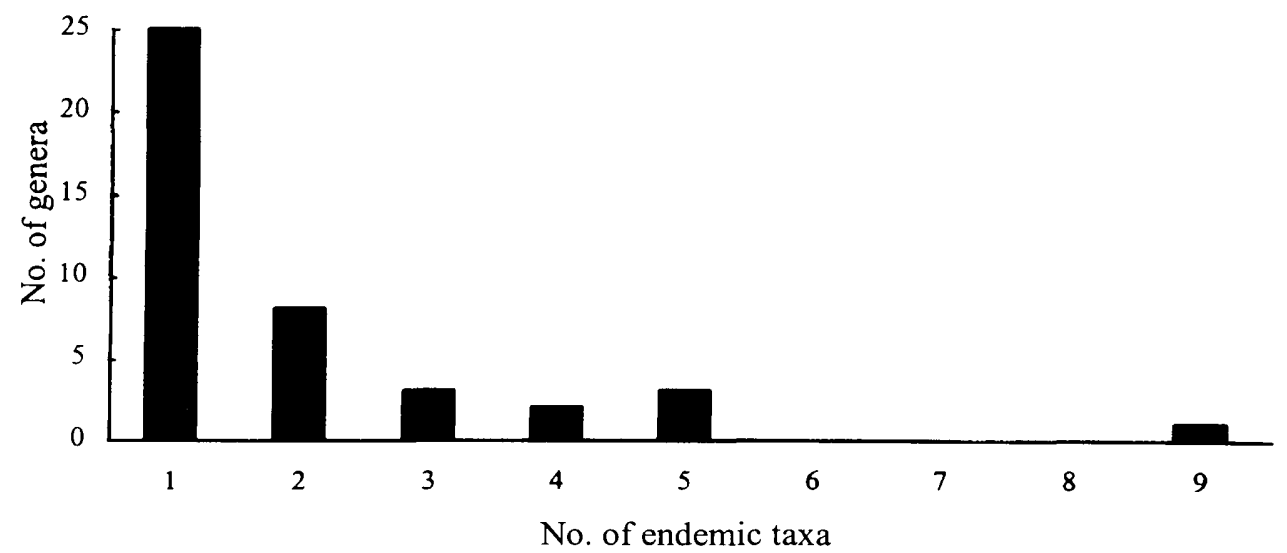

Fig. 10. Within-genus diversity in the endemic flora of the Cape Verde Islands, expressed as the number of endemic species and subspecies in each genus (e.g., each of 25 genera contains a single endemic taxon, and one genus contains nine endemic taxa). 


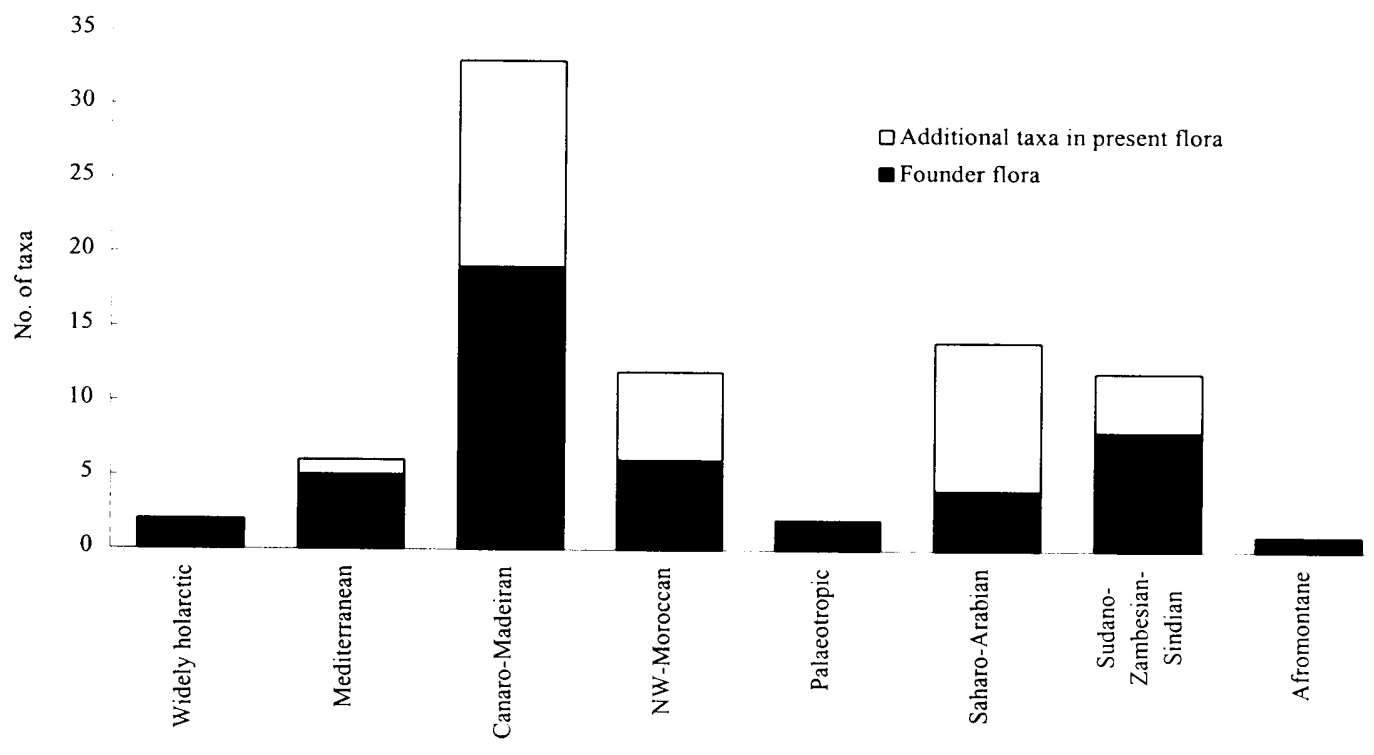

Fig. 11. Phytogeography of the endemic flora of the Cape Verde Islands and the putative founders of this flora.

Each of these four largest elements contained at least one large genus: Echium, Limonium, and Tornabenea in the Canaro-Madeiran element, Diplotaxis in the Saharo-Arabian element. Lotus in the NW-Moroccan element, and Conyza in the Sudano-Zambesian-Sindian element. The Mediterranean element was fifth in size, comprising six endemic taxa. The remaining three elements, the Widely holarctic, the Palaeotropic, and the Afromontane element, each contained only one or two taxa (Tab. 7, Fig. 11).

Based on the systematic relationships of the endemic groups, we estimated that a minimum number of 47 founder taxa evolved into the present endemic flora of 82 species and subspecies in the archipelago (Tab. 7). Twenty-five endemic taxa were the only endemic representatives of their genera in the Cape Verde Islands, thus representing 25 founder taxa. The remaining 57 taxa represented 17 genera (Tab. 6) and belonged to 22 groups of closely related taxa, and each of these groups probably evolved from a single ancestral taxon colonizing the Cape Verde Islands. In 12 genera (Campanula, Campylanthus, Diplotaxis. Echium, Frankenia, Kickxia, Lobularia, Lotus, Nauplius, Papaver, Tornabenea, and Verbascum), all endemic taxa appeared to be very closely related and were probably derived from a single founder taxon. The taxa of the five remaining genera were divided into ten groups of closely related taxa which probably were derived from a single founder taxon (Tab. 7). These genera and groups are Carex (1: C. antoniensis; 2: C. paniculata ssp. hansenii), Conyza (1: C. feae, C. pannosa, C. varia; 2: C. schlechtendalii), Launaea (1: L. picridioides; 
Tab. 7. Phytogeography of the endemic flora of the Cape Verde Islands and the putative founders of this flora. The differentiation index is calculated as the ratio (number of present taxa)/(number of founder taxa).

\begin{tabular}{|c|c|c|c|c|c|c|}
\hline \multirow{2}{*}{$\begin{array}{l}\text { Phytogeographic element in } \\
\text { the Cape Verde Island }\end{array}$} & \multicolumn{2}{|c|}{ Present taxa } & \multicolumn{2}{|c|}{ Founder taxa } & \multirow{2}{*}{$\begin{array}{l}\text { Differentia- } \\
\text { tion index }\end{array}$} & \multirow{2}{*}{$\begin{array}{l}\text { Taxon or groups of taxa assumed to } \\
\text { have evolved from a single founder taxon }\end{array}$} \\
\hline & No. & $\%$ & No. & $\overline{\%}$ & & \\
\hline Widely holarctic & 2 & 2.4 & 2 & 4.3 & 1.0 & $\begin{array}{l}\text { Carex antoniensis } \\
\text { Carex paniculata ssp. hansenii }\end{array}$ \\
\hline Mediterranean & 6 & 7.3 & 5 & 10.6 & 1.2 & $\begin{array}{l}\text { Centaurium tenuiflorum ssp. viridense } \\
\text { Euphorbia tuckeyana } \\
\text { Papaver gorgoneum (two subspecies) } \\
\text { Paronychia illecebroides } \\
\text { Umbilicus schmidtii }\end{array}$ \\
\hline Canaro-Madeiran & 33 & 40.2 & 19 & 40.4 & 1.7 & $\begin{array}{l}\text { Aeonium gorgoneum } \\
\text { Artemisia gorgonum } \\
\text { Asparagus squarrosus } \\
\text { Campylanthus glaber (two subspecies) } \\
\text { Echium (four taxa) } \\
\text { Erysimum caboverdeanum } \\
\text { Globularia amygdalifolia } \\
\text { Helianthemum gorgoneum } \\
\text { Limonium braumii, } L \text {. brunneri } \\
\text { Limonium jovi-barba, L. lobinii, L. sundingii } \\
\text { Lobularia canariensis (two subspecies) } \\
\text { Nauplius daltonii (two subspecies). N. smithii } \\
\text { Periploca laevigata ssp. chevalieri } \\
\text { Phagnalon melanoleucum } \\
\text { Satureja forbesii } \\
\text { Sideroxylon marginata } \\
\text { Sonchus daltonii } \\
\text { Tolpis farinulosa } \\
\text { Tornabenea (five species) }\end{array}$ \\
\hline NW-Moroccan & 12 & 14.6 & 6 & 12.8 & 2.0 & $\begin{array}{l}\text { Frankenia ericifolia (two subspecies) } \\
\text { Launaea picridioides } \\
\text { Lotus (five species) } \\
\text { Polycarpaea gayi } \\
\text { Pulicaria burchardii ssp. longifolia } \\
\text { Verbascum (two species) }\end{array}$ \\
\hline Palaeotropic & 2 & 2.4 & 2 & 4.3 & 1.0 & $\begin{array}{l}\text { Aristida cardosoi } \\
\text { Brachiaria lata ssp. caboverdiana }\end{array}$ \\
\hline Saharo-Arabian & 14 & 17.1 & 4 & 8.5 & 3.5 & $\begin{array}{l}\text { Diplotaxis (nine taxa) } \\
\text { Kickxia elegans (three subspecies) } \\
\text { Lavandula rotundifolia } \\
\text { Phoenix atlantidis }\end{array}$ \\
\hline Sudano-Zambesian-Sindian & 12 & 14.6 & 8 & 17.0 & 1.5 & $\begin{array}{l}\text { Campanula (two species) } \\
\text { Conyza feae, C. pannosa, C. varia } \\
\text { Conyza schlechtendalii } \\
\text { Forsskaolea procridifolia } \\
\text { Launaea gorgadensis, } L . \text { thalassica } \\
\text { Pulicaria diffusa } \\
\text { Sarcostemma daltonii } \\
\text { Sporobolus minutus ssp. confertus }\end{array}$ \\
\hline Afromontane & 1 & 1.2 & 1 & 2.1 & 1.0 & Eragrostis conertii \\
\hline $\begin{array}{l}\text { Total holarctic elements } \\
\text { Total tropic elements }\end{array}$ & $\begin{array}{l}53 \\
29\end{array}$ & $\begin{array}{l}64.6 \\
35.4\end{array}$ & $\begin{array}{l}32 \\
15\end{array}$ & $\begin{array}{l}68.1 \\
31.9\end{array}$ & $\begin{array}{l}1.7 \\
1.9\end{array}$ & \\
\hline Total & 82 & 100.0 & 47 & 100.0 & 1.7 & \\
\hline
\end{tabular}


2: L. gorgadensis, L. thalassica), Limonium (1: L. braunii, L. brunneri; 2: L. jovi-barba, L. lobinii, L. sundingii), and Pulicaria (1: P. burchardii ssp. longifolia; 2: P. diffusa).

The phytogeographic spectrum of the putative founder flora differed somewhat from that of the present endemic flora (Tab. 7, Fig. 11). The holarctic dominance was even more pronounced in the founder flora than in the present flora. The holarctic proportion increased from $64.6 \%$ to $68.1 \%$, and the tropic proportion decreased from $35.4 \%$ to $31.9 \%$.

The average differentiation index for the endemic flora was 1.74 , i.e., each founder taxon had differentiated, on the average, into 1.74 present taxa. The tropic founders had differentiated into an average of 1.93 taxa, whereas the holarctic founders had differentiated into an average of 1.66 taxa. This difference was mainly determined by the high level of differentiation in the Saharo-Arabian Diplotaxis, in which a single founder probably had differentiated into the nine present taxa. Thus, the Saharo-Arabian element was less important in the founder flora, where it probably only was represented by four taxa $(8.5 \%$ of the founders), compared to its 14 taxa (17.1\%) in the present endemic flora.

\section{DISTRIBUTIONAL PATTERNS}

\section{Individual island floras, areas, and altitudes}

The number of endemic species and subspecies on individual islands varied from 11 on Maio, representing only $13 \%$ of the entire endemic flora, to 47 on Santo Antão, representing $57 \%$ of the entire endemic flora (Tab. 8, Fig. 12). A total of 30 endemic taxa, about one third of the entire endemic flora, were restricted to a single island. In contrast to the driest islands, where virtually no single-island endemics have evolved, there were several endemics restricted to Santo Antão, São Nicolau, or Fogo (11, 7, and 6, respectively). The total number of endemics as well as the number of single-island endemics strongly increased from the eastern via the southern to the northern island group (Tab. 8).

The number of endemic taxa was positively correlated with area of the individual islands, although not significantly so $(r=0.48, p=0.16, n=10$; correlation with $\log$ (area): $r$ $=0.49, \mathrm{p}=0.15)$. The relationship was particularly strong within the northern and within the southern island group, especially when based on a logarithmic scale (Fig. 13). Within the northern island group, the number increased abruptly with area from 13 on the smallest island, Santa Luzia, via 35 on São Vicente to 45 on São Nicolau, but it increased only slightly further to the largest island, Santo Antão $(r=0.81, p=0.19, n=4$; correlation with $\log$ (area): $r=$ $0.97, p=0.03$ ). Within the southern island group, the number of endemics increased with area from 25 on Brava to 37 on Fogo, but it did not increase further with area $(r=0.83, p=0.38, n$ $=3$; correlation with $\log ($ area): $r=0.96, p=0.17$ ). Santiago also harboured 37 endemic taxa, although this island is more than twice as large as Fogo. There was no correlation between number of taxa and area within the eastern island group $(r=0.16, p=0.90, n=3$; correlation with $\log$ (area): $r=0.08, p=0.95$ ).

The number of endemic taxa was also positively correlated with maximum island altitude $(\mathrm{r}=0.76, \mathrm{p}=0.01, \mathrm{n}=10)$, most strongly so for the northern $(\mathrm{r}=0.88, \mathrm{p}=0.13, \mathrm{n}=$ 4) and the southern island groups $(r=0.67, p=0.53, n=3$; Fig. 14). The lowermost four 
Tab. 8. Endemism, area (after Westermann 1969), and altitude of the Capeverdean islands.

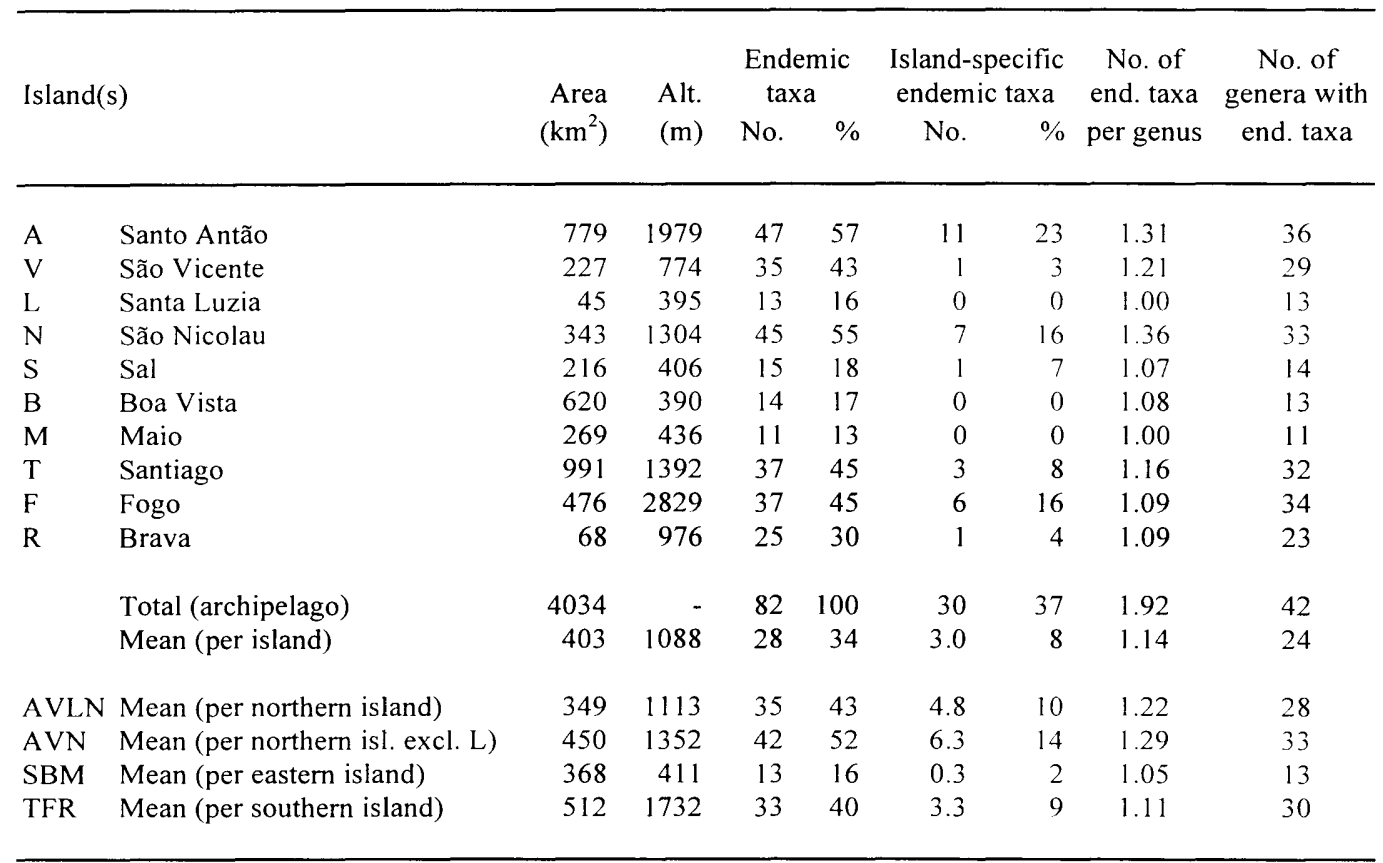

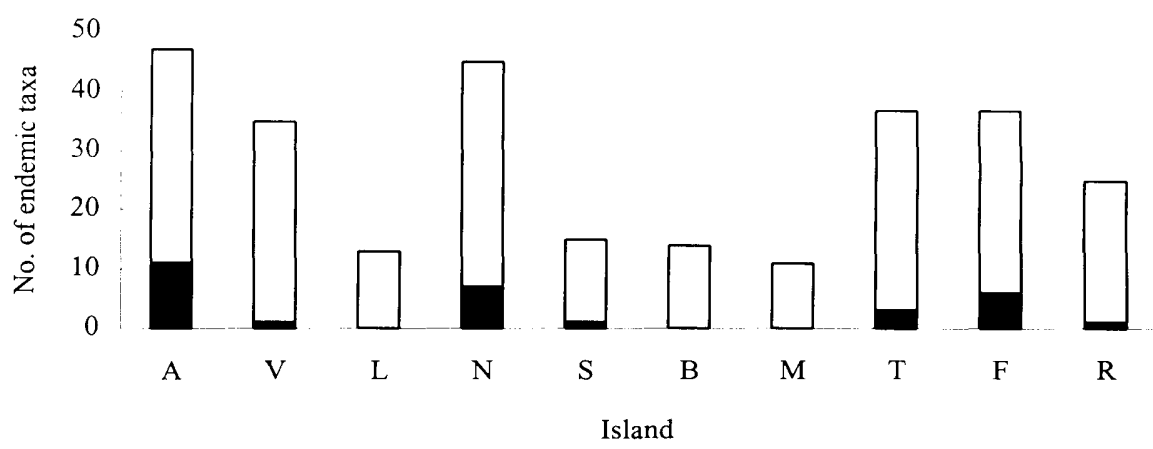

Fig. 12. Number of endemic species and subspecies on individual Capeverdean islands. Taxa restricted to a single island are shaded. Islands: A - Santo Antão, V - São Vicente, L - Santa Luzia, N - São Nicolau, S - Sal, B - Boa Vista, M - Maio, T - Santiago, F - Fogo, R - Brava. 


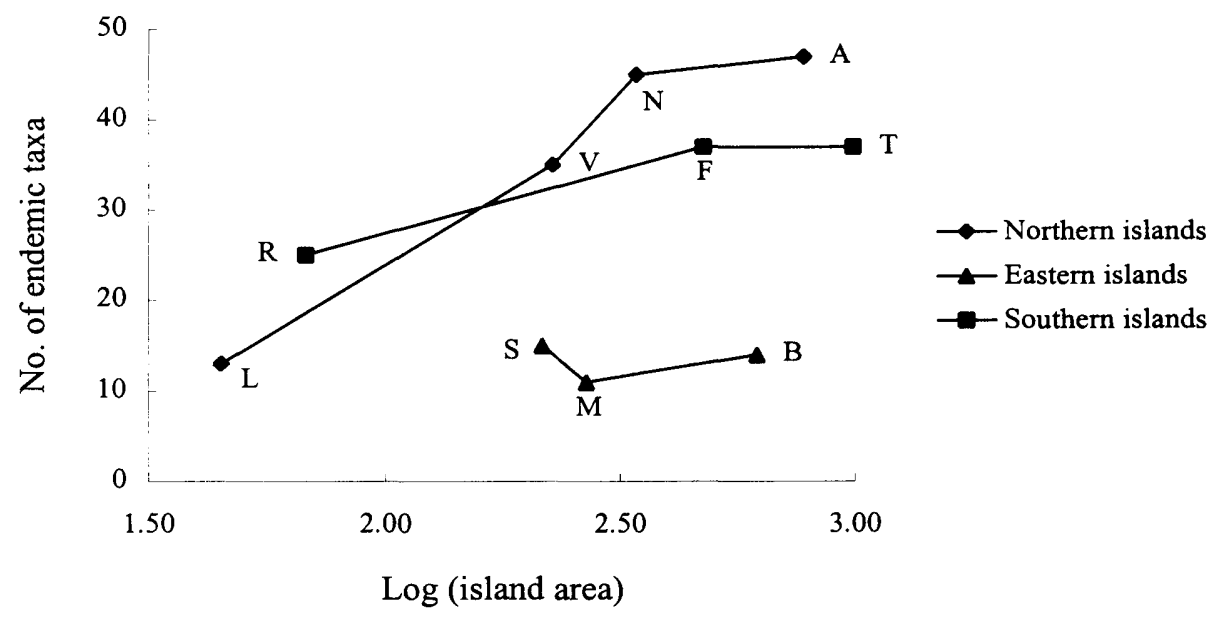

Fig. 13. Relationship between area and number of endemic species and subspecies on individual Capeverdean islands. Islands: A - Santo Antão, V - São Vicente, L - Santa Luzia, N - São Nicolau, S - Sal, B - Boa Vista, M - Maio, T - Santiago, F - Fogo, R - Brava.

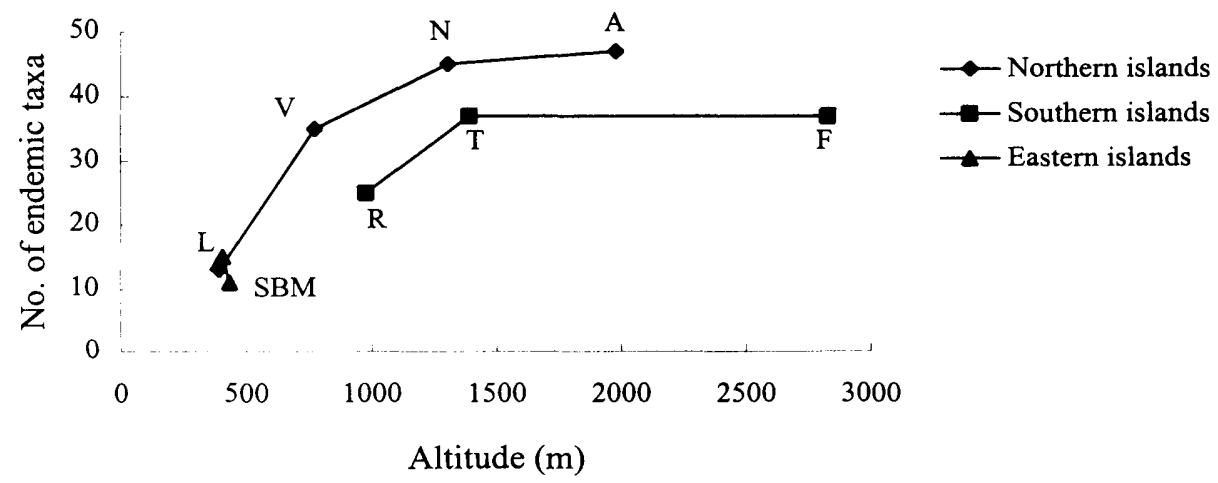

Fig. 14. Relationship between altitude and number of endemic species and subspecies on individual Capeverdean islands. Islands: A - Santo Antão, V - São Vicente, L - Santa Luzia, N - São Nicolau, S - Sal, B - Boa Vista, M - Maio, T - Santiago, F - Fogo, R - Brava. 
islands (390-436 m) harboured only 11-15 endemic taxa. The number of taxa increased strongly with altitude up to 37-45 endemics on islands with mountains at about $1300-1400 \mathrm{~m}$ (São Nicolau and Santiago), corresponding to the upper limit of the humid zone (cf. Figs 2-4). and showed virtually no increase above this limit.

The number of genera with endemic taxa was only slightly higher in the northern island group than in the southern one (Tab. 8). The main reason for the higher number of endemics on the northern islands was thus a higher degree of differentiation within each genus. The mean number of endemic taxa per genus was 1.29 on the three main northern islands and only 1.11 on the southern islands.

\section{Floristic similarity between islands}

Fifty-two of the 82 endemic taxa were shared between two or more islands (Fig. 15). Most of these taxa (38) were shared between two to five islands, and only 14 taxa were shared among six to ten islands. This abrupt decrease (Fig. 15) reflected the conspicuous ecological difference between the mountainous western islands and the flat eastern islands. Many taxa occurred on several of the six western islands, but only a few taxa occurred on western as well as eastern islands. The most widely distributed taxa were Aristida cardosoi and Kickxia elegans ssp. elegans, which occurred on all of the ten main islands, Euphorbia tuckeyana and Forsskaolea procridifolia, which occurred on nine islands, and Nauplius daltonii ssp. vogelii. Paronychia illecebroides, Sarcostemma daltonii, and Sideroxylon marginata, which occurred (or have occurred) on eight islands.

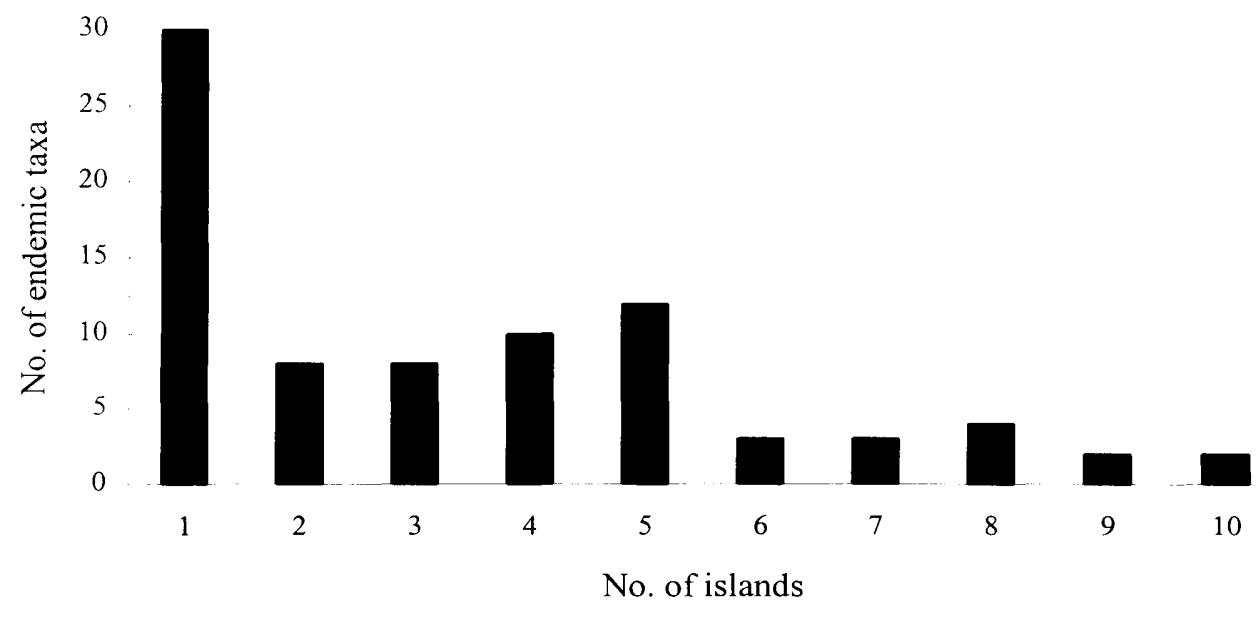

Fig. 15. Number of endemic species and subspecies restricted to a single Capeverdean island or shared between two or more islands. 
Tab. 9. Floristic similarity between Capeverdean islands, expressed as Dice indices based on shared endemic taxa.

\begin{tabular}{lccccccccc}
\hline & S. Antão & S. Vicente & S. Luzia & S. Nicolau & Sal & Boa Vista & Maio & Santiago & Fogo \\
& & & & & & & & & \\
S. Vicente & 0.68 & & & & & & & \\
S. Luzia & 0.37 & 0.46 & & & & & & \\
S. Nicolau & 0.72 & 0.78 & 0.34 & & & & & \\
Sal & 0.26 & 0.40 & 0.57 & 0.27 & & & & \\
Boa Vista & 0.30 & 0.45 & 0.44 & 0.34 & 0.69 & & & \\
Maio & 0.24 & 0.35 & 0.58 & 0.25 & 0.62 & 0.64 & & \\
Santiago & 0.62 & 0.58 & 0.32 & 0.63 & 0.35 & 0.43 & 0.33 & \\
Fogo & 0.62 & 0.50 & 0.32 & 0.59 & 0.31 & 0.31 & 0.25 & 0.70 & \\
Brava & 0.53 & 0.47 & 0.32 & 0.51 & 0.30 & 0.31 & 0.22 & 0.61 & 0.65 \\
& & & & & & & & & \\
\hline
\end{tabular}

The most similar island pair based on shared endemic taxa was São Vicente and São Nicolau. These islands shared $63 \%$ of their entire endemic flora, and $89 \%$ of the São Vicente flora was also found on São Nicolau (similarity coefficient 0.78; Tab. 9). Slightly less similar island pairs were Santo Antão and São Nicolau, Santiago and Fogo, and Santo Antão and São Vicente. The similarities between the species-poor eastern islands were somewhat lower. The highest similarity between islands belonging to different geographic island groups was between one northern island, São Nicolau, and one southern island, Santiago (0.63). The least similar island pairs were those consisting of one eastern and one western island, e.g., Maio and Brava (0.22), and Maio and Santo Antão (0.24; Tab. 9).

The UPGMA and CA/MST analyses based on the taxon $\times$ island matrix showed a similar, distinct grouping of islands, almost perfectly matching their geographic positions (Figs 16, 17). There was two distinct highest-level clusters in the UPGMA analysis: (1) the six major western islands, and (2) the three eastern islands (in one subcluster) and Santa Luzia. The 'western cluster' was subdivided into one 'northern cluster' with Santo Antão, São Vicente, and São Nicolau, and one 'southern cluster' with Santiago, Fogo, and Brava (Fig. 16).

In the CA analysis, $57.3 \%$ of the variation was accounted for by the first three axes (Fig. 17). This analysis clarified the position of the northern, ecologically deviating (small, low, and dry) island of Santa Luzia. The first axis $(24.8 \%$ of the variation) separated the eastern from the western islands, with Santa Luzia in an intermediate position, connected to the eastern island of Maio as well as the northern island of São Vicente by the minimum spanning tree. The second axis (18.1\% of the variation) divided the seven western islands into two distinct groups, one southern and one northern. The minimum spanning tree connected São Nicolau in the northern group with Santiago in the southern group. The third axis (14.4\% of the variation) divided the northern island group, placing Santo Antão and São Nicolau in extreme positions because of their high number of single-island endemics (Fig. 17). 


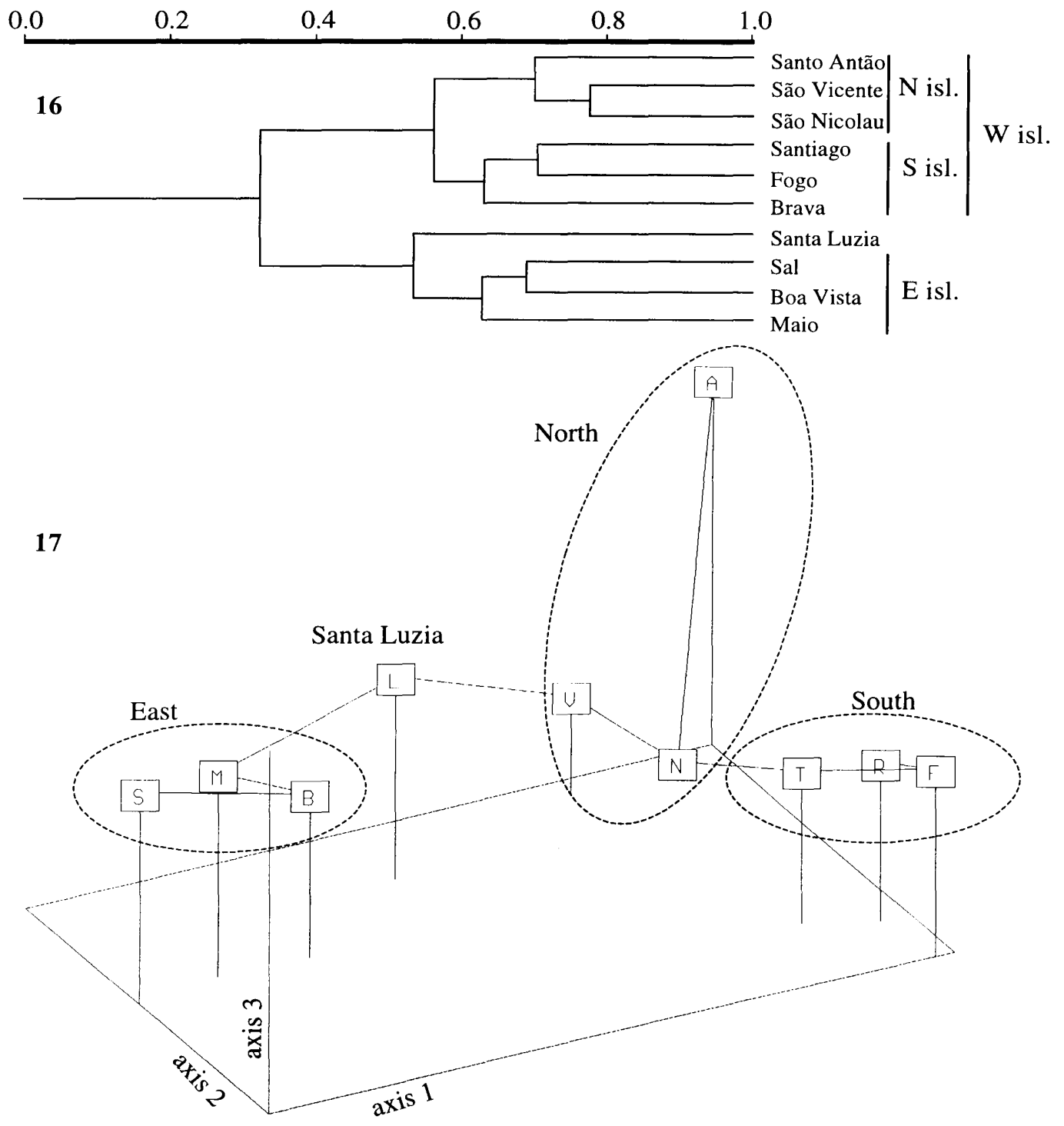

Figs 16-17. Analyses of floristic similarity between Capeverdean islands, calculated from shared endemic species and subspecies. Fig. 16. Cluster analysis (UPGMA). Fig. 17. Correspondence analysis (with minimum spanning tree superimposed). Islands: A - Santo Antão, V - São Vicente, L - Santa Luzia, N - São Nicolau, S - Sal, B - Boa Vista, M - Maio, T - Santiago, F - Fogo, R - Brava. 


\section{Distributional elements}

Five distributional elements were recognized (Fig. 18) based on the analyses of floristic similarity between islands (Figs 16,17): (1) the northern element, with 26 taxa restricted to the four northern islands; (2) the southern element, with 15 taxa restricted to the three southern islands; (3) the western element, with 21 taxa restricted to the seven western islands and occurring on at least one of the southern and at least one of the northern islands; (4) the eastern element, with three taxa restricted to the three southern islands; and (5) the ubiquitous element, with 17 taxa shared among island(s) in the eastern island group and island(s) in the western island group.

The large northern element included many single-island endemics (19 of 26 taxa, 73\%). Only two taxa in this element were shared among all four of the northern islands (Echium stenosiphon ssp. stenosiphon and Launaea picridioides), three taxa were shared among the three major islands of Santo Antão, São Vicente, and São Nicolau (Aeonium gorgoneum, Frankenia ericifolia ssp. caboverdeana, and Launaea gorgadensis), and two taxa were shared between São Vicente and São Nicolau (Limonium jovi-barba and Lobularia canariensis ssp. spathulata).

The southern element also contained many single-island endemics (10 of 15 taxa, $67 \%$ ). Only two of the taxa were shared among all three islands (Campanula bravensis and Centaurium tenuiflorum ssp. viridense). Two taxa, Diplotaxis varia and Echium hypertropicum, were shared between the two most distant southern islands, Santiago and Brava. Interestingly, the Fogo representatives of these two genera have evolved into distinct taxa, Diplotaxis hirta and Echium vulcanorum. A single taxon was shared between Santiago and Fogo (Lotus jacobaeus).

The western element contained per definition no single-island endemics. Only two taxa occurred on all of the six major western islands, Campylanthus glaber ssp. glaber and Conyza feae. It was noteworthy that nearly half of the western taxa (10 of $21,48 \%$ ) occurred on as many as five of the major western islands, and most of these were absent either from the smallest one of the three major northern islands, São Vicente (four taxa), or the smallest one of the southern islands, Brava (four taxa). The remaining nine western taxa occurred on two (1 taxon), three (2 taxa), or four (6 taxa) of the western islands. There was no dominant distributional patterns for these nine taxa; most of them occurred in unique islandcombinations. The flora of Santo Antão contained almost the entire western element. Only two of western taxa were absent from Santo Antão, where they had been substituted by locally evolved vicariant taxa (Papaver gorgoneum ssp. theresias and Tornabenea bischoffii). Three of the western taxa (Artemisia gorgonum, Helianthemum gorgoneum, and Tolpis farinulosa) were absent from São Nicolau, but no vicariant taxa had evolved on this island. All but four of the western taxa occurred on Fogo, where two of the lacking taxa had been replaced by vicariant taxa. Six western taxa were absent from Santiago, in spite of its considerable size and height, and only one of these taxa (Tornabenea insularis) had been replaced by a vicariant taxon ( $T$. annua). The smallest islands, Brava and São Vicente, harboured only about half of the western element ( 12 of 21 taxa, $57 \%$ ).

The small eastern element only consisted of Diplotaxis glauca (Sal and Boa Vista), Pulicaria burchardii ssp. longifolia (Sal), and Sporobolus minutus ssp. confertus (Sal and Maio). Most of the taxa occurring on the eastern islands were also found on the western islands, and thus belonged to the ubiquitous element. 


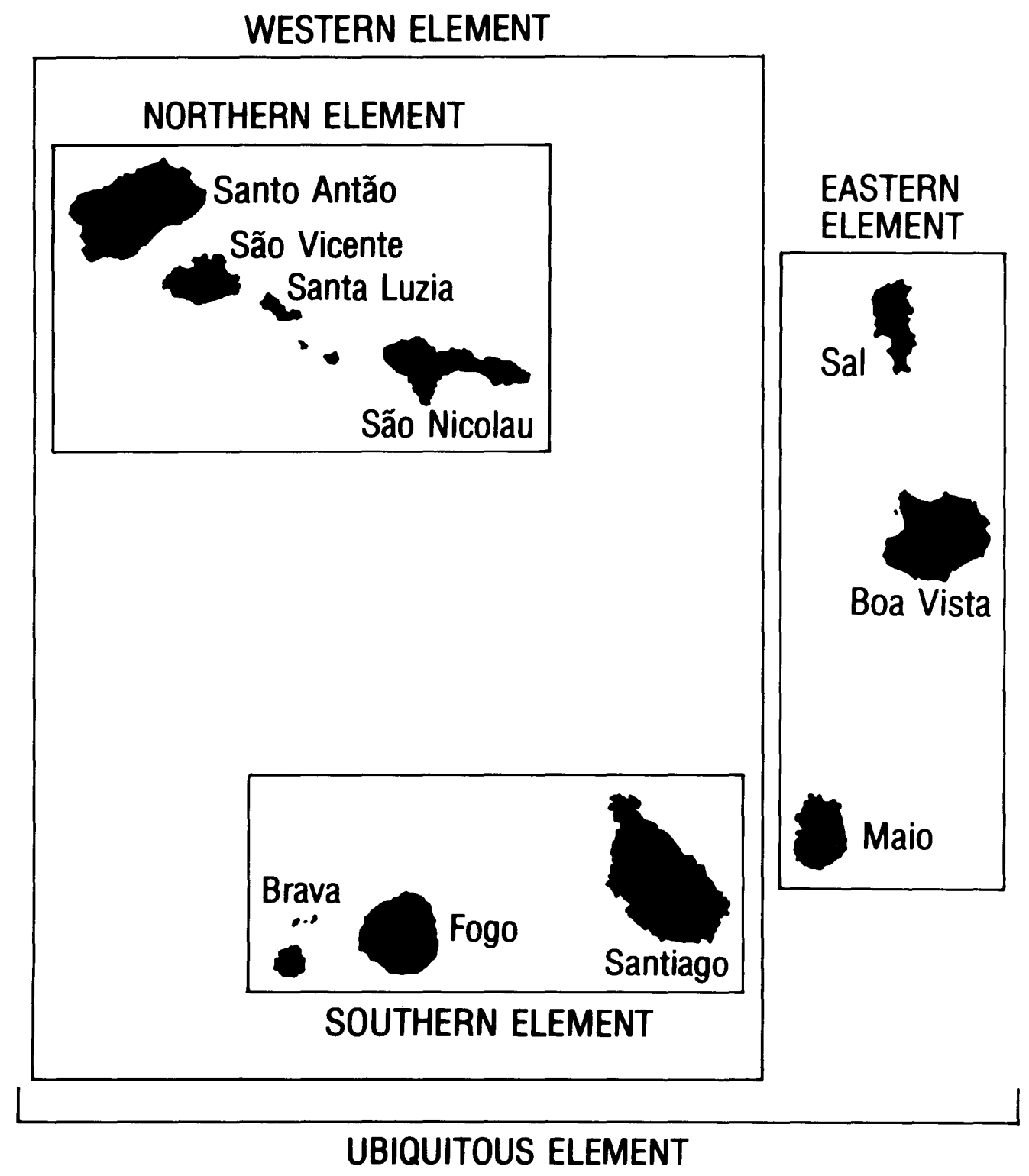

Fig. 18. Five distributional elements recognized in the endemic Capeverdean flora on the basis of the analyses of floristic similarity between islands (cf. Figs 16, 17). 
The majority (12) of the 17 taxa in the ubiquitous element were distributed on at least one island in all of the three geographic island groups (northern, eastern, and southern). Eleven of these taxa were distributed on six or more islands, and one (Brachiaria lata ssp. caboverdiana) was known from four islands. The remaining five taxa in this element were not really ubiquitous, but showed deviating distributions. Four of them, Limonium brunneri, Lotus brunneri, Phoenix atlantidis, and Pulicaria diffusa, had an eastern centre of distribution but also occurred on one or two of the western islands, usually São Vicente, Santa Luzia, or Santiago, which all have large flat and arid areas. The fifth of the deviating taxa was Asparagus squarrosus, which occurred on all of the northern and all of the eastern islands but not on the southern ones, where it was replaced by its non-endemic sister taxon A. scoparius.

\section{ECOLOGY AND ECOGEOGRAPHY}

\section{Humidity, altitude, and diversity}

The relationship between species diversity, humidity, and altitude was analyzed by counting the total number of endemic taxa occurring in each zone of humidity and in each altitudinal $200 \mathrm{~m}$ interval based on their main altitudinal distribution (Tabs 4,10). The number of taxa strongly increased with increasing humidity $(r=0.97, p=0.01, n=5)$, in particular from the extremely arid zone, where only 7 endemic taxa occurred, via the arid and semiarid zones to the subhumid zone, where 63 endemic taxa occurred (Fig. 19). There was only a slight increase in number of taxa from the subhumid zone to the humid zone. Only $9 \%$ of the endemic flora occurred in the extremely arid zone, whereas almost $80 \%$ of the endemic flora occurred in the humid zone. This result showed that most species occurring in the driest zones were ecological generalists that occurred in more humid zones as well, whereas most species occurring in the more humid zones were ecological specialists that were absent from drier zones.

The number of endemic taxa found in each $200 \mathrm{~m}$ altitudinal interval generally increased up to 800-1000 $\mathrm{m}$ and slowly decreased above this altitude (Fig. 20). More than half of the endemic flora (45 taxa) occurred at altitudes between $800 \mathrm{~m}$ and $1000 \mathrm{~m}$, whereas less than one third of the flora (24 taxa) occurred at altitudes below $200 \mathrm{~m}$.

Quite a large number of species had their upper altitudinal limits above $2000 \mathrm{~m}$ in the archipelago (Tab. 4). Nine endemic taxa had been recorded from the very top of the Pico of Fogo (2800-2829 m): Centaurium tenuiflorum ssp. viridense, Conyza feae, Conyza varia, Diplotaxis hirta, Paronychia illecebroides, Periploca laevigata ssp. chevalieri, Phagnalon melanoleucum, Satureja forbesii, and Verbascum cystolithicum. Other endemic taxa growing at or above $2400 \mathrm{~m}$ on the Pico and/or at the caldeira rim on Fogo were Campanula bravensis and Forsskaolea procridifolia $(2700 \mathrm{~m})$, Tolpis farinulosa $(2600 \mathrm{~m})$, Euphorbia tuckeyana $(2500 \mathrm{~m})$, and Artemisia gorgonum, Echium vulcanorum, Erysimum caboverdeanum, Globularia amygdalifolia, and Lavandula rotundifolia $(2400 \mathrm{~m})$. 
Tab. 10. Ecological and distributional elements in the endemic vascular flora of the Cape Verde Islands. Zones of humidity: H1 - the extremely arid zone, H2 - the arid zone, H3 - the semiarid zone, H4 - the subhumid zone, H5 - the humid zone.

\begin{tabular}{|c|c|c|c|c|c|c|c|c|c|c|c|c|c|c|c|c|c|c|c|}
\hline \multirow[t]{2}{*}{$\begin{array}{l}\text { Distributional } \\
\text { element }\end{array}$} & \multicolumn{2}{|c|}{ No. of taxa } & \multicolumn{3}{|c|}{ Ecological element } & \multicolumn{5}{|c|}{$\begin{array}{l}\text { Drought tolerance } \\
\text { (min. zone of hum.) }\end{array}$} & \multicolumn{5}{|c|}{$\begin{array}{l}\text { Humidity and } \\
\text { species richness }\end{array}$} & \multirow{2}{*}{$\begin{array}{c}\text { Mean } \\
\text { zone of } \\
\text { humidity }\end{array}$} & \multicolumn{3}{|c|}{ Altitudinal groups } \\
\hline & Total & $\%$ & Xeroph. & Mesoph. & Hygroph. & $\mathrm{Hl}$ & $\mathrm{H} 2$ & $\mathrm{H} 3$ & $\mathrm{H} 4$ & H5 & $\mathrm{HI}$ & $\mathrm{H} 2$ & $\mathrm{H} 3$ & $\mathrm{H} 4$ & H5 & & Coastal & Ubiq. & Montane \\
\hline North & 26 & 31.7 & 1 & 12 & 13 & 0 & 1 & 12 & 6 & 7 & 0 & 1 & 13 & 17 & 22 & 4.21 & 3 & 4 & 19 \\
\hline South & 15 & 18.3 & 0 & 8 & 7 & 0 & 0 & 7 & 7 & 1 & 0 & 0 & 7 & 13 & 10 & 4.07 & 1 & 2 & 12 \\
\hline West & 21 & 25.6 & 0 & 10 & 11 & 0 & 0 & 11 & 10 & 0 & 0 & 1 & 12 & 20 & 20 & 4.19 & 1 & 2 & 18 \\
\hline Ubiquitous & 17 & 20.7 & 13 & 4 & 0 & 5 & 8 & 4 & 0 & 0 & 5 & 13 & 14 & 13 & 13 & 2.88 & 5 & 10 & 2 \\
\hline East & 3 & 3.7 & 3 & 0 & 0 & 2 & 1 & 0 & 0 & 0 & 2 & 2 & 1 & 0 & 0 & 1.50 & 3 & 0 & 0 \\
\hline Total & 82 & 100.0 & 17 & 34 & 31 & 7 & 10 & 34 & 23 & 8 & 7 & 17 & 47 & 63 & 65 & 3.80 & 13 & 18 & 51 \\
\hline
\end{tabular}




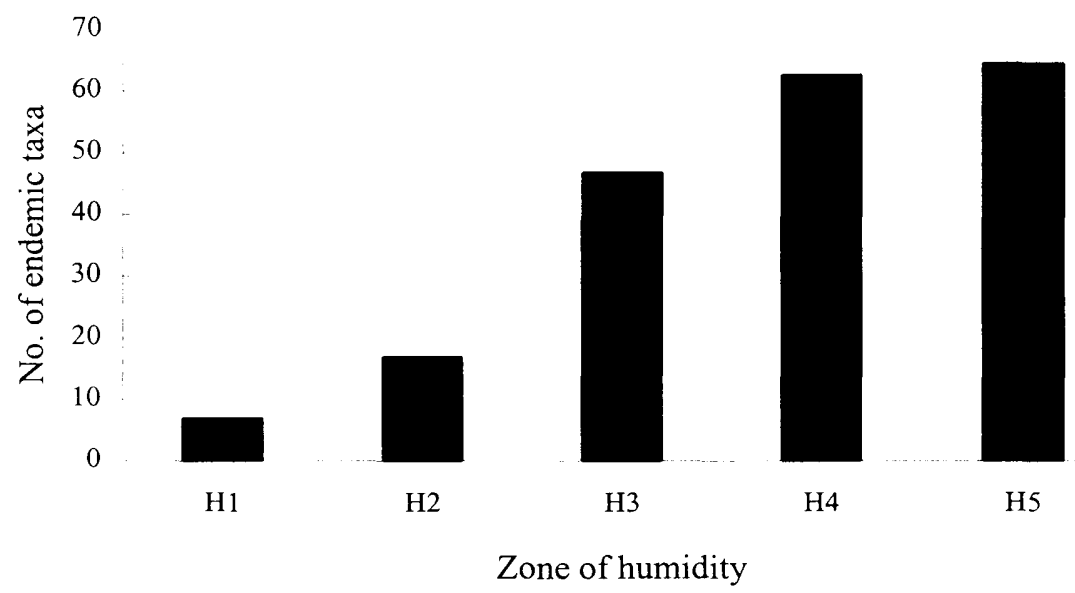

Fig. 19. Number of endemic taxa occurring in different zones of humidity in the Cape Verde Islands. H1 - the extremely arid zone; H2 - the arid zone; H3 - the semiarid zone; H4 - the subhumid zone; H5 - the humid zone.

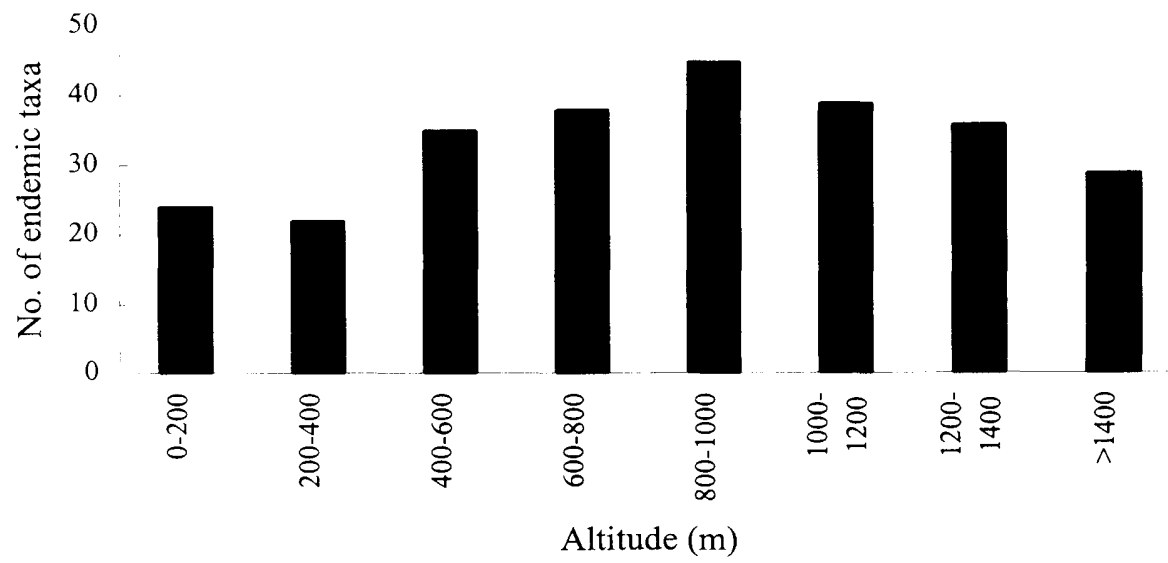

Fig. 20. Number of endemic taxa occurring at different altitudinal levels in the Cape Verde Islands. 


\section{Ecological groups}

The endemic taxa were classified into three ecological groups based on their drought tolerance, estimated by the minimum zone of humidity in which they regularly occurred: (1) xerophytes, which regularly occurred in the extremely arid or arid zones, (2) mesophytes, which regularly occurred in the semiarid zone but not in drier zones, and (3) hygrophytes, which regularly occurred in the subhumid or humid zones but not in drier zones (Fig. 21, Tabs $4,10)$. The mesophytes and hygrophytes were by far the largest groups. comprising 34 and 31 taxa, respectively. Seventeen taxa belonged to the xerophytic group. Thus, nearly $80 \%$ of the endemic flora was absent from the arid and extremely arid zones, which cover the largest proportion of the land area in the archipelago (Figs 5-7).

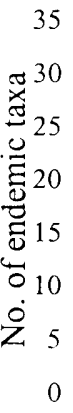

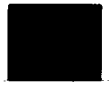

$\mathrm{H} 1$

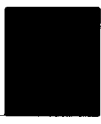

$\mathrm{H} 2$

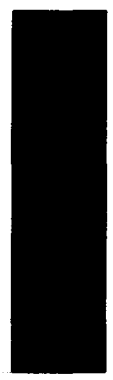

H3

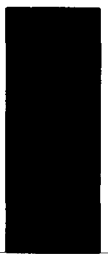

$\mathrm{H} 4$

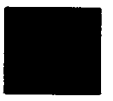

H5

Minimum zone of humidity

Fig. 21. Drought tolerance of the endemic taxa of the Cape Verde Islands, expressed as the minimum zone of humidity in which they regularly occur. H1 - the extremely arid zone; H2 the arid zone; H3 - the semiarid zone; H4 - the subhumid zone; H5 - the humid zone.

The endemic taxa were also classified into three groups based on their main altitudinal distribution: coastal, altitudinally ubiquitous, and montane taxa (Fig. 22, Tab. 10). Most of the endemics (51 taxa) were montane, with their main occurrence above $400 \mathrm{~m}$. Only 13 taxa were coastal, with their main occurrence between sea-level and $200 \mathrm{~m}$. The remaining 18 taxa were more or less altitudinally ubiquitous, some of them spanning the entire altitudinal gradient from sea-level to $2800 \mathrm{~m}$. All hygrophytes (31 taxa) and more than half of the mesophytes (19 taxa) belonged to the montane group, which only comprised a single xerophyte (Diplotaxis antoniensis). The coastal group was dominated by xerophytes but also contained some mesophytes. The altitudinally ubiquitous group contained about the same number of xerophytes and mesophytes.

The hygrophytes were all ecological specialists in the sense that they were restricted to the two most humid zones. Most of them were restricted to cliffs and gravelly slopes in the largest mountain ranges, and they rarely occurred below 400-600 m altitude. In contrast, the 


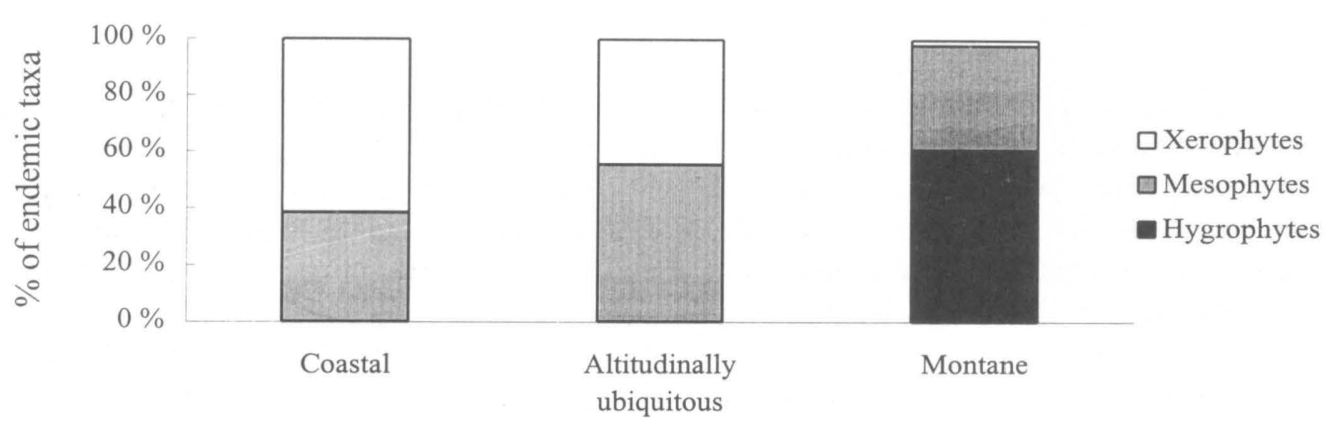

Altitudinal group

Fig. 22. Altitudinal and ecological groups in the endemic flora of the Cape Verde Islands.

meso- and xerophytes were more heterogeneous, showing large within-group differences in ecological amplitude. Some xero- and mesophytes were ecological specialists, with their entire distribution restricted to one or two zones of humidity and a narrow, usually lowland altitudinal range, whereas other taxa were ecologically more ubiquitous, occurring in a variety of habitats in three, four, or all five of the humidity zones and over a wide range of altitudes.

Typical xerophytic specialists were Diplotaxis glauca, Limonium brunneri, Phoenix atlantidis, and Pulicaria spp., which were mainly restricted to arid, sandy coasts or lowland, sandy or gravelly slopes and plains. Typical xerophytic generalists, occurring in a wide array of habitats in arid as well as humid areas, were Aristida cardosoi, Forsskaolea procridifolia, Lotus purpureus, Nauplius daltonii ssp. vogelii, Paronychia illebroides, and Sarcostemma daltonii.

The mesophytic specialists included (1) taxa mainly growing in semiarid habitats along northeast-, north-, or northwest-exposed coasts, such as Campylanthus glaber ssp. spathulatus, Frankenia ericifolia ssp. caboverdeana, and Limonium braunii; (2) local endemics with their main occurrence in the central caldeira area of Fogo, such as Erysimum caboverdeanum and Verbascum cystolithicum; and (3) other taxa such as Diplotaxis vogelii, which exclusively occurred in cliffs and gravelly slopes in the lower montane areas of São Vicente. Most mesophytes were generalists occurring equally abundantly in semiarid, subhumid, and humid areas. Typical examples of this group were Echium stenosiphon ssp. stenosiphon, Euphorbia tuckeyana, Polycarpaea gayi, Satureja forbesii, and Verbascum capitis-viridis.

\section{Ecogeography}

The rapid increase in species richness with increasing humidity was due to the taxa belonging to the northern, western, and southern distributional elements, whereas the ubiquitous and eastern elements deviated from this trend. Subhumid and humid zones are absent from the eastern islands. There was no increase in species number with increasing humidity for taxa belonging to the ubiquitous element, except from the extremely arid zone ( 5 taxa) to the arid 
zone (13 taxa); rather, the species number was virtually constant through successively more humid zones (13-14-13-13). This trend showed that most of the geographically ubiquitous taxa were also ecologically ubiquitous. More than half of the geographically ubiquitous taxa were also altitudinally ubiquitous. The vast majority of the taxa of the northern, southern, and western distributional elements were montane. All eastern taxa were coastal.

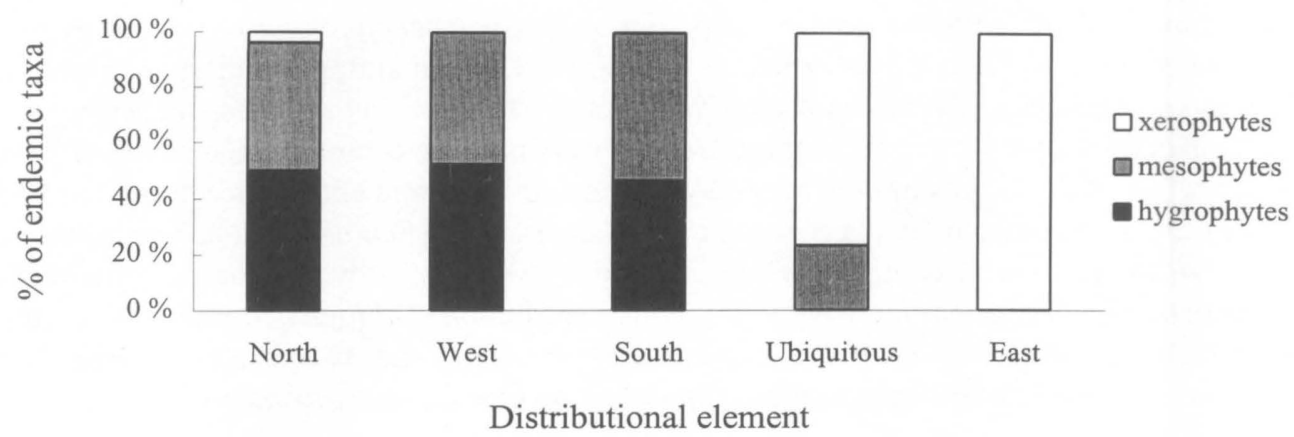

Fig. 23. Ecological and distributional elements in the endemic flora of the Cape Verde Islands.

The northern element

In addition to the single xerophyte Diplotaxis antoniensis, the northern element contained almost equal numbers of hygrophytes (13 taxa) and mesophytes (12 taxa; Fig. 23). This element contained all but one of those hygrophytes that were entirely confined to the humid zone. These seven taxa were very local endemics occurring in only one (rarely two) of the following three, northeast-exposed montane areas, the most favourable areas with respect to climatic humidity in the entire archipelago: (1) the Cova-Paul area on NE Santo Antão (Carex antoniensis, Carex paniculata ssp. hansenii, Diplotaxis gorgadensis ssp. brochmannii); (2) the Monte Gordo area on W São Nicolau (Conyza schlechtendalii, Nauplius smithii), and (3) the Alto das Cabaças range on E São Nicolau (Conyza schlechtendalii, Diplotaxis sundingii, Limonium sundingii). These three areas, together with the Monte Verde area on São Vicente, were also the richest ones in other endemic taxa. The remaining six hygrophytes in the northern element also occurred in the subhumid zone and had wider montane distributions with centers in the same four richest areas: Echium stenosiphon ssp. lindbergii, Papaver gorgoneum ssp. theresias, and Tornabenea bischoffii on Santo Antão, Frankenia ericifolia ssp. montana and Lotus arborescens on São Nicolau, and Limonium jovi-barba on São Vicente and São Nicolau. All but one of the northern hygrophytes were single-island endemics, and only five of the 12 northern mesophytes were single-island endemics (e.g., Diplotaxis gorgadensis ssp. gorgadensis on Santo Antão and D. gracilis on São Nicolau). The other northern mesophytes typically occurred on all of the three major northern islands. 
The southern element

This element also comprised almost equal numbers of hygrophytes ( 7 taxa) and mesophytes (8 taxa), but no xerophytes. Limonium lobinii was the only southern hygrophyte entirely confined to the humid zone; it occurred exclusively in the Serra da Malagueta mountains on Santiago. Four of the seven southern hygrophytes were single-island endemics, with their main occurrence in one or two of the three most favourable southern montane areas: the two major mountain areas on Santiago, Serra do Pico do Antonia and Serra do Malagueta (Limonium lobinii, Nauplius daltonii ssp. daltonii, Tornabenea annua) and the northern montane slopes of Fogo (Tornabenea tenuissima). The remaining southern hygrophytes, Campanula bravensis, Centaurium tenuiflorum ssp. viridense, and Echium hypertropicum, had their main distribution in these three areas as well as in the central montane area of Brava. Notably, five of the eight southern mesophytes were single-island endemics confined to Fogo, three of them with their main distribution in the caldeira area (Echium vulcanorum, Erysimum caboverdeanum, Verbascum cystolithicum), one with a lowland/coastal distribution (Tornabenea humilis), and one with a very wide distribution (Diplotaxis hirta). One southern mesophyte was endemic to Brava (Launaea thalassica), and two southern mesophytes occurred on two of the southern islands (Diplotaxis varia and Lotus jacobaeus).

The western element

This element contained 11 hygrophytes and 10 mesophytes. No hygrophytes were entirely confined to the humid zone, but most of them had their main occurrences in the abovementioned, most favourable mountain areas on the northern and southern islands. The western element contained several taxa which have been important components of the former, extensive shrubland vegetation in the Cape Verde Islands, such as the hygrophytes Conyza pannosa and Globularia amygdalifolia and the mesophytes Artemisia gorgonum, Conyza feae, Conyza varia, and Periploca laevigata ssp. chevalieri.

The ubiquitous element

This element contained four mesophytes with their main distribution on the western islands: Polycarpaea gayi, Sideroxylon marginata, and Verbascum capitis-viridis, all of which are extinct today on the eastern islands, and Euphorbia tuckeyana, which is very rare on the eastern islands today. The majority of the ubiquitous taxa (13 of 17) were xerophytes. Five of them were extreme xerophytes regularly occurring in the extremely arid zone as well as the arid zone: Aristida cardosoi, Asparagus squarrosus, Lotus brunneri, Phoenix atlantidis, and Pulicaria diffusa. The two first-mentioned of these taxa also regularly occurred in more humid zones, whereas Lotus brunneri, Phoenix atlantidis, and Pulicaria diffusa were xerophytic specialists with their main distribution on the eastern islands. The remaining eight ubiquitous xerophytes usually avoided the extremely arid zone, and only one of these taxa, Limonium brunneri, was a xerophytic specialist with its main distribution on the eastern island of Sal. The other seven taxa also regularly occurred in more humid zones, most of them even in the humid zone. The ecologically most ubiquitous ones were Paronychia illecebroides, Forsskaolea procridifolia, Nauplius daltonii ssp. vogelii, and Sarcostemma 
daltonii, which occurred on eight or nine islands in a variety of habitats, in the arid, semiarid, subhumid, and humid zones, and from sea level to $1800-2800 \mathrm{~m}$.

The eastern element

The three taxa belonging to the eastern element were xerophytic specialists occurring in coastal and lowland areas, usually in sandy habitats: Diplotaxis glauca, which occurred or have occurred in arid and semiarid areas on Sal and Boa Vista, Pulicaria burchardii ssp. longifolia, which occurred in the extremely arid zone on Sal, and Sporobolus minutus ssp. confertus, which occurred in the extremely arid and arid zones on Sal and Maio.

\section{RELATIONSHIPS BETWEEN PHYTOGEOGRAPHY AND ECOGEOGRAPHY}

The phytogeographic spectra varied considerably among individual island floras and among geographic island-group floras (Tab. 11, Fig. 24). The floras of most western islands had a fraction of holarctic taxa that was fairly similar to that of the total endemic flora $(65 \%)$, whereas the floras of the eastern islands had smaller fractions of holarctic taxa $(45-50 \%)$. The fraction of holarctic taxa was largest on Fogo (70\%), Santa Luzia (69\%), and Santo Antão $(66 \%)$. Santa Luzia also had a high fraction of holarctic taxa although this northern island was classified together with the eastern islands in the cluster analysis based on floristic similarity between islands, and intermediately between the eastern and northern islands in the ordination analysis of the same data set (Figs 16, 17).

Among the holarctic elements, the Canaro-Madeiran element distinctly decreased in importance from the northern and southern island groups to the eastern island group, whereas the NW-Moroccan element was relatively more important in the east (Fig. 24). In the speciespoor eastern floras, the latter element was represented by the Sal-endemic Pulicaria burchardii ssp. longifolia as well as some widespread genera (Frankenia, Lotus, and Verbascum). Most tropic elements showed a relative increase from the northern and southern island groups to the eastern island group.

An analysis with respect to distributional elements showed that the ubiquitous as well as the eastern elements had considerably lower fractions of holarctic taxa than the other three elements (Fig. 25). The western and southern elements had the highest fractions of CanaroMadeiran taxa, whereas such taxa were absent from the eastern element.

The majority of the hygrophytic taxa (74\%) and mesophytic taxa $(68 \%)$ were holarctic, whereas only $41 \%$ of the xerophytic taxa were holarctic (Fig. 26). The widely holarctic taxa (Carex) were hygrophytes, and most Mediterranean and Canaro-Madeiran taxa were hygrophytes or mesophytes. The NW-Moroccan element and the tropic elements typically increased in relative importance from the hygrophytic group, via the mesophytic group, to the xerophytic group. The holarctic proportion in the endemic flora also increased with altitude (Fig. 27). Thus, the hygrophytic and montane endemic flora in the Cape Verde Islands was mainly holarctic, the xerophytic and coastal flora was much more tropic in character, and the mesophytic and altitudinally ubiquitous flora was intermediate in its affinities. 
Tab. 11. Number of taxa in combined phytogeographic and ecogeographic elements in the endemic vascular flora of the Cape Verde Islands. Abbreviations of islands: A - Santo Antão, V - São Vicente, L - Santa Luzia (incl. Branco and Raso), N - São Nicolau, S - Sal, B - Boa Vista, M - Maio, T - Santiago, F - Fogo, R - Brava (incl. two islets). Distributional elements: N - Northern, W - Western, S Southern, U - Ubiquitous, E - Eastern. Ecological elements: H - Hygrophytic, M - Mesophytic, X - Xerophytic. Altitudinal groups: Coastal, Altitudinally ubiquitous, Montane.

\begin{tabular}{|c|c|c|c|c|c|c|c|c|c|c|c|c|c|c|c|c|c|c|c|c|c|c|c|c|c|}
\hline \multirow{3}{*}{$\begin{array}{l}\text { Phytogeographic } \\
\text { element } \\
\text { H - holarctic, T - tropic }\end{array}$} & \multirow{2}{*}{\multicolumn{2}{|c|}{ No. of taxa }} & \multirow{2}{*}{\multicolumn{9}{|c|}{ No. of taxa on individual islands }} & \multicolumn{3}{|c|}{ No. of taxa in isl. groups } & \multirow{2}{*}{\multicolumn{5}{|c|}{$\begin{array}{c}\text { Distributional } \\
\text { elements }\end{array}$}} & \multirow{2}{*}{\multicolumn{3}{|c|}{$\begin{array}{c}\text { Ecological } \\
\text { elements }\end{array}$}} & \multicolumn{3}{|c|}{ Altitudinal groups } \\
\hline & & & & & & & & & & & & North & South & East & & & & & & & & & Coastal & Ubiq. & Montane \\
\hline & Total & $\%$ & A & $\mathrm{V}$ & L N & $\mathrm{N} S$ & $\mathrm{~B}$ & $\mathrm{M}$ & $\mathrm{T}$ & $\mathrm{F}$ & $\mathrm{R}$ & AVLN & TFR & SBM & $\mathrm{N}$ & $\mathrm{W}$ & $\mathrm{S}$ & $\mathrm{U}$ & $\mathrm{E}$ & $\mathrm{H}$ & $\mathrm{M}$ & $\mathrm{X}$ & $0-200 \mathrm{~m}$ & $0-2800 \mathrm{~m}$ & $>400 \mathrm{~m}$ \\
\hline Widely holarctic $(\mathrm{H})$ & 2 & 2.4 & 2 & 0 & $\begin{array}{ll}0 & 0\end{array}$ & $\begin{array}{ll}0 & 0\end{array}$ & $0 \quad 0$ & 0 & 0 & 0 & 0 & 2 & 0 & 0 & 2 & 0 & 0 & 0 & 0 & 2 & 0 & 0 & 0 & 0 & 2 \\
\hline Mediterranean $(\mathrm{H})$ & 6 & 7.3 & 4 & 2 & 24 & 41 & 12 & 1 & 4 & 5 & 2 & 5 & 5 & 2 & 1 & 2 & 1 & 2 & 0 & 4 & 1 & 1 & 0 & 2 & 4 \\
\hline Canaro-Madeiran $(\mathrm{H})$ & 33 & 40.2 & 19 & 13 & 518 & 183 & 32 & 21 & 141 & 17 & 12 & 25 & 22 & 4 & 91 & 12 & 8 & 4 & 0 & 15 & 15 & 3 & 5 & 4 & 24 \\
\hline NW-Moroccan (H) & 12 & 14.6 & 6 & 6 & 27 & 73 & 33 & 2 & 4 & 4 & 1 & 9 & 5 & 5 & 5 & 0 & 2 & 4 & 1 & 2 & 7 & 3 & 3 & 3 & 6 \\
\hline Palaeotropic (T) & 2 & 2.4 & 1 & 2 & 12 & 21 & 12 & 1 & 2 & 1 & 1 & 2 & 2 & 2 & 0 & 0 & 0 & 2 & 0 & 0 & 0 & 2 & 0 & 2 & 0 \\
\hline Saharo-Arabian (T) & 14 & 17.1 & 7 & 4 & 25 & 53 & 33 & 2 & 5 & 3 & 2 & 11 & 6 & 3 & 7 & 2 & 2 & 2 & 1 & 3 & 7 & 4 & 3 & 3 & 8 \\
\hline Sudano-Zambesian-Sindian $(T)$ & 12 & 14.6 & 7 & 7 & 18 & 84 & 42 & 3 & 7 & 6 & 7 & 8 & 9 & 4 & 2 & 4 & 2 & 3 & 1 & 4 & 4 & 4 & 2 & 4 & 6 \\
\hline Afromontane $(\mathrm{T})$ & 1 & 1.2 & 1 & 1 & $\begin{array}{ll}0 & 1\end{array}$ & 10 & $\begin{array}{ll}0 & 0\end{array}$ & 0 & 1 & 1 & 0 & 1 & 1 & 0 & 0 & 1 & 0 & 0 & 0 & 1 & 0 & 0 & 0 & 0 & 1 \\
\hline Total, holarctic elements $(\mathrm{H})$ & 53 & 64.5 & 31 & 21 & 929 & 297 & 77 & 52 & 222 & 261 & 15 & 41 & 32 & 11 & 171 & 141 & 111 & 10 & 1 & 23 & 23 & 7 & 8 & 9 & 36 \\
\hline Total, tropic elements $(\mathrm{T})$ & 29 & 35.3 & 16 & 14 & 416 & 168 & 87 & 61 & 151 & 111 & 10 & 22 & 18 & 9 & 9 & 7 & 4 & 7 & 2 & 8 & 11 & 10 & 5 & 9 & 15 \\
\hline
\end{tabular}




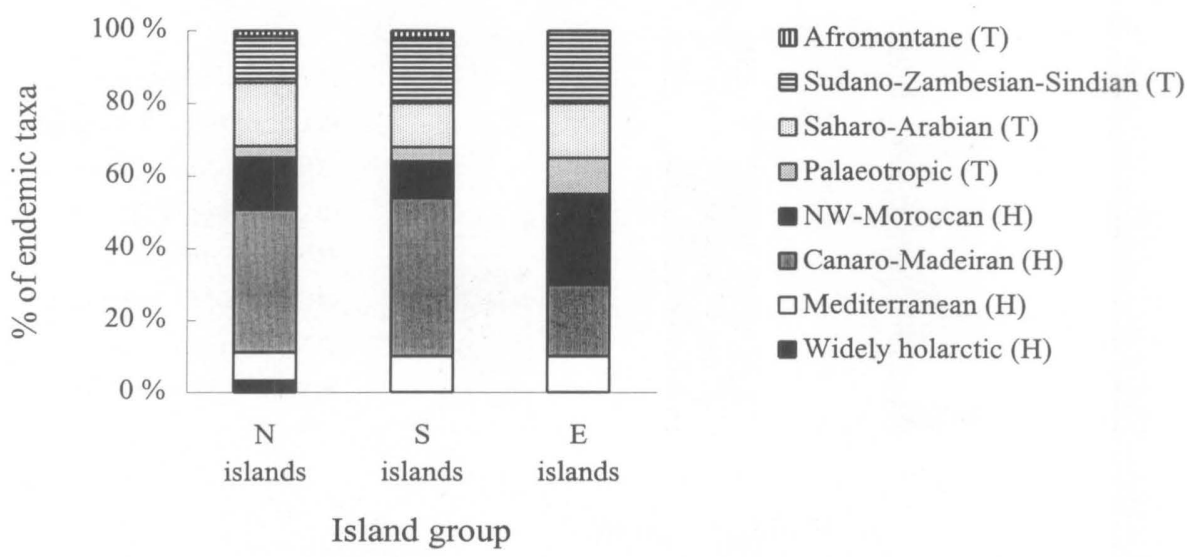

Fig. 24. Phytogeography of the endemic floras of the northern, southern, and eastern Capeverdean island groups. H - Holarctic, T- Tropic.

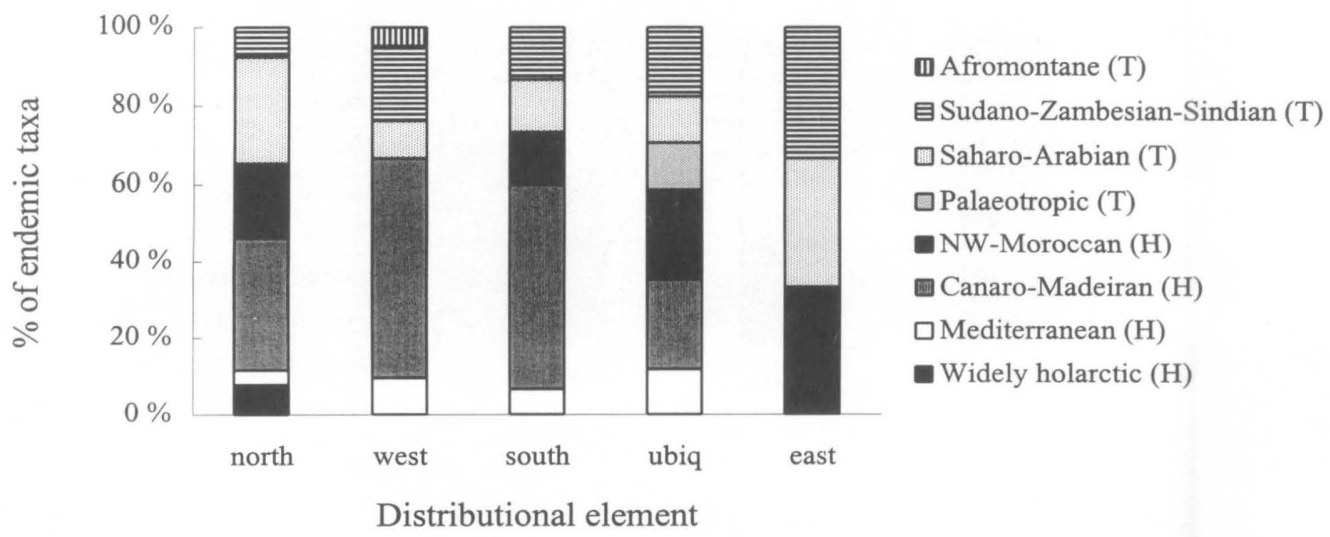

Fig. 25. Phytogeographic elements and intra-archipelago distributional elements in the endemic flora of the Cape Verde Islands. H - Holarctic, T- Tropic. 


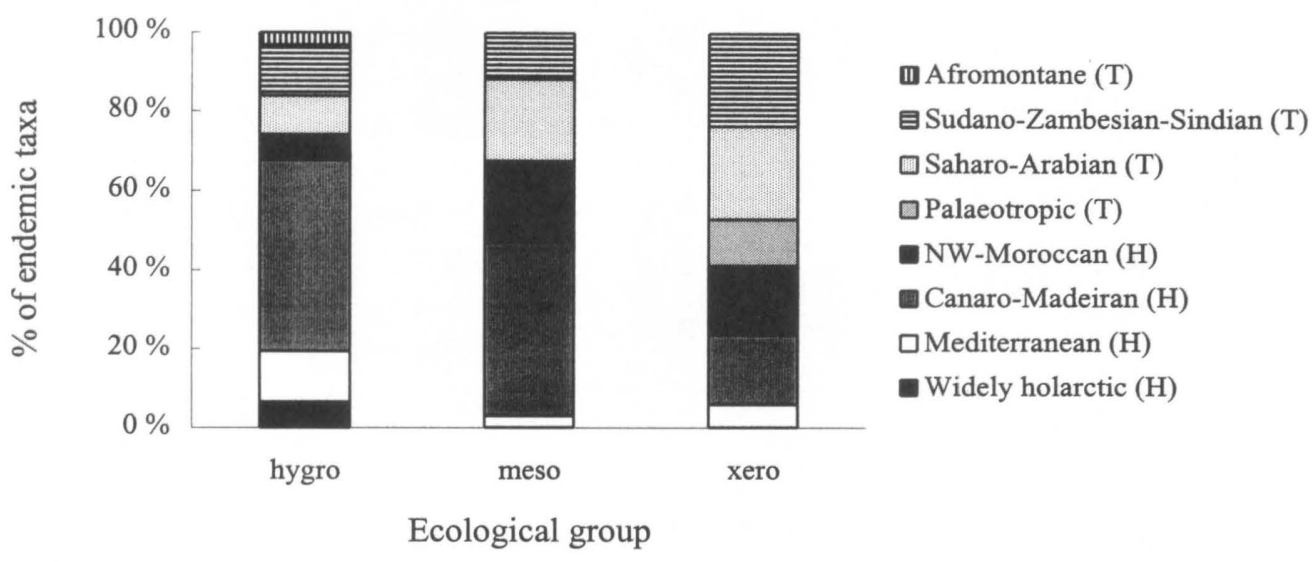

Fig. 26. Phytogeography of ecological groups (hygrophytes, mesophytes, and xerophytes) in the endemic flora of the Cape Verde Islands. H - Holarctic, T- Tropic.

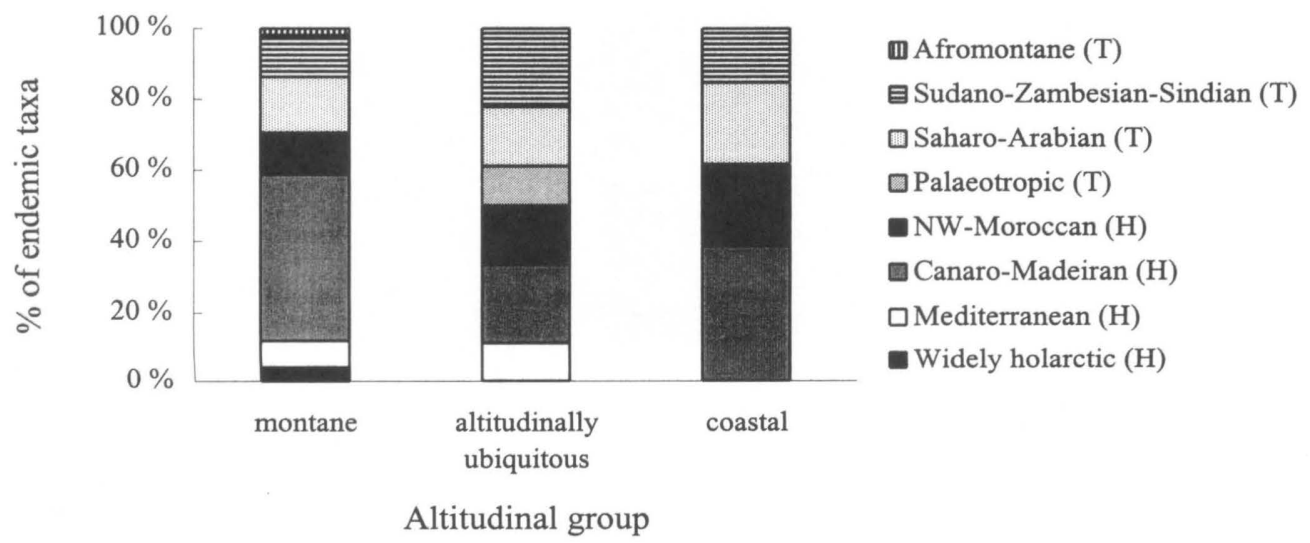

Fig. 27. Phytogeography of altitudinal groups in the endemic flora of the Cape Verde Islands. Montane taxa - main distribution above $400 \mathrm{~m}$, altitudinally ubiquitous taxa - distributed more or less along the entire coast-mountain gradient, coastal taxa - main distribution below $200 \mathrm{~m}$. $\mathrm{H}$ - Holarctic, T- Tropic. 


\section{RELATIONSHIPS BETWEEN MORPHOLOGICAL AND ECOGEOGRAPHIC VARIATION}

The degree of morphological variation within taxa, which was scored on a 1-4 scale (Tab. 4), was positively correlated with all four estimates of the geographic and ecological amplitudes of the taxa. The strongest correlations were obtained for the combination of humidity and altitude (as number of scores in the main table in the ecogeographic map; $r=0.51, p<0.001$, $\mathrm{n}=80$ ), altitudinal amplitude $(\mathrm{r}=0.50, \mathrm{p}<0.001, \mathrm{n}=80)$, and amplitude with respect to humidity alone $(\mathrm{r}=0.48, \mathrm{p}<0.001, \mathrm{n}=80)$. Slightly weaker correlation was obtained for the size of geographic distribution (as number of islands; $r=0.40, p<0.001, n=80$ ). Thus, geographically and ecologically restricted endemics tended to be less morphologically variable than geographically and ecologically more ubiquitous endemics. Single-island endemics had a mean morphological variation score of 1.7 , whereas endemics distributed on six or more islands had a mean morphological variation score of 2.8 . Taxa belonging to the northern distributional element, which tended to have a fairly restricted ecology and distribution, had a mean variation score of 1.8 , whereas more widespread taxa, such as those of the western and ubiquitous elements, had mean variation scores of 2.5-2.6.

\section{KARYOLOGY}

Chromosome numbers were now known for 52 of the 82 endemic species and subspecies (63.4\%; Tab. 12). New chromosome numbers were obtained for three taxa: Conyza feae, $2 \mathrm{n}=$ 18; C. pannosa, $2 \mathrm{n}=36$; and C. varia, $2 \mathrm{n}=36$ (Tab. 12). This is the first count reported for $C$. pannosa, a confirmation of previous counts of $C$. varia, and a new number for $C$. feae. Infra(sub)specific variation in chromosome number had been reported for Conyza feae $(2 \mathrm{n}=18$, 24?), Forsskaolea procridifolia $(2 \mathrm{n}=14,44)$, Periploca laevigata ssp. chevalieri $(2 \mathrm{n}=22,36$ ?), Sarcostemma daltonii $(2 \mathrm{n}=22,44)$, and Tornabenea insularis $(2 \mathrm{n}=16$ ?, 18; questionable numbers indicated).

\section{CONSERVATION}

\section{General conservation status}

More than half (45 taxa, 55\%) of the 82 endemic species and subspecies in the Cape Verde Islands were threatened, placed in one of the Red List categories (Tabs 13, 14; Fig. 28). Thirty-five taxa (43\%) were classified as Lower Risk, and two species, Phoenix atlantidis and Pulicaria burchardii ssp. longifolia, were insufficiently known and classified as Data Deficient. No taxa were presently known as Extinct or Prolonged Absence for the entire 
Tab. 12. Chromosome numbers, types of polyploidy, and types of endemism in the Capeverdean flora. Abbreviations of islands: A Santo Antão, V - São Vicente, N - São Nicolau, S - Sal, T - Santiago, F - Fogo, R - Brava.

\begin{tabular}{|c|c|c|c|c|c|c|}
\hline Taxon & $2 n$ & $\begin{array}{l}\text { Ploidal } \\
\text { level }\end{array}$ & $\begin{array}{c}\text { Base } \\
\text { no. }(\mathrm{x})\end{array}$ & $\begin{array}{l}\text { Diploid or type } \\
\text { of polyploid }\end{array}$ & Type of endemic & $\begin{array}{l}\text { Reference and origin } \\
\text { of material (island) }\end{array}$ \\
\hline Aeonium gorgoneum & 36 & $4 x$ & 9 & palaeopolyploid & schizoendemic & Liu 1989 (no loc.) \\
\hline Artemisia gorgonum & 18 & $2 \mathrm{x}$ & 9 & diploid & schizoendemic & Borgen $1975(A)$ \\
\hline Brachiaria lata ssp. caboverdiana & 48 & ? & ? & mesopolyploid & schizoendemic & Zizka $1986(\mathrm{~T})$ \\
\hline Campanula bravensis & 54 & $?$ & $?$ & mesopolyploid & schizoendemic & Gomes et al. 1995a (F) \\
\hline Campanula jacobaea & 54 & $?$ & $?$ & mesopolyploid & schizoendemic & Gomes et al. 1995a (N) \\
\hline Campylanthus glaber ssp. glaber & 14 & $2 \mathrm{x}$ & 7 & diploid & schizoendemic & Gomes et al. 1995a (N) \\
\hline Campylanthus glaber ssp. spathulatus & 14 & $2 \mathrm{x}$ & 7 & diploid & schizoendemic & Bramwell \& Murray 1972 (A) \\
\hline Conyza feae & 18 & $2 \mathrm{x}$ & 9 & diploid & $\begin{array}{l}\text { schizoendemic (patroend. } \\
\text { rel. to remaining spp.) }\end{array}$ & This paper $(\mathrm{F})$ \\
\hline Conyza feae & $24 ?$ & $3 x ?$ & 9 & $?$ & $?$ & Borgen $1980(\mathrm{~A})$; hybrid? (see text) \\
\hline Conyza pannosa & 36 & $4 \mathrm{x}$ & 9 & neopolyploid & apoendemic & This paper (A) \\
\hline Conyza schlechtendalii & 36 & $4 \mathrm{x}$ & 9 & neopolyploid & apoendemic & Gomes et al. $1995 \mathrm{a}(\mathrm{N})$ \\
\hline Conyza varia & 36 & $4 \mathrm{x}$ & 9 & neopolyploid & apoendemic & Borgen $1975(\mathrm{~A}, \mathrm{~F})$; this paper $(\mathrm{F})$ \\
\hline Diplotaxis glauca & 26 & $2 x(4 x ?)$ & $13(?)$ & dipl. (or palaeop.) & schizoendemic & Goméz-Campo 1978 (no loc.) \\
\hline Diplotaxis gorgadensis ssp. brochmannii & 26 & $2 x(4 x ?)$ & $13(?)$ & dipl. (or palaeop.) & schizoendemic & Borgen $1975(\mathrm{~A})$ \\
\hline Diplotaxis gracilis & 26 & $2 x(4 x ?)$ & $13(?)$ & dipl. (or palaeop.) & schizoendemic & Rustan $1996(\mathrm{~N})$ \\
\hline Diplotaxis hirta & 26 & $2 x(4 x ?)$ & $13(?)$ & dipl. (or palaeop.) & schizoendemic & Borgen 1975 (F); Rustan 1996 (F) \\
\hline Diplotaxis sundingii & 26 & $2 x(4 x ?)$ & $13(?)$ & dipl. (or palaeop.) & schizoendemic & Rustan $1996(\mathrm{~N})$ \\
\hline Euphorbia tuckeyana & 20 & $2 x(4 x ?)$ & $10(6 ?)$ & dipl. (or palaeop.) & schizoendemic & $\begin{array}{l}\text { Bramwell \& Murray } 1972 \text { (A); Borgen } \\
1980 \text { (S); Ortega } 1980 \text { (no loc.) }\end{array}$ \\
\hline Forsskaolea procridifolia & 14 & $2 x ?$ & $7 ?$ & diploid & $\begin{array}{l}\text { schizoendemic? (patroend. } \\
\text { rel. to } 2 n=44 \text { cytotype?) }\end{array}$ & Bramwell \& Murray $1972(\mathrm{~T})$ \\
\hline Forsskaolea procridifolia & 44 & $4 \mathrm{x}$ & 11 & neopolyploid? & $\begin{array}{l}\text { apoendemic? (rel. to } \\
2 \mathrm{n}=14 \text { cytotype) }\end{array}$ & Borgen $1975(A, V)$ \\
\hline Frankenia ericifolia ssp. caboverdeana & 20 & $4 x$ & 5 & mesopolyploid & schizoendemic? & Zizka $1986(\mathrm{~N})$ \\
\hline
\end{tabular}




\begin{tabular}{|c|c|c|c|c|c|c|}
\hline Globularia amygdalifolia & 16 & $2 \mathrm{x}$ & 8 & diploid & schizoendemic & Borgen $1980(A)$ \\
\hline Helianthemum gorgoneum & 20 & $4 \mathrm{x}$ & 5 & mesopolyploid & schizoendemic & Borgen $1975(\mathrm{~F})$ \\
\hline Kickxia elegans ssp. elegans & 18 & $2 \mathrm{x}$ & 9 & diploid & schizoendemic & Borgen $1980(\mathrm{~V})$; Zizka 1986 (A) \\
\hline Kickxia elegans ssp. dichondrifolia & 18 & $2 x$ & 9 & diploid & schizoendemic & $\begin{array}{l}\text { Borgen } 1975 \text { (A); } \\
\text { Ortega \& Navarro 1977b (no loc.) }\end{array}$ \\
\hline Launaea gorgadensis & 36 & $4 \mathrm{x}$ & 9 & neopolyploid & apoendemic & Kilian 1988 (A: two pops.) \\
\hline Launaea picridioides & 18 & $2 \mathrm{x}$ & 9 & diploid & $\begin{array}{l}\text { schizoendemic (patroend. } \\
\text { rel. to } L \text {. gorgadensis } \\
\text { and } L . \text { thalassica) }\end{array}$ & $\begin{array}{l}\text { Aldridge \& Ortega } 1976(\mathrm{~A}) \\
\text { Kilian } 1988(\mathrm{~N})\end{array}$ \\
\hline Launaea thalassica & 36 & $4 \mathrm{x}$ & 9 & neopolyploid & apoendemic & Kilian $1988(\mathrm{R})$ \\
\hline Limonium braunii & 12 & $2 \mathrm{x}$ & 6 & diploid & schizoendemic & $\begin{array}{l}\text { Bramwell \& Murray } 1972(\mathrm{~A}) \\
\text { Erben } 1986 \text { (A); Lobin et al. } 1995(\mathrm{~N})\end{array}$ \\
\hline Limonium brunneri & 12 & $2 x$ & 6 & diploid & schizoendemic & $\begin{array}{l}\text { Erben } 1986 \text { (S); Lobin et al. } 1995 \\
\text { (S: two pops.) }\end{array}$ \\
\hline Limonium jovi-barba & 12 & $2 x$ & 6 & diploid & schizoendemic & Borgen $1975(\mathrm{~V})$; Erben $1986(\mathrm{~V})$ \\
\hline Limonium lobinii & 12 & $2 \mathrm{x}$ & 6 & diploid & schizoendemic & $\begin{array}{l}\text { Kilian \& Leyens } 1994(\mathrm{~T}) \text {; Lobin et al. } \\
1995(\mathrm{~T})\end{array}$ \\
\hline Limonium sundingii & 12 & $2 x$ & 6 & diploid & schizoendemic & Lobin et al. $1995(\mathrm{~N})$ \\
\hline Lobularia canariensis ssp. fruticosa & 22 & $2 x(4 x ?)$ & $11(6 ?)$ & dipl. (or palaeop.) & schizoendemic & Borgen 1987 (A: 3 pops., N) \\
\hline Lobularia canariensis ssp. spathulata & 22 & $2 x(4 x ?)$ & $11(6 ?)$ & dipl. (or palaeop.) & schizoendemic & Borgen $1984(\mathrm{~V})$; Borgen $1987(\mathrm{~V}, \mathrm{~N})$ \\
\hline Lotus brunneri & 14 & $2 \mathrm{x}$ & 7 & diploid & schizoendemic & Borgen $1975(\mathrm{~S})$ \\
\hline Lotus jacobaeus & 14 & $2 \mathrm{x}$ & 7 & diploid & schizoendemic & Ortega 1980 (no loc.) \\
\hline Lotus purpureus & 14 & $2 \mathrm{x}$ & 7 & diploid & schizoendemic & Bramwell \& Murray 1972 (A) \\
\hline Nauplius daltonii ssp. daltonii & 14 & $2 \mathrm{x}$ & 7 & diploid & schizoendemic & $\begin{array}{l}\text { Borgen } 1975(\mathrm{~T}) \\
\text { Halvorsen \& Borgen } 1986 \text { (T: } 2 \text { pops.) }\end{array}$ \\
\hline Nauplius daltonii ssp. vogelii & 14 & $2 \mathrm{x}$ & 7 & diploid & schizoendemic & Halvorsen \& Borgen $1986(\mathrm{~A}, \mathrm{~V}, \mathrm{~N}, \mathrm{~F})$ \\
\hline
\end{tabular}

Reference and origin

of material (island) 


\begin{tabular}{|c|c|c|c|c|c|c|}
\hline Taxon & $2 n$ & $\begin{array}{l}\text { Ploidal } \\
\text { level }\end{array}$ & $\begin{array}{l}\text { Base } \\
\text { no. (x) }\end{array}$ & $\begin{array}{l}\text { Diploid or type } \\
\text { of polyploid }\end{array}$ & Type of endemic & $\begin{array}{l}\text { Reference and origin } \\
\text { of material (island) }\end{array}$ \\
\hline Nauplius smithii & 14 & $2 \mathrm{x}$ & 7 & diploid & schizoendemic & Halvorsen \& Borgen $1986(\mathrm{~N})$ \\
\hline Papaver gorgoneum ssp. gorgoneum & 38 & $?$ & $?$ & mesopolyploid & $\begin{array}{l}\text { apoendemic (schizoend. } \\
\text { rel. to ssp. theresias) }\end{array}$ & Kadereit \& Lobin 1990 (no loc.) \\
\hline Papaver gorgoneum ssp. theresias & 38 & $?$ & $?$ & mesopolyploid & $\begin{array}{l}\text { apoendemic (schizoend. } \\
\text { rel. to ssp. gorgoneum) }\end{array}$ & Kadereit \& Lobin 1990 (A) \\
\hline Periploca laevigata ssp. chevalieri & 22 & $2 \mathrm{x}$ & 11 & diploid & schizoendemic & Borgen $1975(\mathrm{~F})$; Gomes et al. 1995a (F) \\
\hline Periploca laevigata ssp. chevalieri & $36 ?$ & $?$ & $?$ & & & Zizka $1986(\mathrm{~F})$, erroneous? \\
\hline Polycarpaea gayi & 18 & $2 \mathrm{x}$ & 9 & diploid & schizoendemic & Borgen $1980(A)$ \\
\hline Sarcostemma daltonii & 22 & $2 \mathrm{x}$ & 11 & diploid & $\begin{array}{l}\text { schizoendemic (patroend. } \\
\text { rel. to } 2 n=44 \text { cytotype) }\end{array}$ & Aldridge \& Ortega 1976 (A) \\
\hline Sarcostemma daltonii & 44 & $4 \mathrm{x}$ & 11 & neopolyploid & apoendemic & Liede \& Meve 1993 (no loc.) \\
\hline Sonchus daltonii & 18 & $2 x$ & 9 & diploid & schizoendemic & Kilian $1988(A, F)$ \\
\hline Tolpis farinulosa & 18 & $2 \mathrm{x}$ & 9 & diploid & schizoendemic & Kilian 1988 (F) \\
\hline Tornabenea annua & 18 & $2 \mathrm{x}$ & 9 & diploid & schizoendemic & Bramwell \& Murray 1972 (T) \\
\hline Tornabenea bischoffii & $22 ?$ & $2 x$ & $?$ & diploid & schizoendemic & Bramwell \& Murray 1972 (A) \\
\hline Tornabenea humilis & 18 & $2 \mathrm{x}$ & 9 & diploid & schizoendemic & Gomes et al. 1995a (F) \\
\hline Tornabenea insularis & $16 ?$ & $2 \mathrm{x}$ & $?$ & diploid & schizoendemic & Borgen $1980(\mathrm{~N})$, erroneous? \\
\hline Tornabenea insularis & 18 & $2 x$ & 9 & diploid & schizoendemic & Zizka 1986 (N: 2 pops.) \\
\hline Tornabenea tenuissima & $16 ?$ & $2 \mathrm{x}$ & $?$ & diploid & schizoendemic & Borgen $1974(\mathrm{~F})$, erroneous? \\
\hline Verbascum cystolithicum & ca 54 & $6 x ?$ & $9 ?$ & mesopolyploid? & $?$ & Borgen $1975(\mathrm{~F})$ \\
\hline
\end{tabular}


archipelago. Two endemic taxa, Conyza schlechtendalii and Sporobolus minutus ssp. confertus, had previously been regarded as extinct but were recently rediscovered.

Three taxa were considered Critically Endangered, all of them extremely local endemics of the northern hygrophytic element (Carex antoniensis. ('arex paniculata ssp. hansenii, and Conyza schlechtendalii), and 11 taxa were considered Endangered. Thus. 17\% (14 taxa) of the endemic flora faced a high risk of extinction in the near future. Most of the endangered taxa were shrubs which formerly have had much wider geographic distributions as important components of various indigenous meso- and hygrophytic shrubland vegetation types in the Cape Verde Islands. The endangered taxa were Conyza feae, C. pannosa, C. varia, Echium hypertropicum, E. vulcanorum, Erysimum caboverdeanum, Frankenia ericifolia ssp. montana, Nauplius daltonii ssp. daltonii, $N$. smithii, Periploca laevigata ssp. chevalieri, and Sideroxylon marginata. Several of these taxa were already Extinct or Critically Endangered on individual islands. The remaining 31 Red List taxa were fairly evenly distributed among the Vulnerable (14 taxa), Indeterminate (8 taxa), and Rare categories ( 9 taxa; Tab. 13, Fig. 28).

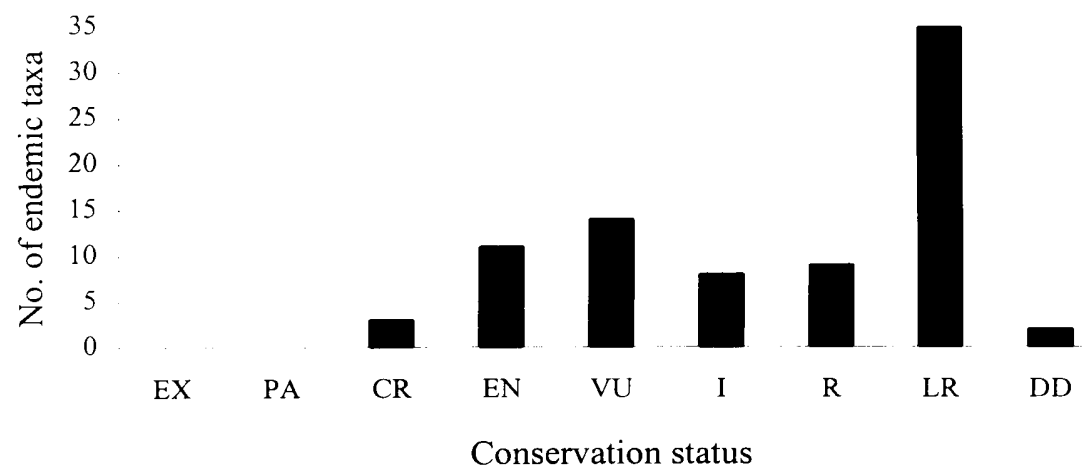

Fig. 28. Conservation status of the endemic species and subspecies of the Cape Verde Islands. EX - Extinct; PA - Prolonged Absence; CR - Critically Endangered; EN - Endangered; VU Vulnerable; I - Indeterminate (but probably CR, EN, or VIJ); R - Rare; LR - I cower Risk; DD - Data Deficient.

\section{Conservation status of individual island floras}

There were conspicuous differences among individual islands with respect to the status of their endemic floras. The proportions of threatened taxa and/or the proportions of extinct taxa were much higher on the dry, species-poor eastern islands and São Vicente than the other islands (Tab. 14, Fig. 29).

A total of 16 single-island extinctions were recorded: five on São Vicente. three on Sal and Boa Vista, two on Maio, and one on São Nicolau, Fogo. and Brava. In addition. two taxa were recorded as most likely extinct (Prolonged Absence) on São Vicente. and one taxon was recorded as most likely extinct on Santiago. Thus, about $20 \%$ of the endemic single-island 
Tab. 13. Conservation status of the endemic vascular flora of the Cape Verde Islands. Abbreviations of islands: A - Santo Antão, V - São Vicente, L - Santa Luzia (incl. Branco and Raso), N - São Nicolau, S - Sal, B - Boa Vista, M - Maio, T - Santiago, F - Fogo, R - Brava (incl. two islets). Conservation categories: EX - Extinct, PA - Prolonged Absence, CR Critically Endangered, EN - Endangered, VU - Vulnerable, I - Indeterminate (but probably CR, EN, or VU), R - Rare, LR - Lower Risk, DD - Data Deficient.

\begin{tabular}{|c|c|c|c|c|c|c|c|c|c|c|c|c|}
\hline & \multirow[t]{2}{*}{ Taxon } & \multirow{2}{*}{$\begin{array}{l}\text { General } \\
\text { status }\end{array}$} & \multicolumn{10}{|c|}{ Status on individual islands } \\
\hline & & & $\mathrm{A}$ & $\mathrm{v}$ & $\mathrm{L}$ & $\mathrm{N}$ & S & B & M & $\mathrm{T}$ & $\mathrm{F}$ & $\mathrm{R}$ \\
\hline 1 & Aeonium gorgoneum & LR & LR & EN & & LR & & & & & & \\
\hline 2 & Aristida cardosoi & LR & LR & LR & DD & LR & LR & LR & DD & LR & LR & LR \\
\hline 3 & Artemisia gorgonum & VU & VU & & & & & & & $\mathrm{CR}$ & VU & \\
\hline 4 & Asparagus squarrosus & LR & LR & LR & DD & LR & VU & LR & I & & & \\
\hline 5 & Brachiaria lata ssp. caboverdiana & VU & & VU & & EX & & VU & & LR & & \\
\hline 6 & Campanula bravensis & LR & & & & & & & & $\mathrm{R}$ & LR & LR \\
\hline 7 & Campanula jacobaea & LR & LR & LR & & LR & & & & LR & & \\
\hline 8 & Campylanthus glaber ssp. glaber & VU & VU & EN & & VU & & & & EN & VU & VU \\
\hline 9 & Campylanthus glaber ssp. spathulatus & LR & LR & & & & & & & & & \\
\hline 10 & Carex antoniensis & $\mathrm{CR}$ & $\mathrm{CR}$ & & & & & & & & & \\
\hline 11 & Carex paniculata ssp. hansenii & $\mathrm{CR}$ & $\mathrm{CR}$ & & & & & & & & & \\
\hline 12 & Centaurium tenuiflorum ssp. viridense & LR & & & & & & & & LR & LR & LR \\
\hline 13 & Conyza feae & EN & VU & EX & & EN & & & & $\mathrm{CR}$ & VU & $\mathrm{CR}$ \\
\hline 14 & Conyza pannosa & EN & $\mathrm{EN}$ & $\mathrm{CR}$ & & $\mathrm{CR}$ & & & & $\mathrm{CR}$ & & $\mathrm{CR}$ \\
\hline 15 & Conyza schlechtendalii & $\mathrm{CR}$ & & & & $\mathrm{CR}$ & & & & & & \\
\hline 16 & Conyza varia & EN & VU & EX & & EN & & & & & VU & $\mathrm{CR}$ \\
\hline 17 & Diplotaxis antoniensis & LR & LR & & & & & & & & & \\
\hline 18 & Diplotaxis glauca & VU & & & & & VU & EX & & & & \\
\hline 19 & Diplotaxis gorgadensis ssp. brochmannii & $\mathrm{VU}$ & VU & & & & & & & & & \\
\hline 20 & Diplotaxis gorgadensis ssp. gorgadensis & LR & LR & & & & & & & & & \\
\hline 21 & Diplotaxis gracilis & $\mathrm{VU}$ & & & & Vu & & & & & & \\
\hline 22 & Diplotaxis hirta & LR & & & & & & & & & LR & \\
\hline 23 & Diplotaxis sundingii & $\mathrm{R}$ & & & & $\mathrm{R}$ & & & & & & \\
\hline 24 & Diplotaxis varia & I & & & & & & & & I & & I \\
\hline 25 & Diplotaxis vogelii & I & & I & & & & & & & & \\
\hline 26 & Echium hypertropicum & $\mathrm{EN}$ & & & & & & & & EN & & $\mathrm{CR}$ \\
\hline 27 & Echium stenosiphon ssp. lindbergii & 1 & I & & & & & & & & & \\
\hline 28 & Echium stenosiphon ssp. stenosiphon & LR & LR & VU & DD & LR & & & & & & \\
\hline 29 & Echium vulcanorum & EN & & & & & & & & & EN & \\
\hline 30 & Eragrostis conertii & $\mathrm{R}$ & $\mathrm{R}$ & $\mathrm{R}$ & & $\mathrm{R}$ & & & & $\mathrm{R}$ & $\mathrm{R}$ & \\
\hline 31 & Erysimum caboverdeanum & EN & & & & & & & & & EN & \\
\hline 32 & Euphorbia tuckeyana & VU & VU & $\mathrm{CR}$ & $\mathrm{DD}$ & EN & EN & VU & & $\mathrm{CR}$ & VU & EN \\
\hline 33 & Forsskaolea procridifolia & LR & LR & $\mathrm{LR}$ & $\mathrm{DD}$ & LR & LR & & LR & LR & LR & $\mathrm{LR}$ \\
\hline 34 & Frankenia ericifolia ssp. caboverdeana & LR & LR & $\mathrm{R}$ & & LR & & & & & & \\
\hline 35 & Frankenia ericifolia ssp. montana & $\mathrm{EN}$ & & & & EN & & & & & & \\
\hline
\end{tabular}


Tab. 13 (cont.)

\begin{tabular}{|c|c|c|c|c|c|c|c|c|c|c|c|c|}
\hline & \multirow[t]{2}{*}{ Taxon } & \multirow{2}{*}{$\begin{array}{l}\text { General } \\
\text { status }\end{array}$} & \multicolumn{10}{|c|}{ Status on individual islands } \\
\hline & & & A & V & $\mathrm{L}$ & $\mathrm{N}$ & S & B & $\mathrm{M}$ & $\mathrm{T}$ & $\mathrm{F}$ & $\mathrm{R}$ \\
\hline 36 & Globularia amygdalifolia & VU & VU & & & EN & & & & $\mathrm{CR}$ & VU & VU \\
\hline 37 & Helianthemum gorgoneum & LR & LR & & DD & & & & & & LR & LR \\
\hline 38 & Kickxia elegans ssp. dichondrifolia & LR & LR & LR & & LR & & & & LR & & \\
\hline 39 & Kickxia elegans ssp. elegans & LR & LR & LR & $\mathrm{DD}$ & LR & LR & VU & VU & LR & LR & LR \\
\hline 40 & Kickxia elegans ssp. webbiana & LR & LR & & & & & & & & & \\
\hline 41 & Launaea gorgadensis & LR & LR & $\mathrm{R}$ & & LR & & & & & & \\
\hline 42 & Launaea picridioides & LR & LR & LR & DD & LR & & & & & & \\
\hline 43 & Launaea thalassica & $\mathrm{R}$ & & & & & & & & & & $\mathrm{R}$ \\
\hline 44 & Lavandula rotundifolia & LR & LR & EN & & LR & & & & LR & LR & \\
\hline 45 & Limonium braunii & LR & LR & & & LR & & & & & LR & LR \\
\hline 46 & Limonium brunneri & LR & & $\mathrm{PA}$ & DD & & LR & & & & & \\
\hline 47 & Limonium jovi-barba & $\mathrm{R}$ & & $\mathrm{R}$ & & $\mathrm{R}$ & & & & & & \\
\hline 48 & Limonium lobinii & $\mathrm{R}$ & & & & & & & & $\mathrm{R}$ & & \\
\hline 49 & Limonium sundingii & $\mathrm{R}$ & & & & $\mathrm{R}$ & & & & & & \\
\hline 50 & Lobularia canariensis ssp. fruticosa & I & 1 & & & 1 & & & & I & 1 & $\mathrm{EX}$ \\
\hline 51 & Lobularia canariensis ssp. spathulata & I & & I & & 1 & & & & & & \\
\hline 52 & Lotus arborescens & $\mathrm{R}$ & & & & $\mathrm{R}$ & & & & & & \\
\hline 53 & Lotus brunneri & LR & & EX & & & LR & $\mathrm{R}$ & $\mathrm{R}$ & & & \\
\hline 54 & Lotus jacobaeus & LR & & & & & & & & LR & LR & \\
\hline 55 & Lotus latifolius & LR & LR & & & & & & & & & \\
\hline 56 & Lotus purpureus & LR & LR & LR & & LR & & DD & & LR & LR & LR \\
\hline 57 & Nauplius daltonii ssp. daltonii & EN & & & & & & & & EN & & \\
\hline 58 & Nauplius daltonii ssp. vogelii & LR & LR & $\mathrm{EN}$ & DD & LR & & & VU & LR & LR & $\mathrm{CR}$ \\
\hline 59 & Nauplius smithii & EN & & & & EN & & & & & & \\
\hline 60 & Papaver gorgoneum ssp. gorgoneum & $\mathrm{Vu}$ & & & & $\mathrm{Vu}$ & & & & & Vu & \\
\hline 61 & Papaver gorgoneum ssp. theresias & LR & LR & & & & & & & & & \\
\hline 62 & Paronychia illecebroides & LR & LR & LR & DD & LR & & $\mathrm{EN}$ & EN & LR & LR & \\
\hline 63 & Periploca laevigata ssp. chevalieri & EN & VU & & & EN & & & & $\mathrm{CR}$ & VU & $\mathrm{CR}$ \\
\hline 64 & Phagnalon melanoleucum & LR & LR & LR & & LR & & & & LR & LR & \\
\hline 65 & Phoenix atlantidis & DD & & & DD & & DD & $\mathrm{DD}$ & $\mathrm{DD}$ & DD & & \\
\hline 66 & Polycarpaea gayi & LR & LR & EX & $\mathrm{DD}$ & LR & $\mathrm{EX}$ & & & LR & LR & \\
\hline 67 & Pulicaria burchardii ssp. longifolia & DD & & & & & DD & & & & & \\
\hline 68 & Pulicaria diffusa & $\mathrm{VU}$ & & & & & LR & VU & EX & $\mathrm{PA}$ & EX & \\
\hline 69 & Sarcostemma daltonii & LR & LR & LR & & LR & $\mathrm{R}$ & $\mathrm{R}$ & & LR & LR & LR \\
\hline 70 & Satureja forbesii & I & I & & & EN & & & & VU & I & I \\
\hline 71 & Sideroxylon marginata & EN & EN & $\mathrm{CR}$ & & $\mathrm{CR}$ & EX & EX & & EN & $\mathrm{EN}$ & CR \\
\hline 72 & Sonchus daltonii & I & I & $\mathrm{CR}$ & & VU & & & & $\mathrm{CR}$ & I & \\
\hline 73 & Sporobolus minutus ssp. confertus & $\mathrm{R}$ & & & & & EX & & $\mathrm{R}$ & & & \\
\hline 74 & Tolpis farinulosa & 1 & 1 & PA & & & & & & & I & EN \\
\hline 75 & Tornabenea annua & VU & & & & & & & & VU & & \\
\hline 76 & Tornabenea bischoffii & $\mathrm{VU}$ & VU & & & & & & & & & \\
\hline
\end{tabular}


Tab. 13 (cont.)

\begin{tabular}{|c|c|c|c|c|c|c|c|c|c|c|c|c|}
\hline & \multirow[t]{2}{*}{ Taxon } & \multirow{2}{*}{$\begin{array}{l}\text { General } \\
\text { status }\end{array}$} & \multicolumn{10}{|c|}{ Status on individual islands } \\
\hline & & & A & $\mathrm{V}$ & $\mathrm{L}$ & $\mathrm{N}$ & $\mathrm{S}$ & B & $\mathrm{M}$ & $\mathrm{T}$ & $\mathrm{F}$ & $\mathbf{R}$ \\
\hline 77 & Tornabenea humilis & LR & & & & & & & & & LR & \\
\hline 78 & Tornabenea insularis & LR & & VU & & LR & & & & & & VU \\
\hline 79 & Tornabenea tenuissima & VU & & & & & & & & & VU & \\
\hline 80 & Umbilicus schmidtii & $\mathrm{R}$ & $\mathrm{R}$ & & & $\mathrm{R}$ & & & & $\mathbf{R}$ & $\mathbf{R}$ & \\
\hline 81 & Verbascum capitis-viridis & VU & LR & EX & & VU & & $\mathrm{EX}$ & EX & VU & & \\
\hline 82 & Verbascum cystolithicum & LR & & & & & & & & & LR & \\
\hline
\end{tabular}

Tab. 14. Conservation statistics for individual islands. Abbreviations of islands: A - Santo Antão, V - São Vicente, L - Santa Luzia (incl. Branco and Raso), N - São Nicolau, S - Sal, B Boa Vista, M - Maio, T - Santiago, F - Fogo, R - Brava (incl. two islets).

No. of end. taxa No. of end. taxa in individual isl. floras Total $\begin{array}{llllllllllll}\text { entire archip. } & A & V & L & N & S & B & M & T & F & R\end{array}$

\begin{tabular}{|c|c|c|c|c|c|c|c|c|c|c|c|}
\hline Extinct & 0 & 0 & 5 & 0 & 1 & 3 & 3 & 2 & 0 & 1 & 1 \\
\hline Prolonged Absence & 0 & 0 & 2 & 0 & 0 & 0 & 0 & 0 & 1 & 0 & 0 \\
\hline Critically Endangered & 3 & 2 & 4 & 0 & 3 & 0 & 0 & 0 & 7 & 0 & 7 \\
\hline Endangered & 11 & 2 & 4 & 0 & 8 & 1 & 1 & 1 & 4 & 3 & 2 \\
\hline Vulnerable & 14 & 9 & 3 & 0 & 5 & 2 & 4 & 2 & 3 & 9 & 3 \\
\hline Indeterminate & 8 & 5 & 2 & 0 & 2 & 0 & 0 & 1 & 2 & 4 & 2 \\
\hline Rare & 9 & 2 & 4 & 0 & 6 & 1 & 2 & 2 & 4 & 2 & 1 \\
\hline Lower Risk & 35 & 27 & 11 & 0 & 20 & 6 & 2 & 1 & 15 & 18 & 9 \\
\hline Data Deficient & 2 & 0 & 0 & 13 & 0 & 2 & 2 & 2 & 1 & 0 & 0 \\
\hline Total & 82 & 47 & 35 & 13 & 45 & 15 & 14 & 11 & 37 & 37 & 25 \\
\hline
\end{tabular}


floras was probably extinct on each of the eastern islands and São Vicente, compared to less than $4 \%$ on the other islands. Thirteen taxa with single-island extinctions were recorded: Brachiaria lata ssp. caboverdeana, Conyza feae, C. varia, Diplotaxis glauca, Limonium brunneri, Lobularia canariensis ssp. fruticosa, Lotus brunneri, Polycarpaea gayi, Pulicaria diffusa, Sideroxylon marginata, Sporobolus minutus ssp. confertus, Tolpis farinulosa, and Verbascum capitis-viridis.

The total proportion of threatened taxa on individual islands varied from $43 \%$ on Santo Antão to $89 \%$ on Maio. The flora of Santa Luzia was too insufficiently known to allow for classification. Among the western islands, the proportion of threatened taxa was highest on São Vicente (69\%), Brava (64\%), and Santiago (58\%). The total proportion of taxa classified as Endangered, Critically Endangered, Prolonged Absence, and Extinct was much higher on São Vicente and Brava (more than $40 \%$ of the flora) than Santo Antão and Fogo (less than $10 \%$ of the flora), and this proportion was intermediate on Santiago and São Nicolau. This variation reflected the different degrees of human influence on different islands, with São Vicente and Brava as the most disturbed ones.

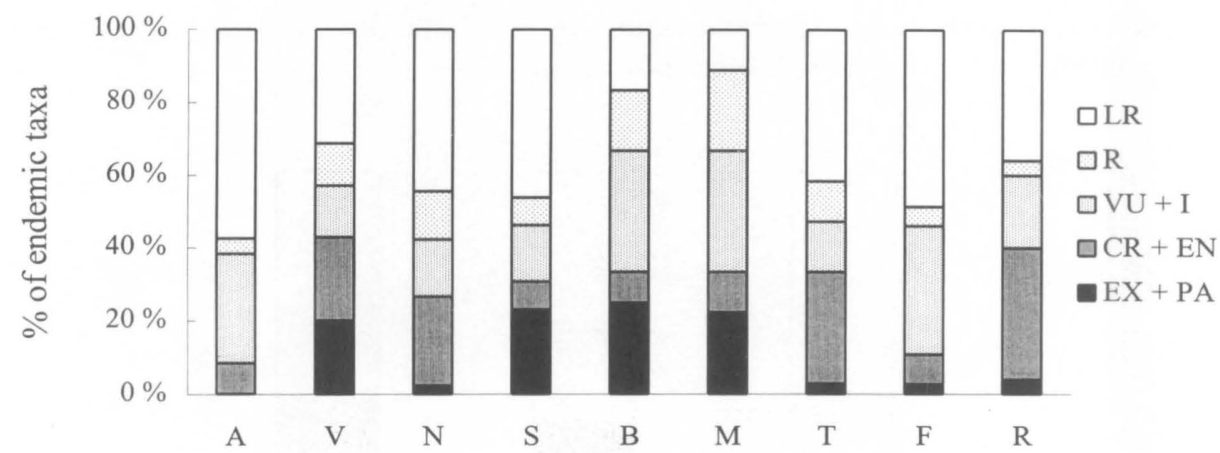

Island

Fig. 29. Relative conservation status of endemic species and subspecies in individual Capeverdean island floras. Islands: A - Santo Antão, V - São Vicente, N - São Nicolau, S Sal, B - Boa Vista, M - Maio, T - Santiago, F - Fogo, R - Brava. Status categories: EX Extinct; PA - Prolonged Absence; CR - Critically Endangered; EN - Endangered; VU Vulnerable; I - Indeterminate (but probably CR, EN, or VU); R - Rare; LR - Lower Risk.

\section{Conservation status and ecogeography}

Whereas the vast majority (24 taxa, 77\%) of the 31 endemic hygrophytes were threatened, $50 \%$ of the mesophytes and only $27 \%$ the xerophytes were threatened, reflecting that humaninduced or human-accelerated desertification was the main threat to the endemic Capeverdean flora (Fig. 30). No xerophytes were Critically Endangered or Endangered. Three xerophytes were Vulnerable (Brachiaria lata ssp. caboverdiana, Diplotaxis glauca, Pulicaria diffusa), 
and one xerophyte was Rare (Sporobolus minutus ssp. confertus). These taxa were extinct on at least one island. Although as many as 17 hygrophytes were Critically Endangered or Endangered, none of these taxa was extinct on single islands. The threatened hygrophytes typically were local, often single-island endemics that showed declining distributions in the most favourable mountainous regions.

There were similar, high proportions of threatened taxa in the western $(67 \%)$, southern $(60 \%)$, and northern distributional elements $(58 \%)$, all of which contained a considerable number of hygrophytes. The ubiquitous element only contained $31 \%$ threatened taxa. Two of the three taxa in the eastern element were threatened (Diplotaxis glauca, Sporobolus minutus ssp. confertus), and the third taxon in this element was Data Deficient (Pulicaria burchardii ssp. longifolia).

Although the hygrophytes generally were considered most strongly threatened, all single-island extinctions concerned more or less widespread mesophytes (six taxa) and xerophytes (five taxa). These taxa belonged to the ubiquitous (six taxa), western (three taxa), and eastern elements (two taxa). This pattern reflected that desertification and human destruction of habitats had been most extensive on São Vicente and the eastern islands, where most of the single-island extinctions had been recorded. On the other islands, the populations of the endemic species have so far possibilities to withdraw to higher elevations and inaccessible cliff areas in the more humid mountains.

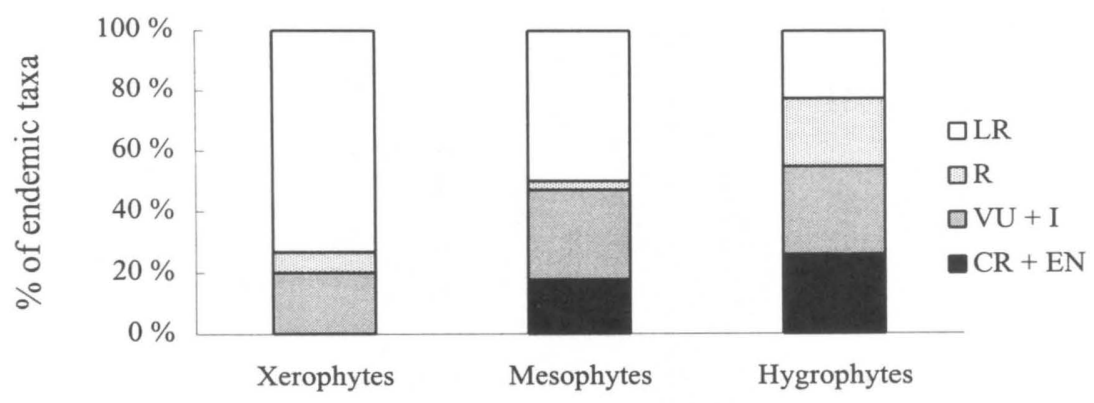

Ecological group

Fig. 30. Relative conservation status of ecological groups in the endemic flora of the Cape Verde Islands. Status categories: CR - Critically Endangered; EN - Endangered; VU Vulnerable; I - Indeterminate (but probably CR, EN, or VU); R - Rare; LR - Lower Risk. 


\title{
DISCUSSION
}

\author{
KARYOLOGY
}

\section{Proportion and types of polyploids}

Of the 52 taxa for which chromosome numbers have been counted, 38 taxa $(73.1 \%)$ can be interpreted as diploids and 14 taxa (26.9\%) as polyploids (Tab. 12). Only a single taxon, Aeonium gorgonum $(2 \mathrm{n}=36)$, can unambiguously be interpreted as palaeopolyploid. Eight taxa $(15.4 \%)$ can be interpreted as mesopolyploids, and five taxa $(9.6 \%)$, plus the tetraploid cytotype of Sarcostemma daltonii, can be interpreted as neopolyploids (Tab. 12). The meso- and neopolyploids are discussed below in connection with types of endemics.

Most species of Aeonium have $2 \mathrm{n}=36$, which is the lowest chromosome number found in this genus (Liu 1989). The chromosome number $2 \mathrm{n}=18$ has, however, been reported in other genera of the Crassulaceae (Bolkhovskikh et al. 1969), and A. gorgonum can therefore most reasonably be interpreted as a palaeotetraploid based on $\mathrm{x}=9$. In addition, it is possible that the Capeverdean taxa of Diplotaxis, Lobularia, and Euphorbia are palaeopolyploids rather than diploids.

The five species of Diplotaxis for which chromosome numbers have been counted all have $\mathrm{n}=13$, which also has been reported in their most closely related species outside the Cape Verde Islands, D. harra (Harberd 1972, Amin 1972, Gómez-Campo 1978). The basic numbers in Diplotaxis are $\mathrm{x}=7,9,10,11$, and 13 (Harberd 1972). It has been suggested that the species with $2 \mathrm{n}=26$ have originated after a tetraploidization of $\mathrm{x}=7$ to $2 \mathrm{n}=28$ with a subsequent aneuploid drop (Harberd 1976). Recent enzyme electrophoretic data (Anderson \& Warwick 1995) do not seem to support this particular hypothesis, but rather suggest that all of the known basic numbers are based on polyploidy. Duplications at several isozyme loci were observed in 102 species of tribe Brassiceae, including Diplotaxis harra, but a similar number of duplications was observed in taxa with different haploid chromosome numbers. This result suggests a widespread occurrence in the tribe of a secondarily-balanced polyploid genome structure (Anderson \& Warwick 1995).

The entire Lobularia canariensis complex, which is represented by two endemic Capeverdean subspecies, has the chromosome number $n=11$ (Borgen 1987). The only other chromosome numbers in this genus are $n=12$ and $n=23$, and Borgen (1987) hypothesizes that the common ancestor of extant Lobularia was based on $\mathrm{x}=6$. The hypothesis that $\mathrm{n}=11$ in Lobularia canariensis may have originated after tetraploidization to $\mathrm{n}=12$ with a subsequent dysploid change has recently been supported by enzyme electrophoretic data; the species showed duplications at several electrophoretic loci (Borgen 1997). A similar hypothesis may be proposed for Euphorbia tuckeyana, which has $\mathrm{n}=10$, a number also found in several Macaronesian and North African relatives of this species (e.g., E. regis-jubae; Ardévol González et al. 1993). The chromosome number $n=6$ has also been reported in the genus (Bolkhovskikh et al. 1969), and it is thus possible that $n=10$ in Euphorbia originated after tetraploidization with a subsequent aneuploid drop. 


\section{Types of endemics}

There are no palaeoendemics in the strict sense in the Capeverdean flora. The species of Tornabenea may be interpreted as palaeoendemics in a wider sense which also includes oligotypic genera (cf. Bramwell et al. 1972). In the strict sense, however, these diploid species are schizoendemics. Among the 52 taxa investigated, the vast majority (47 taxa, 90.4\%) are probably schizoendemic, including five taxa which are schizoendemic as well as patro- or apoendemic (Tab. 12). Three taxa (5.8\%) are probably patroendemic (and also schizoendemic), and seven taxa $(13.5 \%)$ are probably apoendemic, including two taxa which also are schizoendemic. In addition, the cytotypes of Sarcostemma daltonii represent one patroendemic and one apoendemic cytotype (Tab. 12).

\section{Schizoendemics}

Most of the schizoendemic taxa show a fairly clear-cut ecogeographic distributional pattern in the Cape Verde Islands, reflecting their evolution by ecogeographic differentiation without change in ploidal level, i.e., adaptive radiation and/or vicariant evolution. The largest groups of schizoendemics are found in Diplotaxis, in which the five taxa investigated (of totally nine taxa) are diploids or possibly palaeopolyploids, Lotus, in which the three investigated taxa (of totally five taxa) are diploids, Tornabenea, in which all five taxa are diploids, and Limonium, in which all five taxa are diploids. Among other genera with more than one endemic taxon in the Capeverdean flora, diploid schizoendemics are found in Kickxia, Lobularia, Nauplius, and Campylanthus. Examples of genera with only a single schizoendemic, diploid taxon are Artemisia, Globularia, Polycarpaea, Sonchus, and Tolpis (Tab. 12).

Aeonium gorgonum is a schizoendemic palaeopolyploid (cf. above). Examples of schizoendemic mesopolyploids are Campanula bravensis and C jacobaea (cf. Leyens \& Lobin 1995); Brachiaria lata ssp. caboverdiana, which has the same polyploid chromosome number $(2 \mathrm{n}=48)$ as its sister taxon ssp. lata (Bolkhovskikh et al. 1969); probably Frankenia ericifolia ssp. caboverdeana, which is tetraploid as several other taxa in this genus (Bolkhovskikh et al. 1969, Moore 1973, 1974, Goldblatt 1984); and Helianthemum gorgoneum, which is tetraploid $(2 \mathrm{n}=20)$ as its Canarian relatives (Ardévol González et al. 1993; $2 \mathrm{n}=10$ is also known in this genus, cf. Bolkhovskikh et al. 1969). Other examples of polyploid schizoendemism are found in combination with patro- and/or apoendemism.

Patro- and apoendemics

Reliable examples of patro- and/or apoendemics in the Capeverdean flora are found in the genera Conyza, Launaea, Papaver, and Sarcostemma (Tab. 12). There are also possible examples of these types of endemism connected to the infra(sub)specific variation in chromosome number in Forsskaolea and Periploca. There are, however, no straightforward ploidal relationships between the different chromosome numbers reported in the two latter genera, and these numbers must be confirmed by additional studies.

The different ploidal levels of Conyza feae (diploid, $2 \mathrm{n}=18$ ) and the closely related $C$. varia (tetraploid, $2 \mathrm{n}=36$ ) are particularly interesting, because the occurrences of these two species do not follow the typical, clear-cut ecogeographic pattern found for other Capeverdean endemics. These species are widely distributed and partly sympatric in the archipelago, and they 
often grow intermingled in the same habitat. Only a few specimens can be interpreted as hybrids between $C$. feae and $C$. varia. Thus, these species are probably partly isolated reproductively because of their different ploidal levels. Conyza feae is patroendemic relative to C. varia as well as to the tetraploids $C$. pannosa and $C$. schlechtendalii, which thus are neopolyploid apoendemics in the Capeverdean flora.

The genus Launaea provides excellent examples of three types of endemism, schizoendemism and patroendemism (L. picridioides), and apoendemism (L. gorgadensis and $L$. thalassica). Five species of Launaea occur in the Cape Verde Islands, of which four are more or less closely related: the non-endemic, mainly Sudano-Zambesian-Sindian diploid L. intyhacea $(2 \mathrm{n}=18$; Bolkhovskikh et al. 1969), which is widely distributed in the archipelago, and three endemic perennials (Kilian 1988). The endemics are the diploid L. picridioides $(2 \mathrm{n}=18)$, which is distributed on the northern islands, the tetraploid L. gorgadensis $(2 \mathrm{n}=36)$, which has an almost completely overlapping distribution with both the diploids $L$. intybacea and $L$. picridioides, and the tetraploid $L$. thalassica $(2 n=36)$, which is restricted to the southern island of Brava. Thus, the diploid $L$. picridioides is schizoendemic relative to the non-endemic diploid $L$. intybacea, and patroendemic relative to the neotetraploids $L$. gorgadensis and $L$. thalassica. Based on morphology and geographic distribution, it has been suggested that the tetraploid $L$. gorgadensis originated from a cross between the diploids $L$. picridioides and $L$. intyhacea, whereas the origin of $L$. thalassica is more obscure (Kilian 1988).

The two subspecies of the endemic Papaver gorgoneum, ssp. gorgoneum and ssp. theresias, are both polyploids with the aneuploid chromosome number $2 \mathrm{n}=38$ (Kadereit \& Lobin 1990). These subspecies are thus schizoendemic relative to each other. Papaver gorgoneum is apoendemic relative to its putatively most closely related species, the Mediterranean $P$. pinnatifidum, which is tetraploid with $2 \mathrm{n}=28$ ( $\mathrm{x}=7$; Kadereit 1988). It has been suggested that $P$. gorgoneum evolved by dysploid changes in an inbreeding founder population in the Cape Verde Islands, possibly introduced by man (Kadereit \& Lobin 1990).

\section{THE PRESENT FLORA IS PROBABLY YOUNG}

Contrary to the commonly cited opinion of Sunding (1979) and others, we will argue on the basis of our results for the endemics that the present Capeverdean flora is young, perhaps established and evolved within less than a few hundred thousand years, and that it probably is younger than at least certain elements of the floras of the Canary Islands and Madeira. The general impression of the endemics restricted to the Cape Verde Islands is that they are only slightly differentiated morphologically from their sister groups. There is a striking lack of taxonomically isolated endemics, and very few endemics are geographically highly disjunct from their sister groups. Such endemics are commonly interpreted as old elements of island floras, either as products of long-term in-situ evolution or as relicts of formerly wider geographic distributions. We will show that our conclusions also are supported by recent palaeontological data (Boekschoten \& Manuputty 1993) and by recent molecular analyses of Macaronesian plant groups (e.g., Francisco-Ortega et al. 1995a, 1995b, 1996a, 1996b, Kim et al. 1996). The molecular data also suggest that the hypothesis that the high level of insular woodiness is evidence of a primitive and old nature of island floras, has to be rejected as well. 
The level of endemism is low: age or ecology?

The level of endemism at the species level in the Cape Verde Islands is low (10.5\%) and similar to that of Madeira (9.5\%; Dalgaard 1994), but much lower than that of the Canary Islands (25.5\%; Humphries 1979; Tab. 15). The levels of endemism are much higher when based on the estimated native floras of all archipelagos (Tab. 15), but such figures should be compared with caution because it is difficult to determine with certainty if species are native or introduced.

When calculated as the average number of endemic species per main island or per square kilometer land area, it is much more obvious that the level of endemism is considerably lower in the Cape Verde Islands than in Madeira and the Canary Islands (Tab. 15). There are only 7.2 endemic species per island in the Cape Verde Islands, and 7 to 9 times as many in Madeira and the Canary Islands (53.0 and 65.7, respectively). There are only 0.016 Capeverdean endemics per $\mathrm{km}^{2}$, four times this number in the Canary Islands, and nine times this number in Madeira.

The lower level of endemism in the Cape Verde Islands compared to Madeira and the Canary Islands has usually been ascribed to the less diverse ecology in the Cape Verdes, resulting in lower levels of adaptive radiation and possibly lower levels of inter-island vicariance (e.g., Humphries 1979, Sunding 1979). Although low habitat diversity probably is the most important explanation for the lower diversity of endemics at the species level in the Cape Verde Islands, the differences in diversity may also be explained by differences in age of the floras. All or most evolutionary lineages of Tertiary age may have gone extinct in the Cape Verde Islands in unfavourable climatic periods. Some of these lineages may have survived in the more humid

Tab. 15. Endemism at the species level in the Cape Verde Islands, the Canary Islands, and Madeira (archipelago-specific endemics). Data for the Cape Verde Islands are according to this study and Lobin \& Zizka (1990), for the Canary Islands after Humphries (1979), and for Madeira after Dalgaard (1994). Only islands larger than $50 \mathrm{~km}^{2}$ are included.

\section{Cape Verde Islands Canary Islands Madeira}

No. of islands

Total area $\left(\mathrm{km}^{2}\right)$

9

No. of endemic spp.

4034

65

No. of endemic spp. per island

7.2

0.016

621

224

10.5

7

No. of endemic spp. per $\mathrm{km}^{2}$

Total no. of spp. in total flora

29.0

7273

728

$460 \quad 106$

65.7

53.0

0.146

1110

670

$\%$ endemic spp. in total flora

$\%$ endemic spp. in native flora

0.063

1800

9.5

25.5

15.8 
archipelagos such as the Canary Islands and Madeira, and some of the surviving lineages may have formed the starting points for renewed diversification in later, more favourable climates. Thus, the low level of endemism in the Cape Verde Islands may be explained by the low number of different habitats available into which founder species may radiate, combined with a lack of surviving palaeoendemic stocks from which neoendemics could have radiated.

\section{The striking absence of palaeoendemics}

There is not only a low number of Capeverdean endemics, but most of them appear to be only slightly differentiated morphologically from their sister groups. It is likely that the endemics and their non-endemic sisters are very closely related, and it is no reason to assume that they have been isolated from each other for long time periods. Except for a single endemic genus (Tornabenea), all Capeverdean taxa are endemic at the species or subspecies level.

In the most narrow sense, palaeoendemics are diploid or palaeopolyploid endemics of monotypic sections or genera (Favarger \& Contandriopoulos 1961), of which there are none in the Capeverdean flora. In a somewhat wider sense, also including oligotypic genera, Tornabenea may be interpreted as a palaeoendemic genus, in which five neoendemic (schizoendemic) species have evolved from a palaeoendemic ancestor. In contrast, the floras of the Canary Islands and Madeira harbour several examples of strictly defined palaeoendemics as well as a number of endemic genera. For the Canary Islands, Borgen (1979) lists 11 strict palaeoendemics, including 10 monotypic genera (e.g., Plocama, Vieria) and one monotypic section (Sanguisorba sect. Dendriopoterium). For Madeira, Dalgaard (1994) lists three strict palaeoendemics (diploid monotypic genera, e.g., Monizia) as well as three oligotypic genera (e.g., Phyllis). In a comparison among the Macaronesian archipelagos. Humphries (1979) lists 17 genera that are strictly endemic to the Canary Islands and 12 genera that are endemic to more than one Macaronesian archipelago, mainly the Canaries and Madeira.

In an even wider sense, palaeoendemics are endemic taxa that are taxonomically and/or geographically isolated from their sister groups. It has been suggested that many, if not most, of the geographically disjunct affinities of many Atlantic island endemics are due to extinction, partly as a consequence of the climatic changes during the late Tertiary and Quaternary periods (Cronk 1992). Parts of the Macaronesian flora have often been considered to be relicts of the Late Tertiary floras of the Tethyan region in Europe and northern Africa (Meusel 1952, Sunding 1979). Quite a large number of taxa or close relatives of taxa which presently occur in the Macaronesian archipelagos have been found as fossils in middle and southern Europe. They may have survived on the islands because of the high mountains available as refugia and because the climate was stabilized by the influence of the ocean, but went extinct in the Mediterranean because of the cooling and drying towards the end of the Tertiary (Sunding 1979). These fossils provide the strongest evidence for a relictual nature of parts of the Macaronesian flora.

None of the Capeverdean endemics have, however, been found among the Mediterranean Tertiary fossils. Only three of the fossils occur in this archipelago, either itself (the sporedispersed Adiantum reniforme) or as a closely related taxon (Dracaena draco, Phoenix atlantidis). The Capeverdean endemic Phoenix atlantidis is, however, closely related to or perhaps conspecific with African taxa of Phoenix, and it does not necessarily represent an ancient flora element on the islands. The Macaronesian endemic Dracaena draco, which also occurs in the Cape Verde Islands, was until recently believed to have its closest extant relatives 
in East Africa, a disjunction which has been suggested to be caused by extinction following the formation of deserts in northern Africa at the transition between the Tertiary and Quaternary periods (Sunding 1979). The occurrence of $D$. draco in the Cape Verde Islands may, however, result from a much more recent colonization from the African mainland; the species was recently discovered in Morocco (Benabid \& Cuzin 1997).

\section{The low level of polyploidy gives no evidence of an ancient flora}

The very low proportion of polyploids $(26.9 \%$ of the $63.4 \%$ recorded) in the endemic Capeverdean flora is similar to that in the endemic Canarian flora $(24.4 \%$ of the $62 \%$ recorded; these calculations also include Macaronesian endemics; Borgen 1979), and lower than that in the endemic Madeiran flora (40.3\%; Dalgaard 1994). Similar or somewhat higher proportions of polyploids than those in the endemic Capeverdean and Canarian floras have been reported in, for example, the entire island floras of the Canary Islands (28\%; Borgen 1979), the Cyclades (35\%; Tischler \& Wulff 1953-63), Sicily (37\%; Tischler 1934), and Madeira (40\%; Dalgaard 1994), and the continental floras of Equatorial W Africa (26\%; Morton 1966), Timbuktu (31\%; Hagerup 1931), Nigeria (34\%; Gill 1990), and northern Sahara (38\%; Reese 1957; see review in Borgen 1979).

The higher proportion of polyploidy in the endemic Madeiran flora has been explained, in part, by the lack of large (diploid) genera in Madeira (Dalgaard 1994). The evolution of many diploid species in large Macaronesian genera such as Argyranthemum, Echium, and Sonchus in the Canary Islands contributes to a lower proportion of polyploidy based on species number. In the Cape Verde Islands, the level of polyploidy is lowered by evolution of several taxa at the diploid level in groups such as Limonium, Nauplius, Tornabenea, and Diplotaxis (as pointed out, however, it is possible that the latter group is palaeopolyploid rather than diploid).

The low level of polyploidy in Macaronesian archipelagos has frequently been interpreted as support for the hypothesis that a large proportion of the Macaronesian flora is of great age. It has also been explained by low selective value of polyploids in the stable, diverse, and favourable Macaronesian island environment (e.g., Borgen 1979). As pointed out by Humphries (1979), however, richness of diploid taxa only tells that evolution mainly has been gradual and proceeded at the diploid level, irrespective of age. In addition, although a particular polyploidization event may be an old one (palaeopolyploid), further evolution may have proceeded gradually at a higher ploidal level than diploid (Humphries 1979). The few potential palaeopolyploids in the endemic Capeverdean flora (Aeonium, Diplotaxis, Lobularia, and Euphorbia) do certainly not provide any evidence of an ancient element of the flora. The chromosome numbers of the Capeverdean representatives of these genera are shared with species in other geographic areas, which means that the polyploidization events must have predated the colonization of the Cape Verde Islands, and that the evolution of the endemics within the archipelago occurred gradually without further change in chromosome number.

The most important result of the karyological analysis is that it shows the relative importance of gradual versus abrupt (polyploid) intra-archipelago evolution. We have restricted the term neopolyploids to polyploids with related taxa at lower ploidal levels in the Capeverdean flora, i.e., to taxa which may have evolved in situ by polyploidy. Only five Capeverdean endemics (9.6\%; Conyza, Launaea) fit this definition, which means that the vast majority of endemic taxa $(90.4 \%)$ most likely has evolved by gradual evolution without change in 
chromosome number (homoploid, i.e., diploid or constant polyploid number). These taxa are thus schizoendemics, which may be of very variable age. The same estimate of schizoendemism $(90 \%)$ has been made for the endemic Canarian flora (Humphries 1979).

The reason for the low level of polyploidy in the Cape Verde Islands is still unclear. It is noteworthy that there are similar, very low proportions of polyploidy in two insular floras (the Cape Verde Islands and the Canaries) as well as one continental flora (Equatorial W Africa). This observation does not support the hypothesis that the low proportion of polyploidy in the Canary Islands is directly connected to the insular environment. The frequency of polyploidization may rather be more generally related to levels of migration. isolation time, and frequency of secondary contacts between previously isolated populations (the secondary contact hypothesis; Stebbins 1985). The number of repeated cycles of isolation and reunion of diverged populations may have been particularly low in the Cape Verde Islands, the Canary Islands, and Equatorial W Africa.

\section{Recent geological, palaeontological, and molecular data: further evidence of a young flora}

One of the main arguments in favour of the hypothesis that the Cape Verde Islands have a particularly old flora has been the dating of rocks of pre-Tertiary (Cretaceous or Jurassic) age on Maio (Krejci-Graf 1961, Klerkx \& De Paepe 1971). These are the oldest rocks found in Macaronesia, coinciding more or less with the opening of the Atlantic Ocean by continental drift. However, the possibility that these rocks originally were submarine was pointed out by Sunding (1979), and it has later been verified that these rocks were formed by marine sediments. They contain fossils of organisms which lived at depths of about $1000 \mathrm{~m}$ (Boekschoten \& Manuputty 1993).

The oldest reliably dated rocks formed above sea-level have been found on Maio and São Nicolau, dating from the late Tertiary (Pliocene, approx. 2.3-7 million years BP). but it is possible that the eastern Capeverdean islands emerged in the Miocene (approx. 7-26 million years BP; Boekschoten \& Manuputty 1993). On the other Capeverdean islands only Quaternary sediments have been found, dated to less than 2.3 million years BP (Boekschoten \& Manuputty 1993). Thus, the Capeverdean islands may represent a range of ages similar to the Canary Islands and Madeira. The Canary Islands vary in age from 21 (Fuerteventura), 14 (Gran Canaria), 2 (Gomera), to 0.8 million years (El Hierro), and Madeira is about 5 million years old (reviewed by Francisco-Ortega et al. 1996a; see references therein). Recently, 13 million years old plant fossils have been discovered on Gran Canaria (García-Talavera et al. 1995, 1996), suggesting that this island was colonized soon after its origin. It is noteworthy that the youngest one of the Canarian Islands, El Hierro, harbours six island-specific endemics in Sonchus, Echium, and Aeonium, although it is only 800,000 years old (Tab. 16). This observation supports the hypothesis that speciation may occur very rapidly on oceanic islands (e.g., Lowrey \& Crawford 1985, Crawford et al. 1987a, 1987b).

Molecular studies of the Macaronesian flora have recently provided new insights into the possible age and diversification of the endemic plants. Molecular phylogenies of several groups indicate that the island taxa may be derived rather than basal relative to closely allied continental taxa (e.g., Warwick \& Black 1993, Knox \& Palmer 1995, Mes \& Hart 1996, Susanna et al. 1995, Kim et al. 1996). The ITS phylogeny of the Sonchus alliance, for example, shows a general trend towards increased woodiness, and it is likely that the ancestor of the entire 
Tab. 16. Level and relative importance of distinct adaptive radiation and inter-island vicariance in some genera shared between the Cape Verde Islands, the Canary Islands, and Madeira. Data for Madeira and the Canary Islands are extracted from Hansen \& Sunding (1993). Number of endemic species is given for each island; the number in parenthesis refers to endemics restricted to a single island (island-specific species). Cape Verde Islands: A - Santo Antão, V - São Vicente, N - São Nicolau, T - Santiago, F - Fogo, R - Brava. Canary Islands: P - La Palma, H - Hierro, G - Gomera, T - Tenerife, C - Gran Canaria, F - Fuerteventura, L - Lanzarote.

\begin{tabular}{|c|c|c|c|c|c|c|c|c|c|c|c|c|c|c|c|c|c|c|}
\hline \multirow[b]{2}{*}{ Genus/island } & \multicolumn{8}{|c|}{ Cape Verde Islands } & \multicolumn{9}{|c|}{ Canary Islands } & \multirow{2}{*}{$\frac{\text { Madeira }}{\mathrm{M}}$} \\
\hline & A & V & $\mathrm{N}$ & $\mathrm{T}$ & $\mathrm{F}$ & $\mathrm{R}$ & $\begin{array}{c}\text { Total } \\
\text { no. of } \\
\text { island- } \\
\text { spec. } \\
\text { spp. }\end{array}$ & $\begin{array}{c}\text { Total } \\
\text { no. of } \\
\text { spp. }\end{array}$ & $\mathrm{P}$ & $\mathrm{H}$ & G & $\mathrm{T}$ & $\mathrm{C}$ & $\mathrm{F}$ & $\mathrm{L}$ & $\begin{array}{l}\text { Total } \\
\text { no. of } \\
\text { island- } \\
\text { spec. } \\
\text { spp. }\end{array}$ & $\begin{array}{c}\text { Total } \\
\text { no. of } \\
\text { spp. }\end{array}$ & \\
\hline Sonchus & $1(0)$ & $1(0)$ & $1(0)$ & $1(0)$ & $1(0)$ & 0 & 0 & 1 & $3(2)$ & $4(3)$ & $3(2)$ & $8(5)$ & $4(2)$ & 0 & 0 & 14 & 17 & 3 \\
\hline Echium & $1(0)$ & $1(0)$ & $1(0)$ & $1(0)$ & $1(1)$ & $1(0)$ & 1 & 3 & $7(5)$ & $3(1)$ & $5(1)$ & $11(5)$ & $7(2)$ & $3(1)$ & $2(1)$ & 16 & 23 & 2 \\
\hline Aeonium & $1(0)$ & $1(0)$ & $1(0)$ & 0 & 0 & 0 & 0 & 1 & $10(4)$ & $6(2)$ & $11(7)$ & $13(8)$ & $7(4)$ & $1(0)$ & $2(1)$ & 26 & 34 & 2 \\
\hline Tolpis & $1(0)$ & $1(0)$ & 0 & 0 & $1(0)$ & $1(0)$ & 0 & 1 & $3(1)$ & $2(0)$ & $3(0)$ & $5(2)$ & $1(0)$ & 0 & 0 & 3 & 7 & 2 \\
\hline Euphorbia & $1(0)$ & $1(0)$ & $1(0)$ & $1(0)$ & $1(0)$ & $1(0)$ & 0 & 1 & $3(0)$ & $2(0)$ & $7(3)$ & $5(1)$ & $3(0)$ & $4(1)$ & $2(0)$ & 5 & 11 & 2 \\
\hline Helianthemum & $1(0)$ & 0 & 0 & 0 & $1(0)$ & $1(0)$ & 0 & 1 & 0 & 0 & 0 & $2(2)$ & $2(2)$ & $1(0)$ & $3(2)$ & 6 & 7 & 0 \\
\hline
\end{tabular}


alliance was a herbaceous perennial (Kim et al. 1996). Thus, the common suggestion that the predominance of woody life forms in Macaronesia supports that the flora is of considerable age may be erroneous. The molecular data rather support Carlquist's $(1970,1974)$ alternative hypothesis that the dominance of woody endemics on islands results from increase in woodiness in response to the uniformity of insular climates.

Based on ITS sequence data, Kim et al. (1996) suggested that main radiation of the Sonchus alliance occurred about 2.8-2.3 million years ago, and they raised the question of why this apparently successful, extensive radiation first took place when most of the Canary Islands were several million years old and probably occupied by established vegetation. They hypothesized that because this major radiation coincides with the first glaciation of the northern hemisphere 2.8 million years ago and the beginning of the Sahara desertification 2.5 million years ago at the transition to the Quaternary, much of the former flora in the Canaries and northwestern Africa may have gone extinct and left many open habitats, thus promoting the Sonchus radiation.

It is possible that there have been several major periods of radiation of Macaronesian genera. Genetic analysis of the extensively radiated genus Argyranthemum, endemic to the Canary Islands, the Salvage Islands, and Madeira, and allied genera suggests that the initial radiation among the genera took place about the same time as for the Sonchus alliance (3.0-2.5 million years ago), but that a second radiation occurring only 700,000-600,000 years ago resulted in speciation within Argyranthemum (Francisco-Ortega et al. 1995a). The second radiation may thus have occurred after the first Quaternary glaciation affected southern Europe.

\section{Origins and extinctions of successive Capeverdean floras - a possible scenario}

The examples referred above fit a model involving neoendemics radiating from palaeoendemic stocks after drastic environmental change, extinctions, and opening of new habitats. The presence in the Canaries and Madeira of a number of palaeoendemics, endemic genera, and taxa now extinct in Europe suggests that some old elements of their floras survived the desertification and cooling at the transition to the Quaternary. In the Cape Verde Islands, on the other hand, the virtual absence of such elements may suggest that the entire or most of the Capeverdean flora went extinct in response to the desertification of northern Africa. If only the low eastern Capeverdean islands and São Nicolau were present at that time (cf. Boekschoten \& Manuputty 1993), the late-Tertiary flora of the Cape Verde Islands may have been very poor and vulnerable to desertification.

The presently increasing desertification of the Cape Verde Islands has already resulted in several documented single-island extinctions of endemic taxa, in particular on the eastern islands (e.g., the xerophytes Diplotaxis glauca and Pulicaria diffusa, and the mesophytes Polycarpaea gayi, Sideroxylon marginata, and Verbascum capitis-viridis; Tab. 4). It is reasonable to assume that further dramatic increase in desertification also may affect the high montane endemic floras of the western islands. It is well known that northern Africa has experienced several dramatic cycles of wet and dry periods during the Quaternary, also during the last 200,000-300,000 years (e.g., Hooghiemstra et al. 1992, Andersen \& Borns 1994). The secondary period of radiation postulated in Argyranthemum in the Canaries and Madeira may coincide with opening of habitats after such a period of increased desertification. This desertification period may have reduced the floras of these northern archipelagos but entirely extirpated the flora of the Cape 
Verde Islands, which may have been more vulnerable to the desertification because of its geographic position.

It is thus possible that there have been several cycles of more or less complete flora extinctions and novel colonizations of the Cape Verde Islands during the Quaternary, and that the present flora may be relatively young. The present endemic flora was founded by a limited number of colonizers, perhaps 47 taxa, requiring only 47 events of dispersal to the archipelago. Most founders were probably undramatically recruited from nearby $(500 \mathrm{~km}$ ) western Africa, as suggested by Sunding (1973b, 1979). As much as $40 \%$ of the present Capeverdean endemics have their closest relatives today in the Canary Islands and Madeira (Tab. 7), but it is unlikely that the ancestors of the entire element migrated directly to the Cape Verde Islands via longdistance $(1500 \mathrm{~km})$ dispersal. Most of these Capeverdean and Canaro-Madeiran taxa rather had common ancestors that belonged to former Mediterranean floras, which migrated southwards and northwards several times in the late Tertiary and Quaternary in response to climatic changes. It has recently been suggested that Sonchus daltonii evolved in the Cape Verde Islands after long-distance dispersal from the western Canaries because it formed a fairly well-supported monophyletic group with two Canarian species in an ITS phylogeny (Kim et al. 1996), but it is also possible that the ancestor of this group once occurred in mainland Africa.

The phytogeographic relationships of the present endemic Capeverdean flora (Tab. 7, Fig. 11) suggest that it was founded by at least two main waves of immigrants, both via dispersal from western Africa, but in different climatic periods. One wave consisted of plants of Mediterranean origin, and probably arrived in a period when the Mediterranean flora had migrated southwards following climate change. These meso-hygrophytic elements are today mainly found in the humid, montane parts of the Cape Verde Islands. Another wave consisted of more xerophytic founders originating from a tropic, arid flora. These elements are today mainly found in the arid lowlands of the Cape Verde Islands (Figs 26, 27).

\section{PATTERNS OF EVOLUTION}

Relative importance of adaptive radiation, inter-island vicariance, polyploid evolution, and hybridization

The level of endemism in the Cape Verde Islands is fairly high (29\%) relative to the estimated native proportion of the flora (Tab. 15), but the total native flora is poor compared to the Canaries and Madeira. Thus, the number of spontaneous dispersal events to the archipelago has been low. The present native flora was probably founded by some 200 immigrant species, of which some 47 species evolved into endemics, if it is disregarded that some of the present endemics may have evolved on the continent, dispersed to the islands, and later gone extinct on the continent. Most of these 47 founder species (31 spp., 66\%) evolved into a single endemic taxon. Only 16 founders (34\%) diversified by adaptive radiation and/or inter-island vicariance, or rarely by polyploid speciation, resulting in 51 endemic taxa.

In contrast to the Canary Islands, where diploid hybrid speciation has been demonstrated (Brochmann 1987), there are no documented examples of natural hybridization resulting in stabilized hybrid derivative taxa at homoploid level in the Capeverdean flora. In the Cape Verde 
Islands, hybridization involving endemic taxa has only been observed in a few genera, e.g., Lavandula (Rustan \& Brochmann 1993), Conyza (this study), and possibly Tornabenea (Rustan \& Brochmann, unpubl. data). However, many other Capeverdean endemics show conspicuous clinal variation that most parsimoniously can be interpreted as a result of primary differentiation along a continuous humidity gradient (see below) rather than secondary clinality established after hybridization, but primary and secondary clines may be impossible to distinguish with certainty (see discussion in Brochmann et al. 1995).

Because the present endemic flora of 82 taxa may have been founded by 47 taxa, 47 of the present endemics may be regarded as a result of vicariant evolution relative to the source area of the founder species. The remaining 35 taxa evolved by one of three main processes: (1) gradual adaptive radiation into different ecological zones, selection being more important than genetic drift; (2) gradual inter-island vicariance, genetic drift probably being more important than selection; or (3) abrupt speciation following polyploidization. Polyploid evolution may have resulted in a maximum of five, possibly only two $(6 \%)$ of these 35 taxa, typical adaptive radiation in 13 taxa (37\%), and inter-island vicariance in 20 taxa (57\%; Tabs 4, 7, 12).

Distinct adaptive radiation into different ecological zones on a single island has occurred most frequently on some of the western islands, mainly on Santo Antão and São Nicolau, and less frequently on Santiago and Fogo. Typically, such radiation has resulted in one coastal, xerophytic or mesophytic taxon, and one montane, hygrophytic taxon, often at the subspecies level. Good examples are found in Echium, Lotus, Diplotaxis, Kickxia, and Campylanthus on Santo Antão; in Frankenia, Lotus, and Diplotaxis on São Nicolau; in Nauplius on Santiago; and in Tornabenea on Fogo. In almost all cases where there are more than one representative of a genus on a single island, the taxa are differentiated into xero-, meso-, and/or hygrophytes. This observation suggests that these taxa have originated by adaptive radiation and that they mainly are isolated ecologically.

Typical inter-island vicariance has most often occurred in Diplotaxis, Tornahenea, Echium, and Limonium. In most cases, these taxa occur in similar ecological zones on different islands, suggesting that they are isolated geographically rather than ecologically. A clear pattern of ecogeographic differentiation is thus typical within most endemic groups consisting of two or more taxa. The most striking exceptions to this pattern are found in Conyza and Launaea, in which polyploid evolution has been important. Several of the taxa in Conyza and Launaea have rather similar or overlapping ecogeographic distribution in the archipelago, suggesting that difference in chromosome number rather than geography or ecology keeps the taxa separate.

The low level of endemism in the Cape Verde Islands compared to the Canaries when calculated as the average number of endemic species per island or per square kilometre (Tab. 15) is caused by a much lower level of adaptive radiation as well as a much lower level of interisland vicariance. This can be quantified by comparing diversity in genera that occur in both archipelagos (Tab. 16). The genera Sonchus, Aeonium, Tolpis, Euphorbia, and Helianthemum are all represented by a single Capeverdean endemic, which typically occurs on most of the western islands. There is a single island-specific endemic species in Echium, which is represented by totally three endemic species in the Cape Verde Islands. In striking contrast to this pattern, the genera Sonchus, Echium, and Aeonium are represented by 17-34 endemic species in the Canaries, of which 14-26 are restricted to a single island (Tab. 16; cf. Hansen \& Sunding 1993). Many of the individual Canarian islands harbour more than one island-specific species, suggesting that there has been extensive evolution by inter-island vicariance as well as intra-island adaptive radiation. A similar, but less extensive pattern is found in Canarian Tolpis, 
Euphorbia, and Helianthemum. Even in the Madeiran archipelago, which comprises a few islands only, the number of endemics is higher than in the Cape Verde Islands (Tab. 16).

\section{Adaptive radiation: typically clinal in widespread groups}

The low level of adaptive radiation in the Cape Verde Islands can partly be explained by the lower level of ecological diversity on these islands compared to the Canaries and Madeira. Because of their geographic position, the Cape Verde Islands are less influenced by the humid trade wind. The lack of forests in the Cape Verde Islands not only means that there are fewer habitats available for radiation, but also indicates that the gradient of humidity caused by the trade wind is shorter because the most humid habitats are absent.

Another important difference between the Cape Verde Islands and the other archipelagos is the much more gradual transition between the ecological zones in the Cape Verde Islands. In this archipelago, there is typically a more or less continuous gradient in humidity and vegetation from arid coasts to more humid mountains, and from subhumid-semiarid northern coasts to aridextremely arid southern coasts. The lack of distinct ecological barriers or discontinuities hampers radiation into distinct taxa. There is probably sufficiently high levels of gene flow among populations occurring in different parts of the ecological gradient to prevent speciation, in spite of strong differential selection. Thus, the continuous, tree-less gradients of humidity in the Cape Verde Islands typically promote evolution of eco-morphological clines of populations rather than classic adaptive radiation into distinct taxa. Further complicating this pattern is the possibility for evolution of more or less similar clines of populations along more or less similar ecological gradients on different islands, resulting in an overall, very complex pattern of morphological and ecological variation in some endemic groups. This type of evolution necessitates application of a wide species concept. Typically, ecologically and geographically ubiquitous endemic taxa in the Cape Verde Islands are morphologically very polymorphic.

The best documented example of genetically based, parallel ecoclinal evolution in the Capeverdean flora is found in Frankenia (Brochmann et al. 1995). Other examples are Campylanthus glaber, Echium stenosiphon, Kickxia elegans, and Polycarpaea gayi (see Brochmann 1993 and Brochmann et al. 1995 for discussion). 


\title{
TAXONOMY
}

\author{
DICOTYLEDONEAE
}

APIACEAE

This family is represented by eight genera with about 13 species of which five are endemic. All endemic species belong to the endemic genus Tornabenea.

\section{Tornabenea Parl.}

'together with K. H. Schmidt

Tornabenea is the only genus that is endemic to the Cape Verde Islands. The most closely related genus is possibly Melanoselinum Hoffm. (tribe Apioideae-Laserpitieae sensu Drude), which is endemic to Madeira and the Azores. Carpological characters of Tornabenea and Melanoselinum suggest that these genera are related to other members of ApioideaeLaserpitieae which are restricted to the Mediterranean and the adjacent Near East. However, some species of Tornabenea show a similarity to the genus Daucus L., which belongs to the tribe Apioideae-Dauceae. This affinity was emphasized by Drude (1898) based on many characters of the fruits, flowers, and umbels.

Tornabenea is a widespread and morphologically variable genus which occurs on all of the major western islands from sea-level up to $1850 \mathrm{~m}$. This survey of Tornabenea is based on a preliminary study of a large material from many herbaria, including most of the types. We have applied a wide species concept and recognize five species, but the genus Tornabenea needs a thorough revision which is in progress (Lobin \& Schmidt, unpubl. data).

The species may be referred to three groups. The first group comprises the herbaceous species, i.e., the type species $T$. insularis, $T$. annua, and $T$. humilis sp. nov. The second group consists of $T$. bischoffii, and the third group consists of $T$. tenuissima. Both of the latter species are stout perennials with woody trunks, but they differ conspicuously in fruit characters. Four of the species are interpreted as upper montane hygrophytes with their main occurrences in favourable mountain areas above $600 \mathrm{~m}$, whereas a single species, T. humilis, is a lowland/coastal mesophyte distributed below $500 \mathrm{~m}$ altitude on Fogo. Four species are confined to a single island, i.e., the northern species T. bischoffii (Santo Antão) and the three southern species T. annua (Santiago), T. tenuissima (Fogo), and T. humilis (Fogo). A single species, $T$. insularis, is more widespread and occurs on two of the northern islands, São Vicente and São Nicolau, and on one of the southern islands, Brava. 
Key to the genus Tornabenea

1 Involucre consisting mainly of entire bracts; root slender; style about $2 \mathrm{~mm}$ long

1 Involucre consisting mainly of pinnately divided bracts; with rootstock or a stout root; style

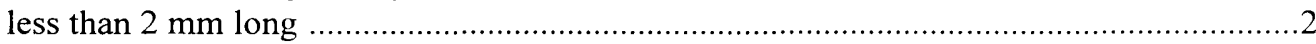

2 (1) Plant with a slender woody stem at flowering time, often more than $1 \mathrm{~m}$ high; fruiting umbel hemispherical to spherical 3

2 Plant without a woody stem or only basal part of stem woody at flowering time, less than 1 $\mathrm{m}$ high; fruiting umbel flat to hemispherical ..................................................................

3 (2) Leaflets usually broadly ovate; mericarp dark brown, up to $2 \mathrm{~mm}$ long and $1.5 \mathrm{~mm}$ broad, lateral wings without spines or slightly serrated .................................. T. bischoffii

3 Leaflets usually filiform; mericarp reddish brown, up to $3.9 \mathrm{~mm}$ long and $2.3 \mathrm{~mm}$ broad, lateral wings with distinct spines

T. tenuissima

4 (2) Lateral umbels exceeding the primary one T. humilis

4 Primary umbel exceeding the lateral ones. T. insularis

Tornabenea annua (Figs 31, 32)

Tornabenea annua Bég., Ann. Mus. Civico Storia Nat. Giacomo Doria 48: 39 (1920) $\equiv$ Melanoselinum annuum (Bég.) A. Chev., Bull. Mus. Nat. Hist. Natur., sér. 2, 7: 144 (1935). - Type: S. Tiago, dintorni di Orgãos Grandes, 300-600 m, 3.-4.1898, Fea (holotype: GDOR!).

Illustration: Lobin (1986b: Fig. 33).

Description. Delicate, annual or biennial herb up to $0.8 \mathrm{~m}$ high, with moderately dense indument of short, simple, and strigose hairs; stem branched from near the base; root slender. Leaves up to $35 \mathrm{~cm}$ long, delicate, fern-like, 2-3-pinnate with 3-6 pairs of pinnae, ultimate leaf segments lanceolate to ovate, lamina broadly oblong-ovoid to deltoid in outline. Flowering umbel more or less flat, up to $7.5 \mathrm{~cm}$ in diameter; fruiting umbel slightly constricted; peduncles of terminal umbels up to $23 \mathrm{~cm}$ long; number of rays up to 35 . Involucre inconspicuous, bracts $7-8$, up to $1.5 \mathrm{~cm}$ long, entire, rarely somewhat bi- or trifid. Involucel inconspicuous, bracts 5-6, up to $6 \mathrm{~mm}$ long. Petals white, with inflexed tip, not radiating. Mericarp light brown, $3.5 \mathrm{~mm}$ long (excluding style) and $1.5 \mathrm{~mm}$ wide, strongly compressed dorsally, lateral ribs enlarged with small spines, beak conspicuous; style up to $2 \mathrm{~mm}$ long, slender, erect.

Variation. The material is fairly homogeneous. Because of its annual habit and entire involucral bracts, T. апnua is easy to recognize. Despite its annual appearance, however, the species is probably often biennial.

Chromosome number: $2 \mathrm{n}=18$ (Santiago, Ribeira Sto. Domingo, Bramwell \& Murray 1972, Bramwell et al. 1972, sub Melanoselinum hirtum).

Distribution and ecology. Tornabenea annua is a southern hygrophyte restricted to montane areas on Santiago. It occurs in the subhumid and humid zones, primarily in the two major mountain ranges, Serra do Pico da Antonia and Serra da Malagueta, and their 


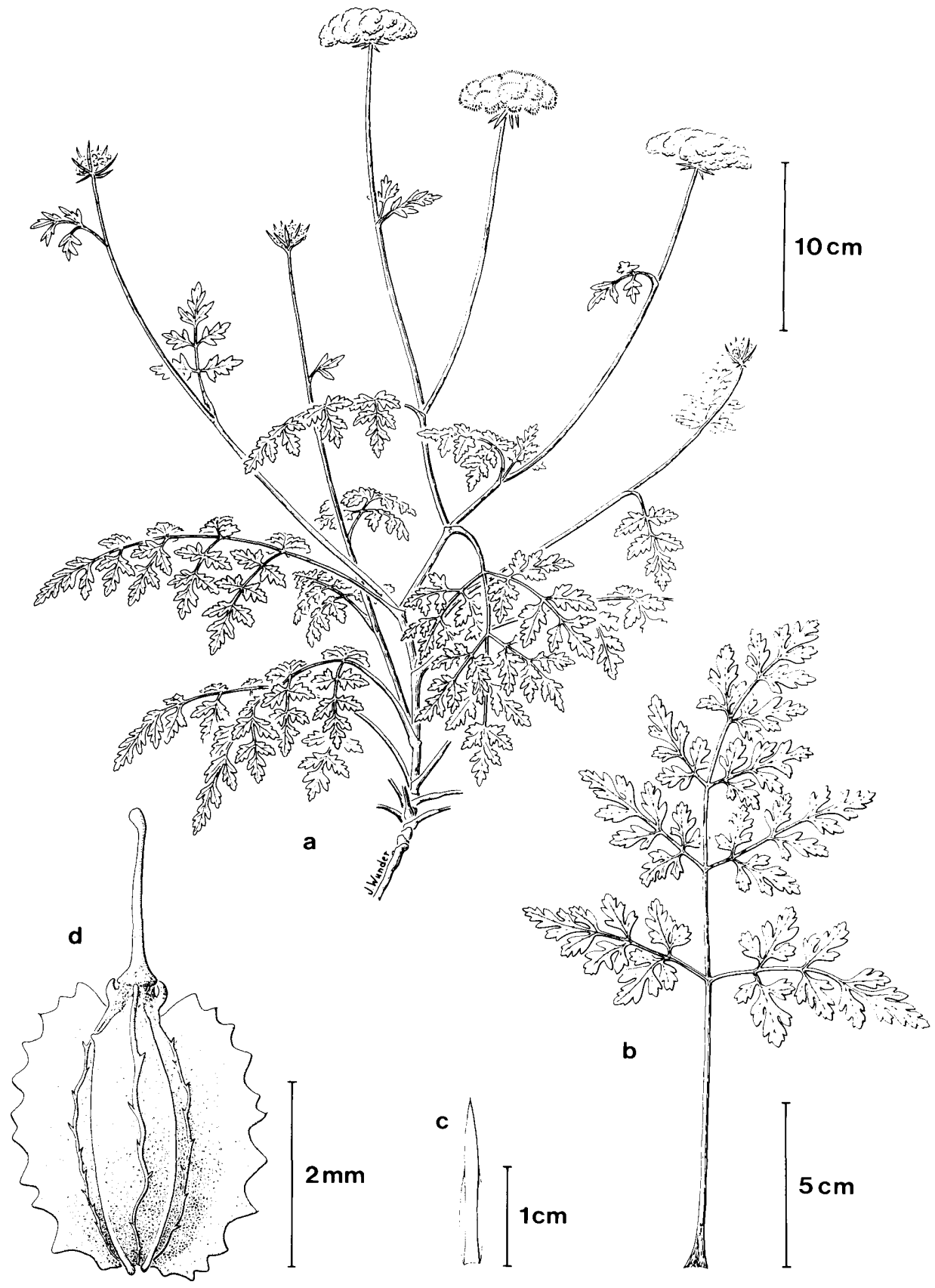

Fig. 31. Tornabenea annua. a. Habit; b. Leaf; c. Involucral bract; d. Mericarp. Drawn by J. Wunder. 


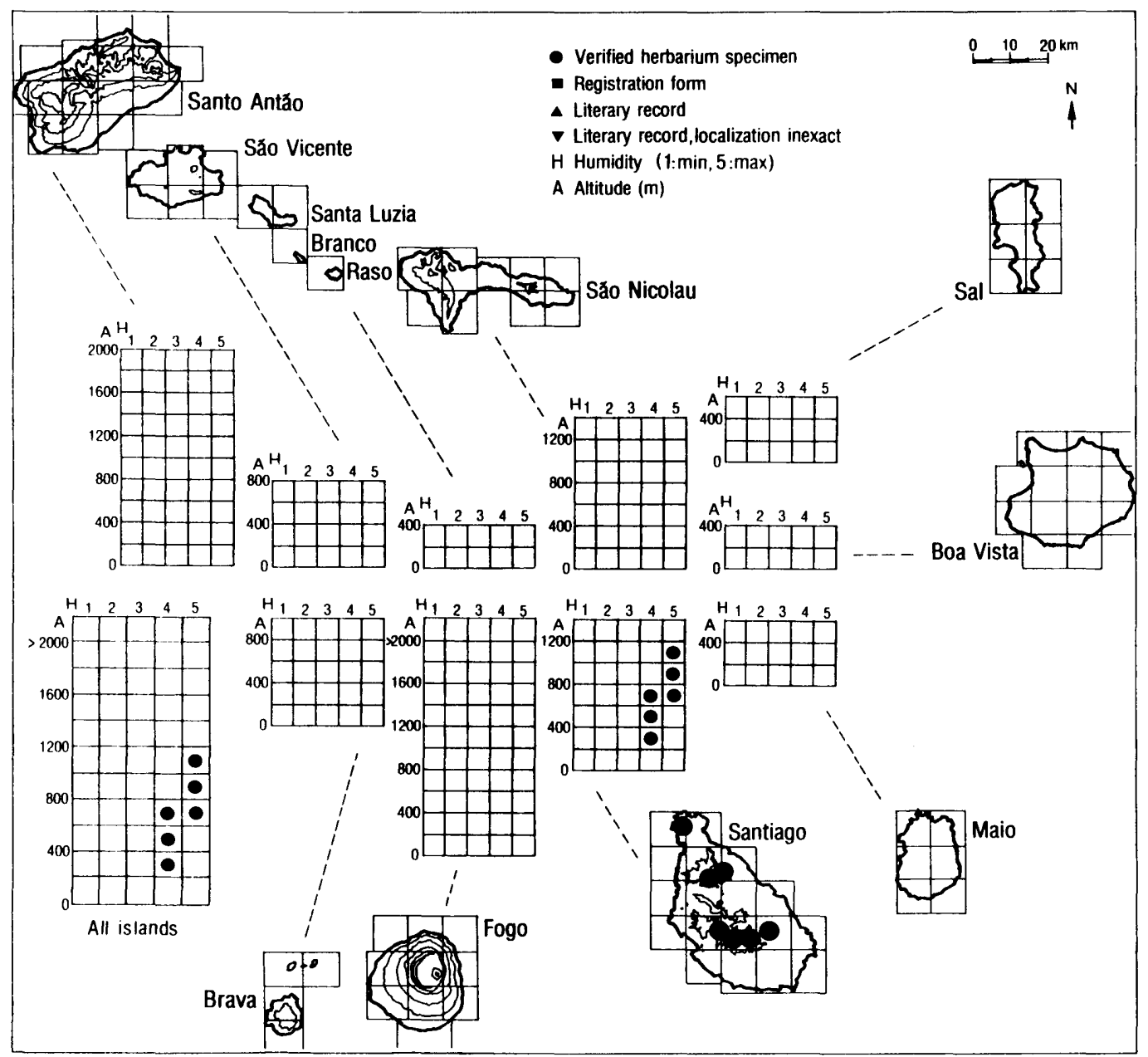

Fig. 32. Ecogeographic distribution of Tornabenea annua.

surrounding uplands, but it also occurs at Monte Graciosa in the northernmost part of the island. The main altitudinal distribution is between $650 \mathrm{~m}$ and $1000 \mathrm{~m}$. The uppermost record is at $1050 \mathrm{~m}$ in Serra da Malagueta (leg. Lobin), and the lowermost records are at $340 \mathrm{~m}$ in Ribeira de Godim in the southern, central part of the island and at $500 \mathrm{~m}$ at Monte Graciosa (leg. Rustan \& Brochmann). The plants grow primarily in montane, gravelly slopes and plains, less frequently in valleys.

Abundance. The species is still fairly widespread on Santiago, but the remaining populations represent only a fraction of the former distribution range of the species. Most of the suitable habitats have been destroyed by intensive cultivation. Tornabenea annua is considered to be Vulnerable (VU). 
Tornabenea bischoffii (Figs 33, 34)

Tornabenea bischoffii J. A. Schmidt, Beitr. Fl. Cap Verd. Ins.: 254 (1852) = Melanoselinum bischoffii (J. A. Schmidt) A. Chev., Bull. Mus. Nat. Hist. Natur., sér. 2, 7: 144 (1935). — Type: In rupestribus mont. altiorum ins. S. Antonii, 3.1851, J. A. Schmidt. — Lectotype (designated by Lobin 1986b: 148): W!; isolectotype: MB!

Illustration: Gomes et al. (1995b: p. 9).

Description. Stout perennial up to $1.5 \mathrm{~m}$ high, with woody stem up to $1.5 \mathrm{~cm}$ in diameter, with large rootstock, all parts of the plant with a pleasant fragrance. Leaves up to $35(-50) \mathrm{cm}$ long, 2(-3)-pinnate with up to 7 pairs of pinnae, ultimate leaf segments usually broadly ovate, occasionally very narrow, filiform; lamina deltoid-ovate in outline, sheath large and conspicuous. Flowering umbel hemispherical, nearly spherical when fruiting, up to $9 \mathrm{~cm}$ in diameter, number of rays up to 40 . Involucre conspicuous; bracts up to $10(-15$ ?), up to $3 \mathrm{~cm}$ long, pinnately divided; bracts in fruiting umbel slightly deflexed. Involucel with trifid, bifid, or entire bracts. Petals white. Mericarp dark brown, up to $2 \mathrm{~mm}$ long (excluding style) and 1.5 $\mathrm{mm}$ wide, only slightly compressed dorsally, beak present; style about $1 \mathrm{~mm}$ long, slender, deflexed or flexuose.

Variation. As circumscribed here, $T$. bischoffii shows considerable intraspecific variation. The material from the northeastern part of its distribution area (e.g., Ribeira do Paul, Cova, and Ribeira da Torre) is fairly homogeneous, characterized by broadly ovate leaflets. The material from the western part of the distribution area differs by its conspicuously narrow leaflets and resembles T. tenuissima from Fogo.

Chromosome number: $2 \mathrm{n}=22$ (Santo Antão, Ribeira do Paul, Bramwell \& Murray 1972, Bramwell et al. 1972).

Distribution and ecology. Tornabenea bischoffii is a northern hygrophyte restricted to three montane areas on Santo Antão: 1) the northeastern, most favourable part of the island (Pico da Cruz - Ribeira do Paul - Cova - Ribeira da Torre), 2) the central, northwestern slopes of the island (Lombo do Mar - Ribeira do Alto Mira), and 3) below the northwest-exposed, steep cliff walls northeast of the Tope de Coroa massif in the southwestern part of the island. The species is primarily confined to the humid and subhumid zones between $700 \mathrm{~m}$ and 1300 $\mathrm{m}$. The lowermost record is at $310 \mathrm{~m}$ in the semiarid zone (Ribeira do Alto Mira, leg. Rustan \& Brochmann), possibly representing a secondary, ephemeral population. The uppermost records are at $1450 \mathrm{~m}$ at Pico da Cruz (leg. Rustan \& Brochmann) and above Ribeira da Torre (leg. Leyens). The species prefers steep, northeast-exposed cliff habitats in the northeastern part of its distribution area, but it is otherwise occurring in steep and gravelly montane slopes.

Abundance. The species is fairly frequent only in the northeastern part of Santo Antão, especially in the heavily cultivated area around Ribeira do Paul. It has a very scattered occurrence in the other montane areas, where it has declined because of loss of suitable habitats. Tornabenea bischoffii is considered to be Vulnerable (VU). 


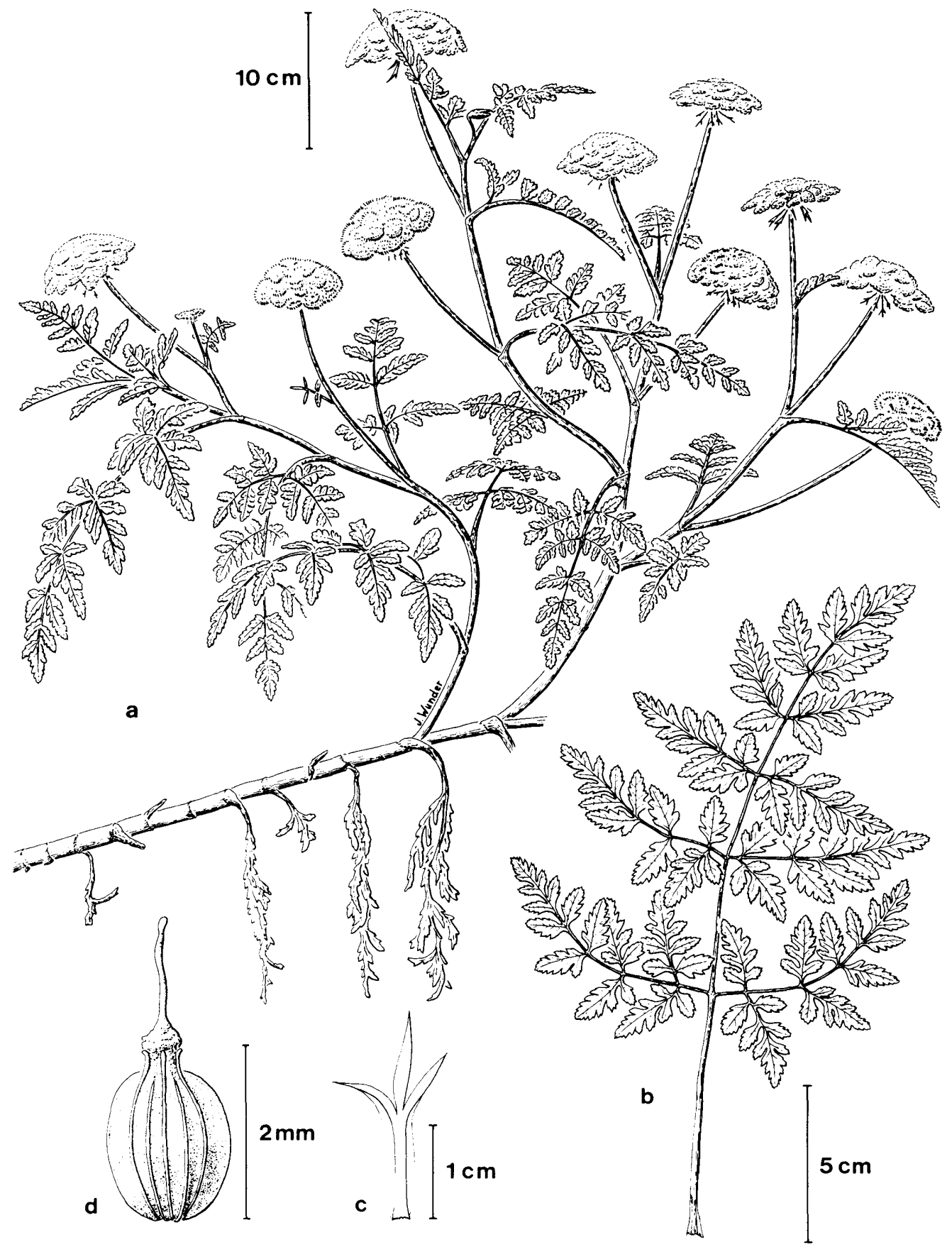

Fig. 33. Tornabenea bischoffii. a. Habit; b. Leaf; c. Involucral bract; d. Mericarp. Drawn by J. Wunder. 


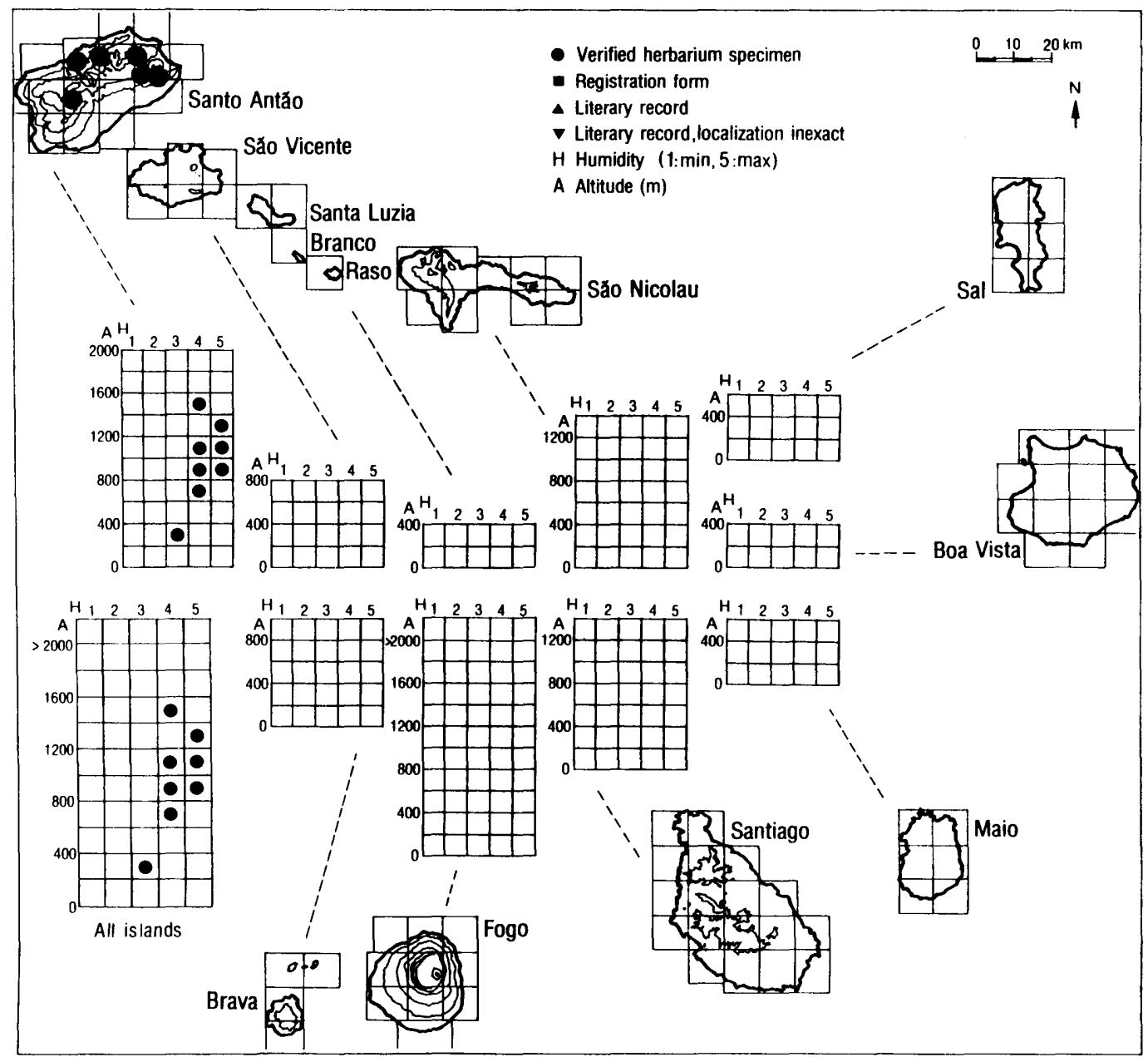

Fig. 34. Ecogeographic distribution of Tornabenea bischoffii.

\section{Tornabenea humilis (Figs 35, 36)}

Tornabenea humilis Lobin \& K. H. Schmidt, sp. nov. [ $=$ Tornabenea depressa I. Gomes, S. Gomes, M. T. Vera Cruz, N. Kilian, Leyens \& Lobin, Plantas endémicas e árvores indigenas de Cabo Verde: 9 (1995), nom. nud.]. - Type: Fogo, Lavastrom nördlich der Abzweigung nach Corvo, ca. $300 \mathrm{~m}$ hoch, 8.12.1982, Lobin $262 I$ (holotype: FR; isotypes: B, K, O, Herb. Lobin).

Illustration: Gomes et al. (1995b: p. 9 sub T. depressa).

Planta valde robusta in omnibus partibus, habitus humilis vel prostratus, internodia in longitudine abbreviata, axis primaria cum umbella primi ordinis brevis, erectus, ramificationes laterales cum umbellis secundariis et tertiariis distincte longiores quam axis primaria, tertiariis distincte longiores quam axis primaria, saepe procumbentes vel adscendentes, folia robusta, coriacea, folia involucralia robusta, pinnata, mericarpia valde complanata, late-ovata vel orbiculata, costae marginales et dorsales aculeis robustis. 

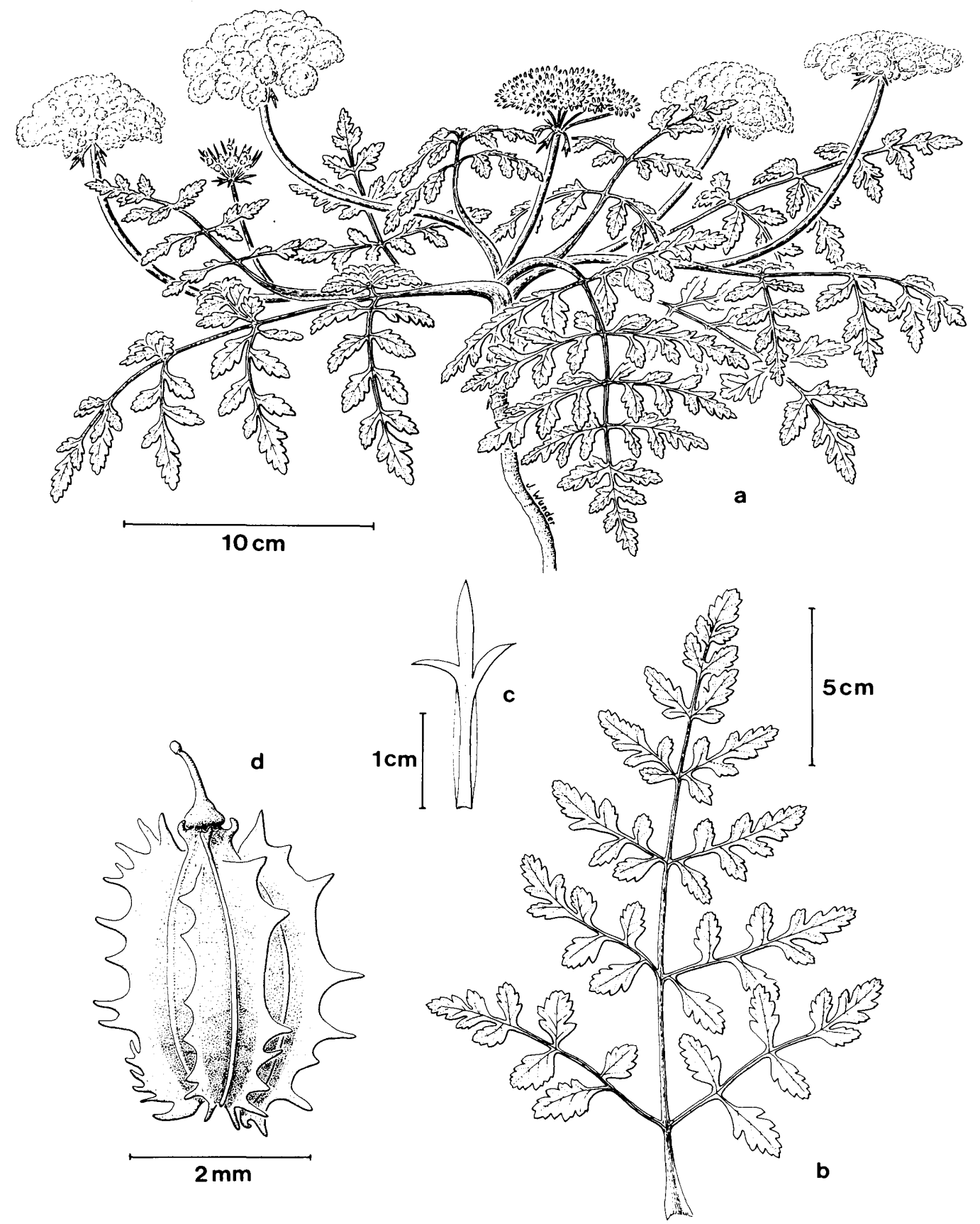

Fig. 35. Tornabenea humilis. a. Habit; b. Leaf; c. Involucral bract; d. Mericarp. Drawn by J. Wunder. 


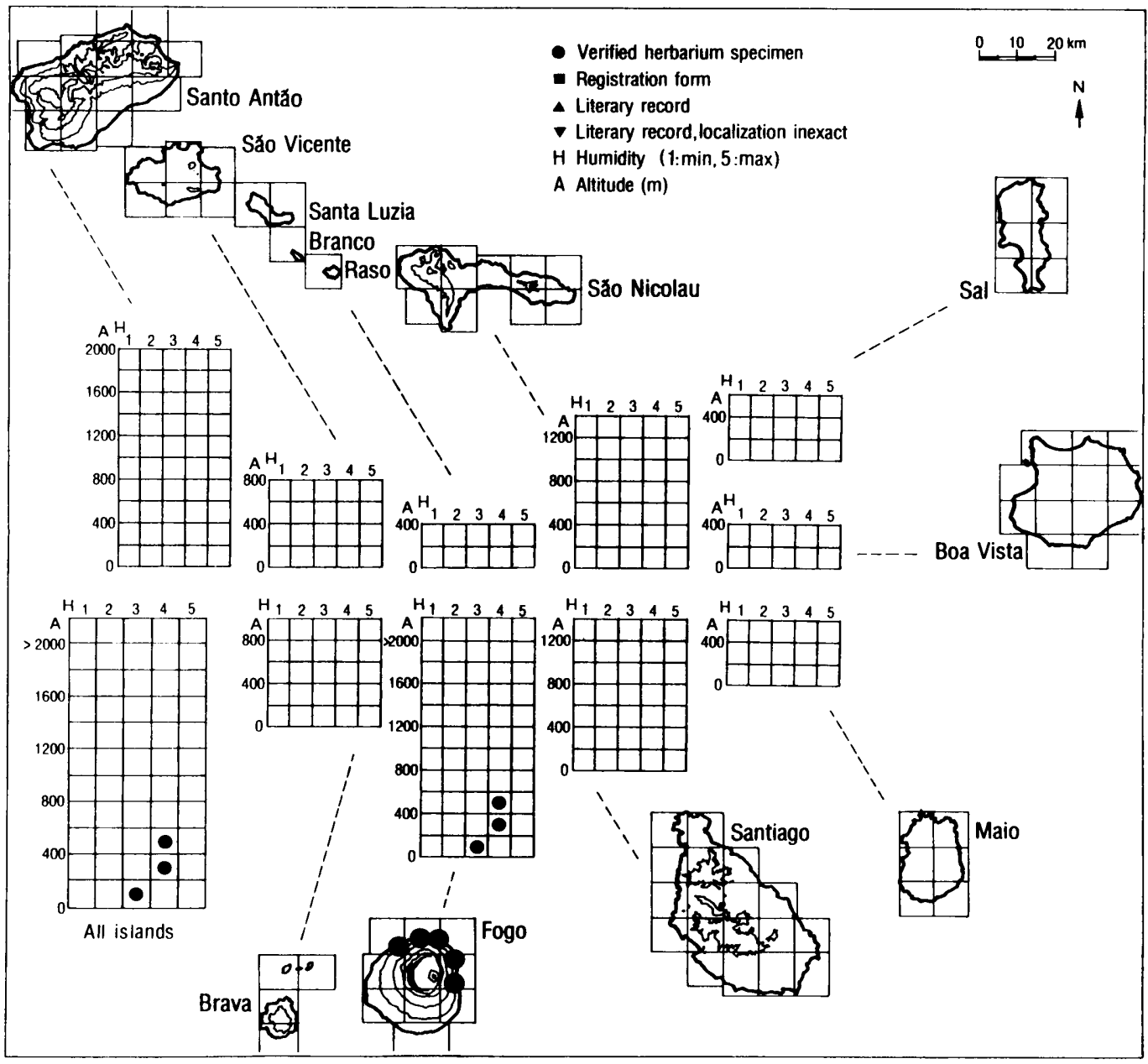

Fig. 36. Ecogeographic distribution of Tornabenea humilis.

Description. Perennial (or biennial?) herb up to $0.4 \mathrm{~m}$ high, glabrous or sparsely covered with short, strigose hairs, stem branched from near the base, with a stout root; terminal umbel on a short, erect stem; lateral stems longer, exceeding the terminal one and descending. Leaves up to $30 \mathrm{~cm}$ long, subcoriaceous, 1-2-pinnate with up to 4(-8) pairs of pinnae, ultimate leaf segments ovate, lamina broadly oblong to elliptical in outline. Flowering umbel more or less flat to hemispherical, up to $7.5 \mathrm{~cm}$ in diameter, peduncles of terminal umbels up to $11 \mathrm{~cm}$ long, number of rays up to 50 . Involucre conspicuous, bracts up to 12 , up to $2.6 \mathrm{~cm}$ long, pinnately divided. Involucel of small, entire bracts. Petals white. Mericarp brown to grey, up to $5 \mathrm{~mm}$ long (excluding style) and $4.5 \mathrm{~mm}$ wide, strongly compressed dorsally, disc-shaped, lateral and dorsal ribs enlarged with irregularly developed, conspicuous spines; style up to 1 $\mathrm{mm}$ long, erect. 
Variation. The material is variable in some characters, and the delimitation of this coastal species versus the montane $T$. tenuissima needs further examination. Some populations, in particular those occurring at intermediate altitudes and humidity, appear transitional between these two species.

Chromosome number: $2 \mathrm{n}=18$ (Fogo, between Ribeira S. Jorge and the village S. Jorge, roadside, Gomes et al. 1995a sub T. spec. A).

Distribution and ecology. Tornabenea humilis is a southern mesophyte restricted to lowland areas on northwestern and northeastern Fogo. It occurs in the semiarid and subhumid zones, mainly between $100 \mathrm{~m}$ and $300 \mathrm{~m}$. The uppermost record is at $480 \mathrm{~m}$ along the northern coast and the lowermost one at $50 \mathrm{~m}$ along the northeastern coast (leg. Rustan \& Brochmann). The plants grow on lava or in gravelly coastal slopes.

Abundance. The species is rather common in the lowlands of Fogo. It is considered to be Lower Risk (LR).

\section{Tornabenea insularis (Figs 37, 38)}

Tornabenea insularis (Parl.) Parl. in Hooker, J. Bot. Kew Gard. Misc. 2: 370 (1850) झ Tetrapleura insularis Parl. in Hooker, Niger Fl.: 131 (1849) =Melanoselinum insulare (Parl.) A. Chev., Bull. Mus. Nat. Hist. Natur., sér. 2, 7: 144 (1935). — Type: In insula S. Vincentii, Vogel (holotype: K!).

= Tornabenea hirta J. A. Schmidt, Beitr. Fl. Cap Verd. Ins.: 253 (1852). -- Type: In montosis asperis, Mont. Vered., ad 1500 ped. usque ad apicem, ins. S. Vincentii, 1.2.1851, J. A. Schmidt (holotype: HBG!).

Illustrations: Chevalier (1935a: Figs 3, 4).

Description. Stout, perennial herb up to $0.9 \mathrm{~m}$ high, with moderately dense to dense indument of short, strigose hairs or long, soft hairs; stem branched from near the base, with a (often very large) rootstock; all parts of the plant with a pleasant fragrance. Leaves up to $30 \mathrm{~cm}$ long, subcoriaceous to delicate, 1-2-pinnate with 3-6 pairs of pinnae, ultimate leaf segments broadly oblong-ovoid to ovate, lamina broadly oblong to deltoid-ovate in outline. Flowering umbel more or less flat to hemispherical, up to $9 \mathrm{~cm}$ in diameter, peduncles of terminal umbels up to $29 \mathrm{~cm}$ long, number of rays up to 60 . Involucre conspicuous, bracts $4-13$, up to $2.8 \mathrm{~cm}$ long, pinnately divided; bracts in fruiting umbel slightly deflexed. Involucel of 7-9 narrow, trifid, bifid, or entire bracts. Petals white, often with pink venation, with inflexed tip, petals in marginal position slightly to distinctly radiating. Mericarp light brown, $2 \mathrm{~mm}$ long (excluding style) and 1.5 mm wide, with a beak; style 0.5-0.7 mm long, slender, deflexed or flexuose.

Variation. As circumscribed here, this species is highly variable in several characters. Further studies are needed to clarify if several taxa should be recognized.

Chromosome number: $2 \mathrm{n}=18(16$ ?) $(2 \mathrm{n}=16$, São Nicolau, Alto Joaquina, $500 \mathrm{~m}$, Borgen 1980, sub T. hirta; $2 \mathrm{n}=18$, São Nicolau, $\mathrm{N}$ of Vila da Ribeira Brava, Ribeira Tucada, Zizka 1986, sub T. annua; 2n = 18, São Nicolau, Monte Gordo, 800-1200 m, Zizka 1986). The single, aberrant count of $2 n=16$ needs confirmation.

Distribution and ecology. Tornabenea insularis is a western hygrophyte occurring on São Vicente, São Nicolau, and Brava. Most populations occur in montane areas between 600 $\mathrm{m}$ and $1200 \mathrm{~m}$ within the subhumid and humid zones, but as circumscribed herein, the species also comprises a few, stable coastal populations in the semiarid zone of northern São Nicolau $(100-400 \mathrm{~m})$ and northern Brava $(70 \mathrm{~m}$, leg. Rustan \& Brochmann). On São Vicente, it is restricted to Monte Verde and the adjacent mountain Gôa Alto, where it grows between $450 \mathrm{~m}$ (leg. Sunding) and $770 \mathrm{~m}$ (many observations). The uppermost record from São Nicolau is at 


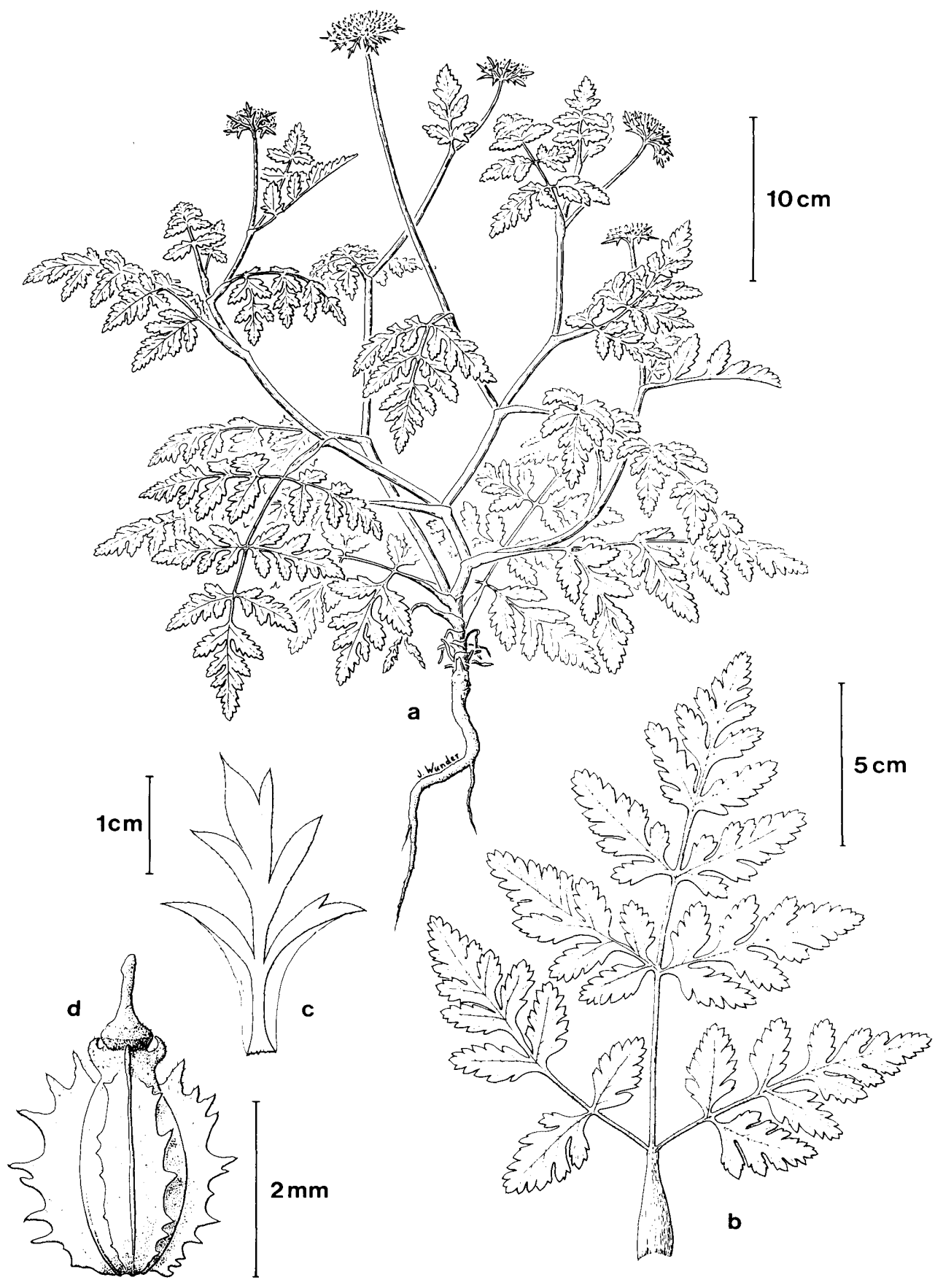

Fig. 37. Tornabenea insularis. a. Habit; b. Leaf; c. Involucral bract; d. Mericarp. Drawn by J. Wunder. 


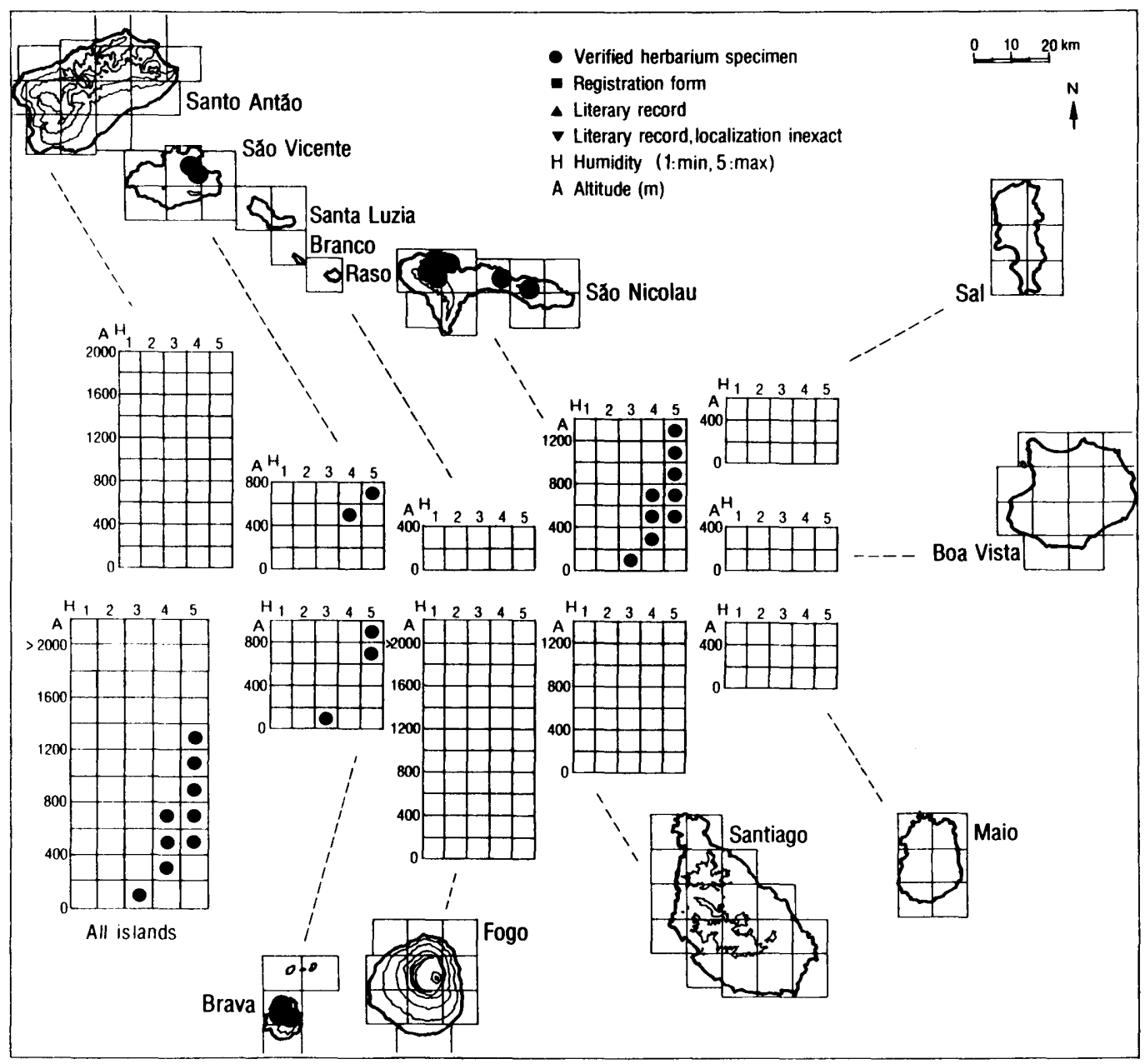

Fig. 38. Ecogeographic distribution of Tornabenea insularis.

$1300 \mathrm{~m}$ at Monte Gordo (leg. Gomes, Lobin \& Schmidt), and from Brava at $900 \mathrm{~m}$ at Monte Fontainhas (leg. Rustan \& Brochmann). The plants grow in cliffs and gravelly slopes.

Abundance. The species is still rather common on São Nicolau. On São Vicente. the present distribution is mainly restricted to the top of Monte Verde, representing only a small relict of a much wider distribution on this island (cf. Krause 1892). Tornabenea insularis is classified as Vulnerable (VU) on São Vicente and Brava, but it is generally considered to be Lower Risk (LR). 


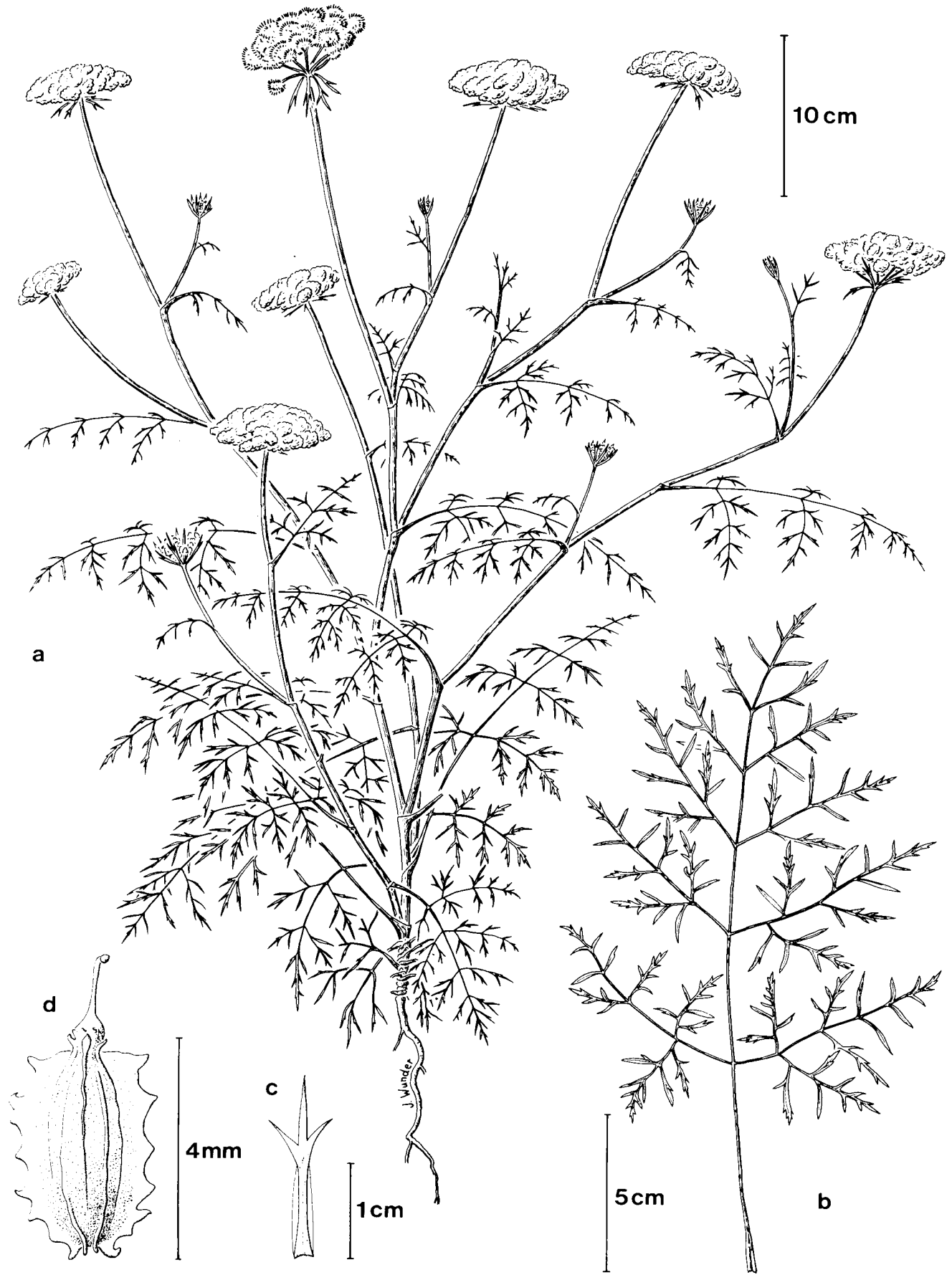

Fig. 39. Tornabenea tenuissima. a. Habit; b. Leaf; c. Involucral bract; d. Mericarp. Drawn by J. Wunder. 


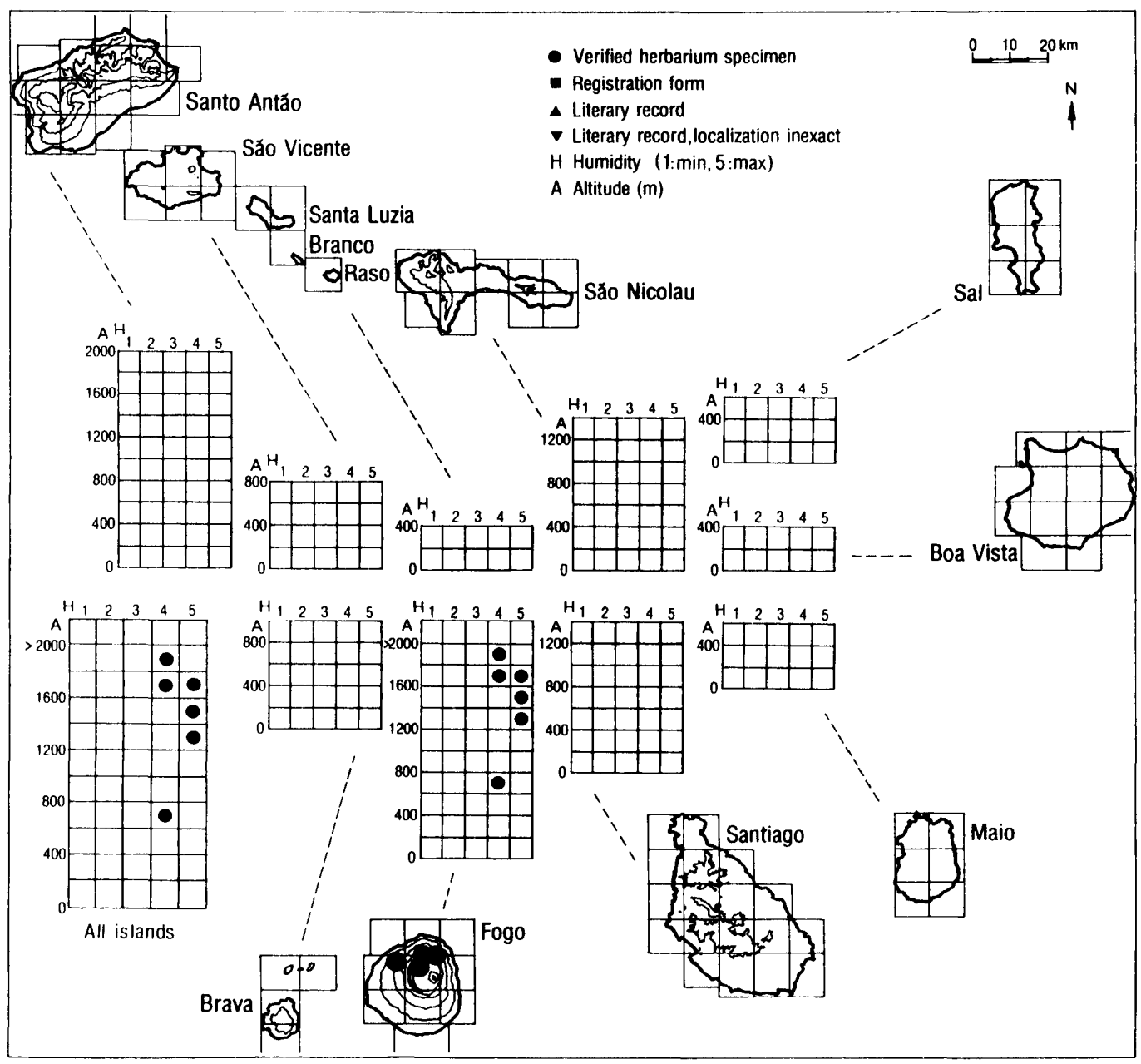

Fig. 40. Ecogeographic distribution of Tornabenea tenuissima.

\section{Tornabenea tenuissima (Figs 39, 40)}

Tornabenea tenuissima (A. Chev.) A. Hansen \& Sunding, Flora Macaronesia Checklist, ed. 2, 1: 92 (1979) $\equiv$ Melanoselinum tenuissimum A. Chev., Bull. Mus. Nat. Hist. Natur., sér. 2, 7: 143 (1935). - Type: Fogo, Pico Pires, 600-800 m, dans le rocailles, 8.8.1936, Chevalier 44188 (holotype: P!).

Illustrations: Chevalier (1935a: Fig. 2, 1935b: p. 140).

Description. Stout perennial up to $1 \mathrm{~m}$ high, stem woody with diameter up to $1 \mathrm{~cm}$, with large rootstock. Leaves up to $40 \mathrm{~cm}$ long, 2-3-pinnate with up to 6(-7) pairs of pinnae; leaf segments simple, rigid, with more or less recurved margins, ultimate leaf segments very narrow, filiform, 0.5-2 mm wide; lamina deltoid in outline. Flowering umbel hemispherical, nearly spherical when fruiting, up to $9 \mathrm{~cm}$ in diameter. Involucre conspicuous, bracts up to 10 , 
up to $2 \mathrm{~cm}$ long, pinnately divided, segments slender, narrow. Involucel consisting of trifid, bifid, or rarely entire bracts. Petals white. Mericarp dark reddish brown, up to $3.9 \mathrm{~mm}$ long (excluding style) and $2.3 \mathrm{~mm}$ wide, compressed dorsally, lateral ribs with irregularly developed, light brown spines; style up to $1.4 \mathrm{~mm}$ long, slender, flexuose.

Variation. The material is variable in leaf morphology. Most of the populations are characterized by very narrow, filiform, and often rigid leaflets, but some populations have broader leaflets and thus resemble $T$. bischoffii. The delimitation of $T$. tenuissima, which with the present circumscription is restricted to Fogo, versus T. bischoffii, which is restricted to Santo Antão, needs further clarification.

Chromosome number: $2 \mathrm{n}=16$ (?) (Fogo, Caldeira rim around Chã das Caldeiras near Fernão Gomes, Borgen 1974). This aberrant chromosome number needs verification.

Distribution and ecology. Tornabenea tenuissima is a southern hygrophyte restricted to the most favourable montane areas on Fogo, including the northern part of the caldeira, the Monte Velha area, and the upper, northern slopes of the island. It is confined to the humid and subhumid zones, mainly between $1200 \mathrm{~m}$ and $1700 \mathrm{~m}$. The uppermost record is at $1850 \mathrm{~m}$ above Monte Velha (leg. Leyens), and the lowermost one at $750 \mathrm{~m}$ in Ribeira de Coroa (leg. Lewejohann).

Abundance. The species is fairly common in the northernmost, elevated part of Fogo, but its total distribution area is very limited and diminished by afforestations. Tornabenea tenuissima is considered to be Vulnerable (VU).

\section{ASCLEPIADACEAE}

This family is represented by four genera with four species. Two taxa, one species and one subspecies of a non-endemic species, are endemic.

\section{Periploca L.}

Periploca is a genus of opposite-leafy shrubs with milky latex and comprises about ten species distributed in N, E, and W Africa, S Europe, and S Asia. In the Cape Verde Islands, the genus is represented by one endemic subspecies of the $\mathrm{N}$ African/S Mediterranean $P$. laevigata.

Literature: Browicz (1966).

\section{Periploca laevigata}

Periploca laevigata Aiton, Hort. Kew., ed. 1: 301 (1789). - Type: Cultivated in Hort. Kew. from material collected by Masson in the Canary Islands in $1779(\mathrm{~K})$.

Description. Shrub up to $3 \mathrm{~m}$ high, with ascending to erect, sometimes twining branches. Leaves subsessile, persistent, leathery, linear to broadly elliptical or obovate, margin entire. Inflorescence axillary or terminal, with few to several flowers. Flowers $1-1.5 \mathrm{~cm}$ in diameter; 
corolla lobes oblong, greenish yellow outside, purplish violet with lighter margin and a central, white spot inside; gynostegial corona with 5 filiform, deeply violet lobes that are somewhat shorter than and alternating with the corolla lobes. Fruit of two follicles.

Note. The Capeverdean material of Periploca is usually recognized as a distinct species, P. chevalieri Browicz (e.g., Hansen \& Sunding 1993). Browicz (1966) distinguished the three closely related species $P$. laevigata Aiton, $P$. chevalieri Browicz, and $P$. angustifolia Labill. mainly based on leaf characters, but he was in doubt whether the Capeverdean $P$. chevalieri rather should be regarded as a subspecies of $P$. laevigata. After comparing the Capeverdean plants with $P$. laevigata and $P$. angustifolia, we agree with Kunkel (1970) and Markgraf (1972) that all three taxa should be treated as subspecies of a single species. In contrast to Kunkel (1970), however, who stated that the Capeverdean taxon also occurs in the Canary Islands, we agree with Browicz (1966) that the leaf shape of the Capeverdean plants is so uniform and different from that of most of the Canarian plants that they should be recognized as different taxa. Subspecies angustifolia (Labill.) Markgraf is characterized by its short leaves (less than $3.5 \mathrm{~cm}$ ) that are arranged in 3-5-leaved fascicles on older shoots, whereas the two other subspecies are characterized by absence of fascicles and longer leaves (up to $7 \mathrm{~cm}$ ). Subspecies chevalieri invariably has narrow leaves (length to width ratio of 611), whereas ssp. laevigata usually has conspicuously broader leaves (length to width ratio of 2.5-5).

The three subspecies of $P$. laevigata are geographically clearly separated: ssp. angustifolia has a S Mediterranean distribution with outposts in the Hoggar Mountains and Western Sahara, ssp. laevigata is confined to the Canary Islands and the Salvage Islands, and ssp. chevalieri occurs in the Cape Verde Islands (Browicz 1966). All subspecies mainly prefer semiarid to subhumid, more or less open, stony or rocky habitats.

Periploca laevigata s. lat. is most closely related to P. somaliensis Browicz, which only is known from the mountains of north-eastern Somalia (Browicz 1966).

\section{Periploca laevigata ssp. chevalieri (Figs 41, 42)}

Periploca laevigata Aiton ssp. chevalieri (Browicz) G. Kunkel, Cuad. Bot. Canaria 8: 11 (1970) $\equiv$ Periploca chevalieri Browicz, Arb. Kórnickie 11: 38 (1966). — Type: Fogo, Chã das Caldeiras, 23.-24.7.1934, Chevalier 44879 (holotype: $\mathrm{K}$; isotypes: C, P).

Illustrations: Barbosa (1961: Fig. 38 sub $P$. laevigata), Browicz (1966: Figs 12, 13,15 sub $P$. chevalieri), Lobin (1986b: Fig. 29, 1986d: Figs 3-6 sub P. chevalieri), Gomes et al. (1995b: p. 9).

Description. Shrub up to $2 \mathrm{~m}$ high, strongly branched; branches ascending to erect, often twining when young. Leaves persistent, fairly uniform, linear-lanceolate to lanceolate, up to 7 $\mathrm{cm}$ long and up to $1 \mathrm{~cm}$ wide, glabrous, apex acute to acuminate, margin entire. Inflorescence terminal or axillary, 3-20-flowered. Calyx up to $3 \mathrm{~mm}$ long, deeply dissected. Corolla lobes oblong, obtuse, 5-6 mm long and 2-3 mm wide. Follicles linear-lanceolate in outline, up to $13.5 \mathrm{~cm}$ long, erect when immature, later spreading, finally horizontal or almost so. Seeds dark brown to blackish, 6-9 mm long, 2-3 mm broad, hair-tuft 3-3.5 $\mathrm{cm}$ long.

Variation. Material from all islands except Santiago was examined and found to be fairly homogeneous, in particular in leaf shape.

Chromosome number: $2 \mathrm{n}=22,36(?)(2 \mathrm{n}=22$, Fogo, Chã das Caldeiras, N part, 1600 $\mathrm{m}$, Borgen 1975; $2 \mathrm{n}=22$, Fogo, path from settlement Miguel Gonçalves below Monte Duarte 


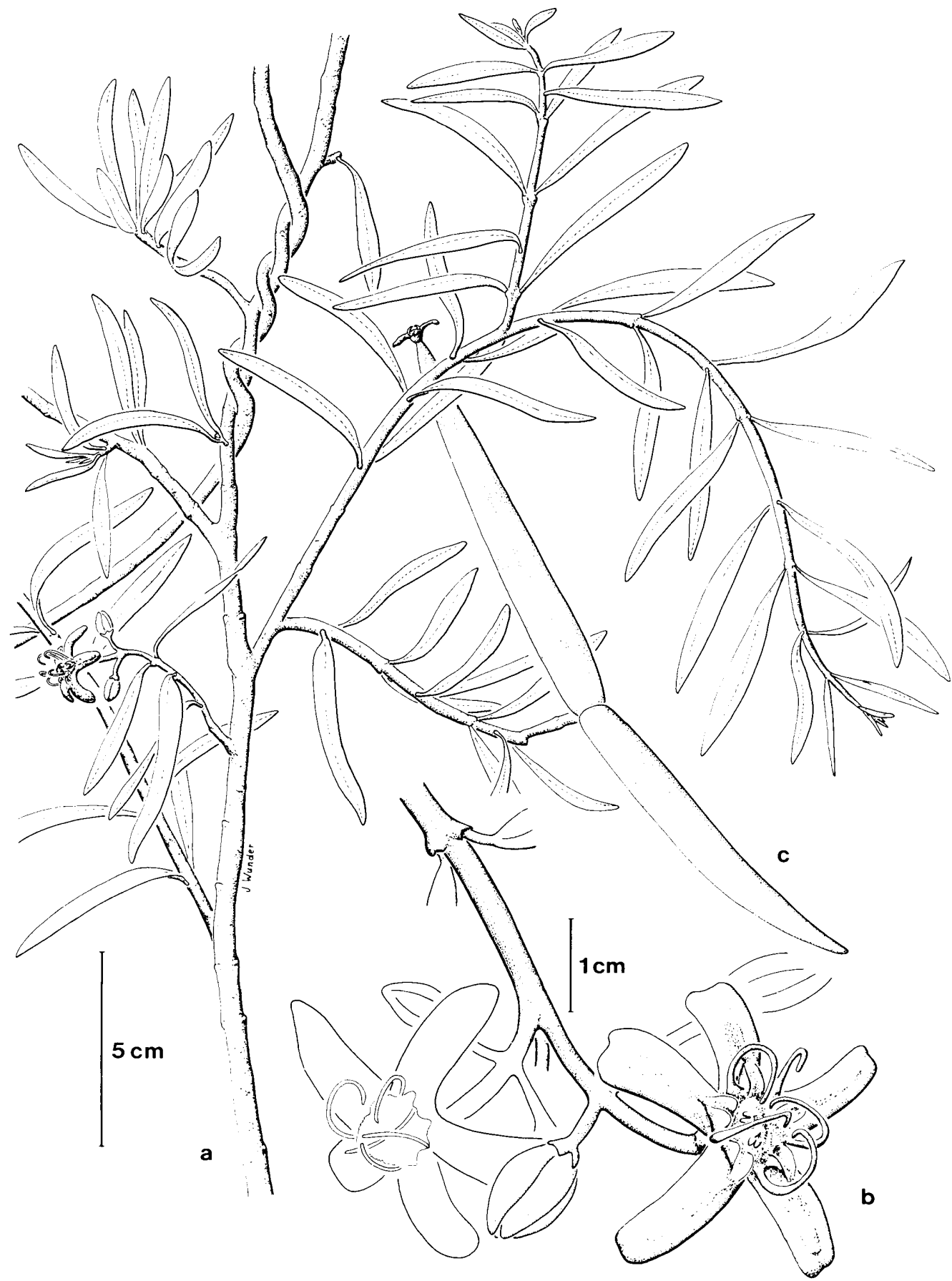

Fig. 41. Periploca laevigata ssp. chevalieri. a. Habit; b. Flowers; c. Fruit. Drawn by J. Wunder. 


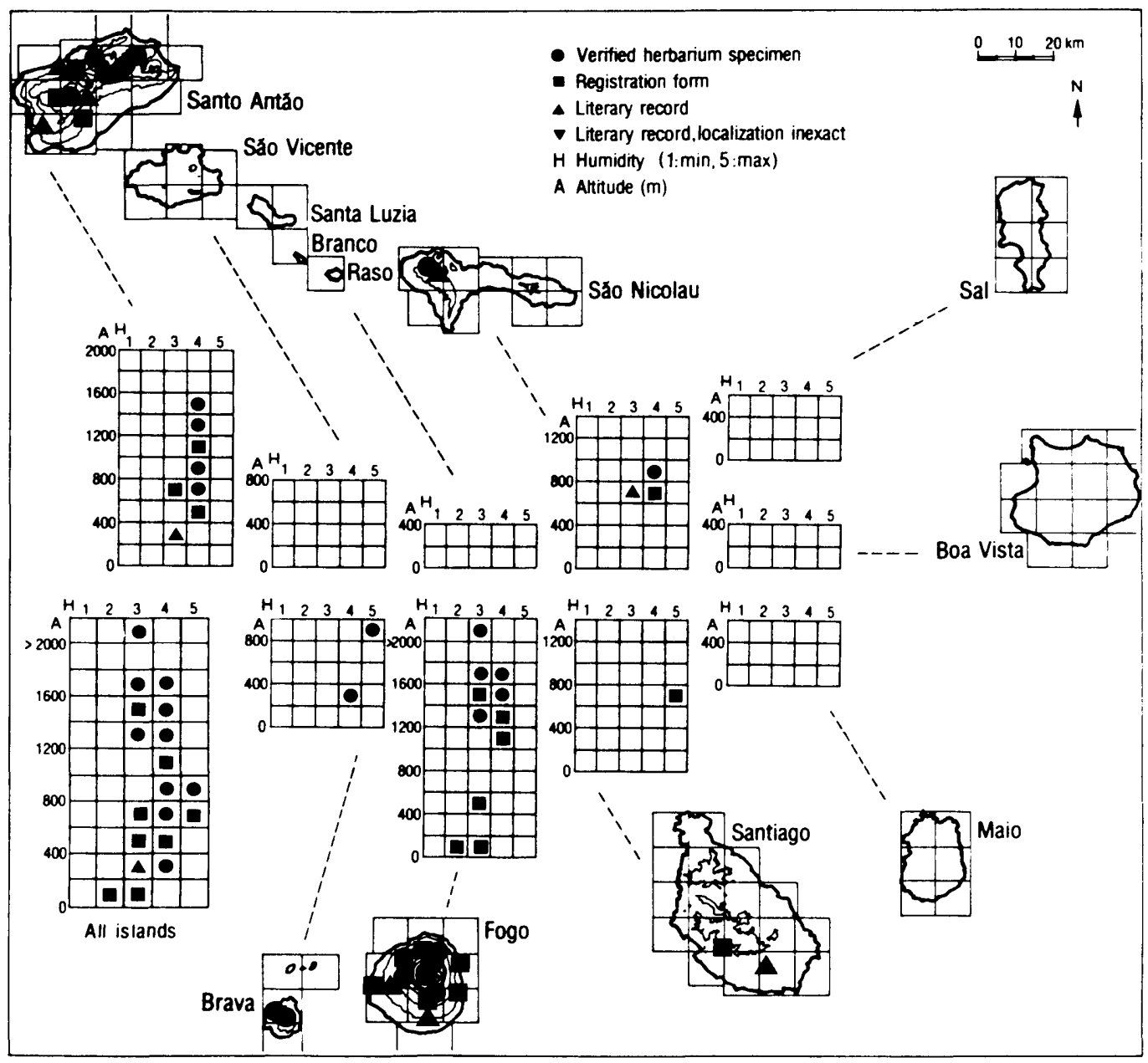

Fig. 42. Ecogeographic distribution of Periploca laevigata ssp. chevalieri.

to the caldeira rim, 1300-1500 m, Gomes et al. 1995a; $2 \mathrm{n}=36$, Fogo, Chã das Caldeiras, Zizka 1986). The number of $2 \mathrm{n}=22$ has also been found in all other Periploca taxa investigated so far, including $P$. laevigata ssp. laevigata and ssp. angustifolia (cf. Gomes et al. 1995a). The deviating count of $2 n=36$ in ssp. chevalieri evidently needs confirmation.

Related taxa. The Capeverdean subspecies is most closely related to ssp. laevigata from the Canary Islands and the Salvage Islands.

Distribution and ecology. Periploca laevigata ssp. chevalieri is a western mesophyte occurring on Santo Antão, São Nicolau, Santiago, Fogo, and Brava, but it is absent from São Vicente. Most localities are situated in the semiarid and subhumid zones; only one locality is known in the arid zone and one locality in the humid zone. The main altitudinal range is between $400 \mathrm{~m}$ and $1800 \mathrm{~m}$. The lowermost record is at $5 \mathrm{~m}$ on Fogo (Brochmann \& Rustan 
1988) and the uppermost one at 2700-2800 m near the peak of Pico Novo on the same island (Gomes et al. 1995a). Periploca laevigata ssp. chevalieri was previously an important component of the natural montane vegetation in the Cape Verde Islands. The subspecies formed a dense, thicket-like scrub vegetation together with Lavandula rotundifolia, mainly on south-facing slopes.

Abundance. On all of the islands, the abundance of $P$. laevigata ssp. chevalieri has seriously declined because of frequent cutting (see, e.g., Chevalier 1935a). At present, the subspecies is locally abundant only on Fogo and Santo Antão, but on the latter island, it is threatened by afforestations. On São Nicolau, it has a very scattered occurrence and considered to be Endangered (EN), and its status on Brava is Critically Endangered (CR). The only records from Santiago date from 1934 (leg. Chevalier) and 1993 (Mato Gegé at $600 \mathrm{~m}$, obs. I. Gomes, pers. comm.), and the subspecies is Critically Endangered (CR) on this island. Periploca laevigata ssp. chevalieri is generally considered to be Endangered (EN).

\section{Sarcostemma R. Br.}

Sarcostemma, in its most widely accepted, narrower sense, is a genus of 10-15 leafless, prostrate, climbing or shrubby, succulent species with latex and with flowers in sessile, globular umbels. The genus is distributed in the subtropics and tropics of the Old World and Australia. Most of the species, including the only species of the genus in the Cape Verde Islands, belong to the widespread and taxonomically difficult $S$. viminale (L.) R. Br. complex.

\section{Sarcostemma daltonii (Figs 43, 44)}

Sarcostemma daltonii Decne. in Hooker, Icon. Pl. 8: ad tab. 768 (1848). - Syntypes: Ad apicem collinum et in rupestribus maritimis ins. S. Jacobi, 11.1839, J. D. Hooker $(\mathrm{K})$; in ins. S. Jacobi, 5.4.1822, Forbes /I (K); in ins. S. Antonii, 6.1841, Vogel $22(\mathrm{~K})$; in ins. S. Vincentii, Vogel (K). [= Sarcostemma nudum C. Sm. in Tuckey, Narr. Exped. Zaire: 251 (1818), nom. nud.]

Illustrations: Decaisne (1848: Fig. 768), Webb (1849: Fig. 14), Chevalier (1935a: Tab. 5c), Lobin (1986b: Fig. 30, 1986d: Figs 7-9), Brochmann \& Rustan (1988: Fig. 1), Gomes et al. (1995b: p. 10).

Description. Leafless, succulent, creeping to overhanging and mat-forming, strongly branched subshrub with milky latex in all parts; branches long-articulate, up to several meters long and up to $1 \mathrm{~cm}$ in diameter, glaucous, glabrous. Leaves reduced to inconspicuous, triangular, acute scales, soon turning brownish. Inflorescence usually at the end of short (only a few cm long) lateral branches, umbelliform, 10-30-flowered. Pedicels glabrous. Corolla lobes cream-coloured to yellowish-green, stiff, abaxially concave and with revolute margins; gynostegial corona whitish. Fruit with one follicle, linear-lanceolate in outline, up to $10 \mathrm{~cm}$ long, glabrous. Seeds numerous, brown, hair-tufted.

Variation. The species is fairly uniform on all islands.

Chromosome number: $2 \mathrm{n}=22,44(2 \mathrm{n}=22$, Santo Antão, Aldridge \& Ortega 1976 (the locality is probably Ribeira Brava, cf. Sventenius 1971); $2 \mathrm{n}=44$, without locality, Liede $\&$ Meve 1993). Additional chromosome counts are necessary to confirm these reports of both diploid and tetraploid numbers in the Capeverdean plants.

Related taxa. Recently, Liede \& Meve (1993) referred the Capeverdean plants to $S$. viminale ssp. thunbergii (Don) Liede \& Meve, which is distributed in S Africa, Namibia, and 


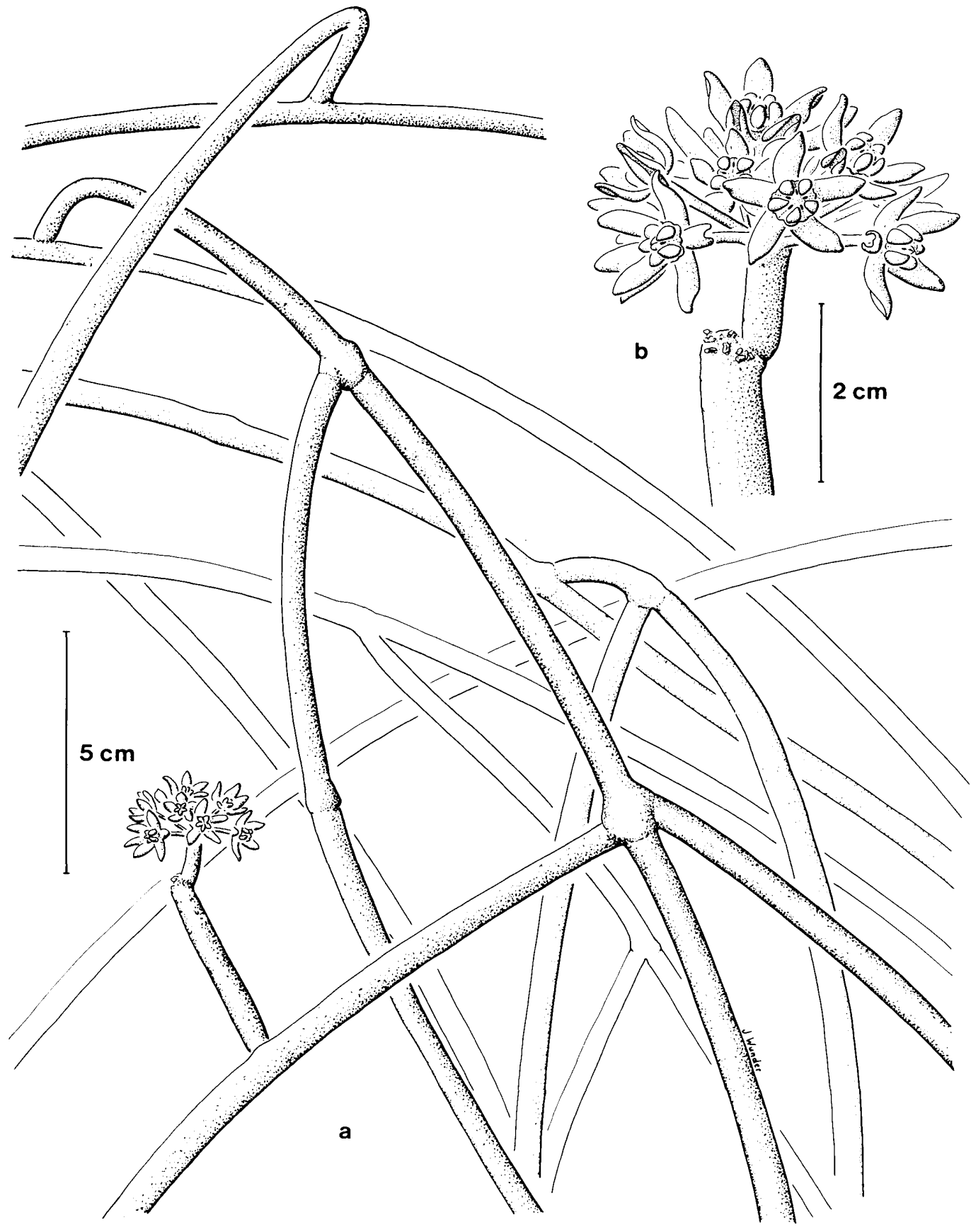

Fig. 43. Sarcostemma daltonii. a. Habit; b. Inflorescence. Drawn by J. Wunder. 


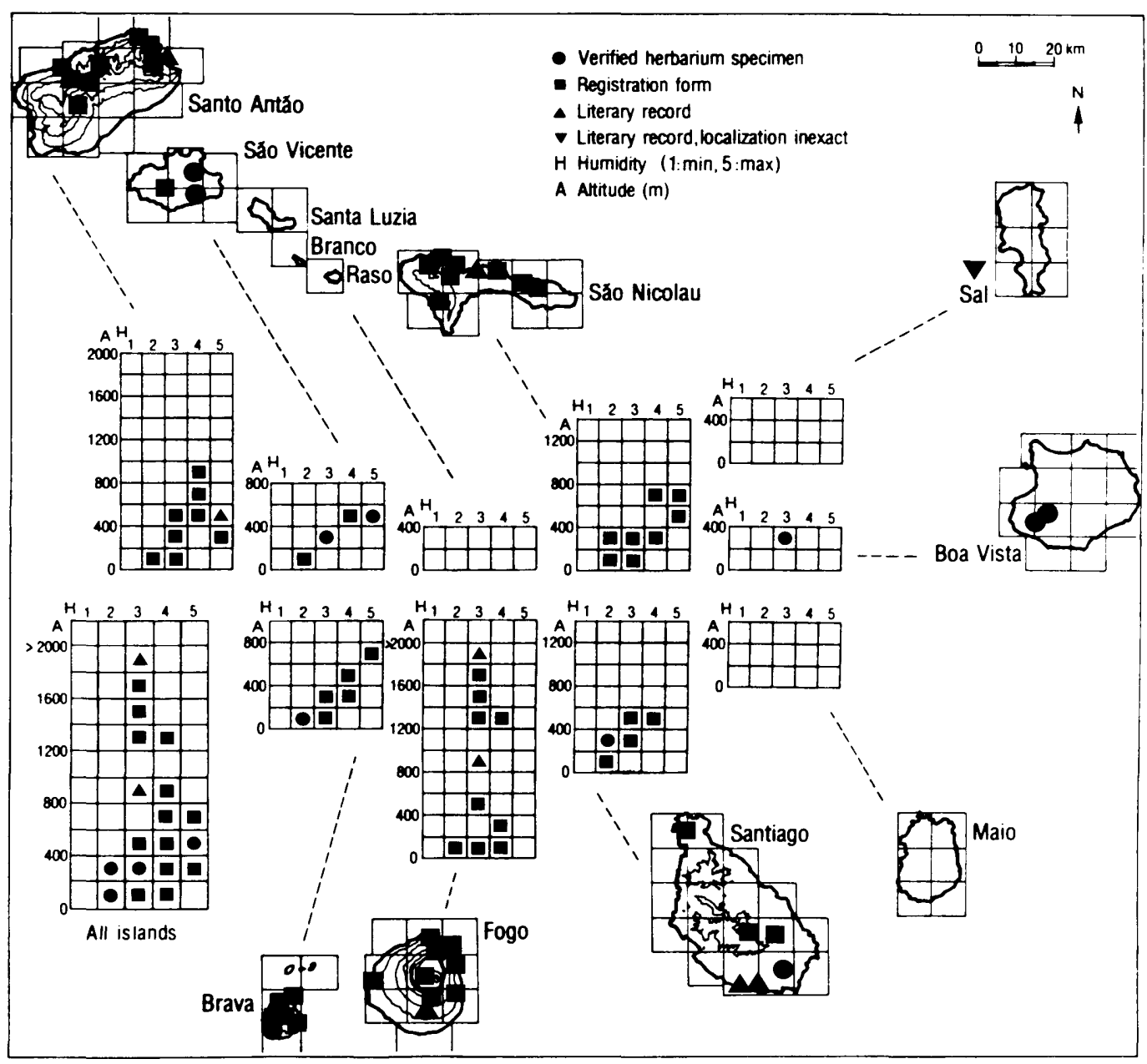

Fig. 44. Ecogeographic distribution of Sarcostemma daltonii.

possibly in W Africa. Their conclusion was based on the morphological similarity between Capeverdean and SW African plants as well as on the tetraploid chromosome number they observed in both Capeverdean and SW African material, but they were apparently not aware of the diploid number previously counted in Capeverdean material by Aldridge \& Ortega (1976). In addition, the relationship between Capeverdean and W African mainland populations of Sarcostemma has not yet been clarified, and we conclude that it is premature to re-evaluate the taxonomic status of the Capeverdean plants (see also Gomes et al. 1995a).

Distribution and ecology. Sarcostemma daltonii is a ubiquitous xerophyte occurring on Santo Antão, São Vicente, São Nicolau, Sal, Boa Vista, Santiago, Fogo, and Brava. The species is widely distributed on all of the western islands, but it was recently reported also from the eastern islands of Sal (without locality, Basto 1988) and Boa Vista (without locality, 
Basto 1988; two adjacent mountains, Gomes et al. 1995a). It is equally frequent in the arid, semiarid, and subhumid zones, and less common in the humid zone. The species occurs from sea-level to $1830 \mathrm{~m}$ (Fogo; Gilli 1976), but it has its main occurrence between $100 \mathrm{~m}$ and 600 $\mathrm{m}$. Sarcostemma daltonii is a characteristic component of the indigenous Capeverdean vegetation and extensively covers hillsides, gravel slopes, edges of ribeiras, and rock walls. It also occurs on recently deposited volcanic rocks as one of the first pioneers of vascular plants.

Abundance. Sarcostemma daltonii is strongly undercollected because it is difficult to preserve, and most of the records are field-note registrations (Brochmann \& Rustan 1988). The species is common on all western islands, but probably rare on the eastern islands of Sal and Boa Vista. We were not able to verify its occurrence on Sal in spite of thorough search. Sarcostemma daltonii is generally considered to be Lower Risk (LR).

\section{ASTERACEAE}

This family is represented by 38 genera with some 58 species. Sixteen taxa are endemic: 14 species, one of them with two subspecies, and one subspecies of a non-endemic species.

\section{Artemisia L.}

Artemisia (tribe Anthemideae) is a large and widespread genus, including some 390 species distributed in the Old and New World, predominantly in the Northern Hemisphere. The small capitules are usually arranged in many-capitulate panicles, and the achenes lack pappus. The genus is represented by a single, endemic species in the Cape Verde Islands.

Artemisia gorgonum (Figs 45, 46)

Artemisia gorgonum Webb in Hooker, Niger Fl.: 142 (1849). -- Type: "Capvert. Herbier rapporté du Portugal en 1808 par M. Geoffrey St. Hilaire" [1784-1787, Silva Feijão] (holotype: Fl-W!).

Illustrations: Chevalier (1935a: Tab. 6b), Brochmann \& Rustan (1988: Fig. 2), Gomes et al. (1995b: p. 11).

Description. Strongly branched, erect, dense, aromatic shrub up to $2 \mathrm{~m}$ high. Branches robust, whitish tomentose when young, glabrescent and brownish with age. Leaves bi- to tri-pinnatisect, up to $8 \mathrm{~cm}$ long and $6 \mathrm{~cm}$ wide, whitish tomentose, with narrowly elliptical to almost linear lobes. Synflorescence a dense, thyrsoid panicle with numerous small capitules. Involucral bracts more or less imbricate, broadly ovate; inner bracts brownish, scarious, herbaceous only along the midrib. Flowers yellowish, tubular; outer flowers female; central flowers hermaphrodite. Achenes obovoid, without pappus.

Variation. Populations from all recorded islands were examined, revealing no essential variation. 1975).

Chromosome number: $2 \mathrm{n}=18$ (Santo Antão, Lombo das Pedras, $1300 \mathrm{~m}$, Borgen 


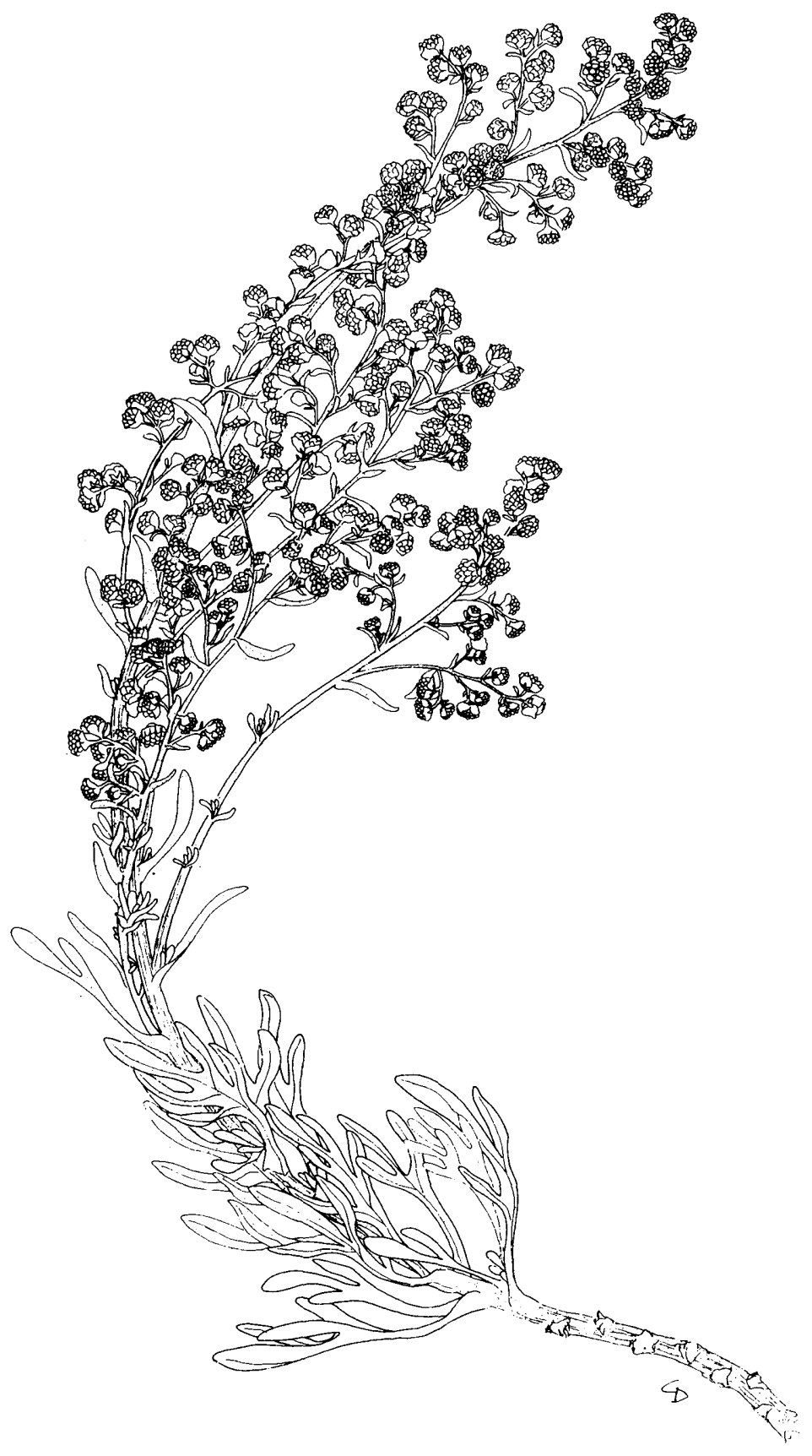

$\stackrel{1 \mathrm{~cm}}{1}$

Fig. 45. Artemisia gorgonum. Drawn by C. Dervin. 


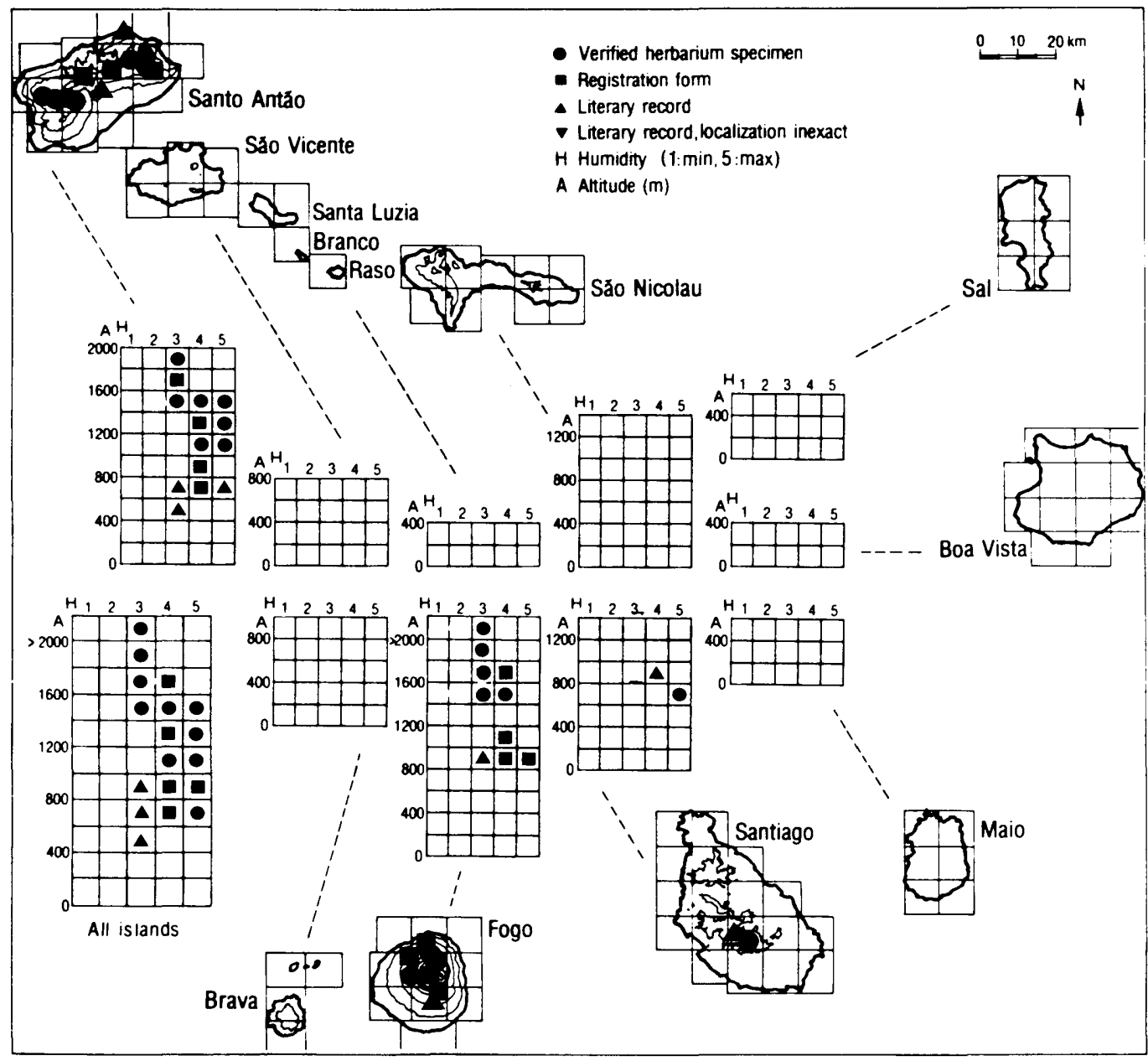

Fig. 46. Ecogeographic distribution of Artemisia gorgonum.

Related taxa. Artemisia gorgonum is closely related to the Canarian A. thuscula Cav., but it differs from that species in involucre and flower characters (Webb 1849).

Distribution and ecology. Artemisia gorgonum is a western mesophyte recorded from montane areas in Santo Antão, Santiago, and Fogo. The localities are evenly distributed among the semiarid, subhumid, and humid zones, mainly between $800 \mathrm{~m}$ and $2000 \mathrm{~m}$. The lowermost record is at about $400 \mathrm{~m}$ on Santo Antão (Henriques 1896), and the uppermost ones at 2200-2400 m on Pico Novo and the old crater rim on Fogo (leg. Kilian \& Leyens). The species grows mainly in gravelly montane slopes and plains. It is a characteristic component of the scrub vegetation in these areas, which today are largely destroyed except for some rather poor fragments. 


\begin{abstract}
Abundance. Although many of the records of this species are dated after 1970, many populations of $A$. gorgonum are clearly diminishing, and some populations are probably already extinct because of habitat destruction and cutting. The species is Vulnerable (VU) on Santo Antão and Fogo. It has only been recorded twice from Santiago, first by Chevalier in 1934 in the Serra do Pico da Antonia mountains (Chevalier 1935a), and it was not rediscovered on this well-explored island before 1994 (Gomes et al. 1995a). The rediscovered population consists only of 10-15 plants, some of them very old, and occurs on cultivated slopes near Rui Vaz in the Serra do Pico da Antonia mountains. Artemisia gorgonum is considered Critically Endangered (CR) on Santiago, and it is generally considered to be Vulnerable (VU).
\end{abstract}

\title{
Conyza L.
}

The genus Conyza (tribe Astereae) includes some 60 species mainly distributed in the tropical and subtropical regions of the world. Some species are widespread weeds. In the Cape Verde Islands, the genus is represented by five species, of which four are endemic. The species of Conyza are distinguished from superficially similar representatives of the genera Blumea and Pluchea, which also occur in the Cape Verde Islands, by their flower colour (pure yellow or whitish, greenish, or brownish yellow), by their obtuse, ecaudate anther base, by the style branches in the hermaphrodite flowers, which have triangular-acute to lanceolate appendages, and by their compressed, obovoid-oblong achenes with twin-hairs.

Literature: Heim (1984), Wild (1969).

Key to the genus Conyza

1 Synflorescence loosely elongated-paniculate; leaves linear-lanceolate

[C. bonariensis]

1 Synflorescence (resp. partial synflorescences) densely umbellate-paniculate and leaves narrowly to broadly lanceolate or spathulate, or synflorescence loosely umbellatepaniculate and leaves ovate to obovate or broadly lanceolate to spathulate

2 (1) Capitules 5-10 $\mathrm{mm}$ in diameter, in few-capitulate and loose umbellate-paniculate synflorescences; style distinctly exceeding the corolla in the outer, female flowers .............3

2 Capitules $2-5 \mathrm{~mm}$ in diameter, in dense, many-capitulate, distinctly umbellate-paniculate synflorescences; style equalling the corolla in the outer, female flowers

3 (2) Plant annual, less than $30 \mathrm{~cm}$ high; outer, female flowers distinctly ligulate

C. schlechtendalii

3 Plant pauciennial to perennial, herbaceous to subshrubby, up to $1.5 \mathrm{~m}$ high; outer, female flowers not ligulate C. pannosa 
4 (2) Subshrub or shrub up to $2 \mathrm{~m}$ high and $1.5 \mathrm{~m}$ in diameter, often almost hemispherical; leaves obovoid to broadly elliptical; outer, female flowers usually distinctly ligulate

C. varia

4 Slender, erect, distinctly candelabrous-like branched subshrub or shrub less than $1 \mathrm{~m} \mathrm{high}$; leaves narrowly spathulate to narrowly lanceolate; outer, female flowers without ligules or rarely indistinctly ligulate C. feae

\section{Conyza feae (Figs 47, 48)}

Conyza feae (Bég.) Wild, Bol. Soc. Brot., sér. 2, 43: 256 (1969) $\equiv$ Nidorella feae Bég., Ann. Mus. Civico Storia Nat. Giacomo Doria 48: 50 (1920). - Type: Fogo, sul cono del Pico Novo o volcano, 1700-2500 m, 19.6.1898, Fea (holotype: GDOR!).

= Nidorella nobrei A. Chev., Rev. Bot. Appl. Agric. Trop. 15: 875 (1935). - Type: Sto. Antão, Cova, $1300 \mathrm{~m}$, Chevalier 45604 (holotype: $\mathrm{P}$; isotype: $\mathrm{COI}$ ).

Illustrations: Chevalier (1935a: Tab. 12 sub Nidorella nobrei), Wild (1969: Figs 1(3), 2(3)), Heim (1984: Figs 3 p.p., 4-5), Lobin (1986b: Fig. 25), Gomes et al. (1995b: p. 11).

Description. Erect, slender, candelabrous-like branched subshrub or shrub up to $0.6 \mathrm{~m}$ high; main axes regularly overtopped by almost opposite branches; younger branches hairy and glandular-sticky. Leaves crowded at the upper part of the branches, narrowly lanceolate to (narrowly) spathulate and strongly attenuate towards base, up to $5 \mathrm{~cm}$ long and $0.5-1 \mathrm{~cm}$ wide, margin variably dentate. Uppermost leaves reduced. Synflorescence a dense, umbellate panicle with many capitules. Capitules small, 2.5-4 $\mathrm{mm}$ in diameter, with 50-80 outer, filiform, tubular (rarely inconspicuously ligulate) female and 2-6 central hermaphrodite tubular flowers; flowers yellow. Achenes 0.3-0.8 mm long. Pappus white.

Variation. The species is conspicuously variable in pubescence, leaf shape, and dentation of the leaf margin. Some populations obviously contain hybrids between $C$. feae and C. varia (see below).

Chromosome number: $2 \mathrm{n}=18,24(?)(2 \mathrm{n}=18$, counted in cult. progeny (Acc. no. 029-03-95-10 in B) of origin: Fogo, Monte Palha, $600 \mathrm{~m}, 21.01 .1994$, leg. Kilian 3275 \& Leyens; $2 \mathrm{n}=24$, Santo Antão, Montanho Conceicão, $1200 \mathrm{~m}$, Borgen 1980). The deviating count of $2 \mathrm{n}=24$ (Borgen 1980) may represent a hybrid between $C$. feae and $C$. varia (see below).

Related taxa. Conyza feae is most closely related to $C$. varia. These species are similar in characters such as capitulum size, synflorescence shape, and style length in female flowers, but they differ in habit and presence of ligules of the female flowers, and partly in ecology (see below). In addition, $C$. feae is most likely regularly diploid with $2 \mathrm{n}=18$, whereas $C$. varia is tetraploid with $2 \mathrm{n}=36$. Conyza feae and C. varia grow intermingled in some sites, and some plants which are intermediate in some morphological characters (habit, leaf shape, and presence of indistinct ligules) are evidently hybrids. Hybridization may thus explain most of the morphological variation mentioned by Heim (1984). The different ploidal levels of the parental species suggest, however, that they are at least partly reproductively isolated. The deviating chromosome count of $2 n=24$ (Borgen 1980) probably represents an aneuploid reduction from triploid level $(2 \mathrm{n}=27)$ in a hybrid between $C$. feae and $C$. varia (cf. Gomes et al. 1995a).

Distribution and ecology. Conyza feae is a western mesophyte recorded from Santo Antão, São Vicente, São Nicolau, Santiago, Fogo, and Brava. Most localities are situated in 


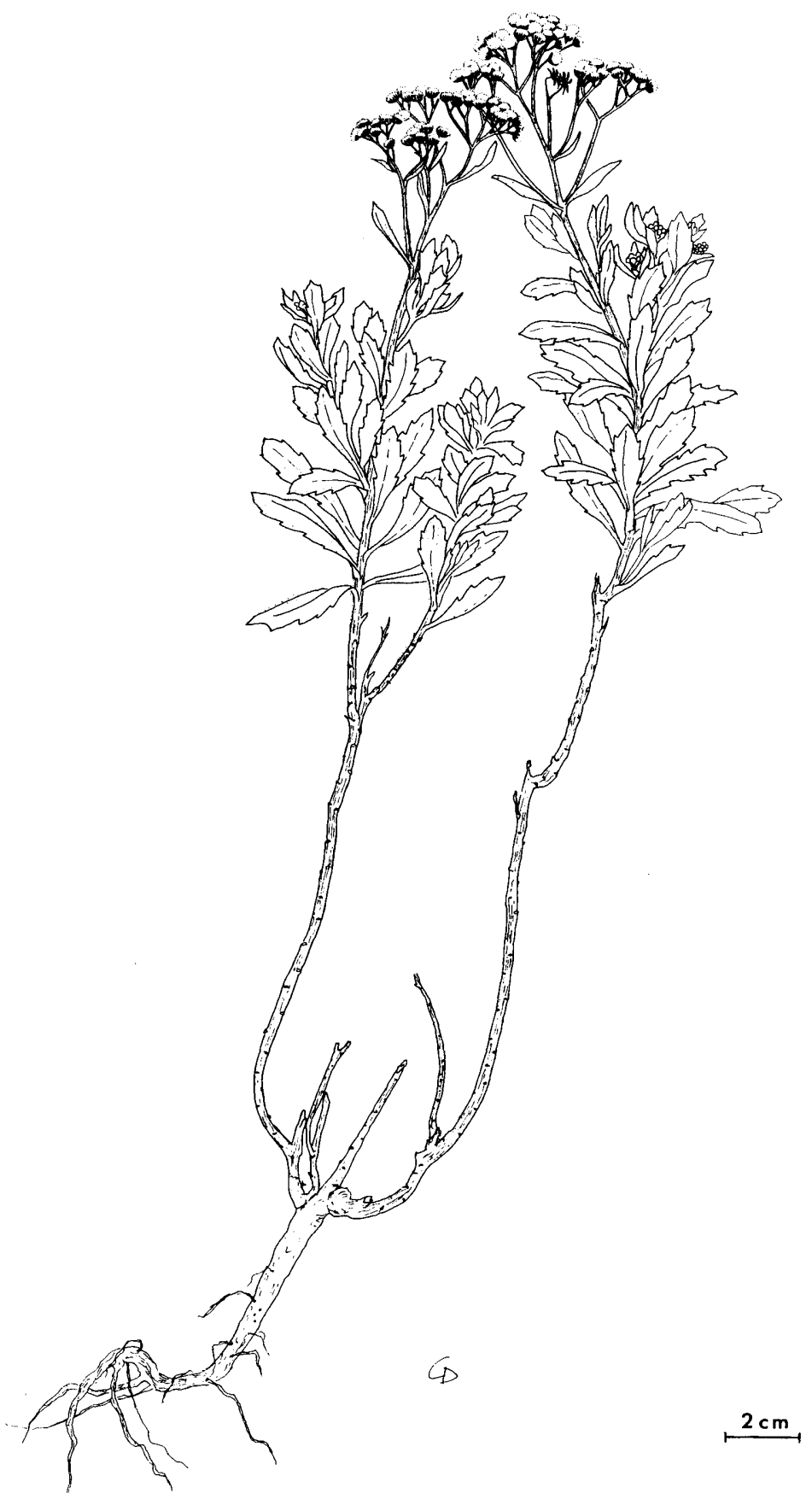

Fig. 47. Conyza feae. Drawn by C. Dervin. 


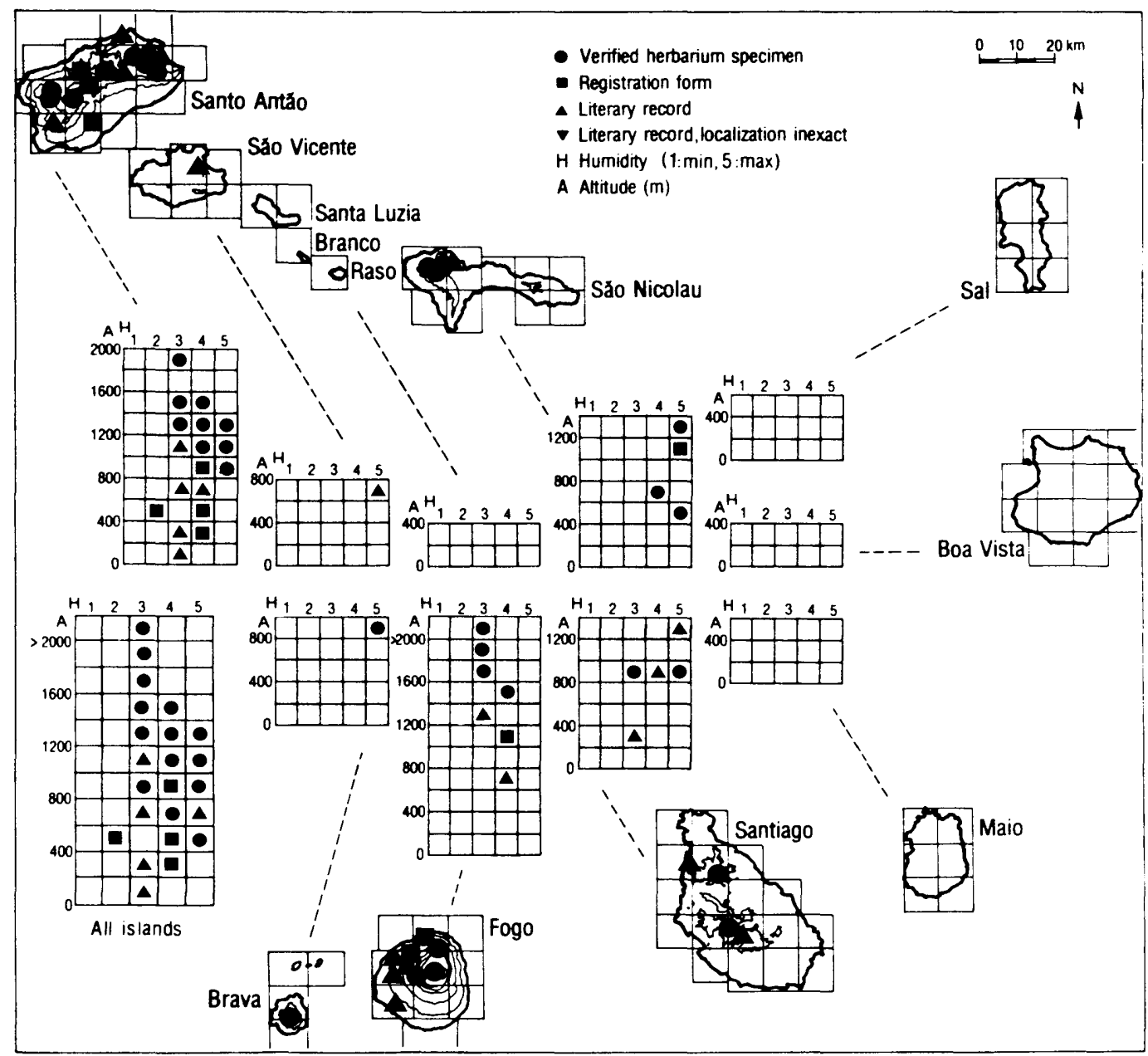

Fig. 48. Ecogeographic distribution of Conyza feae.

the semiarid zone, but the species is also common in more humid areas. It has been reported only once from the arid zone (southern Santo Antão). The main altitudinal distribution is between $600 \mathrm{~m}$ and $1600 \mathrm{~m}$. The lowermost record is at $150 \mathrm{~m}$ on northern Santo Antão (leg. Lowe), and the species extends to $2800 \mathrm{~m}$ on the volcanic cone of Fogo (leg. Fea, leg. Kilian \& Leyens). Conyza feae and C. varia occupy largely the same general areas, but C. varia is usually confined to depressions, grooves, and small ribeiras, and C. feae is mainly found in drier, rocky or stony slopes. This difference in habitat preference explains why C. feae is more abundant in the semiarid zone than C. varia.

Abundance. Conyza feae has been recorded after 1970 from all islands except São Vicente, but it is probably declining on several islands. The only record from São Vicente dates from 1866 (leg. Lowe), and the species is most likely Extinct (EX) on this well-explored 
island. Only two populations are known on Brava, discovered in 1982 (Monte Fontainhas; Rustan \& Brochmann 1985) and 1995 (a few plants near Serrado; leg. Leyens), and the species is considered to be Critically Endangered (CR) on this island. It has strongly declined on São Nicolau, where it is Endangered (EN), and on Santiago, where it is Critically Endangered (CR). Although Conyza feae is still fairly common on Santo Antão and Fogo, it is generally considered to be Endangered (EN).

Conyza pannosa (Figs 49, 50)

Conyza pannosa Webb in Hooker, Niger Fl.: 135 (1849). - Type: In ins. S. Vicentii ad partem tertium superiorum Montis Verede, 6.1841, Vogel 52 (holotype: K).

= Conyza lurida J. A. Schmidt, Beitr. Fl. Cap Verd. Ins.: 186 (1852). - Type: Sto. Antão, 3.1851, J.A. Schmidt (holotype: HBG!; isotypes: GOET!, S!).

= Conyza lurida J. A. Schmidt var. humilis Bolle, Bonplandia 8: 131 (1860). - Syntypes: In ins. S. Nicolau, Monte Caraminjo, Bolle (B, destroyed); ins. S. Vicente, Monte Verde, Bolle (B, destroyed); in S. Antonii, Ribeira Paul, Bolle (B, destroyed).

Illustrations: Heim (1984: Fig. 1), Gomes et al. (1995b: p. 11).

Description. Erect herb or subshrub up to $1.5 \mathrm{~m}$ high and $1 \mathrm{~m}$ wide; branches often sparsely hairy and partly glandular. Leaves broadly lanceolate to spathulate or obovate, up to $13 \mathrm{~cm}$ long and $4 \mathrm{~cm}$ wide, somewhat attenuate towards the base; young leaves hispid, partly densely glandular; margin dentate to coarsely crenate. Synflorescence a loose, umbellate, fewcapitulate panicle. Capitula 5-10 mm in diameter with 200-400 outer, filiform, tubular female flowers and 10-20 hermaphrodite central flowers; flowers greenish yellow. Achenes 0.6-1.5 mm long. Pappus dirty-white.

Variation. The plants show considerable variation in pubescence, leaf shape, and dentation of the leaf margin.

Chromosome number: $2 \mathrm{n}=36$ (counted in cult. progeny (Acc. no. 029-04-95-10 in B) of origin: Santo Antão, NE facing escarpment into Ribeira do Paul, 1000-1200 m, 29.12.1993, leg. Kilian 2981 \& Leyens). This is the first count published for C. pannosa.

Related taxa. Conyza pannosa is possibly most closely related to C. schlechtendalii. but it is easily distinguished from that species by its habit and non-ligulate female flowers.

Distribution and ecology. Conyza pannosa is a western hygrophyte recorded from Santo Antão, São Vicente, São Nicolau, Santiago, and Brava, but it is absent from Fogo. The species is confined to the humid zone on all islands except Santo Antão, where it also has been recorded from several sites in the subhumid and semiarid zones. The main altitudinal distribution is between $500 \mathrm{~m}$ and $1000 \mathrm{~m}$. The species has been found below $500 \mathrm{~m}$ only on Santo Antão, where it has its lowermost locality at $60 \mathrm{~m}$ in the Ponta do Sol area (leg. Rustan \& Brochmann). The uppermost record is at $1300 \mathrm{~m}$ at Monte Gordo on São Nicolau (Bolle $1860 \mathrm{a})$. Conyza pannosa grows in gravelly plains and slopes in rocky montane areas, in seasonally wet ribeiras, and (rarely) in cliffs.

Abundance. There are recent records of C. pannosa from all islands, but most of the populations are very small. Krause (1892) cited a label of a specimen collected in 1841 (leg. Vogel), stating that C. pannosa was abundant in the upper third of Monte Verde on São Vicente at that time. The species is very rare in this area today, obviously because of severe habitat destruction, and it is classified as Critically Endangered (CR) on São Vicente. The species still has a scattered distribution on Santo Antão, but we have only observed a single or 


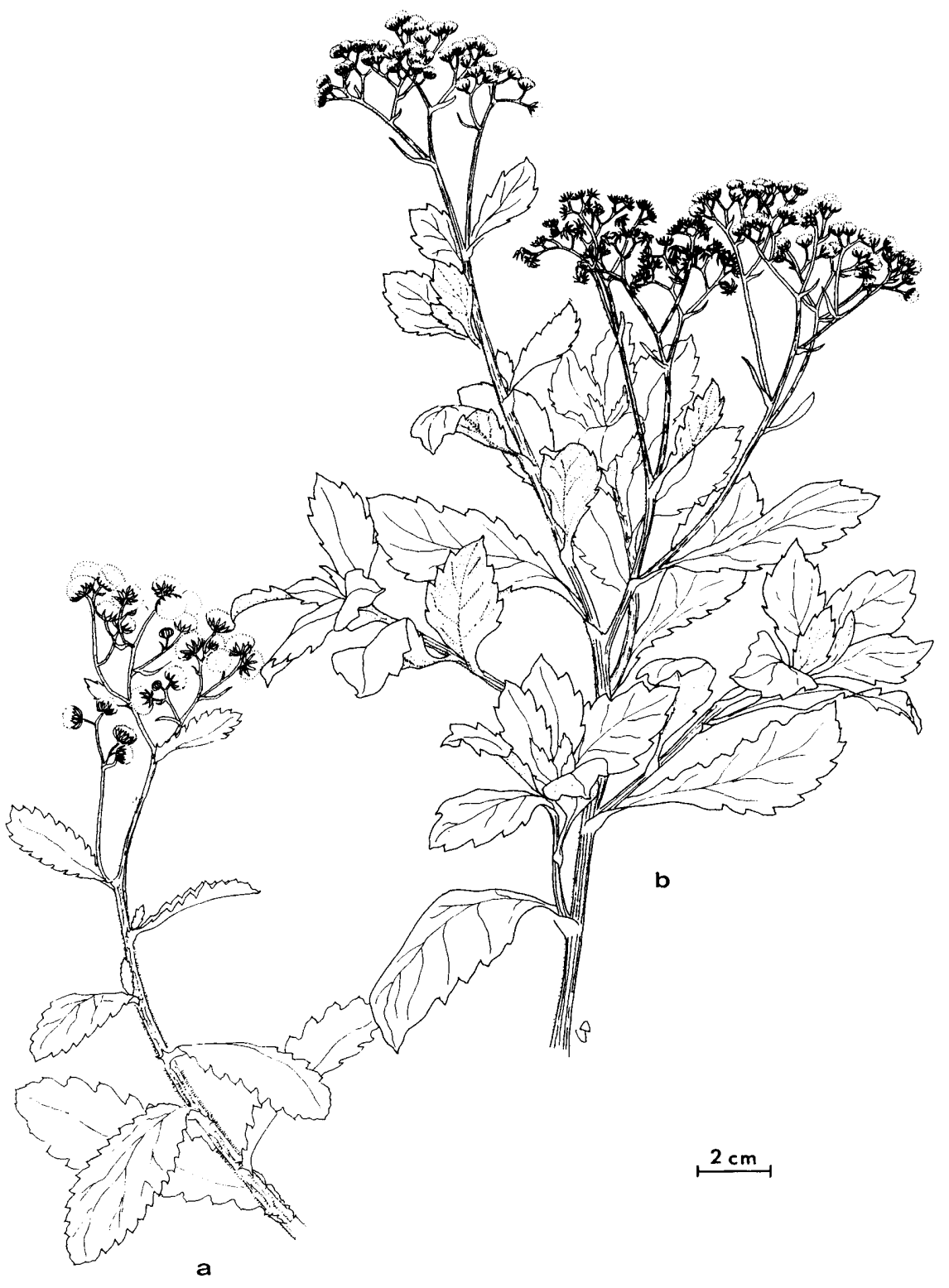

Fig. 49. Conyza pannosa (a) and C. varia (b). Drawn by C. Dervin. 


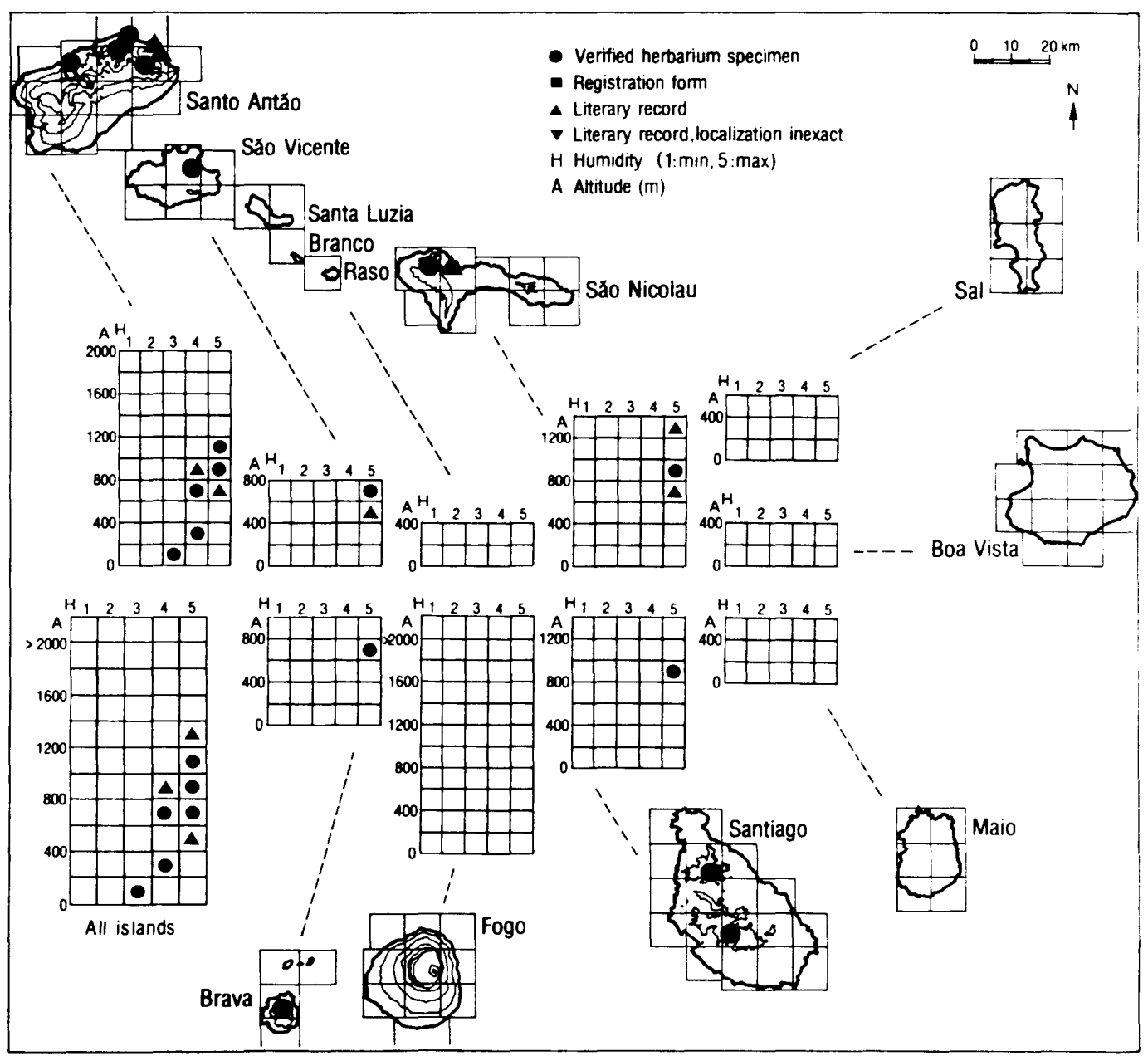

Fig. 50. Ecogeographic distribution of Conyza pannosa.

very few plants at each site, and the species is considered to be Endangered (EN) on this island. On all other islands, the species is today very rare and confined to small areas in the most favourable, humid mountains, and it is classified as Critically Endangered (CR) on these islands. Conyza pannosa is generally considered to be Endangered (EN).

\section{Conyza schlechtendalii (Figs 51, 52)}

Conyza schlechtendalii Bolle, Bonplandia 7: 294 (1859), - Type: In ins. S. Nicolai, praecipue ad summi Gourdo, [1851], Bolle (holotype: B (destroyed); isotypes: COI, Z). - Lectotype (designated by Heim 1984: 159): $Z$ (photo!).

Illustrations: Heim (1984: p. 160, Tab. 1), Gomes et al. (1995a: p. 1). 


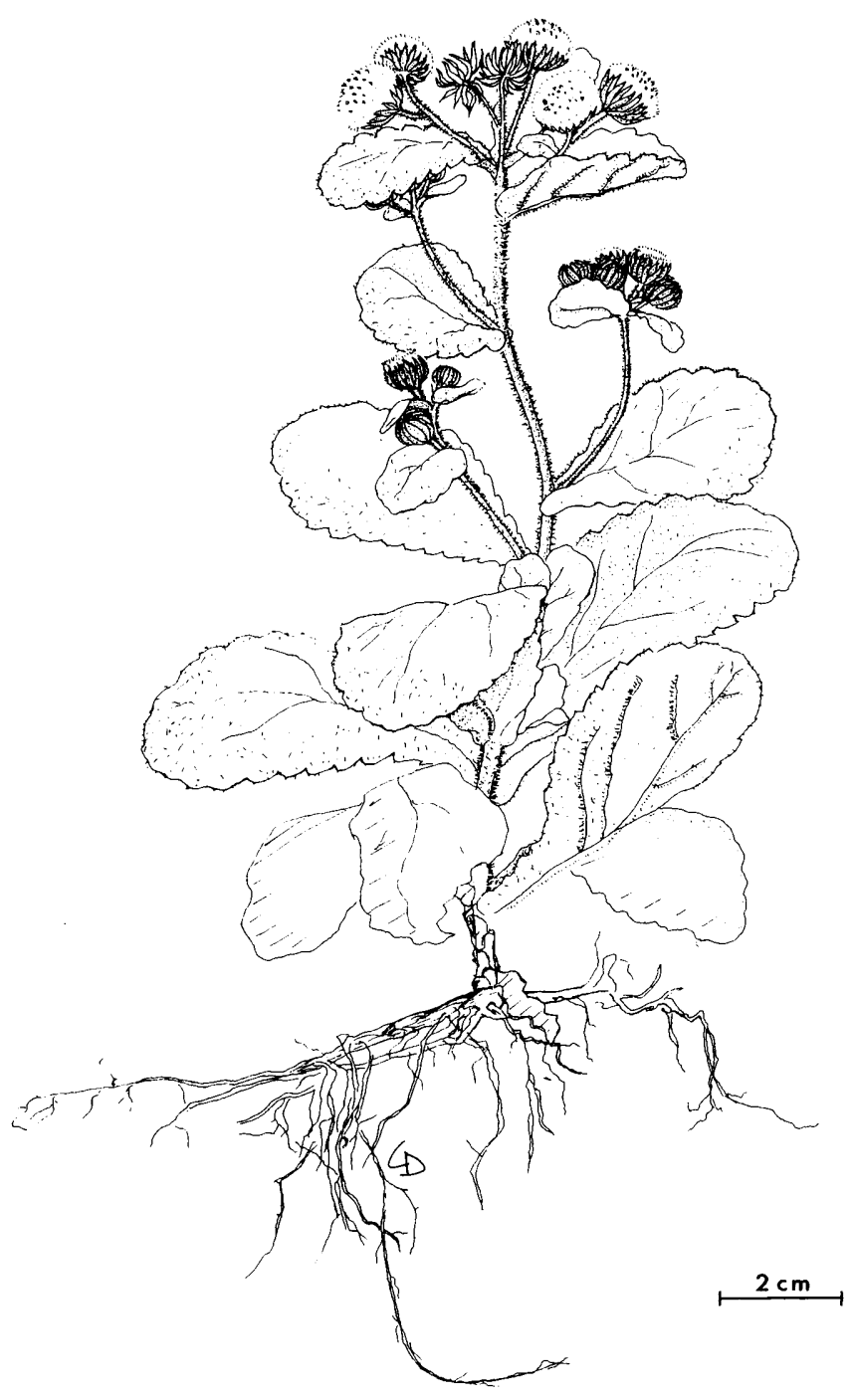

Fig. 51. Conyza schlechtendalii. Drawn by C. Dervin. Reprinted from Gomes et al. (1995a), Willdenowia 25 (with permission). 


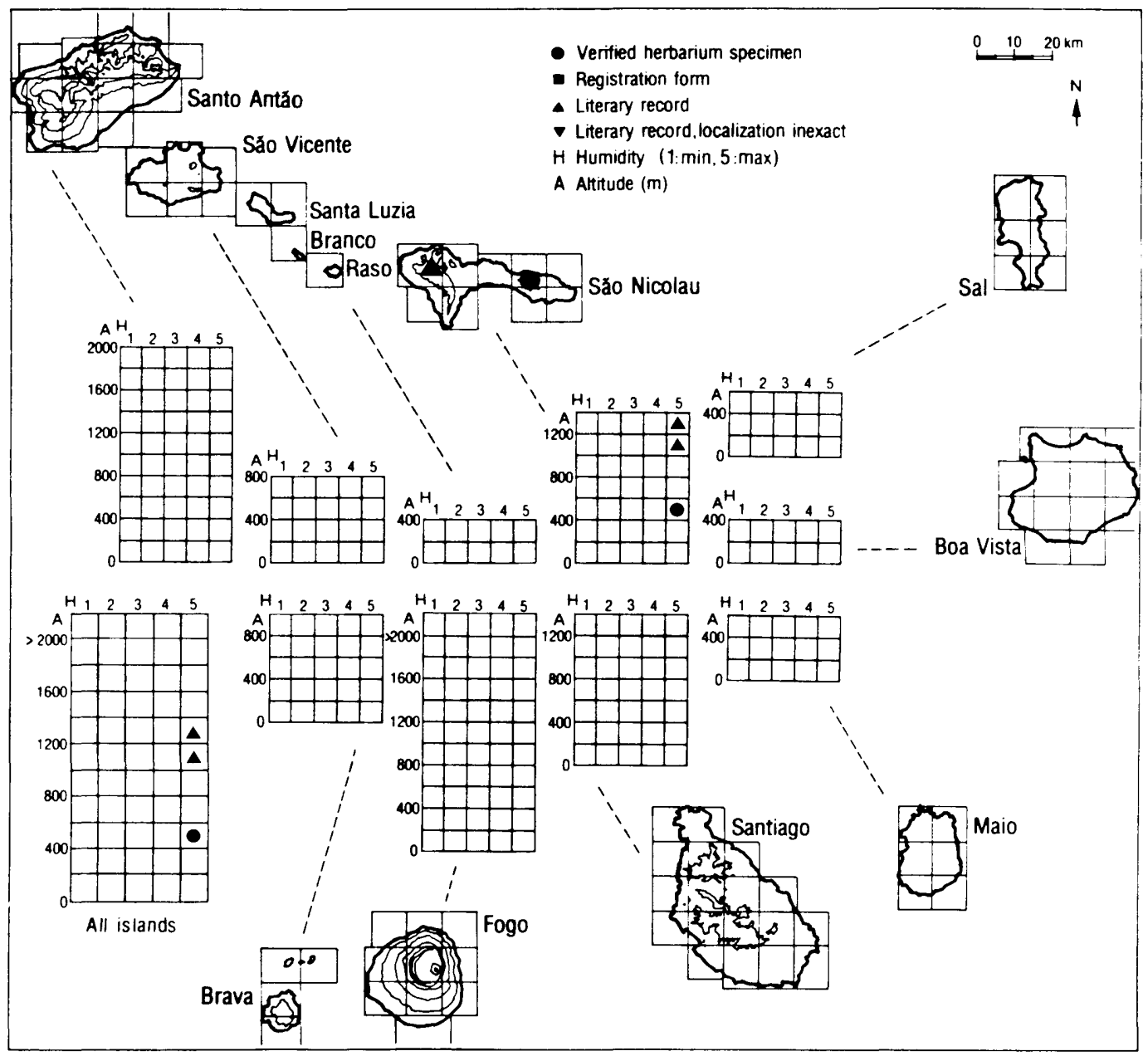

Fig. 52. Ecogeographic distribution of Conyza schlechtendalii.

Description. Annual herb up to $0.3 \mathrm{~m}$ high, strongly pubescent. Leaves crowded near the base, obovate to ovate, up to $6 \mathrm{~cm}$ long and $3 \mathrm{~cm}$ wide, somewhat glandular; upper leaves similar to the basal ones but smaller. Synflorescence a loose, few-capitulate, umbellate panicle. Capitules large, $0.8-1.0 \mathrm{~mm}$ in diameter, with more than 300 outer, distinctly ligulate female flowers and more than 20 central, hermaphrodite flowers; flowers yellow. Achenes 0.8-1.1 mm long. Pappus white.

Variation. The small sample of a few specimens examined is rather homogeneous. Bolle (1859b) stated that the flowers are deep brown (faded?); in our material, the flowers are purely yellow.

Chromosome number: $2 \mathrm{n}=36$ (São Nicolau, Alto das Cabaças, $550 \mathrm{~m}$, Gomes et al. 1995a). 
Related taxa. Conyza schlechtendalii has the same tetraploid chromosome number as C. varia and also has the ligulate female flowers in common with this species. It is distinct from $C$. varia, however, by its larger capitules and loose synflorescence. In these characters, as well as in growth form, $C$. schlechtendalii resembles $C$. pannosa more closely.

Distribution and ecology. Conyza schlechtendalii is a northern hygrophyte which only is known from two localities in the humid, main mountain ranges on São Nicolau: summit $(1300 \mathrm{~m}$ ) and slopes of Monte Gordo (Bolle 1859b) and the upper edge of the coastal bluffs at Alto das Cabaças (500-600 m; Gomes et al. 1995a). The species seems to be confined to open places and grows in broad rock crevices with some soil and on almost naked, recently eroded soil.

Abundance. This peculiar species was not rediscovered before 1994, more than 140 years after the type collection was made by Bolle in 1851 (Gomes et al. 1995a). Bolle (1859b) observed the species in large numbers at Monte Gordo, but it has never been recollected at this locality, which later has been visited by many botanists. The Alto das Cabaças range, on the other hand, has been poorly explored until recently. In January 1995, several hundreds to possibly one thousand plants of $C$. schlechtendalii were observed in Alto das Cabaças (Gomes et al. 1995a). It is likely that this annual species has poor competitive ability and depends on abundant moisture for germination, and that the population size may vary considerably from year to year depending on the rain season. The species may have been able to survive in the Alto das Cabaças mountains because these mountains are less affected by goat grazing than the Monte Gordo area. Conyza schlechtendalii is considered to be Critically Endangered (CR).

\section{Conyza varia (Figs 49, 53)}

Conyza varia (Webb) Wild, Bol. Soc. Brot., sér. 2, 43: 255 (1969) E Erigeron varium Webb in Hooker, Niger Fl.: 134 (1849) p.p., sensu lectotypi $\equiv$ Nidorella varia (Webb) J. A. Schmidt, Beitr. Fl. Cap Verd. Ins.: 184 (1852). - Syntypes: In ins. S. Antonii, Vogel 9 [= Conyza feae]; in ins. S. Vincentii, a medio ad apicem Montis Verede, Vogel 48, 49 [= Conyza feae]; in ins. S. Nicolai, 27.3.1822, Forbes 36 (BM, K, LISU, MO); in ins. S. Antonii, Forbes (K). - Lectotype (designated by Wild 1969: 255): Forbes [36] (K).

$=$ Nidorella floribunda Lehm. in Lehm. \& Otto, Del. Sem. Hort. Hamburg. 1851: 8 (1851). - Type: Cultivated from the Cape Verde Islands (holotype: HBG; isotypes: M, S).

= Nidorella steetzii J. A. Schmidt, Beitr. Fl. Cap Verd. Ins.: 185 (1852). -- Type: In collibus et rupestribus ins. S. Antonii, 3.1851, J. A. Schmidt (holotype: HBG; isotypes: W, P).

$=$ Nidorella nubigena Bolle, Bonplandia 7: 294 (1859) $\equiv$ Nidorella steetzii J. A. Schmidt var. tomentosa Steetz in Peters, Naturw. Reise Mossambique, Bot. 2: 399 (1864). - Type: S. Nicolai, summo Monte Gourdo ad 5000' alt., 7.1851, Bolle (holotype: B, destroyed; isotype: P).

= Nidorella forbesii Lowe ex Cout., Arq. Univ. Lisboa 2: 49 (1915). - Syntypes: Ad caminho da Caldeira, 22.2.1864, Lowe (LISU!, BM, MO); ins. S. Nicolai, 12.1852, Cardoso (COI, LISU!). - Lectotype (designated by Lobin 1986b: 112): Lowe (LISU!; isolectotypes: BM, MO).

Illustrations: Wild (1969: Figs 1(2), 2(2)), Heim (1984: Figs 2, 3 p.p.), Lobin (1986b: Fig. 26), Gomes et al. (1995b: p. 11).

Description. Subshrub or shrub up to $2 \mathrm{~m}$ high and $1.5 \mathrm{~m}$ in diameter, often almost hemispherical, with variable indument but always conspicuously glandular-sticky. Leaves obovate to broadly elliptical, up to $8 \mathrm{~cm}$ long and $3 \mathrm{~cm}$ wide, somewhat attenuate towards base; margin variably dentate. Synflorescence a dense, many-capitulate, umbellate panicle. Capitules small, 3-5 mm in diameter, with 30-50 outer, usually distinctly ligulate female 


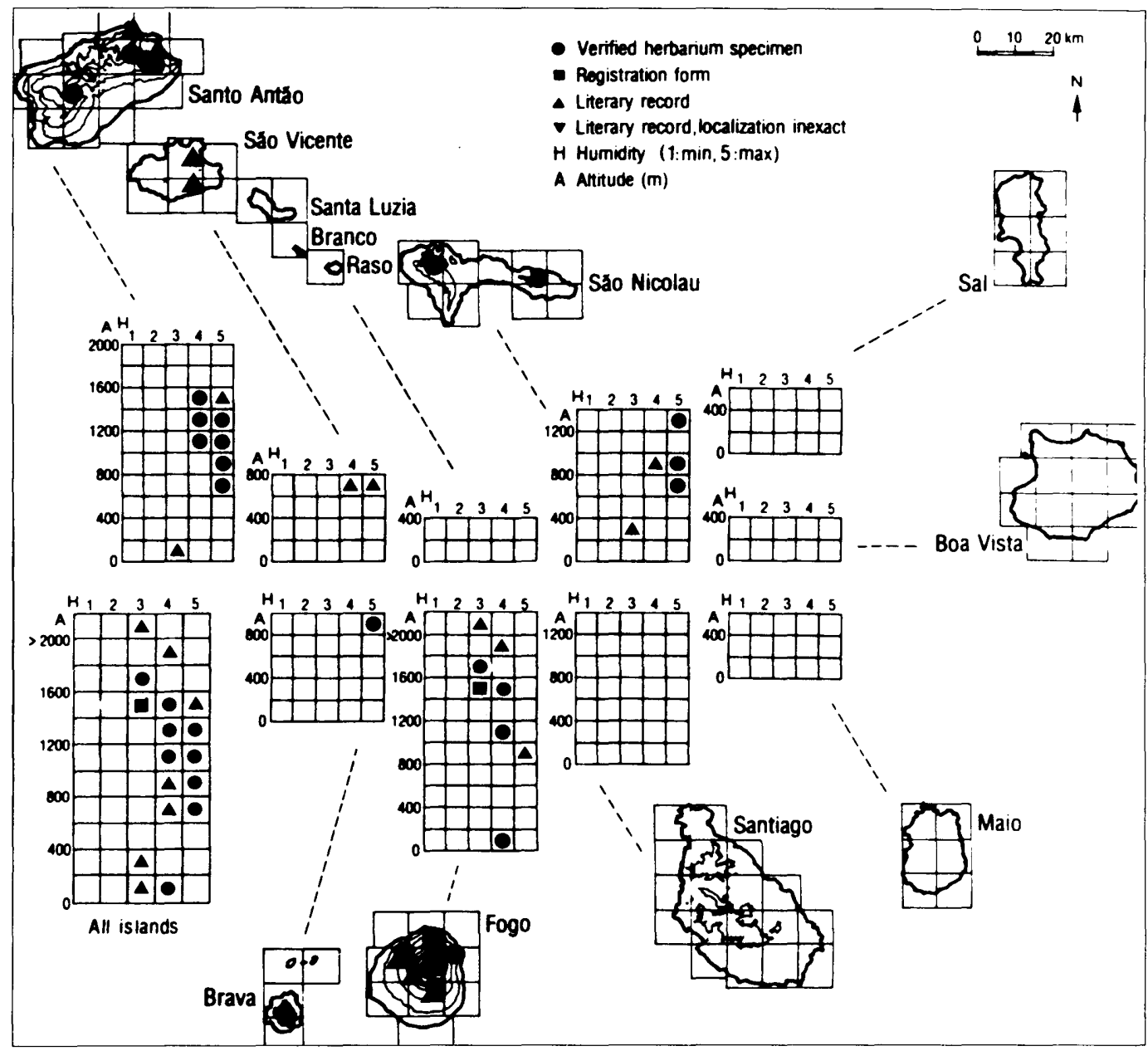

Fig. 53. Ecogeographic distribution of Conyza varia.

flowers and 2-5 central hermaphrodite flowers; flowers yellow. Achenes 0.7-1.0 mm long. Pappus whitish to reddish.

Variation. The plants show some variation, especially in pubescence. The populations on Fogo deviate somewhat by their almost glabrous branches and leaves, and by their finely denticulate leaf margins.

Chromosome number: $2 \mathrm{n}=36(2 \mathrm{n}=36$, Santo Antão, $N$ of Lombo das Pedras, 1050 $\mathrm{m}$, Borgen 1975; $\mathrm{n}=36$, Fogo, between Monte Contador and the caldeira rim, $1900 \mathrm{~m}$, Borgen 1975; $2 \mathrm{n}=36$, counted in cult. progeny (Acc. no. 029-05-95-10 in B) of origin: Fogo, path from settlement Miguel Gonçalves below Monte Duarte up to the caldeira rim, escarpments of small ribeira, 1200-1300 m, 23.01.1994, leg. Kilian 3303 \& Leyens).

Related taxa. See C. feae and C. pannosa. 
Distribution and ecology. Conyza varia is a western mesophyte occurring on Santo Antão, São Vicente, São Nicolau, Fogo, and Brava. It has not been recorded with certainty from Santiago (see note). The species is mainly distributed within the subhumid and humid zones (see also $C$. feae). A few lowland records have been given from the semiarid zone on Santo Antão and São Nicolau, and the species has also been recorded from the semiarid zone of the crater rim and the volcanic cone of Fogo. The main altitudinal distribution is between $800 \mathrm{~m}$ and $1600 \mathrm{~m}$. The lowermost record is at $80 \mathrm{~m}$ on Fogo (Brochmann \& Rustan 1988) and the uppermost records are from $2800 \mathrm{~m}$ on the same island (Lobin 1982c). The species probably once formed a dense scrubland with Artemisia gorgonum, Globularia amygdalifolia, and Euphorbia tuckeyana, covering the N, NE, and NW slopes of the Capeverdean islands.

Abundance. Conyza varia has been collected after 1970 on all islands except São Vicente, but it is declining in all areas. The species has only been recorded twice from São Vicente (1864, leg. Lowe; and 1873, leg. Moseley), and it is most likely Extinct (EX) on this island. Only a few populations are left on São Nicolau, where the species is classified as Endangered (EN). Only two populations discovered in 1982 (Monte Fontainhas; Rustan \& Brochmann 1985) and 1994 (Serrado, 20-30 small plants; leg. Leyens) are known on Brava, where the species is considered Critically Endangered (CR). Conyza varia is generally considered to be Endangered (EN).

Note. Hansen \& Sunding $(1985,1993)$ and Heim (1984) erroneously report the species from Santiago, based on confusion of their redetermined material (compare the material lists in Sunding 1982 and Heim 1984).

\section{Launaea Cass.}

This genus belongs to the tribe Lactuceae and comprises about 54 species mainly distributed in the S Mediterranean, Africa, and SW Asia. With its five species, among them three endemics, Launaea is the largest genus of tribe Lactuceae in the Cape Verde Islands.

Literature: Kilian (1988).

Key to the genus Launaea

1 Spinescent, more or less hemispherical, almost leafless shrub ................. [L. arborescens]

1 Herbs, subshrubs, or shrubs, never spinescent ...................................................

2 (1) 5 inner involucral bracts

L. thalassica

28 (rarely up to 12) inner involucral bracts

3 (2) Plant entirely herbaceous, annual; anther-tube (excluding appendages) shorter than 1.5 $\mathrm{mm}$; marginal achenes black, 3-4.5 mm long, shortly beaked [L. intybacea]

3 Plant with distinct woody caudex, perennial; anther-tube (excluding appendages) longer than $2.5 \mathrm{~mm}$; marginal achenes (4-)4.5-6.5 mm long, apically somewhat attenuate but never beaked 
4 (3) Leaves dark green and somewhat shiny above, minutely sinuate-dentate with minutely undulate margin; flowering stem curved-erect, often overhanging; flowers bright yellow; achenes whitish to pale brown L. picridioides

4 Leaves fresh green and not shiny above, irregularly sinuate-dentate to pinnatifid with coarsely undulate margin; flowering stem stiff and erect; flowers pale yellow; achenes greyish to black L. gorgadensis

\section{Launaea gorgadensis (Figs 54, 55)}

Launaea gorgadensis (Bolle) N. Kilian, Willdenowia 18: 167 (1988) = Sonchus gorgadensis Bolle, Bonplandia 7: 298 (1859) [三 Sonchus bollei Sch. Bip., Bonplandia 7: 298 (1859), pro syn.]. -- Syntypes: In insulae S. Nicolai valle Ribeira Brava, [9. 1851], Bolle (B, destroyed); in S. Antonii insulae rupibus maritimis prope Paul, [1852-53], Bolle (B, destroyed). - Neotype (designated by Kilian 1988: 167): Sto. Antão, Rib. dos Orgãos, $25^{\circ} 05^{\prime} 30^{\prime \prime} \mathrm{W}, 17^{\circ} 11^{\prime} 30^{\prime \prime} \mathrm{N}, 450 \mathrm{~m}, 9.12 .1985$, N. Kilian 801 (FR!; isoneotypes: B!, BM!, K!, O!, herb. INIDA!).

Illustrations: Kilian (1988: Figs 13E, F, 23, 24, 26), Gomes et al. (1995b: p. 12).

Description. Perennial with milky latex in all parts, flowering up to $1 \mathrm{~m}$ high. with woody, branching caudex; tuft-like with few to several compact or prolonged basal rosettes. Flowering stem stiff and erect, leafy in lower half or rarely leafless. Rosette leaves and basal leaves narrowly spathulate, acute, up to $19 \mathrm{~mm}$ long and $4.5 \mathrm{~mm}$ wide, irregularly sinuatedentate to pinnatifid, margin coarsely undulate. Synflorescence with ascending-erect branches very variable in length, sometimes absent and then with capitules clustered at the main axis. Capitules with 16-22 flowers. Involucre slender, cylindrical, (12-)13-15 mm long, with 8 (occasionally up to 10) inner involucral bracts. Flowers pale yellow, invariably 5-toothedligulate and hermaphrodite; anther-tube (excluding appendages) 2.6-3.2 mm long. Achenes 5$6.6 \mathrm{~mm}$ long, prismatic; inner achenes greyish, more or less columnar, slightly transversely wrinkled, with 4 main ribs; marginal achenes black, with 5 main ribs, sharply wrinkled, apically more or less attenuate. Pappus 7-8 $\mathrm{mm}$ long, persistent, white, with numerous downy rays and a smaller number of thicker rays.

Variation. Conspicuous variation was observed in the structure of the synflorescence. Development of synflorescence branches is sometimes largely suppressed, resulting in a compact and somewhat spike-like synflorescence; such plants of Launaea gorgadensis superficially resemble $L$. picridioides. Alternatively, the synflorescence branches in $L$. gorgadensis may be as well developed as those in $L$. intybacea. Depending on whether the flowering stem is produced by the rosette shoot with or without prolongation of the rosette axis, the flowering stem in L. gorgadensis varies from leafless to leafy in the lower half.

Chromosome number: $2 \mathrm{n}=36(2 \mathrm{n}=36$, Santo Antão, above Fontainhas, towards Monte Manuel dos Joelhos, $450 \mathrm{~m} ; 2 \mathrm{n}=36$, Santo Antão, Ribeira dos Orgãos, $450 \mathrm{~m} ; 2 \mathrm{n}=$ 36, Santo Antão, below Monte Joanna, 350 m, Kilian 1988).

Related taxa. It is possible that Launaea gorgadensis is most closely related to East African species, in particular L. petitiana (A. Rich.) N. Kilian (Kilian, unpubl. data). Alternatively, the tetraploid L. gorgadensis may have evolved in the Cape Verde Islands by hybridization between the native diploids L. picridioides and possibly L. intybacea (Jacq.) $\mathrm{P}$. Beauv. (Kilian 1988), or an extinct, close relative of the latter species. This hypothesis is supported by the chromosome numbers of these three species and also by the intermediate morphology and ecology of $L$. gorgadensis relative to L. picridioides and L. intybacea. 


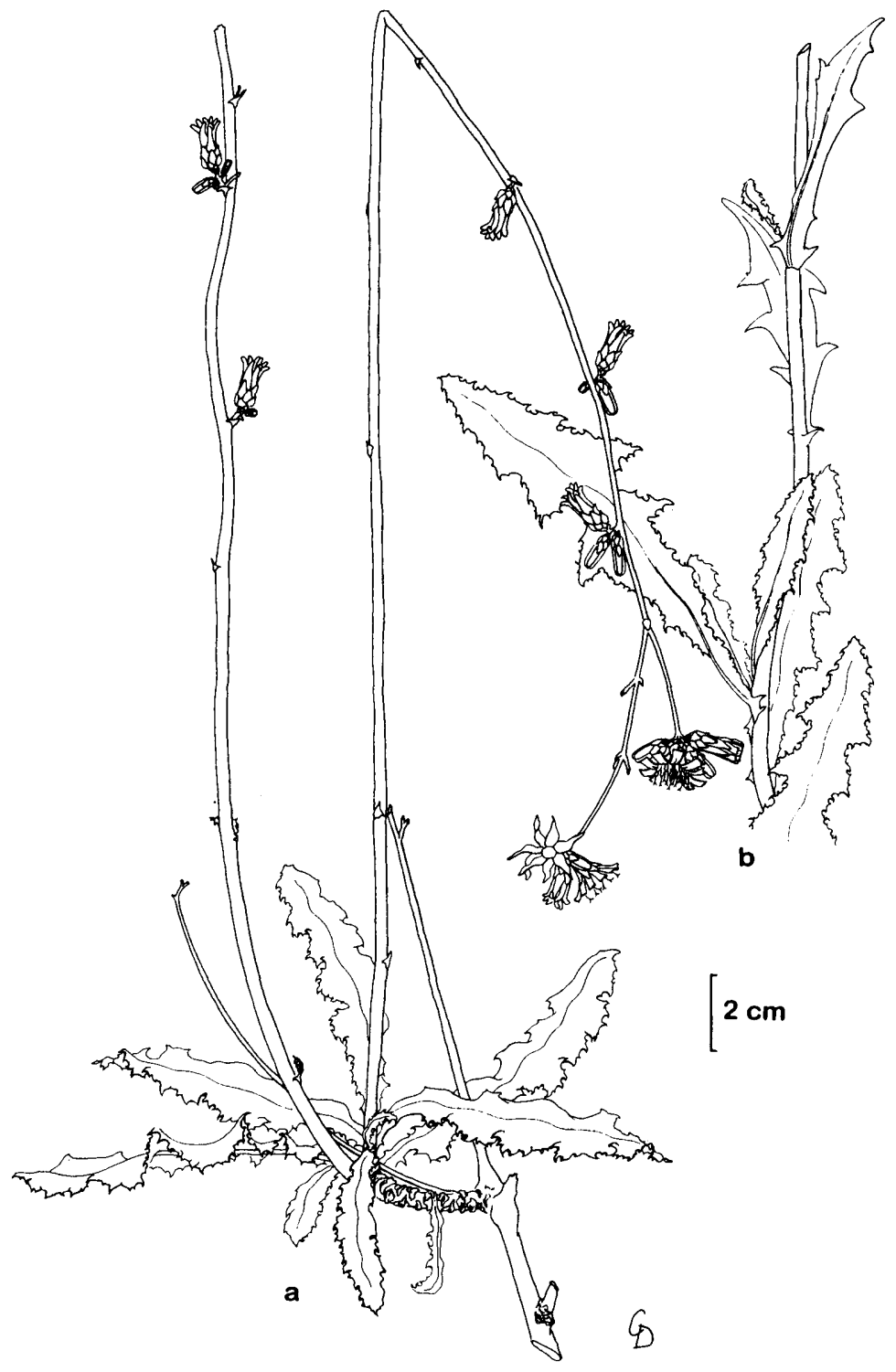

Fig. 54. Launaea gorgadensis. a. Habit; b. Part of stem with leaves. Drawn by C. Dervin. Reprinted from Kilian (1988), Willdenowia 18 (with permission). 


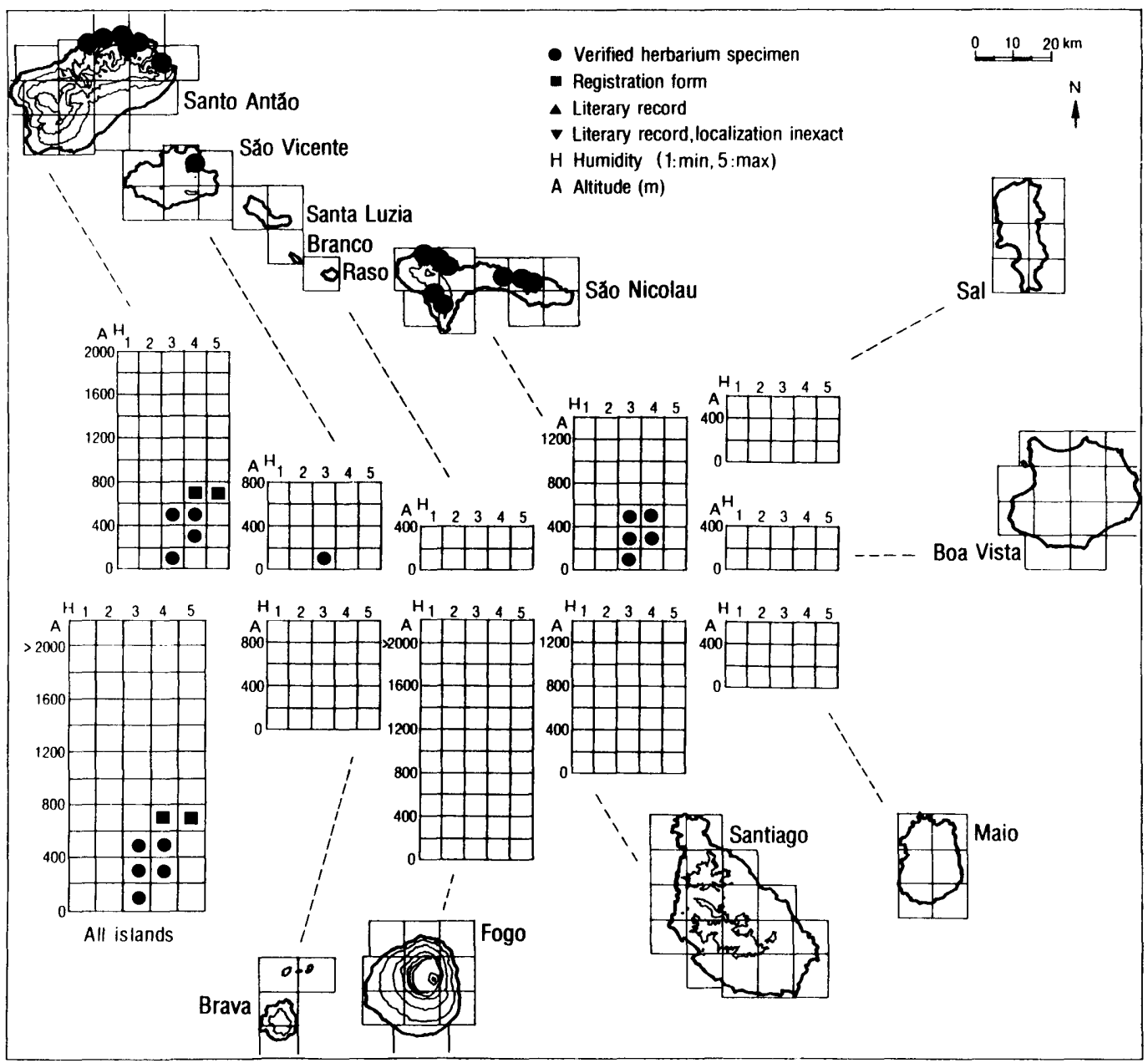

Fig. 55. Ecogeographic distribution of Launaea gorgadensis.

Distribution and ecology. Launaea gorgadensis is a northern mesophyte, occurring on Santo Antão, São Vicente, and São Nicolau. It is most frequent in the semiarid zone, but some populations occur in the subhumid zone and a single population occurs in the humid zone. Notably, the species is absent from the most favourable, humid mountain areas, and it is more common in the semiarid zone than L. picridioides. Thus, the tetraploid L. gorgadensis is ecologically intermediate between the xerophytic diploid $L$. intybacea and the mesophytic diploid $L$. picridioides, which have been hypothesized as possible progenitors of $L$. gorgadensis (Kilian 1988). Launaea gorgadensis occurs mainly between $100 \mathrm{~m}$ and $450 \mathrm{~m}$. The lowermost record is at $20 \mathrm{~m}$ on eastern São Nicolau (leg. Rustan \& Brochmann); the uppermost one at $700 \mathrm{~m}$ in Monte Manuel dos Joelhos on northern Santo Antão (obs. Kilian). The plants grow in gravelly coastal and lower montane slopes, rarely in cliffs. 


\begin{abstract}
Abundance. Launaea gorgadensis was described in 1859 as Sonchus gorgadensis (Bolle 1859b) but misunderstood until recently (Kilian 1988). There are only few records of this species before 1972 (one specimen from 1895, leg. Cardoso, without locality; and three specimens from 1934, leg. Chevalier, Santo Antão). The species is, however, widespread and locally common on São Nicolau. On Santo Antão, it has recently been found further westwards along the northern coast (leg. Kilian \& Leyens), and it is thus fairly common along the northeastern and northwestern coasts of this island. On São Vicente, it has only been collected twice in the Monte Verde area, and it is considered Rare (R) on this island. Launaea gorgadensis is generally considered to be Lower Risk (LR).
\end{abstract}

\title{
Launaea picridioides (Figs 56, 57)
}

Launaea picridioides (Webb) Engl., Pflanzenw. Afrikas 1: 820 (1910) = Rhabdotheca picridioides Webb in Hooker, Icon. Pl. 8: ad tab. 761 (1848) $\equiv$ Microrhynchus picridioides (Webb) Walp., Ann. Bot. Syst. 1: 463 (1858) $\equiv$ Lactuca picridioides (Webb) Henriq., Bol. Soc. Brot. 13: 150 (1896). — Syntypes: Isla San Nicolau, Forbes 34 (K!); St. Vincent, am Mont Verede, 6.1841, Vogel 43, 44 (K!, FI-W!). — Lectotype (designated by Kilian 1988: 160): Vogel 43 (K!).

Illustrations: Webb (1848: Fig. 761, 1849: Fig. 11 sub Rhabdotheca picridioides), Kilian (1988: Figs 13C, D, 19, 20), Gomes et al. (1995b: p. 12).

Description. Small, cushion-forming rosette shrub with milky latex in all parts, flowering up to $0.7 \mathrm{~m}$ high, with procumbent, woody, strongly and regularly branching caudex with many (up to 80) leaf rosettes. Flowering stem slender, curved-erect, often overhanging, always leafless. Rosette leaves narrowly spathulate, acute, up to $17 \mathrm{~cm}$ long and $2 \mathrm{~cm}$ wide, usually regularly and minutely spinulosely sinuate-dentate; margin minutely undulate; lamina dark green and somewhat shiny above. Synflorescence compact, often tuft-like, without distinct branches and capitules clustered at the main axis. Capitules with 13-18 flowers. Involucre slender, cylindrical, 10-13 mm long, with 8 inner involucral bracts. Flowers bright yellow, invariably 5-toothed-ligulate and hermaphrodite; anther-tube (excluding appendages) 2.6-3.4 $\mathrm{mm}$ long. Achenes 4-6.5 mm long; inner achenes \pm columnar, pale, smooth, with 4 main ribs; marginal achenes somewhat transversely wrinkled, with 5 main ribs, pale to pale brown. Pappus 5-7 mm long, persistent, white, with numerous downy rays and a smaller number of thicker rays.

Variation. Launaea picridioides is a conspicuous, fairly homogeneous species which hardly can be confused with other species. Notably, some plants on São Nicolau have indistinctly undulate leaf margins, but other plants are intermediate between this form and the common form with undulate leaves.

Chromosome number: $2 \mathrm{n}=18$ ( $2 \mathrm{n}=18$, São Nicolau, Ribeira Carão, 200-300 m, Kilian 1988; $\mathrm{n}=9$, Santo Antão (the locality is probably between Ribeira Brava and Ribeira do Paul, cf. Sventenius 1971), Aldridge \& Ortega 1976).

Related taxa. Launaea picridioides is most closely related to $L$. viminea Batt. from the Atlas Mountains and L. secunda (C. B. Clarke) Hook. f. from the Western Himalayas (Kilian, unpubl. data).

Distribution and ecology. Launaea picridioides is a northern mesophyte occurring on Santo Antão, São Vicente, Branco, and São Nicolau. It is most frequent in the semiarid and subhumid zones, and less frequent in the humid zone. The species is mainly distributed between $200 \mathrm{~m}$ and $900 \mathrm{~m}$. Along the steep northern coast of Santo Antão and São Nicolau, it 


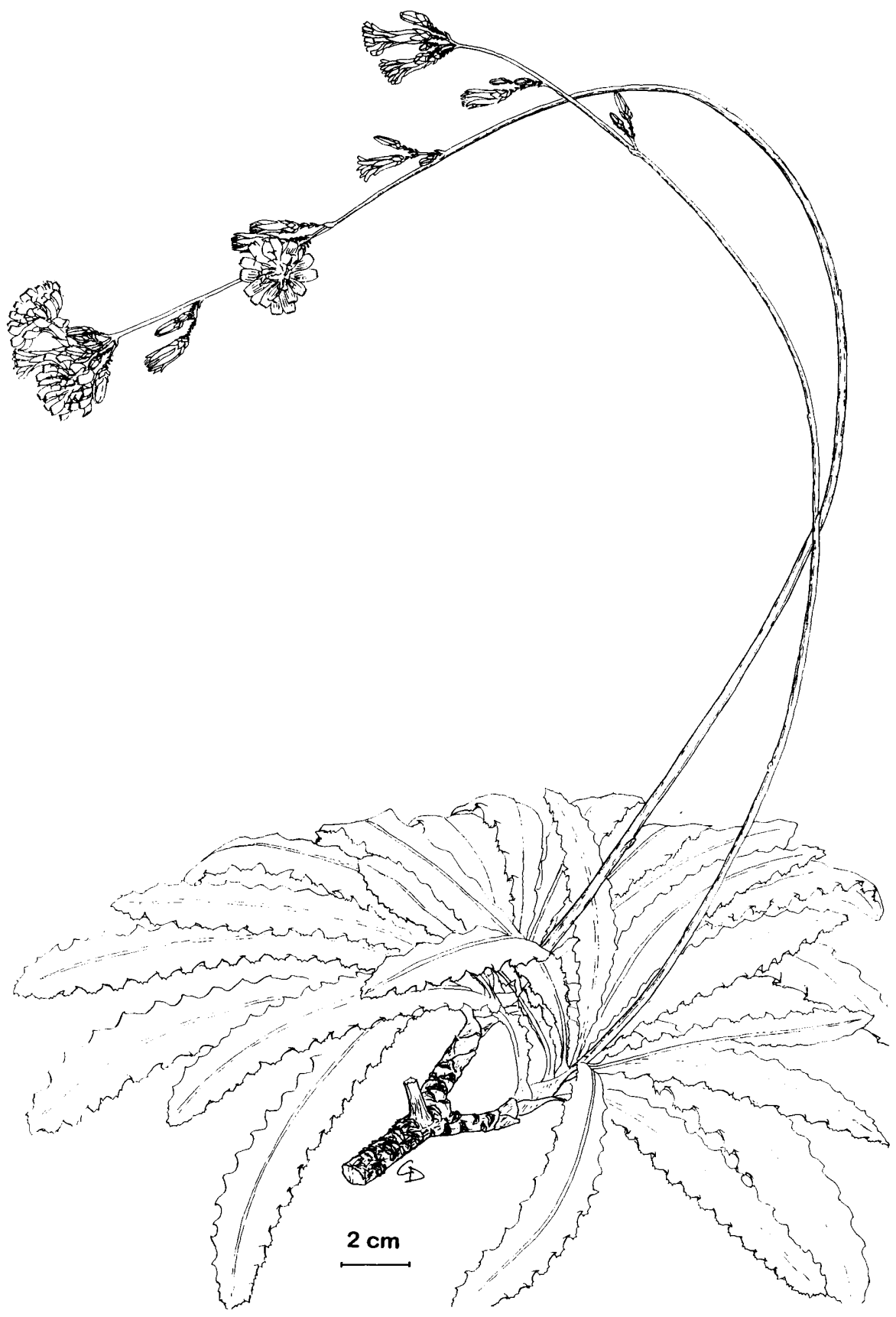

Fig. 56. Launaea picridioides. Drawn by C. Dervin. 


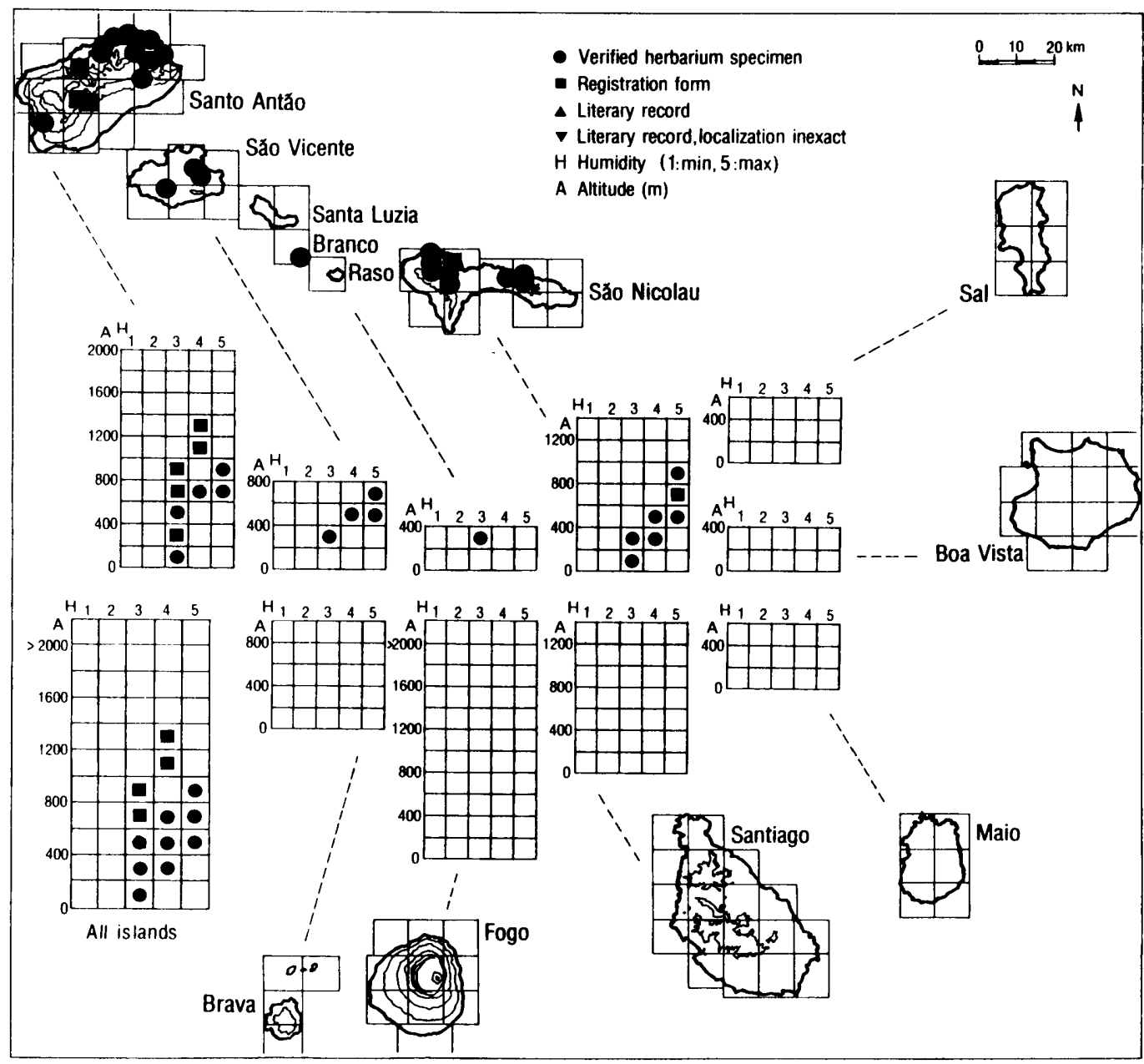

Fig. 57. Ecogeographic distribution of Launaea picridioides.

is often found almost down to sea level, and it extends to $1400 \mathrm{~m}$ on Santo Antão (Brochmann $\&$ Rustan 1988). The plants grow in cliffs and gravelly slopes in montane, colline, and coastal areas.

Abundance. Launaea picridioides has been recorded from all major islands after 1980 . It is widespread and locally common on Santo Antão and São Nicolau, but it is restricted to three mountains on São Vicente (Monte Verde, Tope de Caixa, and Gôa Alto). The species has been collected once (1968) at the highest point of the poorly investigated islet of Branco (leg. de Naurois). Launaea picridioides is generally considered to be Lower Risk (LR). 
Launaea thalassica (Figs 58, 59)

Launaea thalassica N. Kilian, Brochmann \& Rustan, Willdenowia 16: 491 (1987). — Type: Brava, Ribeira da Agua, oberhalb Lavadura, am Abstieg von N.S. do Monte, 350 m, 244ㄴ $43^{\prime \prime} \mathrm{W}, 1^{\circ} 51^{\prime} 40^{\prime \prime} \mathrm{N}, 22.1 .1986, \mathrm{~N}$. Kilian 1200 (holotype: FR!; isotypes: B!, BM!, COI!, K!, O!).

Illustrations: Kilian et al. (1987: Fig. 1), Kilian (1988: Figs 13G, H, 28, 29), Gomes et al. (1995b: p. 12).

Description. Perennial with milky latex in all parts, flowering up to $0.6 \mathrm{~m}$ high, with woody, branching caudex and a few, compact basal rosettes. Flowering stem ascending to erect, regularly leafless. Rosette leaves up to $16 \mathrm{~cm}$ long and $3 \mathrm{~cm}$ wide, narrowly spathulate with rounded apex, shallowly sinuate-dentate, indistinctly undulate or plane, upper surface dull green. Synflorescence with few, simple, overhanging branches up to $35 \mathrm{~cm}$ long. Capitules with 6-11 flowers. Involucre slender, cylindrical, 11-13.5 mm long, with 5 inner involucral bracts. Flowers pale yellow, invariably 5-toothed-ligulate and hermaphrodite; anther-tube (excluding appendages) 1.6-2.0 mm long. Achenes 5-6 mm long; inner achenes columnar, pale to ash-grey, with 4 main ribs, smooth to somewhat transversely wrinkled; marginal achenes somewhat compressed and curved, with 5 main ribs, distinctly transversely wrinkled. greyish brown. Pappus 6-7 $\mathrm{mm}$ long, persistent, white, with numerous downy rays and a smaller number of thicker rays.

Variation. The species is distinct and homogeneous, only varying somewhat in size characters.

Chromosome number: $2 \mathrm{n}=36$ (Brava, Ribeira da Agua above Lavadura, towards N. S. do Monte, $350 \mathrm{~m}$, Kilian 1988).

Related taxa. Launaea thalassica is possibly most closely related to L. taraxacifolia (Willd.) Amin ex C. Jeffrey, a perennial species originating from the Abyssinian Highlands but today fairly widespread as a weed or ruderal, or even as a cultivated species in Tropical W Africa (Kilian, unpubl. data). The tetraploid chromosome number of L. thalassica may, however, indicate that the species originated as a hybrid between unknown, possibly extinct, parental species in the Cape Verde Islands (Kilian 1988).

Distribution and ecology. Launaea thalassica is a southern mesophyte restricted to the small island of Brava. It is most abundant in the subhumid and humid zones, mainly between $300 \mathrm{~m}$ and $500 \mathrm{~m}$, but the species also occurs in the semiarid zone. The lowermost record is at $50 \mathrm{~m}$ and the uppermost one at $640 \mathrm{~m}$ (leg. Rustan \& Brochmann). The species is mainly distributed in the northern and northeastern parts of the island, where it grows together with Campanula bravensis, Diplotaxis varia, and Pteris vittata in gravelly or rocky slopes, in cliffs, and often in steep edges of ribeiras. It has also been found along irrigation canals and as a weed in cultivated areas.

Abundance. Although L. thalassica was collected already by Lowe in 1864, the species was first described in 1987 based on several populations discovered in the 1980s (Kilian et al. 1987). Launaea thalassica is locally common on Brava, but it is considered to be Rare (R) because of its very limited total distribution area. 


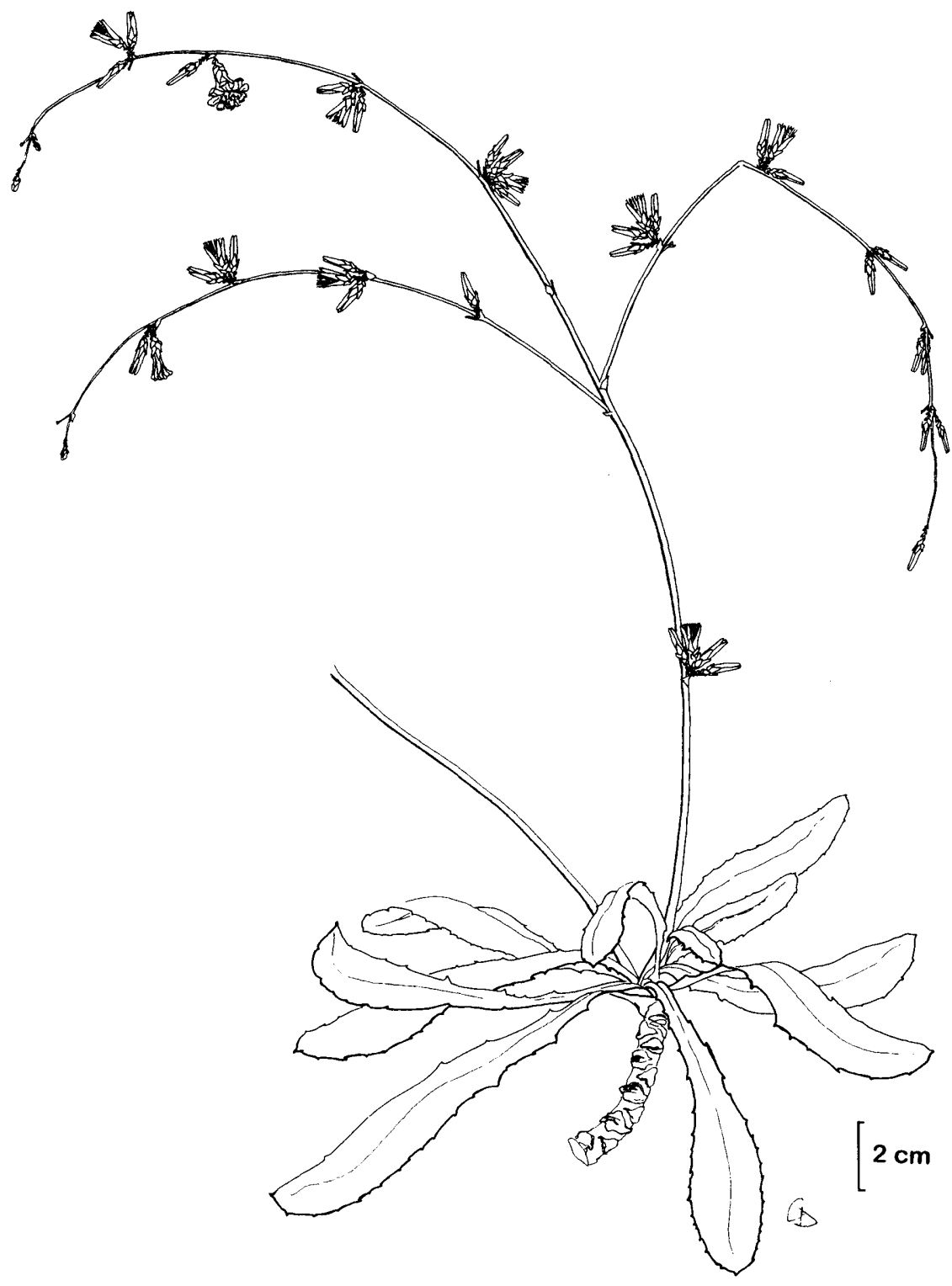

Fig. 58. Launaea thalassica. Drawn by C. Dervin. Reprinted from Kilian (1988), Willdenowia 18 (with permission). 


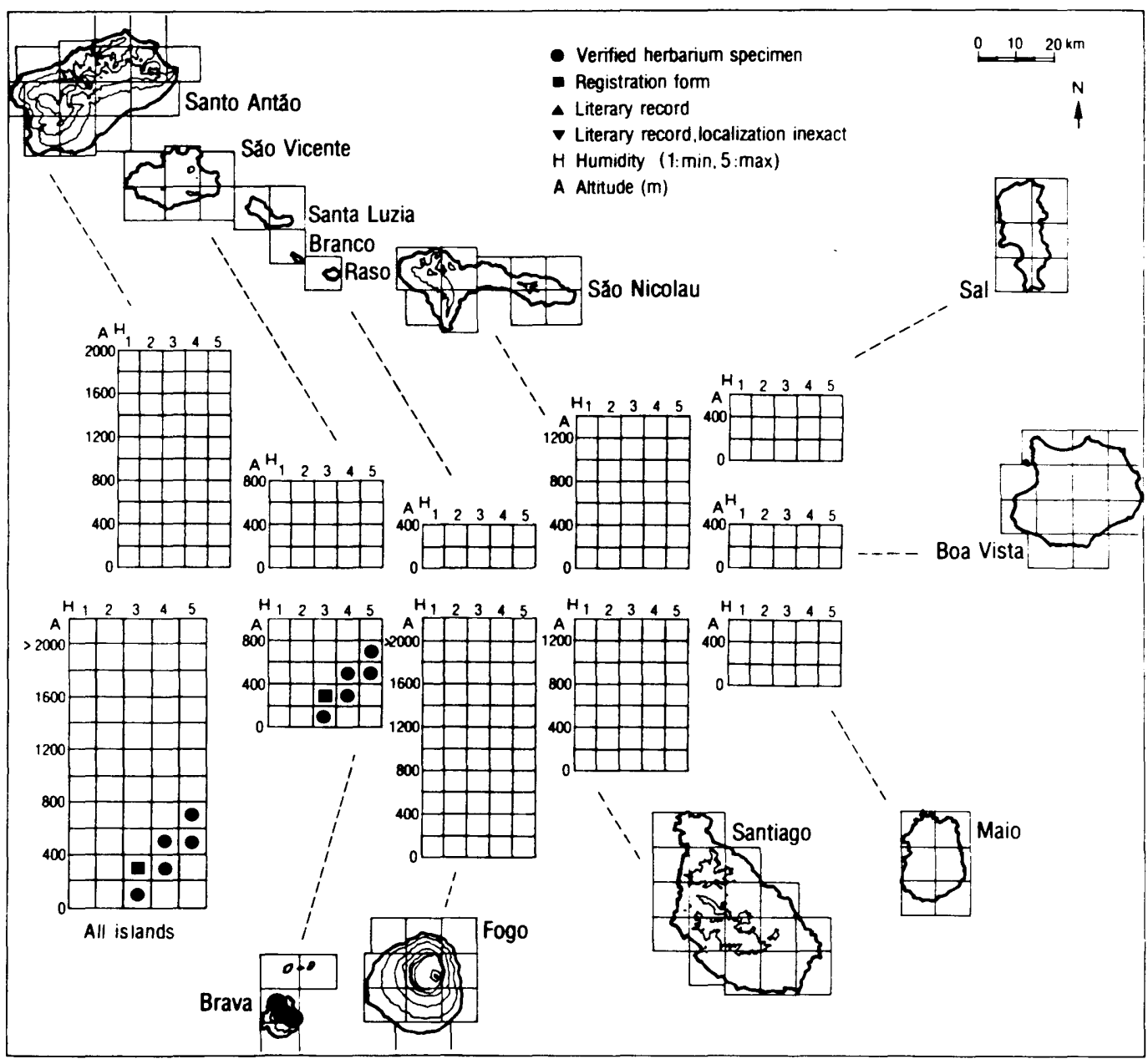

Fig. 59. Ecogeographic distribution of Launaea thalassica.

Nauplius (Cass.) Cass.

The genus Nauplius (tribe Inuleae) in the revised sense (Wiklund 1987) comprises eight species with five subspecies, distributed in the Canary Islands, the Cape Verde Islands, the S Mediterranean, $\mathrm{N}$ Africa, and Arabia. In the Cape Verde Islands, the genus is represented by two endemic species, of which one comprises two subspecies.

Literature: Halvorsen \& Borgen (1986), Wiklund (1987). 


\section{Key to the genus Nauplius}

1 Leaves crowded towards apices of the branches; involucre 16-19 mm wide ........... smithii

1 Leaves rather distant towards apices of the branches; involucre $9-13 \mathrm{~mm}$ wide 2

2 (1) Palea entirely glabrous; leaf margin denticulate $N$. daltonii ssp. daltonii

2 Palea apically pubescent; leaf margin entire N. daltonii ssp. vogelii

\section{Nauplius daltonii}

Nauplius daltonii (Webb) Wiklund, Nord. J. Bot. 7: 15 (1987) $\equiv$ Odontospermum daltonii Webb in Hooker, Niger Fl.: 140 (1849) $\equiv$ Asteriscus daltonii (Webb) Walp., Ann. Bot. Syst. 2: 844 (1852) $\equiv$ Bubonium daltonit (Webb) Halvorsen, Sommerfeltia 3: 80 (1986). - Syntypes: In collibus alt. 1000 ad 2000 ped. que vallem S. Dominici obvallant in ins. S. Jacobi, 11.1839, J. D. Hooker 204 (FI-W); in rupestribus sinus Tarrafal ins. S. Antonii, 2.4.1822, Forbes $[=N$. daltonii ssp. vogelii] - Lectotype (designated by Halvorsen \& Borgen 1986: 80): J. D. Hooker 204 (FI-W).

Description. Usually cushion-forming, moderately to strongly branched shrub up to $0.5 \mathrm{~m}$ high; branches ascending to erect, tomentose-villose when young, glabrescent with age, leaves more or less distant towards apices. Leaves oblanceolate to narrowly oblanceolate, up to $7 \mathrm{~cm}$ long and $1.5 \mathrm{~cm}$ wide, sericeous; apex rounded to acute. Capitules terminal, solitary; involucre subglobose, $5-13 \mathrm{~mm}$ in diameter; receptacle paleate. Flowers yellow; outer flowers female with a 3-toothed ligule up to $10 \mathrm{~mm}$ long; inner flowers hermaphrodite, tubular. Achenes of ligulate flowers triquetrous, achenes of tubular flowers terete, all achenes with a corona-like pappus of tufted, brownish hairs.

Variation. The infraspecific variation is considerable. Two subspecies can be distinguished, but some transitional populations occur.

Related taxa. Nauplius daltonii is most closely related to $N$. smithii, but it is easily distinguished from this species by its smaller size, leafy branches, and smaller capitules.

\section{Nauplius daltonii ssp. daltonii (Figs 60, 61)}

Nauplius daltonii (Webb) Wiklund ssp. daltonii

Illustrations: Brochmann \& Rustan (1983: Fig. 1), Halvorsen \& Borgen (1986: Figs 3A, 4C, 8A, E, 39 sub Bubonium daltonii ssp. daltonii), Wiklund (1987: Fig. 1C).

Description. Moderately branched shrub. Leaves oblanceolate, usually denticulate, more or less acute. Receptacle with glandular but entirely glabrous paleae. Involucre 9-13 $\mathrm{mm}$ in diameter. Ligule of outer flowers 6-10 mm long.

Variation. This subspecies is relatively uniform, but some populations that are transitional towards ssp. vogelii occur in the lower parts of the mountains of Santiago.

Chromosome number: $2 \mathrm{n}=14(2 \mathrm{n}=14$, Santiago, Pico da Antonia, $960 \mathrm{~m}$, Borgen 1975; $2 \mathrm{n}=14$, Santiago, Serra da Malagueta, $850 \mathrm{~m}$, Halvorsen \& Borgen 1986; 2n $=14$, Santiago, Serra da Malagueta, 920-1020 m, Halvorsen \& Borgen 1986). Borgen's (1975) count of $2 \mathrm{n}=18$ was based on misidentified material and is omitted (cf. Halvorsen \& Borgen 1986). 


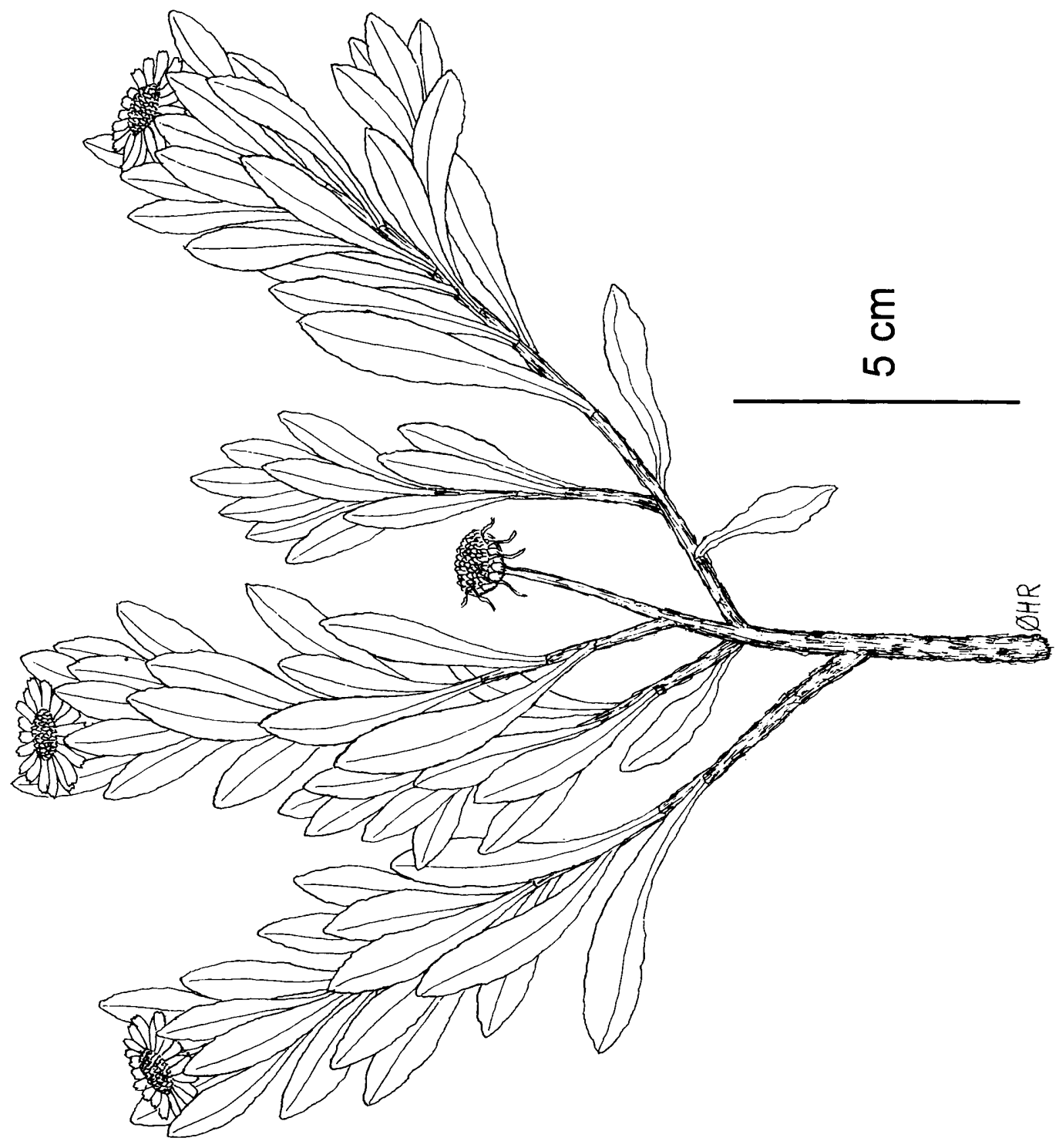

Fig. 60. Nauplius daltonii ssp. daltonii. Drawn by Ø. H. Rustan. Reprinted from Halvorsen \& Borgen (1986), Sommerfeltia 3. 


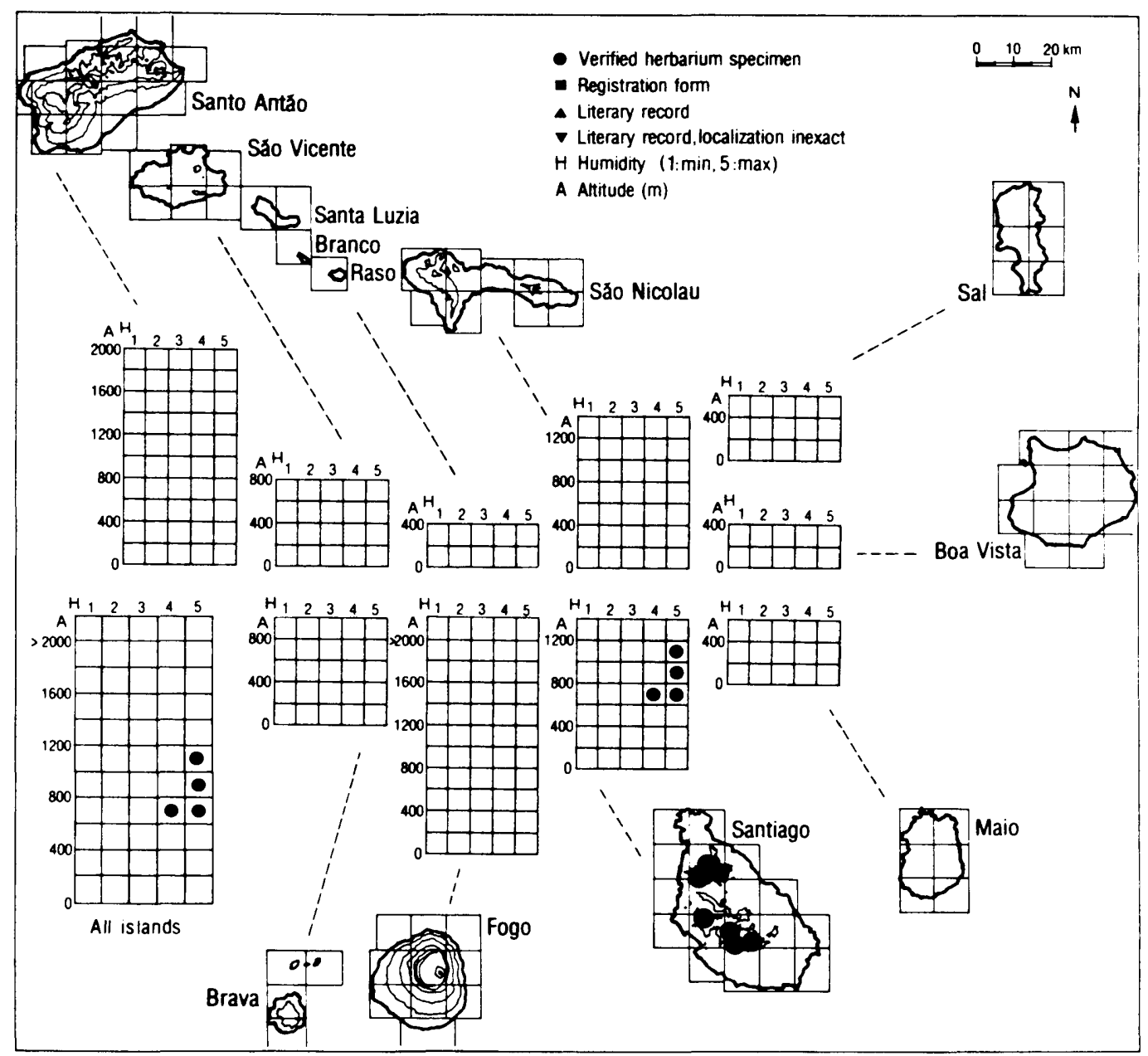

Fig. 61. Ecogeographic distribution of Nauplius daltonii ssp. daltonii.

Related taxa. Nauplius daltonii ssp. daltonii is closely related to but distinguished from ssp. vogelii by its glabrous paleae and acute leaves with denticulate margins.

Distribution and ecology. Nauplius daltonii ssp. daltonii is a southern hygrophyte, confined to the two main mountain ranges on Santiago (Serra do Pico da Antonia and Serra da Malagueta). It is mainly found in the humid zone, rarely in the subhumid zone. The species grows from (640-)800 m to $1020 \mathrm{~m}$ in gravelly mountain slopes and cliffs, together with, e.g., Echium hypertropicum and Lotus jacobaeus. Populations that are transitional between the two subspecies occur at intermediate altitudes and humidity.

Abundance. This subspecies is restricted to two small areas, and its total population size has been severely reduced because of human influence. Nauplius daltonii ssp. daltonii is considered to be Endangered (EN). 
Note. The map is based on material from various herbaria revised by T. Halvorsen, Oslo (cf. Halvorsen \& Borgen 1986).

\section{Nauplius daltonii ssp. vogelii (Figs 62, 63)}

Nauplius daltonii (Webb) Wiklund ssp. vogelii (Webb) Wiklund, Nord. J. Bot. 7: 15 (1987) $\equiv$ Odontospermum vogelii Webb in Hooker, Niger Fl.: 140 (1849) Asteriscus vogelii (Webb) Walp., Ann. Bot. Syst. 2: 844 (1852) $\equiv$ Bubonium daltonii (Webb) Halvorsen ssp. vogelii (Webb) Halvorsen, Sommerfeltia 3: 82 (1986). - Syntypes: S. Vicente, "Spitze des Monte Verde", 6.1841, Vogel 46, 80 (FI-W, K); in ins. Vincentii, 1.4.1822, Forhes 2. Lectotype (designated by Halvorsen \& Borgen 1986: 82): Vogel 46, 80 [sheet with fragments of collection numbers 46 and 80 ; however, a single element should better be selected] (K; isolectotype FI-W).

= Odontospermum vogelii Webb var. darwinii Webb in Hooker, Niger Fl.: 140 (1849) $\equiv$ Asteriscus vogelii (Webb) Walp. var. darwinii (Webb) Walp., Ann. Bot. Syst. 2: 844 (1982). _- Type: [Cape Verde Islands], Darwin (holotype: FI-W).

= Odontospermum arborescens Gandoger, Bull. Soc. Bot. France 65: 39 (1918). - Type: [Cape Verde Islands], S. Vicente, 2.1879, Thiebaut (holotype: LY).

Illustrations: Wawra (1866: Fig. 12 sub Odontospermum vogelii), Halvorsen \& Borgen (1986: Figs 3B, 10C, 40 sub Bubonium daltonii ssp. vogelii), Gomes et al. (1995b: p. 12).

Description. Strongly branched shrub varying from densely cushion-shaped to irregularly spreading. Leaves oblanceolate-linear; apex usually rounded; margin entire. Involucre subglobose, $5-13 \mathrm{~mm}$ in diameter. Paleae glandular, apically pubescent. Ligule of outer flowers 2-8 mm long.

Variation. This subspecies is variable in habit and several size characters. Coastal populations of ssp. vogelii often have strongly succulent leaves. Deviating populations, which resemble $N$. smithii in some characters and $N$. daltonii ssp. daltonii in others, occur in the mountains of eastern São Nicolau.

Chromosome number: $2 \mathrm{n}=14(2 \mathrm{n}=14$, Santo Antão, Monte Jado d'Arado, $1300 \mathrm{~m}$; $2 \mathrm{n}=14$, São Vicente, Monte Verde, $500 \mathrm{~m} ; 2 \mathrm{n}=14$, São Vicente, Monte Verde, $680 \mathrm{~m} ; \mathrm{n}=$ 7, São Nicolau, Alto Joaquina, 590-618 m; $\mathrm{n}=7$, Fogo, Ponta de Vale de Cavaleiros, $50 \mathrm{~m}$, Halvorsen \& Borgen 1986).

Related taxa: See above.

Distribution and ecology. Nauplius daltonii ssp. vogelii is a ubiquitous xerophyte occurring on Santo Antão, São Vicente, Branco, São Nicolau, Maio, Santiago. Fogo, and Brava (including the islet Ilheu de Cima). This subspecies has a wide ecological amplitude; it is equally frequent in the arid, semiarid, and subhumid zones but usually absent from the humid zone, except for a few populations on São Vicente and São Nicolau. The subspecies is distributed from sea-level to $1940 \mathrm{~m}$ at Tope de Coroa on Santo Antão (Brochmann \& Rustan 1988). On Santiago, ssp. vogelii is usually confined to coastal areas below $400 \mathrm{~m}$ and replaced by ssp. daltonii in more elevated, humid areas. Nauplius daltonii ssp. vogelii is characteristic of two different vegetation types in the Cape Verde Islands. It is part of the indigenous coastal vegetation, in particular on Santo Antão, Fogo, and Brava, but it is also a typical component of the scrub vegetation of higher zones, in particular on Santo Antão.

Abundance. There are many recent records of this subspecies from most islands, and it is still fairly common on Santo Antão, São Nicolau, and Fogo. However. as for several typical taxa of the indigenous scrub vegetation, the abundance of $N$. daltonii ssp. vogelii is generally declining. Recent surveys suggest that the subspecies is Endangered (EN) on São Vicente, although many populations have been reported from this island. In the previous century, the 


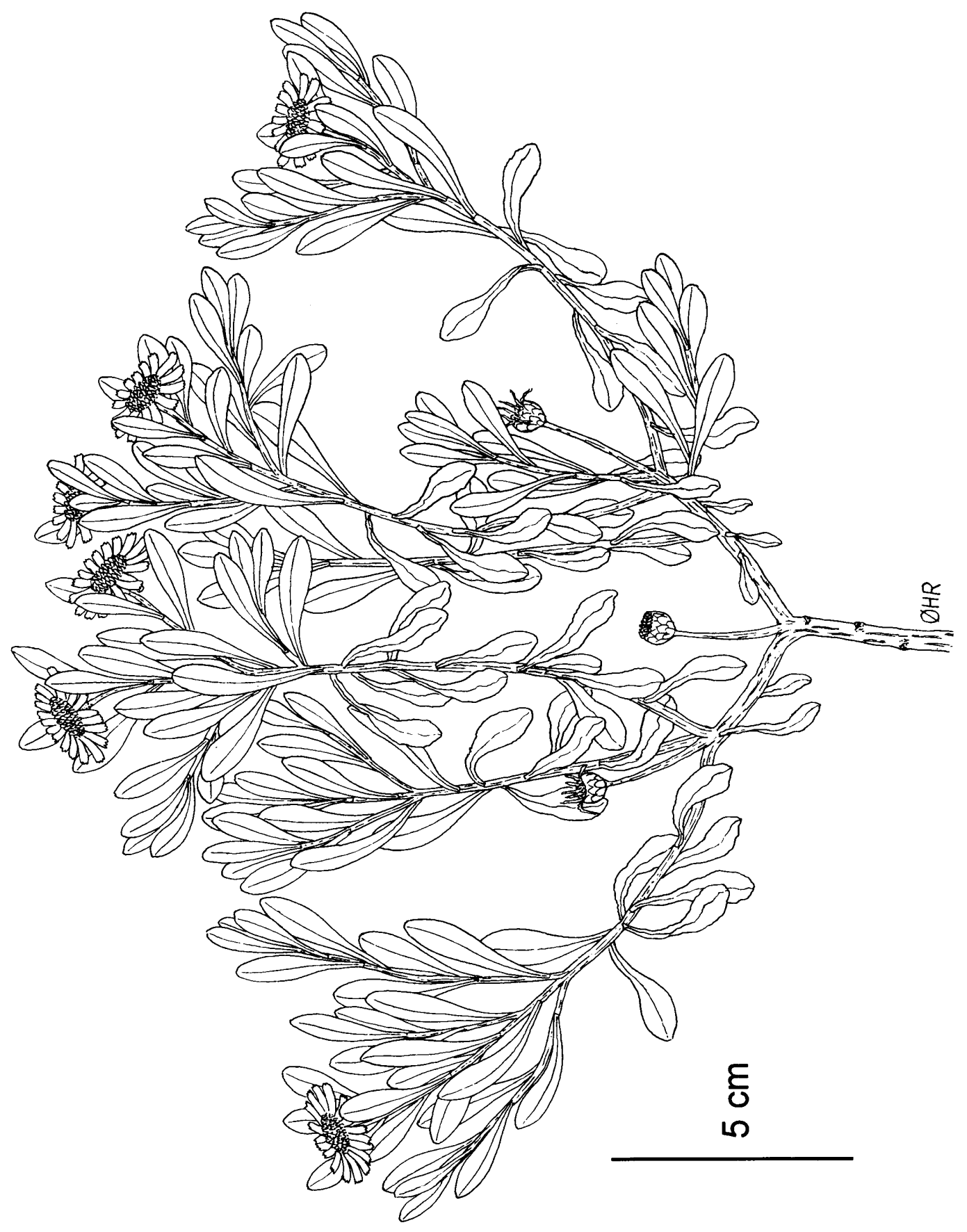

Fig. 62. Nauplius daltonii ssp. vogelii. Drawn by Ø. H. Rustan. Reprinted from Halvorsen \& Borgen (1986), Sommerfeltia 3. 


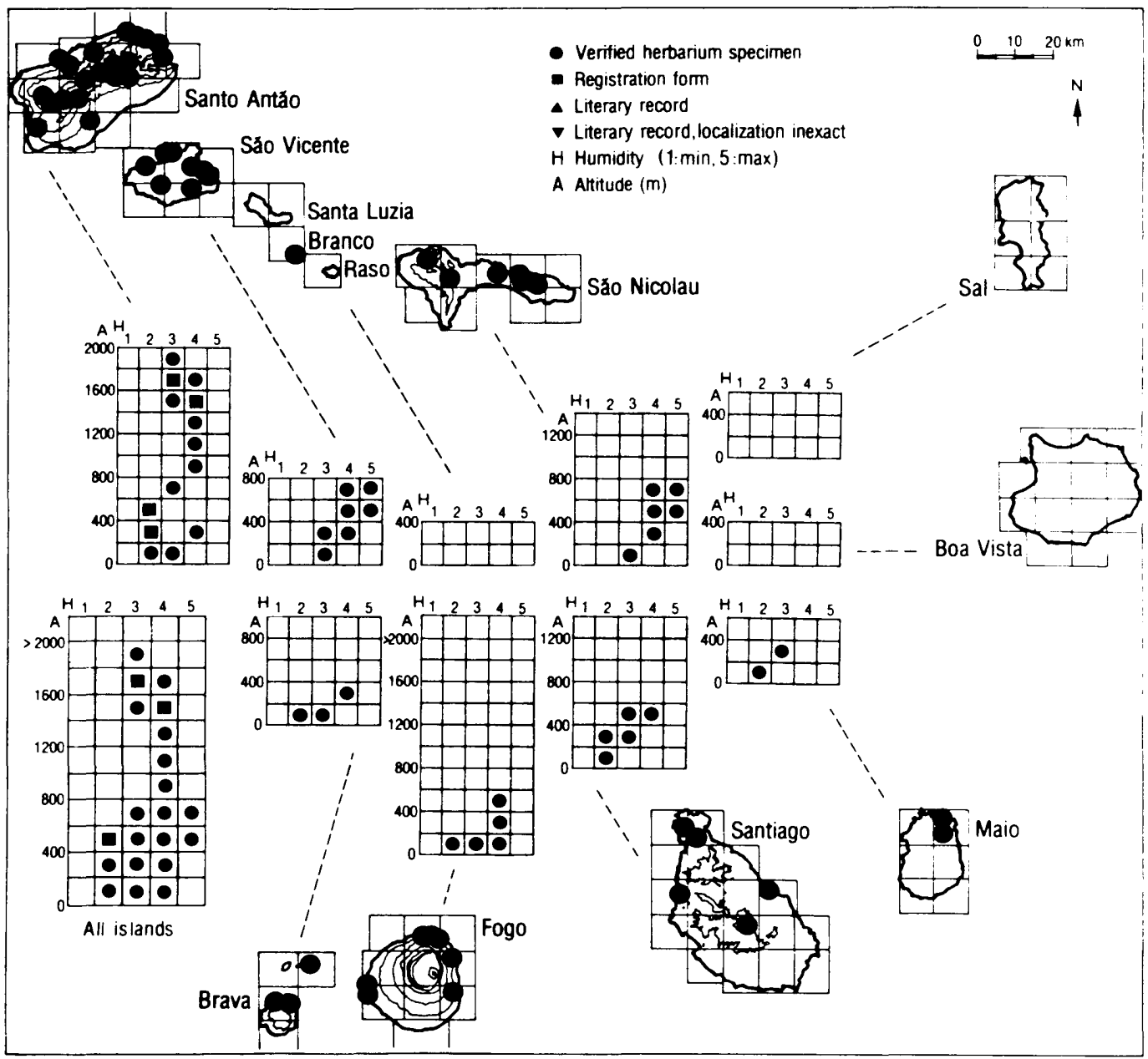

Fig. 63. Ecogeographic distribution of Nauplius daltonii ssp. vogelii.

subspecies was one of the most abundant taxa on the lower mountains of São Vicente as well as above $250 \mathrm{~m}$ on Monte Verde (cf. citations in Krause 1892). On Brava. the only known record of ssp. vogelii dated from 1866 (leg. Lowe) until a small population was rediscovered in 1986 (leg. Kilian), as well as a larger population on the adjacent islet Ilheu de Cima (leg. Leyens \& Gomes; Gomes et al. 1995a). Its status on Brava is considered Critically Endangered (CR). Notably, ssp. vogelii was unknown on the eastern islands until 1988, when it was discovered on Monte de Santo António and in Lage Branca on Maio (leg. de Matos; Basto \& Diniz 1993). The subspecies is still abundant on Monte de Santo António on Maio (Gomes et al. 1995a), but it is considered Vulnerable (VU) on this intensively pastured island. Nauplius daltonii ssp. vogelii is generally classified as Lower Risk (LR). 
Note. The map is based on material from various herbaria revised by T. Halvorsen, Oslo (see Halvorsen \& Borgen 1986), our own recent collections (cf. Gomes et al. 1995a) and registration form data, and records from Basto \& Diniz (1993).

Nauplius smithii (Figs 64, 65)

Nauplius smithii (Webb) Wiklund, Nord. J. Bot. 7: 15 (1987) $\equiv$ Odontospermum smithii Webb in Hooker, Niger Fl.: 139 (1849) $\equiv$ Asteriscus smithii (Webb) Walp., Ann. Bot. Syst. 2: 844 (1852) $\equiv$ Bubonium smithii (Webb) Halvorsen, Sommerfeltia 3: 77 (1986). - Type: In rupibus ins. S. Nicolai, Forbes. - Lectotype (designated by Halvorsen \& Borgen 1986: 76): "Monte Grande, St. Nicolas, 30.3.1822, Forbes 6" (G-BOIS!).

Illustrations: Sunding (1982: Fig. 1 sub Asteriscus smithii, 1985: Fig. 3 sub Odontospermum smithii), Halvorsen \& Borgen (1986: Figs 3C, 4A, 6A, 8B, 10D, 12D, 38 sub Bubonium smithii), Lobin (1986a: Fig. 3, 1986b: Fig. 27 sub Asteriscus smithii), Wiklund (1987: Fig. 1D), Gomes et al. (1995b: p. 13).

Description. Strongly branched, usually regularly cushion-shaped shrub up to $0.8 \mathrm{~m}$ high and $1.5 \mathrm{~m}$ wide. Branches strongly lignified, villose, glabrescent with age, leaves more or less crowded towards apices of the branches. Leaves oblanceolate to obovate, up to $11 \mathrm{~cm}$ long and $4 \mathrm{~cm}$ wide, sericeous; apex rounded; margin entire. Capitules solitary, terminal; involucre subglobose, 16-19 mm in diameter; receptacle paleate. Flowers yellow; outer flowers female with a 3-toothed ligule up to $14 \mathrm{~mm}$ long; inner flowers hermaphrodite, tubular. Achenes of ligulate flowers triquetrous, achenes of tubular flowers terete, all achenes with a corona-like pappus of tufted, brownish hairs.

Variation. Nauplius smithii is a uniform and distinct species.

Chromosome number: $2 \mathrm{n}=14(2 \mathrm{n}=14$, São Nicolau, between Cachaço and Monte Gordo, 900 m; n =7, São Nicolau, SE of Monte Gordo, Halvorsen \& Borgen 1986).

Related taxa. Nauplius smithii is closely related to $N$. daltonii, but it is easily distinguished from that species by its larger leaves, broader involucre, and longer ligules.

Distribution and ecology. Nauplius smithii is a northern hygrophyte, only occurring at and near Monte Gordo on São Nicolau. It is confined to the humid zone between 900 and $1300 \mathrm{~m}$, growing in northeast-exposed slopes. The plants dominate the scrub vegetation in this area together with Euphorbia tuckeyana.

Abundance. The species is confined to an area of a few square kilometres. This only known population presently (1995) comprises several hundreds of individuals. Part of the population has disappeared during the last decades because of afforestations with Eucalyptus, but further afforestation projects in this area have meanwhile been renounced. Nauplius smithii is considered to be Endangered (EN).

Note. Nauplius smithii was also recorded from Tarrafal (Ribeira Grande) on Santo Antão by Cardoso at the end of the last century. This area has, however, been intensively explored, and the record is excluded because Cardoso visited both São Nicolau and Santo Antão and probably confused his material (cf. Halvorsen \& Borgen 1986). 


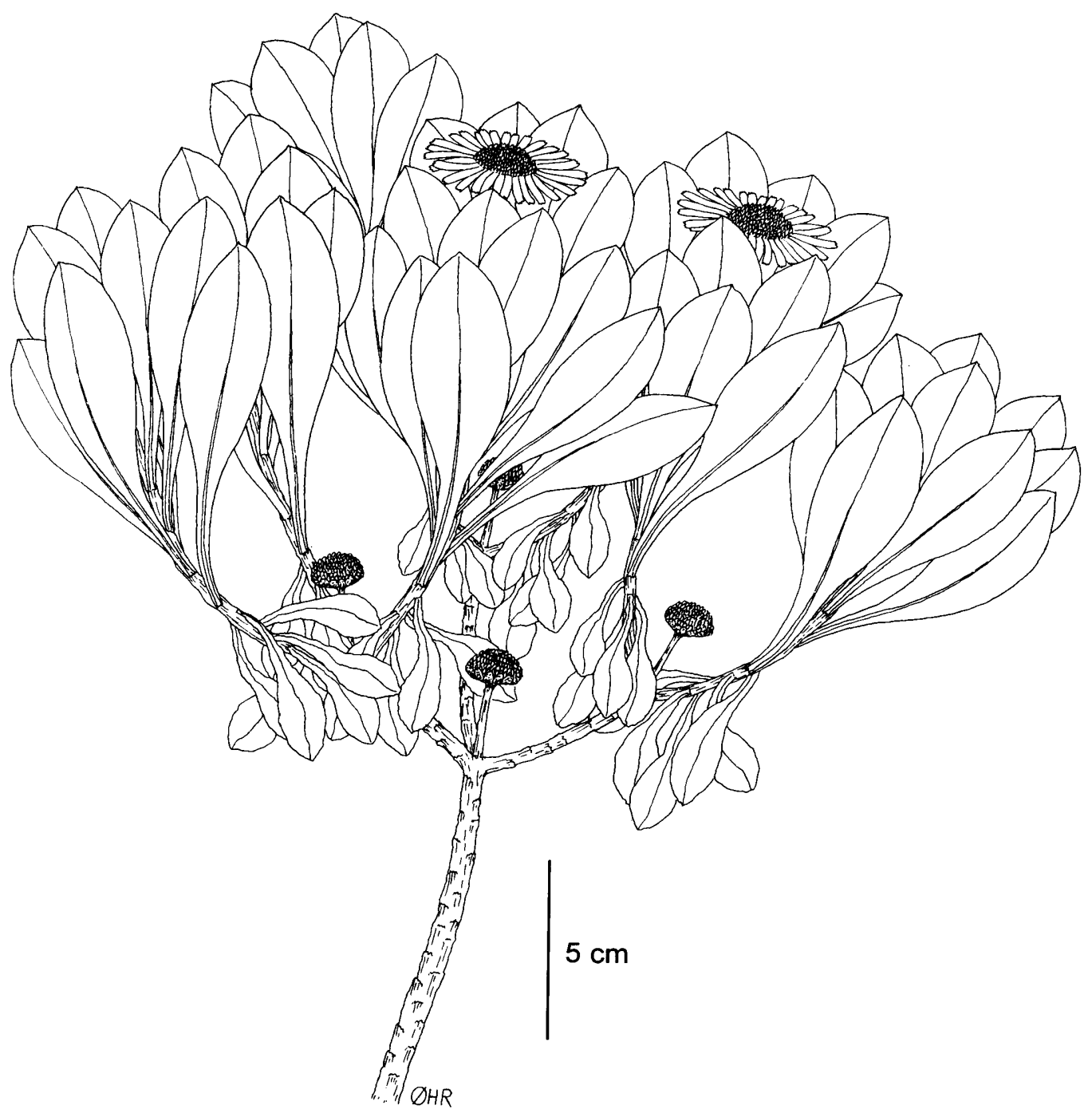

Fig. 64. Nauplius smithii. Drawn by $\varnothing$. H. Rustan. Reprinted from Halvorsen \& Borgen (1986), Sommerfeltia 3. 


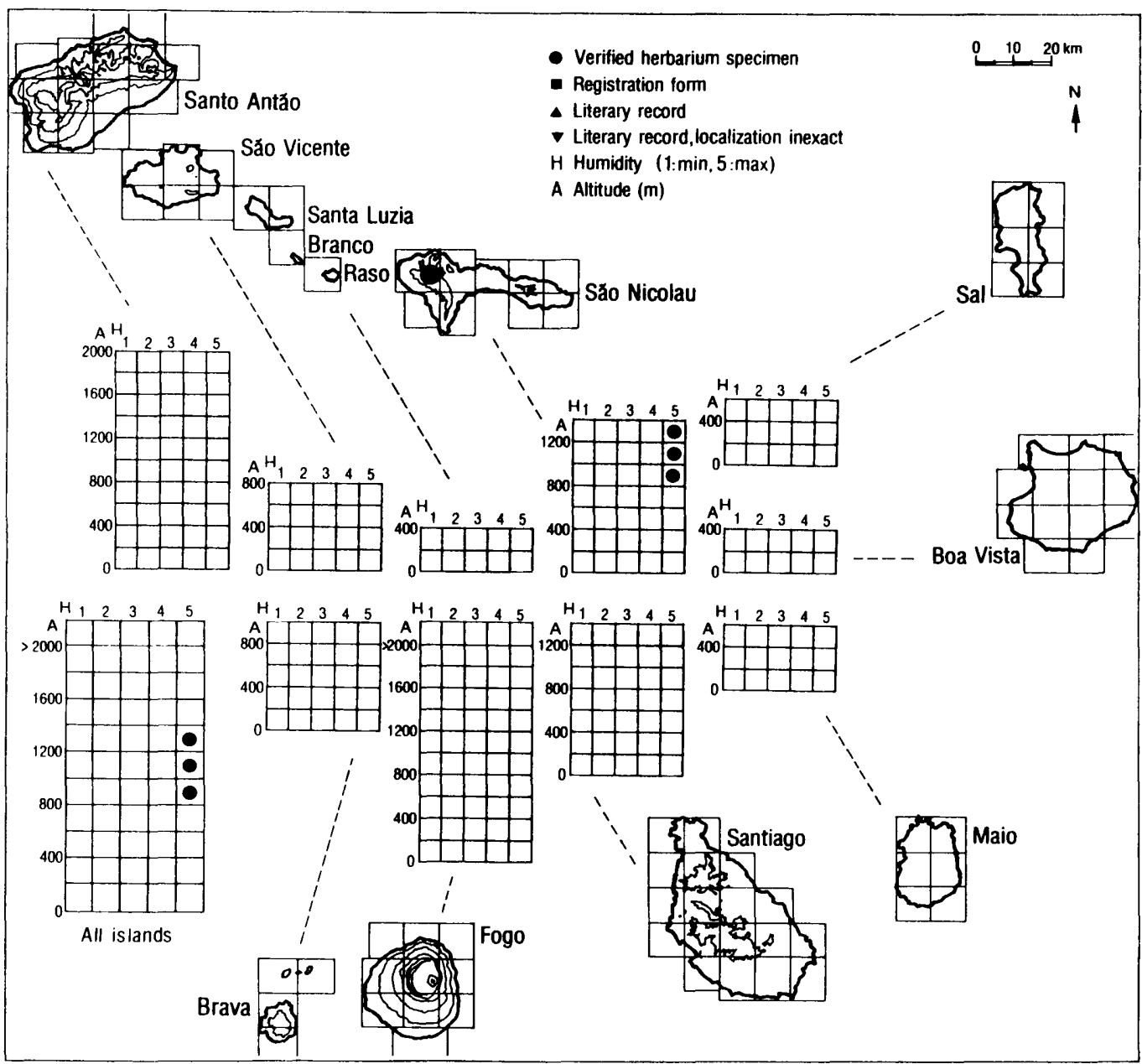

Fig. 65. Ecogeographic distribution of Nauplius smithii.

\section{Phagnalon Cass.}

The genus Phagnalon (tribe Inuleae) comprises some 40 species of herbs and dwarf shrubs distributed in Europe, N Africa, and SW Asia. One species is endemic to the Canary Islands, and one species is endemic to Madeira. In the Cape Verde Islands, the genus is represented by a single endemic species. 


\section{Phagnalon melanoleucum (Figs 66, 67)}

Phagnalon melanoleucum Webb in Hooker, Icon. Pl. 8: ad tab. 764 (1848). - Type: In Monte Verede, ins. S. Vincentii, ultra alt. 1000 ped. usque ad apicem, 6.1841 , Vogel $37(\mathrm{~K})$.

= Phagnalon luridum Webb in Hooker, Niger Fl.: 136 (1849) $\equiv$ Phagnalon melanoleucum Webb var. luridum (Webb) A. Chev., Rev. Bot. Appl. Agric. Trop. 15: 877 (1935). - Type: In Monte Verede, ins. S. Vincentii, ultra ad 1000 ped. 6.1841 , Vogel $51(\mathrm{~K})$.

Illustrations: Webb (1848: Fig. 764, 1849: Fig. 9), Gomes et al. (1995b: p. 13).

Description. Sparsely branched dwarf shrub up to $0.3 \mathrm{~m}$ high. Branches slender, whitish tomentose when young, glabrescent with age. Lower leaves broadly oblanceolate, acute, up to $4 \mathrm{~cm}$ long and $2.5 \mathrm{~cm}$ wide; upper leaves smaller and narrowly linear-oblanceolate; upper surface of lamina sparsely pubescent, lower surface densely whitish tomentose; margin shallowly sinuate-dentate to entire, usually revolute. Synflorescence terminal, loosely paniculate and leafy, with few to several capitules, overtopped by lower branches. Capitules funnel-shaped; involucre at anthesis up to $0.5 \mathrm{~mm}$ in diameter, later spreading; involucral bracts imbricate with blackish-purple to blackish scarious margin and tip. Flowers yellowish. apically often somewhat tinged with purple, tubular; outer flowers female, inner flowers hermaphrodite. Achenes oblong, up to $1.2 \mathrm{~mm}$ long, pubescent; pappus $4 \mathrm{~mm}$ long, consisting of few whitish rays.

Variation. The species is fairly homogeneous, mainly showing some variation in leaf size and habit. It varies from dense, dwarf-cushions less than $0.1 \mathrm{~m}$ high to rather open, spreading-erect shrublets up to $0.3 \mathrm{~m}$ high depending on the habitat.

Chromosome number: Unknown.

Related taxa. The species is possibly most closely related to P. umbelliforme DC. from the Canary Islands, but further investigations are necessary.

Distribution and ecology. Phagnalon melanoleucum is a western hygrophyte occurring on Santo Antão, São Vicente, São Nicolau, Santiago, and Fogo, but it is absent from Brava. It is equally frequent in the subhumid and humid zones, and it has only been reported twice from the semiarid zone. The main altitudinal distribution is between $800 \mathrm{~m}$ and $1800 \mathrm{~m}$, but on Fogo, the species is also frequent on the old crater rim above $2000 \mathrm{~m}$ (leg. Kilian \& Leyens) and on Pico Novo up to $2800 \mathrm{~m}$ (Lobin 1982c). The lowermost record is at $300 \mathrm{~m}$ on northwestern Santo Antão (Brochmann \& Rustan 1988). The plants usually grow in cliffs and on rocky ground.

Abundance. The species has recently been observed on all recorded islands. It is widespread and locally common on Santo Antão, Fogo, and São Nicolau, and less common on São Vicente and Santiago. Phagnalon melanoleucum is generally classified as Lower Risk (LR).

\section{Pulicaria Gaertn.}

The genus Pulicaria (tribe Inuleae) includes some 80 species distributed in Europe, Asia, N Africa, and subtropical NE Africa. The genus is recognized by achenes with a dimorphic pappus consisting of an outer corona of connate scales and an inner row of some barbellate bristles. The genus is represented by two endemic taxa of section Francoeuria in the Cape Verde Islands: one species and one subspecies of a non-endemic species. Re-evaluation of the 


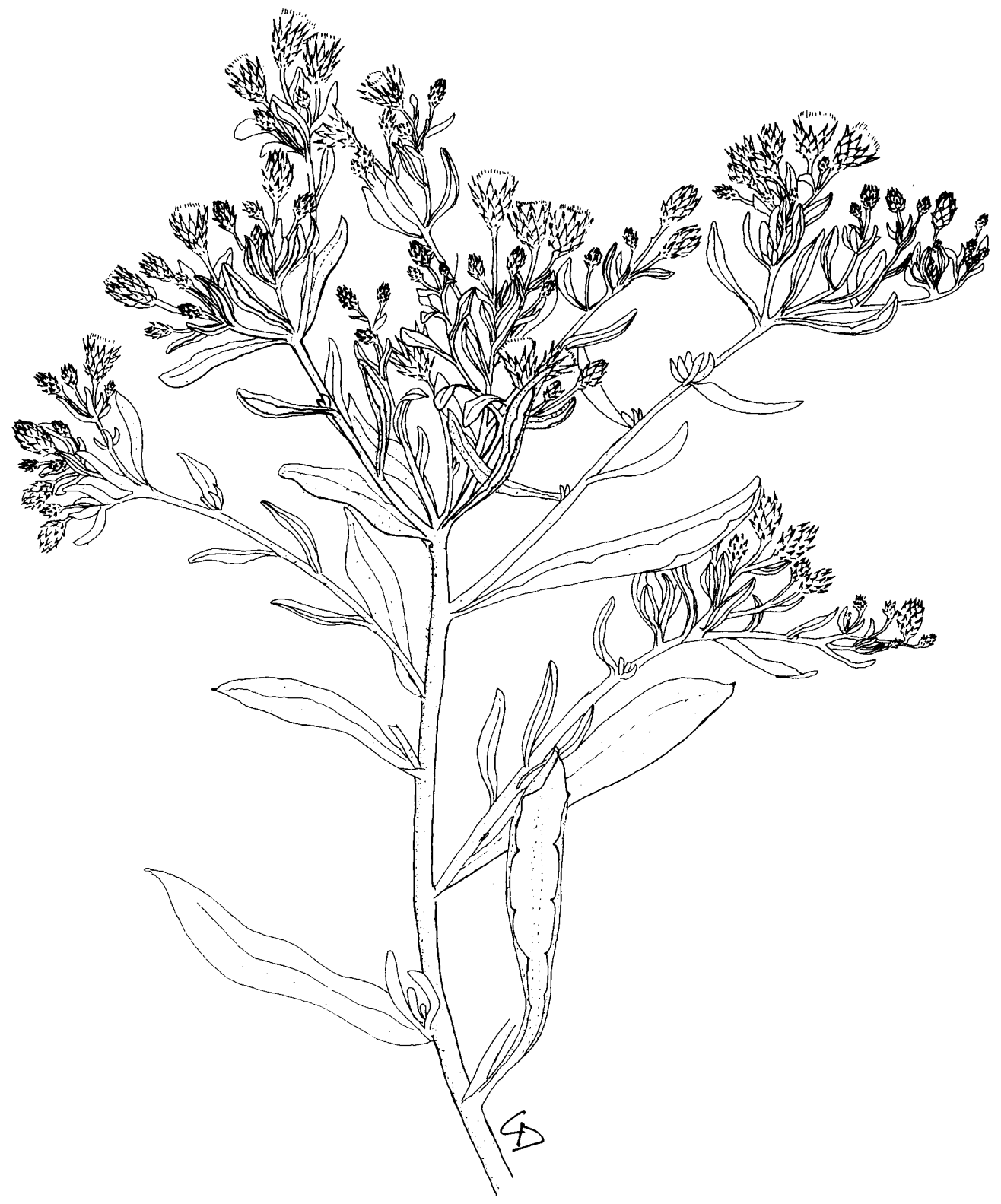

$1 \mathrm{~mm}$

Fig. 66. Phagnalon melanoleucum. Drawn by C. Dervin. 


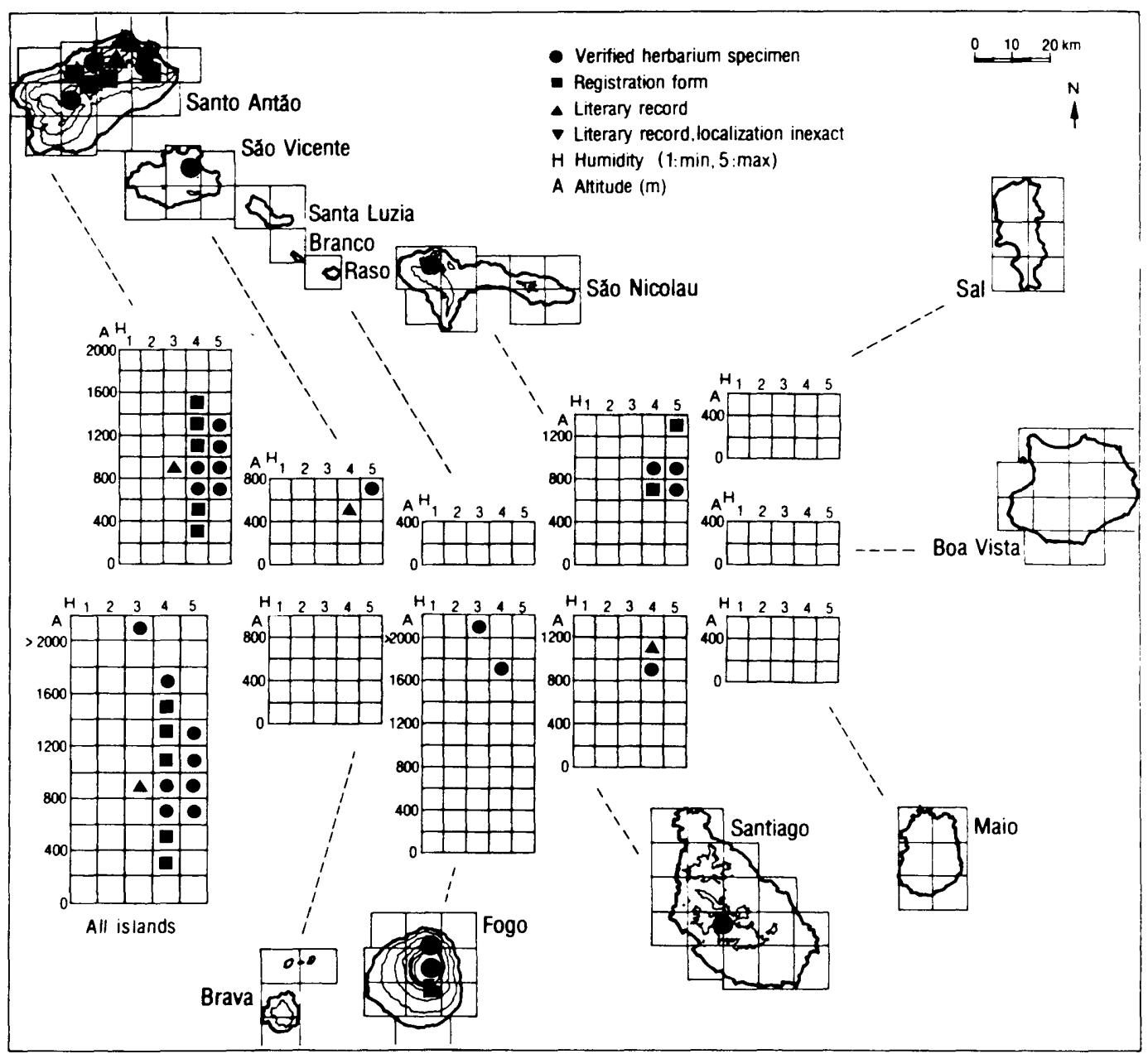

Fig. 67. Ecogeographic distribution of Phagnalon melanoleucum.

material revealed that a third endemic taxon, $P$. undulata ssp. fogensis, described by GamalEldin (1981), is not different from Pulicaria diffusa (see note under this species).

Literature: Gamal-Eldin (1981).

Key to the genus Pulicaria

1 Middle cauline leaves up to $0.5 \mathrm{~cm}$ wide; involucre base distinctly white-tomentose; achene with scattered hairs; outer, corona-like pappus $0.2-0.3 \mathrm{~mm}$ long, inner pappus of 10-15 setae.

$P$. burchardii ssp. longifolia

1 Middle cauline leaves up to $2 \mathrm{~cm}$ wide; involucre base scarcely white-tomentose; achene entirely glabrous; outer pappus $0.4-0.5 \mathrm{~mm}$ long, inner pappus of 7-9 setae. P. diffusa 


\section{Pulicaria burchardii}

Pulicaria burchardii Hutch. in Hooker, Icon. Pl. 31: ad tab. 3056 (1916). - Type: Canary Islands, Fuerteventura, near Handia, Burchard (holotype: K).

Description. Herbaceous to basally woody, procumbent to ascending-erect, whitish to greyish-whitish-tomentose perennial, glabrescent with age, up to $0.3 \mathrm{~m}$ high. Leaves entire, narrowly spathulate to more or less linear, middle cauline leaves up to $6 \mathrm{~cm}$ long and $0.5 \mathrm{~cm}$ wide, with attenuate, semiamplexicaule base, apex rounded. Capitules terminal, solitary, globose; involucre $1.5 \mathrm{~cm}$ in diameter, basally or almost entirely whitish tomentose, with linear involucral bracts. Flowers yellow, outer ones female, ligulate, inner ones hermaphrodite, tubular. Achenes 1-1.5 mm long, more or less cylindrical, 5-ribbed, pale brown, surface with scattered, spreading hairs; pappus consisting of an outer, scaly corona $0.2-0.35 \mathrm{~mm}$ long, and an inner pappus of 10-20 setae, $2-4 \mathrm{~mm}$ long.

Note. Pulicaria burchardii is distributed in coastal, NW Saharian Africa and on the easternmost islands of the Canarian and Capeverdean archipelagos. Two geographically separated subspecies of $P$. burchardii were recognized by Gamal-Eldin (1981), mainly differing in pappus and leaf characters. The typical subspecies is only known from Fuerteventura in the Canary Islands and adjacent coasts of the African mainland (SW Morocco and Western Sahara). This subspecies is characterized by middle cauline leaves that are 1.2-2.0 $\mathrm{cm}$ long and at most $2.5 \mathrm{~mm}$ wide, and by an inner and an outer pappus that are free from each other and fall off separately. The Capeverdean endemic, ssp. longifolia, is characterized by middle cauline leaves that are $4.5-6.0 \mathrm{~cm}$ long and up to $0.5 \mathrm{~cm}$ wide, and by an inner and an outer pappus that are basally connate and fall off together.

\section{Pulicaria burchardii ssp. longifolia (Figs 68, 69)}

Pulicaria burchardii Hutch. ssp. longifolia Gamal-Eldin, Phanerogam. Monogr. 14: 283 (1981). - Type: Sal. Sta. Maria, Dünen bei den Salzpfannen, mit vielen eingestreuten Korallenblöcken, 19.10.1934, Dinklage 3186 (holotype: BM!).

Illustration: Gamal-Eldin (1981: Fig. 223a, b).

Description. Perennial herb or subshrub with ascending-erect, rarely procumbent branches. Branches leafy, leaves and branches whitish tomentose, glabrescent with age. Involucre basally whitish tomentose. Achenes $1.0 \mathrm{~mm}$ long; pappus with an outer, scaly corona $0.2-0.3$ $\mathrm{mm}$ long and an inner pappus of 10-15 setae, 3-4 mm long; corona and setae basally connate, falling off together.

Variation. The small sample of a few specimens studied of this extremely rare taxon is homogeneous with respect to the diagnostic characters. Living plants have not been seen by us.

Chromosome number: Unknown. $2 \mathrm{n}=18$ has been reported for the typical subspecies (Canary Islands, Febles \& Ortega 1982).

Distribution and ecology. Pulicaria burchardii ssp. longifolia is an eastern xerophyte restricted to Sal. The only known locality is situated in the extremely arid zone between sealevel and $10 \mathrm{~m}$, where it was reported from coastal sand dunes at the salt pans near Santa Maria (Gamal-Eldin 1981). 


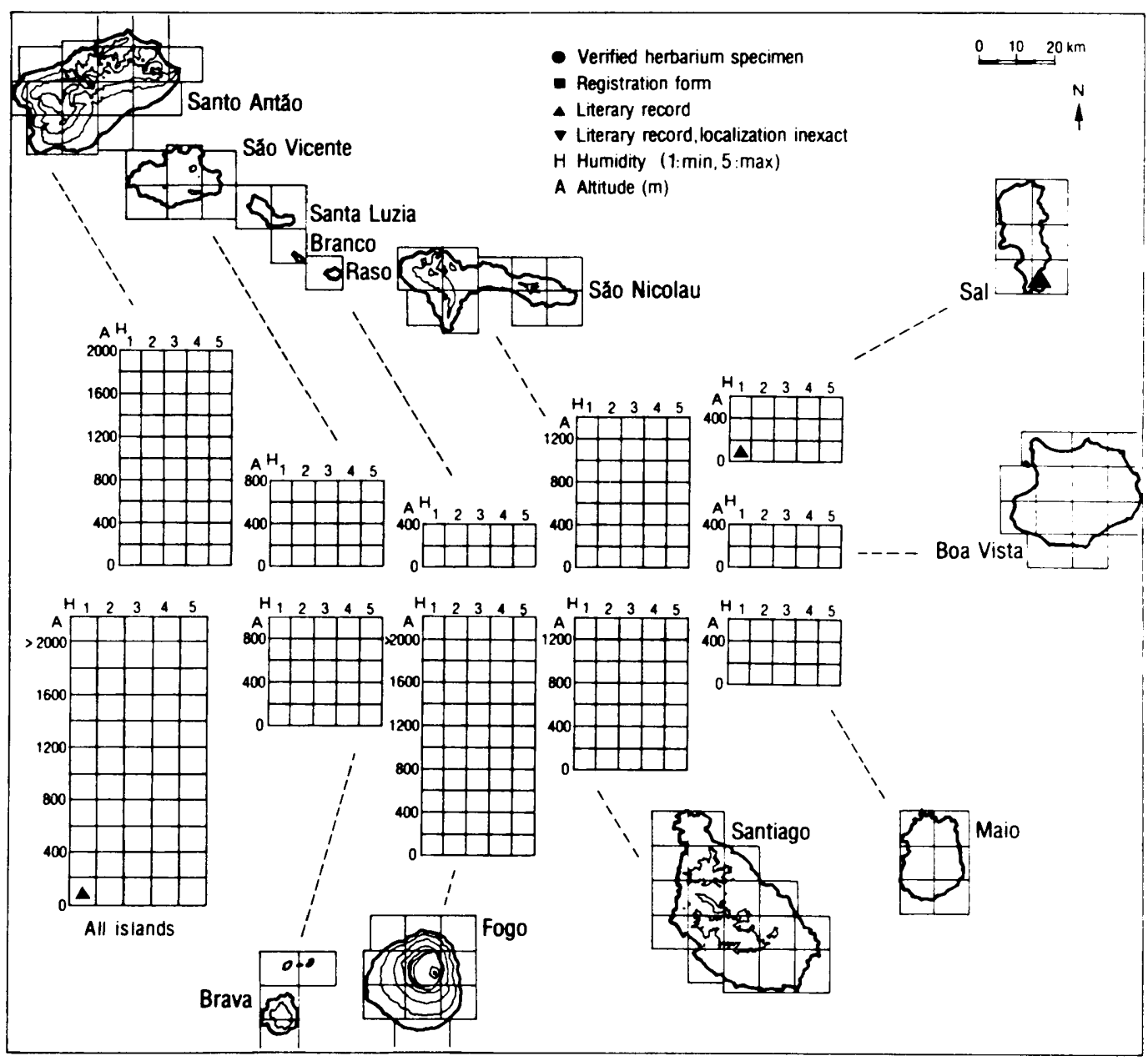

Fig. 68. Ecogeographic distribution of Pulicaria burchardii ssp. longifolia.

Abundance. Only three collections are known with certainty, possibly from the same site: 1851 (Sal, without locality, leg. Schmidt, HBG!), $1851 / 52$ (Sal, without locality, leg. Bolle, FI-W), 1934 (Sal, near Santa Maria, leg. Dinklage, type collection at BM!). The Santa Maria area is well explored, and many collections including $P$. diffusa have recently been made in this area. Recent attempts to find P. burchardii ssp. longifolia have failed, but it cannot be excluded that the species has been overlooked. Pulicaria burchardii ssp. longifolia is considered to be Data Deficient (DD). 


\section{Pulicaria diffusa (Figs 69, 70)}

Pulicaria diffusa (Shuttlew.) Pett., Comm. Biol. Soc. Scient. Fenn. 22: 58 (1960) $\equiv$ Francoeuria diffusa Shuttlew., Flora 23, Beibl. 1: 72 (1840). - Type: Provenit magna copia in lapidosis ins. Sal, Brunner (holotype: FI-W).

$=$ Pulicaria crispa (Forssk.) Benth. ex Oliv. ssp. fogensis Gamal-Eldin, Phanerogam. Monogr. 14: 270 (1981) $\equiv$ Pulicaria undulata L. ssp. fogensis (Gamal-Eldin) A. Hansen \& Sunding, Sommerfeltia 1: 6 (1985). Type: Fogo, dry bed of a Rib ${ }^{\mathrm{a}}$ between S. Laurenço \& the town, 24.3.1864, Lowe (holotype: BM No. 40542!, isotype: BM No. 40451!).

Illustrations: Gamal-Eldin (1981: Fig. 203), Gomes et al. (1995b: p. 13).

Note. The collecting date of the type collection of P. crispa ssp. fogensis Gamal-Eldin is erroneously quoted in the protologue as "28.V.1875", which actually is the acquisition date of the herbarium Lowe in BM; on both sheets of the type collection the collecting date is given on Lowe's original label as "M[ar]ch 24th [18]64".

Description. Procumbent to ascending perennial herb or ascending to erect subshrub; branches leafy, leaves and branches whitish tomentose, glabrescent with age. Middle cauline leaves (narrowly) spathulate, up to $9 \mathrm{~cm}$ long and $2 \mathrm{~cm}$ wide, with somewhat enlarged, almost sheathing, semiamplexicaule base; apex rounded; margin irregularly crenate or dentate to crenulate or denticulate and usually somewhat undulate. Capitules terminal, solitary, globose. Involucre scarcely tomentose even at base, up to $1.5 \mathrm{~cm}$ in diameter, involucral bracts linear. Flowers yellow; outer flowers female, ligulate; inner flowers hermaphrodite, tubular. Achenes 0.6-1.0 mm long, glabrous; pappus deciduous, consisting of an outer, scaly corona, 0.4-0.5 $\mathrm{mm}$ long, and an inner pappus of 7-9 setae, $2-3 \mathrm{~mm}$ long, both basally connate, falling off together.

Variation. Pulicaria diffusa flowers already in the first year when the plants still are entirely herbaceous. Leaf size and density of the tomentose indument vary considerably, and this variation seems to be related to the habitat. Plants on cultivated and irrigated land (Sal, Terra Boa, leg. Sunding), for example, have well-developed, long stems with glabrescent cauline leaves up to $6 \mathrm{~cm}$ long and $2 \mathrm{~cm}$ wide, whereas a plant from the arid coast of the same island (leg. Sunding) is compact with very short, lignified flowering axes, leaves with a more persisting indument, not exceeding $3 \mathrm{~cm}$ in length and $0.5 \mathrm{~cm}$ in width (most leaves only $0.2-$ $0.3 \mathrm{~cm}$ wide).

Chromosome number: Unknown.

Related taxa. Pulicaria diffusa is most closely related to P. undulata L. (= P. crispa (Forssk.) Benth. ex Oliv.), a variable, widespread and mainly Saharo-Arabian/Sudanian species, of which four subspecies (excluding ssp. fogensis) were recognized by Gamal-Eldin (1981). Pulicaria diffusa is very similar to the Sudanian P. crispa (= undulata) ssp. argyrophylla Gamal-Eldin, and we are in doubt if $P$. diffusa actually is specifically distinct from $P$. undulata. It is possible that a subspecific rank within the latter species is more appropriate for the Capeverdean taxon, but more material from the Sudanian region needs to be examined.

Distribution and ecology. Pulicaria diffusa is a ubiquitous xerophyte, so far recorded from the eastern desert islands of Sal, Boa Vista, and Maio as well as from the southern islands of Santiago and Fogo. It occurs in the arid and extremely arid zones, mainly between sea level and $50 \mathrm{~m}$. The species has been found up to $370 \mathrm{~m}$ at Monte Grande on Sal (obs. Lobin) and somewhere between $100-400 \mathrm{~m}$ in the arid zone of western Fogo. Pulicaria diffusa 


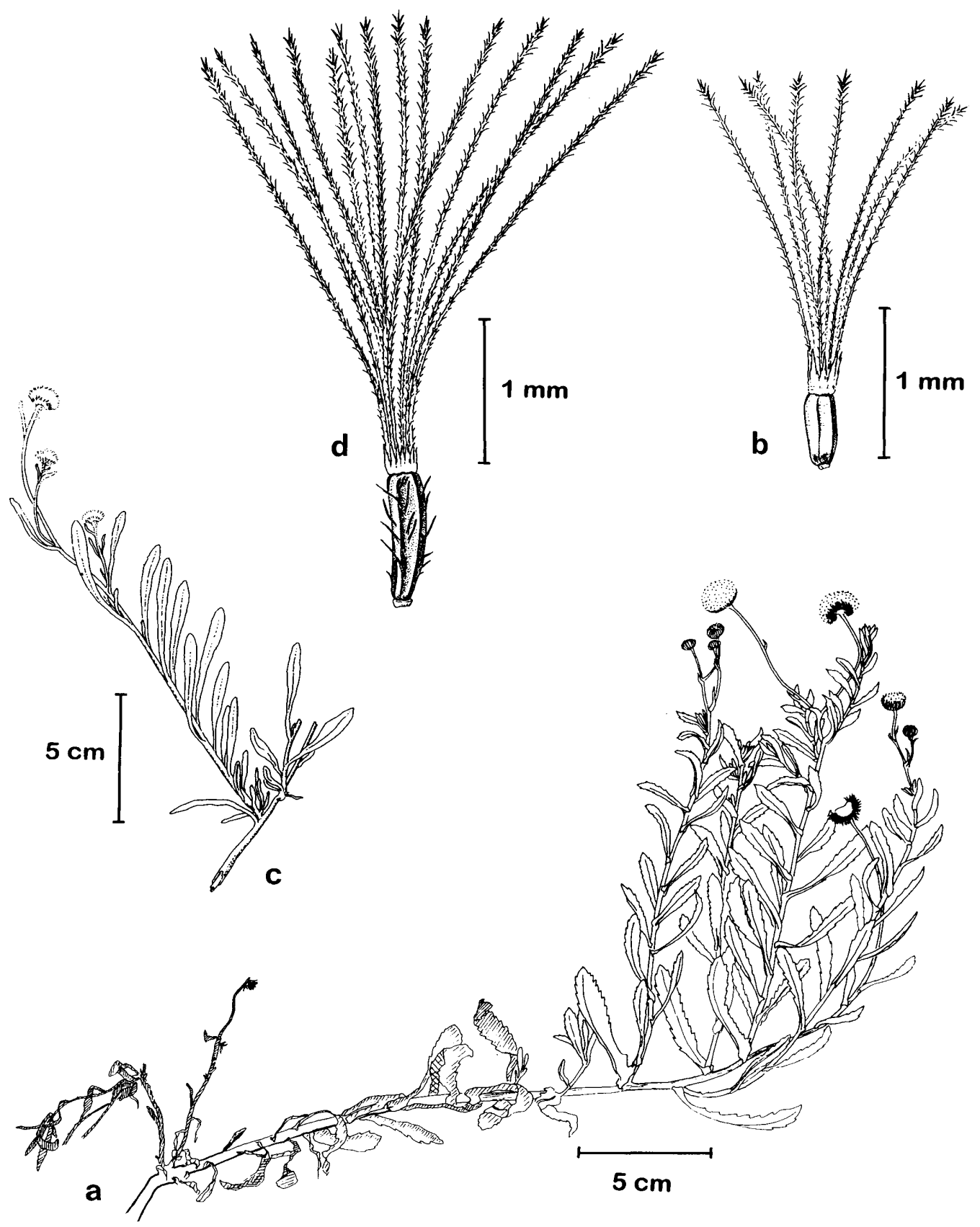

Fig. 69. Pulicaria diffusa and P. burchardii ssp. longifolia. a. P. diffusa, flowering branch; b. $P$. diffusa, achene; c. $P$. burchardii ssp. longifolia, flowering branch; d. P. burchardii ssp. longifolia, achene. Drawn by C. Dervin (a) and M. Rodewald (b-d). 


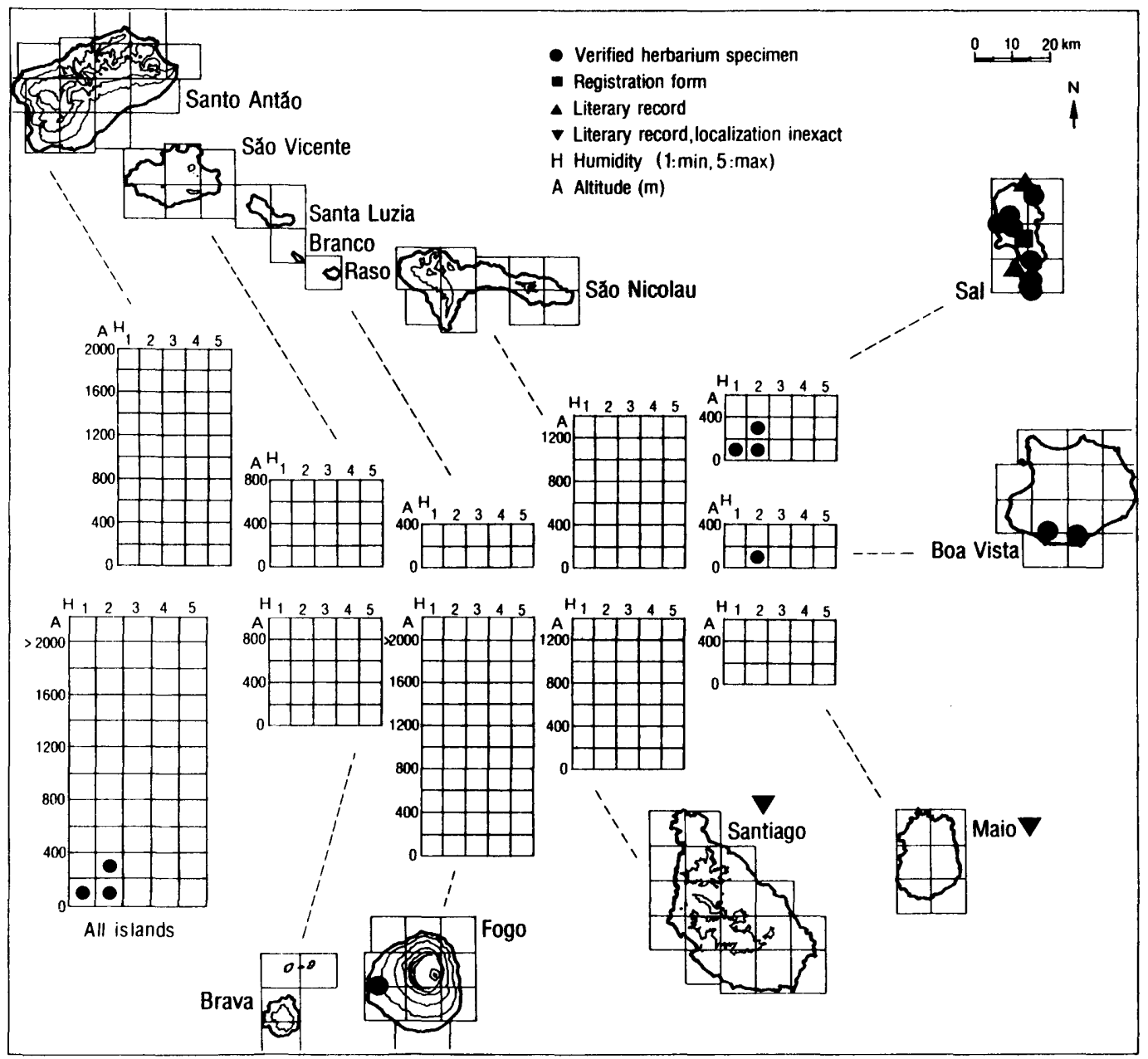

Fig. 70. Ecogeographic distribution of Pulicaria diffusa.

grows mainly in stony, gravelly, and sandy habitats such as depressions, furrows, and stream beds, and also in cultivated land.

Abundance. The species has been recorded several times from Sal and Boa Vista after 1970. Several large populations are known on Sal. It is, however, strongly declining on Boa Vista because of goat grazing, and it is Vulnerable (VU) on this island. On Maio, it was recorded as frequent by Schmidt (1852) and Chevalier (1935a), but it has never been recollected and considered to be Extinct (EX) on this island. It is also considered Extinct (EX) on Fogo, where the only collection dates from 1864 (the type of P. crispa ssp. fogensis, see above). On Santiago, $P$. diffusa has only been found once (at "Figuirinha" in 1970; Sventenius 1971), and it is classified as Prolonged Absence (PA) on this island. Pulicaria diffusa is generally considered to be Vulnerable (VU). 
Note. We found that $P$. crispa ssp. fogensis Gamal-Eldin, based on the only Pulicaria collection so far known from Fogo, did not differ from Pulicaria diffusa in any respect. The leaf shape, structure of the involucre, as well as achene and pappus morphology of the plant from Fogo are within the variation range observed in $P$. diffusa. In particular, we could not confirm Gamal-Eldin's (1981) measurements of the outer pappus ( $0.8 \mathrm{~mm}$ long) and the inner pappus (3.5-4 mm long) in the plant from Fogo versus $0.4-0.5 \mathrm{~mm}$ and $2-3 \mathrm{~mm}$, respectively. in $P$. diffusa.

\section{Sonchus L.}

Depending on its delimitation, the genus Sonchus (tribe Lactuceae) includes 60-70 species, widely distributed in Europe, Asia, N America, Africa, and Australia. Some species are cosmopolitan weeds. In the Cape Verde Islands, the genus is represented by a single endemic species of subgenus Dendrosonchus, which is a group of rosette shrubs confined to the Canary Islands, Madeira, and the Cape Verde Islands. In addition, the annual, cosmopolitan weed $S$. oleraceus L. occurs in the Cape Verde Islands.

\section{Sonchus daltonii (Figs 71, 72)}

Sonchus daltonii Webb in Hooker, Icon. Pl. 8: ad tab. 765 (1848). - Syntypes: S. Jacobi, in cacumine collis abrupti alt. 1500 ped. in valle S. Dominici, 11.1839, J. D. Hooker 199; S. Vincente, ad apicem Montis Verede, 6.1841, Vogel. - Lectotype (designated by Boulos 1974: 13): [unlabelled specimen ex herb. Hooker, the single specimen extant] (K!).

Illustrations: Webb (1848: Fig. 765, 1849: Fig. 10), Boulos (1974: Fig. 7), Lobin (1986b: Fig. 32), Kilian (1988: Figs 31, 32, 34), Gomes et al. (1995b: p. 14).

Literature: Boulos (1974), Aldridge (1976a, 1976b, 1977, 1979), Kilian (1988).

Description. Erect rosette shrub with milky latex in all parts, flowering up to $0.7(-1.5) \mathrm{m}$ high, with sparsely branched woody caudex up to $5 \mathrm{~cm}$ in diameter, terminated by a few, large leaf rosettes. Synflorescence stem stout, leafy, including synflorescence up to $0.5 \mathrm{~m}$ long. Caudex and synflorescence stem with white medulla. Rosette leaves elliptical to narrowly spathulate in outline, up to $50 \mathrm{~cm}$ long and $12.5 \mathrm{~cm}$ wide, pinnatifid with (3-)5-10 pairs of triangular to rounded segments; cauline leaves broadly lanceolate, pinnatifid to entire, with roundish auriculate base, smaller than rosette leaves and upwards reduced to bracts. Synflorescence umbellate-paniculate with (5-)10-20(-50) capitules. Capitules subglobose, up to $4 \mathrm{~cm}$ in diameter, with up to 580 yellow, 5-toothed-ligulate, hermaphrodite flowers. Achenes 2.5-3.1 mm long, transversely wrinkled, compressed, brown; pappus 10-12 mm long, subdeciduous, with numerous downy rays and 10-15 thicker rays.

Variation. The species is distinct and homogeneous, only showing some variation in size, number of leaf lobes, and leaf incision. Exceptionally large individuals occur in the humid Monte Velha area on Fogo.

Chromosome number: $2 \mathrm{n}=18(2 \mathrm{n}=18$, Fogo, without locality; $2 \mathrm{n}=18$, Santo Antão, Ribeira do Paul, 1200 m, Kilian 1988).

Related taxa. Sonchus daltonii is closely related to $S$. congestus Willd. from Tenerife and Gran Canaria (Aldridge 1976a, 1976b, Boulos 1972, 1974). 


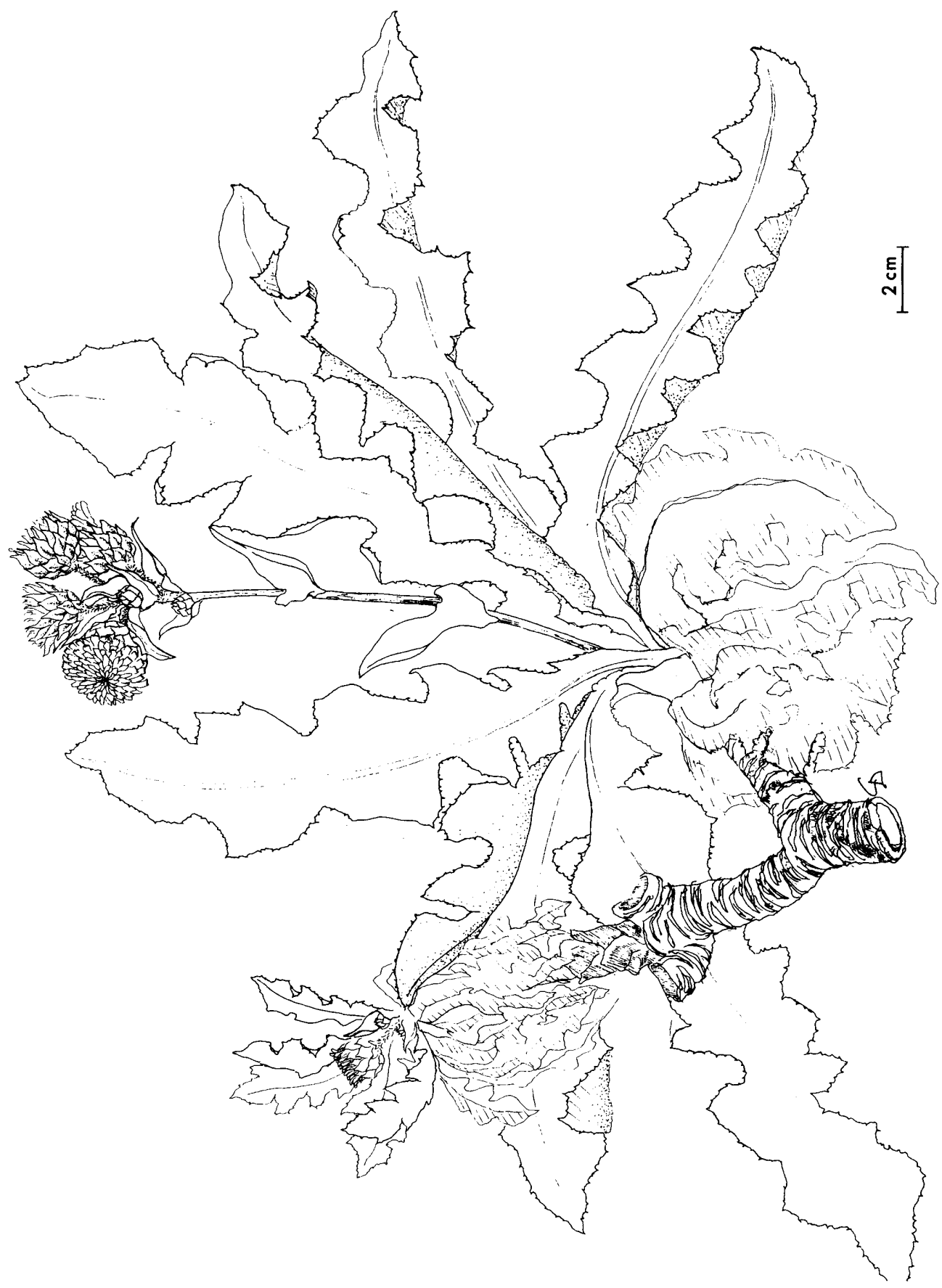

Fig. 71. Sonchus daltonii. Drawn by C. Dervin. 


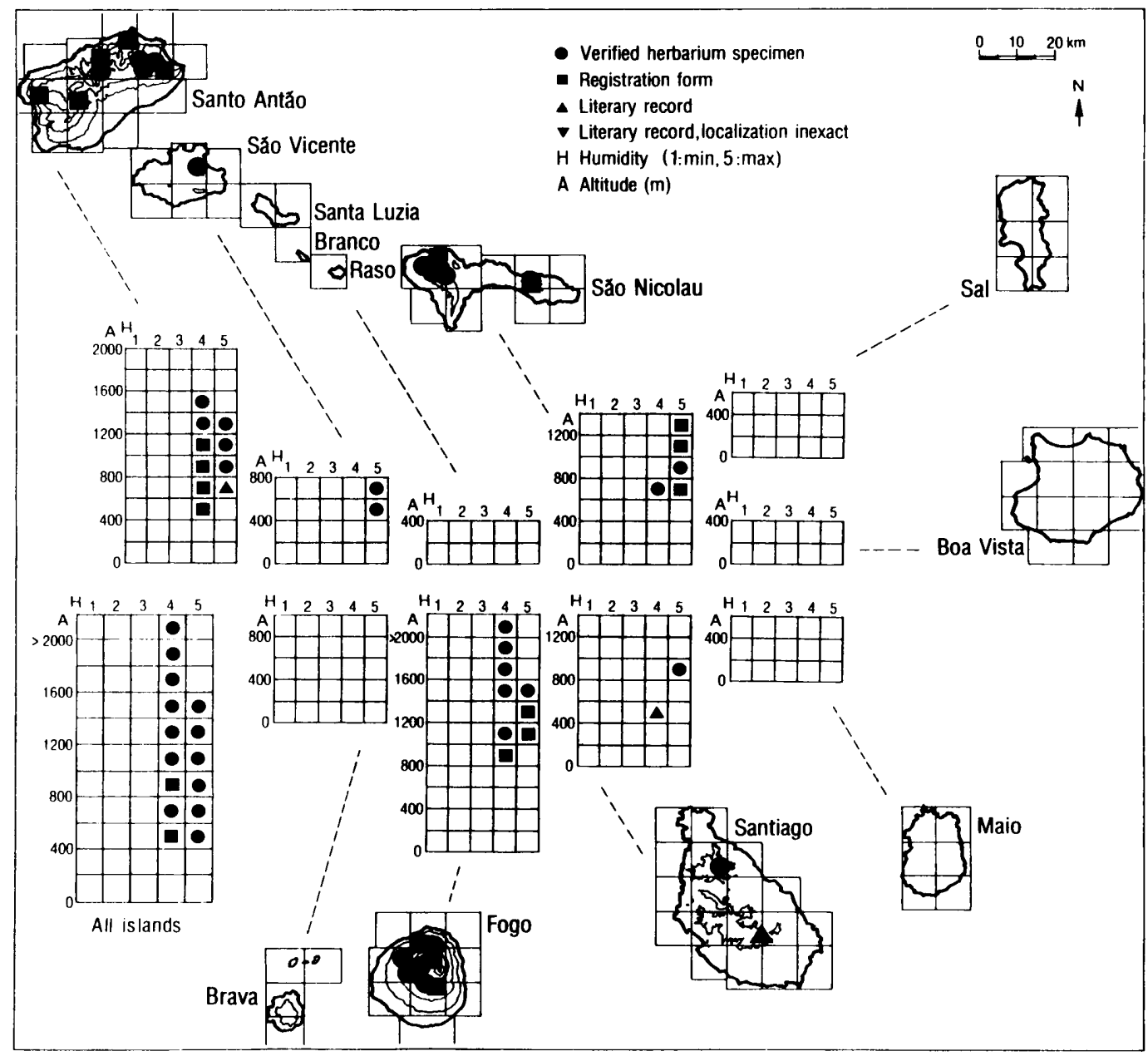

Fig. 72. Ecogeographic distribution of Sonchus daltonii.

Distribution and ecology. Sonchus daltonii is a western hygrophyte recorded from Santo Antão, São Vicente, São Nicolau, Santiago, and Fogo, but it is absent from Brava. It is equally frequent in the subhumid and humid zones, mainly between $800 \mathrm{~m}$ and $1800 \mathrm{~m}$. The lowermost records are at $450 \mathrm{~m}$ on Santo Antão (obs. Kilian), at $500 \mathrm{~m}$ on Santiago (leg. Hooker) and at $550 \mathrm{~m}$ on São Vicente (leg. Sunding). The uppermost record is at $2200 \mathrm{~m}$ on Fogo (leg. Kilian). Sonchus daltonii is a typical cliff species, mainly growing in steep, moist, north- to northeast-exposed bluffs together with, i.a., Aeonium gorgoneum, Campanula spp., Lotus spp., Phagnalon melanoleucum, and Tolpis farinulosa.

Abundance. The species has been collected or observed on all recorded islands after 1970. However, plants with a woody caudex are rare today because the species is a favourite livestock fodder and widely collected. The species is widespread on Santo Antão and Fogo, 
but some of the populations are small. On São Nicolau, the populations are small and scattered, and the species is considered Vulnerable (VU) on this island. On São Vicente, the species is represented by a single population at Monte Verde; this population comprised only six plants in 1995 (Gomes et al. 1995a). On Santiago, a single population was recorded in 1839 (leg. Hooker) at $500 \mathrm{~m}$ in Ribeira de São Domingos; this population is probably extinct. A second population with about 20 plants was recently discovered in the northern mountain range on Santiago (Serra da Malagueta; Gomes et al. 1995a). Sonchus daltonii is Critically Endangered (CR) on both São Vicente and Santiago, but it is generally considered to be Indeterminate $(\mathrm{I})$ at present.

\section{Tolpis Adans.}

The genus Tolpis (tribe Lactuceae) comprises almost 20 species, mainly distributed in the Mediterranean and the Mid-Atlantic archipelagos. In the Cape Verde Islands, the genus is represented by a single, endemic species.

\section{Tolpis farinulosa (Figs 73, 74)}

Tolpis farinulosa (Webb) J. A. Schmidt, Beitr. Fl. Cap Verd. Ins.: 202 (Jan. 1852) ESchmidtia farinulosa Webb in Hooker, Niger Fl.: 143 (1849). — Type: St. Vincent, nahe der Spitze des Mont Verede, 6.1841, Vogel 53 (holotype: $\mathrm{K} !)$.

$=$ Tolpis glandulifera Bolle, Bonplandia 7: 298 (1859). - Syntypes: In insulae S. Antonii jugis altissimis, loco dicto Bordeiras, 11.1852, Bolle (B, destroyed); in Bravae monte Coroada Terra, 12.1852, Bolle (B, destroyed).

Illustrations: Jarvis (1984: Fig. 1), Kilian (1988: Figs 37, 38), Gomes et al. (1995b: p. 14).

Literature: Jarvis (1984), Kilian (1988).

Description. Perennial with milky latex in all parts, flowering up to $0.7 \mathrm{~m}$ high, with woody, scarcely branched, erect caudex up to $20 \mathrm{~cm}$ high and with 1-2 terminal leaf rosettes. Rosette leaves up to $20 \mathrm{~cm}$ long and $6 \mathrm{~cm}$ wide, narrowly elliptical to spathulate in outline, shallowly sinuate-dentate to deeply pinnatifid, glabrous to somewhat pubescent; tooth tips of leaf margin with a black papilla. Synflorescence stem leafless with several branches: synflorescence loosely paniculate. Capitules with (25-)45-95 yellow, 5-toothed-ligulate, hermaphrodite flowers; involucre at anthesis up to $7 \mathrm{~mm}$ long and $3.5 \mathrm{~mm}$ in diameter, later spreading. Achenes 1.1-1.5 mm long, glabrous, black; pappus with a corona of scales $0.1 \mathrm{~mm}$ long and 2-12 fragile setae, 2.4-3.5 mm long.

Variation. The species is polymorphic, especially in leaf characters. Most specimens have sinuate-dentate leaves with teeth of variable size, but the leaves are deeply pinnatifid in some plants. However, such variation has been observed even within local populations. The species is most variable on Fogo. The number of pappus setae in plants from the northern islands is usually 2-6, whereas plants from the southern islands have (6-)8-12 pappus setae.

Chromosome number: $2 \mathrm{n}=18$ (Fogo, Monte Velha, $1500 \mathrm{~m}$, Kilian 1988).

Related taxa. Tolpis farinulosa is most closely related to the Canarian $T$. laciniata (Sch. Bip. ex Webb \& Berth.) Webb (Jarvis 1984).

Distribution and ecology. Tolpis farinulosa is a western hygrophyte occurring on Santo Antão, São Vicente, Fogo, and Brava. It is equally frequent in the subhumid and humid 


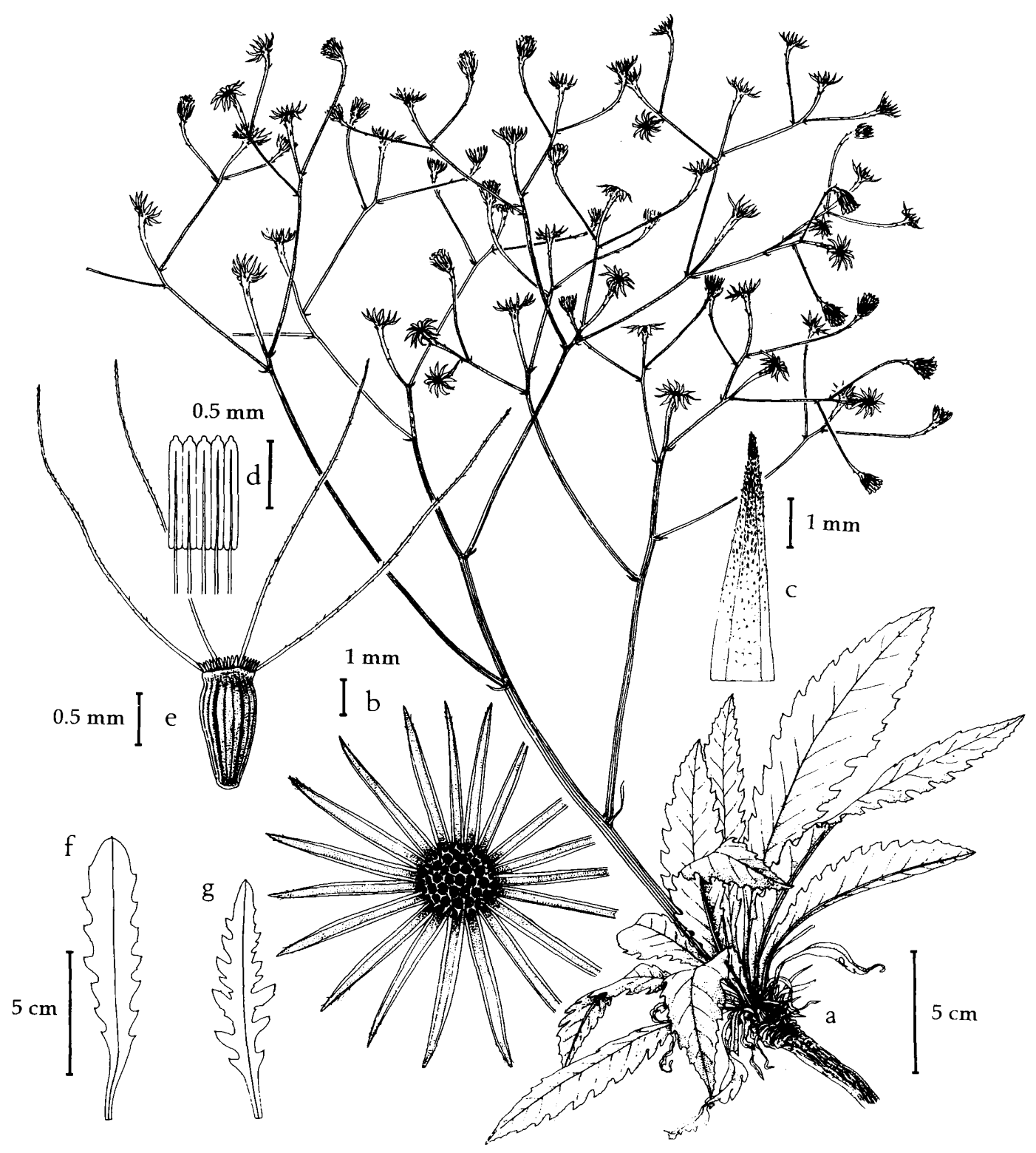

Fig. 73. Tolpis farinulosa. a. Habit; b. Receptacle after achene dispersal showing alveoli; c. Involucral bract; d. Anthers; e. Achene; f-g. Leaves. Drawn by M. Tebby. Reprinted from Jarvis (1984), Cour. Forsch.-Inst. Senckenberg 68 (with permission). 


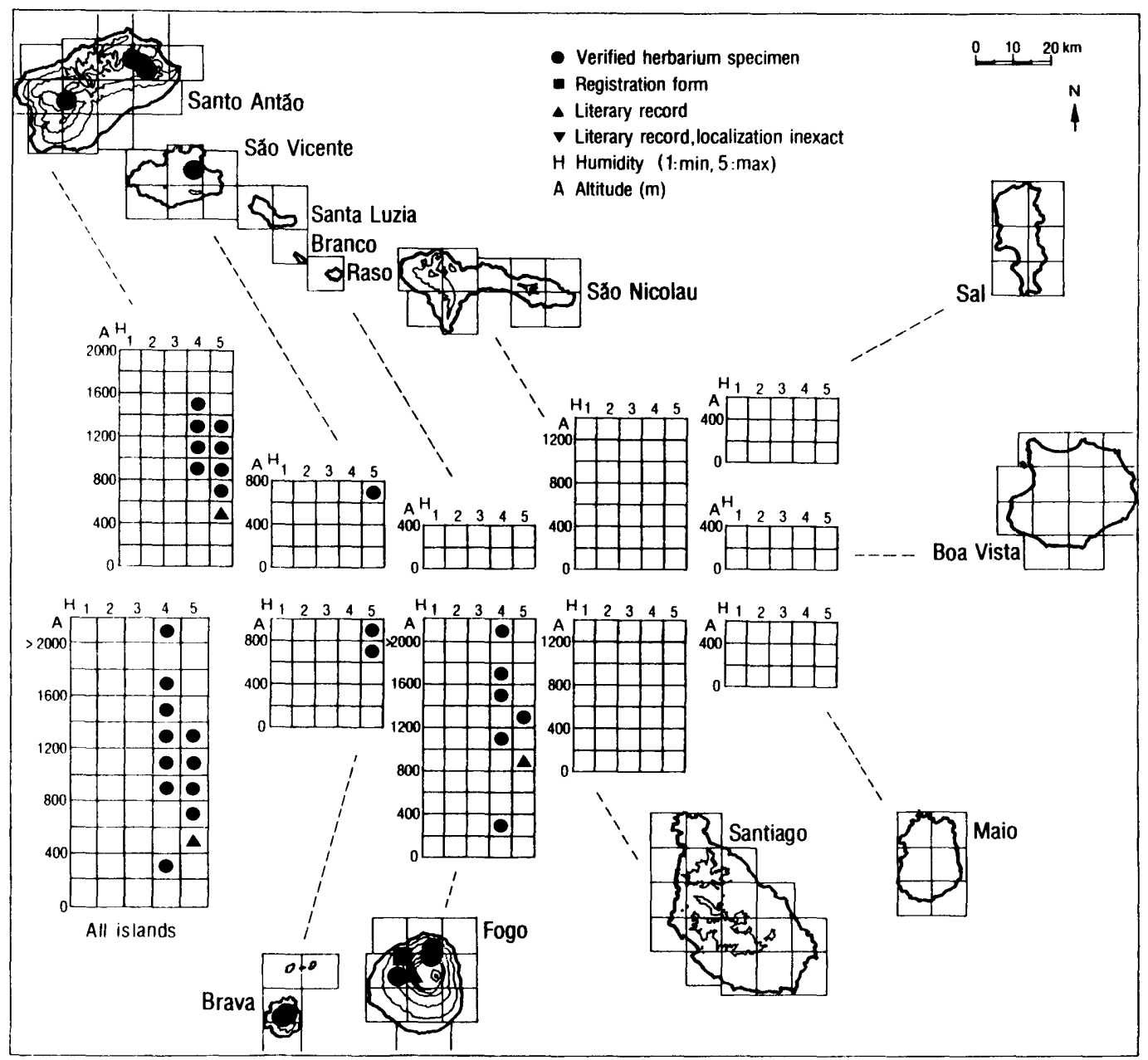

Fig. 74. Ecogeographic distribution of Tolpis farinulosa.

zones, mainly between $800 \mathrm{~m}$ and $1800 \mathrm{~m}$. The species has only been found twice below 700 $\mathrm{m}$ (between $400 \mathrm{~m}$ and $600 \mathrm{~m}$ in Campo de Cão on Santo Antão, leg. Cardoso, and at $250 \mathrm{~m}$ in a ribeira on northern Fogo, leg. Lewejohann). The uppermost record is at $2500-2600 \mathrm{~m}$ on Fogo (leg. Kilian \& Leyens). The plants grow in moist north- to northeast-exposed cliffs, escarpments, and steep slopes.

Abundance. The species has been collected in all islands after 1970. Large, but only few populations are known on Santo Antão (the largest one in Ribeira da Torre), Fogo, and Brava. On São Vicente, a single population has been recorded at the top of Monte Verde; this population has not been observed since 1976 (leg. Sunding), and the species is classified as Prolonged Absence (PA) on this island. The species is Endangered (EN) on Brava, where the 
known populations are heavily grazed and confined to the most elevated, degraded slopes in the centre of the island. Tolpis farinulosa is generally classified as Indeterminate (I).

\section{BORAGINACEAE}

This family is represented by four genera with eight species. Four taxa belonging to the genus Echium are endemic.

\section{Echium L.}

The genus Echium comprises some 40 annual and perennial species distributed from W Asia to $\mathrm{S}$ Europe and the mid-Atlantic archipelagos. Approximately 28 taxa, some of them woody, have evolved by adaptive radiation in the mid-Atlantic archipelagos. In the Cape Verde Islands, the genus is represented by three endemic species, of which one has two subspecies. The three Capeverdean species were classified into three different sections by Bramwell (1972), suggesting that they have different Canarian species as their closest relatives and that they immigrated independently into the Cape Verde Islands. However, recent molecular analyses suggest that all Echium taxa that are endemic to the mid-Atlantic islands form a monophyletic group, and also that the Capeverdean taxa are most closely related to each other (Böhle et al. 1994, Böhle 1995). Thus, it is possible that the classification of the three Capeverdean species into three different sections rather reflects that there has been extensive parallel evolution in morphological characters among the mid-Atlantic archipelagos.

Literature: Bramwell (1972), Martins (1995).

Key to the genus Echium

1 Inflorescence lax, with a few lateral cymes and long internodes; corolla deep purplish-blue

Inflorescence a dense, ovate to subconical, thyrsoid panicle; corolla whitish to somewhat tinged with blue or pink

2 (1) Indument of large, rough-based trichomes; calyx segments ovate; corolla subsalveriform

E. stenosiphon ssp. stenosiphon

2 Indument of small, white, pustular-based trichomes; calyx segments narrowly lanceolate; corolla more or less campanulate E. stenosiphon ssp. lindbergii

3 (1) Leaves narrowly lanceolate, less than $2 \mathrm{~cm}$ wide, densely whitish hispid to sericeous with long pustular-based trichomes; corolla laterally somewhat compressed

E. vulcanorum

3 Leaves broadly lanceolate, $3-5 \mathrm{~cm}$ wide, densely greyish hispid with small pustular-based trichomes; corolla not laterally compressed 


\title{
Echium hypertropicum (Figs 75, 76)
}

\begin{abstract}
Echium hypertropicum Webb in Hooker, Niger Fl.: 155 (1849). - Type: "Capvert. Herbier rapporté du Portugal en 1808 par M. Geoffrey St. Hilaire" [1784-1787, Silva Feijão] (holotype: P).

= Echium hypertropicum Webb var. nudum Coincy, Bull. Herb. Boissier, ser. 2, 3: 497 (1903) [\$Echium nudum Lowe in sched., nom. ined.]. - Type: Brava, 28.3.1864, Lowe (holotype: P; isotype: K).

Illustrations: Chevalier (1935b: Tab. 7c), Lobin (1986b: Figs 15, 16), Rustan \& Brochmann (1993: Fig. 1), Gomes et al. (1995a: Fig. 2), Gomes et al. (1995b: p. 15).
\end{abstract}

Description. Strongly branched, compact, hemispherical shrub up to $2.5 \mathrm{~m}$ high; young branches densely pubescent, glabrescent with age. Leaves broadly lanceolate, up to $20 \mathrm{~cm}$ long and $5 \mathrm{~cm}$ wide, densely greyish hispid with small, pustular trichomes, apex obtuse to nearly acute, margin entire. Inflorescence a dense, ovoid, thyrsoid panicle. Calyx up to $6 \mathrm{~mm}$ long, lobes slightly unequal, densely hispid. Corolla white or pinkish, broadly funnel-shaped, not compressed laterally, lobes slightly unequal. Stamens exserted. Mericarps dark brown to blackish, tuberculate.

Variation. The species is distinct and uniform. Old plants up to $2.5 \mathrm{~m}$ high and with the typical hemispherical habit have become very rare. For a discussion of $E$. hypertropicum var. nudum Lowe ex Coincy, see Bramwell (1972: 103).

Chromosome number: Unknown.

Related taxa. Echium hypertropicum is probably most closely related to $E$. vulcanorum, but it differs from this species by its subglabrous branches and greyish, finely hispid leaves.

Distribution and ecology. Echium hypertropicum is a southern hygrophyte restricted to Santiago and Brava. The species has also been recorded from Santo Antão and Fogo, but these reports are most likely erroneous (cf. Gomes et al. 1995a). The species occurs in the humid and subhumid zones, mainly between $500 \mathrm{~m}$ and $900 \mathrm{~m}$. The lowermost records are at 200$360 \mathrm{~m}$ on Brava (Gomes et al. 1995a), the uppermost record is at $1100 \mathrm{~m}$ on Santiago (Sunding 1982). The plants grow in gravelly slopes in rocky areas.

Abundance. On Santiago, the species is very locally distributed in the two main mountain ranges, Serra do Pico da Antonia and Serra da Malagueta. Echium hypertropicum was an important component of the indigenous scrub vegetation, but it has severely declined because of extensive cutting (see also Chevalier 1935a). On Brava, only a few plants of $E$. hypertropicum have survived, and the species is Critically Endangered (CR) on this island. Echium hypertropicum is generally considered to be Endangered (EN).

\section{Echium stenosiphon}

Echium stenosiphon Webb in Hooker, Icon. PI. 8: ad tab. 772 (1848). - Syntypes: In insula S. Nicolai, 29.3.1822, Forbes $32(\mathrm{~K})$; in Monte Verede, ins. S. Vincentii ultra 1000 ped. alt., 6.1841, Vogel 81. Lectotype (designated by Bramwell 1972: 97): Forbes 32 (K).

Description. Moderately branched, ascending, lax shrub up to $1.3 \mathrm{~m}$ high. Stem brownish, nearly glabrous to hispid with white pustular trichomes. Leaves ovate to ovate-lanceolate, up to $10 \mathrm{~cm}$ long and $5 \mathrm{~cm}$ wide, indument variable, apex obtuse to acute, margin entire. Inflorescence lax with long internodes, few-flowered. Calyx up to $7 \mathrm{~mm}$ long, densely hispid. 


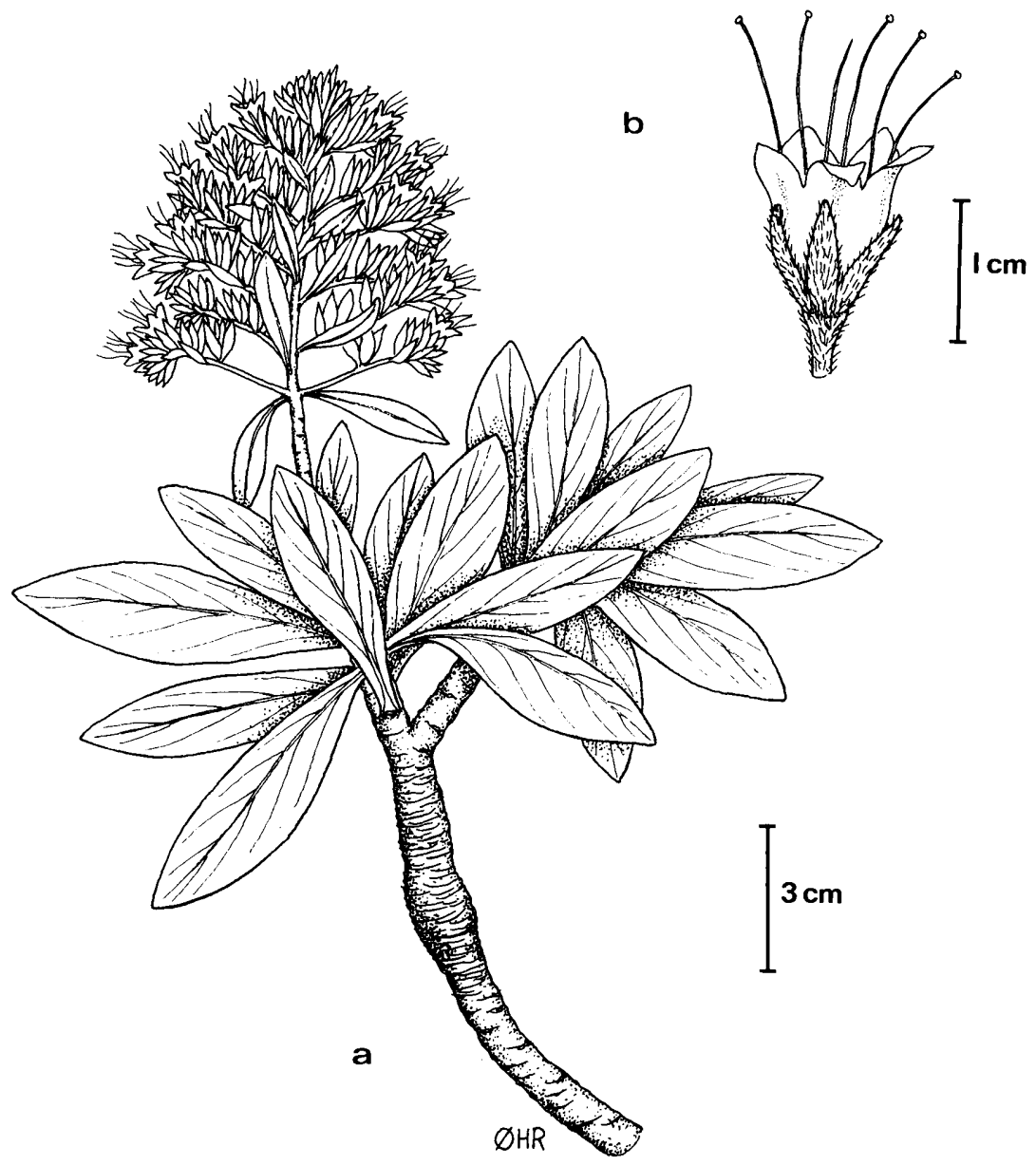

Fig. 75. Echium hypertropicum. a. Habit; b. Flower. Drawn by Ø. H. Rustan. 


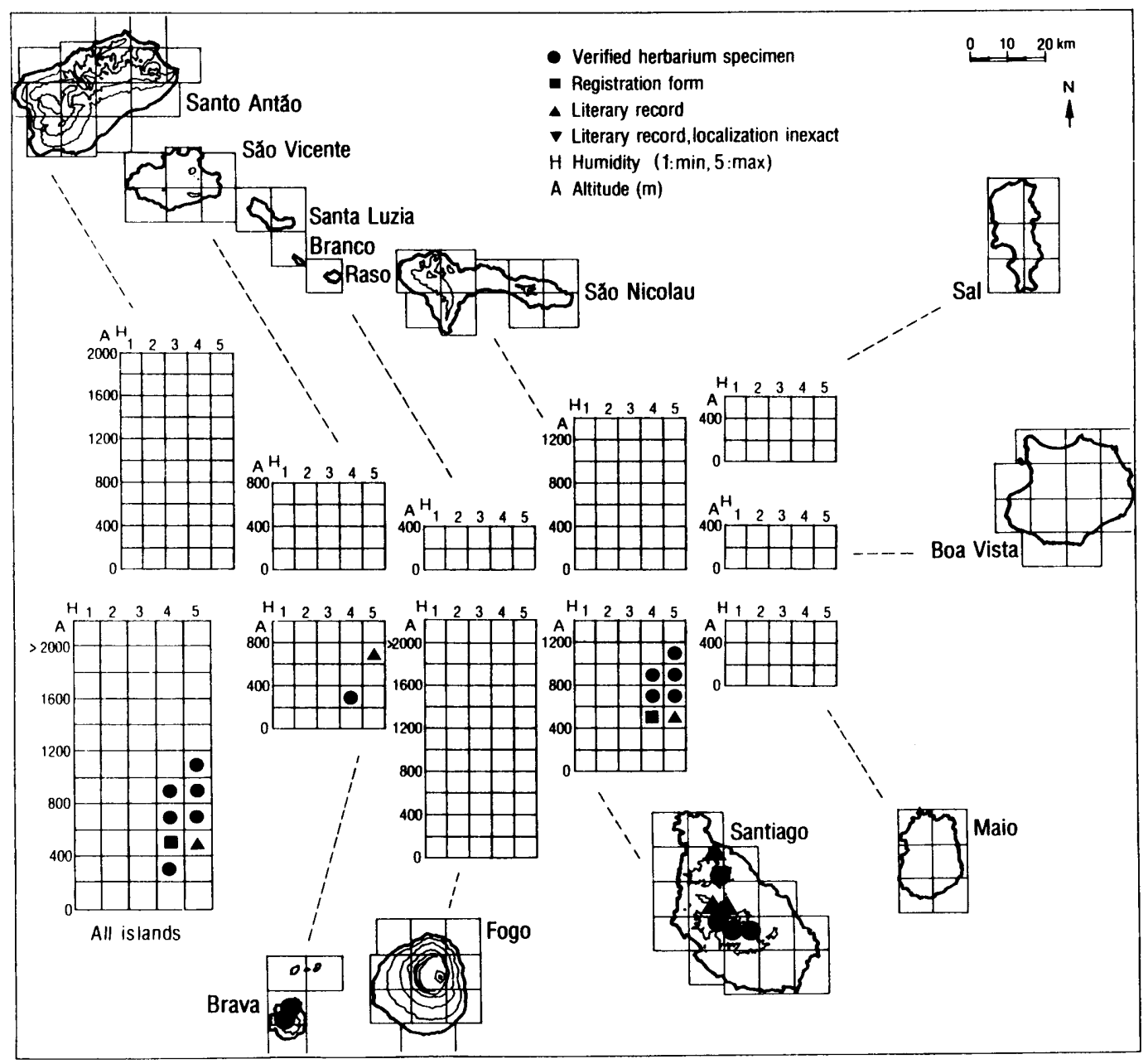

Fig. 76. Ecogeographic distribution of Echium hypertropicum.

Corolla deep purplish-bluish, subsalveriform to somewhat campanulate, up to $18 \mathrm{~mm}$ long. lobes short and nearly equal. Two stamens exserted. Mericarps greyish, echinulate.

Variation. The infraspecific variation is considerable. Two subspecies can be distinguished, but some transitional populations occur on Santo Antão.

Related taxa. See above. 
Echium stenosiphon ssp. stenosiphon (Figs 77, 78)

Echium stenosiphon Webb ssp. stenosiphon

= Echium glabrescens Pett., Comm. Biol. Soc. Scient. Fenn. 22: 39 (1960). — Type: S. Nicolau. Monte Gordo, 15.12.1953, H. Lindberg (holotype: $\mathrm{H}$ !).

Illustrations: Webb (1848: Fig. 772, 1849: Fig. 15), Chevalier (1935b: Tab. 7c), Pettersson (1960: Tab. 3(2), Tab. 4(3-4) sub E. glabrescens, 3(3), 5(1-2)), Lobin (1986b: Fig. 14), Rustan \& Brochmann (1993: Fig. 2), Gomes et al. (1995b: p. 15).

Description. Stem usually hispid with spiny, rough-based trichomes. Leaves ovate, usually with a pronounced indument of rough-based trichomes, apex obtuse. Calyx lobes ovate. Corolla subsalveriform.

Variation. This subspecies is very variable, especially in indument characters. Considerable variation was observed in density and size of leaf trichomes in the material from São Vicente and São Nicolau, but on these two islands, it does not seem to have occurred distinct ecotypic differentiation comparable to that on Santo Antão (see also E. stenosiphon ssp. lindbergii).

Chromosome number: Unknown.

Distribution and ecology. Echium stenosiphon ssp. stenosiphon is a northern mesophyte occurring on Santo Antão, São Vicente, Branco (Basto 1987a), and São Nicolau. It is equally common in the semiarid, subhumid, and humid zones, and it is mainly found between $200 \mathrm{~m}$ and $800 \mathrm{~m}$. The lowermost record is at $50 \mathrm{~m}$ on São Nicolau, the uppermost one at $1300 \mathrm{~m}$ on the same island (Rustan \& Brochmann 1993). On Santo Antão, ssp. stenosiphon is mainly confined to the semiarid zone below $200 \mathrm{~m}$, and it is replaced by ssp. lindbergii in more elevated, humid areas. The plants grow in gravelly slopes, roadsides, and field edges, rarely in cliffs.

Abundance. We have observed large populations of E. stenosiphon ssp. stenosiphon in many areas. On São Vicente, the populations are continuously declining, and the subspecies is Vulnerable (VU) on this island. Echium stenosiphon ssp. stenosiphon is generally considered to be Lower Risk (LR).

\section{Echium stenosiphon ssp. lindbergii (Figs 79, 80)}

Echium stenosiphon Webb ssp. lindbergii (Pett.) Bramwell, Lagascalia 2: 97 (1972) E Echium lindhergii Pett.. Comm. Biol. Soc. Scient. Fenn. 22: 36 (1960). - Type: Sto. Antão, Cova, 31.12.1953, H. Lindherg (holotype: $\mathrm{H}$ !).

Illustrations: Pettersson (1960: Figs 1-3, Tab. 3(1), 4(1-2) sub E. lindbergii), Lobin (1986b: Fig. 17), Rustan \& Brochmann (1993: Fig. 3).

Description. Branches usually hispid with small, pustular trichomes. Leaves ovate-lanceolate, with fine, almost silky indument, apex acute. Calyx lobes lanceolate. Corolla somewhat campanulate.

Variation. This subspecies is relatively uniform, but it varies in indument characters. Most specimens are easily distinguished from ssp. stenosiphon by their narrower, acute leaves and more silky indument. Some populations that are intermediate between the two subspecies occur in low mountains on northeastern Santo Antão, and in elevated, subhumid areas in the southwestern part of the island. 


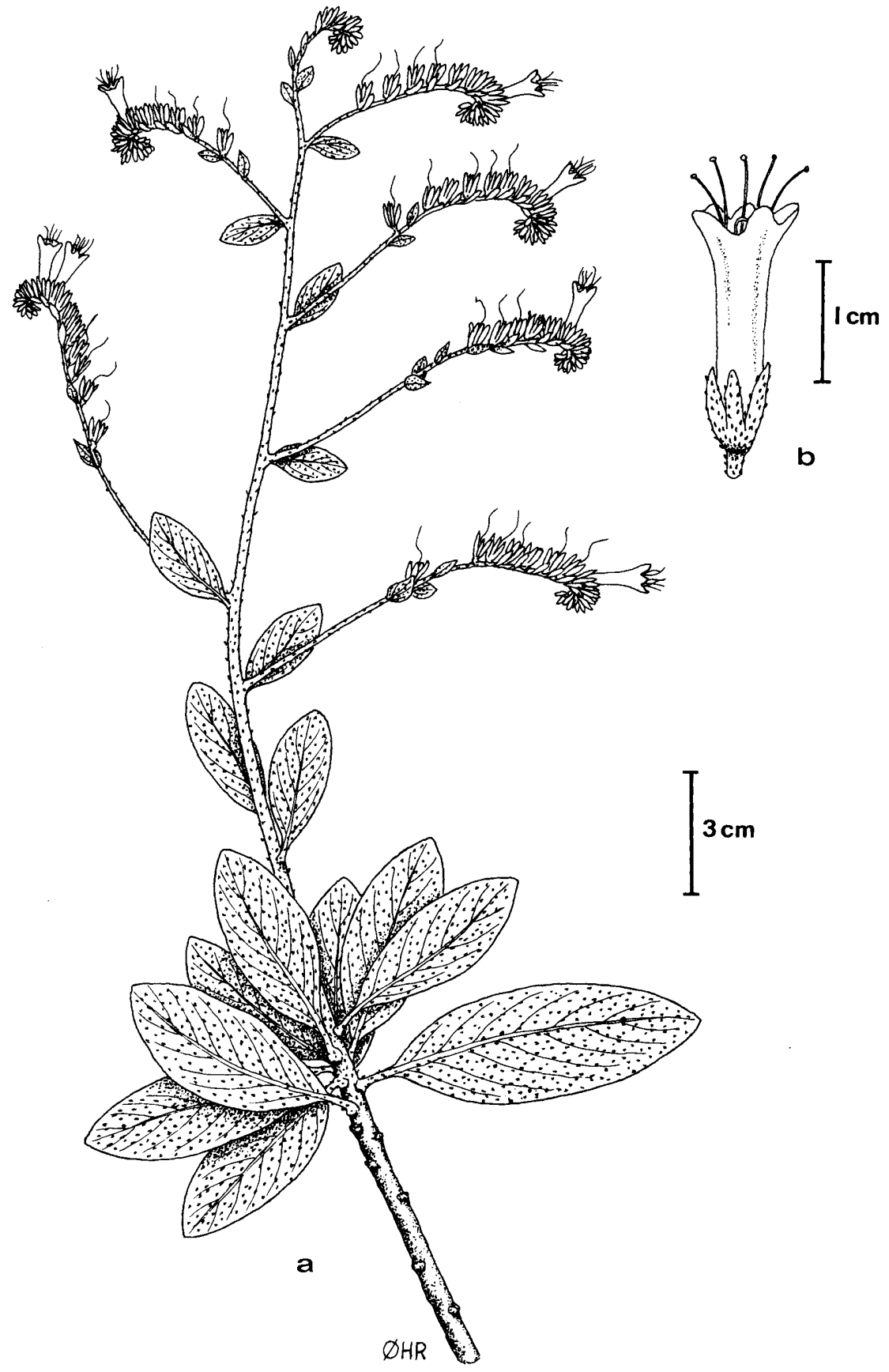

Fig. 77. Echium stenosiphon ssp. stenosiphon. a. Habit; b. Flower. Drawn by Ø. H. Rustan. 


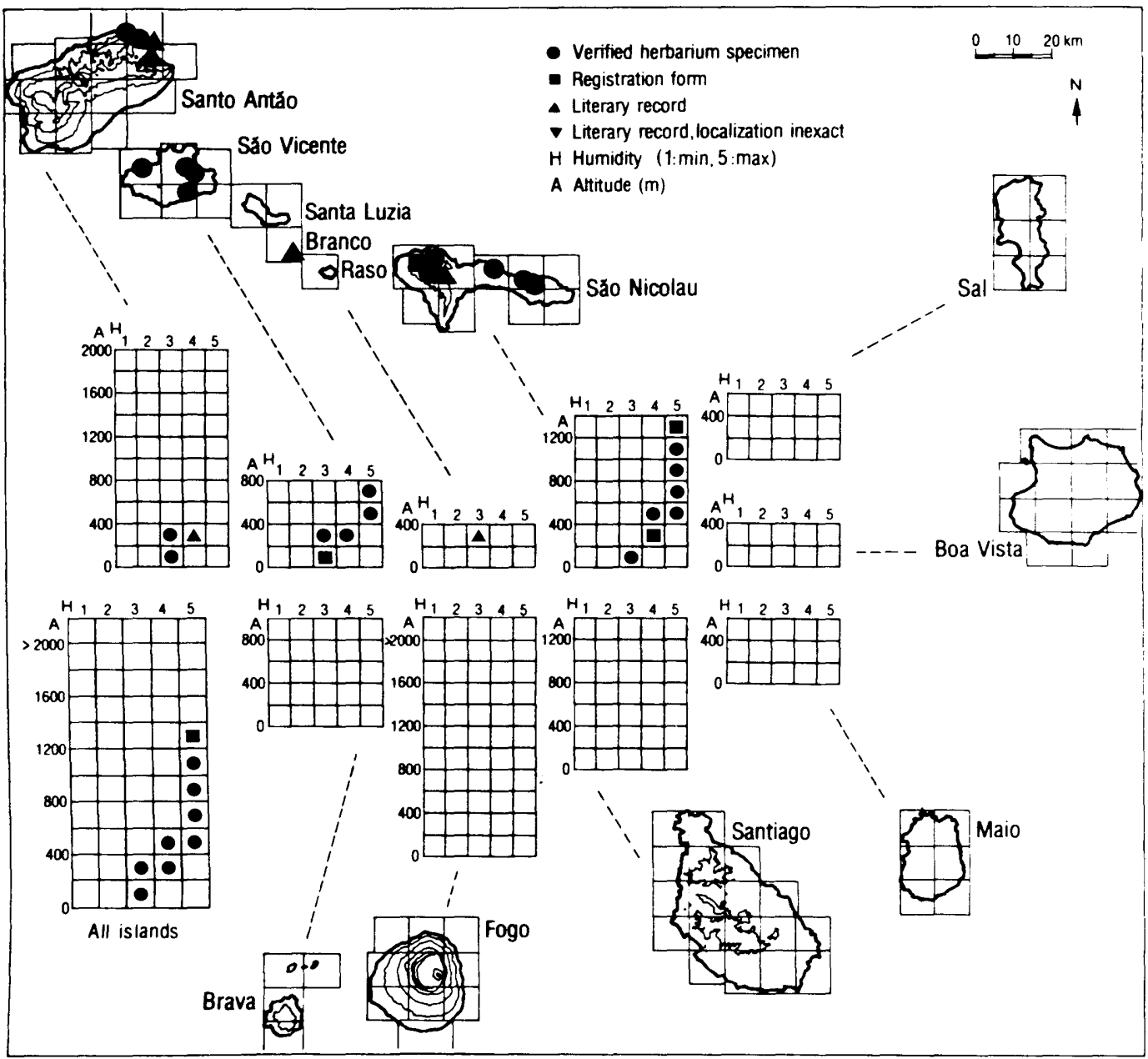

Fig. 78. Ecogeographic distribution of Echium stenosiphon ssp. stenosiphon.

Chromosome number: Unknown.

Distribution and ecology. Echium stenosiphon ssp. lindbergii is a northern hygrophyte restricted to Santo Antão. It occurs in the subhumid and humid zones, mainly between $800 \mathrm{~m}$ and $1400 \mathrm{~m}$. The lowermost record is at $260 \mathrm{~m}$ (Sunding 1982) and the uppermost one at 1470 m (Rustan \& Brochmann 1993). The plants prefer cliff habitats, but they are also found on brown, humus-rich soil in afforestations, on gravelly slopes, and occasionally at edges of fields.

Abundance. This subspecies has been collected and observed many times after 1970. It is still locally common, but the plants are frequently harvested for goat fodder, and it is likely that the populations are seriously declining. At present, Echium stenosiphon ssp. lindbergii is classified as Indeterminate (I). 


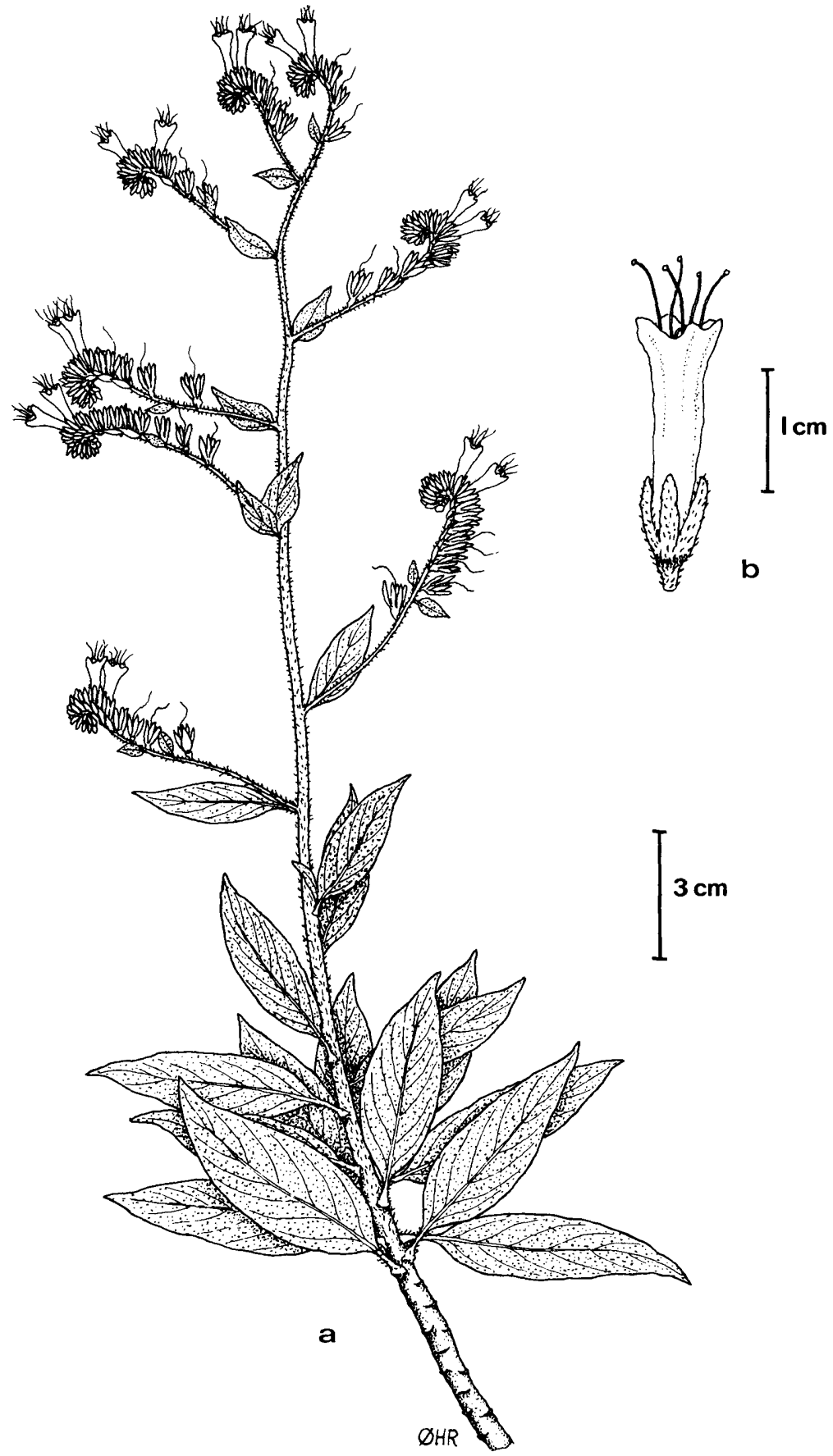

Fig. 79. Echium stenosiphon ssp. lindbergii. a. Habit; b. Flower. Drawn by Ø. H. Rustan. 


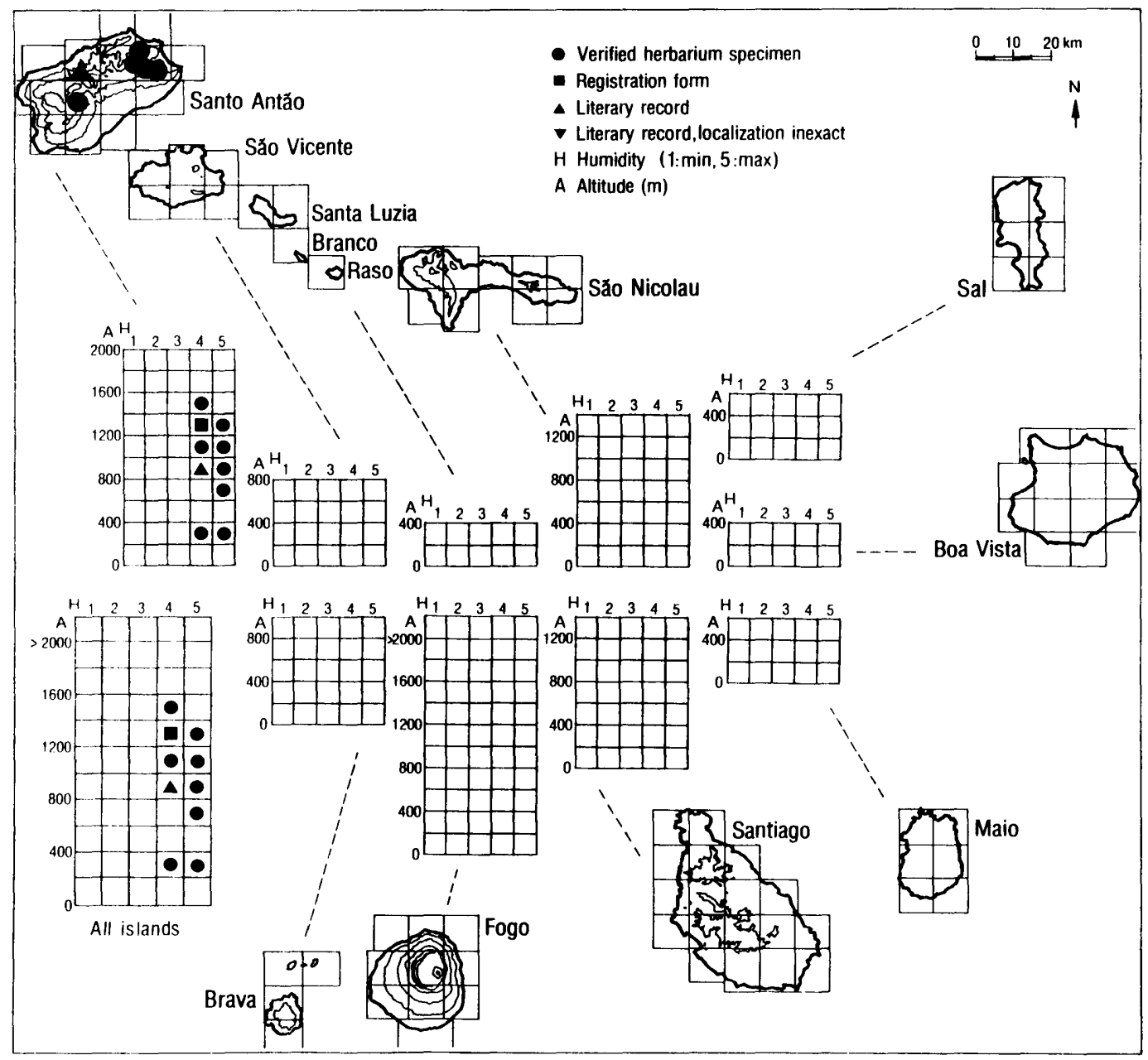

Fig. 80. Ecogeographic distribution of Echium stenosiphon ssp. lindbergii.

Note. The map is mainly based on verified material and registration form data, because the two subspecies frequently have been confused in the literature.

Echium vulcanorum (Figs 81, 82)

Echium vulcanorum A. Chev., Rev. Bot. Appl. Agric. Trop. 15: 915 (1935). - Type: Fogo, commun sur la purtour de la caldeira, à l'extérieur et à l'intérieur et sur tous les mamelons volcaniques environnants de 900 à $2000 \mathrm{~m}, 23.7 .1934$, Chevalier 44871 (holotype: P, not to be found; isotype: P).

Illustrations: Chevalier (1935b: Tab. 15), Rustan \& Brochmann (1993: Fig. 4), Gomes et al. (1995b: p. 16). 


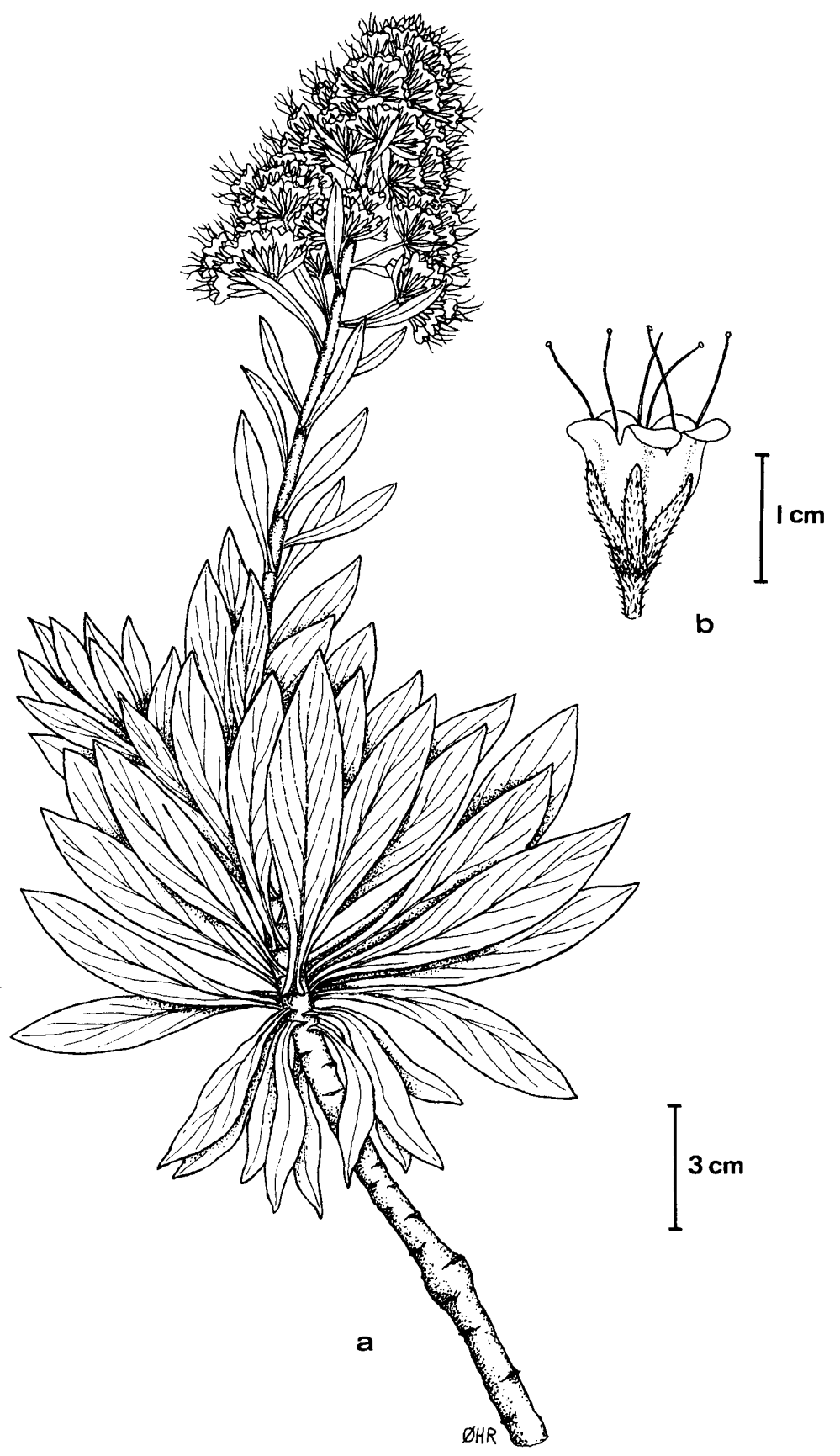

Fig. 81. Echium vulcanorum. a. Habit; b. Flower. Drawn by Ø. H. Rustan. 


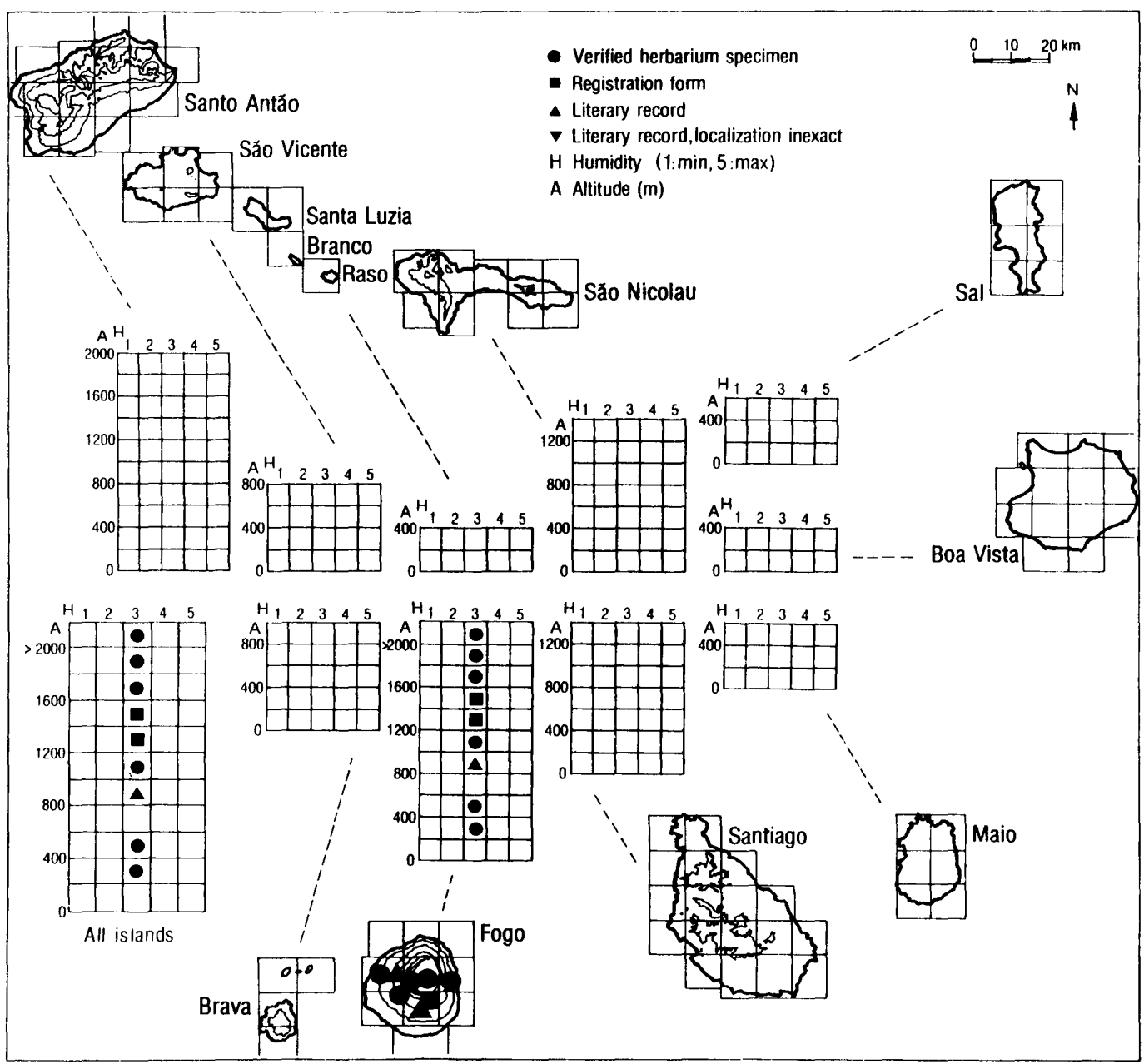

Fig. 82. Ecogeographic distribution of Echium vulcanorum.

Description. Strongly branched, compact, more or less hemispherical shrub up to $2 \mathrm{~m}$ high. Branches densely whitish tomentose. Leaves lanceolate, up to $10 \mathrm{~cm}$ long and $1.5 \mathrm{~cm}$ wide, densely whitish hispid to sericeous with long, pustular trichomes, apex nearly acute, margin entire. Inflorescence a dense, subconical, thyrsoid panicle. Calyx up to $7 \mathrm{~mm}$ long, densely hispid. Corolla white or rarely bluish, funnel-shaped, slightly compressed laterally, lobes slightly unequal. Stamens exserted. Mericarps brownish, echinulate.

Variation. No significant variation was observed.

Chromosome number: Unknown.

Related taxa. Echium vulcanorum is most closely related to E. hypertropicum (see that species). 
Distribution and ecology. Echium vulcanorum is a southern mesophyte restricted to the semiarid zone on Fogo. According to observations in 1934 (Chevalier 1935a), E. vulcanorum was an important component of a scrub vegetation type with Artemisia gorgonum, originally distributed on the southern and western slopes of Fogo. This vegetation occurred from $900 \mathrm{~m}$ to the edge of the caldeira rim at 1900-2500 m, where E. vulcanorum still occurs up to 2300-2400 m (Ormonde 1980, Gomes et al. 1995a). Today, this impressive scrub vegetation type has become largely restricted to elevations above $1800 \mathrm{~m}$, and it is still declining as a result of cutting for firewood, charcoal production, and agriculture. Small, isolated stands and single plants of E. vulcanorum also occur today at $570 \mathrm{~m}$ at Monte Palha in the western part and at $380 \mathrm{~m}$ in the northeastern part of the island, but these populations are most likely secondary (Gomes et al. 1995a). Small populations also occur in the caldeira and on the lower slopes of Pico Novo. The species grows on lava rocks and volcanic gravel.

Abundance. Some populations of this species still comprise a large number of individuals. However, considering its restricted distribution and continuous decline, Echium vulcanorum is classified as Endangered (EN).

\section{BRASSICACEAE}

This family is represented by nine genera with 18 species and subspecies. Twelve taxa belonging to the three genera Diplotaxis, Erysimum, and Lobularia are endemic.

\section{Diplotaxis DC.}

The genus Diplotaxis shows one of the highest levels of diversification among the endemic vascular plant groups in the Cape Verde Islands. In a recent revision (Rustan 1996), nine taxa (eight species, one of them with two subspecies), were recognized. All taxa are endemic to the Cape Verde Islands and belong to section Catocarpum DC. emend. O. E. Schulz. The Capeverdean taxa show close morphological and karyological affinity to the North African and Mediterranean D. harra (Forssk.) Boiss. s. lat. (sect. Catocarpum), a widespread and morphologically very variable species. The five Capeverdean species which have been investigated karyologically all have $2 n=26$ (Borgen 1975, Rustan 1996). This chromosome number has also been reported in D. harra (Harberd 1972 (as D. crassifolia), Amin 1972, Gómez-Campo 1978).

All Capeverdean taxa are suffruticose, yellow-flowered perennials, and show a complex pattern of morphological variation. Several conspicuous characters, e.g., habit, leaf size and shape, and indument, have probably evolved in parallel on different islands, severely confounding the taxonomy of this group. The taxa show a fairly clear-cut ecogeographic pattern in the archipelago. Seven taxa are island-specific, i.e., they occur on a single island only, whereas each of only two taxa, D. glauca and $D$. varia, occur on two more or less closely adjacent islands (Sal and Boa Vista, and Santiago and Brava, respectively).

Only two islands harbour more than a single taxon of Diplotaxis: Santo Antão (three taxa) and São Nicolau (two taxa). The distribution of the taxa on Santo Antão shows a distinct 
ecogeographic pattern, with one xerophytic species occurring in the upper montane plains in the central part of the island ( $D$. antoniensis), one mesophytic subspecies occurring at the northwestern and northeastern mountain slopes of the island (D. gorgadensis ssp. gorgadensis), and one hygrophytic subspecies restricted to the most favourable high mountain area in the northeastern part of the island ( $D$. gorgadensis ssp. brochmannii). On São Nicolau, the two taxa are geographically separated, and have probably evolved in allopatry in accordance with the pattern shown by the island-specific taxa. Diplotaxis gracilis is restricted (except for one coastal population) to the western mountains on São Nicolau, whereas $D$. sundingii is restricted to the eastern mountains.

Biosystematic studies in Capeverdean Diplotaxis (Rustan 1996) indicate that the taxa are self-incompatible and therefore outcrossing (four taxa examined). The taxa are fully interfertile; fertile experimental $F_{1}$ hybrids have been obtained in 30 interspecific combinations. Thus, the Capeverdean taxa are mainly isolated by geographic and partly ecological barriers, and have evolved by vicariant evolution (in most cases) and adaptive radiation (on Santo Antão).

The maps are based on revised material only (cf. Rustan 1996).

Literature: Rustan (1996).

Key to the genus Diplotaxis

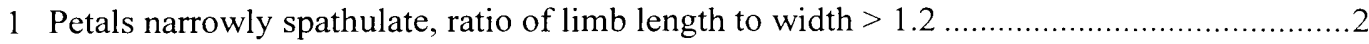

1 Petals broadly spathulate, ratio of limb length to width $<1.2 \ldots \ldots \ldots \ldots \ldots \ldots \ldots \ldots \ldots \ldots \ldots \ldots \ldots \ldots \ldots . .5$

2 (1) Siliques oblong-oblanceolate, $3-4 \mathrm{~mm}$ wide; leaves glabrous, distinctly succulent D. glauca

2 Siliques linear, 1.5-3 mm wide; leaves glabrous-hirsute, not or slightly succulent. 3

3 (2) Sepals 6-7 mm long; outer stamens 5.5-8 mm long, inner stamens $8.5-10 \mathrm{~mm}$ long D. antoniensis

3 Sepals 4.5-5.5 mm long; outer stamens 4.5-6 mm long, inner stamens 6.5-8.5 mm long

4 (3) Siliques 30-45 mm long; leaves glabrous or hirsute.................................... D. varia

4 Siliques 40-80 mm long; leaves hispid .......................................................... hirta

5 (1) Siliques narrowly oblong to oblanceolate, $3-4 \mathrm{~mm}$ wide ……….................. s. sundingii

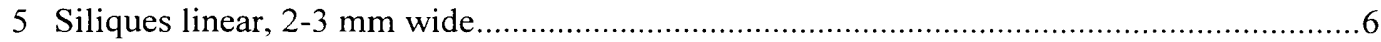

6 (5) Fruiting pedicels 5-9 mm long; sepals 4-6 mm long; outer stamens 4-6 mm long, inner stamens 6-8 $\mathrm{mm}$ long

6 Fruiting pedicels 8-12 mm long; sepals 6-7.5 mm long; outer stamens 7.5-10 mm long, inner stamens $9-12 \mathrm{~mm}$ long. 
7 (6) Petals 10-12 mm long; outer stamens 5.5-6 mm long, inner stamens 7-8 mm long

Petals 8-10 mm long; outer stamens 4-5 mm long, inner stamens 6-7 mm long D. gracilis D. vogelii

8 (6) Plant erect; inflorescence rigid; leaves fleshy, distinctly glaucous-violaceous D. gorgadensis ssp. gorgadensis

8 Plant decumbent; inflorescence slender; leaves thin, green or glaucescent

D. gorgadensis ssp. brochmannii

\section{Diplotaxis antoniensis (Figs 83, 84)}

Diplotaxis antoniensis Rustan, Nord. J. Bot. 16: 35 (1996). - Type: Cape Verde Islands, Santo Antão, Chã da Lagoa, $1160 \mathrm{~m}, 22.1 .1980$, Ø. H. Rustan 870 (holotype: O!).

Illustration: Rustan (1996: Fig. 12).

Description. Erect subshrub up to $1 \mathrm{~m}$ high; main stem branched near the base, old plants often forming large tufts. Branches erect, slightly thinner than stem, with alternate leaves, ending in an apical, erect inflorescence. Stem strongly lignified, up to $8 \mathrm{~mm}$ thick, densely hispid, older parts with greyish brown bark, younger parts glaucous or rarely violaceous; leaf scars present. Lower and middle cauline leaves oblong-obovate, fleshy, hispid or hispidulous, glaucous, $3-7(-16) \mathrm{cm}$ long, $1-3(-10) \mathrm{cm}$ wide; leaf base attenuate with a $1.5-2(-3) \mathrm{cm}$ long petiole; apex obtuse; margin dentate, remotely dentate or irregularly dentate, ciliate; upper leaves linear-spathulate. Inflorescence rigid, glabrous, glaucous, elongating in fruit to $30-50$ $\mathrm{cm}$; branches many, bracteate, 40-60-flowered, siliques alternate in upper half, often crowded towards the tip. Pedicels erect-patent, glabrous, 5-7 mm long, 10-14 mm long and often pendent in fruit. Sepals hirsute, yellowish green or violaceous, 6-7 mm long. Petals sulphuryellow, narrowly spathulate, tapering into a claw, 9-12 mm long, 3.5-4.5 mm wide. Outer stamens 5.5-8 mm long, inner stamens $8.5-10 \mathrm{~mm}$ long; anthers $2.5-2.8 \mathrm{~mm}$ long. Siliques patent-pendent, linear, flattened, $45-55 \mathrm{~mm}$ long, 2-2.5(-3) $\mathrm{mm}$ wide, with 40-60 seeds per loculus, 2-seriate; valves glabrous, glaucous or rarely greenish violaceous, 1-nerved; gynophore (2-)3-5 mm long; beak 0.5-1(-1.5) $\mathrm{mm}$ long. Seeds ellipsoid, yellowish brown to brown, $1.0-1.3 \mathrm{~mm}$ long, $0.6-0.8 \mathrm{~mm}$ wide, surface smooth.

Variation. The species is variable in habit, leaf size and shape, and indument. Three populations in the central part of Santo Antão, at the borderline between the distributions of $D$. antoniensis and D. gorgadensis ssp. gorgadensis, are morphologically more or less transitional between these taxa. These populations occur in ecologically intermediate sites (see below).

Chromosome number: Unknown.

Related taxa. Diplotaxis antoniensis is probably most closely related to $D$. gorgadensis, but can be distinguished by its densely hispid indument, many-branched inflorescence, narrowly spathulate petals, shorter stamens, and slightly smaller seeds. Habitually, $D$. antoniensis is most similar to $D$. hirta, which occurs on Fogo, but it differs by its more stiff and erect inflorescence, and by its larger sepals, petals, and stamens. These two taxa provide an example of parallel evolution in vegetative characters within Diplotaxis. 


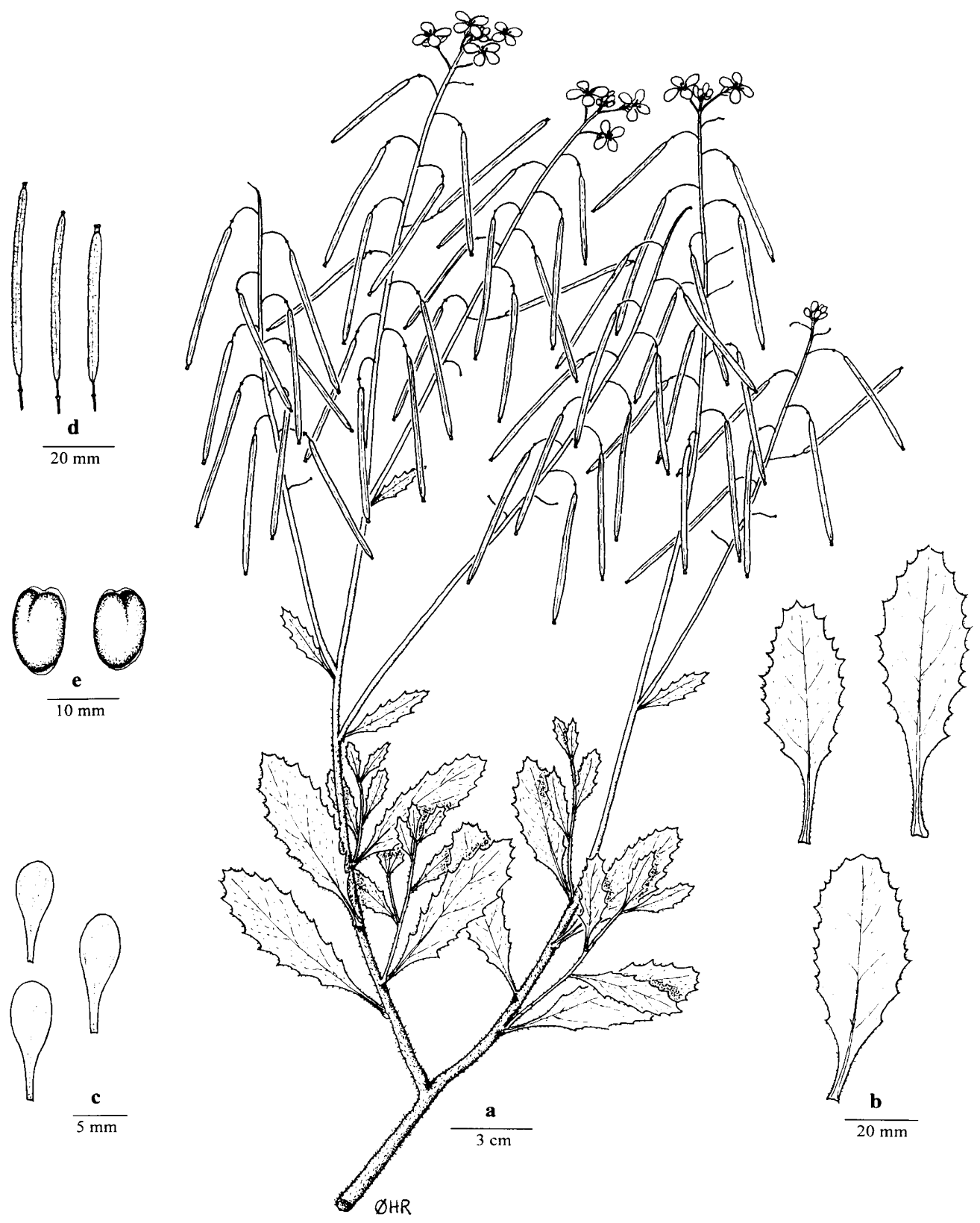

Fig. 83. Diplotaxis antoniensis. a. Habit; b. Leaves; c. Petals; d. Siliques; e. Seeds. Drawn by $\varnothing$. H. Rustan. Reprinted from Rustan (1996), Nord. J. Bot. 16 (with permission). 


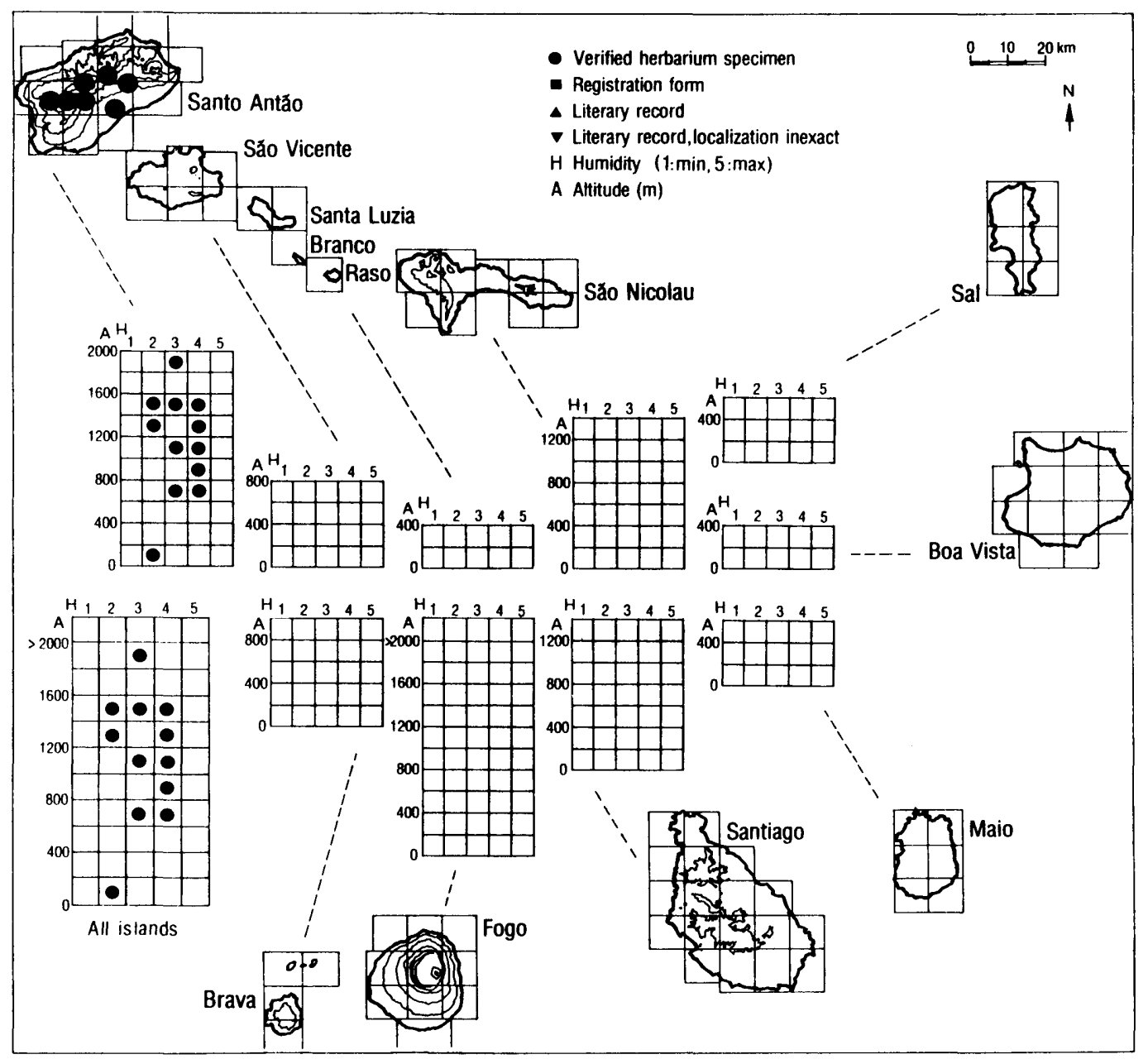

Fig. 84. Ecogeographic distribution of Diplotaxis antoniensis.

Distribution and ecology. Diplotaxis antoniensis is a northern xerophyte, restricted to the elevated montane plains of central Santo Antão. It is equally frequent in the arid, semiarid, and subhumid zones, but is replaced by $D$. gorgadensis ssp. gorgadensis and ssp. brochmannii in the humid zone. Diplotaxis antoniensis occurs mainly between $1100 \mathrm{~m}$ and $1500 \mathrm{~m}$. The lowermost population has been recorded at $630 \mathrm{~m}$ at the eastern limit of the distribution area (leg. Rustan), but the species has also been collected once at about $100 \mathrm{~m}$ in the bottom of a valley on southeastern Santo Antão (leg. Lobin). It is most likely that this collection represents an ephemeral plant dispersed by a river from the montane, primary populations. The uppermost record of the species is at $1940 \mathrm{~m}$ at the summit of Tope de Coroa (leg. Rustan). The species is characteristic of the upper montane plain vegetation of Santo Antão, where it may form tufts up to $2 \mathrm{~m}$ in diameter. The plants grow in gravelly plains and 
slopes, rarely in cliffs, and also occur as weeds in cultivated fields. The populations that are morphologically, ecologically, and geographically transitional between $D$. antoniensis and $D$. gorgadensis ssp. gorgadensis occur in the subhumid zone between $650 \mathrm{~m}$ and $900 \mathrm{~m}$.

Abundance. The records of $D$. antoniensis represent about 12 different populations, most of them observed after 1980. Some populations are large, comprising several hundreds of plants, especially in the central plain of Chã da Lagoa. Although its total distribution area is restricted, Diplotaxis antoniensis is locally very common and considered to be Lower Risk (LR).

\section{Diplotaxis glauca (Figs 85, 86)}

Diplotaxis glauca (J. A. Schmidt) O. E. Schulz, Bot. Jahrb. Syst. 54: 55 (1916) ESinapidendron glaucum J. A. Schmidt, Beitr. Fl. Cap Verd. Ins.: 267 (1852) EBrassica glauca (J. A. Schmidt) Kuntze, Revis. Gen. Pl. 1: 20

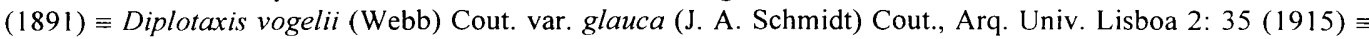
Diplotaxis harra (Forssk.) Boiss. ssp. glauca (J. A. Schmidt) Sobrino Vesperinas, Candollea 48: 143 (1993). Type: In graminosis ins. Boae Vistae, 2.1851, J. A. Schmidt (holotype: HBG!; isotype: GOET!).

Illustrations: Gomes et al. (1995b: p. 17), Rustan (1996: Fig. 13).

Description. Erect subshrub up to $0.8 \mathrm{~m}$ high; main stem branched near the base, old plants often forming large tufts; branches thinner than stem, with alternate leaves, ending in an apical, erect inflorescence. Stem strongly lignified, up to $8 \mathrm{~mm}$ thick, glabrous, older parts with greyish brown bark, younger parts glaucous; leaf scars prominent. Lower and middle cauline leaves oblong-obovate, succulent, glabrous, glaucous, 2-4(-6) cm long, 1.5-2.5(-3.5) $\mathrm{cm}$ wide; leaf base attenuate with $0.5-1.5 \mathrm{~cm}$ long petiole; apex obtuse or acute; margin remotely dentate, glabrous or ciliate; upper leaves linear-spathulate. Inflorescence rigid, glabrous, glaucous, elongating in fruit to $30-45 \mathrm{~cm}$; branches few, bracteate, 30-60-flowered, siliques alternate in upper half. Pedicels erect-patent, glabrous, 5-8 mm long, (6-)7-12(-20) $\mathrm{mm}$ long in fruit. Sepals hirsute, yellowish green, 4-5.5 $\mathrm{mm}$ long. Petals sulphur-yellow, narrowly spathulate, tapering into a claw, 7.5-9 $\mathrm{mm}$ long, 2-4 $\mathrm{mm}$ wide. Outer stamens 5.9$7.3 \mathrm{~mm}$ long, inner stamens $6.8-8.3 \mathrm{~mm}$ long; anthers $2.3-2.5 \mathrm{~mm}$ long. Siliques erect-patent, narrowly oblong to oblanceolate, flattened, $25-35 \mathrm{~mm}$ long, 3-4 mm wide, 40-60 seeds per loculus, diffusely 2-3 seriate; valves glabrous, glaucous, 1-nerved; gynophore (1-)2-2.5 mm long; beak 1-2 mm long. Seeds ellipsoid, reddish brown to dark brown, 0.8-1.0 $\mathrm{mm}$ long, 0.6$0.7 \mathrm{~mm}$ wide, surface smooth.

Variation. The species shows little variation.

Chromosome number: $2 \mathrm{n}=26$ (without locality; determined in material raised from seeds collected by P. Sunding, Oslo; Gómez-Campo 1978).

Related taxa. Diplotaxis glauca and D. sundingii have broad, oblong to oblanceolate siliques, but the two species differ in several characters such as leaf texture, sepal length, and shape and size of petals. Specimens of D. gorgadensis ssp. brochmannii from Santo Antão have often been referred to D. glauca (see D. gorgadensis ssp. brochmannii).

Distribution and ecology. Diplotaxis glauca is an eastern xerophyte, restricted to low mountains and plains on Sal and Boa Vista. It is most frequent in the arid zone, but also occurs in the semiarid zone. The species is distributed from $40 \mathrm{~m}$ on northeastern Sal (leg. Rustan) to $300 \mathrm{~m}$ at Monte Grande on Sal (leg. Sunding). Most sites are situated between 40 $\mathrm{m}$ and $200 \mathrm{~m}$. The plants grow in stony or gravelly plains and slopes. 


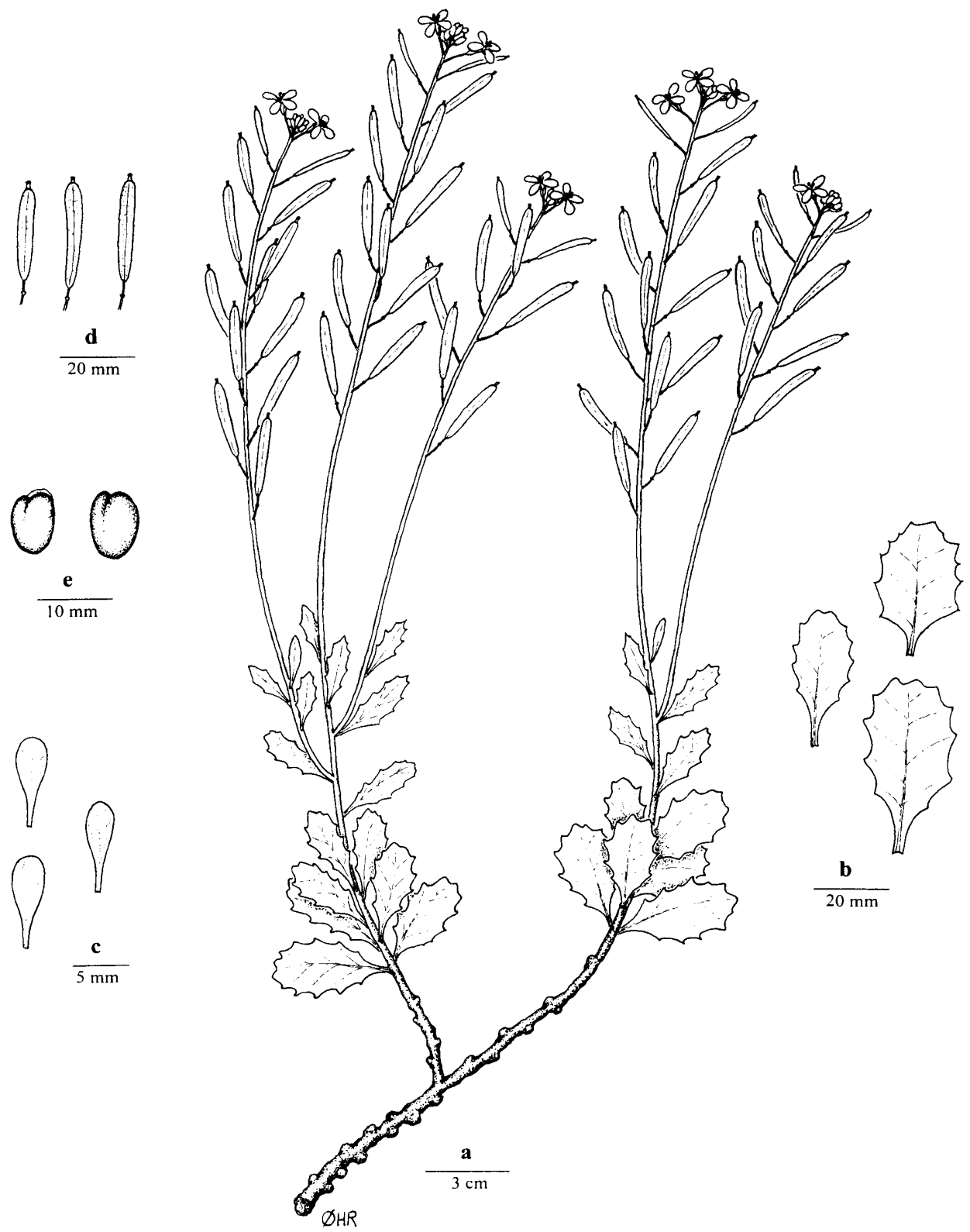

Fig. 85. Diplotaxis glauca. a. Habit; b. Leaves; c. Petals; d. Siliques; e. Seeds. Drawn by $\varnothing$. H. Rustan. Reprinted from Rustan (1996), Nord. J. Bot. 16 (with permission). 


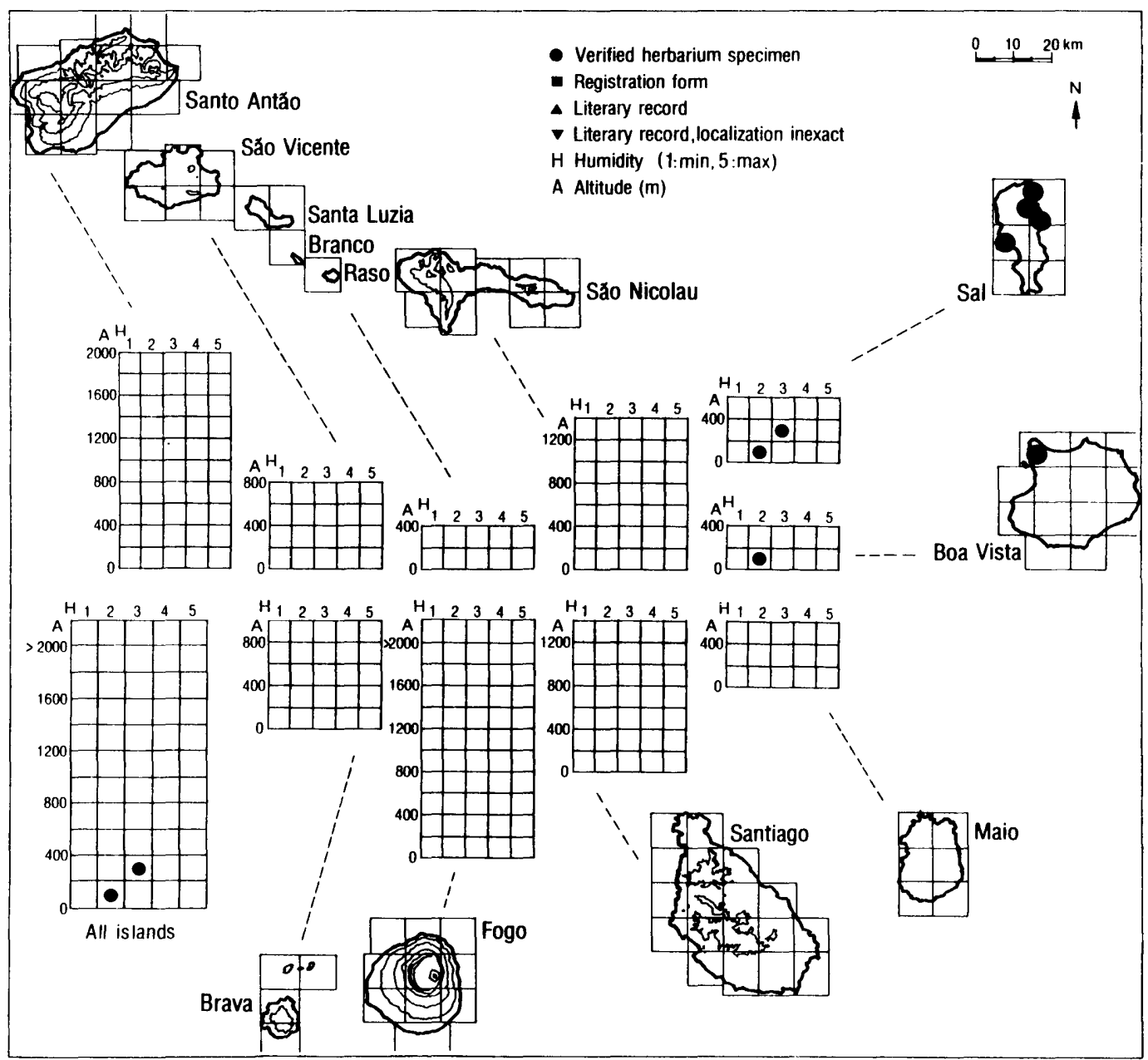

Fig. 86. Ecogeographic distribution of Diplotaxis glauca.

Abundance. The records of $D$. glauca represent about seven different populations. One of the populations on Sal comprised more than 100 plants in 1979 , but the population size of this xerophytic species seems to vary considerably from year to year, and most populations we have observed are small. The species is considered Extinct (EX) on Boa Vista. The only record from this island dates from 1851 (leg. Schmidt; type collection), although the most probable collection sites were investigated in 1979. Diplotaxis glauca is probably declining on Sal because of grazing and agriculture, and the species is classified as Vulnerable (VU). 


\section{Diplotaxis gorgadensis}

Diplotaxis gorgadensis Rustan, Nord. J. Bot. 16: 38 (1996). - Type: Cape Verde Islands, Santo Antão, Ribeira do Paul, along levada on NW-side of Tope Cavaleiro, $350 \mathrm{~m}, 11.1 .1982, \varnothing$. H. Rustan \& C. Brochmann ØHR 1486 (holotype: O!).

Description. Decumbent or erect subshrub up to $1 \mathrm{~m}$ high; main stem branched near the base; branches long, slender or rigid, thinner than stem, with alternate leaves, ending in an apical, pendulous or erect inflorescence. Stem strongly lignified, up to $8 \mathrm{~mm}$ thick, glabrous or hirsutulous, older parts with greyish brown bark, younger parts green, glaucous or violaceous; leaf scars prominent. Lower and middle cauline leaves oblong-obovate, thin or fleshy, glabrous or sparsely hirsutulous, green, violaceous or glaucous, $2-11(-16) \mathrm{cm}$ long, 1-5(-7.5) $\mathrm{cm}$ wide; leaf base attenuate with a $1-2(-3) \mathrm{cm}$ long petiole; apex acute or obtuse; margin dentate, remotely dentate or irregularly dentate, glabrous or ciliate; upper leaves linearspathulate. Inflorescence slender or rigid, glabrous, green, violaceous or glaucous, elongating in fruit to $30-60 \mathrm{~cm}$; branches few or absent, bracteate, 30-70-flowered, siliques alternate in upper half. Pedicels erect-patent or pendent, glabrous, 5-8 mm long, 8-12 mm long in fruit. Sepals glabrous or minutely hirsute, yellowish green or violaceous, $6-7.5 \mathrm{~mm}$ long. Petals sulphur-yellow, broadly spathulate, tapering into a claw, 11-14(-15) mm long, 5-6.5(-7) mm wide. Outer stamens 7.5-10 mm long, inner stamens 9-12 mm long; anthers $2.5-3 \mathrm{~mm}$ long. Siliques erect-patent or patent-pendent, linear or rarely oblanceolate, flattened, $35-50 \mathrm{~mm}$ long, (1.5-)2-2.5(-3) mm wide, 50-70 seeds per loculus, 2-seriate; valves glabrous, green or glaucous, 1-nerved; gynophore 1-3.5 mm long; beak 0.5-2 mm long. Seeds ellipsoid, yellowish brown, 0.8-1.1 $\mathrm{mm}$ long, 0.5-0.7 $\mathrm{mm}$ wide, surface smooth.

Variation. The infraspecific variation is considerable, and two morphologically and ecogeographically distinct subspecies can be distinguished.

Related taxa. Diplotaxis gorgadensis is probably most closely related to $D$ antoniensis, but differs in several characters (see D. antoniensis).

Diplotaxis gorgadensis ssp. gorgadensis (Figs 87, 88)

Diplotaxis gorgadensis Rustan ssp. gorgadensis

Illustration: Rustan (1996: Fig. 14).

Description. Decumbent, suffruticose perennial. Stem glabrous or hirsutulous. Leaves glabrous or scattered hirsute, green, violaceous or glaucescent, thin. Inflorescence slender, branches few or absent. Sepals 6-7.5 mm. Petals sulphur-yellow, broadly spathulate, 11-14 $\mathrm{mm}$ long and 5-6 mm wide. Outer stamens 7.5-10 mm long, inner stamens 9-12 $\mathrm{mm}$ long. Siliques linear with a distinct gynophore, 35-50 mm long and 2-2.5 mm wide. Seeds 0.9-1.0 $\mathrm{mm}$ long and 0.6-0.7 $\mathrm{mm}$ wide.

Variation. The subspecies shows little significant variation.

Chromosome number: Unknown.

Related taxa. The subspecies is closely related to D. gorgadensis ssp. brochmannii (see that subspecies). A few populations are morphologically and ecologically intermediate between Diplotaxis gorgadensis ssp. gorgadensis and D. antoniensis (see that species). 


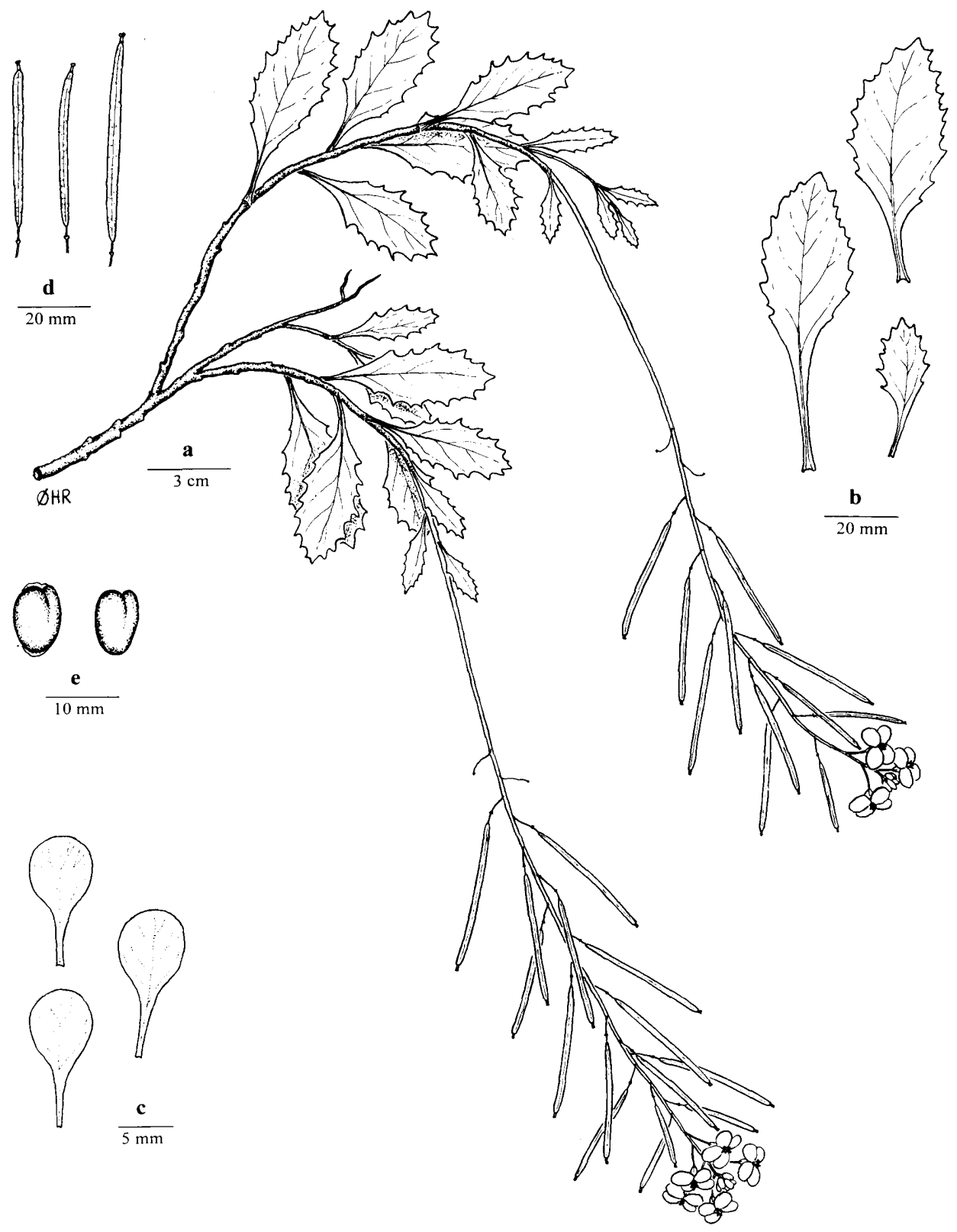

Fig. 87. Diplotaxis gorgadensis ssp. gorgadensis. a. Habit; b. Leaves; c. Petals; d. Siliques; e. Seeds. Drawn by Ø. H. Rustan. Reprinted from Rustan (1996), Nord. J. Bot. 16 (with permission). 


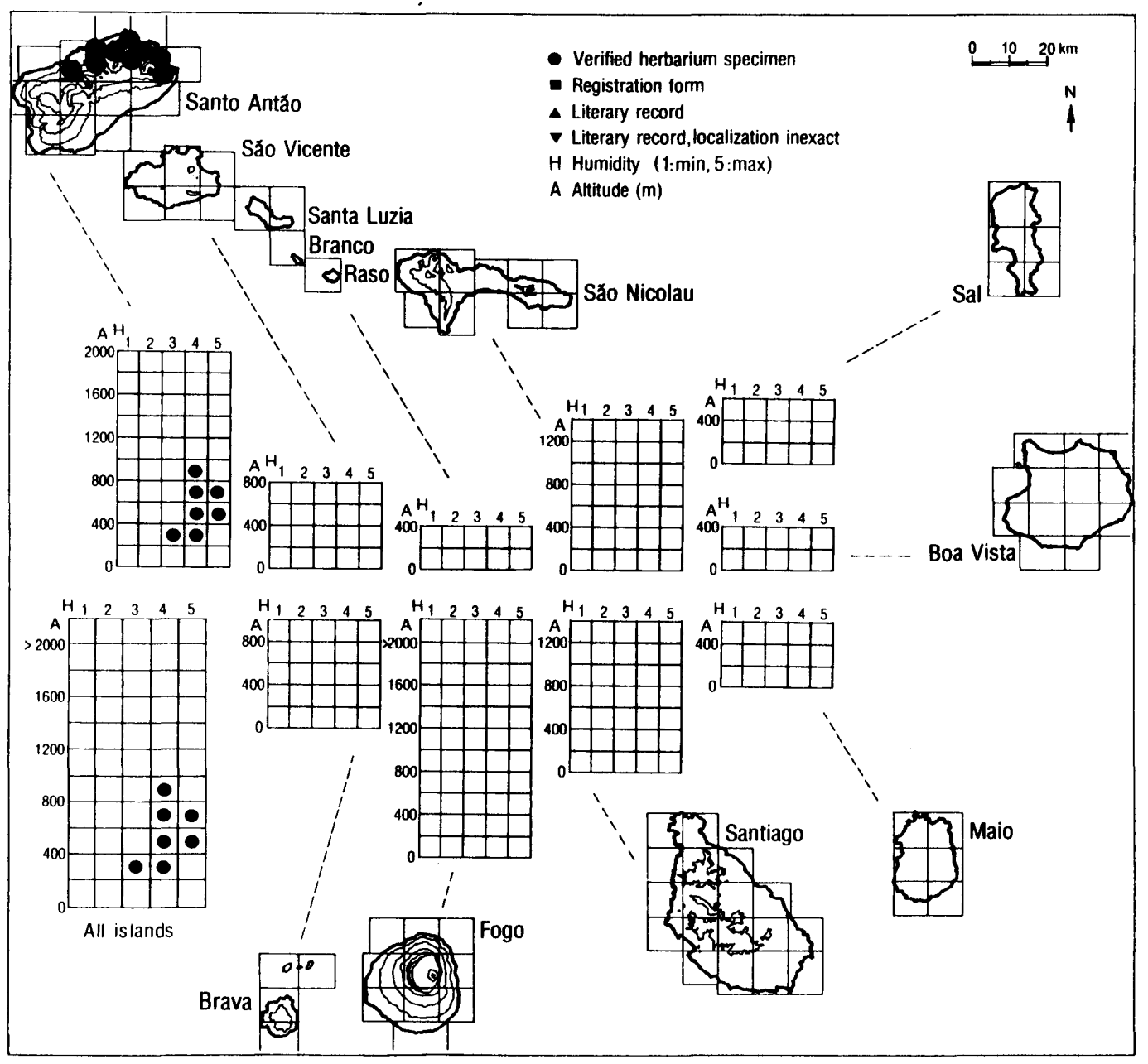

Fig. 88. Ecogeographic distribution of Diplotaxis gorgadensis ssp. gorgadensis.

Distribution and ecology. Diplotaxis gorgadensis ssp. gorgadensis is a northern mesophyte restricted to the northwestern and northeastern mountain slopes of Santo Antão. It is most frequent in the humid zone, but several populations occur in the semiarid and subhumid zones. The main altitudinal distribution is between $450 \mathrm{~m}$ and $800 \mathrm{~m}$. The lowermost population has been recorded at $200 \mathrm{~m}$ in the Ponta do Sol area (leg. Rustan), and several populations extend to about $800 \mathrm{~m}$. The plants usually grow in cliffs and occasionally in gravelly mountain slopes. Diplotaxis gorgadensis ssp. gorgadensis is replaced by the more hygrophytic ssp. brochmannii in more elevated, humid mountains on northeastern Santo Antão, and by the more xerophytic $D$. antoniensis in the arid to subhumid, elevated montane plains in the central part of the island. 


\begin{abstract}
Abundance. The records of $D$. gorgadensis ssp. gorgadensis represent about 20 different populations, most of which have been observed after 1980. Although most populations we have observed are small (less than 20 plants), the subspecies is fairly common within its distribution area. Diplotaxis gorgadensis ssp. gorgadensis is considered to be Lower Risk (LR).
\end{abstract}

Diplotaxis gorgadensis ssp. brochmannii (Figs 89, 90)

Diplotaxis gorgadensis Rustan ssp. brochmannii Rustan, Nord. J. Bot. 16: 41 (1996). - Type: Cape Verde Islands, Santo Antão, Ribeira do Paul, NE of Cova, $1230 \mathrm{~m}, 20.1 .1980$, O. H. Rustan 836 (holotype: ()!).

Illustration: Rustan (1996: Fig. 15).

Description. Erect, suffruticose perennial. Stem glabrous. Leaves glabrous, glaucous to violaceous, fleshy. Inflorescence rigid, branches few or absent. Sepals 6-7.5 mm. Petals sulphur-yellow, broadly spathulate, $11-13.5 \mathrm{~mm}$ long and 5.5-6.5 mm wide. Outer stamens 8.1-8.9 mm long, inner stamens 9.7-10.6 mm long. Siliques linear with a distinct gynophore, 40-50 mm long and 2-2.5 $\mathrm{mm}$ wide. Seeds 0.8-1.1 $\mathrm{mm}$ long and 0.5-0.7 mm wide.

Variation. The subspecies shows little variation, except in leaf shape and size.

Chromosome number: $2 \mathrm{n}=26$ (Santo Antão, Ribeira do Paul NW of Cova, $1050 \mathrm{~m}$, Borgen 1975, sub Sinapidendron gracile).

Related taxa. Diplotaxis gorgadensis ssp. brochmannii differs from ssp. gorgadensis mainly in growth form, stiffness of the inflorescence, leaf texture, and leaf colour. In addition, the two subspecies occur in different habitats (see ssp. gorgadensis). Diplotaxis gorgadensis ssp. brochmannii has often been confused with $D$. glauca, which occurs on Sal, but it can be distinguished by its larger sepals, larger and broadly spathulate petals, longer stamens, and long, linear siliques.

Distribution and ecology. Diplotaxis gorgadensis ssp. brochmannii is a northern hygrophyte with a very limited distribution in the most favourable mountains on northeastern Santo Antão. The subspecies occurs exclusively in the Cova and Pico da Cruz areas and in the upper parts of the adjacent valleys, in particular Ribeira do Paul. All sites are within the humid zone, mainly between $1100 \mathrm{~m}$ and $1300 \mathrm{~m}$. The lowermost record is at $1080 \mathrm{~m}$ in Cova (leg. Rustan), the uppermost one at $1500 \mathrm{~m}$ at Pico da Cruz (leg. Chevalier). The plants grow in north- or northeast-exposed cliffs and gravelly slopes.

Abundance. The records of $D$. gorgadensis ssp. brochmannii represent six different populations, all of which have been observed after 1980. The subspecies is not uncommon within its distribution area, and one of the populations observed in 1982 was fairly large and comprised many juvenile plants. The total distribution is, however, very limited and situated within one of the most important agricultural districts in the Cape Verde Islands. Diplotaxis gorgadensis ssp. brochmannii is considered to be Vulnerable (VU).

Diplotaxis gracilis (Figs 91, 92)

Diplotaxis gracilis (Webb) O. E. Schulz, Bot. Jahrb. Syst. 54: 56 (1916) झ Sinapidendron gracile Webb in Hooker, Icon. Pl. 8: ad tab. 751 (1848). - Type: In vallibus ins. S. Nicolai, 29.3.1822, Forbes 30 (holotype: GEN!).

[= Brassica glauca (J. A. Schmidt) Kuntze, Revis. Gen. Pl. 1: 20 (1891), pro parte].

Illustrations: Webb (1848: Fig. 751, 1849: Fig. 1), Gomes et al. (1995b: p. 17), Rustan (1996: Fig. 16). 


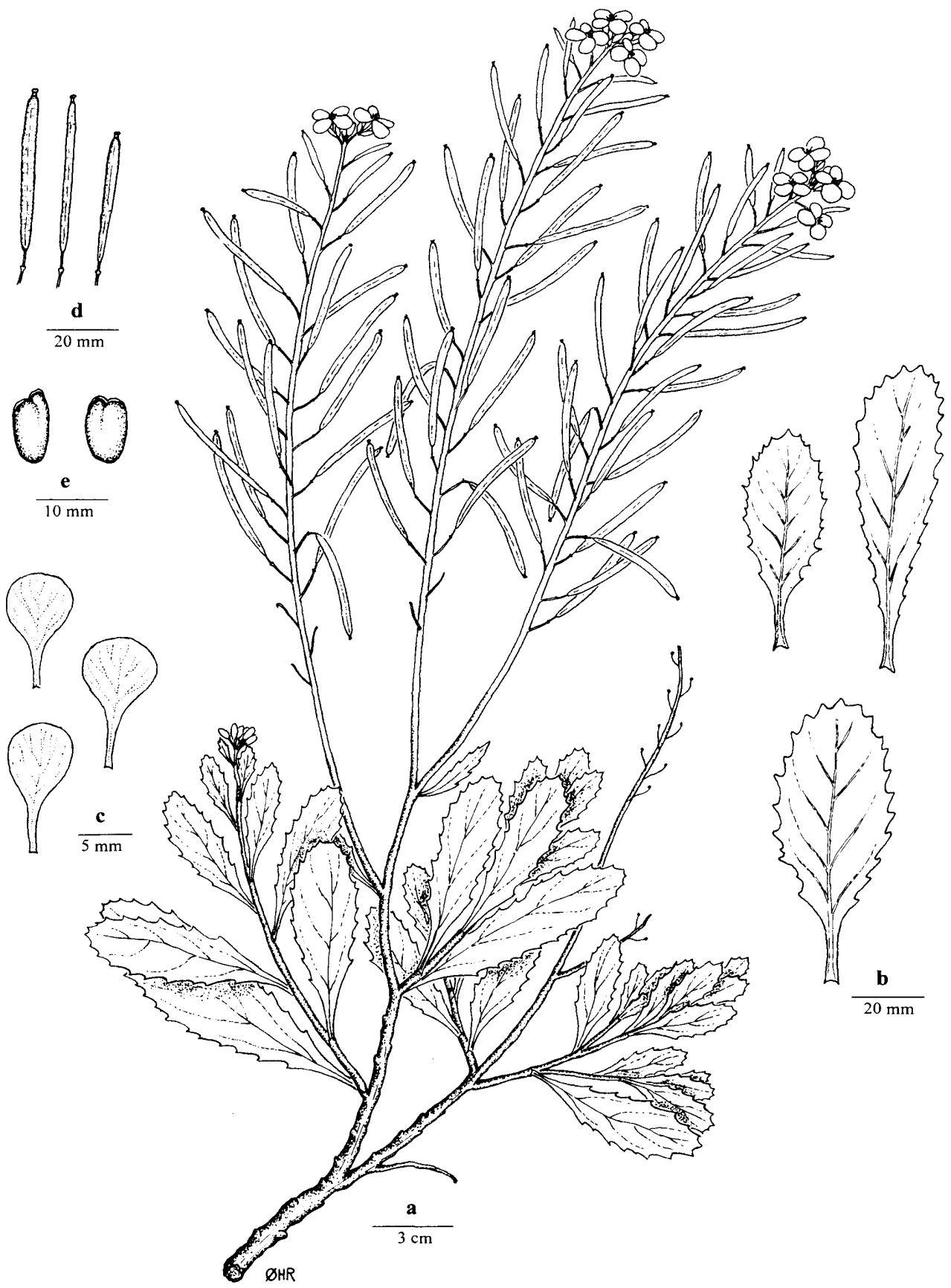

Fig. 89. Diplotaxis gorgadensis ssp. brochmannii. a. Habit; b. Leaves; c. Petals; d. Siliques; e. Seeds. Drawn by Ø. H. Rustan. Reprinted from Rustan (1996), Nord. J. Bot. 16 (with permission). 


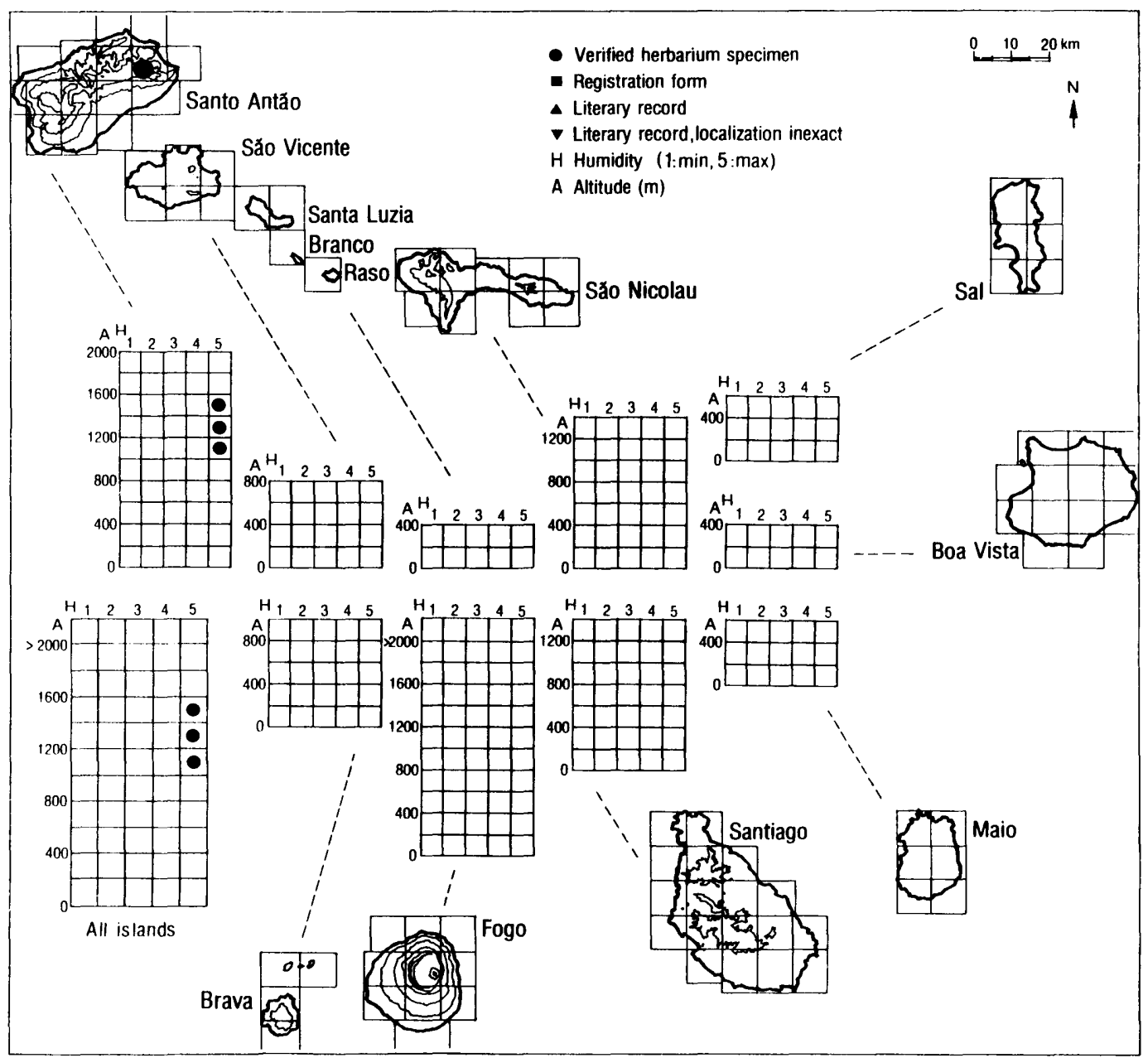

Fig. 90. Ecogeographic distribution of Diplotaxis gorgadensis ssp. brochmannii.

Description. Decumbent or rarely erect subshrub up to $0.7 \mathrm{~m}$ long; main stem strongly branched near the base; branches long, slender, much thinner than stem, with alternate leaves or rarely densely crowded leaves, ending in an apical, pendulous inflorescence. Stem strongly lignified, up to $8 \mathrm{~mm}$ thick, branches about $2 \mathrm{~mm}$ thick, glabrous or hirsutulous, older parts with greyish brown bark, younger parts green or violaceous; leaf scars present. Lower and middle cauline leaves oblong-obovate to widely obovate, rather fleshy, glabrous or rarely hirsutulous, green, glaucescent or violaceous, 1.5-5(-8) $\mathrm{cm}$ long, 1-3(-4) $\mathrm{cm}$ wide; leaf base attenuate with a $0.5-1.5 \mathrm{~cm}$ long petiole; apex obtuse; margin repand to remotely dentate, glabrous or rarely ciliate; upper leaves linear-spathulate. Inflorescence slender, glabrous, 


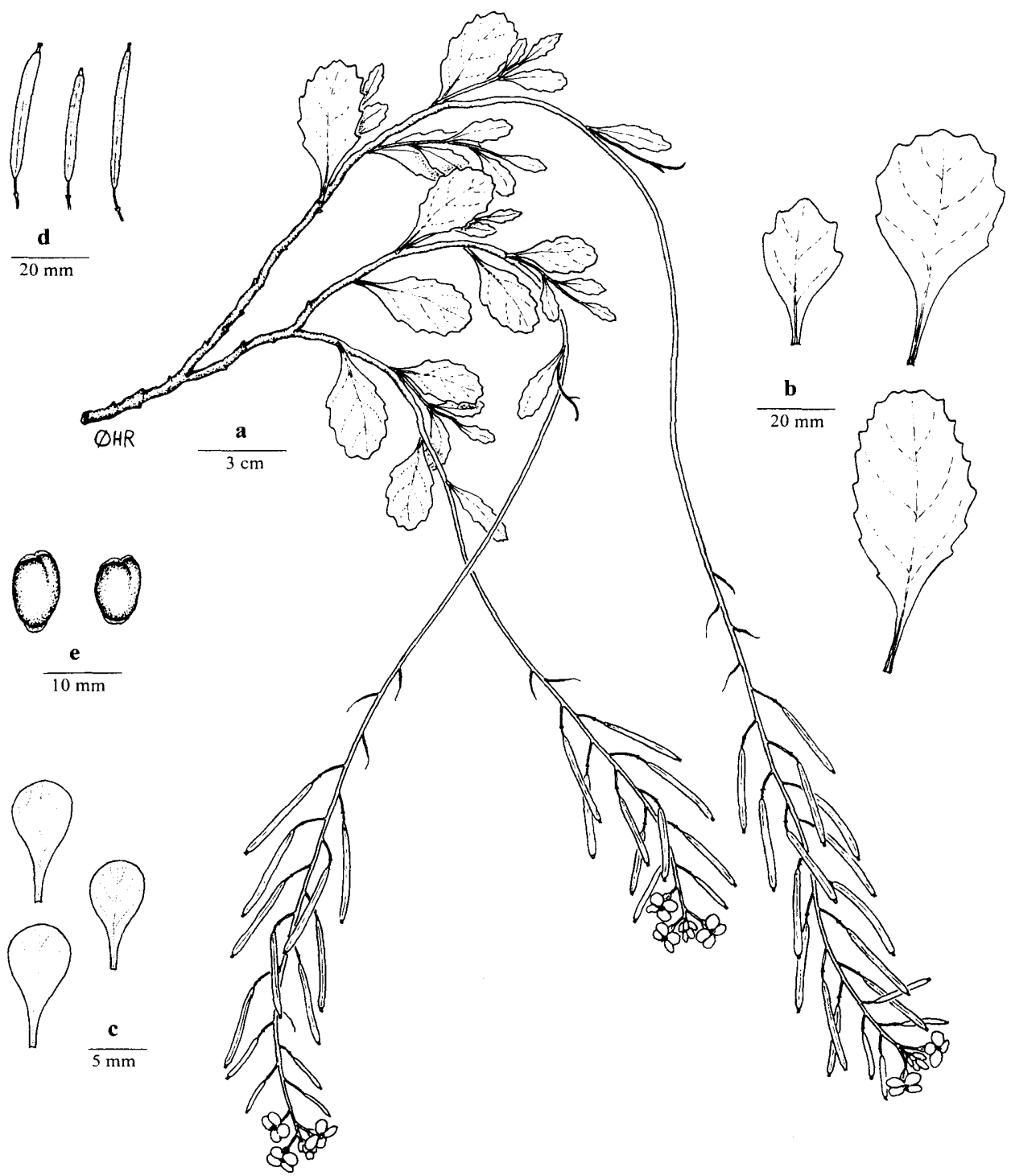

Fig. 91. Diplotaxis gracilis. a. Habit; b. Leaves; c. Petals; d. Siliques; e. Seeds. Drawn by $\varnothing$. H. Rustan. Reprinted from Rustan (1996), Nord. J. Bot. 16 (with permission). 


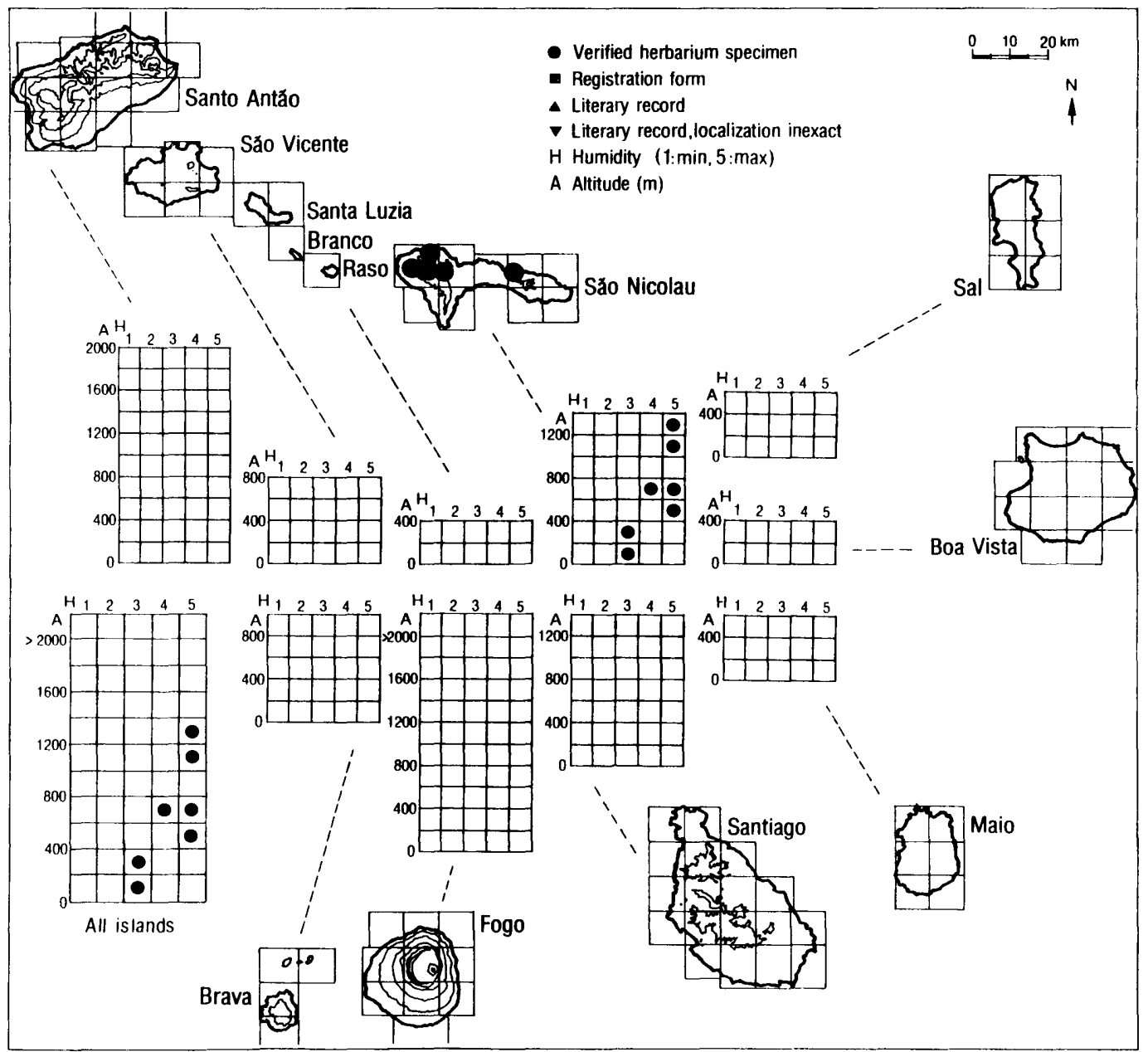

Fig. 92. Ecogeographic distribution of Diplotaxis gracilis.

green, glaucescent or violaceous, elongating in fruit to (20-)30-50 cm; branches few, bracteate, 20-40-flowered, siliques alternate in upper half. Pedicels erect-patent, glabrous, 4-6 $\mathrm{mm}$ long, 6-9 mm long in fruit. Sepals hirsute, yellowish green to violaceous, 4.5-6 mm long. Petals sulphur-yellow, broadly spathulate, tapering into a claw, (9-)10-12 mm long, 4-6(-7) $\mathrm{mm}$ wide. Outer stamens 5.5-7 mm long, inner stamens 7-8 mm long; anthers (1.8-)2-2.4 mm long. Siliques erect-patent, linear, flattened, $20-40 \mathrm{~mm}$ long, 1.5-2.5(-3) mm wide. 20-40 seeds per loculus, 2-seriate; valves glabrous, glaucescent or green, 1-nerved; gynophore (1-) 1.5-3.5 mm long; beak (1-)1.5-2.5 mm long. Seeds ellipsoid, yellowish brown to brown, 0.8$1.0(-1.1) \mathrm{mm}$ long, 0.5-0.7(-0.9) mm wide, surface smooth.

Variation. The populations at and close to Monte Gordo deviate by their erect habit and more hairy, thin leaves. Coastal populations often have glaucous, succulent leaves. The 
only population of $D$. gracilis known from eastern São Nicolau, at the coast below the distribution area of the exclusively montane species $D$. sundingii, has conspicuously wide siliques, suggesting that this population has been introgressed by $D$. sundingii. A similar pattern has been observed in Frankenia in this coastal area (see F. ericifolia ssp. caboverdeana).

Chromosome number: $2 \mathrm{n}=26(\mathrm{n}=13$, São Nicolau, Praia Branca, Rustan 1996).

Related taxa. Diplotaxis gracilis is habitually most similar to D. varia, especially the populations on Brava, but can be distinguished by its broadly spathulate petals, slightly shorter sepals, and smaller seeds. This similarity is probably a result of parallel evolution in response to similar ecological conditions. The most striking difference between the two species on São Nicolau, D. gracilis and D. sundingii, is the shape of the siliques, but these species also differ in growth form, stiffness of the inflorescence, and petal size. Diplotaxis gracilis may also resemble $D$. vogelii on São Vicente, but can be distinguished by its slender, decumbent habit, glabrous or hirsutulous stem, longer stamens, and longer, broader petals.

Distribution and ecology. Diplotaxis gracilis is a northern mesophyte with its main distribution in the western mountains of São Nicolau. A single population occurs along the northern coast in the eastern part of this island (Ponta Comeira). The species is most frequent in the humid zone, but several sites are situated within the subhumid and semiarid zones. Diplotaxis gracilis is mainly a montane species distributed between $600 \mathrm{~m}$ and $1200 \mathrm{~m}$, but some populations occur along the northern coast (down to $30 \mathrm{~m}$ at Ponta Comeira and $40 \mathrm{~m}$ in Ribeira Camarões; leg. Rustan). The uppermost record is at $1250 \mathrm{~m}$ at Monte Gordo (leg. Rustan). The plants usually grow in cliffs, occasionally as weeds in cultivated fields.

Abundance. The records of $D$. gracilis represent about nine different populations, of which most have been observed after 1980. The species is, however, probably declining because its main distribution area is heavily influenced by agriculture. Diplotaxis gracilis is therefore considered to be Vulnerable (VU).

\section{Diplotaxis hirta (Figs 93, 94)}

Diplotaxis hirta (A. Chev.) Rustan \& Borgen, Bocagiana 47: 4 (1979) Sinapidendron hirtum A. Chev., Bull. Mus. Nat. Hist. Natur., sér. 2, 7: 141 (1935) EDiplotaxis harra (Forssk.) Boiss. ssp. hirta (A. Chev.) Sobrino Vesperinas, Candollea 48: 143 (1993). - Syntypes: Ile de Fogo, Chã das Caldeiras, 23.-24.7.1934, Chevalier 44864, 44849 (P!); S. Tiago, de Praia à Ribeira da Barca, Chevalier 44539 (P!). — Lectotype (designated by Rustan \& Borgen 1979: 4): Chevalier 44849 (P!; isolectotypes: P [two sheets]!).

= Sinapidendron hirtum A. Chev. var. paucipilosum A. Chev., Bull. Mus. Nat. Hist. Natur., sér. 2, 7: 142 (1935). - Syntypes: Ile de Fogo, Chupadeiro, 25.-26.7.1934, Chevalier 44891 (P!); Ile de Fogo, Chã das Caldeiras, Chevalier 44958 (P!). - Lectotype (designated by Rustan \& Borgen 1979: 4): Chevalier 44891 (P!).

= Sinapidendron decumbens A. Chev., Bull. Mus. Nat. Hist. Natur., sér. 2, 7: 142 (1935) $\equiv$ Diplotaxis decumbens (A. Chev.) Rustan \& Borgen, Bocagiana 47: 4 (1979). -- Type: Ile de Fogo, Curral Fundo, à $1000 \mathrm{~m}$ d'alt., sur Ribeira Lomba à 15 km NNE S. Filipe, 7.8.1934, Chevalier 45206 (holotype: P!).

Illustration: Rustan (1996: Fig. 17).

Description. Erect or decumbent subshrub up to $0.7 \mathrm{~m}$ high; main stem branched near the base, old specimens often forming large tufts; branches stiff or slender, much thinner than stem, with alternate or crowded leaves, ending in an apical, erect or pendulous inflorescence. Stem strongly lignified, up to $9 \mathrm{~mm}$ thick, branches about $5 \mathrm{~mm}$ thick, moderately to densely hispid, older parts with greyish brown bark, younger parts glaucous or violaceous-green; leaf scars present. Lower and middle cauline leaves oblong-obovate, fleshy or thin, hispid or rarely 


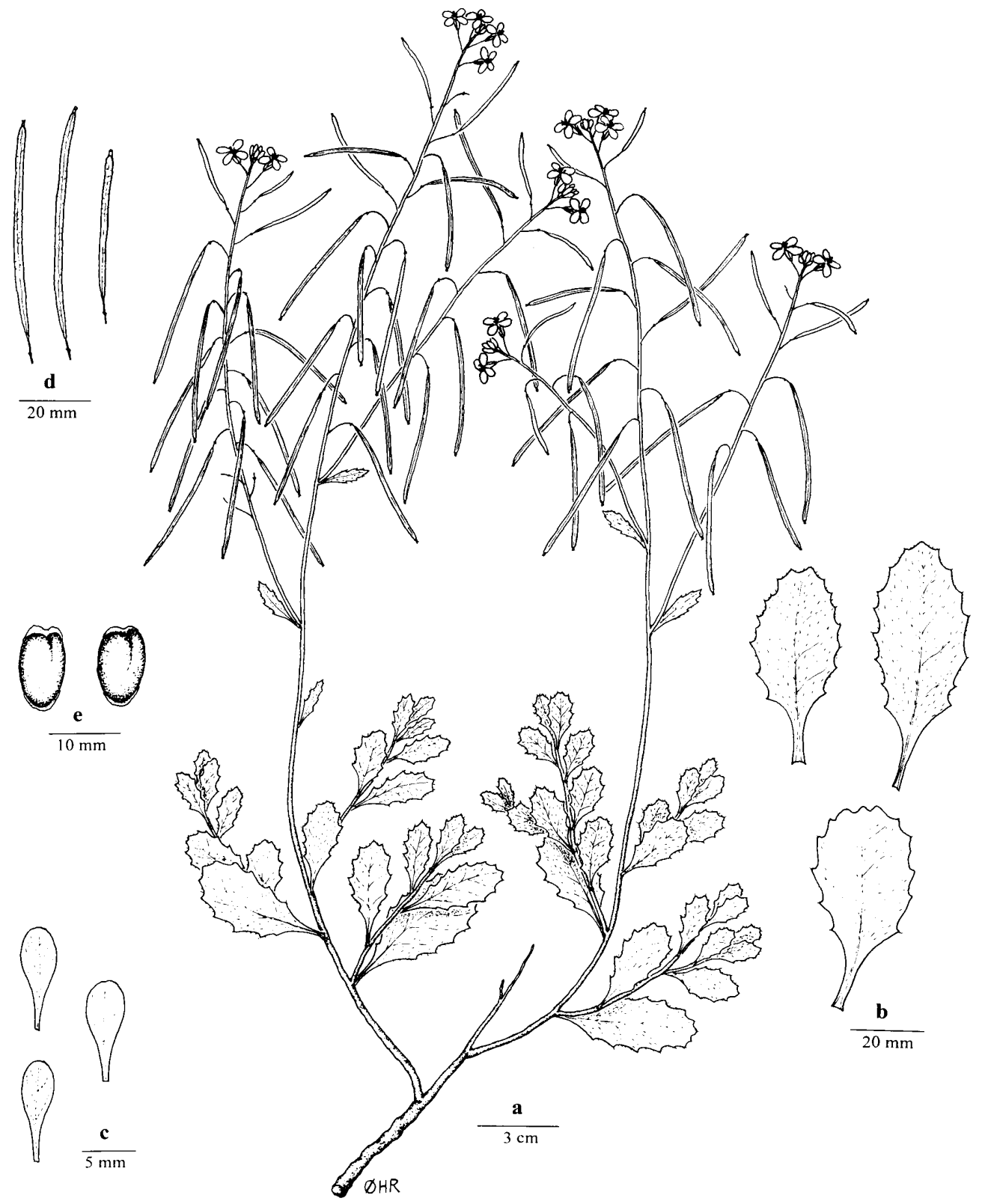

Fig. 93. Diplotaxis hirta. a. Habit; b. Leaves; c. Petals; d. Siliques; e. Seeds. Drawn by Ø. H. Rustan. Reprinted from Rustan (1996), Nord. J. Bot. 16 (with permission). 


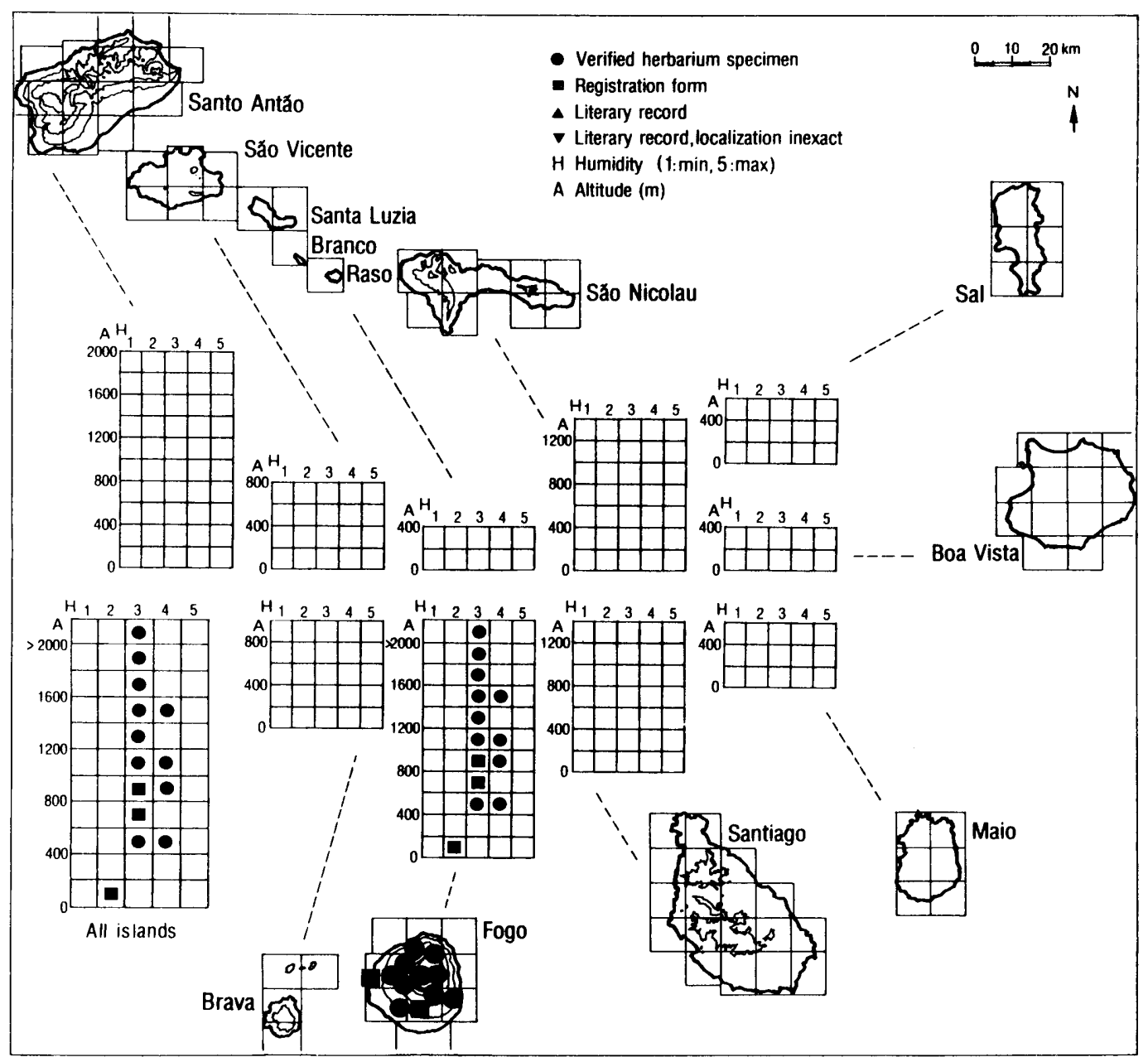

Fig. 94. Ecogeographic distribution of Diplotaxis hirta.

hirsute, glaucous or rarely green, (1-)2-6(-11) $\mathrm{cm}$ long, $(0.5-) 1-3(-5) \mathrm{cm}$ wide; leaf base attenuate with a $0.5-1.5(-2) \mathrm{cm}$ long petiole; apex acute to obtuse; margin dentate, remotely dentate or irregularly dentate, ciliate; upper leaves linear-spathulate. Inflorescence erect or pendulous, slender, glabrous or rarely minutely hirsutulous, glaucous or violaceous, elongating in fruit to $20-50 \mathrm{~cm}$, often persistent; branches many or few, bracteate, 20-50flowered, siliques alternate in upper half. Pedicels erect-patent, glabrous, 4-6(-10) $\mathrm{mm}$ long, $10-20(-25) \mathrm{mm}$ long and often pendent in fruit. Sepals hirsute, yellowish green to violaceous, 4-5.5(-6) mm long. Petals sulphur-yellow, narrowly spathulate, tapering into a claw, 8-10(-11) $\mathrm{mm}$ long, 3-4(-4.5) $\mathrm{mm}$ wide. Outer stamens 4.5-6 $\mathrm{mm}$ long, inner stamens 6.5-8.5 $\mathrm{mm}$ long; anthers 2.1-2.5 mm long. Siliques pendulous or erect-patent, linear, flattened, (30-)40-70(-80) $\mathrm{mm}$ long, (1-)1.5-2 mm wide, 20-40 seeds per loculus, (1-)2-seriate; valves glabrous, glaucous 
or green-violaceous, 1-nerved; gynophore (1.5-)2-3(-4) mm long; beak 1-2 mm long. Seeds oblong, yellowish brown to dark brown, 1.0-1.3 $\mathrm{mm}$ long, 0.6-0.9 $\mathrm{mm}$ wide, surface smooth.

Variation. The species is very variable in habit, indument density, leaf size, and leaf texture. Chevalier's (1935a) descriptions of $D$. hirta var. paucipilosum and $D$. decumbens represent parts of a continuous variation pattern which is considered of no taxonomic significance. Extensive sampling and observations in and around the type locality of $D$. decumbens revealed a mixture of "typical" D. decumbens, "typical" D. hirta, and transitional forms. Plants growing in dry, exposed habitats were erect, densely hispid, and glaucous. In shady, more humid valleys, the plants developed a slender, decumbent habit, and the leaves were larger, less hairy and green. Siliques with more or less uni-seriate seeds were also found in "typical" D. hirta (Rustan 1996).

Chromosome number: $2 \mathrm{n}=26(2 \mathrm{n}=26$, Fogo, Chã das Caldeiras, $1740 \mathrm{~m}$, Borgen 1975 (as Sinapidendron hirtum); $\mathrm{n}=13$, Fogo, Chã das Caldeiras, 1740 m, Rustan 1996).

Related taxa. Many populations of Diplotaxis hirta are habitually resembling $D$. antoniensis, which occurs on Santo Antão (see that species). Other populations show morphological affinities towards D. varia, which occurs on Santiago and Brava, but the populations of $D$. hirta can be distinguished by their longer siliques and shorter sepals.

Distribution and ecology. Diplotaxis hirta is a southern mesophyte. It is restricted to Fogo, but widespread in montane areas on this island. The species is most frequent in the semiarid zone, but it is also known from several sites in the subhumid zone. Notably, D. hirta does never occur in the humid zone; it is absent from the most favourable northern and northeastern mountain slopes of Fogo. Only a single plant has been observed in the arid zone, at $30 \mathrm{~m}$ on the western coast (registration form, Rustan \& Brochmann); this plant was certainly an ephemeral dispersed by a river from the montane, primary populations. The main altitudinal distribution of $D$. hirta is between $800 \mathrm{~m}$ and $2000 \mathrm{~m}$. The lowermost established population has been recorded at $450 \mathrm{~m}$ at the southern mountain slope of Fogo (registration form, Rustan \& Brochmann), and the species extends to the top of the volcanic cone at 2800 $\mathrm{m}$ (leg. Lobin). The species is characteristic of the vegetation on volcanic gravel in the Chã das Caldeiras area, but the plants are also common in cliffs, gravelly slopes, roadsides, and cultivated fields in the southern and southwestern parts of the island.

Abundance. The large number of records of this species represents about 18 different populations. Diplotaxis hirta is widespread and locally very common on Fogo. Some populations are very large, comprising several thousand plants, in particular at the southern slope of the island. Diplotaxis hirta is classified as Lower Risk (LR).

\section{Diplotaxis sundingii (Figs 95, 96)}

Diplotaxis sundingii Rustan, Nord. J. Bot. 16: 47 (1996). - Type: Cape Verde Islands, São Nicolau, Alto das Cabaças, $640 \mathrm{~m}, 2.2 .1982, \emptyset$. H. Rustan \& C. Brochmann ØHR 2031 (holotype: O!).

Illustration: Rustan (1996: Fig. 18).

Description. Erect subshrub up to $0.6 \mathrm{~m}$ high; main stem branched near the base; branches rigid, slightly thinner than stem, with alternate leaves, ending in an apical, erect inflorescence. Stem strongly lignified, up to $4 \mathrm{~mm}$ thick, glabrous or hirsute, older parts with greyish brown bark, younger parts violaceous or green; leaf scars present. Lower and middle cauline leaves oblong-obovate to widely obovate, thin, hirsutulous or hirsute, green, often violaceous along 


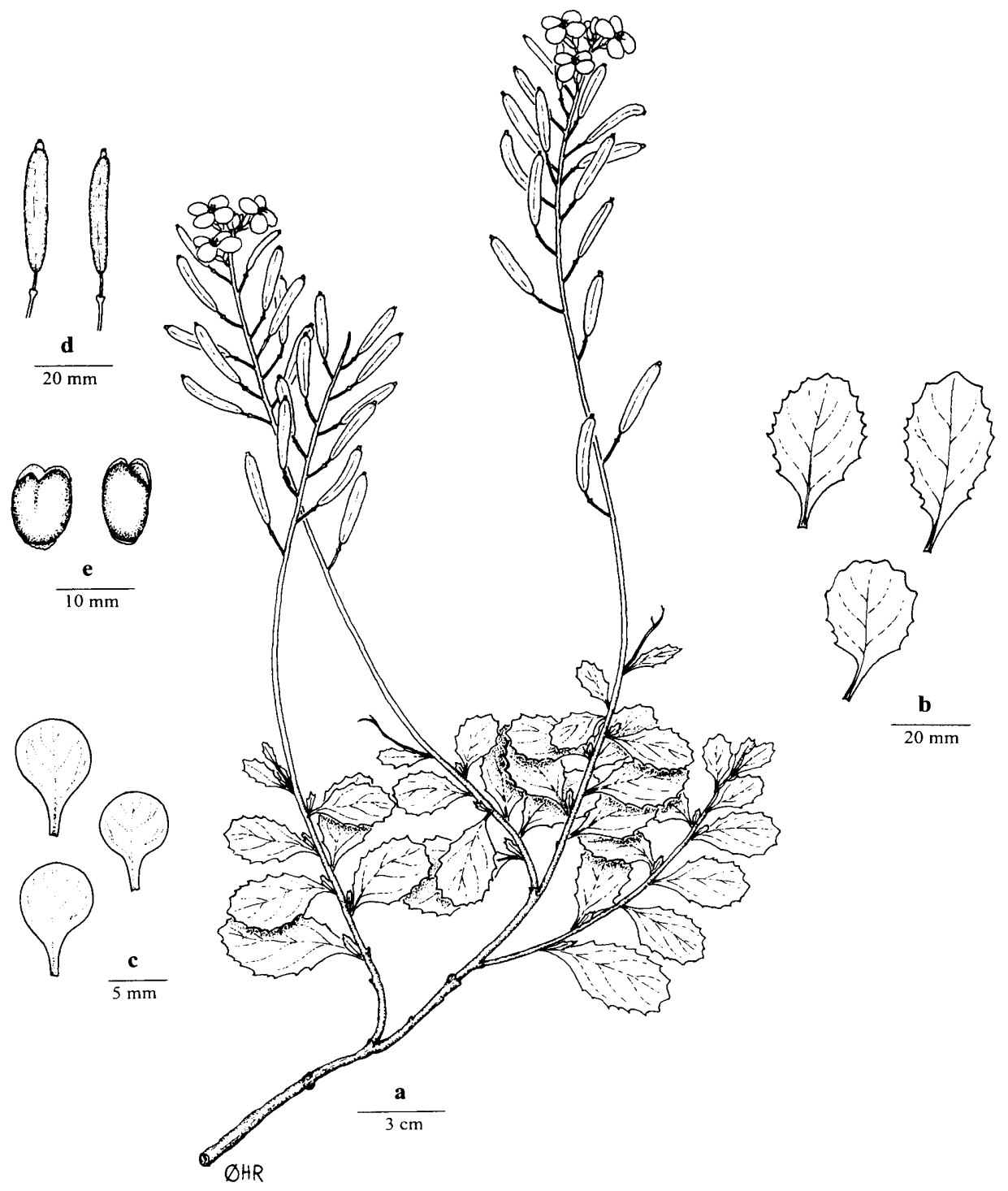

Fig. 95. Diplotaxis sundingii. a. Habit; b. Leaves; c. Petals; d. Siliques; e. Seeds. Drawn by Ø. H. Rustan. Reprinted from Rustan (1996), Nord. J. Bot. 16 (with permission). 


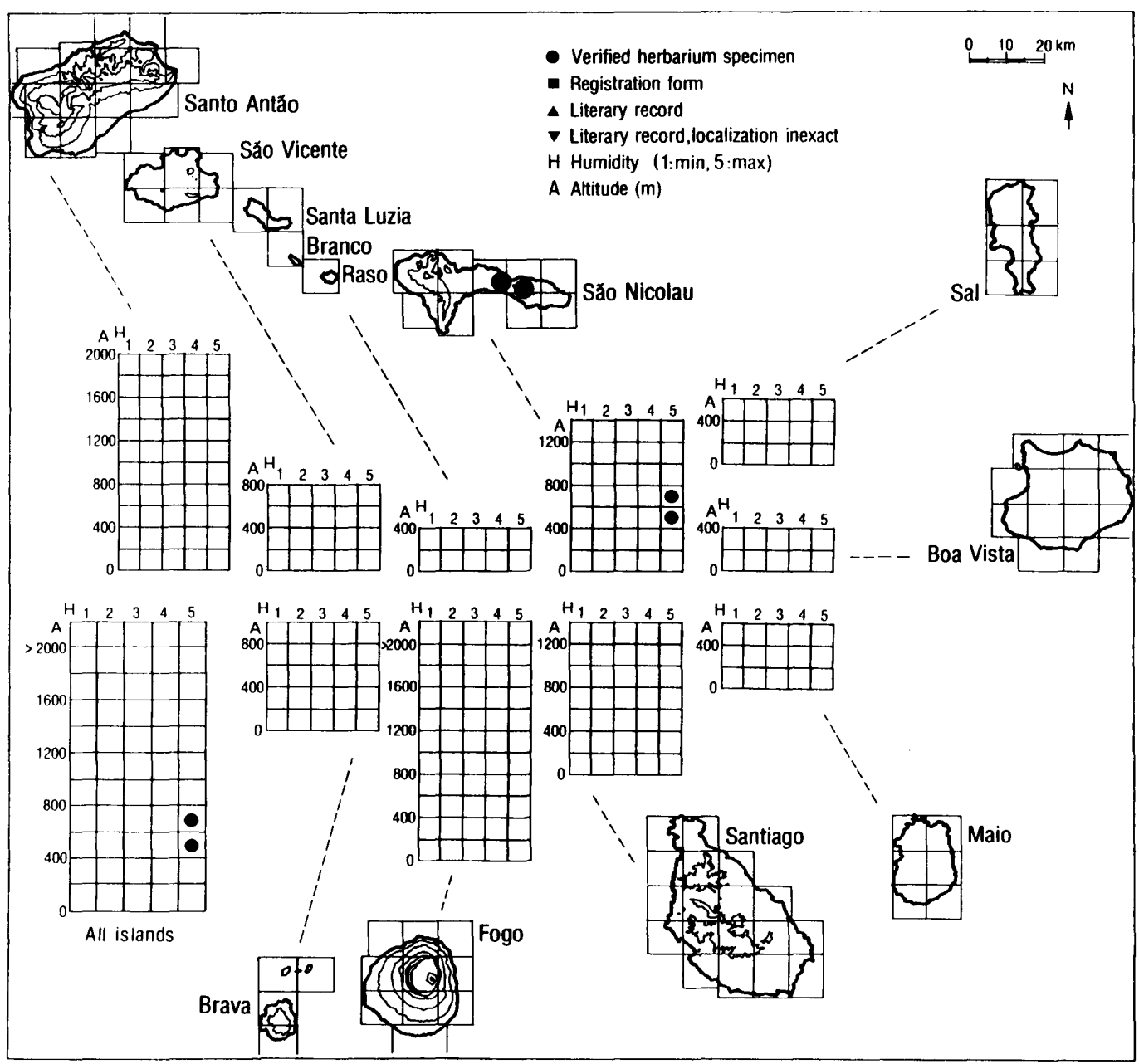

Fig. 96. Ecogeographic distribution of Diplotaxis sundingii.

veins, $2.5-5(-8) \mathrm{cm}$ long, $2-3.5(-5) \mathrm{cm}$ wide; leaf base attenuate with a $1-1.5(-2) \mathrm{cm}$ long petiole; apex obtuse; margin dentate, irregularly dentate or rarely remotely dentate, ciliate; upper leaves spathulate. Inflorescence rigid, glabrous or hirsutulous in lower part, elongating in fruit to $15-40 \mathrm{~cm}$; branches absent or few, bracteate, 30-60-flowered, siliques alternate in upper half and crowded toward the tip. Pedicels erect-patent, glabrous, 5-6 mm long, 6-14 mm long in fruit. Sepals hirsute, yellowish green, 5-6 mm long. Petals sulphur-yellow, broadly spathulate, tapering into a claw, 8-10 mm long, 5-7 mm wide. Outer stamens 5.5-7 mm long, inner stamens 7.5-8.5 mm long; anthers 2.3-2.5 mm long. Siliques erect-patent, narrowly oblong to oblanceolate, flattened, 25-35 mm long, 3-4 mm wide, 30-40 seeds per loculus, 2seriate; valves glabrous, green, 1-nerved; gynophore 1.5-2.5 mm long; beak 1.5-2 mm long. Seeds ellipsoid, yellowish brown, 0.8-1.0 $\mathrm{mm}$ long, 0.5-0.7 $\mathrm{mm}$ wide, surface smooth. 
Variation. The petal colour varies from light sulphur-yellow in the Alto Joaquina population to intense, dark yellow in the Alto das Cabaças population. See also D. gracilis. 1996).

Chromosome number: $2 \mathrm{n}=26(\mathrm{n}=13$, São Nicolau, Alto Joaquina, $500 \mathrm{~m}$, Rustan

Related taxa. Diplotaxis sundingii is most similar to D. glauca, which occurs on Sal (see that species). The second species occurring on São Nicolau, D. gracilis, differs from $D$. sundingii in several characters, but possible introgression has been found in one population (see D. gracilis).

Distribution and ecology. Diplotaxis sundingii is a northern hygrophyte with a very restricted distribution in the mountains on eastern São Nicolau. Only two, disjunct populations are known; one population occurs between $500 \mathrm{~m}$ and $620 \mathrm{~m}$ in the Alto Joaquina mountain (leg. Sunding, leg. Rustan), and one population occurs at $640 \mathrm{~m}$ in the Alto das Cabaças mountain (leg. Rustan, leg. Kilian \& Leyens, leg. Lobin). Both sites are located within the humid zone. A single plant has been collected at $270 \mathrm{~m}$ in the arid zone at the southern slope of Alto Joaquina; this plant occurred in a dry riverbed and was certainly dispersed by the river during the rain season. In the mountains, the plants grow in north- or northeast-exposed cliffs and moist, gravelly slopes.

Abundance. There are only 12 records of this species, representing the two abovementioned populations. Both populations have been observed after 1980. The species is confined to a very small area with a low number of populations (two) and individuals (possibly not more than 200). Diplotaxis sundingii is considered to be Rare (R).

\section{Diplotaxis varia (Figs 97, 98)}

Diplotaxis varia Rustan, Nord. J. Bot. 16: 47 (1996). - Type: Cape Verde Islands, Santiago, between Agua Grande and Cruz de Gotô Bravo, 800-920 m, 16.1.1980, Ø. H. Rustan 814 (holotype: O!).

Illustration: Rustan (1996: Fig. 19).

Description. Erect or decumbent subshrub up to $0.8 \mathrm{~m}$ long; main stem strongly branched near the base; branches slender, much thinner than stem, with alternate leaves, ending in an apical, pendulous inflorescence. Stem strongly lignified, up to $7 \mathrm{~mm}$ thick. glabrous or hirsute, older parts with greyish brown bark, younger parts violaceous or green; leaf scars present. Lower and middle cauline leaves oblong-obovate, ovate or widely obovate, rather thin or fleshy, glabrous or hirsute, green, glaucescent or violaceous, (1.5-)2.5-5(-10) cm long, $(0.5-) 1.5-3.5(-5) \mathrm{cm}$ wide; leaf base attenuate with a $0.5-1(-1.5) \mathrm{cm}$ long petiole; apex acute or obtuse; margin dentate, irregularly dentate or rarely remotely dentate, ciliate; upper leaves spathulate. Inflorescence slender, glabrous, green, glaucescent or violaceous, elongating in fruit to $20-40 \mathrm{~cm}$; branches few or absent, bracteate, 20-40-flowered, siliques alternate in upper half. Pedicels erect-patent, glabrous, 4-8(-12) $\mathrm{mm}$ long, 6-14(-17) mm long in fruit. Sepals hirsute, yellowish green or violaceous, (5-)5.5-7 mm long. Petals sulphur-yellow, narrowly spathulate, tapering into a claw, 8-11(-13) mm long, (3-)3.5-5 mm wide. Outer stamens 5-7 mm long, inner stamens 6.5-8.5 mm long; anthers 2.0-2.5 mm long. Siliques erect-patent, linear, flattened, (25-)30-45(-50) mm long, (1-)1.5-2(-3) mm wide, 30-40 seeds per loculus, 2-seriate; valves glabrous, green, glaucescent or violaceous, 1-nerved; gynophore 1.5-3 mm long; beak 1-3(-4) mm long. Seeds ellipsoid, yellowish brown to brown, 0.9-1.3 $\mathrm{mm}$ long, 0.6-0.8 $\mathrm{mm}$ wide, surface smooth. 


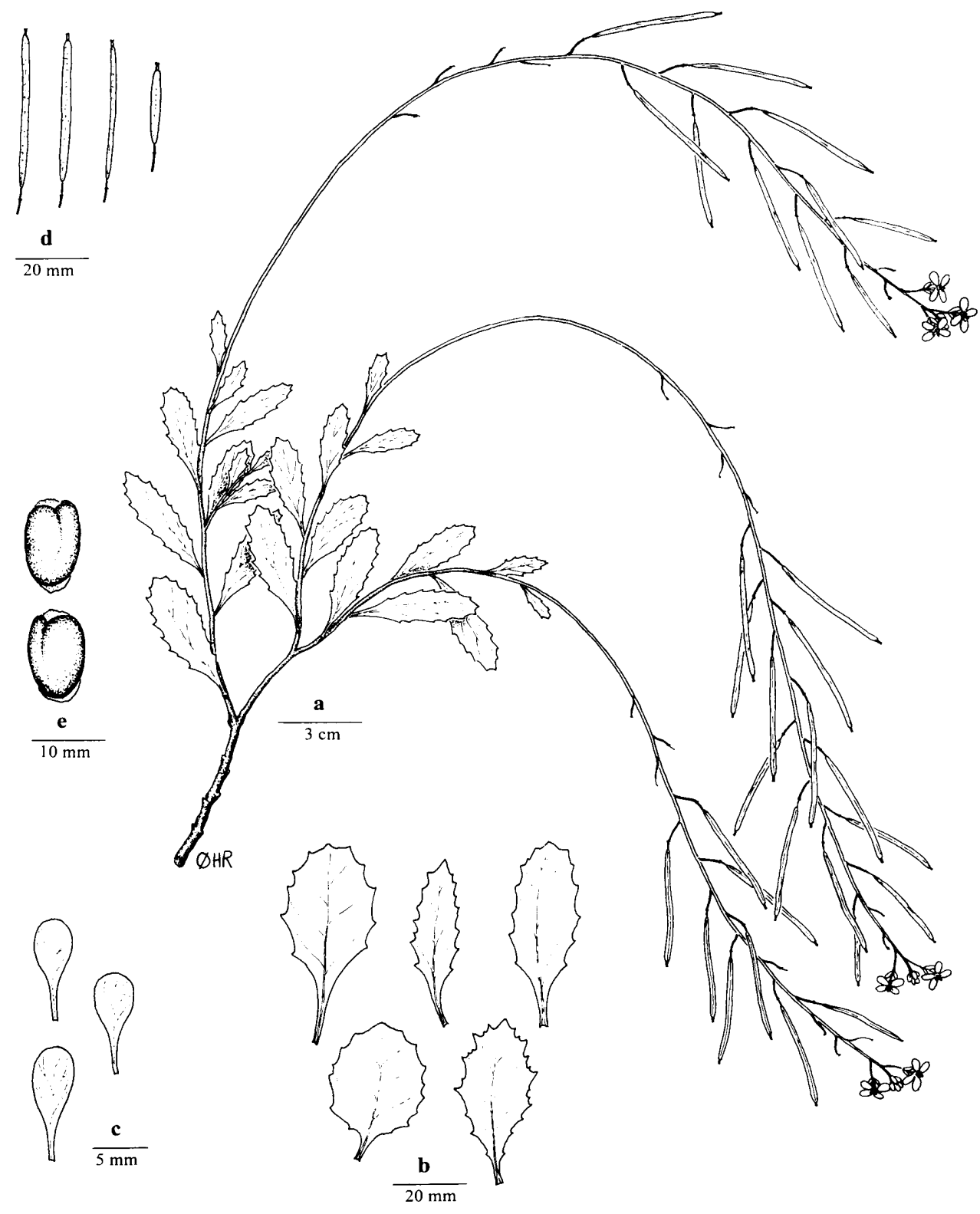

Fig. 97. Diplotaxis varia. a. Habit; b. Leaves; c. Petals; d. Siliques; e. Seeds. Drawn by Ø. H. Rustan. Reprinted from Rustan (1996), Nord. J. Bot. 16 (with permission). 


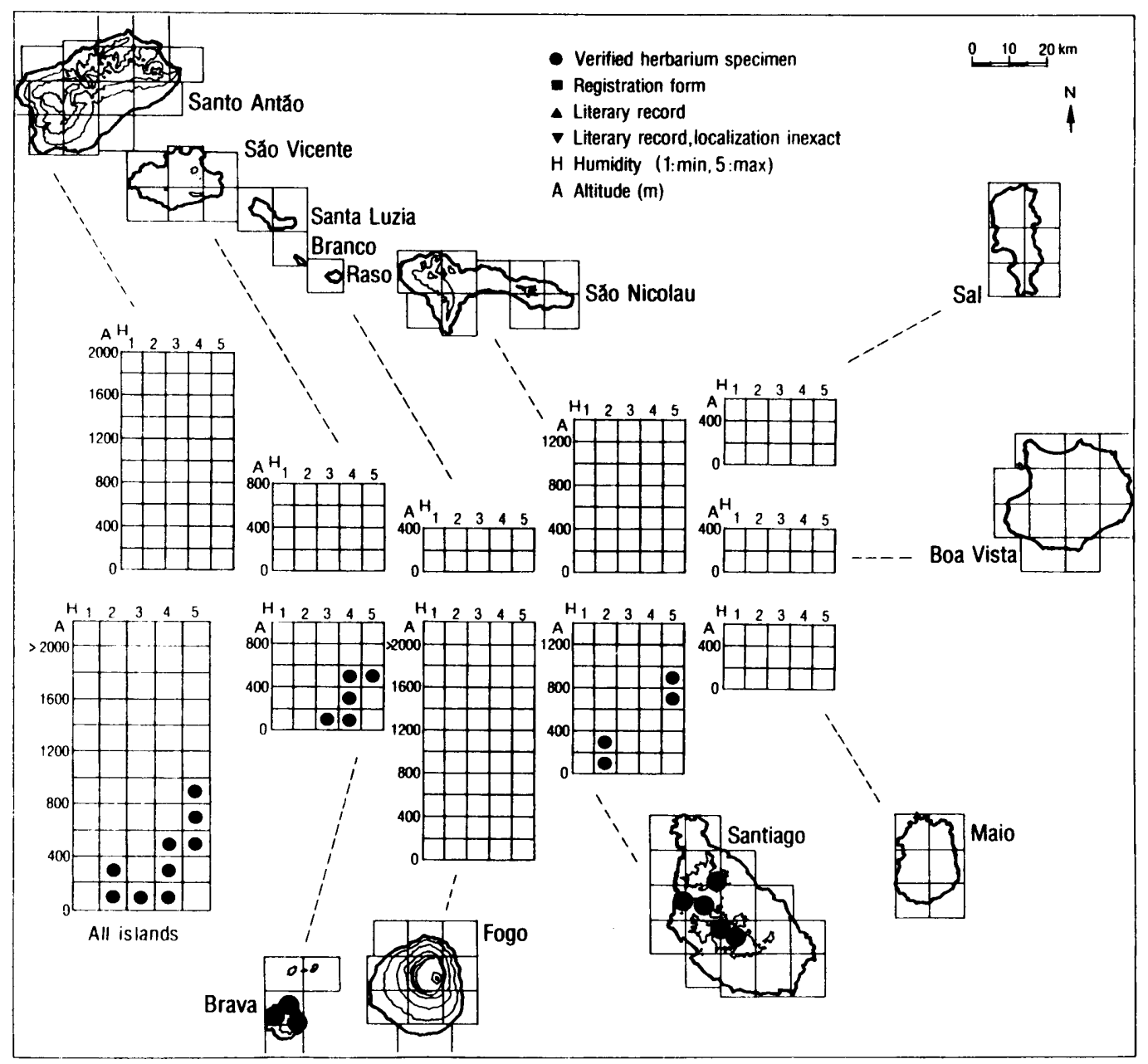

Fig. 98. Ecogeographic distribution of Diplotaxis varia.

Variation. The species is very variable in habit and leaf outline. The coastal populations in Brava deviate by their succulent, small leaves, and small flowers.

Chromosome number: Unknown.

Related taxa. Diplotaxis varia resembles $D$. gracilis, which occurs on São Nicolau, as well as $D$. hirta, which occurs on Fogo (see these species).

Distribution and ecology. Diplotaxis varia is a southern mesophyte with a scattered occurrence on two of the southern islands, Santiago and Brava. Most populations occur in the humid zone, and some populations occur in the subhumid and semiarid zones. One lowland valley population occurs from $150 \mathrm{~m}$ to $230 \mathrm{~m}$ in the arid zone on western Santiago (leg. Rustan); this population is fairly small and possibly secondary, as a large montane population occurs in the upper part of this valley. The species is otherwise montane on Santiago, 
occurring between $600 \mathrm{~m}$ and $920 \mathrm{~m}$ (leg. Rustan). On Brava, the species comprises montane populations as well as several coastal ones. On this island, it is distributed from $20 \mathrm{~m}$ (Monte Gambia at the northeastern coast, leg. Rustan) to $600 \mathrm{~m}$ (Ribeira Fundo do Cachaço, leg. Rustan). The plants usually grow in cliffs, but also occur in gravelly river slopes.

Abundance. The large number of collections of this species represents about 13 different populations. Populations from most of the distribution area have been observed after 1980. Some populations are very large (e.g., more than 1000 plants in the Ribeira Fundo do Cachaço population on Brava). It is nevertheless likely that the populations are generally declining, because most of them are situated in areas heavily influenced by human activities. At present, we classify Diplotaxis varia as Indeterminate (I) because of lack of exact information.

\section{Diplotaxis vogelii (Figs 99, 100)}

Diplotaxis vogelii (Webb) Cout., Arq. Univ. Lisboa 1: 248 (1914) $\equiv$ Sinapidendron vogelii Webb in Hooker,

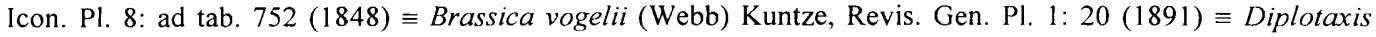
vogelii (Webb) O. E. Schulz, Bot. Jahrb. Syst. 54: 56 (1916), nom. illeg. - Type: In ins. S. Vicentii, 6.1841, Vogel 32 (holotype: G-DC!).

Illustrations: Webb (1848: Fig. 752, 1849: Fig. 2), Rustan (1996: Fig. 20).

Description. Erect subshrub up to $0.4 \mathrm{~m}$ high; main stem branched near the base; branches short, stiff, much thinner than stem, with alternate or densely crowded leaves, ending in an apical, short and erect inflorescence. Stem strongly lignified, up to $10 \mathrm{~mm}$ thick, hispid, older parts with greyish brown bark, younger parts violaceous to green; leaf scars prominent. Lower and middle cauline leaves oblong-obovate, thin or fleshy, hirsute, green, $3-5(-7) \mathrm{cm}$ long, 1$3(-5) \mathrm{cm}$ wide; leaf base attenuate with a $1 \mathrm{~cm}$ long petiole; apex acute or obtuse; margin remotely dentate, irregularly dentate or dentate, ciliate; upper leaves linear-spathulate. Inflorescence slender, glabrous, green to violaceous, elongating in fruit to $20-30 \mathrm{~cm}$; branches absent or few, bracteate, 10-40-flowered, siliques alternate in upper half and often crowded toward the tip. Pedicels erect-patent, glabrous, 5-6 mm long, 5-10 mm long in fruit. Sepals hirsute, yellowish green to violaceous, 4-5 mm long. Petals sulphur-yellow, broadly spathulate, tapering into a claw, (7-)8-10 mm long, 3-4.5 mm wide. Outer stamens 4-5(-6.2) $\mathrm{mm}$ long, inner stamens 6-7(-8) $\mathrm{mm}$ long; anthers $1.8-2.1 \mathrm{~mm}$ long. Siliques erect-patent, linear or narrowly oblong, flattened, $25-40 \mathrm{~mm}$ long, 2-3(-4) $\mathrm{mm}$ wide, 20-40 seeds per loculus, 2-seriate; valves glabrous, green to violaceous, 1-nerved; gynophore 1-2 mm long; beak 1-2(-3) mm long. Seeds ellipsoid, yellowish brown to brown, 0.8-1.1 mm long, 0.5-0.7 $\mathrm{mm}$ wide, surface smooth.

Variation. There is no significant intraspecific variation, except that young plants have conspicuously large, rosulate leaves and few-branched inflorescences, whereas older plants become strongly branched with small, alternate leaves. In coastal, salt-exposed populations, the leaves and siliques are often succulent.

Chromosome number: Unknown.

Related taxa. Diplotaxis vogelii resembles $D$. gracilis, which occurs on São Nicolau, but it differs in several characters (see D. gracilis). 

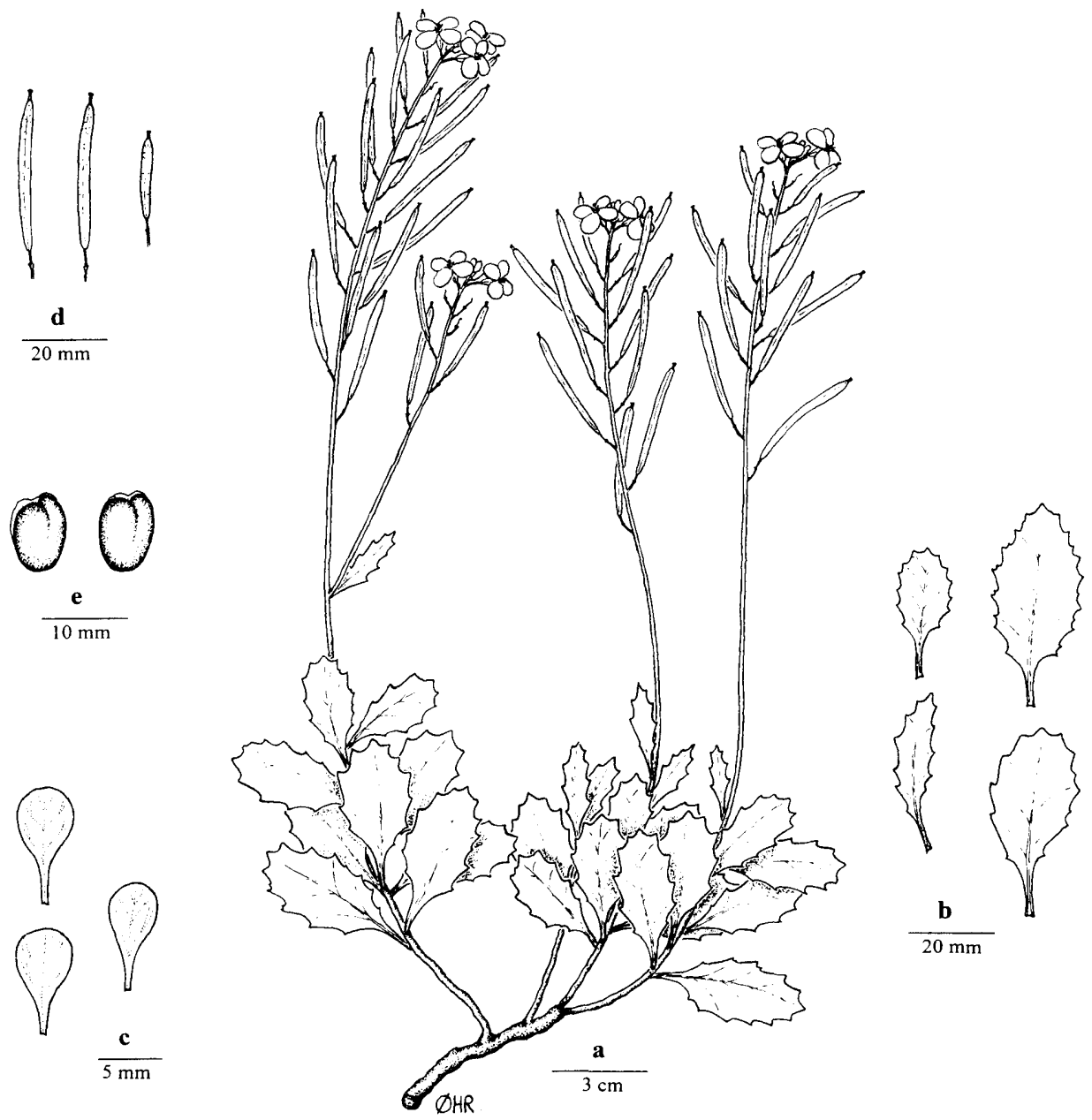

$20 \mathrm{~mm}$

Fig. 99. Diplotaxis vogelii. a. Habit; b. Leaves; c. Petals; d. Siliques; e. Seeds. Drawn by Ø. H. Rustan. Reprinted from Rustan (1996), Nord. J. Bot. 16 (with permission). 


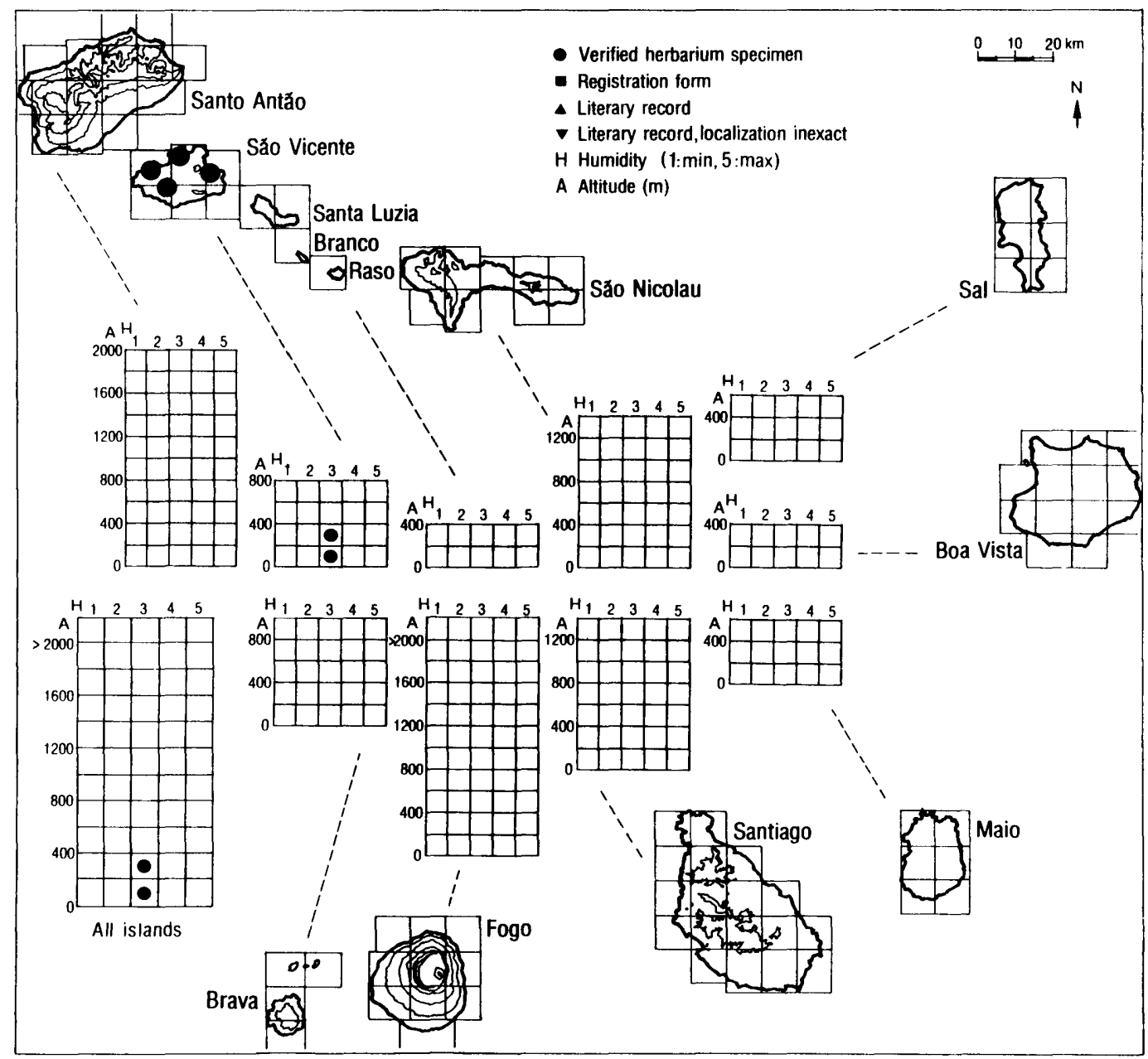

Fig. 100. Ecogeographic distribution of Diplotaxis vogelii.

Distribution and ecology. Diplotaxis vogelii is a northern mesophyte restricted to the lower mountains on São Vicente. It is confined to the semiarid zone, and occurs from $100 \mathrm{~m}$ (Gôa Baixo, leg. Rustan) to $300 \mathrm{~m}$ (Tope de Caixa, leg. Sunding; Tope Suzanna, leg. Rustan). It is absent from the highest and most humid mountain, Monte Verde, where the largest populations of most of the endemic taxa on São Vicente are found. Diplotaxis vogelii grows mainly in north- to northeast-exposed cliffs, but also in gravelly slopes.

Abundance. The records of this species represent about six different populations. Most populations have been observed after 1980. The populations are small; we have not observed more than 30 plants in one population. It is likely that most populations are continuously declining, but because of lack of exact information we presently classify Diplotaxis vogelii as Indeterminate (I). 


\section{Erysimum L.}

The genus Erysimum contains some 120 annual and perennial species distributed in Europe and Asia, with a centre of diversity in the Mediterranean region. The genus is represented by a single, endemic species in the Cape Verde Islands.

Erysimum caboverdeanum (Figs 101, 102)

Erysimum caboverdeanum (A. Chev.) Sunding, Garcia de Orta, Sér. Bot. 2: 11 (1974) $\equiv$ Matthiola caboverdeana A. Chev., Bull. Mus. Nat. Hist. Natur., sér. 2, 7: 139 (1935) $\equiv$ Cheiranthus caboverdeanus (A. Chev.) R. Fern., Garcia de Orta 7: 755 (1959). - Type: Fogo, Chã das Caldeiras, 23.-24.7.1934, Chevalier 44857 (holotype: P).

Illustrations: Chevalier (1935a: Tab. 16 sub Matthiola caboverdeana), Fernandes (1959: Fig. 1 sub Cheiranthus caboverdeanus), Lobin \& Groh (1980: Fig. 10), Rustan \& Brochmann (1985: Fig. 1), Lobin \& Ohm (1987: Fig. 28), Gomes et al. (1995b: p. 17).

Literature: Fernandes (1959), Polatschek (1976).

Description. Moderately branched, ascending to erect subshrub or shrub up to $1 \mathrm{~m}$ high. Branches lignified at least in lower half. Leaves narrowly linear, up to $4 \mathrm{~cm}$ long and $0.2 \mathrm{~cm}$ wide, sparsely pubescent, apex acute, margin nearly entire to finely dentate. Inflorescence dense, terminal. Petals light violet, up to $15 \mathrm{~mm}$ long and $3 \mathrm{~mm}$ broad. Siliques $20-40 \mathrm{~mm}$ long, style distinct. Seeds winged, light brown.

Variation. The material shows no essential variation.

Chromosome number: Unknown.

Related taxa. Erysimum caboverdeanum is apparently most closely related to $E$. bicolor (Hornem.) DC. and E. scoparium (Brouss. ex Willd.) Wettst. of the Canary Islands and Madeira.

Distribution and ecology. Erysimum caboverdeanum is a southern mesophyte, restricted to the central caldeira and the caldeira rim on Fogo. Most of this area is situated within the semiarid zone. The species is mainly found between $1550 \mathrm{~m}$ and $2000 \mathrm{~m}$, but has been recorded up to $2200 \mathrm{~m}$ (Nogueira 1975b) and $2400 \mathrm{~m}$ (leg. Kilian \& Leyens). The plants grow on dry gravel or volcanic lapilli, in scattered vegetation with Artemisia gorgonum, Conyza varia, C. feae, Echium vulcanorum, Satureja forbesii, and Verbascum cystolithicum.

Abundance. The species occurs scattered in an area of about $8 \times 10 \mathrm{~km}$, and most populations are small because of overcollection for fodder and habitat clearing. Erysimum caboverdeanum is considered to be Endangered (EN).

\section{Lobularia Desv.}

The genus Lobularia comprises four species distributed in $\mathrm{W}$ and $\mathrm{S}$ Europe, $\mathrm{N}$ Africa, the Near East, and the Mid-Atlantic archipelagos (the Salvage Islands, the Canary Islands, and the Cape Verde Islands). In the Cape Verde Islands, the genus is represented by a single nonendemic species with two endemic subspecies.

Literature: Borgen (1987). 


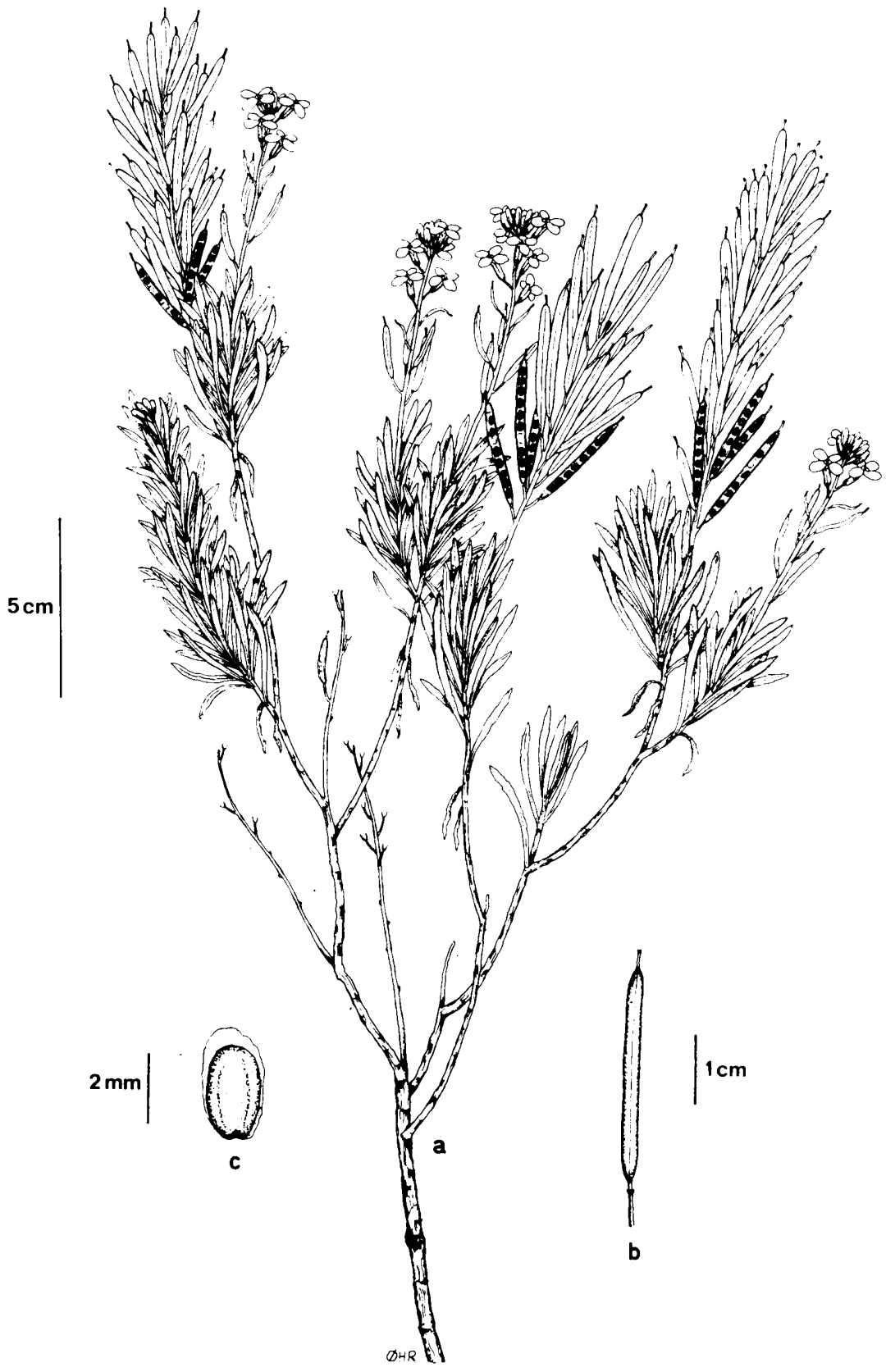

Fig. 101. Erysimum caboverdeanum. a. Habit; b. Silique; c. Seed. Drawn by Ø. H. Rustan. 


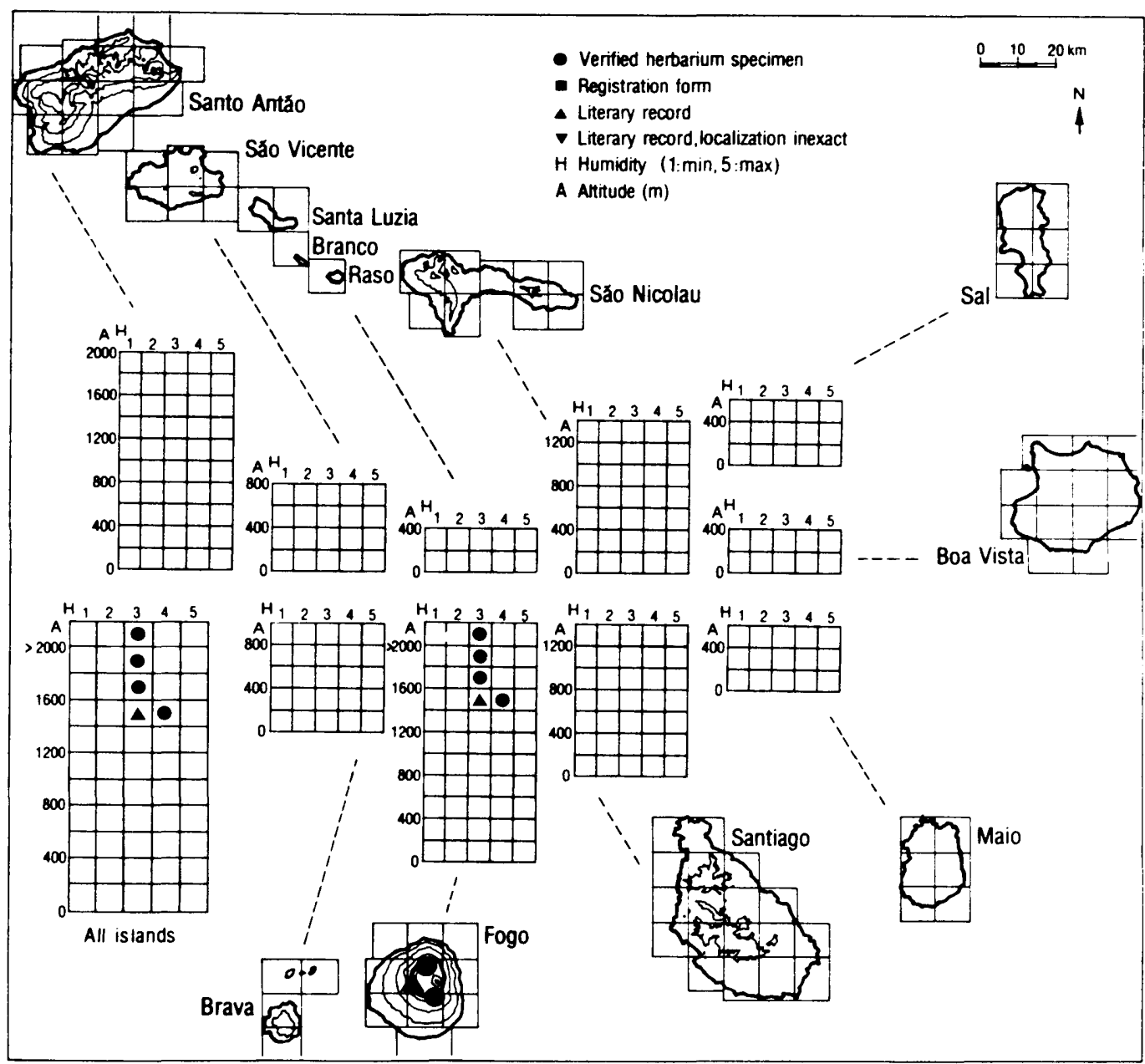

Fig. 102. Ecogeographic distribution of Erysimum caboverdeanum.

\section{Lobularia canariensis}

Lobularia canariensis (DC.) Borgen, Opera Bot. 91: 66 (1987) $\equiv$ Alyssum maritimum (L.) Lam. var. canariense' DC., Syst. Nat. 2: 319 (1821). - Type: In insulis Canariensibus, 1812, Courrant (not to be found). -- Neotype (designated by Borgen 1987: 66): Canary Islands, Gran Canaria, Barranco Angostura SW of Agüimes, $340 \mathrm{~m}$, 6.1.1968, Kunkel 1267 (BM; isoneotypes: C, FR, GOET).

Description. Subshrub or shrub, more rarely annual, succulent herb, erect to procumbent or lax, decumbent to pendulous with main axis usually branched from the base, up to $0.7 \mathrm{~m}$ long. Leaves up to $8 \mathrm{~cm}$ long and $1.6 \mathrm{~cm}$ wide, alternate or rosulate, subglabrous to silvery pubescent. Racemes terminal, open to dense, elongating in fruit. Petals white or creamy, sometimes tinged with purple. Silicules oblong to obovate or elliptical to orbicular, up to 4.5 
$\mathrm{mm}$ long and $6.3 \mathrm{~mm}$ wide; valves subglabrous to pubescent, convex to flat. Seeds compressed, saucer-shaped to lens-shaped, with or without a distinct wing, 1-4 in each locule, $(1-) 2-6(-8)$ in each silicule.

Variation. Lobularia canariensis is a variable complex in which nine subspecies, distributed in the Salvage Islands, the Canary Islands, the Cape Verde Islands, and Morocco have been recognized (Borgen 1987). Crossing experiments have revealed that internal isolation barriers are absent or weak between the subspecies, which are isolated or semiisolated in nature by geographic and ecological barriers (Borgen 1987). The two Capeverdean subspecies are closely related and obviously form a monophyletic group. They are usually fairly well distinguishable as outlined in the following key, but some transitional populations are known from eastern São Nicolau and northern Santiago.

Note. The maps are based on material from various herbaria revised by L. Borgen, Oslo (Borgen 1987). Literary records were excluded because of possible confusion between the two subspecies.

Key to the subspecies of Lobularia canariensis

1 Leaves lanceolate with acute apex, crenate margin, and forking veins; silicules elliptical; seeds $1(-2)$ per locule, indistinctly winged............................................... ssp. fruticosa

1 Leaves spathulate with obtuse or mucronulate apex, entire margin, and one-ribbed venation; silicules ovate to obovate; seeds (1-)2(-3) per locule, distinctly winged .ssp. spathulata

Lobularia canariensis ssp. fruticosa (Figs 103, 104)

Lobularia canariensis (DC.) Borgen ssp. fruticosa (Webb) Borgen, Opera Bot. 91: 70 (1987) $\equiv$ Koniga fruticosa Webb [in Christ], Bot. Jahrb. Syst. 9: 93 (1888). - Type: S. Nicolas, Ribeira Brava, 7.1851, Bolle (holotype: FI-W).

Illustrations: Borgen (1987: Fig. 141), Gomes et al. (1995b: p. 17).

Description. Moderately branched, erect dwarf shrub up to $0.4(-0.7) \mathrm{m}$ high. Branches strongly lignified. Leaves lanceolate, up to $3.1(-8.0) \mathrm{cm}$ long and $1.6 \mathrm{~cm}$ wide, usually only slightly pubescent, apex acute, margin usually crenulate. Inflorescences open. Petals white, occasionally tinged with purple, up to $3.7 \mathrm{~mm}$ long, clawed. Silicules elliptical, up to $4.4 \mathrm{~mm}$ long; usually with a single, sometimes with two, indistinctly winged seeds per locule.

Variation. The material is relatively variable, especially in habit, pubescence, and leaf size. Populations that are transitional between ssp. fruticosa and ssp. spathulata are known from eastern São Nicolau and northern Santiago.

Chromosome number: $2 \mathrm{n}=22(\mathrm{n}=11,2 \mathrm{n}=22$, Santo Antão, Ribeira do Paul, 830 $1020 \mathrm{~m}$ (several populations counted); $2 \mathrm{n}=22$, Santo Antão, Lombo Cebide Vila, $900 \mathrm{~m} ; \mathrm{n}=$ $11,2 \mathrm{n}=22$, Santo Antão, between Montanha Forte de Leite and Ribeira do Paul, $1150 \mathrm{~m} ; \mathrm{n}=$ 11, São Nicolau, Ribeira da Fragata, 730 m, Borgen 1987).

Distribution and ecology. Lobularia canariensis ssp. fruticosa is a western mesophyte occurring on Santo Antão, São Nicolau, Santiago, Fogo, and Brava, but it is absent from São Vicente. It has its main distribution within the humid and subhumid zones, and occurs only scattered in the semiarid zone. The main altitudinal distribution is between $400 \mathrm{~m}$ and 1250 


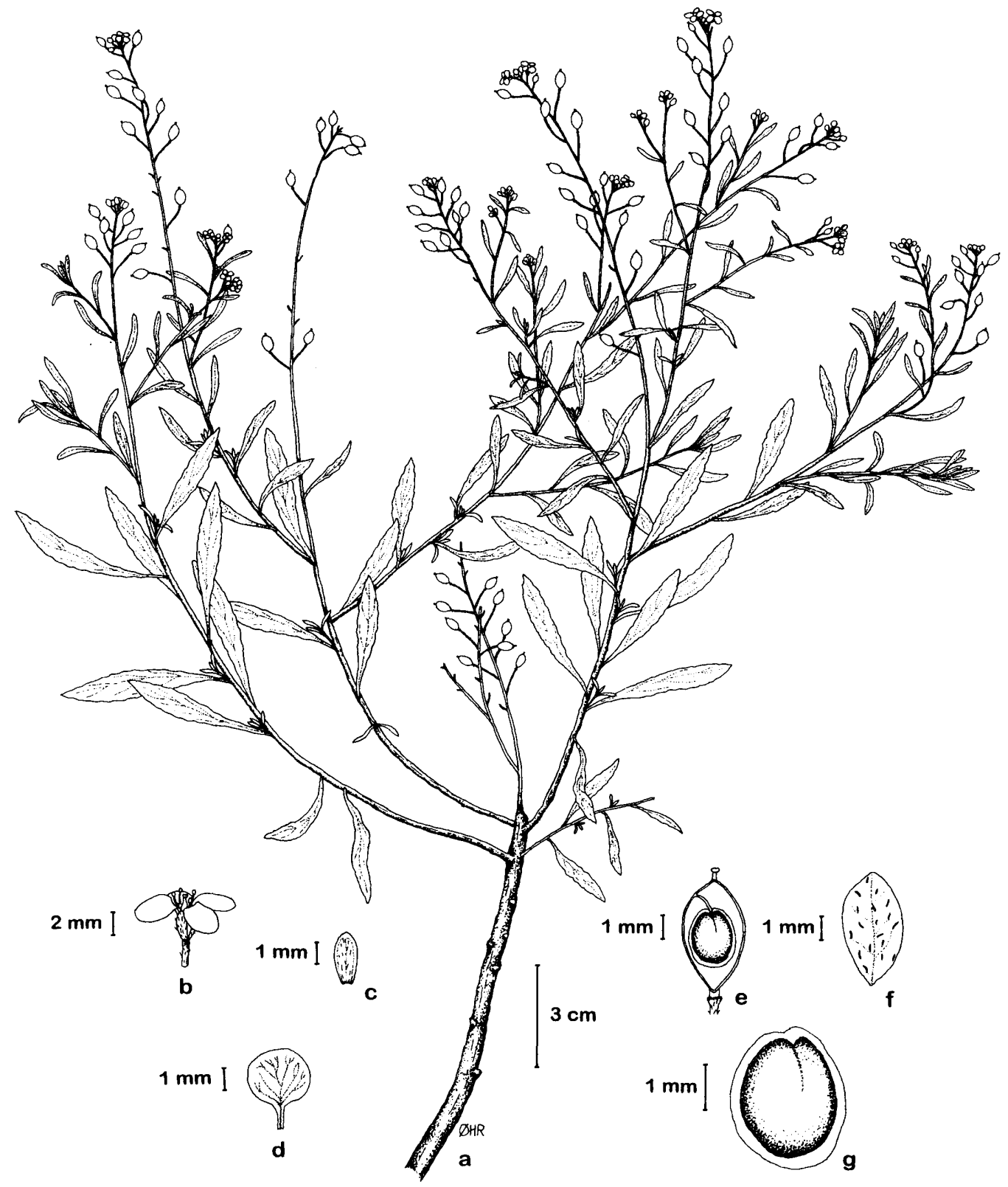

Fig. 103. Lobularia canariensis ssp. fruticosa. a. Habit; b. Flower; c. Sepal; d. Petal; e. Silicule with seed; f. Silicule valve; g. Seed. Drawn by Ø. H. Rustan. Reprinted from Borgen (1987), Opera Bot. 91 (with permission). 


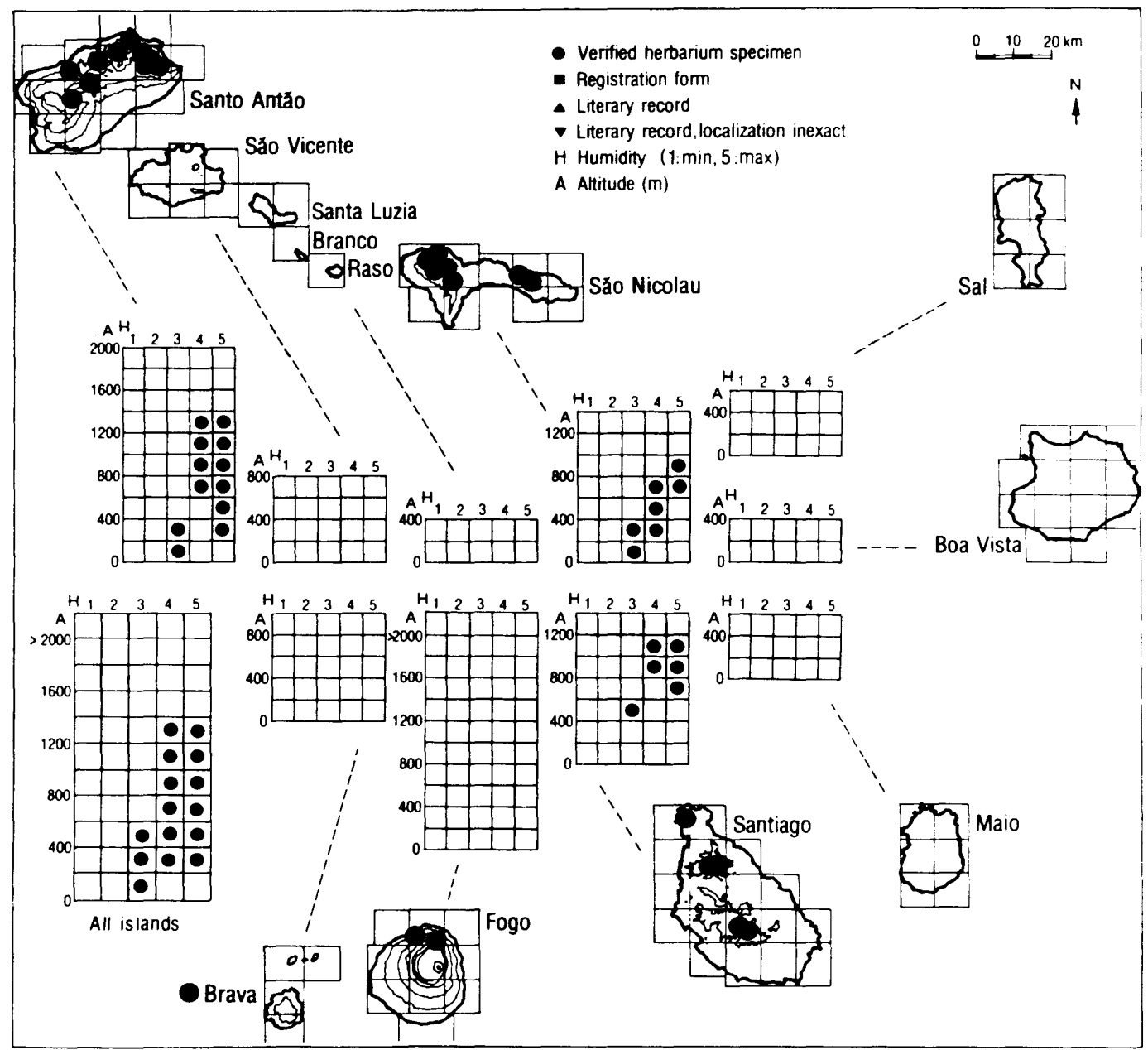

Fig. 104. Ecogeographic distribution of Lobularia canariensis ssp. fruticosa.

$\mathrm{m}$. The lowermost record is at $100 \mathrm{~m}$ on São Nicolau, the uppermost one at $1250 \mathrm{~m}$ on Santo Antão (Borgen 1987). The plants grow in steep cliffs and gravelly places, also at roadsides and in cultivated fields.

Abundance. The subspecies is still widespread on Santo Antão and São Nicolau and occurs scattered on Santiago, but it is probably declining in many areas. The only collection from Brava dates from 1862 (leg. Lowe), and the subspecies is considered Extinct (EX) on this island. Lobularia canariensis ssp. fruticosa is generally classified as Indeterminate (I). 


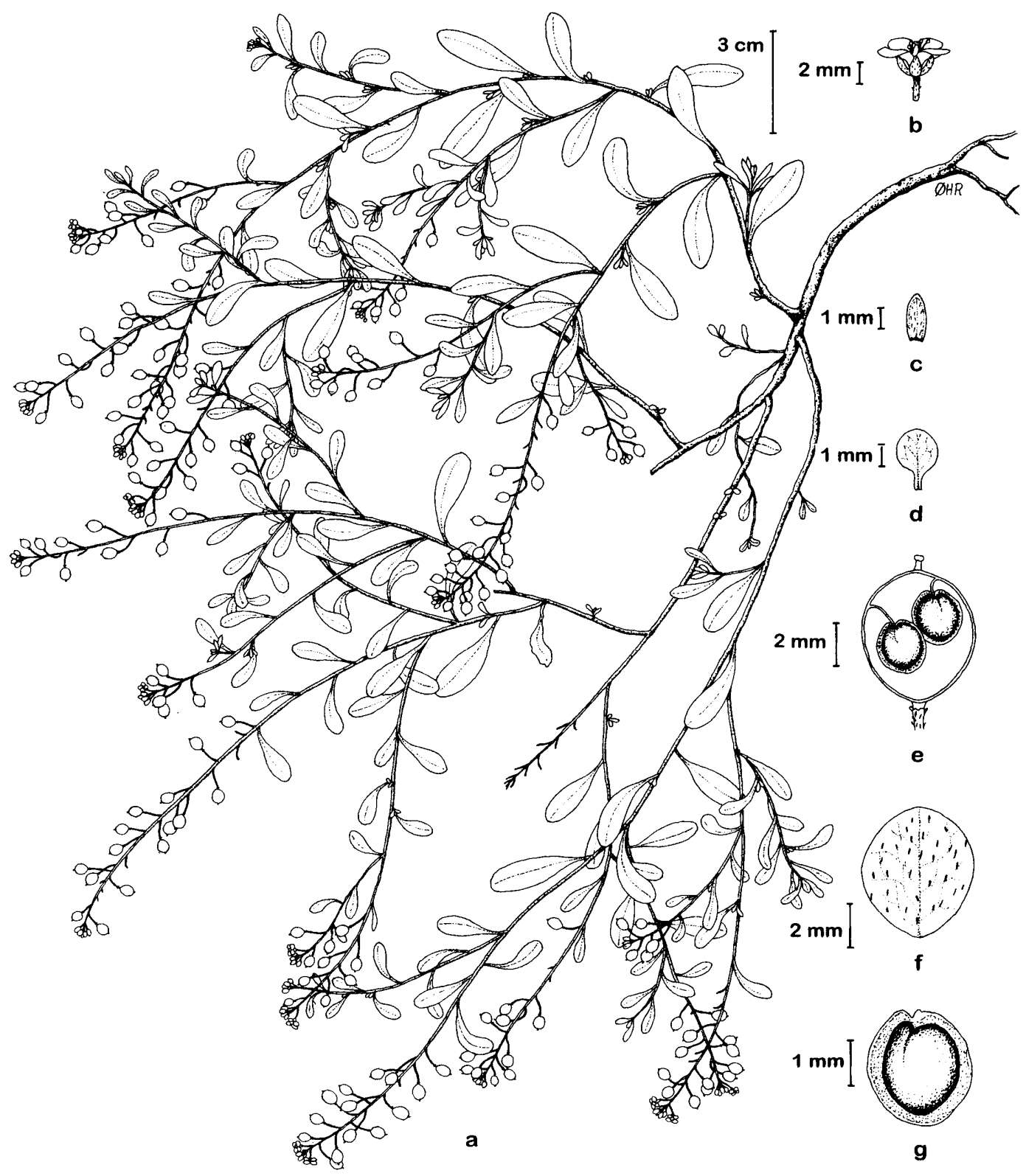

Fig. 105. Lobularia canariensis ssp. spathulata. a. Habit; b. Flower; c. Sepal; d. Petal; e. Silicule with seeds; f. Silicule valve; g. Seed. Drawn by $\varnothing$. H. Rustan. Reprinted from Borgen (1987), Opera Bot. 91 (with permission). 


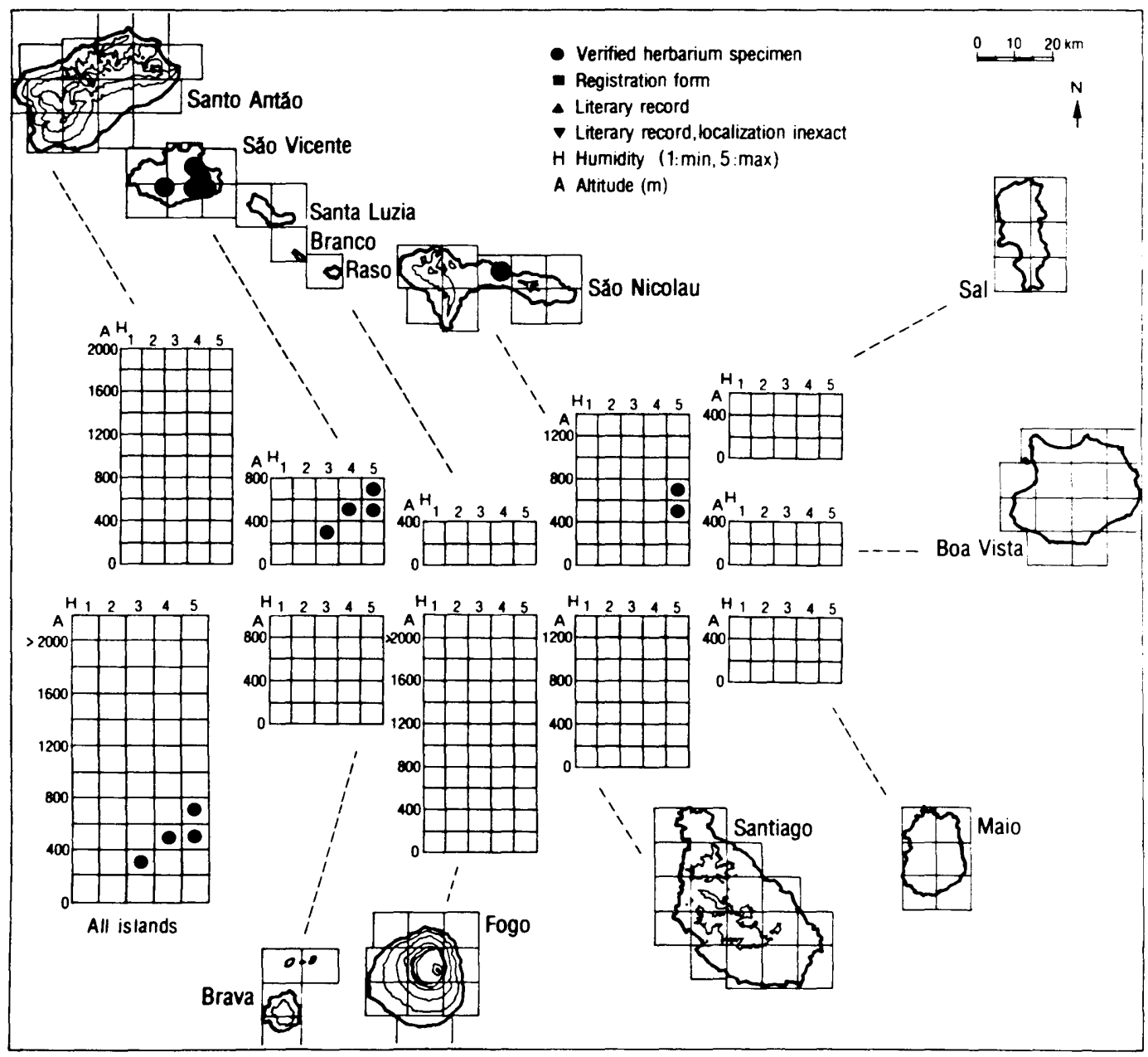

Fig. 106. Ecogeographic distribution of Lobularia canariensis ssp. spathulata.

Lobularia canariensis ssp. spathulata (Figs 105, 106)

Lobularia canariensis (DC.) Borgen ssp. spathulata (J. A. Schmidt) Borgen, Opera Bot. 91 : 80 (1987) $\equiv$ Koniga spathulata J. A. Schmidt, Beitr. Fl. Cap Verd. Ins.: 266 (1852) $\equiv$ Alyssum maritimum (L.) Lam. var. spathulatum (J. A. Schmidt) A. Chev., Rev. Bot. Appl. Agric. Trop. 15: 989 (1935) $\equiv$ Lobularia spathulata (J. A. Schmidt) O. E. Schulz in Engler \& Prantl, Nat. Pflanzenfam. 2(17b): 495 (1936) $\equiv$ Lobularia intermedia Webb ssp. spathulata (J. A. Schmidt) Pett., Comm. Biol. Soc. Scient. Fenn. 22: 20 (1960). — Type: In rupestribus Montis Verede ins. S. Vincentii, 1.2.1851, J. A. Schmidt (not to be found). - Neotype (designated by Borgen 1987: 80): S. Vicente, Monte Verde, NE slopes, $480 \mathrm{~m}$, exp. N, slope $80^{\circ}, 24^{\circ} 56^{\prime} \mathrm{W}, 16^{\circ} 52^{\prime} \mathrm{N}, 29.1 .1980$, Borgen 3500 (O).

= Koniga vogeliana Webb [in Christ], Bot. Jahrb. 9: 92 (1888). - Type: In montosis ins. S. Vicentii, 6.1841 , Vogel 70 (holotype: FI-W; isotype: K).

Illustration: Borgen (1987: Fig. 147). 
Description. Dwarf shrub, usually lax, decumbent to pendulous, moderately branched from the main axis, up to $0.4 \mathrm{~m}$ long. Branches slender, moderately lignified. Leaves spathulate, up to $2.7(-4) \mathrm{cm}$ long and $0.9 \mathrm{~cm}$ wide, almost glabrous, apex obtuse, margin entire. Inflorescences open. Petals white, up to $3.1 \mathrm{~mm}$ long, clawed. Silicules ovate to obovate, up to $4.9 \mathrm{~mm}$ long; usually with two, sometimes with one or three, distinctly winged seeds per locule.

Variation. The material is relatively variable, especially in habit and leaf size. Pendulous populations occur only on São Vicente. The populations on São Nicolau have more stiff and ascending branches (see also ssp. fruticosa).

Chromosome number: $2 \mathrm{n}=22(\mathrm{n}=11,2 \mathrm{n}=22$, São Vicente, Monte Verde, $580 \mathrm{~m}$, Borgen 1984, 1987; $\mathrm{n}=11$, São Vicente, Monte Verde, Borgen 1984; $\mathrm{n}=11,2 \mathrm{n}=22$, São Nicolau, Alto Joaquina, $600 \mathrm{~m}$, Borgen 1987).

Distribution and ecology. Lobularia canariensis ssp. spathulata is a northern mesophyte restricted to São Vicente and São Nicolau. It grows mainly in the subhumid and humid zones, but it also occurs scattered in the semiarid zone on São Vicente. The main altitudinal distribution is between $450 \mathrm{~m}$ and $700 \mathrm{~m}$. The lowermost record is at $300 \mathrm{~m}$ on São Vicente and the uppermost one at $760 \mathrm{~m}$ on the same island (Borgen 1987). The plants grow in steep cliffs and gravelly slopes.

Abundance. The subspecies is still locally common, but it is probably threatened because it has a very limited distribution within areas that are heavily influenced by human activities. Because of lack of exact information on the possible decline of its populations, we presently classify Lobularia canariensis ssp. spathulata as Indeterminate (I).

\section{CAMPANULACEAE}

This family is represented by two genera, of which one (Campanula) consists of two endemic species and one (Wahlenbergia) consists of a single non-endemic species.

\section{Campanula L.}

The genus Campanula comprises about 300 species of herbs or rarely shrubs, mainly distributed in temperate regions of the world. Some species are monocarpic. A large number of species occurs in the Mediterranean, in particular in Turkey. The genus is represented by two endemic species in the Cape Verde Islands.

Literature: Leyens \& Lobin (1995), Figueiredo (1995).

Key to the genus Campanula

1 Corolla campanulate, up to 1.6 times as long as wide, usually deep violet, occasionally light blue to purely white; ovary glabrous, flat C. jacobaea

1 Corolla tubular, at least 1.5 times as long as wide, usually greenish-white, rarely purplish; ovary densely pubescent, conical C. bravensis 
Campanula bravensis (Figs 107, 108)

Campanula bravensis (Bolle) A. Chev., Rev. Bot. Appl. Agric. Trop. 15: 889 (1935) ECampanula jacobaea Webb var. bravensis Bolle, Bonplandia 9: 51 (1861). - Syntypes: In ins. Bravae rupibus altioribus, copiose, 12.1852, Bolle (B, destroyed; K [two specimens]!); ibid., ab incolis Ortiga branca sive Velho teso, [12.1852]. Bolle (B, destroyed); cultivated in the Royal Botanical Garden Berlin (B, destroyed). - Lectotype (designated by Leyens \& Lobin 1995: 222): [Brava], "in rupestribus", 12.1852, Bolle (K!).

Illustrations: Chevalier (1935b: Tab. 13), Gomes et al. (1995b: p. 18), Leyens \& Lobin (1995: Figs Ic$\mathrm{d}, 3 \mathrm{~b}, 4)$.

Description. Strongly branched subshrub with mainly pendulous branches up to $0.8 \mathrm{~m}$ long; younger branches strongly hispid. Basal rosette short-lived; rosette leaves and cauline leaves light green with whitish nerves, densely hispidulous, lanceolate to spathulate or rarely ovate, up to $8 \mathrm{~cm}$ long and $2.1 \mathrm{~cm}$ wide with a length to width ratio of (1.7-)2-4(-5.6), margin entire to dentate. Flowers solitary, nodding; pedicels very variable in length, up to $5.5 \mathrm{~cm}$ long; flower buds lanceolate in outline. Corolla narrowly tubular, greenish-white with prominent greenish nerves, rarely tinged with purple, never purely white, up to $3.2 \mathrm{~cm}$ long and $1.9 \mathrm{~cm}$ wide at the mouth. Calyx lobes usually long and narrow, spreading, densely hispid with short trichomes. Ovary conical, pubescent with short trichomes; style densely hispidulous in lower part.

Variation. Campanula bravensis varies mainly in leaf and calyx characters. In contrast to $C$. jacohaea, most of the variation in C. bravensis was observed within individual populations. 1995a).

Chromosome number: $2 \mathrm{n}=54$ (Fogo, Chã das Caldeiras, 1600-1700 m, Gomes et al.

Related taxa: See C. jacobaea.

Distribution and ecology. Campanula bravensis is a southern hygrophyte distributed on Santiago, Fogo, and Brava. On Santiago, it is restricted to the southern mountain range, Serra do Pico da Antonia, where it grows between $770 \mathrm{~m}$ and $1000 \mathrm{~m}$. Most sites are situated within the humid and subhumid zones. The main altitudinal distribution is between $600 \mathrm{~m}$ and $1600 \mathrm{~m}$; the lowermost record is at $70 \mathrm{~m}$ on northern Fogo (leg. Brochmann \& Rustan) and the uppermost record at $2700 \mathrm{~m}$ on the same island (leg. Kilian \& Leyens). The species is mainly confined to north- to northeast-facing, moist crevices in steep ravines and rocky slopes, and to sites with trickling or seeping water.

Abundance. Because of its restriction to particularly moist or wet habitats, $C$. bravensis has a scattered distribution. Large numbers of plants have been observed in suitable sites. Campanula bravensis is Rare (R) on Santiago, but generally classified as Lower Risk (LR).

Campanula jacobaea (Figs 108, 109)

Campanula jacobaea Webb in Hooker, Icon. Pl. 8: ad tab. 762 (1848) [三 Campanula jacobaea C. Sm. in Tuckey, Narr. Exped. Zaire: 251 (1818), nom. nud.]. - Syntypes: In ins. S. Nicolau fissuris rupium, 27.3.1822, Forbes $35(\mathrm{~K} !)$; in ins. S. Antonii in rupibus collis acuti, Forbes $4(\mathrm{~K} !)$; in vallis S. Dom[ingos], ins. S. Jacobi ad alt. 2000 ped., $11.1839, J$. D. Hooker (K!); in monte Verede, ins. S. Vincentii ab alt. 1500 ped. usque ad summitatem, 6.1841, Vogel 73 (K!); in ins. S. Jacobi, Darwin (K!). — Lectotype (designated by Porter (1986: 85), but see also Leyens \& Lobin 1995: 218): Darwin [279] (K!; isolectotype: CGE!). 


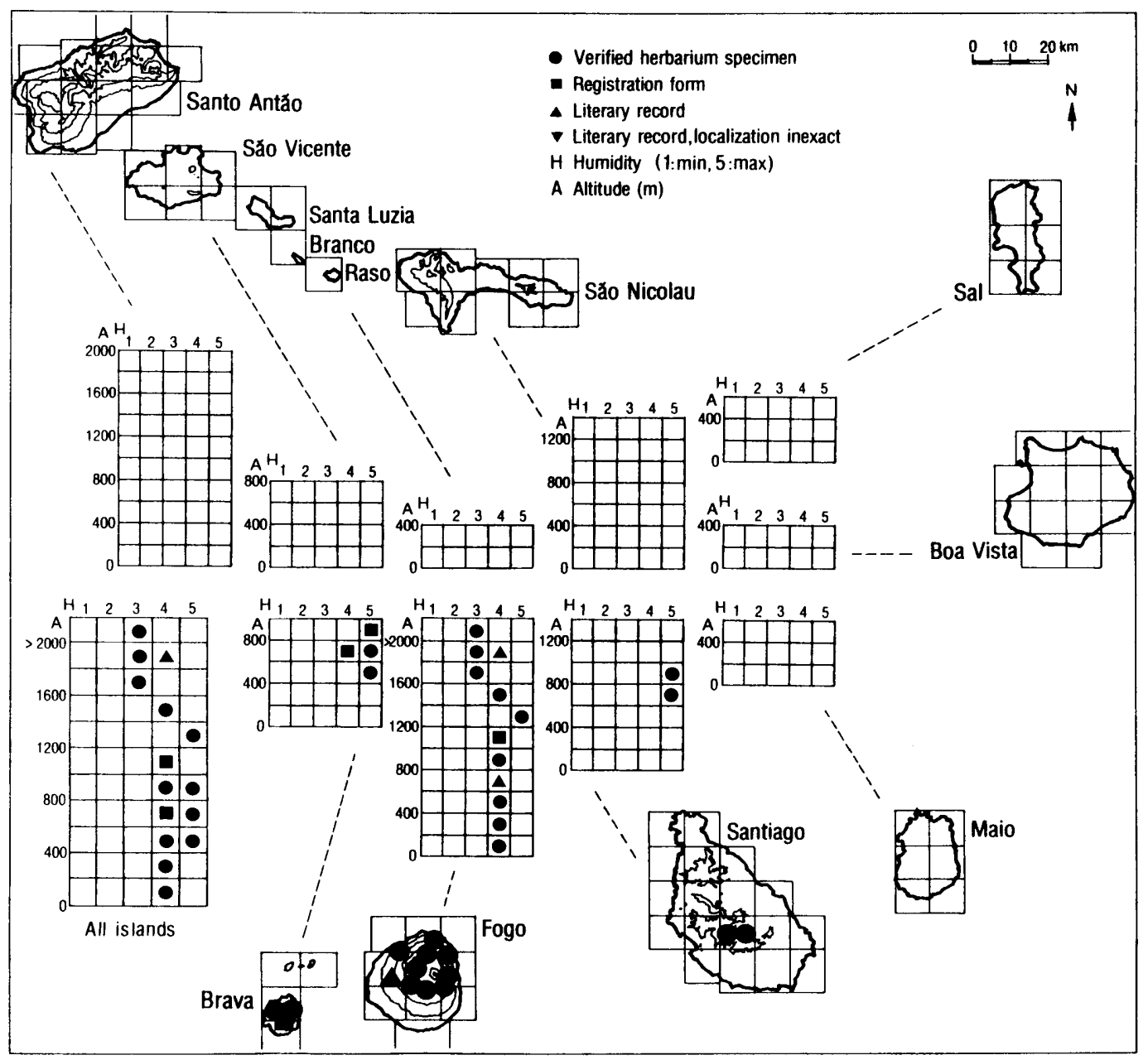

Fig. 107. Ecogeographic distribution of Campanula bravensis.

= Campanula jacobaea Webb var. hispida Bolle, Bonplandia 9: 51 (1861). - Type: In insula Santiago, Bolle ( $\mathrm{B}$, destroyed).

= Campanula jacobaea Webb var. humilis Bolle, Bonplandia 9: 51 (1861). - Syntypes: S. Vicente, Monte Verde, 1852, Bolle (B, destroyed, K!); S. Nicolau ex. gr. secus viam consularem Caminho novo dictam, supra aedes Thomas Pires, Bolle (B, destroyed, K!). - Lectotype (designated by Leyens \& Lobin 1995: 216): S. Vicente, Monte Verde, 1852, Bolle (K!).

Illustrations: Webb (1848: Fig. 762, 1849: Fig. 12), Hooker (1883: Fig. 6703), Sunding (1980: Fig. 4), Brochmann \& Rustan (1983: Fig. 2), Lobin \& Grasmück (1984: Fig. 2), Lobin (1986b: Fig. 5), Lobin et al. (1993: Figs 1-2), Leyens \& Lobin (1995: Figs la-b, 3a), Gomes et al. (1995b: p. 18). 
Description. Subshrub up to $0.6 \mathrm{~m}$ high, strongly branched with ascending or usually pendulous, up to $1 \mathrm{~m}$ long branches. Basal leaves densely rosulate; cauline leaves alternate. sessile, distant; leaves deep green, hispid, ovate to lanceolate, up to $9 \mathrm{~cm}$ long and $2.2 \mathrm{~cm}$ wide, with a length to width ratio of (1.2-)1.6-3(-5.8), apex obtuse to almost acute, margin entire to dentate. Flowers solitary, erect to horizontal, pedicel up to $5.2 \mathrm{~cm}$ long; corolla campanulate, deep violet to whitish blue, rarely purely white, up to $2.9 \mathrm{~cm}$ long and $2.1 \mathrm{~cm}$ wide at the mouth. Calyx lobes short and broad, appressed to the corolla. Ovary flat, glabrous; style glabrous in lower part.

Variation. Campanula jacobaea is highly variable in habit, density of the indument, leaf and calyx characters as well as corolla colour. Similar patterns of variation were observed on all islands, apparently associated with microclimatic conditions. The varieties described of this species are of no taxonomic significance. The corolla colour often varies within individual populations.

Chromosome number: $2 \mathrm{n}=54$ (São Nicolau, Pico Caldeirinha E of Monte Gordo, $1050 \mathrm{~m}$, Gomes et al. 1995a).

Related taxa. The Capeverdean species of Campanula are closely related and probably descended from a single immigrant to the archipelago. Their closest relative is probably $C$. keniensis Thulin from the Ngong Hills in Kenya (Leyens \& Lobin 1995).

Distribution and ecology. Campanula jacobaea is a western hygrophyte (but more mesophytic than $C$. bravensis) distributed on the northern islands of Santo Antão, São Vicente, and São Nicolau, and also on one of the southern islands, Santiago. It is most frequent in the subhumid and humid zones, and occurs only occasionally in the semiarid zone on Santo Antão. The main altitudinal distribution is between $600 \mathrm{~m}$ and $1000 \mathrm{~m}$, but the species has been recorded at $180 \mathrm{~m}$ (leg. Kilian) and at $1460 \mathrm{~m}$ (leg. Brochmann \& Rustan) on Santo Antão. Campanula jacobaea typically grows in crevices of north- to northeast-facing cliffs and escarpments, where moisture is available from the trade wind fog, and it is a characteristic element of the vegetation in these habitats.

Abundance. Campanula jacobaea is abundant in all suitable habitats and islands. On São Vicente, it is confined to the steep, humid slopes of Monte Verde from 460 to $750 \mathrm{~m}$. Campanula jacobaea is generally considered to be Lower Risk (LR).

\section{CARYOPHYLLACEAE}

This family is represented by six genera with ten species. Two species are endemic.

\section{Paronychia Mill.}

The genus Paronychia comprises about 50 species of annuals, perennial herbs, and shrublets widely distributed in subtropical and temperate regions. The genus is represented by a single, endemic species in the Cape Verde Islands. 


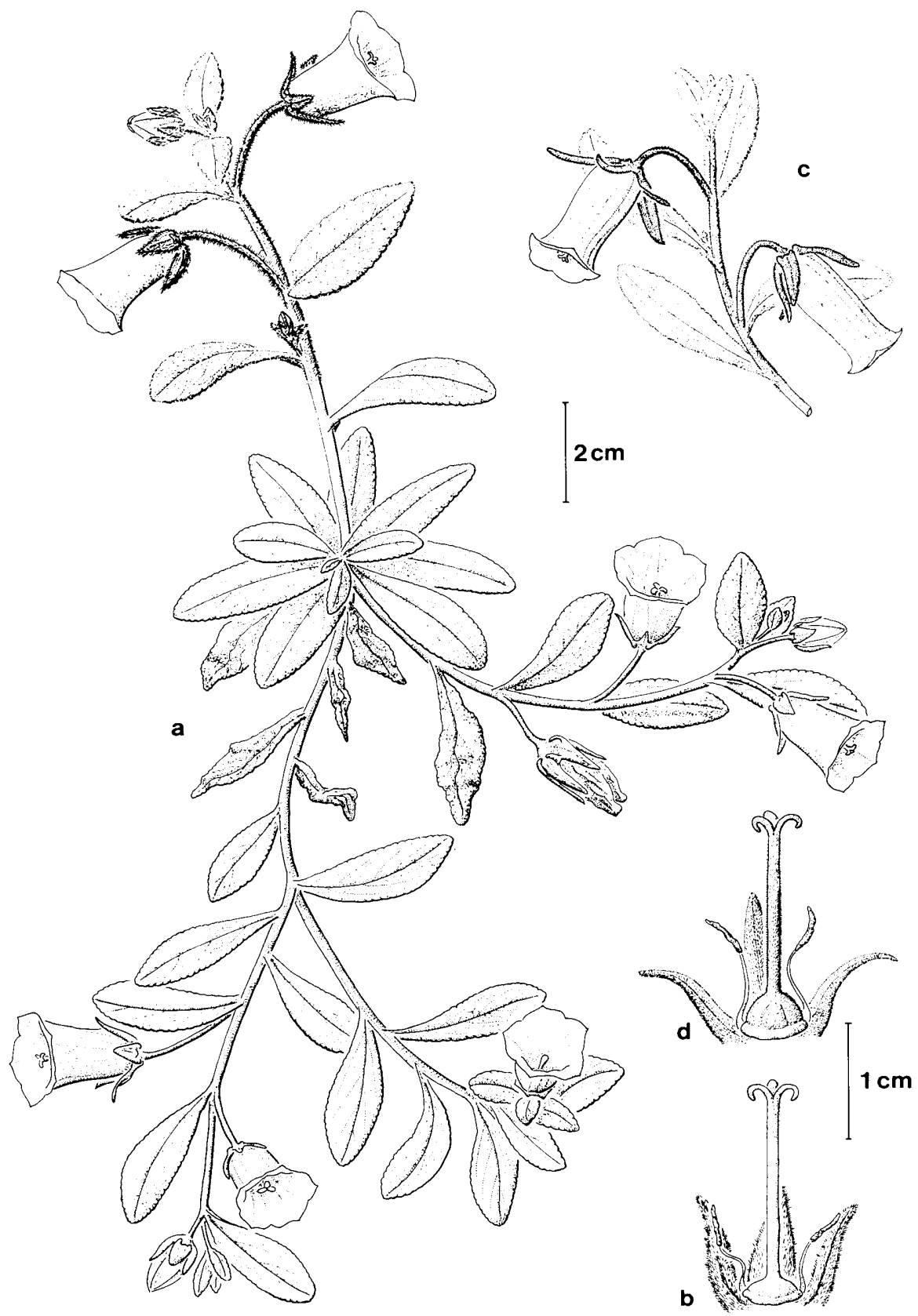

Fig. 108. Campanula bravensis and C. jacobaea. a. C. jacobaea, habit; b. C. jacobaea, gynoeceum; c. C. bravensis, portion of stem with leaves and flowers; d. C. bravensis, gynoeceum. Drawn by J. Wunder. Reprinted from Leyens \& Lobin (1995), Willdenowia 25 (with permission). 


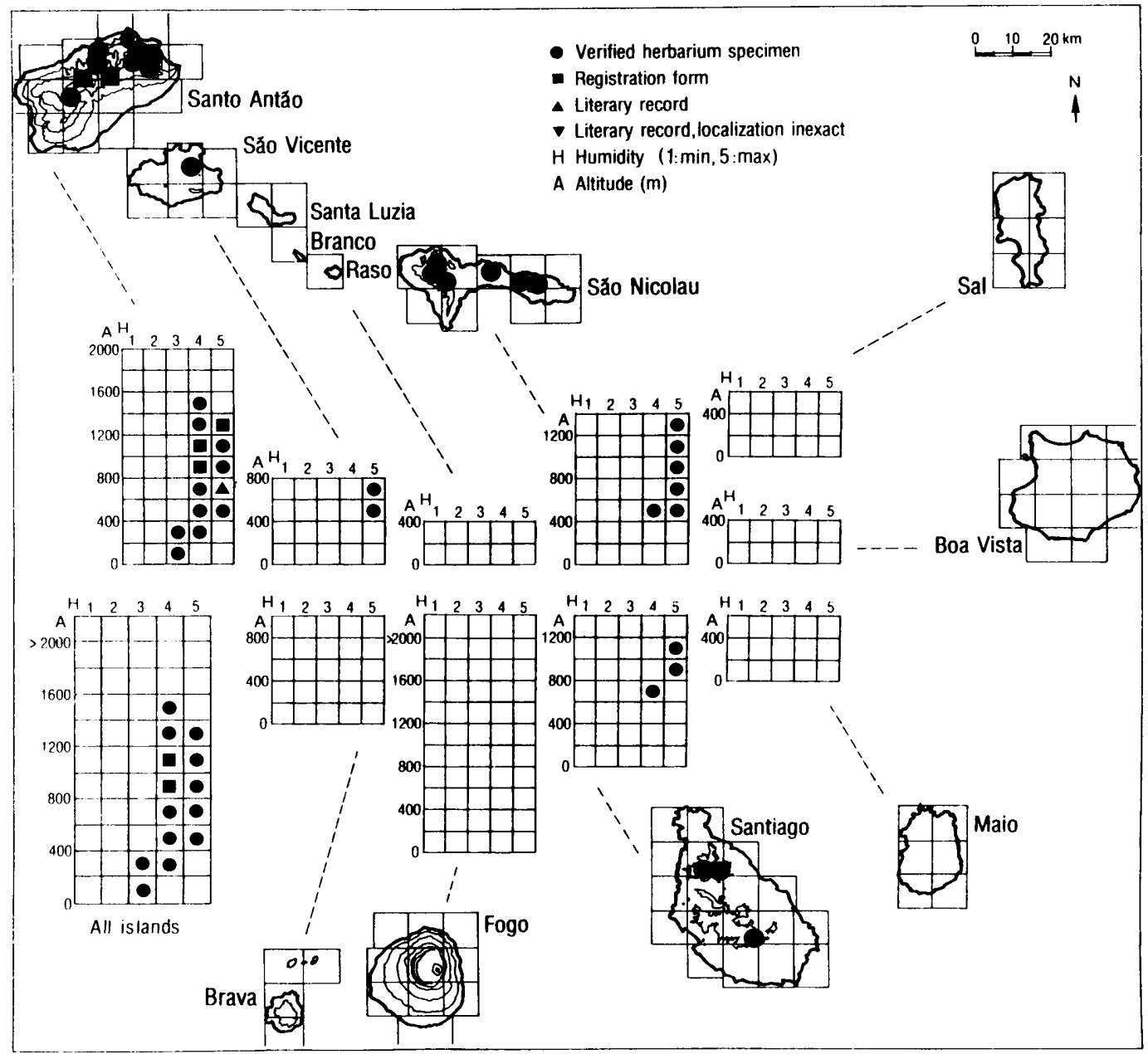

Fig. 109. Ecogeographic distribution of Campanula jacobaea.

\section{Paronychia illecebroides (Figs 110,111)}

Paronychia illecebroides Webb in Hooker, Icon. Pl. 8: ad tab. 756 (1848) [E Herniaria illecebroides C. Sm. in Tuckey, Narr. Exped. Zaire: 250 (1818), nom. nud.]. -- Syntypes: Ins. S. Antonii, Tarrafal, 2.4.1822, Forbes 24; in ins. S. Jacobi, $11.1839, J$. D. Hooker $/ / 2(\mathrm{FI}-\mathrm{W})$; in ins. S. Vincentii ab alt. 500 ped. usque ad acumen Montis Verede, 6.1841, Vogel 25.

= Paronychia illecebroides Webb var. nicolauensis Chaudhri, Meded. Bot. Mus. Herb. Rijksuniv. Utrecht 285: 167 (1968). — Type: São Nicolau, Monte Gordo, 22.4.1864, Lowe (holotype: BM).

Illustrations: Webb (1848: Fig. 756, 1849: Fig. 7), Sunding (1980: Fig. 5), Gomes et al. (1995b: p. 18).

Literature: Chaudhri (1968), Diniz (1995).

Note. Chaudhri (1968: 166), in quoting Herniaria illecebroides C. Sm. as basionym of $P$. illecebroides, overlooked that Smith's name was published as a nomen nudum only. Consequently, his typification of the name H. illecebroides with Smith's original specimen in BM (Smith 3), which was not seen by Webb (see Webb 1849 : 
106), does not apply for the name $P$. illecebroides. A lectotype has hitherto not been designated for the latter name.

Description. Strongly branched, procumbent to ascending perennial herb or subshrub up to $0.5 \mathrm{~m}$ long. Leaves linear-oblong to oblanceolate, rarely linear-lanceolate, up to $1.2 \mathrm{~cm}$ long and $0.3 \mathrm{~cm}$ wide, shortly pubescent, apex acute, margin finely serrulate. Flowers in axillary inflorescences of very variable size. Flowers $1.5-2.4 \mathrm{~mm}$ long, greenish to dark brown, occasionally with a pinkish part; petals $0.4 \mathrm{~mm}$ long. Fruit enclosed in the persistent calyx. Seeds globose.

Variation. The species is very variable, especially in habit and leaf characters. Narrowleaved populations occur in arid habitats, and populations with conspicuously broader leaves occur in moist habitats (described as var. illecebroides and var. nicolauensis Chaudhri. respectively), but this variation is clearly ecoclinal.

Chromosome number: Unknown.

Related taxa. Paronychia illecebroides resembles the Mediterranean P. polygonifolia (Vill.) DC., but differs in shoot structure and floral characters (Chaudhri 1968).

Distribution and ecology. Paronychia illecebroides is a ubiquitous xerophyte occurring on most of the islands (Santo Antão, São Vicente, Santa Luzia, São Nicolau, Boa Vista, Maio, Santiago, and Fogo). Notably, it has not been recorded from Sal and Brava. The species has an extremely wide ecological amplitude and is almost equally abundant in the arid, semiarid, subhumid, and humid zones. It is found from sea-level to the highest elevations in the archipelago (Fogo). On this island, the species is frequent above $1500 \mathrm{~m}$ in Chã das Caldeiras and on the outer escarpments of the crater rim, and it is also frequent on gravel slopes on Pico Novo (leg. Kilian \& Leyens) up to the top at above $2800 \mathrm{~m}$. It seems, however. to be absent in the lowlands of Fogo. The plants grow in a wide array of habitats ranging from arid, coastal gravel slopes to humid cliffs in the mountains.

Abundance. Paronychia illecebroides is most widespread on the northern islands, but we have observed large populations on most of the recorded islands. On Boa Vista and Maio, however, the species is Endangered (EN) because of severe overgrazing. Paronychia illecebroides is generally considered to be Lower Risk (LR).

Note. The unlocalized record from Santa Luzia refers to Nogueira (1975b), and the unlocalized record from Boa Vista refers to Hansen \& Sunding (1985).

\section{Polycarpaea Lam.}

Polycarpaea is a genus of about 50 species of tropical and warm temperate regions. Two species, of which one is endemic, occur in the Cape Verde Islands.

Key to the genus Polycarpaea

1 Plant procumbent; leaves not attenuate into a petiole-like base; both leaf surfaces and most other parts of the plant whitish tomentose ..................................................... [P. nivea $]$

1 Plant ascending to erect; leaves distinctly attenuate into a petiole-like base; upper leaf surface with a less dense indument and always greenish, lower surface and most other parts of the plant greyish tomentose or rarely almost silvery tomentose P. gayi 


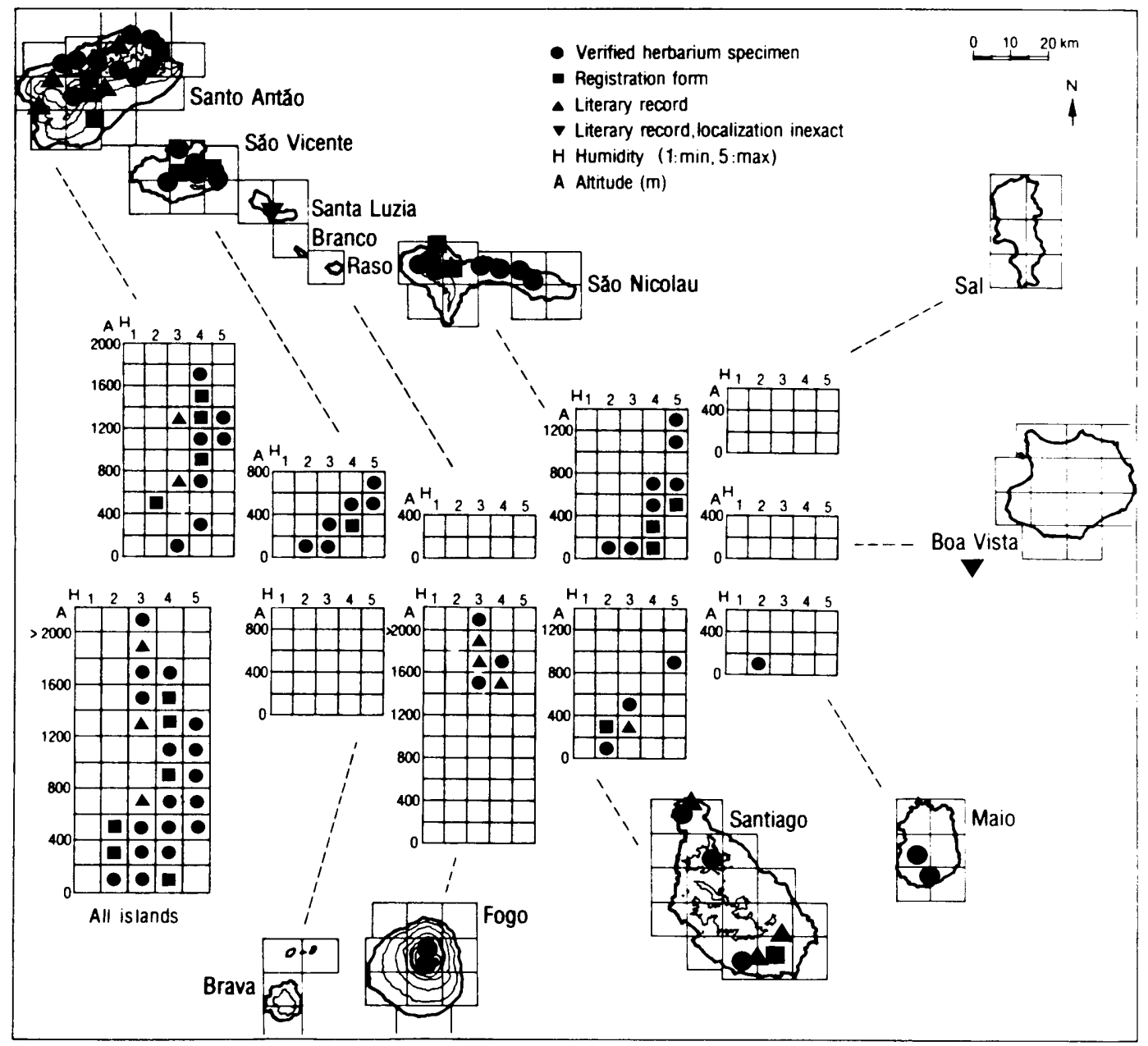

Fig. 110. Ecogeographic distribution of Paronychia illecebroides.

Polycarpaea gayi (Figs 111, 112)

Polycarpaea gayi Webb in Hooker, Niger Fl.: 104 (1849) Polycarpaea gayi Webb var. helichrysoides Webb, ibid. - Syntypes: In ins. Sal petrosis, Brunner 172; "Capvert. Herbier rapporté du Portugal en 1808 par M. Geoffrey St. Hilaire" [1784-1787, Silva Feijão] (P).

= Polycarpaea gayi Webb var. halimoides Webb in Hooker, Niger Fl.: 104 (1849). — Type: "Capvert. Herbier rapporté du Portugal en 1808 par M. Geoffrey St. Hilaire" [1784-1787, Silva Feijão] (P).

= Polycarpaea gayi Webb var. lycioides Webb in Hooker, Niger Fl.: 105 (1849). - Type: "Capvert. Herbier rapporté du Portugal en 1808 par M. Geoffrey St. Hilaire" [1784-1787, Silva Feijão] (P).

Illustration: Gomes et al. (1995b: p. 18).

Literature: Diniz (1995). 
Description. Moderately branched, ascending to erect, occasionally almost procumbent shrub or subshrub up to $0.5 \mathrm{~m}$ high. Branches greyish or rarely silvery tomentose. Leaves opposite to apparently verticillate, shape very variable, broadly ovate to oblanceolate-spathulate, up to $9 \mathrm{~cm}$ long and $4 \mathrm{~cm}$ wide, lower leaf surface densely greyish tomentose or rarely almost silvery tomentose, upper leaf surface greenish with a less dense indument, apex acute to obtuse, margin entire. Stipules small. Flowers in terminal, usually dense cymes. Sepals scarious, whitish to brownish. Petals shorter than sepals. Capsule 3-valved.

Variation. The species is very polymorphic, showing considerable variation in habit, pubescence, leaf size, and leaf shape. The morphological variation is probably continuous and ecoclinal, and the varieties (cf. above), which were described based on single specimens only, appear to be of no taxonomic significance.

Chromosome number: $2 \mathrm{n}=18$ (Santo Antão, Ribeira do Paul, 1050 m, Borgen 1980).

Related taxa. Polycarpaea gayi is most closely related to $P$. nivea (Aiton) Webb, distributed in the Canary Islands, at the Atlantic coast of $\mathrm{N}$ Africa, and at arid, sandy sea-shores of several Capeverdean islands. Populations that are transitional between these species occur in some coastal localities (Brochmann 1993).

Distribution and ecology. Polycarpaea gayi is a ubiquitous mesophyte occurring on most of the islands (Santo Antão, São Vicente, Branco, São Nicolau, Sal, Santiago, and Fogo). The species has not been recorded from Santa Luzia, Boa Vista, Maio, and Brava. It is most frequent in the semiarid and subhumid zones. The species also occurs scattered in the humid zone and only occasionally in the arid zone. It is distributed from sea-level to above $2000 \mathrm{~m}$ on Fogo (Lobin 1982c), but it occurs mainly below $1400 \mathrm{~m}$. The plants usually grow in rocky habitats. On Fogo, $P$. gayi is an early colonizer of young lava fields.

Abundance. The species is common on Santo Antão, São Nicolau, Santiago, and Fogo, where we have observed many large populations. The only record from Sal dates from 1838 (leg. Brunner, syntype), and the only record from São Vicente dates from 1853-1861 (leg. Welwitsch), and the species is considered Extinct (EX) on these islands. Polycarpaea gayi is generally considered to be Lower Risk (LR).

\section{CISTACEAE}

This family is represented by a single genus with one endemic species.

\section{Helianthemum Mill.}

The genus Helianthemum contains some 110 species of shrublets. One of its diversity centres is in the Mediterranean, but it is also distributed from NE Africa to Central Asia, and in $\mathrm{N}$ and $\mathrm{S}$ America. 


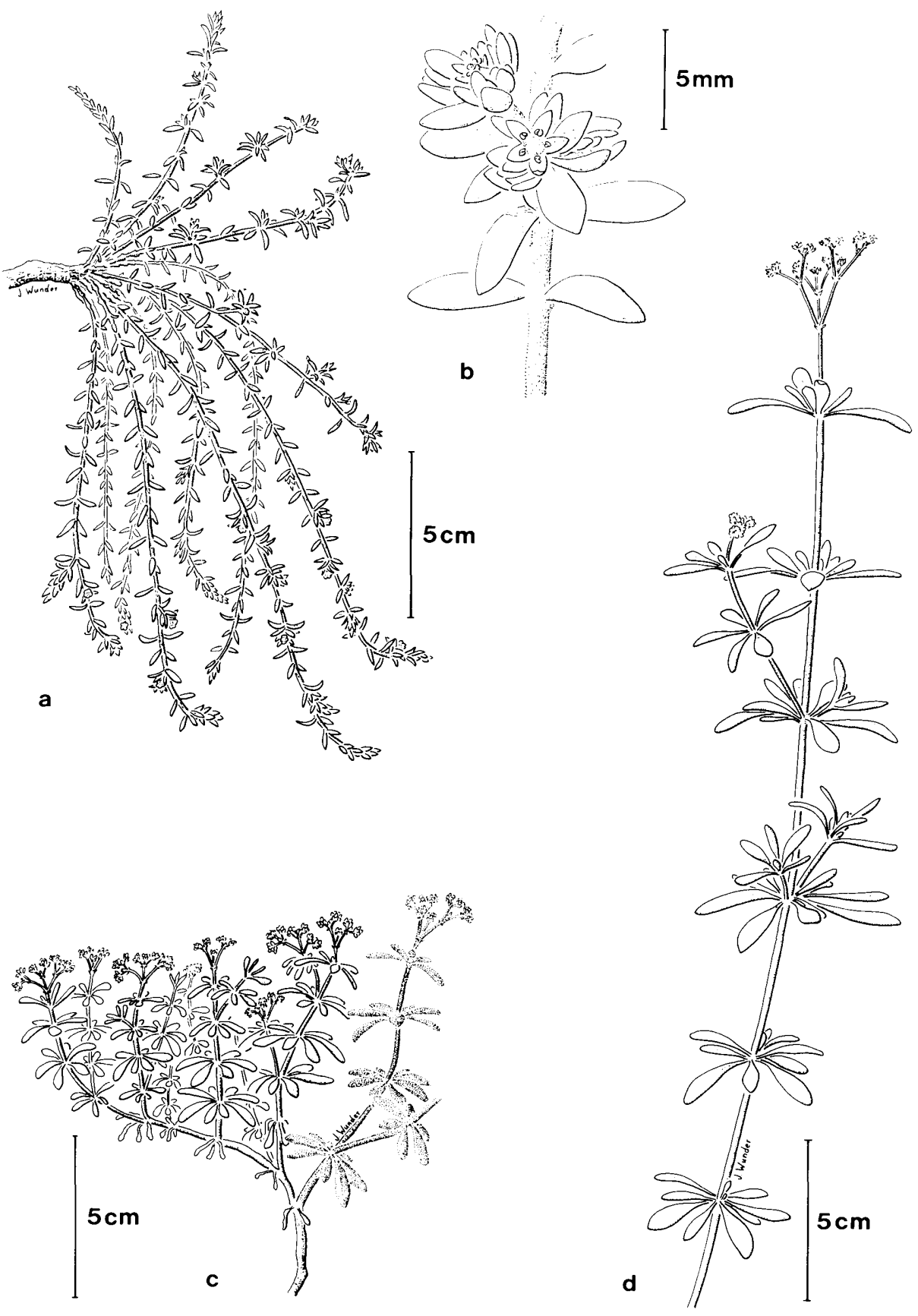

Fig. 111. Paronychia illecebroides and Polycarpaea gayi. a. Paronychia illecebroides, habit; b. P. illecebroides, inflorescence; c. Polycarpaea gayi, habit of stout form; d. P. gayi, habit of slender form. Drawn by J. Wunder. 


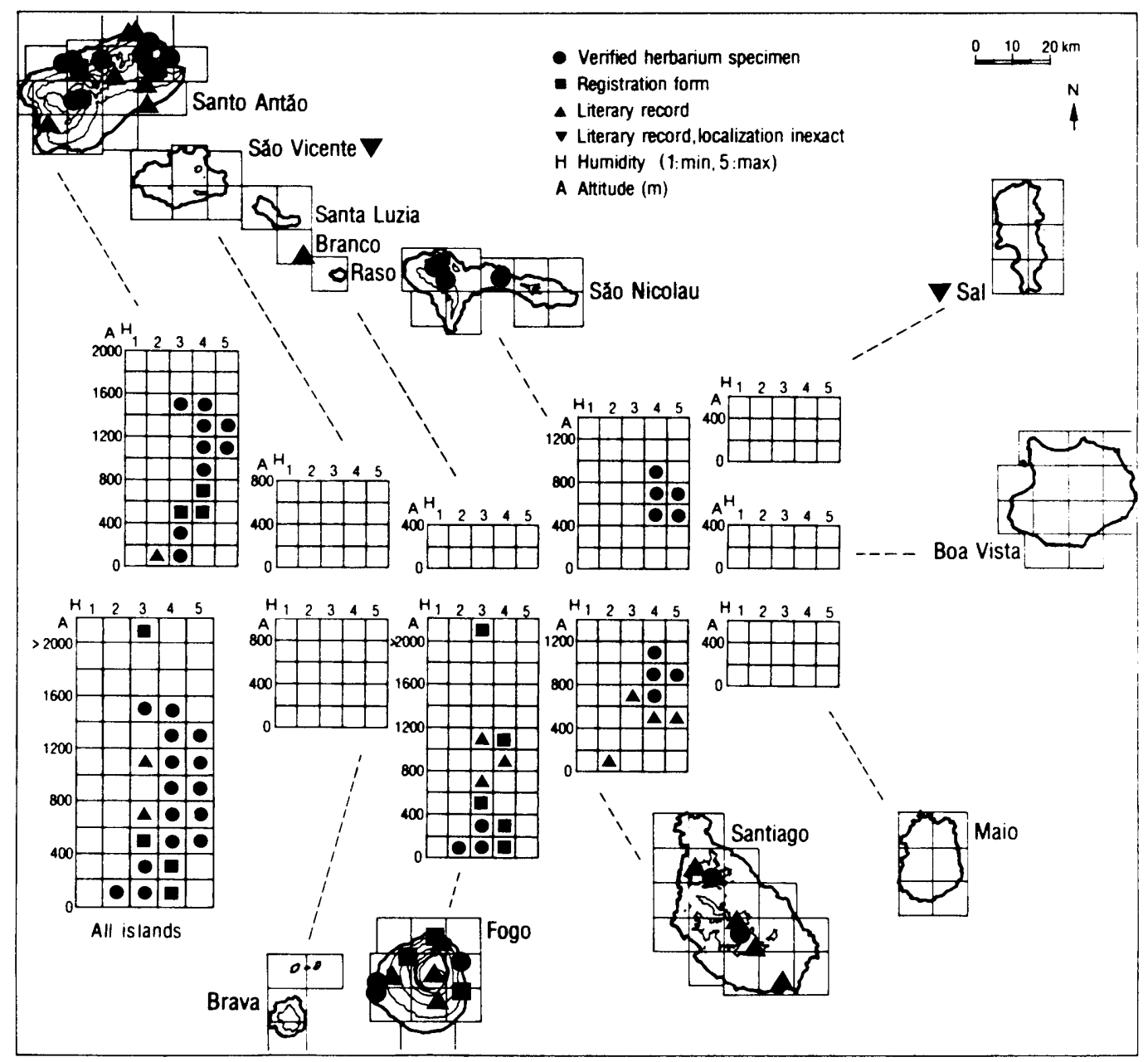

Fig. 112. Ecogeographic distribution of Polycarpaea gayi.

\section{Helianthemum gorgoneum (Figs 113, 114)}

Helianthemum gorgoneum Webb in Hooker, Niger Fl.: 102 (1849). - Type: "Capvert. Herbier rapporté du Portugal en 1808 par M. Geoffrey St. Hilaire" [1784-1787, Silva Feijão] (P).

Illustrations: Willkomm (1856-62: Fig 126A sub H. "gorgonicum"), Gomes et al. (1995b: p. 19).

Literature: Willkomm (1856-62), Grosser (1903), Basto (1995a).

Description. Procumbent to ascending or erect dwarf shrub up to $0.3 \mathrm{~m}$ high; stem and branches with soft, whitish pubescence. Leaves broadly ovate to ovate-lanceolate, up to 2.5 $\mathrm{cm}$ long and $1.3 \mathrm{~cm}$ wide, greyish to whitish pubescent, apex acute, margin entire. Stipules linear-lanceolate. Calyx tomentose. Petals deep yellow, purplish towards the base; stamens deep purple. Capsule roundish, pubescent. Seeds compressed, smooth, brown. 

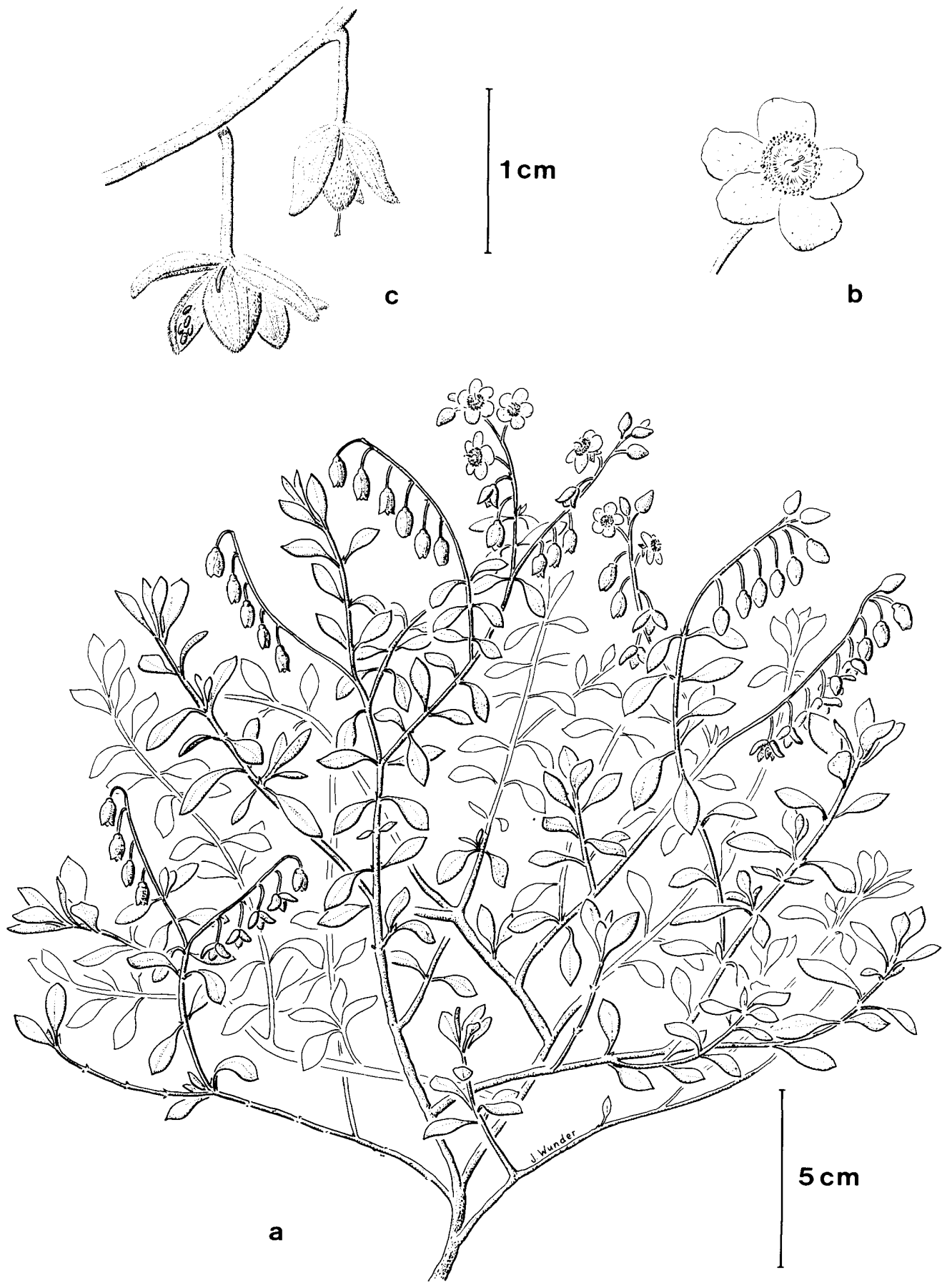

Fig. 113. Helianthemum gorgoneum. a. Habit; b. Flower; c. Fruits. Drawn by J. Wunder. 


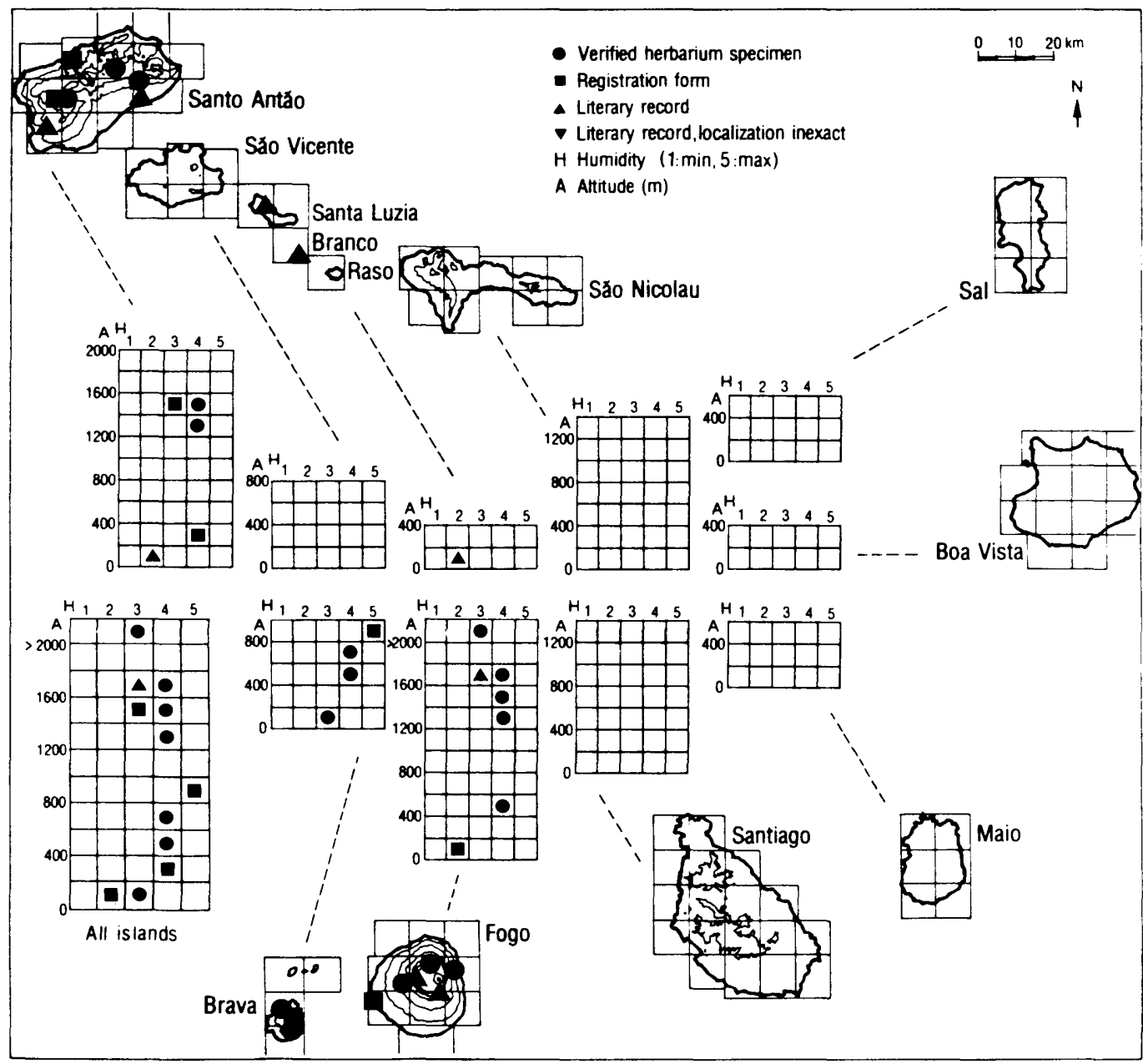

Fig. 114. Ecogeographic distribution of Helianthemum gorgoneum.

Variation. The plants show some variation in habit and pubescence. The species seems to be represented by two ecotypes; one procumbent, coastal ecotype and one more erect. montane ecotype. More material is needed to evaluate if these ecotypes should be recognized at the subspecific level.

Chromosome number: $2 \mathrm{n}=20$ (Fogo, Chã das Caldeiras, $1600 \mathrm{~m}$, Borgen 1975).

Related taxa. Helianthemum gorgoneum is most closely related to $H$. canariense (Jacq.) Pers., which occurs in the Canary Islands and Morocco.

Distribution and ecology. Helianthemum gorgoneum is a western mesophyte occurring on Santo Antão, Branco, Fogo, and Brava, and it has recently also been reported from Santa Luzia (Basto \& Diniz 1993). Interestingly, it is absent from the major western islands of São 
Nicolau and Santiago. It is most frequent in the subhumid and semiarid zones. The species is distributed almost from sea-level on Brava, Santa Luzia, and Branco to about $2200 \mathrm{~m}$ on Fogo (Nogueira 1975b; leg. Kilian \& Leyens). Notably, most localities on Santo Antão and Fogo are situated either in coastal regions below $400 \mathrm{~m}$ or in mountains above $1200 \mathrm{~m}$, possibly reflecting a distinct ecotypic differentiation. The plants seem to prefer volcanic lapilli (whitish, brownish as well as blackish) and sandy ground.

Abundance. Helianthemum gorgoneum is locally common with several large populations on the major islands, and it is generally considered to be Lower Risk (LR).

\section{CRASSULACEAE}

This family is represented by three genera with four species, of which two are endemic.

Aeonium Webb \& Berth.

The genus Aeonium comprises some 38 species of succulents. With the exception of two species, which occur in NE Africa and Yemen, the genus is almost confined to the midAtlantic archipelagos (A. arboreum (L.) Webb \& Berth. also occurs in W Morocco). In the Cape Verde Islands, the genus is represented by a single, endemic species.

Aeonium gorgoneum (Figs 115, 116)

Aeonium gorgoneum J. A. Schmidt, Beitr. Fl. Cap Verd. Ins.: 158 (1852) ESempervivum gorgoneum (J. A. Schmidt) Cout., Arq. Univ. Lisboa 1: 285 (1914). - Type: In rupestribus ins. S. Antonii, 3.1851, J. A. Schmidt (holotype: HBG!).

= Aeonium webbii Bolle, Bonplandia 7: 238 (1859). - Type: In insula S. Vicentii ad jugi Monte Verde radices inque ejus adscensu ad alt. 800-1000 pedum supra mare, Bolle (B, destroyed).

Illustrations: Praeger (1932: Fig. 67), Gomes et al. (1995b: p. 19).

Literature: Praeger (1932), Liu (1989), Mes (1995).

Note. Since neither the holotype in HBG nor isotypes in other herbaria could be found, a neotype was designated by Lobin (1986b: 95). This neotype designation was overlooked by Liu (1989). However, the original material at $\mathrm{HBG}$ was recently found and replaces the neotype.

Description. Erect, sparsely to moderately branched subshrub up to $0.6 \mathrm{~m}$ high, with leaves in dense, terminal rosettes. Inflorescence stem up to $0.3 \mathrm{~m}$ long, leafless. Leaves spathulate to obovate-spathulate, up to $7 \mathrm{~cm}$ long and $3 \mathrm{~cm}$ wide, strongly succulent, glabrous, margin ciliate. Inflorescences terminal, thyrsoid. Calyx campanulate. Petals yellow, up to $8 \mathrm{~mm}$ long and $1.5 \mathrm{~mm}$ broad.

Variation. The material shows only slight variation.

Chromosome number: $2 \mathrm{n}=36(\mathrm{n}=18$, without locality, Liu 1989).

Related taxa. Aeonium gorgoneum was placed by Liu (1989) in section Pittonium A. Berger together with $A$. glutinosum (Aiton) Webb \& Berth. from Madeira and the two species from E Africa and Yemen. However, recent analyses of chloroplast DNA and nuclear DNA sequence variation in Macaronesian Sempervivoideae (including A. gorgoneum) and related 


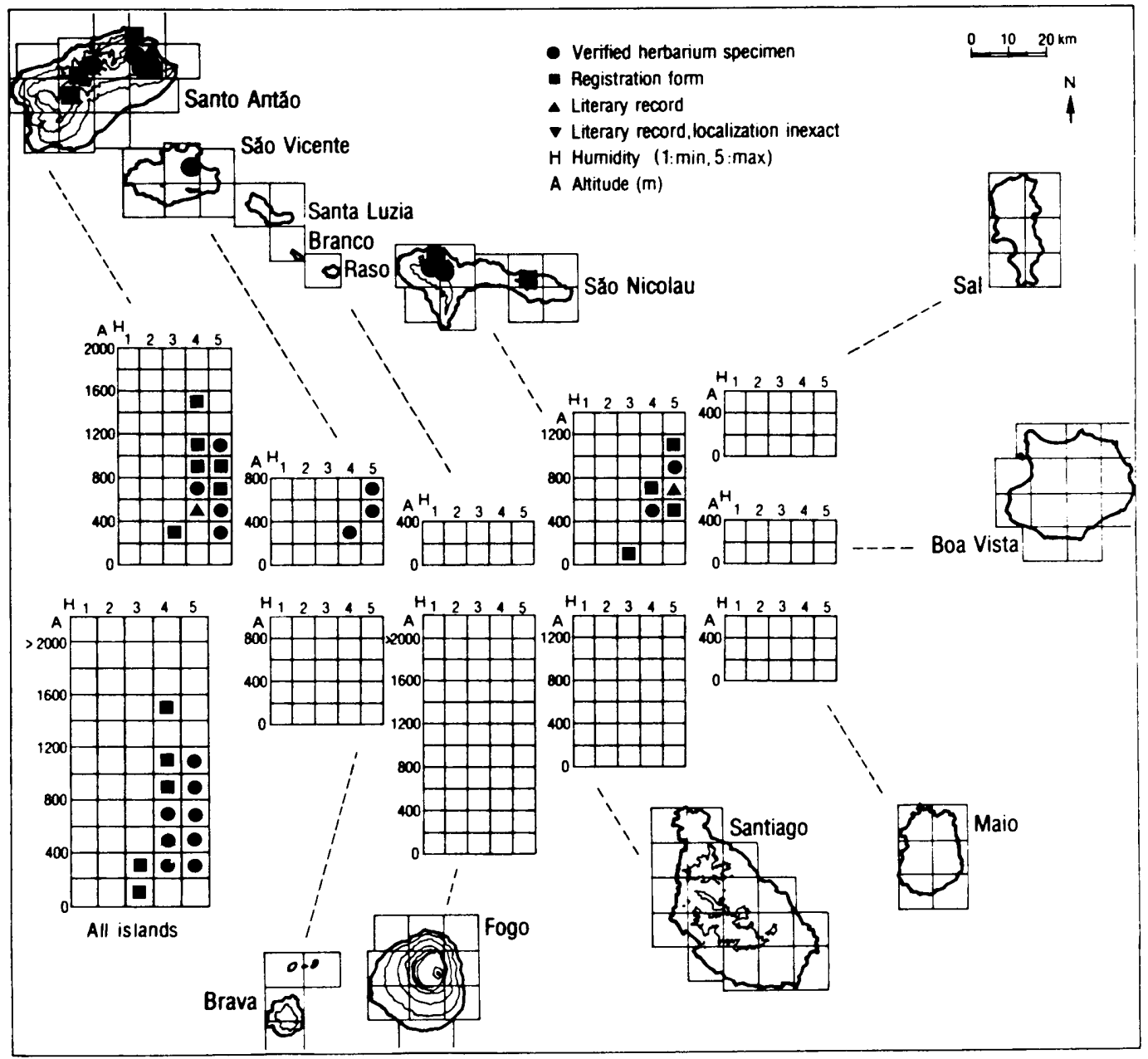

Fig. 115. Ecogeographic distribution of Aeonium gorgoneum.

Sedoideae provided evidence for a revised classification (Mes 1995). These molecular analyses suggest that $A$. gorgoneum is most closely related to A. arboreum, $A$. holochrysum Webb \& Berth., A. rubrolineatum Svent., A. simsii (Sw.) Stearn, all from the Canary Islands, and A. leucoblepharum Webb ex A. Rich. from E Africa and Yemen. Aeonium gorgoneum was therefore placed by Mes (1995) together with these species in section Aeonium, whereas the Madeiran $A$. glutinosum was kept as the only member of section Pittonium.

Distribution and ecology. Aeonium gorgoneum is a northern mesophyte occurring on Santo Antão, São Vicente, and São Nicolau. It is equally frequent in the subhumid and humid zones, and a few localities are situated in coastal cliffs in the semiarid zone. The main 
altitudinal distribution is between $400 \mathrm{~m}$ and $1100 \mathrm{~m}$. The species has been recorded at $100 \mathrm{~m}$ on São Nicolau (registration form, Rustan \& Brochmann), and the uppermost record is at $1500 \mathrm{~m}$ at Pico da Cruz on Santo Antão (Chevalier 1935a). The plants grow exclusively in steep, usually north- to northeast-exposed cliffs, often together with Campanula jacobaea, Sonchus daltonii, and Lotus spp.

Abundance. On Santo Antão and São Nicolau, the species is common and represented by some fairly large populations in particularly favourable habitats. The species is Endangered (EN) on São Vicente, where it is confined to Monte Verde and the total number of individuals is small. Aeonium gorgoneum is generally considered to be Lower Risk (LR).

\section{Umbilicus DC.}

The genus Umbilicus comprises 18 species of annual and perennial herbs with a characteristic foliage. The genus is distributed from the mid-Atlantic archipelagos, W Europe, and the Mediterranean to Iran, and it also occurs in some African mountains. In the Cape Verde Islands, the genus is represented by a single species described as endemic to the archipelago.

\section{Umbilicus schmidtii (Figs 116, 117)}

Umbilicus schmidtii Bolle, Bonplandia 7: 245 (1859). - Syntypes: Insula S. Antonii, Bordeira de Paul, Bolle (B, destroyed); in insula S. Nicolai summo cacumine Montis Gourdo, Bolle (B, destroyed).

Illustration: Gomes et al. (1995b: p. 19).

Description. Unbranched, erect perennial herb up to $0.25 \mathrm{~m}$ high. Glabrous in all parts. Basal leaves orbicular, peltate, up to $6 \mathrm{~cm}$ in diameter, somewhat succulent, margin slightly crenate to almost entire, petioles long. Cauline leaves smaller, shortly petiolated to almost sessile. Inflorescence a long, many-flowered, terminal raceme. Calyx much shorter than the corolla. Corolla brownish-yellow, tubular; lobes short, lanceolate, acuminate.

Variation. No essential variation has been observed.

Chromosome number: Unknown.

Related taxa. The species is fairly similar to the Mediterranean $U$. horizontalis (Guss.) DC. and also resembles the African $U$. botryoides Hochst. ex A. Rich. The taxonomic significance of $U$. schmidtii is uncertain.

Distribution and ecology. Umbilicus schmidtii is a western hygrophyte occurring on Santo Antão, São Nicolau, Santiago, and Fogo. It is confined to small areas in the subhumid and humid zones, mainly between $800 \mathrm{~m}$ and $1600 \mathrm{~m}$. The lowermost records are at $550 \mathrm{~m}$ on Fogo (Monte Palha, leg. Kilian \& Leyens) and at $600 \mathrm{~m}$ on Santo Antão (Sunding 1981), and the uppermost one at $2000 \mathrm{~m}$ on Fogo (Ormonde 1977). The plants grow in north- to northeast-facing, moist cliffs.

Abundance. Umbilicus schmidtii is infrequent even in suitable habitats, and it is generally considered to be Rare (R). 


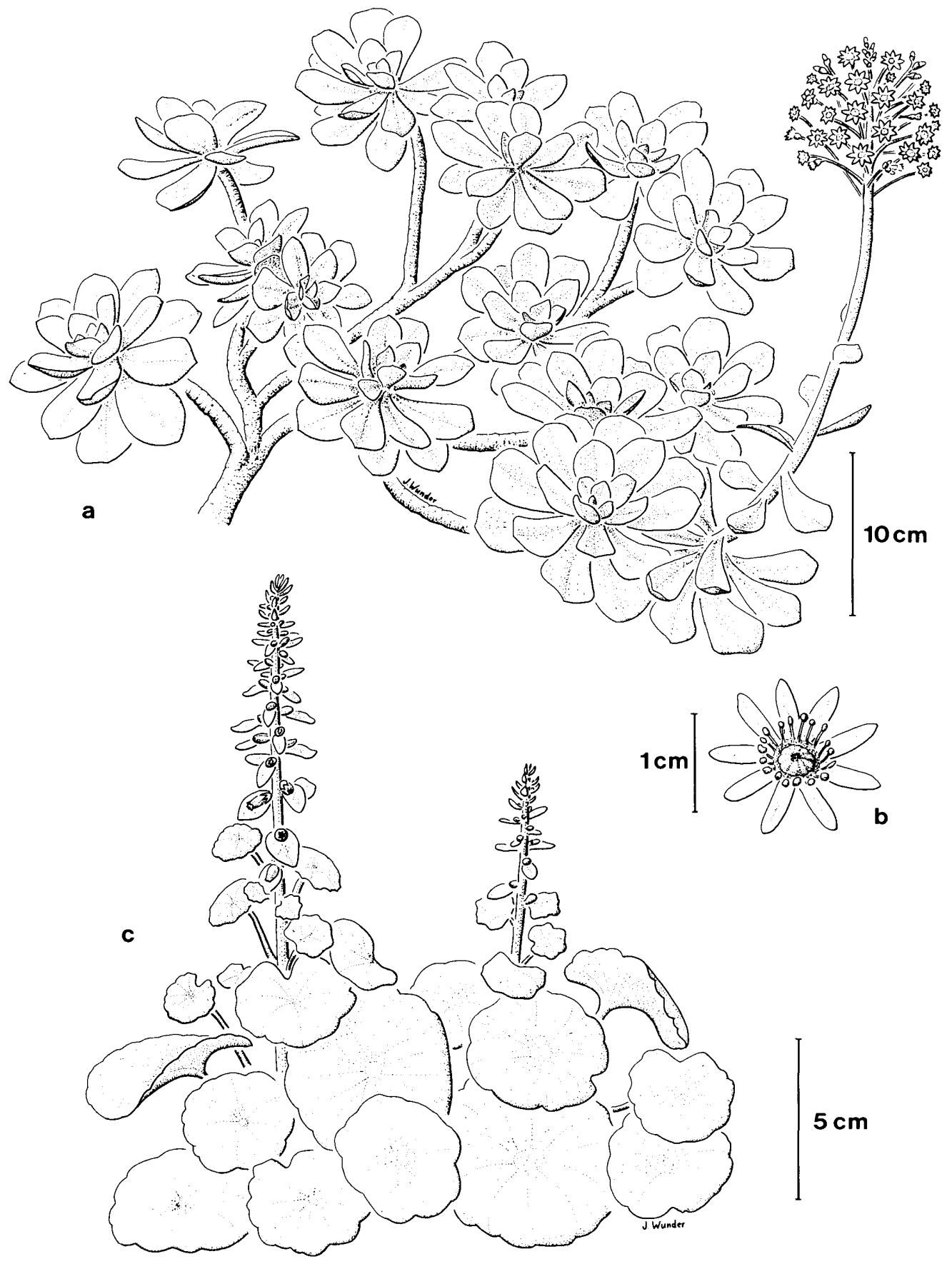

Fig. 116. Aeonium gorgoneum and Umbilicus schmidtii. a. Aeonium gorgoneum, habit; b. A. gorgoneum, flower; c. Umbilicus schmidtii, habit. Drawn by J. Wunder. 


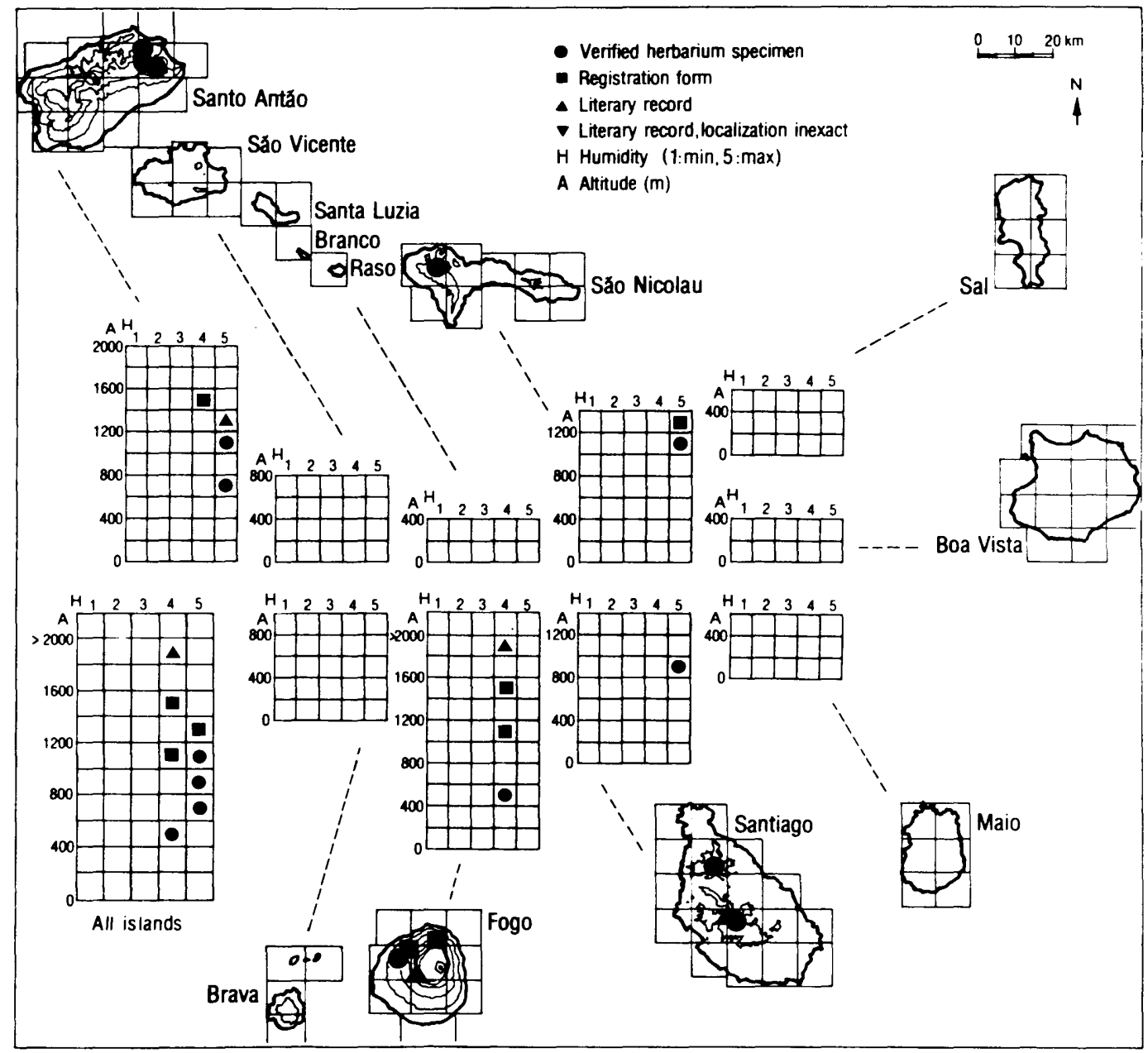

Fig. 117. Ecogeographic distribution of Umbilicus schmidtii.

\section{EUPHORBIACEAE}

This family is represented by nine genera with 34 species, of which one is endemic.

\section{Euphorbia L.}

Euphorbia is the second largest angiosperm genus with its about 1600 species. The genus has a cosmopolitan distribution and comprises succulents as well as annual or perennial, nonsucculent herbs, shrubs, and trees. Several mainly woody taxa have evolved by adaptive 
radiation in the mid-Atlantic archipelagos. The genus is represented by 16 species in the Cape Verde Islands. Fourteen of these species are herbaceous. The two woody species are the endemic E. tuckeyana Webb and the introduced, thicket-forming leafless shrub E. tirucalli L., which occurs on Sal.

Literature: Carter et al. (1984), Figueiredo (1996).

\section{Euphorbia tuckeyana (Figs 118, 119)}

Euphorbia tuckeyana Webb in Hooker, Niger Fl.: 177 (1849). - Syntypes: S. Vicent, 6.1841, Vogel 122 (FI-W, K); ins. S. Jacobi, 11.1839, J. D. Hooker 115 (FI-W, K); "Capvert. Herbier rapporté du Portugal en 1808 par M. Geoffrey St. Hilaire" [1784-1787, Silva Feijão] (P).

= Euphorbia tuckeyana Webb var. mezereum A. Chev., Rev. Bot. Appl. Agric. Trop. 15: 957 (1935). Type: S. Vicente, Monte Verde, vers. 400 m, 1934, Chevalier 45763 (holotype: P).

[= Euphorbia arborescens C. Sm. in Tuckey, Narr. Exped. Zaire: 251 (1818), nom. nud.].

[= Euphorbia tuckeyana Steud., Nomencl. Bot. 1: 615 (1840), nom. nud.].

Illustrations: Chevalier (1935b: Tab. 4a, 7a-b, 8b), Carter et al. (1984: Fig. 2), Lobin (1986b: Figs 18 , 19), Brochmann \& Rustan (1987: Fig. 9), Gomes et al. (1995b: p. 20).

Description. Usually hemispherical, evergreen shrub or small tree up to $3 \mathrm{~m}$ high, strongly branched, with milky latex in all parts. Branches thick and stout, leaves concentrated towards the apices. Leaves oblong to oblong-lanceolate, up to $6 \mathrm{~cm}$ long and $1.6 \mathrm{~cm}$ wide, glabrous, apex acute to obtuse or rarely retuse, margin entire. Cyathial bracts persistent, large, glands entire. Style with slightly bifid tip. Capsule with 3 locules, woody at maturity and suddenly fragmenting septicidally-loculicidally into 6 parts, catapulting the 3 seeds out.

Variation. Some variation was observed in growth form, apparently depending on the habitat. Typically, the plants have a conspicuous hemispherical shape with a more or less developed, but always rather short trunk. Plants in strongly wind-exposed, dry habitats may have a trellis-like habit. There is also some variation in capsule size, leaf size, and leaf apex, but this variation is probably of no taxonomic significance.

Chromosome number: $2 \mathrm{n}=20(2 \mathrm{n}=20$, Santo Antão, Bramwell \& Murray 1972, Bramwell et al. 1972; $2 \mathrm{n}=20$, Sal, Monte Grande, $400 \mathrm{~m}$, Borgen 1980; $\mathrm{n}=10$, without locality, Ortega 1980).

Related taxa. Euphorbia tuckeyana belongs to the E. obtusifolia complex, which also comprises E. obtusifolia Poir. from the Canary Islands and E. regis-jubae Webb \& Berth. from the Canary Islands, SW Morocco, and Western Sahara. Euphorbia tuckeyana is distinguished from E. obtusifolia by its larger and persistent cyathial bracts, larger capsules, and styles with more distinctly bifid tip, and from E. regis-jubae by its much taller growth, glands without horns, styles with less distinctly bifid tip, and distinctly larger capsules (Carter et al. 1984).

Distribution and ecology. Euphorbia tuckeyana is a ubiquitous mesophyte occurring on Santo Antão, São Vicente, Santa Luzia, São Nicolau, Sal, Boa Vista, Santiago, Fogo, and Brava. It has been widely distributed on most islands, but confined to the small mountains on the flat eastern islands of Sal and Boa Vista, and it has not been recorded at all from the eastern island of Maio. The species occurs in the semiarid, subhumid, and humid zones, mainly above $300 \mathrm{~m}$, and only a few localities are situated in the arid zone. The lowermost records are from São Nicolau and Brava, where the species occasionally occurs down to sea-level (Rustan \& Brochmann 1993). On Santo Antão, it extends almost to the summit of 


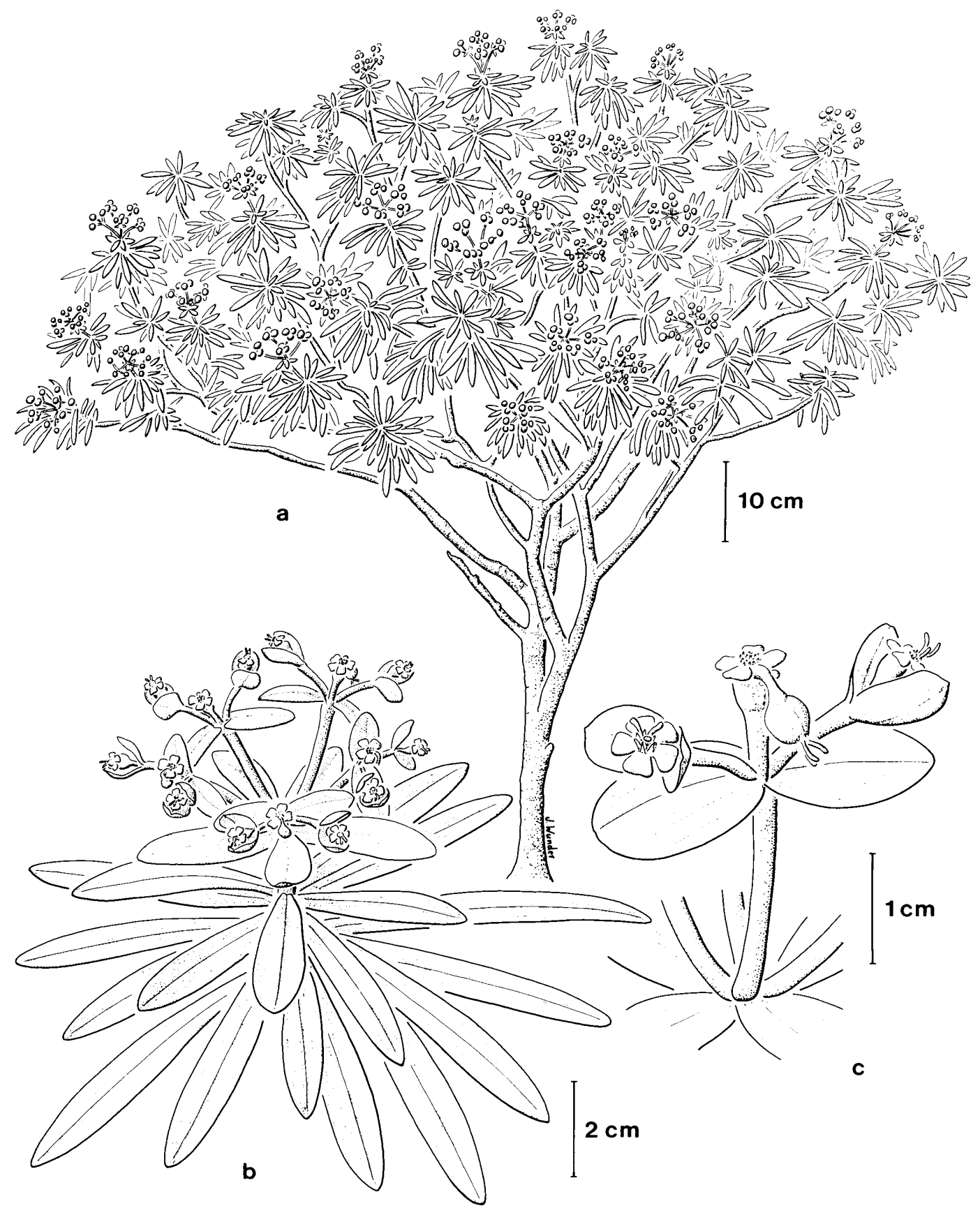

Fig. 118. Euphorbia tuckeyana. a. Habit; b. Branch with leaves and inflorescences; c. Inflorescence. Drawn by J. Wunder. 


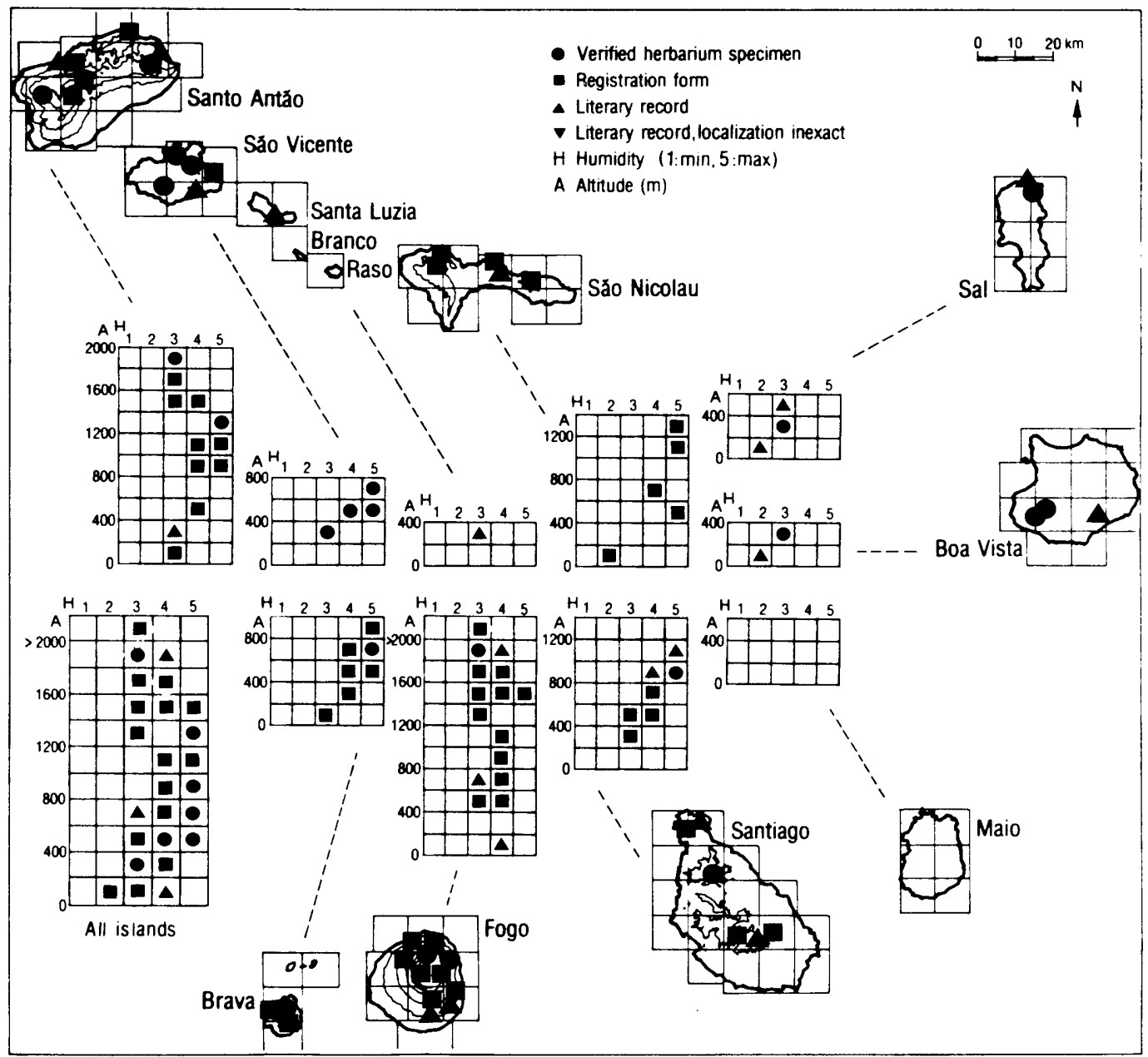

Fig. 119. Ecogeographic distribution of Euphorbia tuckeyana.

Tope de Coroa at $1940 \mathrm{~m}$ (Rustan \& Brochmann 1993). On Fogo, it has been found up to 2400-2500 m, where it frequently occurs on the outer escarpments of the central caldeira rim (leg. Kilian \& Leyens) and occasionally on Pico Novo (Gomes et al. 1995a). Euphorbia tuckeyana is one of the most characteristic species of the indigenous vegetation in the Cape Verde Islands. It once formed the major vegetation type on the islands, an up to $3 \mathrm{~m}$ high scrub vegetation consisting of almost pure stands of E. tuckeyana or mixed stands with other endemic shrubs such as Artemisia gorgonum, Conyza varia, Echium spp., Globularia amygdalifolia, or Nauplius spp. Krause (1892) reported that this scrub vegetation extended down to $70 \mathrm{~m}$ on São Vicente, and that it was the dominating vegetation type on the northern slopes of Monte Verde above $400 \mathrm{~m}$. Today, this vegetation type has almost disappeared from São Vicente. 
Abundance. The species is undercollected because it is difficult to preserve. From Boa Vista, the only records dated from 1897-1898 (leg. Fea) until the species was rediscovered in 1994 (Gomes et al. 1995a). It is still rather abundant on some islands, although it is strongly declining in all areas because of land clearing and extensive use as firewood. Today, the species is Critically Endangered (CR) on São Vicente and Santiago, it is Endangered (EN) on São Nicolau, Sal, and Brava, and it is Vulnerable (VU) on Santo Antão, Boa Vista, and Fogo. Euphorbia tuckeyana is generally considered to be Vulnerable (VU).

\section{FABACEAE}

This family is represented by 28 genera with about 56 species. All endemic taxa (five species) belong to the genus Lotus.

\section{Lotus L.}

The genus Lotus contains annual and perennial species distributed widely throughout the world. A preliminary checklist of Lotus, including Tetragonolobus Scop., enumerates a total of 176 species (Kirkbride 1994). The genus has two principal distributional areas (Grant 1995); the first one centres around the Mediterranean and ranges throughout Europe, southwards to the Sahara, and eastwards through temperate Asia, and the second one centres in western $\mathrm{N}$ America.

Lotus is one of the most widespread and variable genera in the Cape Verde Islands, and about 15 species and varieties have been described as endemic. In addition, the $\mathrm{N}$ African $L$. glinoides Delarbre has been reported from São Vicente. All of the endemic taxa belong to section Pedrosia (Lowe) Brand, which is characterized by a more or less bilabiate calyx, yellow or purple corolla, and 1-toothed style. This section is also distributed in the SW part of the Iberian Peninsula, W Morocco, the Azores, Madeira, and the Canary Islands. A total of about 40 taxa has been described as endemic to the mid-Atlantic archipelagos, often without comparing taxa from different archipelagos, and the genus needs a thorough revision in the entire area. The Capeverdean species of Lotus have been suggested to be most closely related to L. glaucus Aiton s. lat. (Brand 1898), which is widely distributed in Madeira and the Canary Islands. Some of the Capeverdean taxa are, however, morphologically fairly similar to species in Morocco, suggesting that they may rather have a NW African affinity.

This survey of Lotus in the Cape Verde Islands is based on examination of the morphological variation in our own, rather large material from most of the islands (approximately 350 specimens), as well as some material from other herbaria. The material shows a complex pattern of variation which partly seems to be correlated with ecological conditions. Several of the taxa develop larger leaves, denser indument, and heads with more and larger flowers towards higher altitudes and in more humid areas. Other characters, such as corolla colour, show a more random variation. In some of the taxa, specimens with yellow or purple corolla, and specimens with all intermediate combinations of yellow and purple are found intermingled within populations. The taxonomic use of this character is complicated by 
the fact that yellow corollas often become purple or roseus during withering or on dried specimens.

A wide species concept has been adopted in this classification of Lotus, and five species are recognized. Several of the previously described taxa merely seem to represent small parts of the total variation and are based on one or a few herbarium specimens only. In cases where types have not been available, we have based our interpretation of a taxon on the protologue. We recognize $L$. purpureus as a widespread and variable, mainly western xerophytic species. In montane areas on two islands, xerophytic L. purpureus-like ancestors have probably given rise to two meso- or hygrophytic species: L. latifolius (Santo Antão) and L. arborescens (São Nicolau). However, several populations at intermediate altitudes and humidity appear to be more or less morphologically transitional between the local montane taxon and lowland populations of $L$. purpureus, probably reflecting a more or less ecoclinally based evolution. Lotus brunneri is recognized as a mainly eastern xerophytic species, whereas L. jacobaeus is recognized as a southern mesophytic species occurring on Santiago and Fogo.

Because of the considerable taxonomic and nomenclatural confusion in the group, we have omitted literary records of distribution and ecology. In addition to the islands reported here, material of Lotus has also been reported from the islet of Raso (as L. brunneri, Schleich \& Wuttke 1983)

Key to the genus Lotus

1 Style not toothed [L. glinoides]

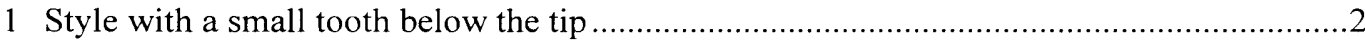

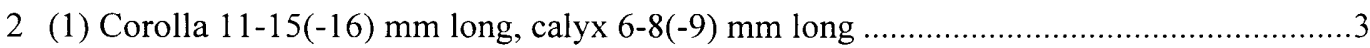

2 Corolla (14-)15-18 mm long, calyx 8-11 mm long ...........................................4

3 (2) Head 3-5-flowered, leaflets linear to oblanceolate L. brunneri

3 Head 1-3(-4)-flowered, leaflets obovate to oblanceolate L. purpureus

4 (2) Peduncle longer than subtending leaf.... L. latifolius

4 Peduncle shorter than or subequal to subtending leaf .5

5 (4) Leaf rachis less than 0.5 times as long as lowest pair of leaflets L. jacobaeus

5 Leaf rachis more than 0.5 times as long as lowest pair of leaflets L. arborescens

Lotus arborescens (Figs 120, 121)

Lotus arborescens Lowe ex Cout., Arq. Univ. Lisboa 1: 289 (1914). - Syntypes: In ins. S. Nicolau, 22.2.1864. Lowe (LISU!); ibid., ad Fonte da Chupadeira, in Monte Queimado, 13.3.1866, Lowe (LISU!). -- Lectotype (designated by Lobin 1986b: 126): "Pedrosia arborescens Lowe, S. Nicolão, 22.2.64", Lowe (LISU!).

Illustration: Lobin (1986b: Fig. 23 sub L. purpureus).

Description. Suffruticose, erect to ascending perennial, 0.4-1.0 m high. Stem stiff, if erect with patent-pendent branches, if ascending diffusely branched, stem and branches glabrous or 


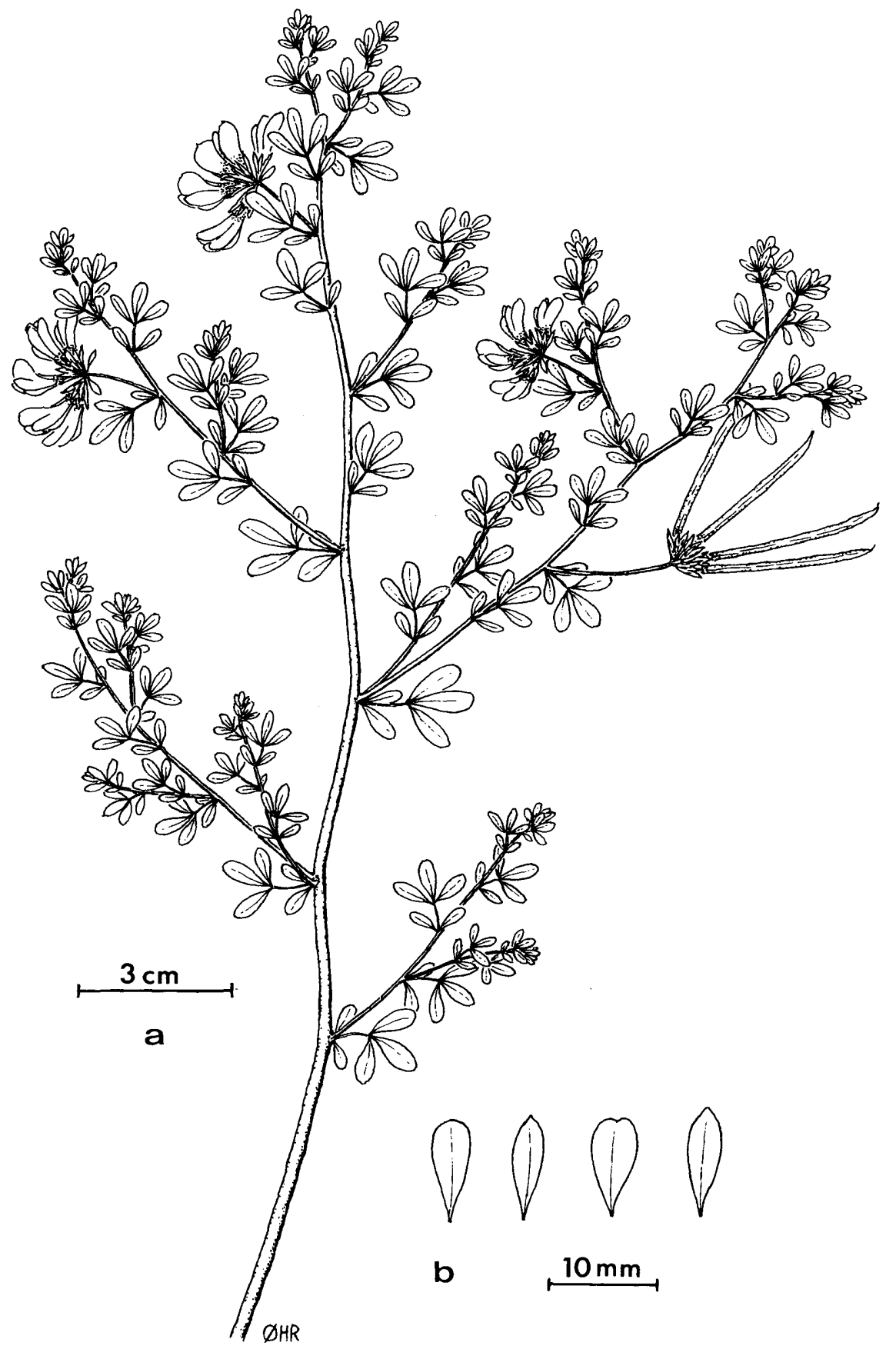

Fig. 120. Lotus arborescens. a. Habit; b. Leaflet variation. Drawn by Ø. H. Rustan. 


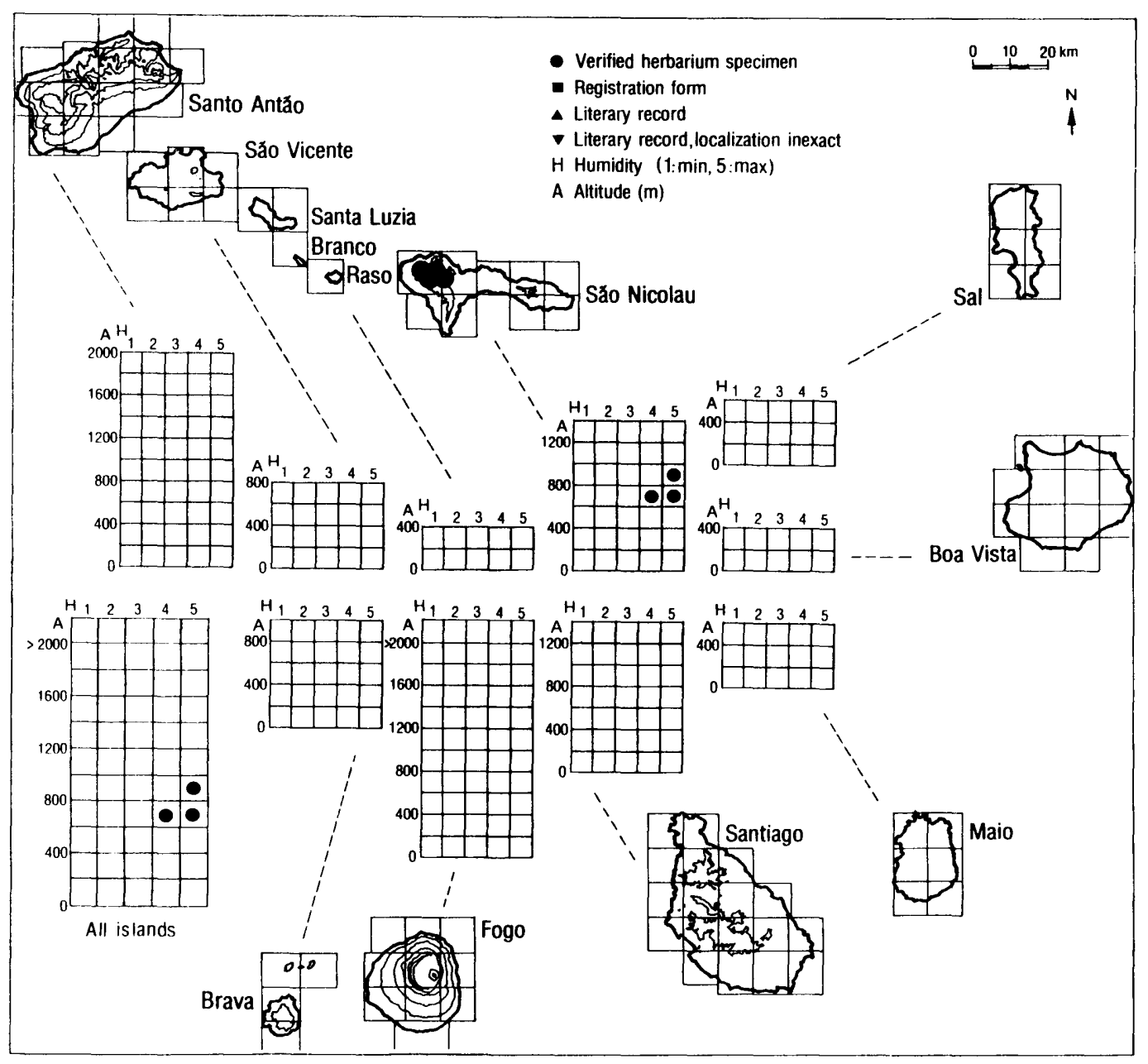

Fig. 121. Ecogeographic distribution of Lotus arborescens.

sericeous. Leaves pubescent or sericeous, rachis more than 0.5 times the length of basal leaflets; upper 3 leaflets (11-)15-25 mm long and (4-)7-10 mm wide, oblanceolate to obovate, apex obtuse, acute, or obcordate, sometimes mucronate; basal 2 leaflets (6-)9-16 mm long and 2-6.5 mm wide, elliptical or obovate. Heads 3-5-flowered; peduncles equally long as leaves or shorter than leaves. Calyx $8-10 \mathrm{~mm}$ long; teeth slightly unequal, curved, linear-triangular with triangular base, equally long as tube or slightly shorter than tube. Corolla $15-18 \mathrm{~mm}$ long, yellow or yellow with purple-tipped wings; standard equally long as keel to $1 \mathrm{~mm}$ longer than keel. Legume 35-45 $\mathrm{mm}$ long and 2-2.5 mm broad, straight.

Variation. The species varies conspicuously in habit. Whereas the plants in some populations are ascending with diffuse branches, plants in other populations are erect with 
patent-pendent branches and densely crowded leaves. Lotus arborescens occurs together with L. purpureus in lower montane areas, and intermediate specimens have been observed.

Chromosome number: Unknown.

Related taxa. See L. purpureus.

Distribution and ecology. Lotus arborescens is a northern hygrophyte restricted to the western mountain range on São Nicolau. It occurs in the subhumid and humid zones between $600 \mathrm{~m}$ (several areas) and $1000 \mathrm{~m}$ (Monte Gordo, leg. Rustan \& Brochmann). The plants usually grow in gravelly, montane slopes and plains.

Abundance. The species is locally fairly common, but it has a very restricted total distribution area. Lotus arborescens is considered to be Rare (R).

Lotus brunneri (Figs 122, 123)

Lotus brunneri Webb in Hooker, Icon. Pl. 8: ad tab. 754 (1848). - Type: Ins. Salis lapidosis magna copia, Brunner (holotype: K!).

[= Lotus jacobaeus L. var. flaviflorus Brunner, Flora 23, Beibl. 1: 86 (1840), nom. nud.].

Illustration: Webb (1848: Tab. 754, 1849: Fig. 3).

Description. Suffruticose, procumbent to ascending perennial up to $0.6 \mathrm{~m}$ high. Stem stiff, diffusely branched, subsericeous. Leaves subsericeous, glaucous, rachis less than or more than 0.5 times the length of basal leaflets; upper 3 leaflets (9-)14-21 mm long and (1.5-)3-6 mm wide, linear to oblanceolate, apex obtuse, acute, or obcordate; basal 2 leaflets often lacking, if present 7-11 mm long and 1-1.5 mm wide, linear. Heads 3-5-flowered; peduncles longer than leaves. Calyx 6-7 mm long; teeth slightly unequal, curved, linear-triangular with triangular base, equally long as tube or slightly shorter than tube. Corolla 11-13 mm long, yellow; standard equally long as keel to $1 \mathrm{~mm}$ longer than keel. Legume $33-47 \mathrm{~mm}$ long and 2-2.5 $\mathrm{mm}$ broad, straight.

Variation. The species is variable in leaf size and shape, but it is otherwise more homogeneous than the other species in the genus.

Chromosome number: $2 \mathrm{n}=14$ (Sal, Ribeira do Joaquim Petinha, Borgen 1975). The report of Bramwell \& Murray (1972) and Bramwell et al. (1972) probably refers to $L$. purpureus (see this species).

Related taxa. Lotus brunneri resembles L. jacobaeus in some characters, but the two species differ in habit, corolla size, peduncle length, and usually in corolla colour, which never is purple in L. brunneri.

Distribution and ecology. Lotus brunneri is a ubiquitous xerophyte with its principal distribution on Sal, but it also occurs on São Vicente, Boa Vista, and Maio. The species was collected on São Vicente in 1851 (leg. Schmidt, HBG!), but we have not seen recent collections from this island. The species is distributed in the extremely arid and arid zones, mainly between sea-level and $80 \mathrm{~m}$, but it has also been collected at $380 \mathrm{~m}$ at Monte Grande in Sal (leg. Lobin). The plants grow on sand along beaches and in coastal as well as inland plains, and also in weed vegetation.

Abundance. The species has been collected recently on all of the three eastern islands. It is still fairly common on Sal, but it is possible that the populations become smaller. It is Rare (R) on Boa Vista and Maio and considered Extinct (EX) on São Vicente. Lotus brunneri is generally considered to be Lower Risk (LR). 


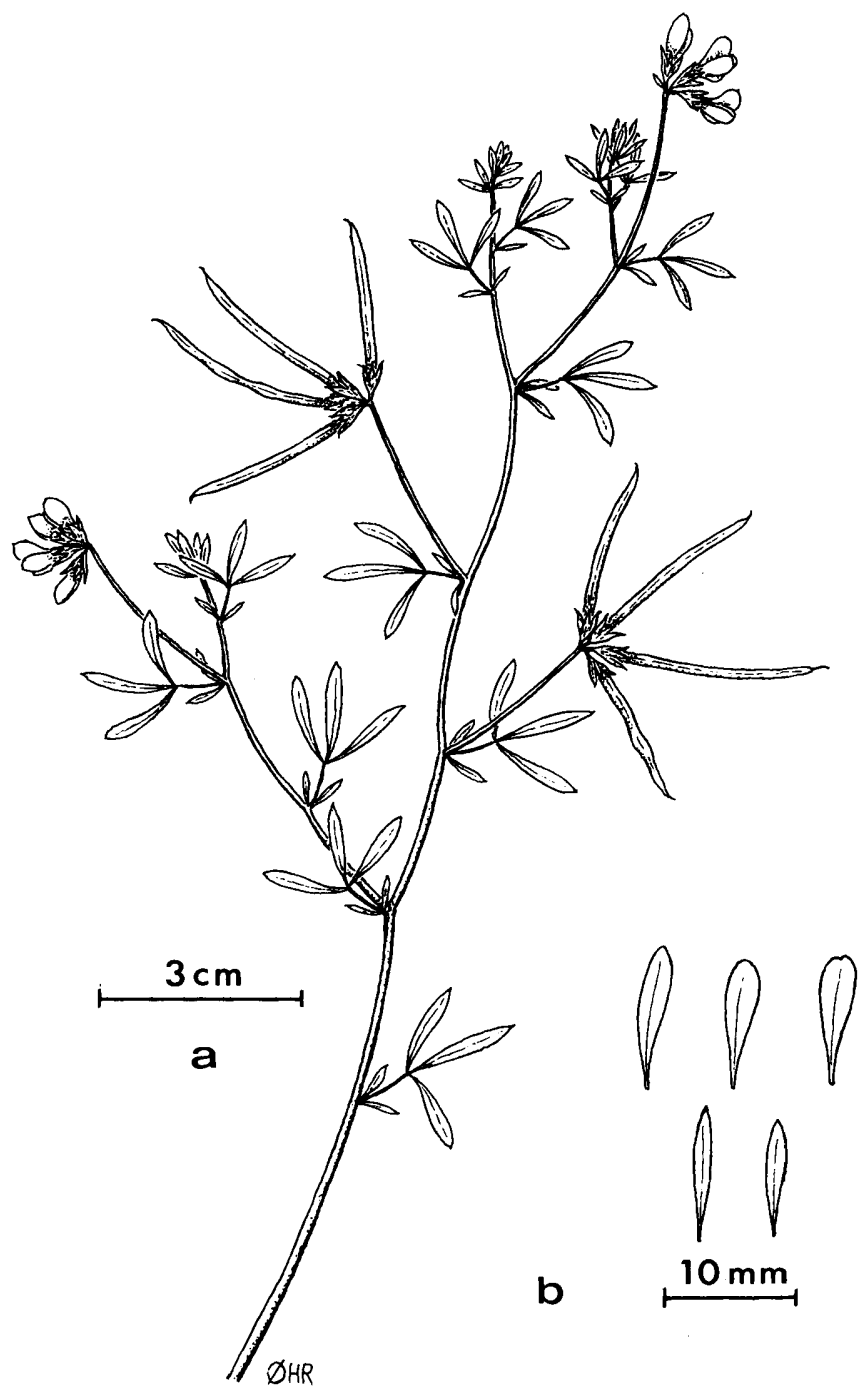

Fig. 122. Lotus brunneri. a. Habit; b. Leaflet variation. Drawn by $\varnothing$. H. Rustan. 


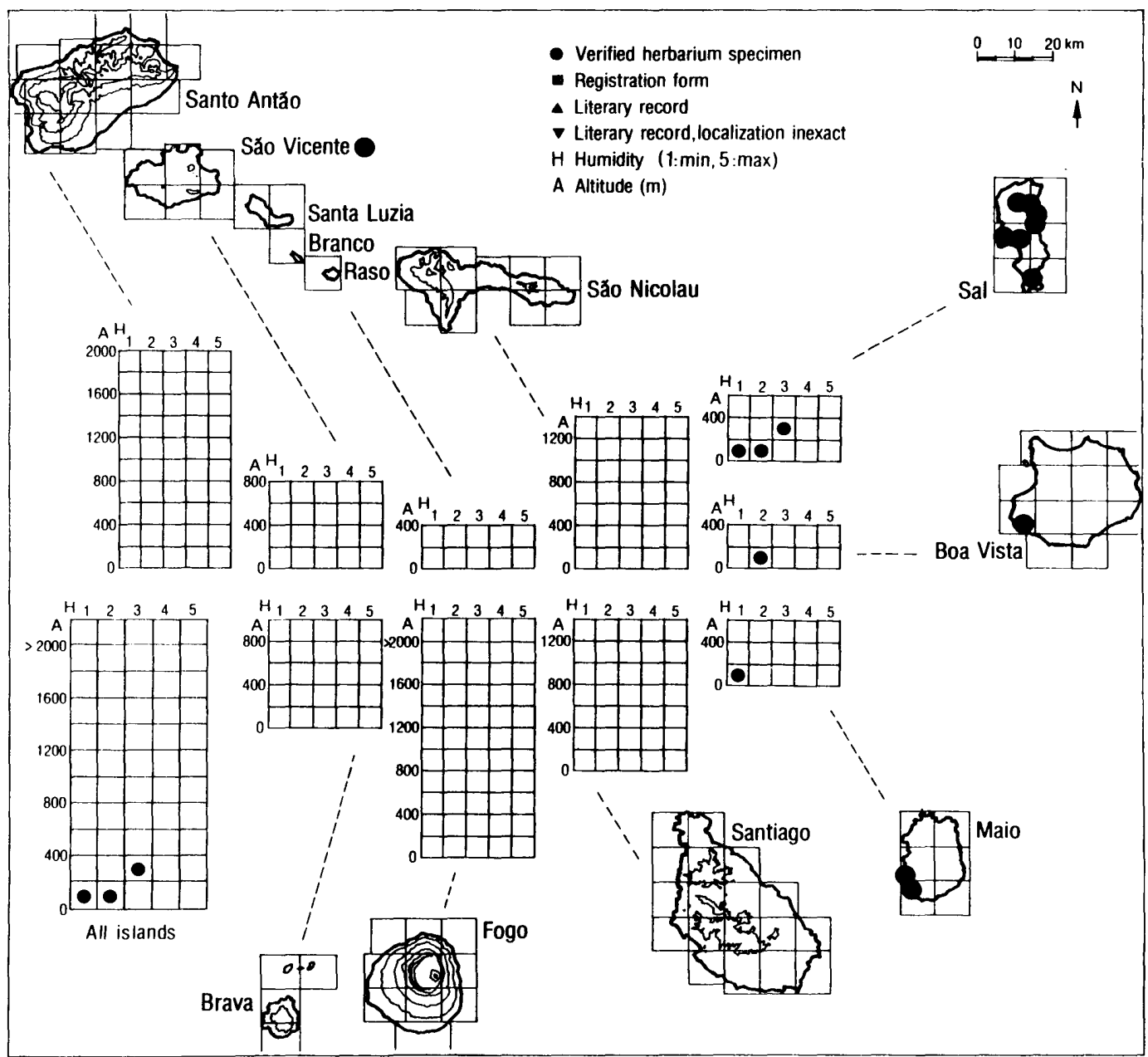

Fig. 123. Ecogeographic distribution of Lotus brunneri.

\section{Lotus jacobaeus (Figs 124, 125)}

Lotus jacobaeus L., Sp. Pl.: 775 (1753) =Lotus lugubris Salisb., Prodr. Stirp. Chap. Allerton: 333 (1796), nom. illeg. = Lotus tristis Moench, Suppl. Meth.: 53 (1802), nom. illeg. — Type (designated by Wijnands 1983: 165): "Lotus jacobaeus" herb. Clifford No. 372.7 (BM).

$=$ Lotus jacobaeus L. var. luteus A. Chev., Rev. Bot. Appl. Agric. Trop. 15: 968 (1935). -- Type: Fogo, Curral Fundo sur Ribeira Lomba, $1000 \mathrm{~m}$, Chevalier 45194 (holotype: P).

$=$ Lotus jacobaeus L. var. villosus A. Chev., Rev. Bot. Appl. Agric. Trop. 15: 968 (1935). — Type: Fogo, Chupadeiro, 1000-1200 m, Chevalier (holotype: P).

= Lotus anthylloides Vent., Jard. Malmaison: ad tab. 92 (1805). - Type: Cult. in Jardin de la Malmaison, origin erroneously stated as S Africa (holotype: W!).

$=$ Lotus melilotoides Webb in Hooker, Niger Fl.: 118 (1849). - Type: "Capvert. Herbier rapporté du Portugal en 1808 par M. Geoffrey St. Hilaire" [1784-1787, Silva Feijão] (holotype: P). 
= Lotus atropurpureus DC., Cat. Pl. Horti Monsp.: 121 (1813). - Type: Cult. in Bot. Gard. Genève from seeds ex Bot. Gard. Montpellier (holotype: G-DC (microfiche!)).

= (fide Brand 1898: 203) Lotus linearis Walp., Linnaea 13: 518 (1839). - Type: [origin erroneously given as Cape Region, S Africa], Lalende in herb. Kunth (B, destroyed).

Illustrations: Commelin \& Commelin (1701: Fig. 83 sub phrasename Lotus angustifolius flore luteo purpurascente), Curtis (1797: Tab. 79), Ventenat (1804-1805: Fig. 92 sub L. anthylloides), Berhaut (1976: Fig. on p. 416), Wijnands (1983: Fig. on p. 165), Lobin (1986b: Fig. 2).

Description. Suffruticose, erect or rarely ascending perennial, 0.4-1.0 m high. Stem stiff, branches erect-patent, glabrous or pubescent. Leaves glabrous, slightly pubescent or sericeous, rachis minute or absent; upper 3 leaflets (10-)20-38 mm long and 3.5-6(-10) $\mathrm{mm}$ wide, linear, narrowly elliptical or oblanceolate, apex acute, often mucronate; basal 2 leaflets (3-)15-25 mm long and (1-)2-5 mm wide, linear, narrowly elliptical or oblanceolate. Heads (3-)4-6-flowered; peduncles subequal to leaves or shorter than leaves. Calyx 8-11. mm long; teeth slightly unequal, curved, linear-triangular with triangular base, equally long as tube or slightly shorter than tube. Corolla 15-17 mm long, purple, yellow, or with various combinations of purple and yellow; standard equally long as keel to 1-2 mm longer than keel. Legume (33-)40-56 mm long and 2-2.5 mm broad, straight.

Variation. The species is variable in leaf shape, leaf size, and corolla colour. On Santiago and Fogo, the corolla colour varies conspicuously from entirely purple or entirely yellow to various combinations of purple and yellow in different parts of the corolla. Some populations appear to be morphologically intermediate between $L$. jacobaeus and $L$. purpureus.

Chromosome number: $2 \mathrm{n}=14$ (Without locality, Ortega 1980). The voucher material needs to be verified because of the widespread taxonomic confusion in the genus.

\section{Related taxa. See L. brunneri.}

Distribution and ecology. Lotus jacobaeus is a southern mesophyte occurring in montane areas on Santiago and Fogo. Most populations occur in the semiarid and subhumid zones, but the species has also been recorded from the humid zone in the Serra do Pico da Antonia area on Santiago. Its main altitudinal distribution is between $600 \mathrm{~m}$ and $2000 \mathrm{~m}$. The lowermost records are from $330 \mathrm{~m}$ in the subhumid, central montane region on southern Santiago and from $480 \mathrm{~m}$ in a locally favourable, northwest-exposed area on eastern Fogo (leg. Rustan \& Brochmann). The uppermost records are from $2300 \mathrm{~m}$ on the caldeira rim on Fogo (leg. Lobin) and from $700 \mathrm{~m}$ on Santiago (leg. Rustan \& Brochmann). The plants grow in gravelly slopes and plains, roadsides, field edges, and only rarely in cliffs.

Abundance. The species is locally very common, in particular in the Chã das Caldeiras area on Fogo, where some populations are fairly large. It appears to be less common on Santiago. Lotus jacobaeus is generally considered to be Lower Risk (LR).

Note. Lotus jacobaeus was the first plant that was described from the Cape Verde Islands. The species was introduced to Europe by Willem Adriaan van der Stel, who in 1699, on his way to S Africa, sent seeds from the island of Santiago to Commelin in Amsterdam (Wijnands 1983: 213). The valid binomial is quoted from Linnaeus' "Hortus Cliffortianus" (1738) and is based on Clifford's plant collection from the Amsterdam garden. Lotus jacobaeus was soon widely distributed among European botanical gardens (e.g., already in ca. 1700 herborized at the Jardin du Roi, Paris, by Vailland (P), see Chevalier 1935a: 967), and it later became a well-known (non-hardy) garden plant mentioned in many encyclopaedias of horticulture up to the present. 


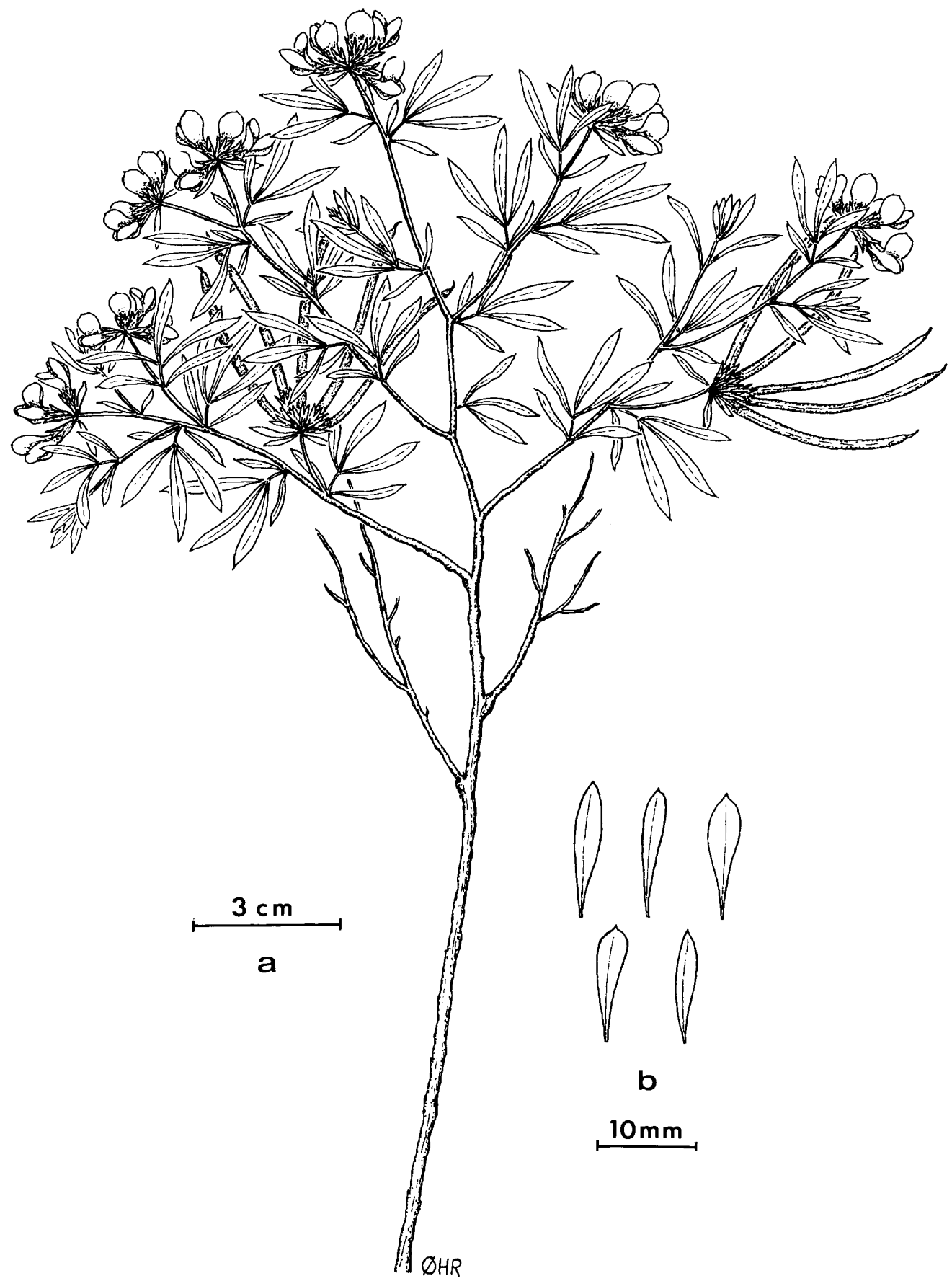

Fig. 124. Lotus jacobaeus. a. Habit; b. Leaflet variation. Drawn by Ø. H. Rustan. 


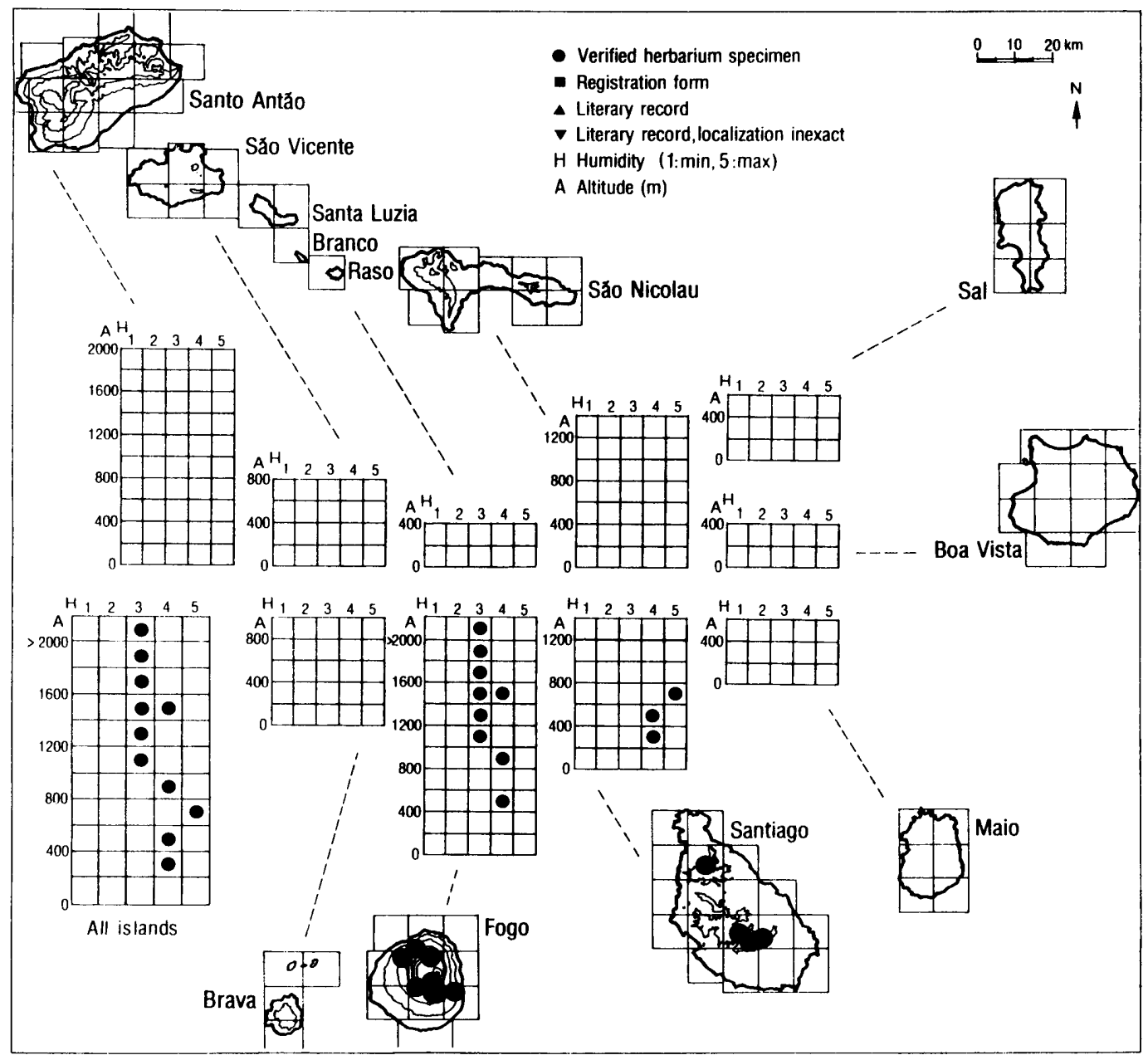

Fig. 125. Ecogeographic distribution of Lotus jacobaeus.

Lotus latifolius (Figs 126, 127)

Lotus latifolius Brand, Bot. Jahrb. Syst. 25: 202 (1898). -- Type: S. Antoine, 1853, Bolle (not traced).

= Lotus oliveirae A. Chev., Rev. Bot. Appl. Agric. Trop. 15: 966 (1935). - Type: Sto. Antão, Cova, $1350 \mathrm{~m}$, sur les contreforts du volcan, 1934, Chevalier 45585 (holotype: P).

Description. Suffruticose, procumbent to ascending perennial, 0.3-1.2 $\mathrm{m}$ high. Stem diffusely branched, pubescent or sericeous. Leaves pubescent, sericeous or villose, rachis less than or more than 0.5 times the length of basal leaflets; upper 3 leaflets very variable in size and shape, (9-)12-23 mm long and (2-)4-12 mm wide, linear-elliptical to oblanceolate or obovate, apex obtuse, acute, or slightly obcordate, often mucronate; basal 2 leaflets (3.5-)6-12 mm long 


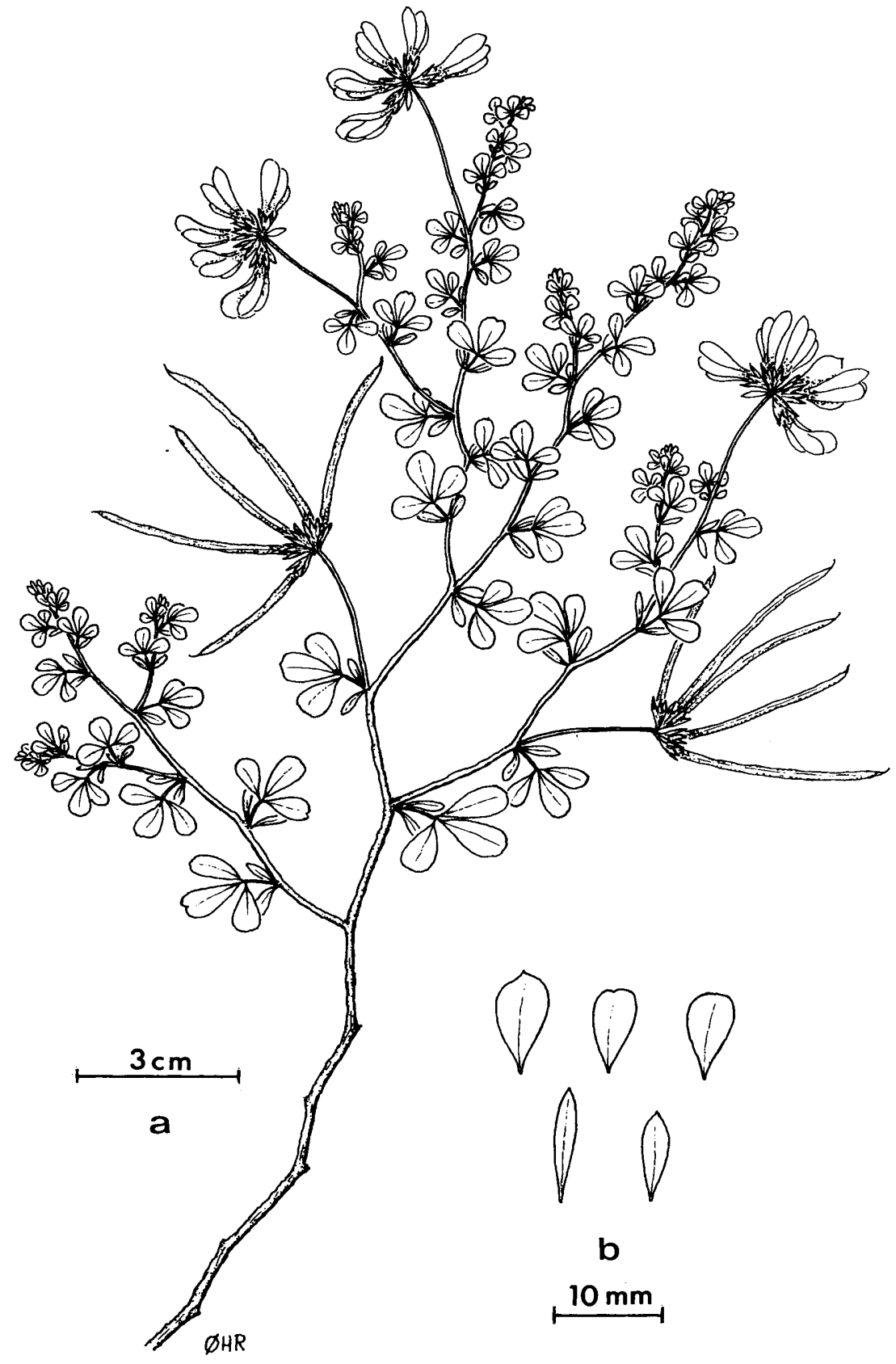

Fig. 126. Lotus latifolius. a. Habit; b. Leaflet variation. Drawn by Ø. H. Rustan. 


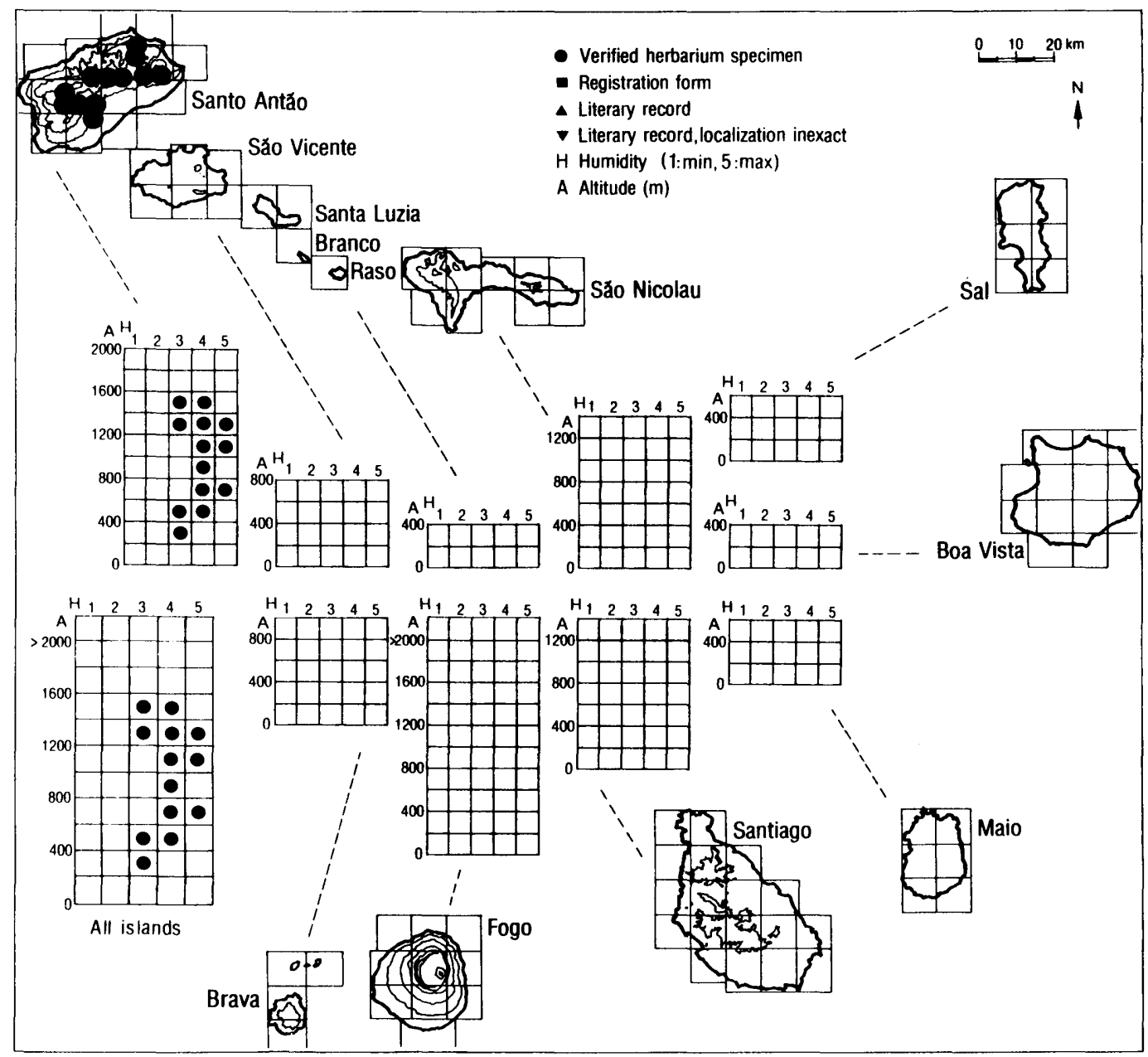

Fig. 127. Ecogeographic distribution of Lotus latifolius.

and (1.5-)2-5.5 mm wide, linear to elliptical. Heads (3-)4-6-flowered; peduncles longer than leaves. Calyx (8-)9-11 mm long; teeth slightly unequal, curved, linear-triangular with triangular base, equally long as tube or slightly shorter than tube. Corolla (14-)16-18 mm long, yellow or yellow with a purple spot on the wings; standard equally long as keel to 1-2 mm longer than keel. Legume (33-)40-52 mm long and 2-2.5 mm broad, straight.

Variation. This species is very polymorphic in leaf shape, leaf size, and indument. In the material examined, two main forms can be distinguished: specimens with obovate, glabrous to sericeous leaves, and specimens with linear-elliptical, villose leaves. However, these forms occur more or less intermingled in some local areas (e.g., in the Cova area), and several intermediate specimens have been found. At present, we therefore prefer not to recognize these forms as distinct taxa. In addition to these two forms, there are some 
populations at lower altitudes on Santo Antão that appear morphologically intermediate between L. latifolius and L. purpureus.

Chromosome number: Unknown.

Related taxa. See L. purpureus.

Distribution and ecology. Lotus latifolius is a northern mesophyte restricted to montane areas on Santo Antão. It is most common in the subhumid zone, but it also occurs frequently in the humid zone (e.g., Ribeira do Paul to Cova) and in the semiarid zone (e.g., the Tope de Coroa area). The species is mainly restricted to the upper montane areas between 600 $\mathrm{m}$ and $1600 \mathrm{~m}$ (leg. Rustan \& Brochmann), but it has been recorded down to $450 \mathrm{~m}$ on the southern slope of the island (leg. Rustan \& Brochmann) and even to $200 \mathrm{~m}$ in Ribeira Grande at the northern coast (leg. Lobin). The lowermost records probably represent secondary occurrences dispersed from the montane populations. The plants usually grow in gravelly plains and slopes, rarely in cliffs, and occasionally on roadsides and field edges. Commonly associated endemics are Conyza feae, Echium stenosiphon, Globularia amygdalifolia, Lavandula rotundifolia, and Paronychia illecebroides.

Abundance. The species is common throughout its distribution area, and we have observed many large populations. Although attention should be paid to the large morphological variation within this species, Lotus latifolius is considered to be Lower Risk (LR).

Lotus purpureus (Figs 128, 129)

Lotus purpureus Webb in Hooker, Icon. Pl. 8: ad tab. 757 (1848). - Type: In arvis et in Euphorbiae tuckeranae [sic] sylvis ins. S. Nicolai, 30.3.1822, Forbes (G-BOISS).

= Lotus bollei Christ, Bot. Jahrb. Syst. 9: 123 (1888). -- Type: Ins. S. Vincent, Monte Verde, 1852, Bolle (B, destroyed).

= Lotus candidissimus A. Chev., Rev. Bot. Appl. Agric. Trop. 15: 965 (1935). - Type: Sto. Antão, Covão, 500-900 m, 6.1935, A. Nobre (holotype: P).

= Lotus coronillaefolius Webb in Hooker, Niger Fl.: 119 (1849) non Guss. (1832), nom. illeg. - Type:

"Capvert. Herbier rapporté du Portugal en 1808 par M. Geoffrey St. Hilaire" [1784-1787, Silva Feijão] (holotype: P).

$=$ ? Lotus bollei Christ var. argenteus A. Chev., Rev. Bot. Appl. Agric. Trop. 15: 965 (1935) $\equiv$ Lotus coronillaefolius Webb (1849) non Guss. (1832) var. argenteus (A. Chev.) Sunding, Garcia de Orta, Sér. Bot. 2: 14 (1974). - Type: Boa Vista, sables maritimes près de Sal Rei, 1934, Chevalier 44360 bis (holotype: P).

$=$ Lotus brunneri Webb var. pusilla A. Chev., Rev. Bot. Appl. Agric. Trop. 15: 965 (1935). - Type: S. Vicente, Mato Inglés, Lowe (holotype: P).

= Lotus hirtulus Lowe ex Cout., Arq. Univ. Lisboa 1: 289 (1914). - Syntypes: Sto. Antão, Ribeira Grande, 3.1864, Lowe (LISU!); ibid., Ponta do Sol, 3.1864, Lowe (LISU!); ibid., Ponta do Sol, 3.1893, Cardoso (LISU!); ibid., João Dias, 2.-3.1894, Cardoso (LISU!); ibid., Monte Joanne, 2.-3.1894, Cardoso (LISU!). Lectotype (designated by Lobin 1986b: 125): "Lotus hirtulus (Lowe), Ilha de Sto. Antão, caminho da Ponta do Sol, Março-Abril, 1893", Cardoso (LISU!).

$=$ Lotus hirtulus Lowe ex Cout. var. laxifolius Lowe ex Cout., Arq. Univ. Lisboa 1: 289 (1914). - Type: Not designated.

Illustration: Lobin (1986b: Fig. 24 sub L. hirtulus).

Description. Suffruticose, procumbent to ascending perennial, 0.1-0.5 $\mathrm{m}$ high. Stem slender, diffusely branched, pubescent or sometimes glabrous. Leaves sparsely to densely pubescent or slightly sericeous, sometimes succulent, rachis more than 0.5 times the length of basal leaflets; upper 3 leaflets $5.5-14(-19) \mathrm{mm}$ long and $3.5-8(-12) \mathrm{mm}$ wide, obovate to 


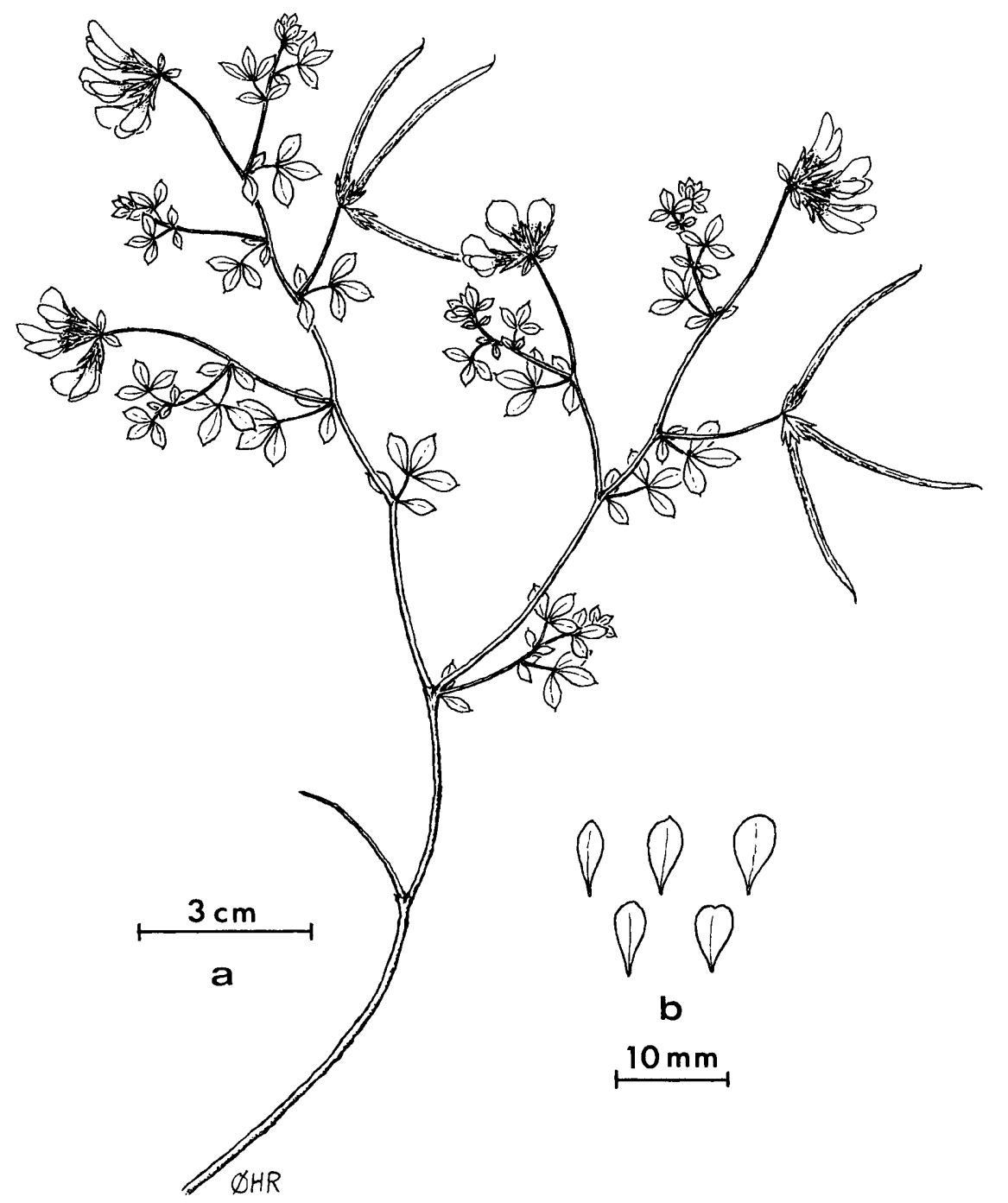

Fig. 128. Lotus purpureus. a. Habit; b. Leaflet variation. Drawn by Ø. H. Rustan. 


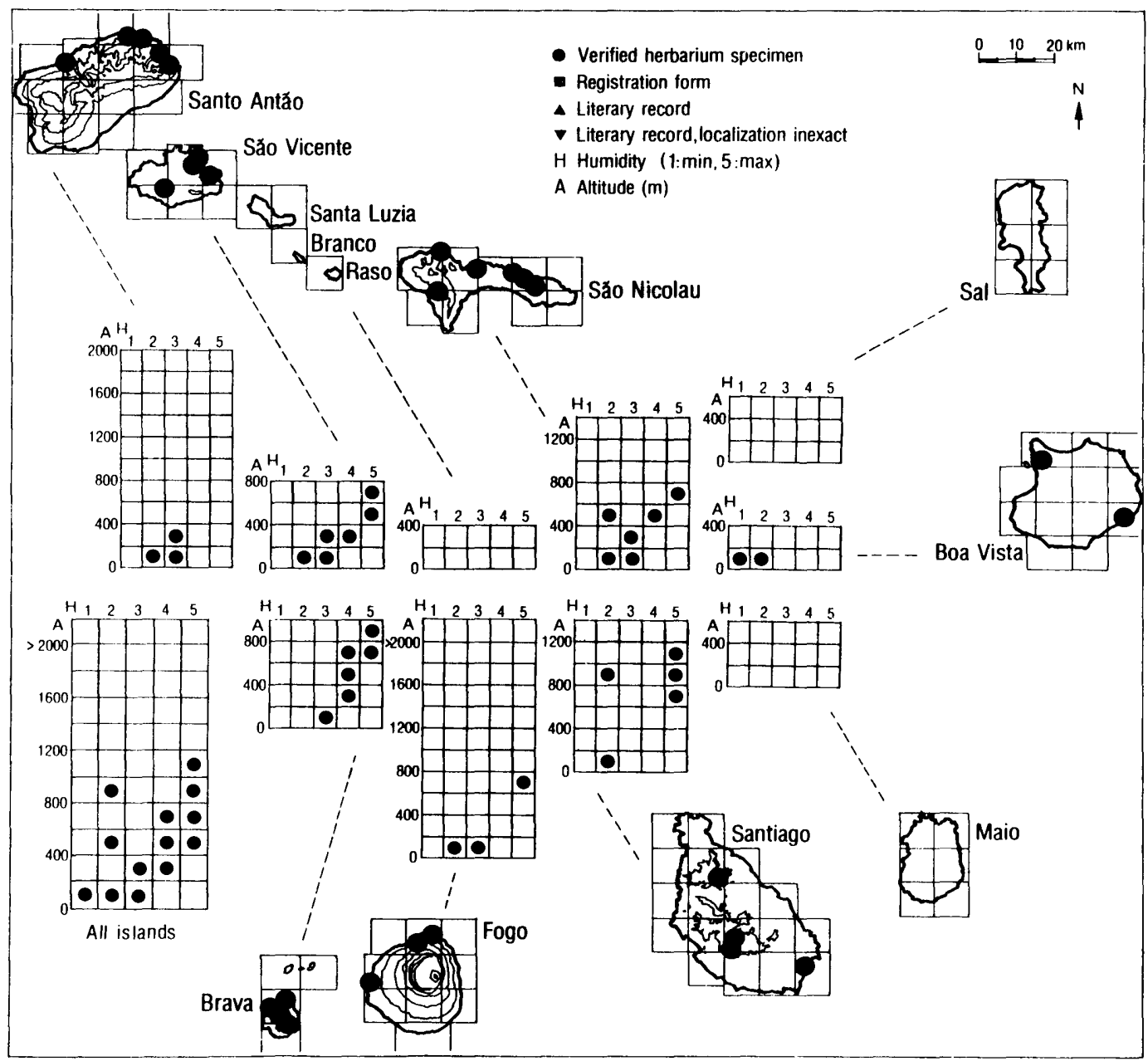

Fig. 129. Ecogeographic distribution of Lotus purpureus.

oblanceolate, apex obtuse, acute, or obcordate, sometimes mucronate; basal 2 leaflets 3-7(-10) $\mathrm{mm}$ long and 2-6(-7.5) $\mathrm{mm}$ wide, ovate, elliptical, or obovate. Heads 1-3(-4)-flowered; peduncles longer than leaves. Calyx 6.5-8(-9) mm long; teeth slightly unequal, curved, lineartriangular with triangular base, equally long as tube or slightly shorter than tube. Corolla 12$15(-16) \mathrm{mm}$ long, yellow, purple, or with various combinations of purple and yellow; standard equally long as keel to 1-2 mm longer than keel. Legume 21-40(-45) $\mathrm{mm}$ long and 2-2.5 $\mathrm{mm}$ broad, straight.

Variation. As many of the endemics that are ecologically and geographically widespread in the archipelago, this species is very polymorphic. The material varies considerably in leaf shape, leaf size, indument density, peduncle length, and corolla colour, but the variation appears complex, and we have not been able to recognize additional, distinct 
taxa within this material. The corolla colour varies among islands from entirely yellow (Santo Antão, São Vicente, Boa Vista, Santiago, and Fogo), yellow or yellow with purple wings (São Nicolau), to yellow, purple, yellow with purple wings, with standard that is externally purple but internally yellow, or with standard with purple veins (Brava). On São Nicolau and Brava, such variation in corolla colour is often found within a single population.

Chromosome number: $2 \mathrm{n}=14$ (Santo Antão, Bramwell \& Murray 1972, Bramwell et al. 1972, as L. brunneri). The reports of Bramwell \& Murray (1972) and Bramwell et al. (1972) appear to be based on the same material, which was collected by Sventenius along the coast between Ribeira Grande and Ponta do Sol (cf. Sventenius 1971). It is thus likely that the report refers to L. purpureus.

Related taxa. Lotus purpureus is probably closely related to L. arborescens and $L$. latifolius. These two species seem to replace L. purpureus at higher altitudes or in more humid areas.

Distribution and ecology. Lotus purpureus is a ubiquitous xerophyte occurring on Santo Antão, São Vicente, São Nicolau, Boa Vista, Santiago, Fogo, and Brava. The species has a wide ecological amplitude, occurring in all zones of humidity and from sea-level up to $1100 \mathrm{~m}$. It is most frequent in the arid, semiarid, and subhumid zones, but it also occurs fairly frequently in the humid zone, and it has also been reported from the extremely arid zone (Boa Vista). The main altitudinal distribution is between sea-level and $600 \mathrm{~m}$, but the species has been found at $760 \mathrm{~m}$ in the gravelly summit area of Monte Verde on São Vicente, at $640 \mathrm{~m}$ in the eastern mountain range on São Nicolau, at $1100 \mathrm{~m}$ in Serra do Pico da Antonia on Santiago, and at $890 \mathrm{~m}$ on Brava (leg. Lobin, leg. Rustan \& Brochmann). The plants grow along sandy and gravelly beaches (with, e.g., Polycarpaea nivea), in coastal plains, slopes, and valleys, in montane, gravelly slopes and plains (with, e.g., Echium stenosiphon ssp. stenosiphon, Lobularia canariensis (both subspecies), and Nauplius daltonii ssp. vogelii), and along roadsides.

Abundance. As presently circumscribed, this species is fairly widespread and common on most of the islands. We consider Lotus purpureus to be Lower Risk (LR).

\section{FRANKENIACEAE}

This family is represented by a single genus.

\section{Frankenia L.}

This genus comprises some 70 species of annuals, perennial herbs, and small (sub)shrubs, distributed along the coasts or in other saline habitats of America, Africa, the Mediterranean, SW Asia, Australia, and New Zealand. In the Cape Verde Islands, the genus is represented by a single species with one non-endemic subspecies and two endemic subspecies. 


\section{Frankenia ericifolia}

Frankenia ericifolia C. Sm. ex DC., Prodr. 1: 350 (1824). - Syntypes: "Canarias", I816, C. Simith (G-DC. microfiche!); "Teneriffe", 1807, Broussonet (G-DC, microfiche!); "Teneriffe ou Mogador", 1897[?], Broussonet (G-DC, microfiche!); Teneriffe, 1820, [...?] (G-DC, microfiche!).

Literature: Brochmann et al. (1995).

Note. No collections were quoted in the protologue. The description is, however, based on the specimens in Candolle's Prodromus herbarium at $\mathrm{G}$, which are quoted here as syntypes.

Description. Procumbent, ascending, or erect subshrub or shrub, 0.2-0.5(-0.8) $\mathrm{m}$ high. Stem slightly to strongly lignified, sparsely to strongly branched; stem and branches reddish brown to brown, densely hirsute to shortly pilose, pubescence denser upwards; older branches often glabrous. Leaves greyish green to fresh green, simple, decussate, narrowly lanceolate to broadly ovate; leaf margins slightly enrolled to strongly revolute, giving an ericoid appearance; basal leaves 3.3-18.5 $\mathrm{mm}$ long and 0.5-5.0 $\mathrm{mm}$ wide; upper leaves needle-like, or lanceolate with broadly revolute leaf margins; midvein prominent; leaf lamina densely hirsute, sometimes glabrous; abaxially glandulose (epidermal salt-excreting glands); petiole base always flattened, forming a thin membranaceous sheath together with the petiole base of the opposite leaf, sheath margin with long, white cilia, ciliation very variable, almost absent to very dense. Flowers in leafy dichasia, subtended by 4 leaf-like bracts fused at the base. Sepals 5 , united for 5/6 of their length to form a strongly ribbed, persistent calyx tube; calyx 2.4-6.6 mm long and 0.9-1.4 mm broad, 2.3-5.7 times as long as broad, pubescent, brownish, reddish brown or red. Petals 5 or rarely 4 , white, whitish rose to pinkish rose, spathulate, $3.0-9.4 \mathrm{~mm}$ long and 0.6-3.2 mm broad, differentiated into claw and limb; limb irregularly toothed, rounded to ovate; a ligule present adaxially in each claw, adnate to the claw for almost its entire length, dividing the inside of the flower into separate compartments containing nectar. Gynoecium 9-10 mm long, stigmas 3. Capsule loculicid. Seeds narrowly to broadly ellipsoid or ovoid, 0.66-1.14 $\mathrm{mm}$ long and 0.28-0.48 $\mathrm{mm}$ wide, hirsute, yellowish brown to brown.

Variation. Frankenia ericifolia shows complex morphological and ecogeographic differentiation in the Cape Verde Islands. In a recent revision based on field-collected specimens and cultivation of population samples and progeny families (Brochmann et al. 1995), the Capeverdean material of Frankenia was referred to a single, variable species, $F$. ericifolia, with three subspecies, ssp. ericifolia, ssp. caboverdeana, and ssp. montana. Subspecies caboverdeana and montana are endemic to the Cape Verde Islands, whereas ssp. ericifolia also occurs in the Canary Islands and NW Africa. A fourth subspecies of $F$. ericifolia, ssp. latifolia (Webb \& Berth.) Brochmann, Lobin \& Sunding, was tentatively recognized as endemic to the Canary Islands. Subspecies latifolia is morphologically most similar to ssp. caboverdeana, but it differs in calyx pubescence and by its shorter calyx, smaller seeds, and longer leaf petioles. Reproductive data suggest that the Capeverdean plants are self-compatible, but mainly outcrossing.

The morphological complexity observed in Capeverdean Frankenia is clearly correlated to ecological and geographic factors. Subspecies montana is the most distinct taxon, and represents a mainly montane, hygrophytic ecotype restricted to São Nicolau. Subspecies ericifolia is most widespread and represents a coastal, xerophytic ecotype, whereas ssp. caboverdeana is restricted to the northern islands and represents a mainly coastal, mesophytic ecotype. Distinct populations of ssp. caboverdeana occur on São Nicolau, whereas many populations of this subspecies on Santo Antão and São Vicente show extensive 
ecoclinal variation towards ssp. ericifolia. The morphological variation within and among the coastal populations of Frankenia has been shown to be genetically based and clearly correlated to the distribution of humidity, which in turn is determined by local topography and exposure to the humid, northeastern trade wind. Subspecies caboverdeana has probably evolved several times in mesic environments from xerophytic, ericifolia-like ancestors (Brochmann et al. 1995).

The non-endemic ssp. ericifolia (Fig. 134) occurs along arid coasts from sea level to 50 m (rarely $200 \mathrm{~m}$ ) on most of the Capeverdean islands (Santo Antão, São Vicente, Santa Luzia, São Nicolau, Sal, Boa Vista, Maio, Fogo, Brava; Fig. 130).

Key to the subspecies of Frankenia ericifolia

1 Stem erect; basal leaves broadly obovate to almost elliptical, less than 2.6 times as long as wide; petals white, 2.1-3.2 $\mathrm{mm}$ broad ssp. montana

1 Stem procumbent to ascending; basal leaves almost linear or narrowly lanceolate to broadly oblanceolate, more than 3.5 times as long as wide; petals pinkish rose or rarely white, $0.6-2.2 \mathrm{~mm}$ broad

2 (1) Stem procumbent; basal leaves short, 3.3-7.0 mm, ericoid, almost linear to narrowly lanceolate; petals up to $4.5 \mathrm{~mm}$ long ................................................ [ssp. ericifolia]

2 Stem ascending; basal leaves long, 8.2-18.5 mm, not ericoid, broadly oblanceolate; petals more than $6.0 \mathrm{~mm}$ long ssp. caboverdeana

Frankenia ericifolia ssp. caboverdeana (Figs 131, 132)

Frankenia ericifolia C. Sm. ex DC. ssp. caboverdeana Brochmann, Lobin \& Sunding, Nord. J. Bot. 15: 620 (1995). - Type: S. Nicolau, steile Meeresküste zwischen Estáncia Bras und der Ribeira Funda, ca. $50 \mathrm{~m}$, 8.10.1979, Lobin 902 (holotype: FR!; isotypes: GOET!, O!, herb. Lobin!).

[= Frankenia ericifolia C. Sm. ex DC. var. latifolia sensu auct., non sensu typi: J. A. Schmidt, Beitr. Fl. Cap Verd. Ins.: 271 (1852); Coutinho, Arq. Univ. Lisboa 1: 209 (1914); Pettersson, Comm. Biol. Soc. Scient. Fenn. 22: 21 (1960); Nogueira, Garcia de Orta, Sér. Bot. 2: 93 (1975)].

[= Frankenia latifolia sensu auct., non sensu typi: Sunding, Garcia de Orta, Sér. Bot. 2: 17 (1974), Fl. Macaronesia Checklist, ed. 2, 1: 49 (1979)].

Illustrations: Brochmann et al. (1995: Figs 1, 3, 4, 11), Gomes et al. (1995b: p. 21).

Description. Ascending to almost erect shrub up to $0.4 \mathrm{~m}$ high. Stem strongly lignified, strongly branched. Leaves fresh green, broadly oblanceolate, basal leaves 8.2-18.5 mm long and 1.7-3.9 mm wide, leaf margin enrolled, petioles usually absent, if present short, $0.5-1.0(-2.0 \mathrm{~mm})$, and not distinctly differentiated from the lamina. Flowers in open dichasia. Calyx 5.0-6.4(-6.6) $\mathrm{mm}$ long and 1.0-1.4(-1.5) $\mathrm{mm}$ broad. Petals whitish rose to pinkish rose or rarely white, $6.0-9.1 \mathrm{~mm}$ long and $0.8-2.2 \mathrm{~mm}$ broad. Seeds narrowly to broadly ellipsoid or ovoid, 0.85-1.14 mm long and 0.30-0.48 mm broad.

Variation. Subspecies caboverdeana is fairly homogeneous, except that it shows ecoclinal variation towards ssp. ericifolia in size characters of leaves, calyces, petals, and seeds. Homogeneous, broad-leaved and typical populations of ssp. caboverdeana only occurs on São Nicolau and along the northeastern coast of Santo Antão. The populations that are 


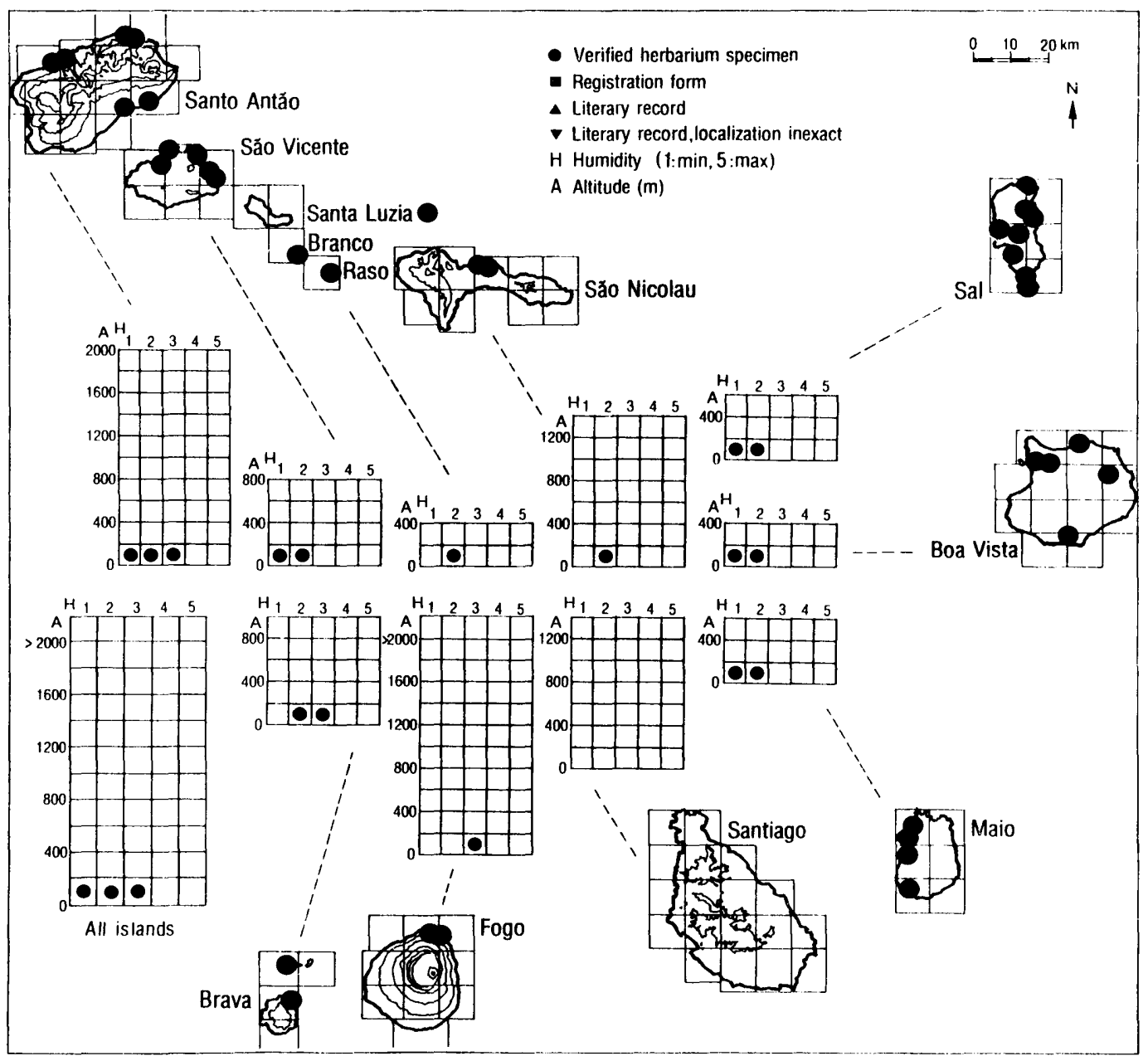

Fig. 130. Ecogeographic distribution of Frankenia ericifolia ssp. ericifolia.

morphologically intermediate between ssp. caboverdeana and ssp. ericifolia occur elsewhere on Santo Antão and São Vicente (Fig. 133). The only white-flowered populations of ssp. caboverdeana have been observed along the coast on eastern São Nicolau, below the range of the invariably white-flowered ssp. montana. This observation may suggest that introgression has occurred between the subspecies in this area.

Chromosome number: $2 \mathrm{n}=20$ (São Nicolau, $\mathrm{N}$ coast, between Estancia Brás and Ribeira Funda, Zizka 1986 as Frankenia n. sp.).

Related taxa: See above.

Distribution and ecology. Frankenia ericifolia ssp. caboverdeana is a northern mesophyte occurring on Santo Antão, São Vicente, and São Nicolau. It is restricted to northexposed coasts between sea-level (e.g., leg. Brochmann \& Rustan) and 120 m (São Vicente; 

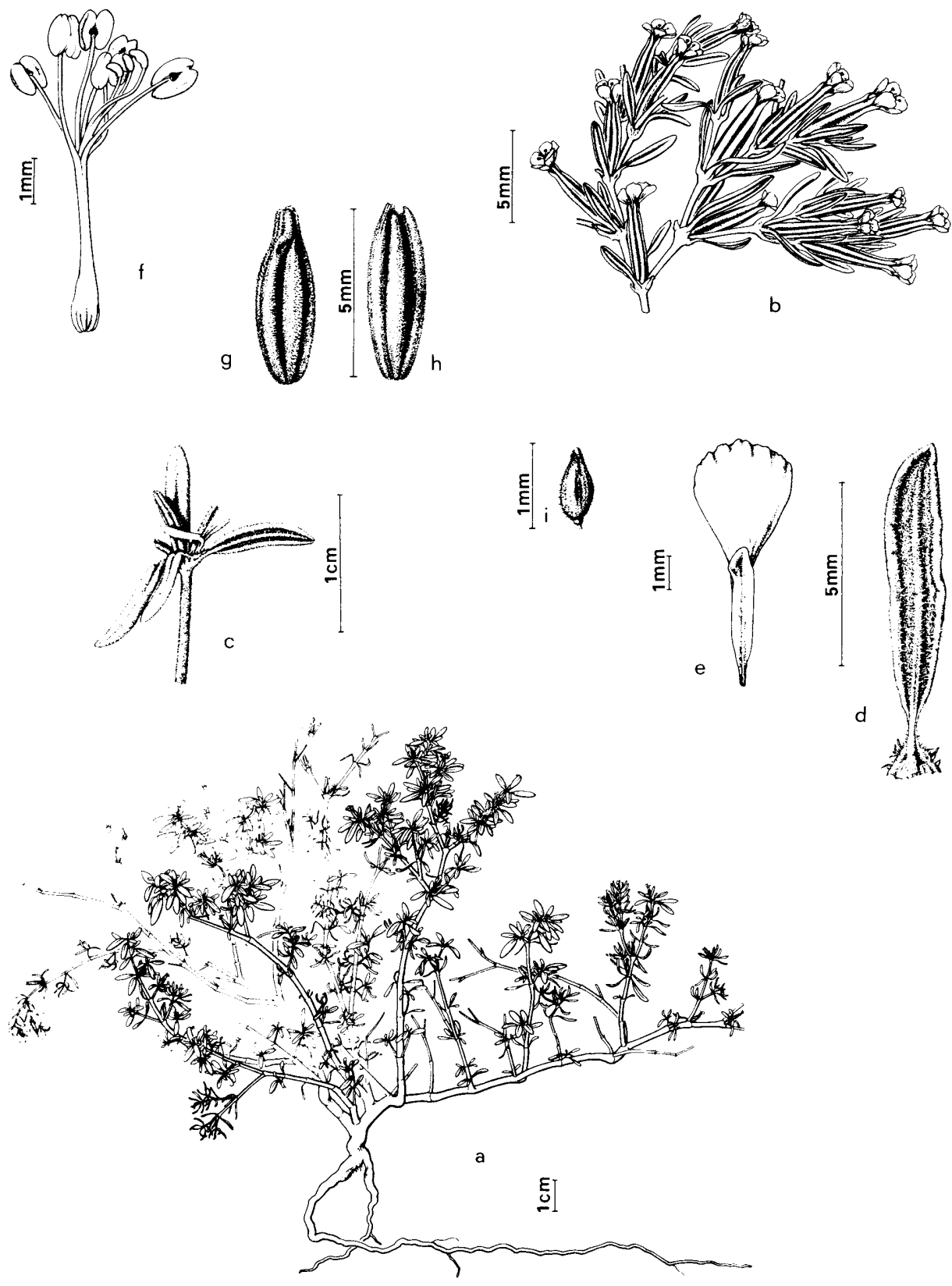

Fig. 131. Frankenia ericifolia ssp. caboverdeana. a. Habit; b. Partial inflorescence; c. Leafy dichasia with accessory stems and one bud; d. Abaxial surface of leaf; e. Petal with adaxial ligule; f. Detail of flower showing stamens and stigmas; g. Young capsule enclosed in calyx; h. Mature capsule enclosed in calyx; i. Seed. Drawn by G. Eder after cultivated material. Reprinted from Brochmann et al. (1995), Nord. J. Bot. 15 (with permission). 


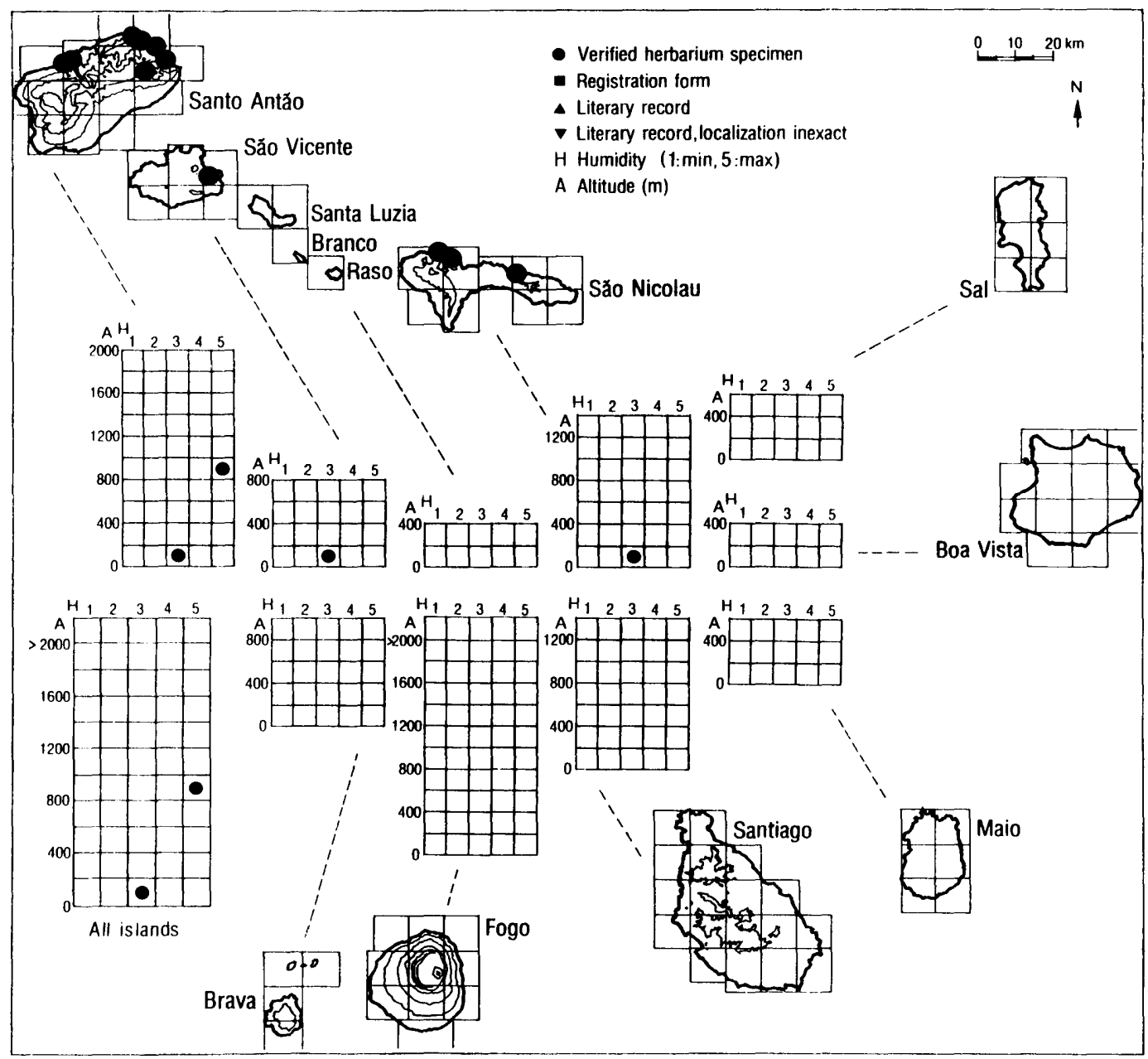

Fig. 132. Ecogeographic distribution of Frankenia ericifolia ssp. caboverdeana.

leg. Brochmann \& Rustan), except for an old record at $800 \mathrm{~m}$ in the Cova area on Santo Antão (leg. Chevalier). Chevalier's specimen clearly belongs to ssp. caboverdeana, which never has been recollected in this well-explored area. All sites are located within the semiarid zone except the one in the Cova area, which is situated within the humid zone. The plants grow in scree slopes, rarely in coastal cliffs.

Abundance. The subspecies is locally common on Santo Antão and São Nicolau, but very rare in its "typical" form on São Vicente. The only known montane population has not been observed since 1934 (Chevalier 1935a) and is probably extinct. All other populations have been observed after 1980, and some of them comprise hundreds of plants. Frankenia ericifolia ssp. caboverdeana is considered to be Lower Risk (LR). 


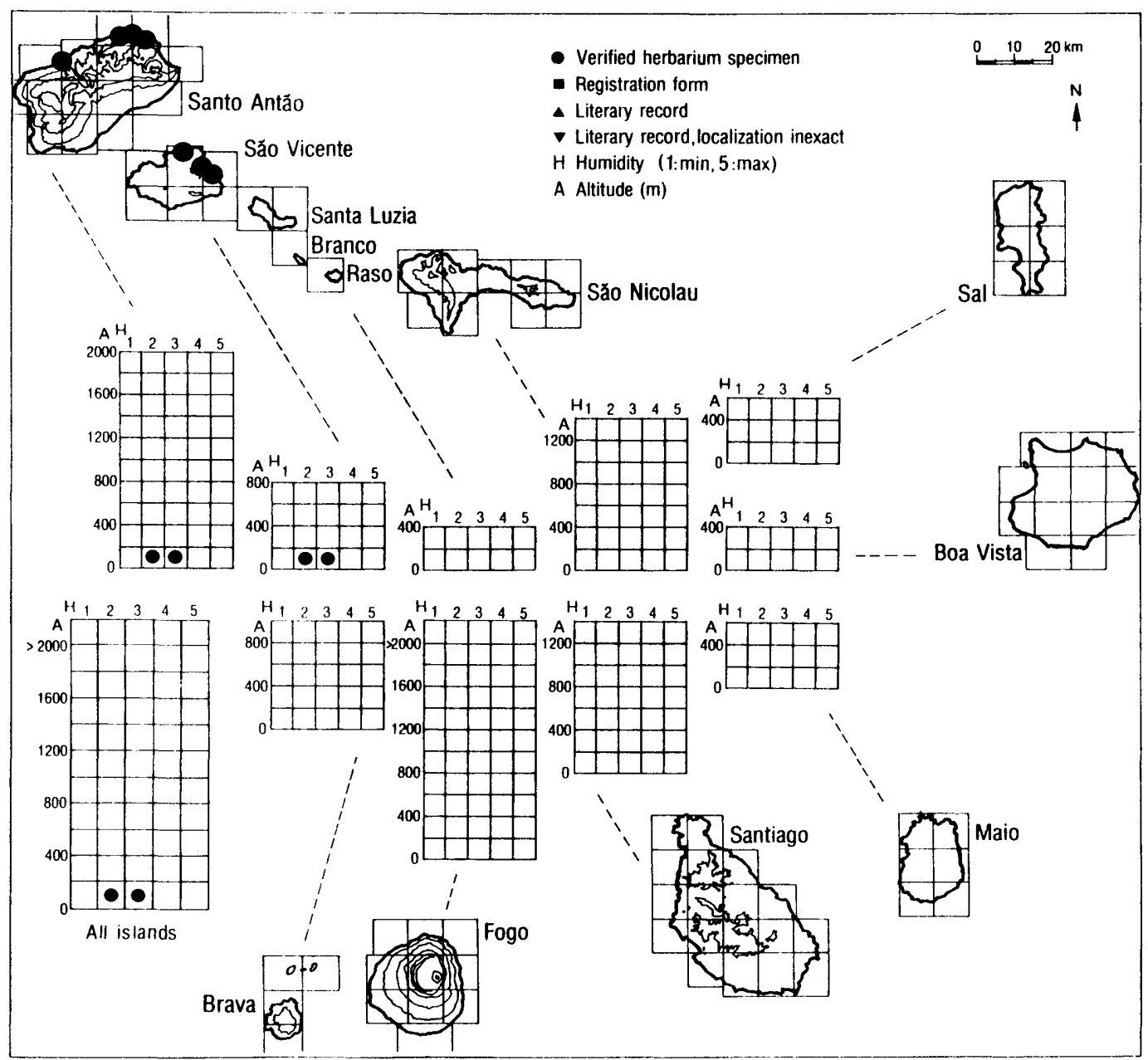

Fig. 133. Ecogeographic distribution of intermediates between Frankenia ericifolia ssp. ericifolia and ssp. caboverdeana.

Frankenia ericifolia ssp. montana (Figs 134, 135)

Frankenia ericifolia C. Sm. ex DC. ssp. montana Brochmann, Lobin \& Sunding, Nord. J. Bot. 15: 622 (1995). - Type: S. Nicolau, Höhenzug S Juncalinho, am Fuss einer Felswand, 400 m, 6.1.1986, Kilian 1058 (holotype: FR!; isotypes: $\mathrm{B} !, \mathrm{O} !)$. [= Frankenia sp., Nogueira, Garcia de Orta, Sér. Bot. 2: 93 (1975)].

Illustrations: Brochmann et al. (1995: Figs 1, 3, 10).

Description. Erect shrub up to $0.5(-0.8) \mathrm{m}$ high. Stem strongly lignified, sparsely branched. Leaves fresh green, broadly obovate to almost elliptic; basal leaves 7.8-11.3 mm long and 


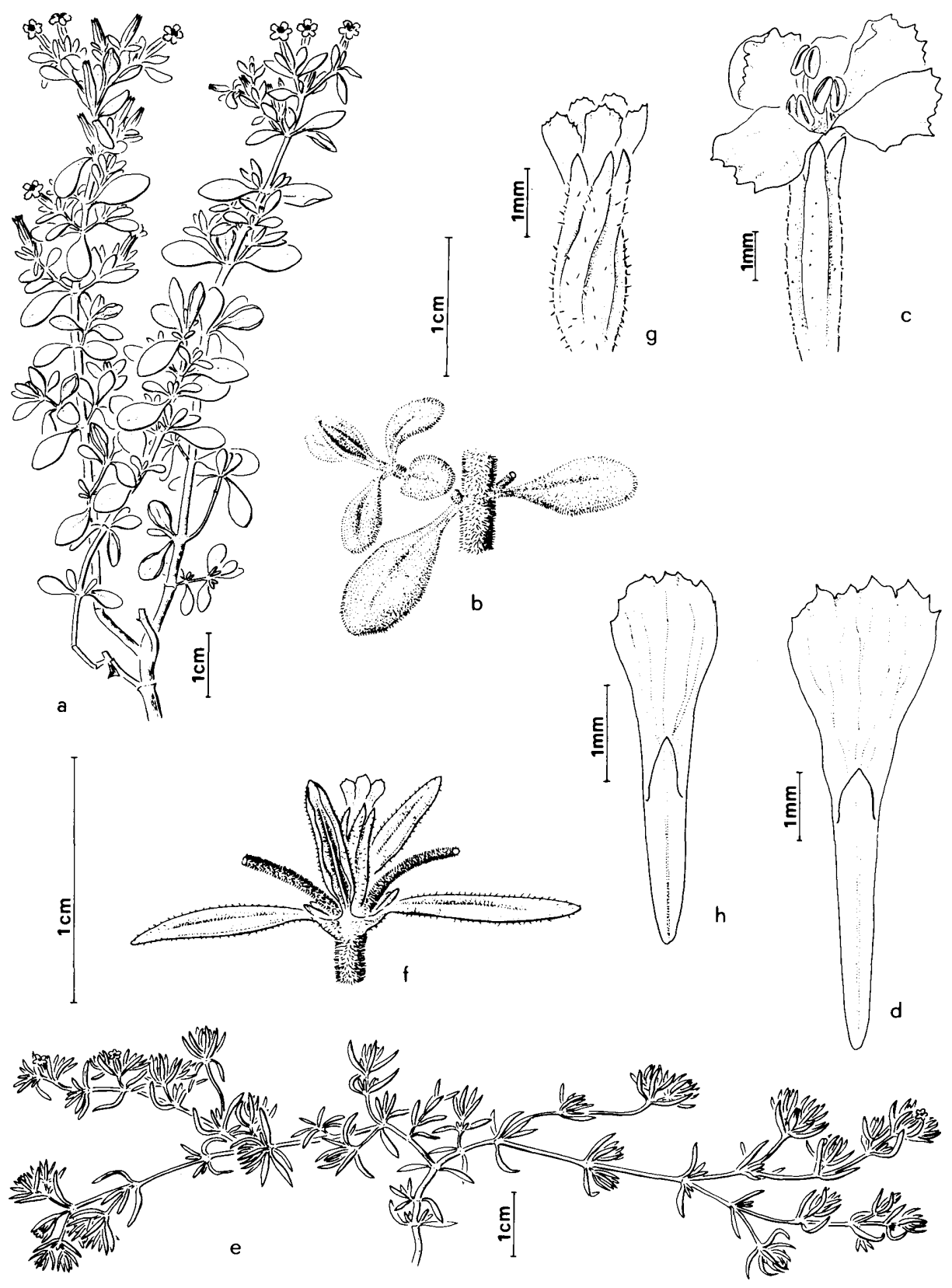

Fig. 134. Frankenia ericifolia ssp. montana and ssp. ericifolia. a-d. ssp. montana: a. Habit; b. Leafy dichasia with accessory stems; c. Flower; d. Petal with adaxial ligule. e-h. ssp. ericifolia: e. Habit; f. Leafy dichasia with accessory stems and one flower; g. Flower; h. Petal with adaxial ligule. Drawn by E. Fischer. Reprinted from Brochmann et al. (1995), Nord. J. Bot. 15 (with permission). 


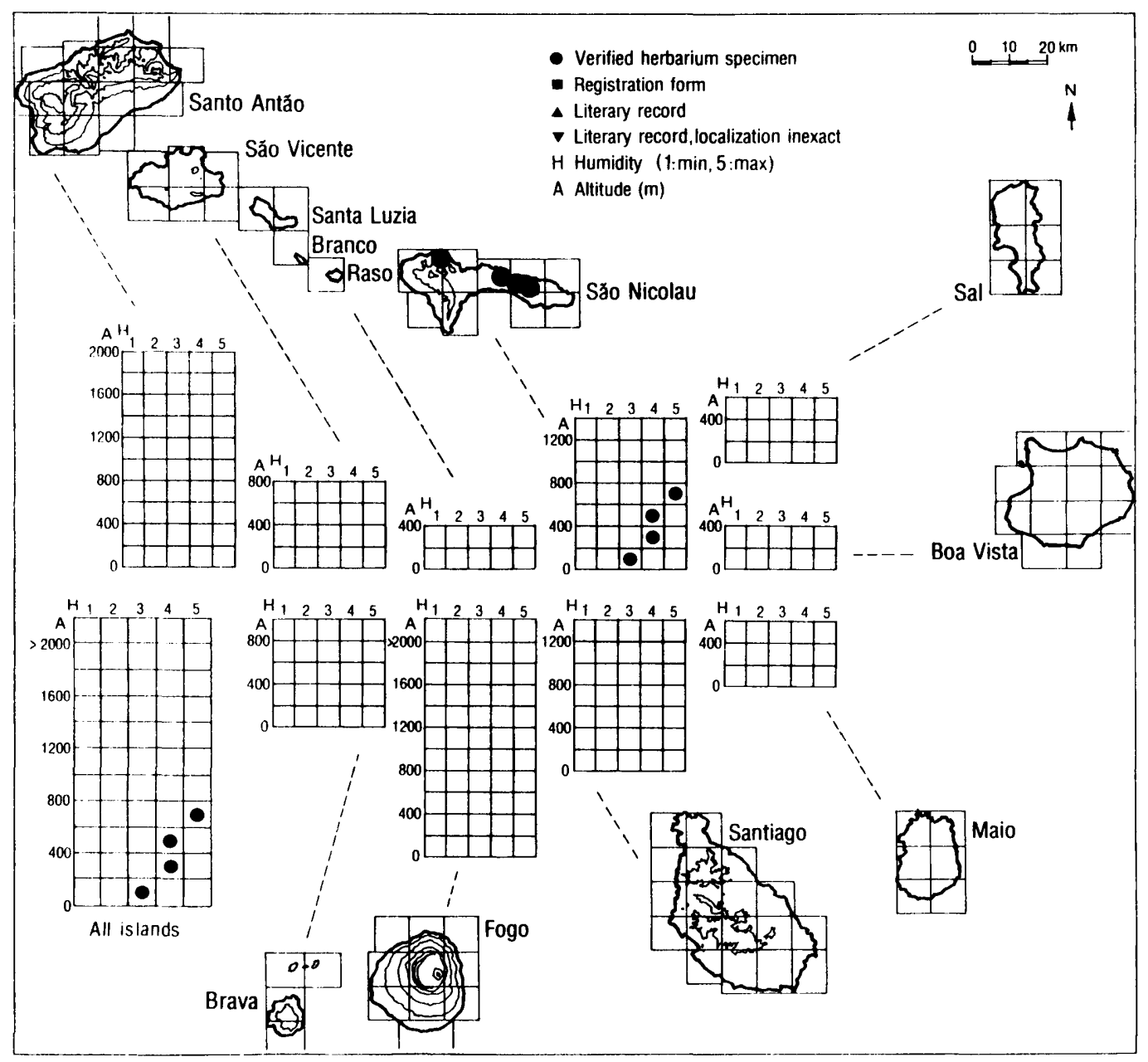

Fig. 135. Ecogeographic distribution of Frankenia ericifolia ssp. montana.

3.1-5.0 mm wide, distinctly petiolated, petiole $0.2-2.0 \mathrm{~mm}$ long, leaf margin slightly enrolled. Calyx 5.2-6.2 mm long and 1.2-1.4 mm broad. Petals white, 7.0-9.4 mm long and 2.1-3.2 $\mathrm{mm}$ broad. Seeds narrowly ellipsoid to narrowly ovoid, $0.85-0.94 \mathrm{~mm}$ long and $0.28-0.30 \mathrm{~mm}$ broad.

Variation. No significant variation has been observed.

Chromosome number: Unknown.

Related taxa. Subspecies montana is probably most closely related to ssp. caboverdeana, but it is easily distinguished by its erect habit, broadly obovate to elliptical leaves, long petioles, and broad, white petals.

Distribution and ecology. Frankenia ericifolia ssp. montana is a northern hygrophyte restricted to the most favourable mountains on São Nicolau. The few main populations occur 
within the subhumid and humid zones in the eastern mountain range (Alto das Cabaças and Alto Joaquina) between $400 \mathrm{~m}$ (leg. Sunding, leg. Kilian) and $640 \mathrm{~m}$ (leg. Rustan \& Brochmann). In addition, the subspecies has been observed in the semiarid zone at $70 \mathrm{~m}$ below the Alto das Cabaças range (leg. Lobin); this locality may be secondary, colonized after dispersal from the main montane populations. In 1994, a single population of ssp. montana was discovered on western São Nicolau (Ribeira Camarões at $320 \mathrm{~m}$, leg. Kilian \& Leyens). The plants typically grow in north- to northeast-exposed cliffs.

Abundance. All of the about six populations of ssp. montana have been observed after 1980 , and each of them comprises less than 50 plants. Because of its very restricted total distribution area and its few, small populations, Frankenia ericifolia ssp. montana is considered to be Endangered (EN).

\section{GENTIANACEAE}

This family is represented by a single genus.

\section{Centaurium Hill}

Centaurium is an almost cosmopolitan genus with about 40-50 annual or herbaceous perennials with sessile, opposite cauline leaves, usually cymose inflorescences, reddish to purplish or rarely whitish to yellow flowers, and slender, many-seeded capsules. This genus is represented in the Cape Verde Islands by a single endemic subspecies of a non-endemic species.

\section{Centaurium tenuiflorum}

Centaurium tenuiflorum (Hoffm. \& Link) Fritsch, Mitt. Naturw. Vereins Univ. Wien, ser. 2, 5: 97 (1907) $\equiv$ Erythraea tenuiflora Hoffm. \& Link, Fl. Portug. 1: 354 (1820). — Type: Portugal, sur le bords de la mer, près d'A-Costa.

Literature: Gomes (1995).

Centaurium tenuiflorum ssp. viridense (Figs 136, 137)

Centaurium tenuiflorum (Hoffm. \& Link) Fritsch ssp. viridense (Bolle) A. Hansen \& Sunding, F1. Macaronesia

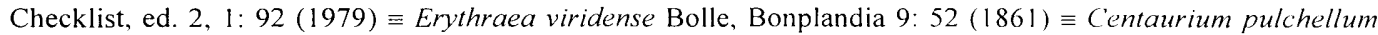
(Sw.) Druce ssp. viridense (Bolle) A. Chev., Rev. Bot. Appl. Agric. Trop. 15: 929 (1935). - Type: In graminosis montium Bravae, Bolle (holotype: $\mathrm{B}$, destroyed).

Illustration: Gomes et al. (1995b: p. 22).

Description. Delicate, erect, annual herb, usually less than $0.2 \mathrm{~m}$ high, glabrous in all parts, without a basal leaf rosette; stem leafy, unbranched or moderately branched in upper part. Inflorescence usually few-flowered. Leaves ovate to elliptic, up to $2 \mathrm{~cm}$ long and $1.5 \mathrm{~cm}$ wide, apex obtuse to acute, margin entire. Flowers shortly pedicellate to almost sessile. Calyx up to 


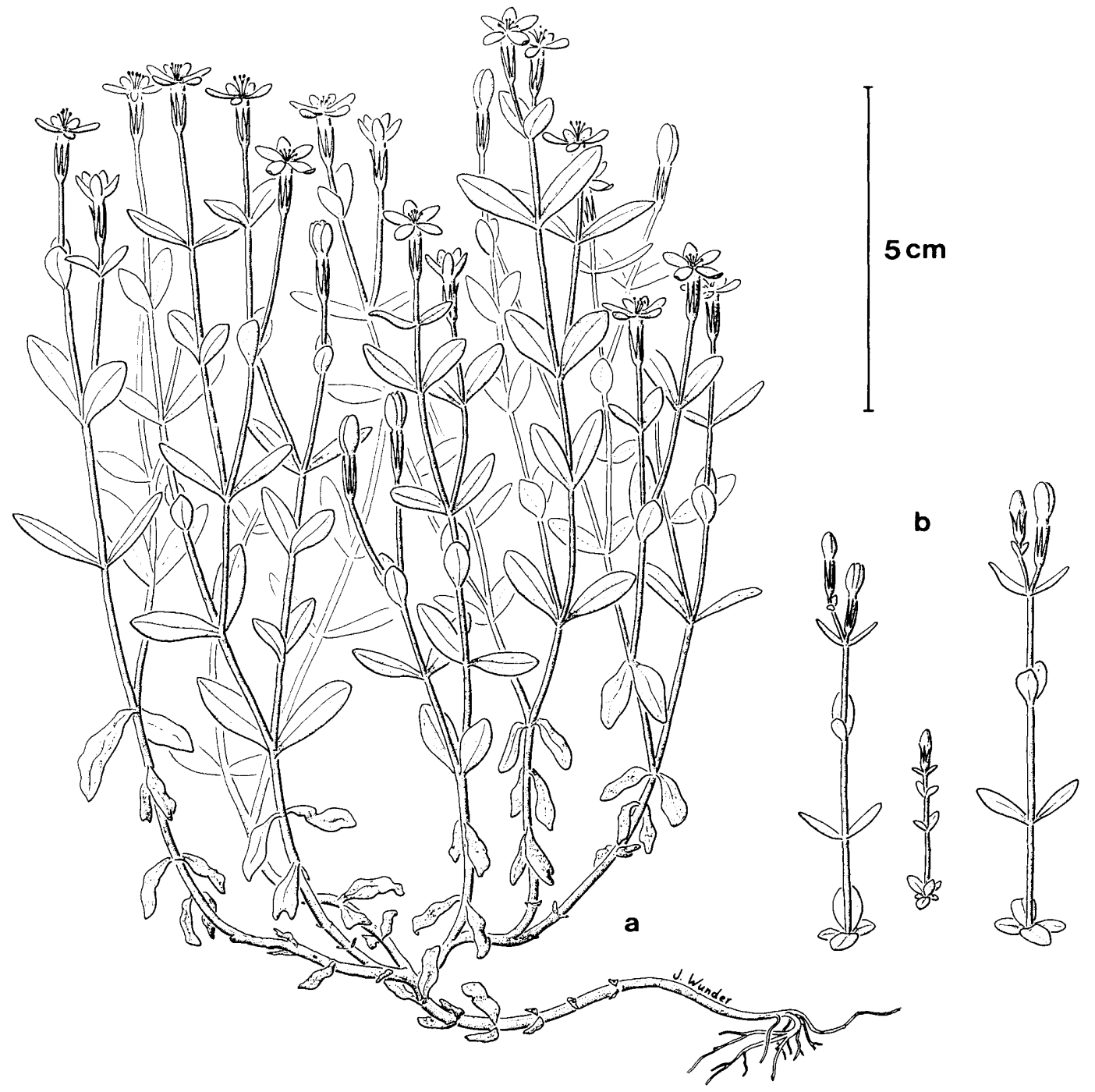

Fig. 136. Centaurium tenuiflorum ssp. viridense. a. Habit of plant growing in a wet site; $b$. Habit of plants growing in a dry site. Drawn by J. Wunder. 


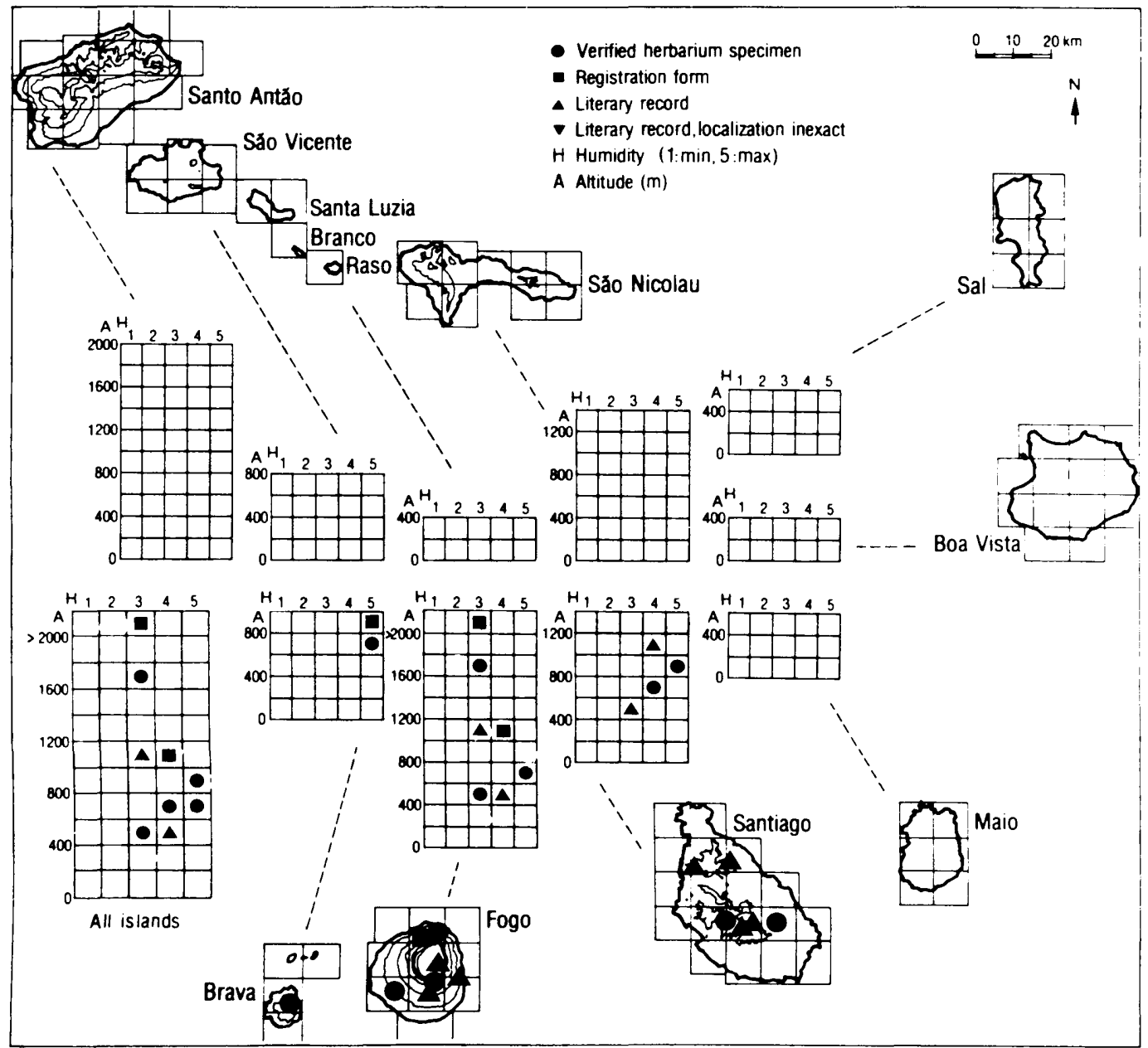

Fig. 137. Ecogeographic distribution of Centaurium tenuiflorum ssp. viridense.

$9 \mathrm{~mm}$ long, calyx lobes almost equalling the corolla tube in length. Corolla up to $17 \mathrm{~mm}$ long, corolla tube somewhat constricted below the limb, corolla lobes deep pink, entire. Capsule linear to narrowly oblong, up to $10 \mathrm{~mm}$ long.

Variation. The material is fairly homogeneous. There is some variation in plant size and branching of the main stem.

Chromosome number: Unknown.

Related taxa. Centaurium tenuiflorum is widespread in $W$ Europe and the Mediterranean, and belongs to the taxonomically difficult $C$. pulchellum aggregate. The Capeverdean plants are fairly similar to plants from the Sahara mountains, e.g. the Hoggar and Tibesti Mountains, usually referred to C. pulchellum (Maire 1933. Ozenda 1977). It is 
questionable whether the Capeverdean Centaurium is correctly associated with C. tenuiflorum rather than with $C$. pulchellum, and whether it actually is endemic to the archipelago.

Distribution and ecology. Centaurium tenuiflorum ssp. viridense is a southern hygrophyte occurring on Santiago, Fogo, and Brava. The subspecies is mainly confined to humid, montane areas between $600 \mathrm{~m}$ and $1700 \mathrm{~m}$. The occurrence in the semiarid and subhumid zones is restricted to locally moist or wet sites. The lowermost records are at $500 \mathrm{~m}$ on Santiago (Nogueira 1976) and Fogo (leg. Kilian), and the uppermost record is at $2800 \mathrm{~m}$ on Pico Novo on Fogo (Lobin 1982c). The plants grow in moist cliffs, ridges, slopes, escarpments, and valleys.

Abundance. The subspecies is locally abundant although its occurrence is scattered. Centaurium tenuiflorum ssp. viridense is considered to be Lower Risk (LR).

\section{GLOBULARIACEAE}

This family is represented by a single genus.

\section{Globularia L.}

The genus Globularia includes about 25 species distributed in S Europe, the Mediterranean, Turkey, the mid-Atlantic archipelagos, N Africa, and in E Africa and Arabia along the Red Sea. The genus is characterized by its usually blue flowers arranged in globular capitules. In the Cape Verde Islands, the genus is represented by a single endemic species. Literature: Schwarz (1939, 1963, 1967), Basto (1995b).

\section{Globularia amygdalifolia (Figs 138, 139)}

Globularia amygdalifolia Webb in Hooker, Niger Fl.: 133 (1849) $\equiv$ Lytanthus amygdalifolius (Webb) Wettst. in Engler \& Prantl, Nat. Pflanzenfam. 4 (3b): 273 (March 1895). - Type: "Capvert. Herbier rapporté du Portugal en 1808 par M. Geoffrey St. Hilaire" [1784-1787, Silva Feijão] (holotype: P).

Illustrations: Schwarz (1939: Figs 16 (5-6), 18 (7-10), Lobin \& Grasmück (1984: Fig. 5), Gomes et al. (1995b: p. 22).

Description. Moderately to strongly branched, erect, evergreen shrub, usually $0.5-1 \mathrm{~m}$, occasionally up to $2 \mathrm{~m}$ high. Leaves alternate, clustered towards the apices of the branches, oblanceolate, rarely lanceolate, strongly attenuate towards base, up to $12 \mathrm{~cm}$ long and $3 \mathrm{~cm}$ wide, somewhat coriaceous, glabrous, apex acute, margin entire. Inflorescence a dense, globular capitule up to $2.5 \mathrm{~cm}$ in diameter, situated axillary on peduncles $3-4 \mathrm{~cm}$ long; groups of 5 to 10 capitules clustered towards apices of branches; peduncles, involucre, calyx, and the subfusiform receptacle pubescent. Calyx deeply 5-partite, with linear-lanceolate lobes. Corolla blue to whitish blue, zygomorphic, with trifid lower lip, destitute of a dimerous lower lip; tube-like basal part adaxially open; stamens 4 , long exserted, one pair inserted in the basal third of the corolla, the upper pair inserted in the middle third of the corolla. 


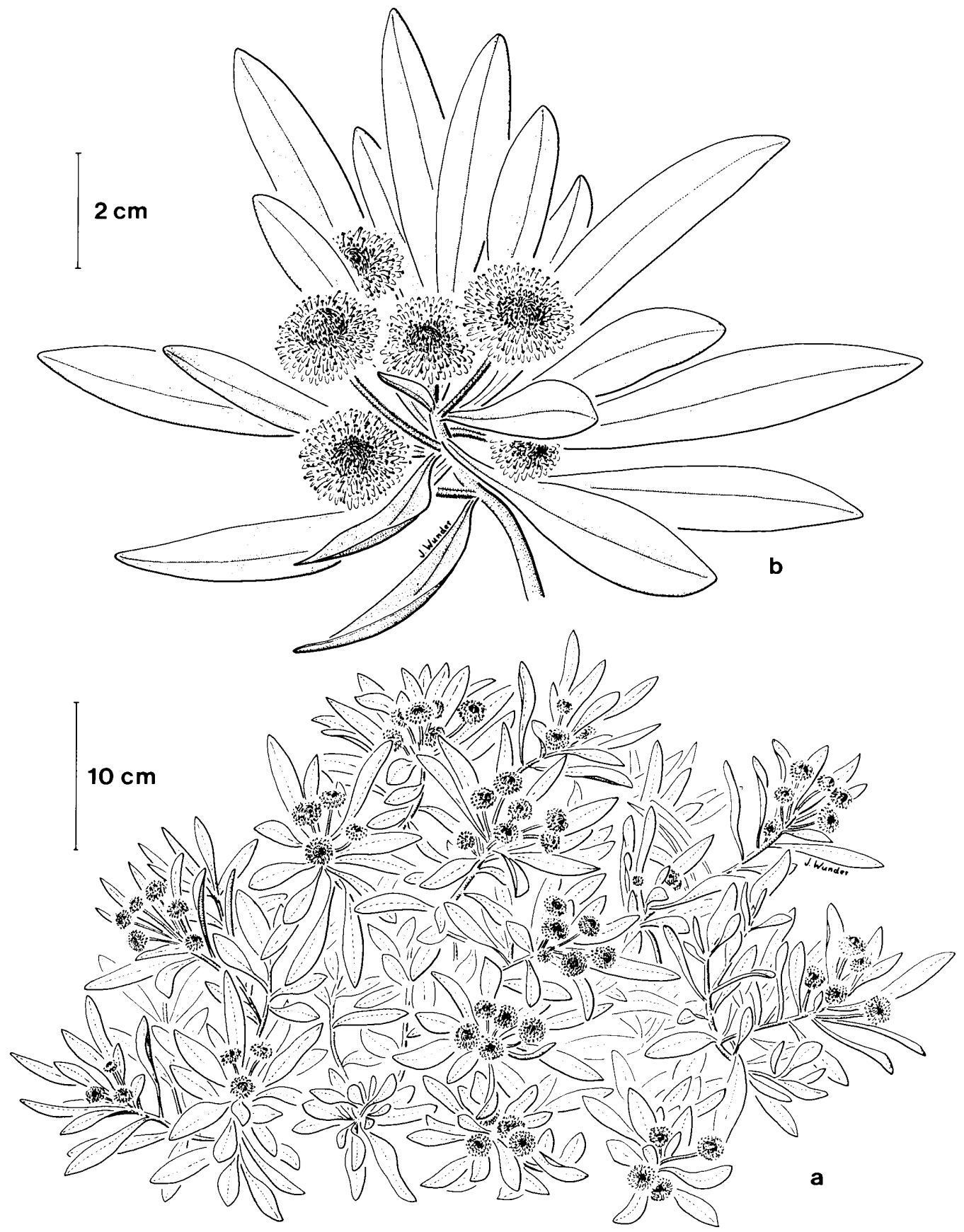

Fig. 138. Globularia amygdalifolia. a. Habit; b. Part of stem with inflorescences. Drawn by J. Wunder. 


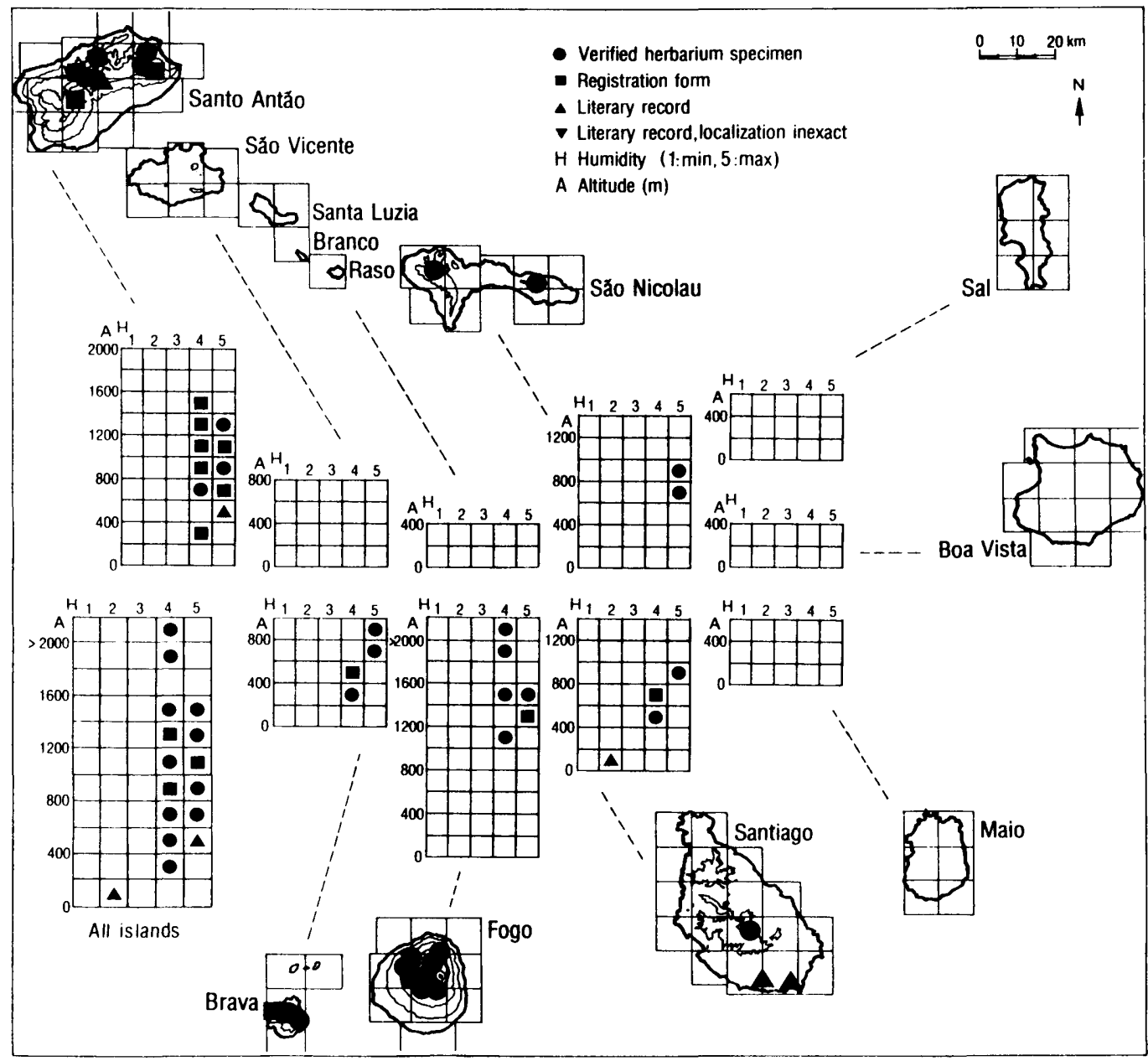

Fig. 139. Ecogeographic distribution of Globularia amygdalifolia.

Variation. No significant variation has been observed. Old plants higher than $0.5-1 \mathrm{~m}$ are extremely rare today. Large plants up to $2 \mathrm{~m}$ are only known from the outer escarpments of the central caldeira on Fogo, as scattered relics of a scrub vegetation type with old individuals of Artemisia gorgonum and Echium vulcanorum.

Chromosome number: $2 \mathrm{n}=16$ (Santo Antão, Cova, $1150 \mathrm{~m}$, Borgen 1980).

Related taxa. Glohularia amygdalifolia is most closely related to G. salicina Lam., which is distributed in Madeira and the Canary Islands, and it is placed together with this species in subgenus Jasionopsis Schwarz section Lytanthus (Wettst.) Schwarz (Schwarz 1939, 1963). Globularia amygdalifolia is distinguished from G. salicina mainly by its larger leaves and capitules, somewhat more strongly divided calyx, narrower involucral scales, and narrower corolla (Schwarz 1939). Whether the Capeverdean taxon actually deserves the rank 
of species or rather should be treated as a subspecies of $G$. salicina needs further investigation.

Distribution and ecology. Globularia amygdalifolia is a western hygrophyte occurring on Santo Antão, São Nicolau, Santiago, Fogo, and Brava, but it is absent from São Vicente. It is mainly occurring in the subhumid and humid zones, but it has also been reported from the arid zone on Santiago. The main altitudinal distribution is between $400 \mathrm{~m}$ and $2200 \mathrm{~m}$. The species has been recorded from below $100 \mathrm{~m}$ on Santiago (Chevalier 1935a). The uppermost records are from the caldeira rim on Fogo up to $2400 \mathrm{~m}$ (leg. Kilian \& Leyens). The plants grow on mountain slopes and less frequently in steep cliffs, and they form a characteristic, but not dominating element of the indigenous montane scrub vegetation in the Cape Verde Islands.

Abundance. The species has a scattered distribution on most islands, and many populations are very small and clearly in serious decline. From Santiago, it has only been recorded in 1897-1898 (leg. Fea), 1934 (leg. Chevalier), 1981 (leg. Rustan \& Brochmann), and 1995 (few plants only; leg. Leyens), and it is considered Critically Endangered (CR) on this island. It is Endangered (EN) on São Nicolau. Globularia amygdalifolia is generally considered to be Vulnerable (VU).

\section{LAMIACEAE}

This family is represented by 13 genera with 27 species and subspecies. Two species are endemic.

\section{Lavandula L.}

This genus comprises 20 species, of which most are subshrubs. The genus is distributed from the mid-Atlantic archipelagos, the Mediterranean, and NE Africa to $\mathrm{N}$ India. The plants contain aromatic oils and are therefore widely cultivated, particularly in S Europe. In the Cape Verde Islands, the genus is represented by three species, of which one is endemic.

Key to the genus Lavandula

1 Lower cauline leaves less than $1 \mathrm{~cm}$ wide, greyish tomentose above, whitish tomentose below, obtuse-pinnatifidly crenate, margin usually revolute; inflorescence a solitary spike; spike comose with sterile, showy, bluish-purplish upper bracts [L. dentata]

1 Lower cauline leaves more than $1 \mathrm{~cm}$ wide, glabrous or pubescent to hispid but never whitish or greyish tomentose; inflorescence usually branched with few spikes; spikes without sterile, showy upper bracts.

2 (1) Lower cauline leaves dentate or crenate to subpinnatifid; spikes usually compact

2 Lower cauline leaves deeply (mostly bi)pinnatifid with narrowly linear segments and rachis, both usually less than $1 \mathrm{~mm}$ wide; spikes loose ..... [L. coronopifolia] 


\section{Lavandula rotundifolia (Figs 140, 141)}

Lavandula rotundifolia Benth., Labiat. Gen. Sp.: 150 (1833) ミStoechas rotundifolia (Benth.) Rchb. f., Österr. Bot. Wochenbl. 7: 161 (1857). - Type: In ins. Sancti Nicolai, 27.3.1822, Forbes 33 (holotype: K).

= Lavandula rotundifolia Benth. var. incisa Bolle, Bonplandia 8: 280 (1860). - Syntypes: In montibus ins. S. Nicolai, supra viam consularem Caminho novo, Bolle (B, destroyed); in ins. S. Vincentii, Maderal, Bolle (B, destroyed).

$=$ Lavandula rotundifolia Benth. var. subpinnatifida Lowe ex A. Chev., Rev. Bot. Appl. Agric. Trop. 15: 911 (1935) [= Lavandula rotundifolia Benth. var. subpinnatifida Lowe ex Chaytor, Bot. J. Linn. Soc. $51: 195$ (1937), nom. inval. et superfl.]. - Type: Fogo, Chã das Caldeiras, 1600-1800 m, Chevalier 44875 (holotype: P). = Lavandula rotundifolia Benth. var. crenata Lowe ex Sunding \& M. C. León Arenciba, Garcia de Orta, Sér. Bot. 5: 129 (1982) [= Lavandula rotundifolia Benth. var. crenata Lowe ex Chaytor, Bot. J. Linn. Soc. 51: 196 (1937), nom. inval.]. - Type: S. Nicolau, Cam. de Caldeira, 1864, Lowe 22 (holotype: BM).

[= Lavandula apiifolia C. Sm. in Tuckey, Narr. Exped. Zaire: 250 (1818), nom. nud.].

Illustrations: Wawra (1866: Fig. 69), Chaytor (1937: Figs p. 155), Gomes et al. (1995b: p. 22).

Literature: Chaytor (1937), Rustan \& Brochmann (1993).

Description. Moderately branched, erect shrub or subshrub up to $0.5(-0.7) \mathrm{m}$ high. Young branches and flowering stems densely and shortly pubescent or sometimes glabrous. Leaves green or rarely glaucous, broadly ovate to ovate or triangular, lamina (1.7-) $3.0-4.5(-6.0) \mathrm{cm}$ long with petiole up to $1.5(-2.0) \mathrm{cm}$ long, sparsely and shortly pubescent or glabrous, apex acute to rounded, base truncate, rounded, or rarely cuneate, margin usually irregularly dentate, sometimes regularly crenate or more or less subpinnatifid. Inflorescence variously branched, peduncles densely and shortly pubescent or rarely glabrous; spikes cylindrical, compact, 3-7($10) \mathrm{cm}$ long in flowering stage. Bracts ovate to broadly ovate, acuminate to acute, shorter than calyx, densely pubescent, apices and nerves often purplish. Calyx 5-6(-7) mm long, densely pubescent, margin of teeth with longer hairs, teeth slightly unequal, the entire calyx or teeth and nerves often purplish. Corolla blue or rarely white, corolla tube about twice as long as calyx, 9-12(-15) mm long, tube and lobes densely pubescent. Nutlet 1.4-1.8 mm long, narrowly oblong, yellowish brown to deep purple brown.

Variation. The species is very variable in indument, inflorescence branching, and leaf characters, in particular in leaf margin. Some coastal as well as some montane populations have entirely glabrous stems and leaves, and the leaves in some coastal populations are distinctly glaucous. The variation within the species appears continuous with no clear ecogeographic pattern, and the varieties described are probably of no taxonomic significance.

A large amount of the variation observed in Capeverdean Lavandula is caused by hybridization between $L$. rotundifolia and the morphologically fairly different, SaharoArabian/Sudanian L. coronopifolia Poir. (= L. stricta Delarbre). These species form large and complex hybrid swarms in some areas (Rustan \& Brochmann 1993). In contrast to $L$. rotundifolia, which primarily is a montane mesophyte growing in cliffs in semiarid to humid areas, L. coronopifolia is a typical xerophyte growing in arid to semiarid gravelly slopes and plains, mainly in lowland and coastal areas of the Cape Verde Islands. The two species frequently meet in montane gravelly plains and slopes in the semiarid and subhumid zones.

The hybrid swarms are easily recognized because they often comprise both "pure" $L$. rotundifolia (leaves large, ovate or triangular with variously dentate margins), "pure" $L$. coronopifolia (leaves smaller, pinnatifid to bipinnatifid with short, linear, and usually entire lobes), as well as plants showing a gradual transition in leaf morphology between the parental species. This pattern of morphological variation suggests that the hybrids are fertile and form 


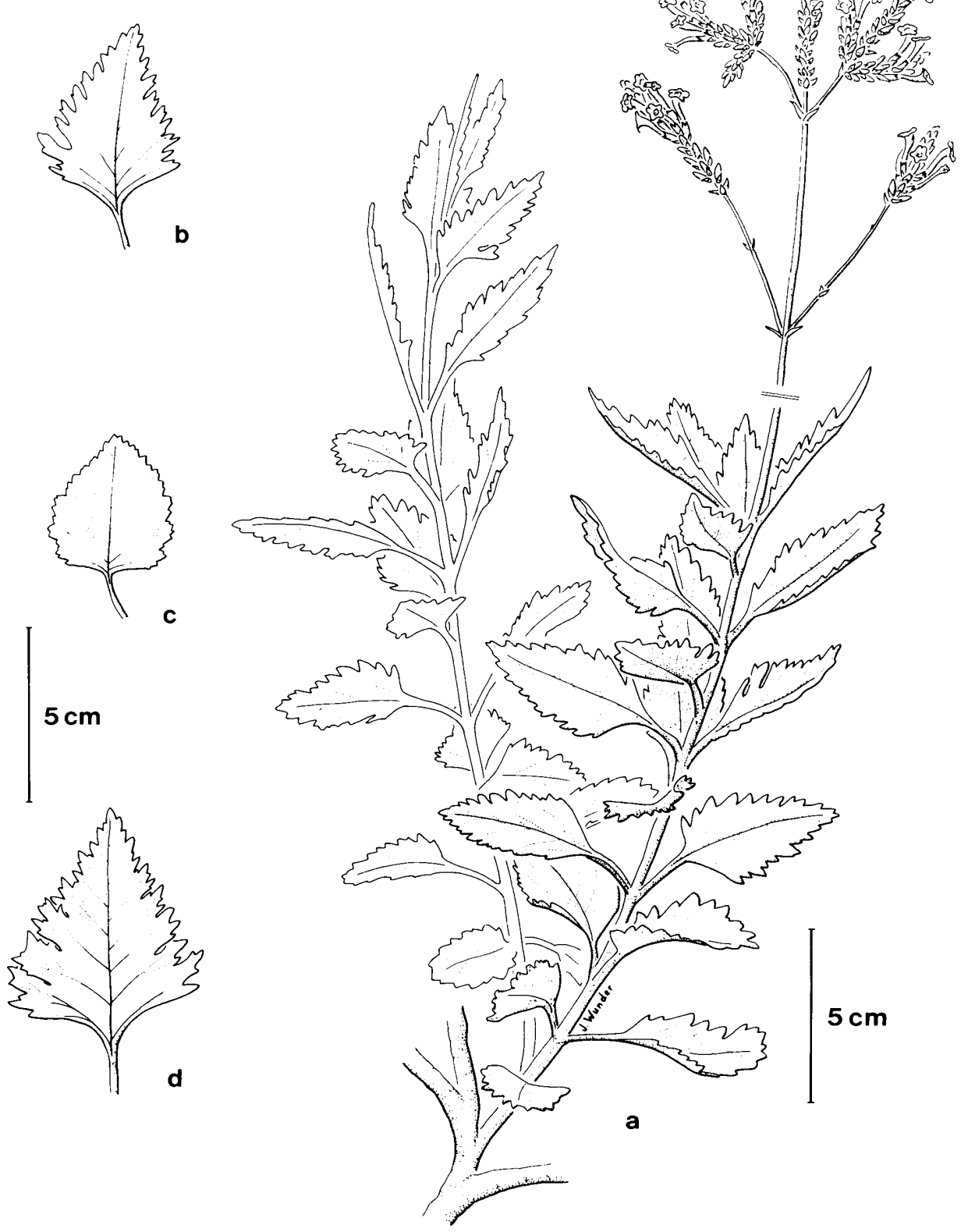

Fig. 140. Lavandula rotundifolia. a. Habit; b-d. Leaves. Drawn by J. Wunder. 


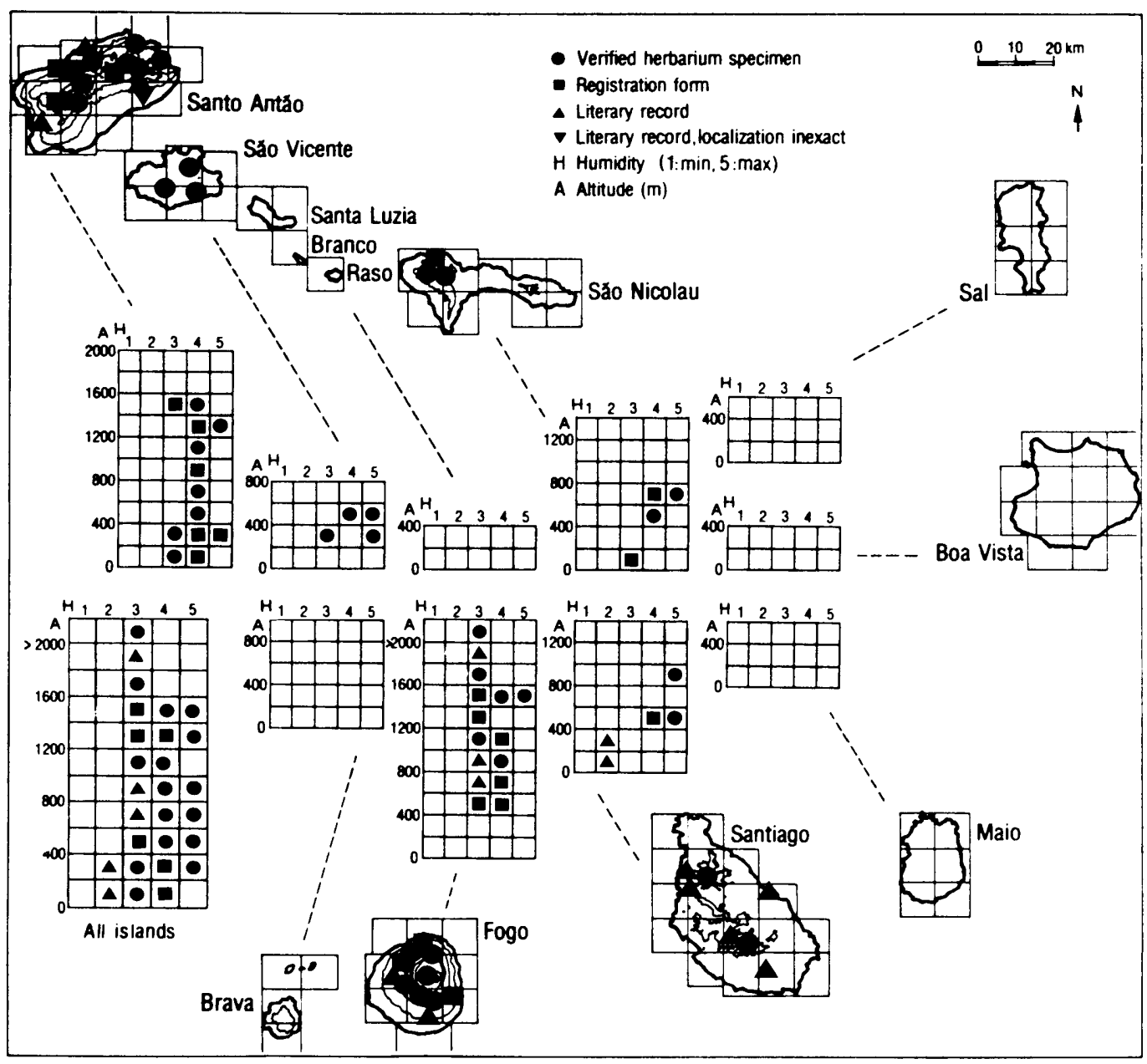

Fig. 141. Ecogeographic distribution of Lavandula rotundifolia.

later-generation hybrids or backcrosses to the parental species. This conclusion is supported by the observation of regular fructification in morphologically intermediate plants. Such hybrid swarms have been reported from two areas on Santo Antão (close to Ribeira do Alto Mira and the Tope de Coroa area, leg. Rustan \& Brochmann), and putative specimens of $L$. coronopifolia $\times$ rotundifolia have also been sampled in two additional sites on Santo Antão, one site on São Vicente, and one site on São Nicolau (Rustan \& Brochmann 1993). Recently, hybrids have been collected in two additional sites on São Nicolau (Monte Gordo and Ribeira Frigata, leg. Kilian \& Leyens).

Chromosome number: Unknown.

Related taxa. The taxonomic relationships of Lavandula rotundifolia are not clear. The species was referred to Pterostoechas Ging. by Chaytor (1937), a section of about 15 species 
distributed in the Mediterranean, North Tropical Africa, and the tropical and temperate Atlantic islands. In the Cape Verde Islands, the only other species of this section is $L$. coronopifolia.

Distribution and ecology. Lavandula rotundifolia is a western mesophyte occurring on most of the major western islands (Santo Antão, São Vicente, São Nicolau, Santiago, and Fogo), but it is absent from Brava. Most populations occur in the semiarid or subhumid zones, but the species is also fairly frequent in the humid zone. It usually avoids the arid zone, but it has been recorded a few times from arid, coastal areas on Santiago (possibly ephemerals dispersed from montane populations). The species occurs mainly between $400 \mathrm{~m}$ and $1500 \mathrm{~m}$, but it has also been recorded several times below $100 \mathrm{~m}$ (e.g., at sea-level on São Nicolau and at $20 \mathrm{~m}$ on Santo Antão; Brochmann \& Rustan, registration forms). The uppermost records are from Fogo, at 1700-1800 m in Chã das Caldeiras (leg. Fea, leg. Chevalier, leg. Gilli, leg. Sunding, leg. Kilian \& Leyens) and at 2200-2400 on the southern crater rim (Bordeira, leg. Kilian \& Leyens). On Santo Antão, it extends to $1480 \mathrm{~m}$ (leg. Rustan \& Brochmann). The plants typically grow in montane cliffs, rarely in gravelly slopes. The species was previously an important component of a drier scrub vegetation type with Periploca laevigata ssp. chevalieri and Globularia amygdalifolia.

Abundance. Lavandula rotundifolia is common on Santo Antão and Fogo, and it is also fairly frequent on São Nicolau and Santiago. Some populations are very large, comprising several hundreds of plants. Its distribution on São Vicente is, however, very restricted today, and the species is Endangered $(\mathrm{EN})$ on this island. Lavandula rotundifolia is generally considered to be Lower Risk (LR).

Note. This species has also been reported from Madeira several times, apparently based on a single account by Chaytor (1937). Her report was based on material collected by Lowe, and it is most likely that this material in fact was collected by Lowe in the Cape Verde Islands and erroneously labelled (cf. Rustan \& Brochmann 1993).

\section{Satureja L.}

This genus comprises about 100 , mostly subshrubby species distributed from the mid-Atlantic archipelagos and the Mediterranean, which constitutes one centre of diversity, to the Himalayas and SW China, and in N America. Satureja is represented by a single, endemic species in the Cape Verde Islands.

\section{Satureja forbesii (Figs 142, 143)}

Satureja forbesii (Benth.) Briq. in Engler \& Prantl, Nat. Pflanzenfam. 4(3a): 299 (1896) $\equiv$ Micromeria forbesii Benth., Labiat. Gen. Sp.: 376 (1834) 三 Clinopodium forbesii (Benth.) Kuntze, Revis. Gen. Pl. 3: 515 (1898). Type: In ins. S. Nicolai [in saxosis Mte. Gourdo, 30.3 .1822 (cf. Webb 1849: 159)], Forbes [5]. — Lectotype (designated by Peréz de Paz 1978: 73): "In Sancti Nicolai, 1822, Forbes" (K).

= Satureja forbesii (Benth.) Briq. var. inodora (J. A. Schmidt) R. H. Willemse, Willdenowia 21: 82 (1991) = Micromeria forbesii Benth. var. inodora J. A. Schmidt, Beitr. Fl. Cap. Verd. Ins.: 222 (1852). - Type: In rupibus ins. S. Antonii, pr. Ribeiram grandem, 3.1851, J. A. Schmidt (holotype: HBG!).

= Satureja forbesii (Benth.) Briq. var. altitudinum (Bolle) R. H. Willemse, Willdenowia 21: 82 (1991) $\equiv$ Micromeria forbesii Benth. var. altitudinum Bolle, Bonplandia 8: 282 (1860). - Type: In ins. S. Antonii jugi excelsi Cumbrae rupibus siccissimis, Bolle (B, destroyed). 

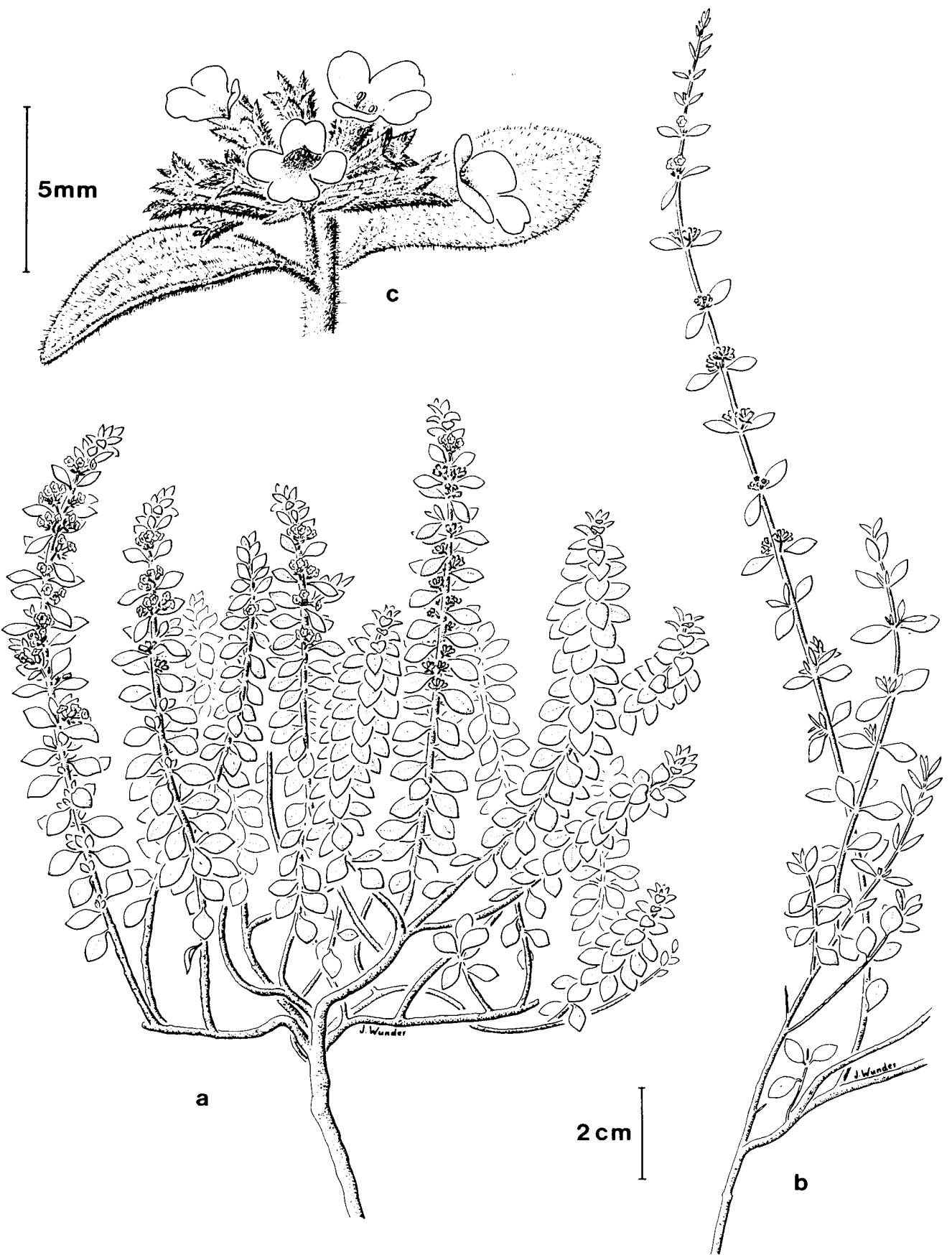

Fig. 142. Satureja forbesii. a. Habit, stout form; b. Habit, slender form; c. Part of stem with inflorescence. Drawn by J. Wunder. 


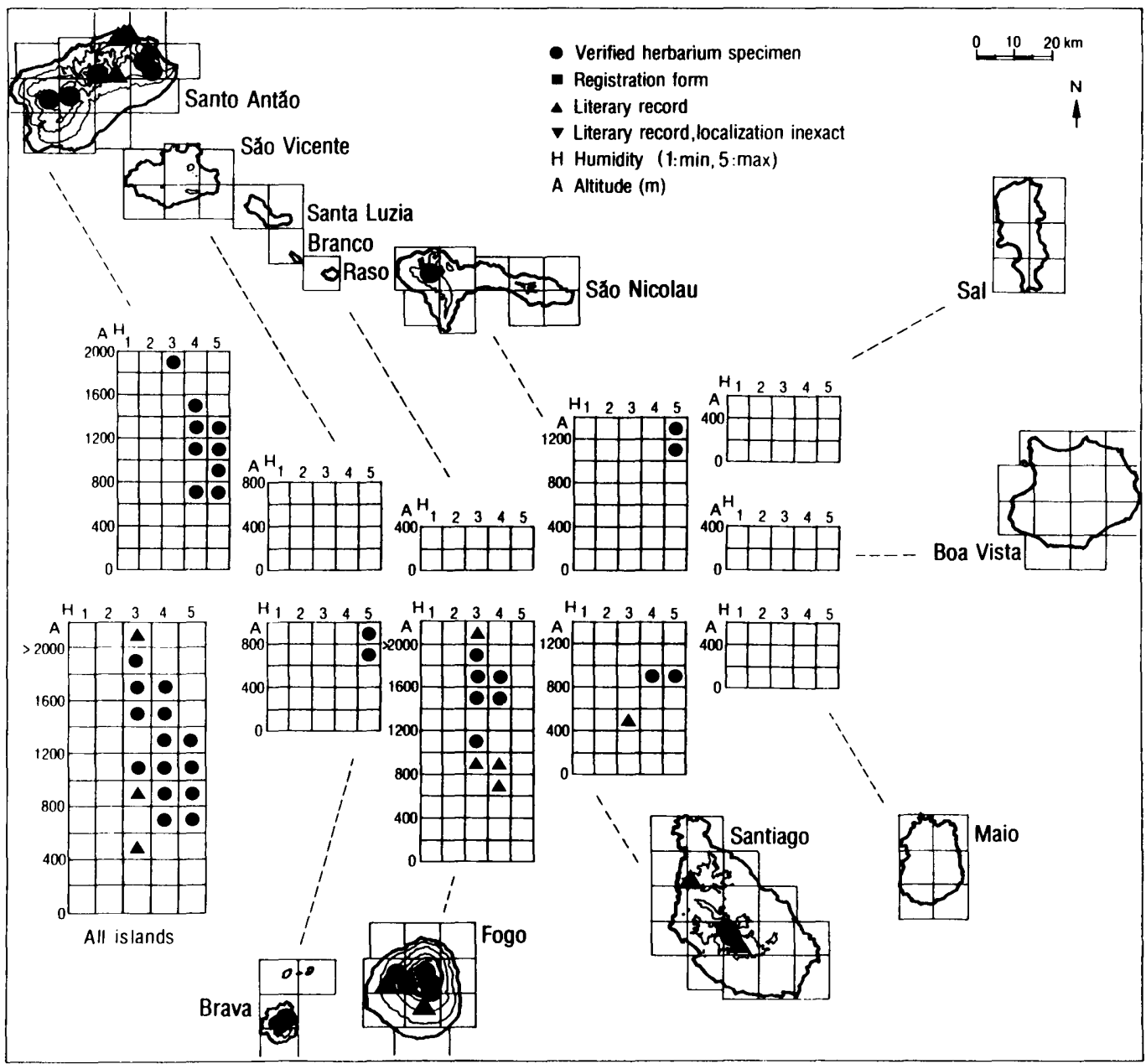

Fig. 143. Ecogeographic distribution of Satureja forbesii.

Illustrations: Pérez de Paz (1978: Figs 17, 18(6-7), Tab. 4A, B), Gomes et al. (1995b: p. 22).

Literature: Pérez de Paz (1978).

Description. Strongly branched, ascending dwarf shrub up to $0.3 \mathrm{~m}$ high; usually strongly aromatic, occasionally odourless. Leaves ovate to elliptical, up to $1.2 \mathrm{~cm}$ long and $0.8 \mathrm{~cm}$ wide, more or less pubescent, sessile to shortly petiolate, apex acute, margin sometimes slightly revolute. Inflorescences axillary, with 3-6 small flowers. Calyx purplish, tubular, slightly zygomorphic. Corolla pinkish to white, hairy. Mericarps dark brown, $0.8 \mathrm{~mm}$ long.

Variation. The species is very polymorphic. Pérez de Paz (1978) distinguished three varieties (var. forbesii, var. inodora, and var. altitudinum) based on odour, leaf petiolation, and leaf density. His revision was, however, only based on a few Capeverdean specimens, and 
the variation appears to be ecoclinal and too complex for delimitation of any infraspecific taxa.

Chromosome number: Unknown.

Related taxa. Satureja forbesii is most closely related to the Canarian S. teneriffae (Poir.) Briq., but it differs in several leaf and floral characters (Pérez de Paz 1978).

Distribution and ecology. Satureja forbesii is a western mesophyte occurring on Santo Antão, São Nicolau, Santiago, Fogo, and Brava, but it is absent from São Vicente. It occurs in the semiarid, subhumid, and humid zones, mainly between $800 \mathrm{~m}$ and $1600 \mathrm{~m}$. The lowermost record is at about $500 \mathrm{~m}$ on Santiago (Ormonde 1980), and the uppermost one at $2830 \mathrm{~m}$ at the top of the volcanic cone of Fogo (Gilli 1976). The plants grow in cliffs and montane gravelly plains and slopes.

Abundance. The species is still common but probably declining on Santo Antão and Fogo, where it comprises some large populations. It is Vulnerable (VU) on Santiago and Endangered (EN) on São Nicolau, where it is confined to the Monte Gordo area, and it is Indeterminate (I) on Brava. Satureja forbesii is generally considered to be Indeterminate (I).

\section{PAPAVERACEAE}

This family is represented by two genera: Papaver, with one endemic species with two subspecies; and Argemone, with the widespread weed $A$. mexicana L., which originates from Central America.

\section{Papaver L.}

The genus Papaver contains about 50 species distributed in temperate regions of Europe, Asia, S Africa, Australia, and N America. Some species are weeds which today have a very wide distribution. Only one species occurs in the Cape Verde Islands, the endemic $P$. gorgoneum (Kadereit \& Lobin 1990). The repeated reports of $P$. rhoeas L. from the Cape Verde Islands (most recently in Hansen \& Sunding 1993) are apparently based on misidentified material of $P$. gorgoneum ssp. gorgoneum.

\section{Papaver gorgoneum}

Papaver gorgoneum Cout., Arq. Univ. Lisboa 1: 284 (1914). -- Syntypes: S. Nicolau, Ribeira da Prata, 1893, Cardoso (LISU!); S. Nicolau, 4.-9.1893, Cardoso I (K!, LISU!); S. Nicolau, Cardoso 67 (LISU); "S. Antão" [labelling erroneous?], Cardoso $1 / 7$ (LISU!). — Lectotype (designated by Lobin 1986b: 130): S. Nicolau, Ribeira da Prata, 1893, Cardoso (LISU!).

Literature: Kadereit \& Lobin (1990).

Description. Annual or sometimes pauciennial, ascending to erect, branched or unbranched herb. Leaves up to $13 \mathrm{~cm}$ long and $4 \mathrm{~cm}$ wide, narrowly obovate, elliptical or narrowly ovate in outline, pinnatipartite; lobes ovate, oblong, elliptical, or obovate in outline, almost patent to 


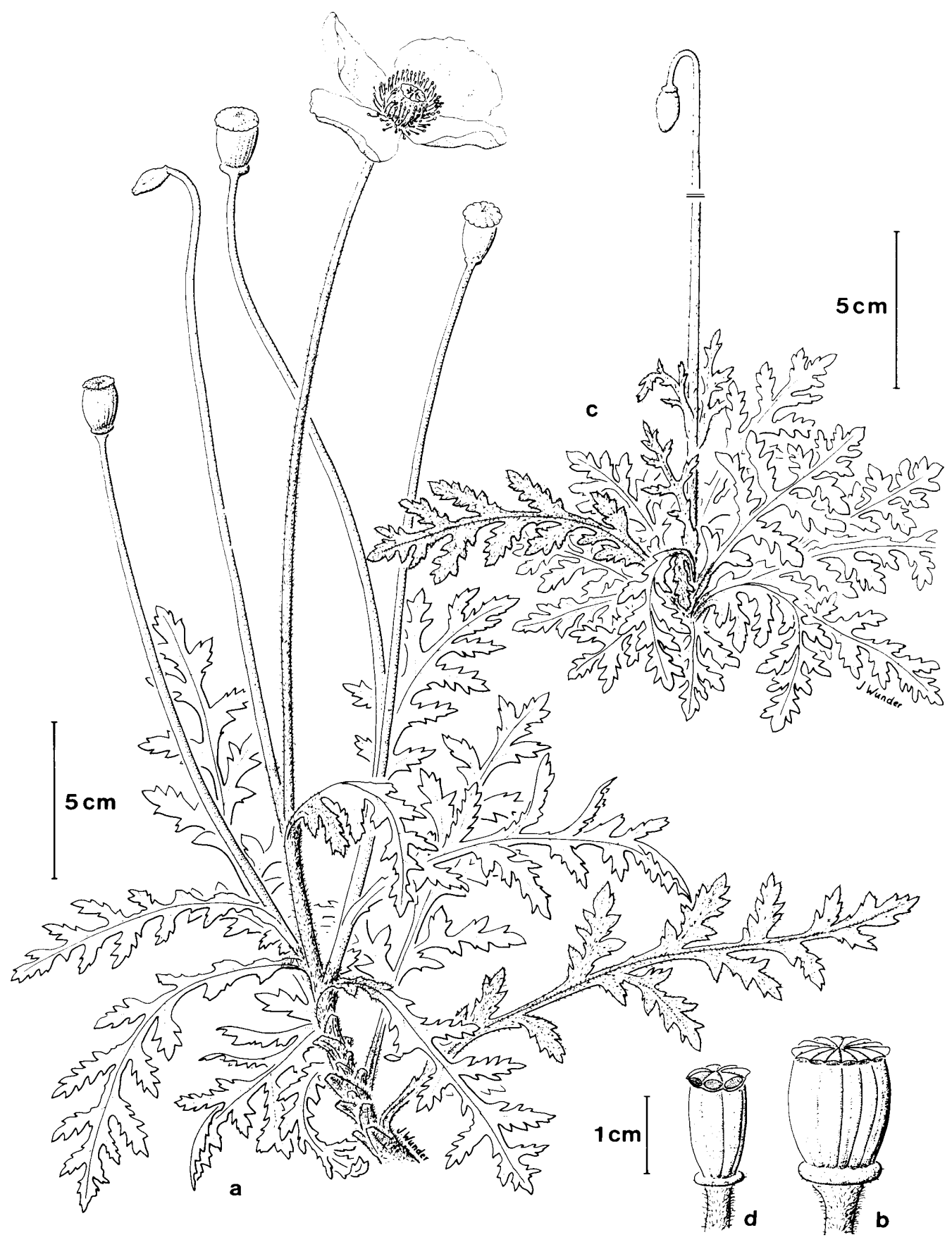

Fig. 144. Papaver gorgoneum ssp. theresias and ssp. gorgoneum. a-b. ssp. theresias: a. Habit; b. Capsule. c-d. ssp. gorgoneum: c. Habit; d. Capsule. Drawn by J. Wunder. 
strongly antrose, pinnatifid to incised, coarsely serrate or entire; lower leaves distinctly petiolated, upper leaves shortly petiolated with distinctly winged petiole or sessile with cuneate base, leaves usually densely setose. Pedicel conspicuously and abruptly broadened below flowers. Flower buds densely setose to almost glabrous. Petals varying between 3 and 8 in number, $10-25 \mathrm{~mm}$ long, obovate with eroded to somewhat laciniate apical margin or deeply bifid, red, without black basal marks. Stamens shorter to slightly longer than ovary; filaments filiform, black; anthers oblong, light yellow; stamens sometimes petaloid. Capsules 8.0-17.0 mm long and 4.0-14.0 mm broad, cylindrical to obovoid, often more or less abruptly contracted at base. Stigmatic disc flat at maturity, as broad as or broader than capsules, with 430 stigmatic rays. Seeds reniform, $0.7 \mathrm{~mm}$ long, light to dark brown.

Variation. The infraspecific variation is considerable, but fairly clearcut. Two subspecies with conspicuous morphological differences can be distinguished, but occasional, morphologically intermediate plants have been observed (Kadereit \& Lobin 1990).

Related taxa. Papaver gorgoneum belongs to section Rhoeadium Spach, and the closest relative of this Capeverdean species is probably $P$. pinnatifidum Moris, which is distributed in the $\mathrm{W}$ and $\mathrm{C}$ Mediterranean, the Canary Islands, Madeira, and the Azores. Both species have filiform, black filaments, light yellow anthers, and glabrous capsules, but $P$. gorgoneum differs from $P$. pinnatifidum by its conspicuous broadening of the pedicel shortly below the flowers, by its cylindrical to obovoid capsules which often are abruptly contracted at the base, and by its different leaf shape. Papaver gorgoneum represents a Mediterranean element in the flora of Cape Verde Islands (Kadereit \& Lobin 1990).

Note. Papaver gorgoneum was misinterpreted for a long time, and some authors have ignored this species because recent collections were lacking. The species was redescribed and divided into two subspecies by Kadereit \& Lobin (1990), based on a number of new collections.

Both subspecies are probably self-compatible and have the unusual, aneuploid chromosome number $2 \mathrm{n}=38$. Papaver gorgoneum is unusual also as it shows an extraordinary large and irregular variation in number of petals (3-8) and stigmatic rays (4-30). The other four species within the $P$. pinnatifidum group in section Rhoeadium are tetraploids with $2 \mathrm{n}=28$ or hexaploids with $2 \mathrm{n}=42(\mathrm{x}=7)$, and the only other basic chromosome numbers known in Papaver are $\mathrm{x}=6$ and $\mathrm{x}=11$ (Kadereit 1988, Kadereit \& Lobin 1990). The peculiar features of $P$. gorgoneum may have evolved by inbreeding in a small founder population in the Cape Verde Islands, perhaps involving dysploid changes in a polyploid based on multiples of 6,7 , or 11 . It cannot be excluded that the original plants were introduced by man (Kadereit \& Lobin 1990).

The maps are based on material from various herbaria revised by Kadereit \& Lobin (1990) and additional, more recent collections.

Key to the subspecies of Papaver gorgoneum

1 Capsule more than twice as long as broad, with less than 10 stigmatic rays ssp. gorgoneum

1 Capsule less than twice as long as broad, with 10-30 stigmatic rays 


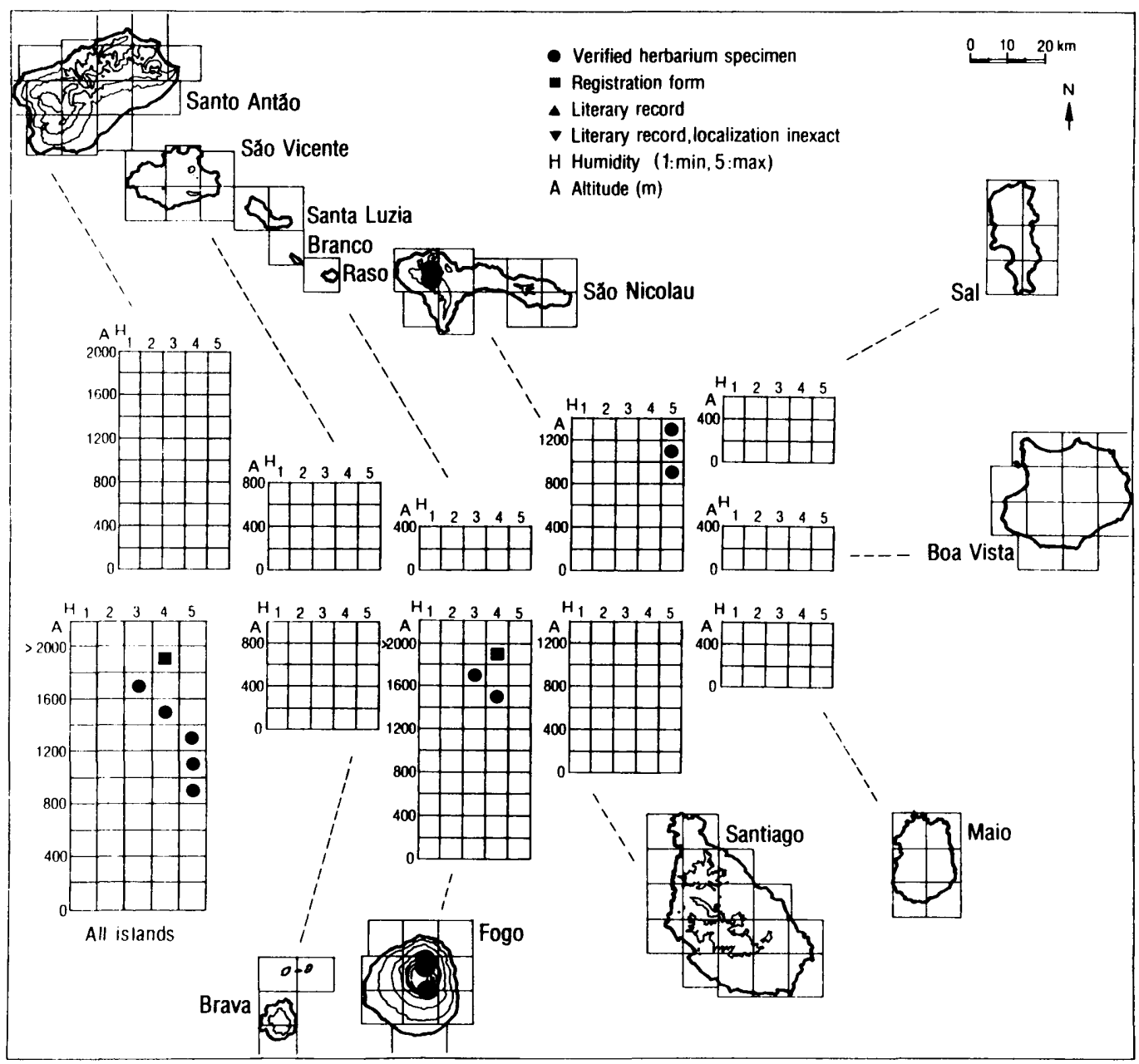

Fig. 145. Ecogeographic distribution of Papaver gorgoneum ssp. gorgoneum.

Papaver gorgoneum ssp. gorgoneum (Figs 144, 145)

Papaver gorgoneum Cout. ssp. gorgoneum

Illustrations: Lobin (1986b: Fig. 28), Kadereit \& Lobin (1990: Fig. 1), Gomes et al. (1995b: p. 23).

Description. Annual herb, unbranched or rarely branched in the middle part of the stem. Lobes of upper leaves closely adjacent. Pedicel with a sparse indument of closely appressed setae or sometimes with very short, patent setae. Capsules more than twice as long as broad, stigmatic rays 4-9.

Variation: See above. 
Chromosome number: $2 \mathrm{n}=38$ (São Nicolau or Fogo, exact locality not known, Kadereit \& Lobin 1990).

Distribution and ecology. Papaver gorgoneum ssp. gorgoneum is a western hygrophyte, but it shows a deviating distribution pattern. This subspecies occurs only on one of the northern islands, São Nicolau, and one of the southern islands, Fogo. It is most frequent in the humid and subhumid zones, and it only rarely occurs in the semiarid zone. On São Nicolau, it is restricted to the Monte Gordo area between $800 \mathrm{~m}$ (leg. Lobin) and $1300 \mathrm{~m}$ (leg. Lindberg), and on Fogo, it occurs in or close to Chã das Caldeiras and the Monte Velha area between $1500 \mathrm{~m}$ (leg. Lobin, leg. Rustan \& Brochmann) and $1900 \mathrm{~m}$ (obs. Leyens, pers. comm.). The plants grow in steep cliffs and slopes with gravel or brown soil.

Abundance. The subspecies is not particularly rare within its distribution areas, but both areas are very restricted. We have observed it on both islands after 1980. Most populations are small, and the vegetation in the entire distribution area is drastically influenced by afforestations, in parts also by agriculture. Papaver gorgoneum ssp. gorgoneum is considered to be Vulnerable (VU).

\section{Papaver gorgoneum ssp. theresias (Figs 144, 146)}

Papaver gorgoneum Cout. ssp. theresias Kadereit \& Lobin, Nord. J. Bot. 9: 646 (1990). - Type: Sto. Antão, Hochfläche bei Agua das Caldeiras, ca. 1200 m, 11.11.1980, Lobin 2I2I (holotype: FR!; isotype: herb. Lobin!).

Illustrations: Kadereit \& Lobin (1990: Fig. 3), Gomes et al. (1995b: p. 23).

Description. Annual or sometimes pauciennial herb, usually branched near the base. Lobes of upper leaves separated by at least twice the basal width of the lobes. Pedicel with a dense indument of appressed, half appressed, and some patent setae, rarely with a dense indument of appressed setae only, glabrescent when old. Capsule less than twice as long as broad, stigmatic rays 10-30, exceptionally less.

Variation: See above.

Chromosome number: $2 \mathrm{n}=38$ (Santo Antão, precise locality not known, Kadereit \& Lobin 1990).

Distribution and ecology. Papaver gorgoneum ssp. theresias is a northern hygrophyte restricted to escarpments in three upper montane areas on Santo Antão: the Pico da Cruz area in the northeastern part, the Monte Morossos area in the central part, and the Tope de Coroa area in the southwestern part. Most localities are situated within the subhumid and humid zones. The plants grow in steep cliffs and gravelly slopes with open vegetation, between 940 $\mathrm{m}$ (Ribeira das Pedras; leg. Sunding) and $1450 \mathrm{~m}$ (Pico da Cruz, leg. Rustan \& Brochmann; Morossos, leg. Leyens). The main altitudinal distribution is between $1200 \mathrm{~m}$ and $1400 \mathrm{~m}$.

Abundance. The total distribution area of Papaver gorgoneum ssp. theresias is limited, and we have only observed a few, scattered, and usually small populations. Large populations are known in the Morossos area (obs. Leyens in 1994, pers. comm.). At present, Papaver gorgoneum ssp. theresias is considered to be Lower Risk (LR). 


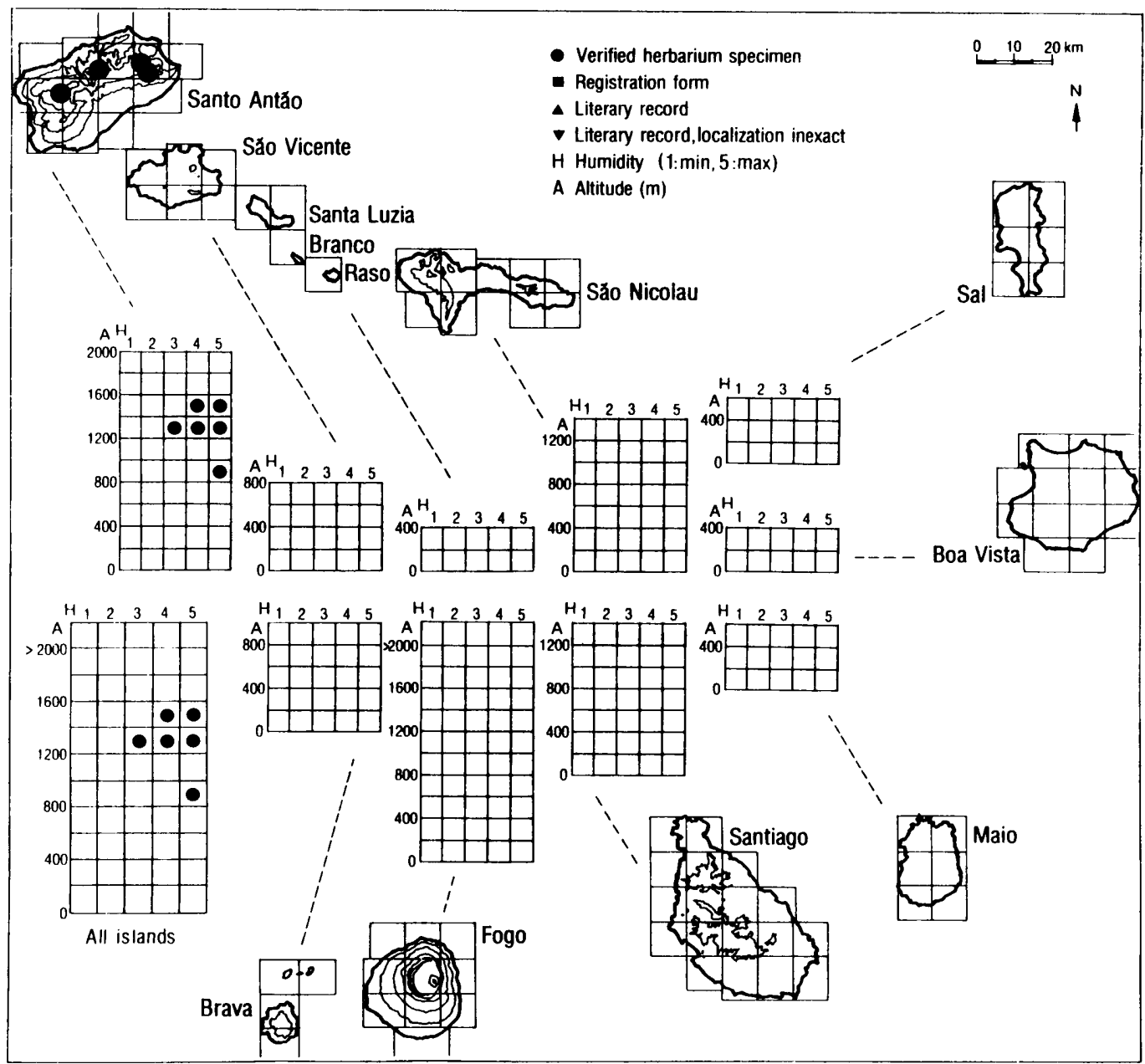

Fig. 146. Ecogeographic distribution of Papaver gorgoneum ssp. theresias.

\section{PLUMBAGINACEAE}

This family is represented by two genera with six species: Plumbago with the non-endemic $P$. zeylanica, and Limonium with five endemic species. 


\section{Limonium Mill.}

Limonium is an almost cosmopolitan genus with a centre of diversity in the Mediterranean region. It comprises some 350 species, most of which are very localized and restricted to coastal habitats. In the Cape Verde Islands, the genus is represented by five species, all endemic to the archipelago.

Literature: Lobin et al. (1995).

Key to the genus Limonium

1 Herbaceous perennial with a dense basal leaf rosette; flowering stems numerous, prostrate to ascending.

1 Cushion-like rosette shrub with a branched, woody caudex and several dense leaf rosettes; flowering stems 1-2 per rosette, ascending to erect

2 (1) Inflorescence axis conspicuously winged, usually prostrate or ascending, strongly proliferous; middle bract of the spikelet distinctly smaller than the outer bract; inner bract 3.6-4.3 mm wide

L. braunii

2 Inflorescence axis angular, strongly branched, ascending, rarely prostrate, rarely somewhat proliferous; middle bract of the spikelet equalling the outer bract in size; inner bract 2.9-3.4 mm wide.

L. brunneri

3 (1) Inflorescence axis conspicuously winged, wing 1-2 mm wide; spike compact with 6-7 spikelets per $0.5 \mathrm{~cm}$.

3 Inflorescence axis rounded or angular; spike lax with 3-5 spikelets per $0.5 \mathrm{~cm}$ .4

4 (3) Calyx fringe at anthesis divided into 5 tooth-like lobes $1.2-1.4 \mathrm{~mm}$ long, calyx ribs reaching the fringe margin L. jovi-barba

4 Calyx fringe at anthesis at most shallowly sinuate, calyx ribs never reaching the fringe margin L. sundingii

\section{Limonium braunii (Figs 147, 148)}

Limonium braunii (Bolle) A. Chev., Rev. Bot. Appl. Agric. Trop. 15: 928 (1935) $\equiv$ Statice braunii Bolle, Index Seminum Hort. Bot. Berol., Append. Pl. Nov. 1861: 4 (1861). - Syntypes: Plant cultivated in the Royal Botanical Garden Berlin from seeds collected by Bolle on Sto. Antão (B, destroyed); Santo Antão, prope Paul, 11.1852, Bolle (B, destroyed, Z!); ibid., Punta do Sol, 11.1852, Bolle (B, destroyed). - Lectotype (designated by Lobin et al. 1995: 200): Sto. Antão, prope Paul, 11.1852, Bolle (Z!).

Illustrations: Gomes et al. (1995b: p. 24), Lobin et al. (1995: Fig. 1h-i).

Description. Perennial herb with a dense basal leaf rosette and numerous, procumbent to ascending flowering stems up to $60 \mathrm{~cm}$ long, with scaly leaves and strongly proliferous, usually with several dense secondary rosettes; inflorescence axes usually distinctly winged, wing up to $2.5 \mathrm{~mm}$ wide but size very variable even within a single individual. Rosette leaves broadly spathulate, up to $8(-8.8) \mathrm{cm}$ long and $4(-5) \mathrm{cm}$ wide with a length to width ratio of (1.3-)1.8-3(-3.8), entire, apex rounded to obcordate and mucronulate; leaves of the secondary rosettes up to $3.3 \mathrm{~cm}$ long and $1.3(-1.6) \mathrm{cm}$ wide with a length to width ratio of (1.6-) 1.8 - 

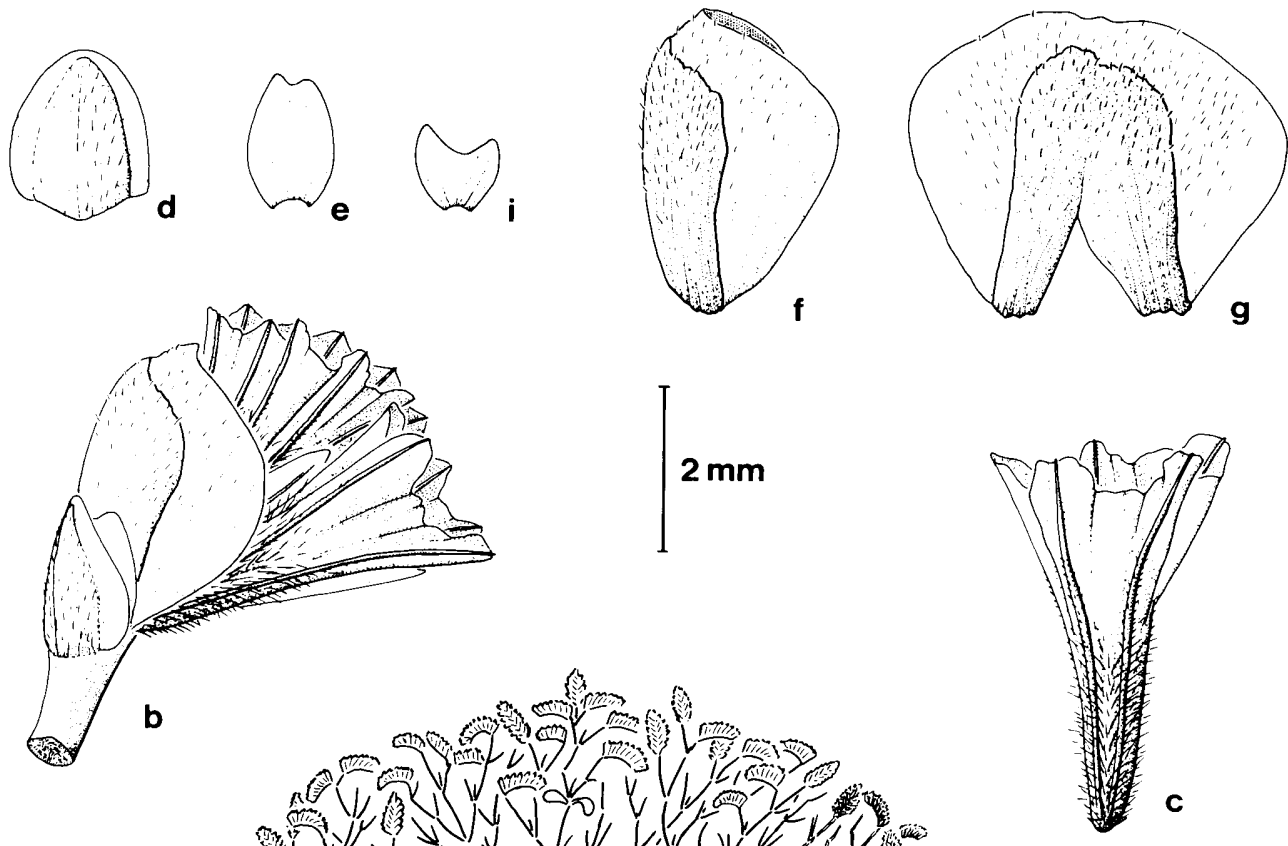

a

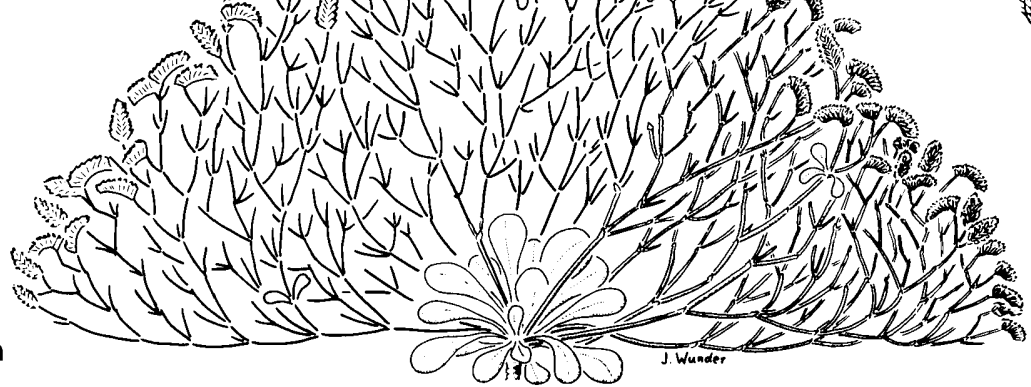

$5 \mathrm{~cm}$

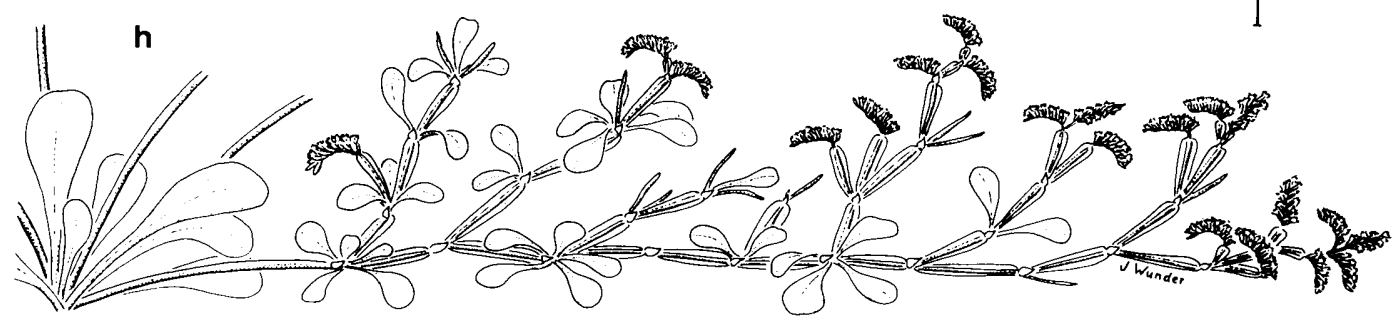

Fig. 147. Limonium brunneri and L. braunii. a-g. L. brunneri: a. Habit; b. Spikelet with outer, middle, and inner bracts; c. Calyx; d. Outer bract; e. Middle bract; f. Inner bract, lateral view; g. Inner bract, abaxial view. h-i. L. braunii: h. Habit; i. Middle bract. Drawn by J. Wunder. Reprinted from Lobin et al. (1995), Willdenowia 25 (with permission). 


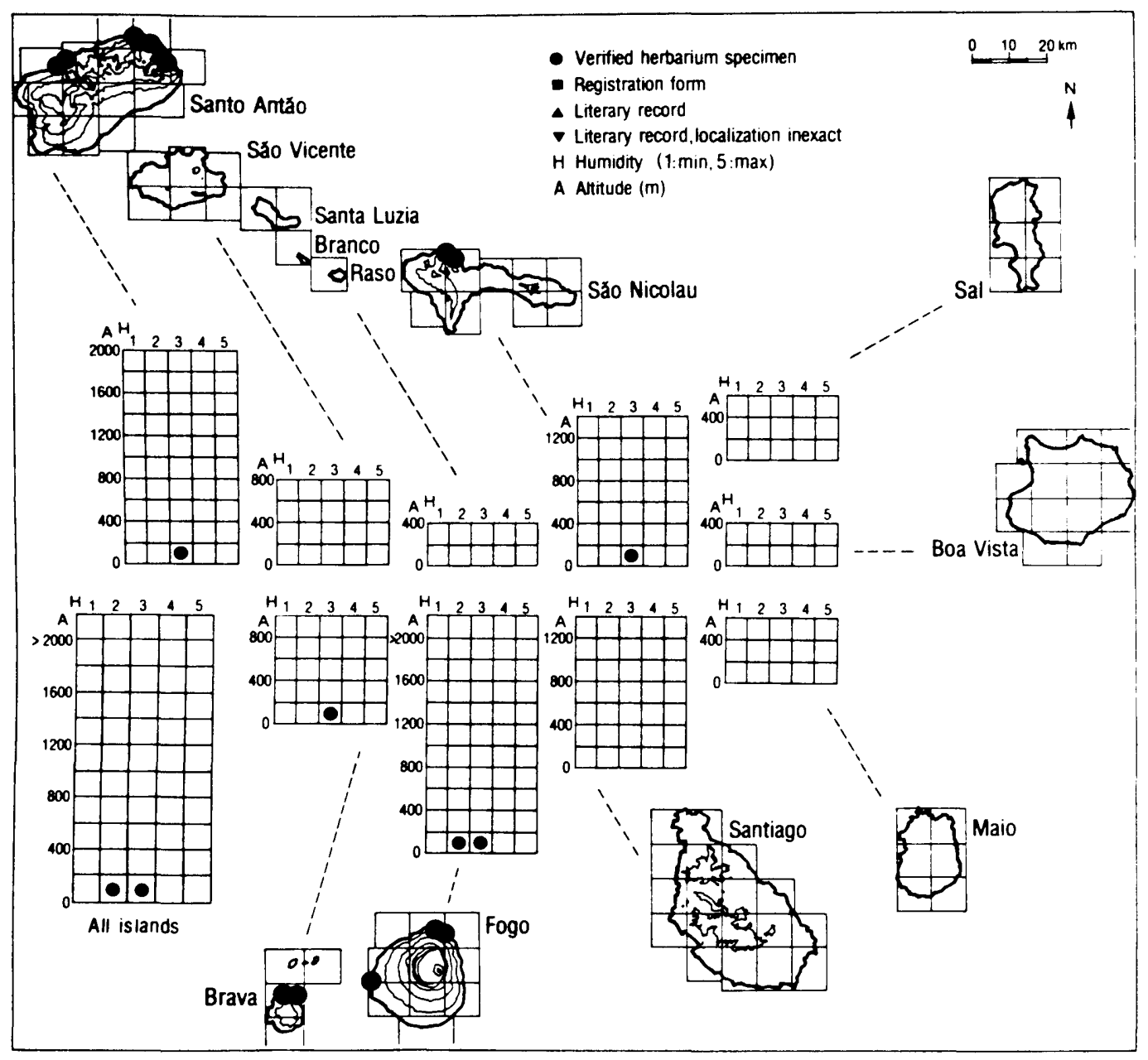

Fig. 148. Ecogeographic distribution of Limonium braunii.

2.3(-2.9), otherwise similar. Inflorescence a terminal panicle, spikes secund, lax to compact, 6-13 mm long, with 5-8 spikelets per $0.5 \mathrm{~cm}$, each spikelet (1-)2-5(-7)-flowered. Spikelets 3bracteate; outer bract 1.8-2.6 mm long and 1.9-2.3 mm wide, $1 / 2$ of the length of the inner bract; middle bract inconspicuous, completely scarious, up to $2 / 3$ of the length of the outer bract; inner bract 3.2-4.8 $\mathrm{mm}$ long and 3.6-4.3 $\mathrm{mm}$ wide; indument of the outer and inner bracts very variable, glabrous to strongly hirsute. Calyx whitish rose to white or rarely bluish, infundibuliform, up to $5.3 \mathrm{~mm}$ long, with long hairs especially in lower half and on the ribs; calyx fringe hyaline, ribs dark reddish brown, just reaching the fringe edge of the flowering calyx. Corolla dark pinkish. Fruit a circumscissile, one-seeded capsule enclosed by the calyx. Seeds smooth, brown. 
Variation. The species is homogeneous except for some variation in habit and large variation in size of the wings on the flowering axes.

Chromosome number: $2 \mathrm{n}=12(2 \mathrm{n}=12$, Santo Antão, $\mathrm{N}$ coast, Bramwell \& Murray 1972, Bramwell et al. 1972; $2 \mathrm{n}=12$, Santo Antão, coast between Ribeira Grande and Ribeira do Barbasco, Erben 1986; 2n = 12, São Nicolau, S of Ribeira Funda, Lobin et al. 1995).

Related taxa. Limonium braunii is most closely related to L. brunneri, and these two species are probably most closely related to L. pectinatum (Aiton) Kuntze from the Canary Islands and the Salvage Islands. The relationships of $L$. braunii and L. brunneri to the three rosette-shrubby species in the archipelago are at present not clear (see also L. jovi-barba).

Distribution and ecology. Limonium braunii is a western mesophyte occurring along northern and northwestern coasts of Santo Antão, São Nicolau, Fogo, and Brava. Most localities are situated in the semiarid zone, and only one locality is known from the arid zone (western Fogo). The species is confined to littoral areas below $100 \mathrm{~m}$, mainly between sea-level and $60 \mathrm{~m}$. The plants grow in gravelly slopes and maritime cliffs together with, e.g. Asparagus squarrosus, Beta procumbens, Campylanthus glaber ssp. spathulatus, Frankenia ericifolia ssp. caboverdeana, Lotus spp., Paronychia illecebroides, and Polycarpaea gayi.

Abundance. The species is very common on Santo Antão and less frequent on São Nicolau, Brava, and Fogo. Limonium braunii is considered to be Lower Risk (LR).

Note. The report of L. braunii from Santa Luzia (Basto \& Diniz 1993) is omitted because of possible confusion with $L$. brunneri.

\section{Limonium brunneri (Figs 147, 149)}

Limonium brunneri (Webb) Kuntze, Revis. Gen. Pl. 2: 395 (1891) = Statice brunneri Webb in DC., Prodr. 12: 639 (1848). - Type: In lapidosis ins. Salis, [1838], Brunner (holotype: FI-W!; isotypes: GOET!, K!, L!, O!). [= Statice edwardsi Franch., Bull. Hebd. Assoc. Sci. France 16./23. Dec. 1883: 20 (1883), nom. nud.]. Illustrations: La Serna Ramos et al. (1982), Gomes et al. (1995b: p. 24), Lobin et al. (1995: Fig. 1a-g).

Description. Perennial herb with a dense basal leaf rosette and numerous, ascending, strongly branched, up to $0.3 \mathrm{~m}$ long flowering stems with scaly leaves and only rarely proliferous, giving the plant a tuft-like appearance. Rosette leaves broadly spathulate, up to $4(-6.2) \mathrm{cm}$ long and $1.2(-1.5) \mathrm{cm}$ wide with a length to width ratio of (1.7-)2.5-5(-5.8), entire, apex rounded to subcordate and mucronulate. Inflorescence axes wingless. Inflorescence a terminal panicle, spikes secund, compact, (3-)5-8(-12) mm long, with 6-8 spikelets per $0.5 \mathrm{~cm}$, each spikelet 2-4(-5)-flowered. Spikelets 3-bracteate; outer bract 1.4-2 mm long and 1.2-1.8 mm wide, $1 / 2$ of the length of the inner bract; middle bract inconspicuous, about as long as the outer bract, completely scarious; inner bract 3.3-4 mm long and 2.9-3.4 mm wide; outer and inner bracts usually hirsute, sometimes glabrous. Calyx white to whitish rose, infundibuliform, 3.7-5.0 $\mathrm{mm}$ long, $1.7-1.3 \mathrm{~mm}$ in diameter, with long hairs especially in lower half and on the ribs, calyx fringe hyaline, ribs dark reddish brown, their tips distinctly exceeding the fringe edge of the flowering calyx. Corolla pinkish. Fruit a circumscissile, oneseeded capsule enclosed by the calyx. Seeds smooth, brown.

Variation. No essential variation was observed.

Chromosome number: $2 \mathrm{n}=12(2 \mathrm{n}=12$, Sal, Punta Jalunga, Erben $1986 ; 2 \mathrm{n}=12$, Sal, Ribeira de Palha Verde, Lobin et al. 1995; $2 \mathrm{n}=12$, Sal, $\mathrm{S}$ of Santa Maria, Lobin et al. 1995). 


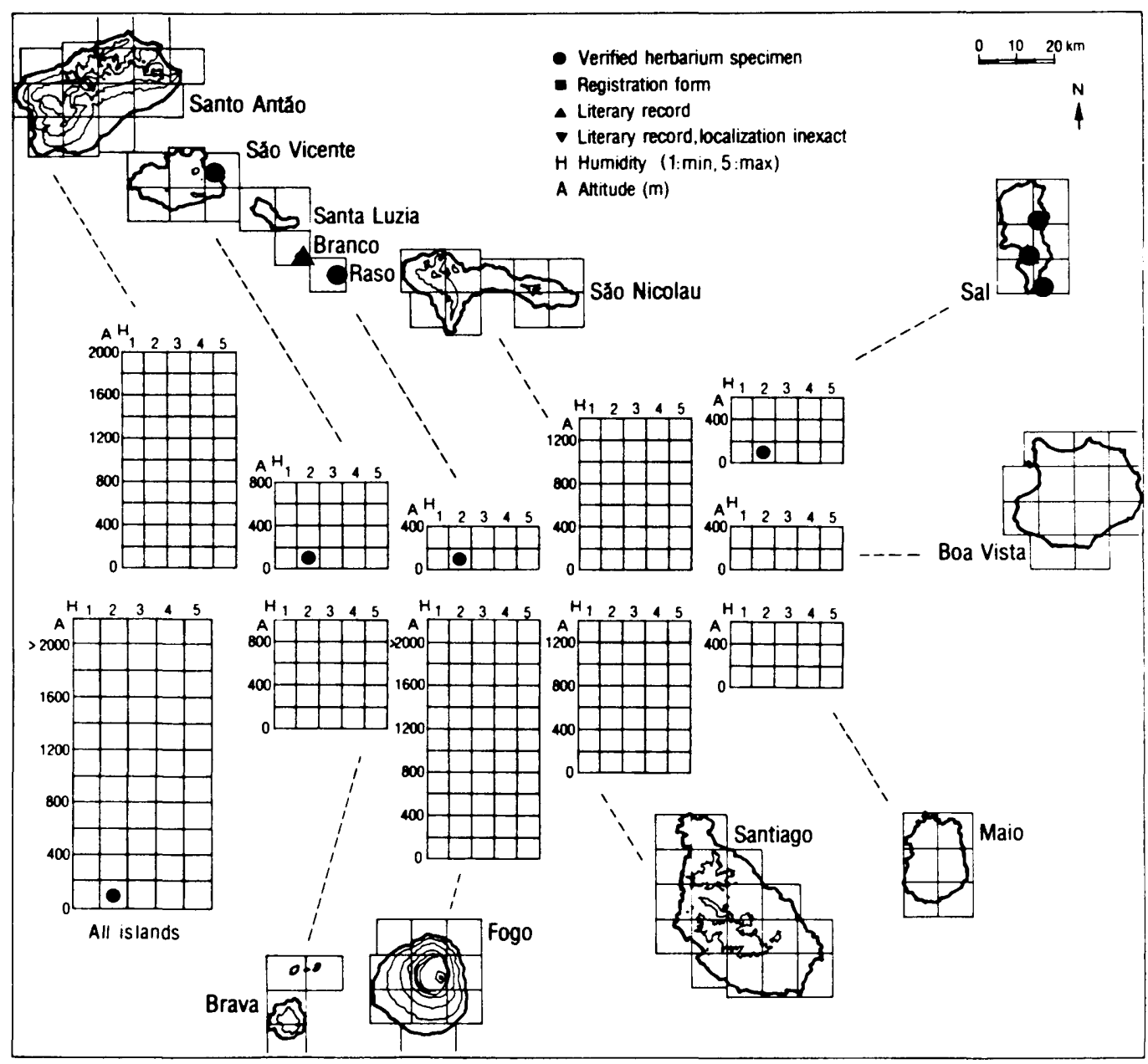

Fig. 149. Ecogeographic distribution of Limonium brunneri.

Related taxa: See L. braunii.

Distribution and ecology. Limonium brunneri is a ubiquitous xerophyte. It occurs only on one of the northern islands, São Vicente, on the two northern islets of Branco and Raso, and on one of the eastern islands, Sal. Thus, it deviates from the usual distributional pattern in this element. It is very rare on São Vicente, probably rare on Branco and Raso, but much more common and locally abundant on Sal, indicating that the species has a close relationship to the eastern xerophytic element. All localities are situated in the arid zone and usually below $50 \mathrm{~m}$. The plants grow in depressions on loamy soil, less frequently on sand, and rarely in coastal, gravelly slopes. Limonium brunneri is often found associated with Asparagus squarrosus, Frankenia ericifolia ssp. ericifolia, Lotus brunneri, Polycarpaea nivea, Sporobolus spicatus, and Suaeda spp. 
Abundance. On São Vicente, the only known population comprised a few individuals in 1981/82 (Rustan \& Brochmann 1985). The species has not been found there since that time although it repeatedly has been searched for (Lobin et al. 1995), and it is thus classified as Prolonged Absence (PA) on São Vicente. Some populations on Sal are large, comprising several hundreds of plants. Limonium brunneri is generally considered to be Lower Risk (LR).

Note. The records of Chevalier (1935a) and Nogueira (1976) from Fogo are omitted because of confusion with L. braunii (Rustan \& Brochmann 1985, Lobin et al. 1995).

\section{Limonium jovi-barba (Figs 150, 151)}

Limonium jovi-barba (Webb) Kuntze, Revis. Gen. Pl. 2: 395 (1891) झStatice jovi-barba Webb in DC., Prodr. 12: 665 (1848). - Type: [S. Vicente], copiosa in rupibus montis Verede ab alt. 1500 ped. usque ad apicem, 6.1841 , Vogel 30 (holotype: FI-W!; isotype: K!).

Illustrations: Gomes et al. (1995b: p. 24), Lobin et al. (1995: Fig. 3).

Description. Small, cushion-like rosette shrub with a branched woody caudex up to $0.4 \mathrm{~m}$ high, carrying up to 30 dense rosettes; caudex branches covered with a conspicuous frill of marcescent foliage; withering leaves revolving from their base; at anthesis each rosette shoot with 1-2 terminal flowering stems, with leaves reduced to inconspicuous scales. Rosette leaves spathulate, up to $10.5(-11.6) \mathrm{cm}$ long and $3.5 \mathrm{~cm}$ wide, with a length to width ratio of 2.4-3.5(-4.7), entire, apex rounded to mucronate. Inflorescence an erect panicle up to $44 \mathrm{~cm}$ long; main axes rounded to angular, normally branched only in the upper half of the axis resulting in a brush-like shape; inflorescence of previous year fairly flexible, remaining intact for a long time. Spikes secund, lax, (8-)10-20 mm long, with 3-5 spikelets per $0.5 \mathrm{~cm}$, each spikelet consisting of 2-3(-4) flowers; spikelets 3-bracteate; outer bract 2.4-2.8 mm long and 1.9-2.2 mm wide, triangular-ovate in outline, acute, with a broad scarious margin; middle bract 2.3-2.6 $\mathrm{mm}$ long and 1.2-1.8 $\mathrm{mm}$ wide, completely scarious, broadly obovate to elliptical in outline, deeply emarginate; inner bract $4.2-4.8 \mathrm{~mm}$ long and $2.8-3.1 \mathrm{~mm}$ wide, obovate, acute to obtuse, with a broad scarious margin, tip of fleshy middle part reaching the margin, glabrous. Calyx at anthesis 4.3-5.2 mm long, glabrous or with some hairs on the base of the tube, calyx ribs reaching the fringe margin, calyx fringe at anthesis divided into 5 toothlike lobes 1.2-1.4 mm long; in fruiting state calyx $5 \mathrm{~mm}$ long with the same shape, but teeth spreading and still well exceeding the inner bract, thus giving the inflorescence a fluffy appearance. Corolla pinkish, 6-7 $\mathrm{mm}$ long, petals spathulate with apex only slightly emarginate, only slightly spreading. Stamens 5 , inserted at the base of the petals, 5-6 mm long, at anthesis exceeding the corolla. Styles 5, free from the base, 8-9 mm long, well exerted during anthesis and even in withered flowers. Fruit a circumscissile, one-seeded capsule enclosed by the calyx. Seeds smooth, brown.

Variation. No significant variation was observed.

Chromosome number: $2 \mathrm{n}=12(2 \mathrm{n}=12$, São Vicente, Monte Verde, $540 \mathrm{~m}$, Borgen $1975 ; 2 n=12$, São Vicente, NW slope of Monte Verde, Erben 1986).

Related taxa. The three rosette shrubs $L$. jovi-barba, L. lobinii, and L. sundingii are very closely related, but their relationship with species outside the Cape Verde Islands is obscure (Lobin et al. 1995). It is possible that all Limonium species in the archipelago have 


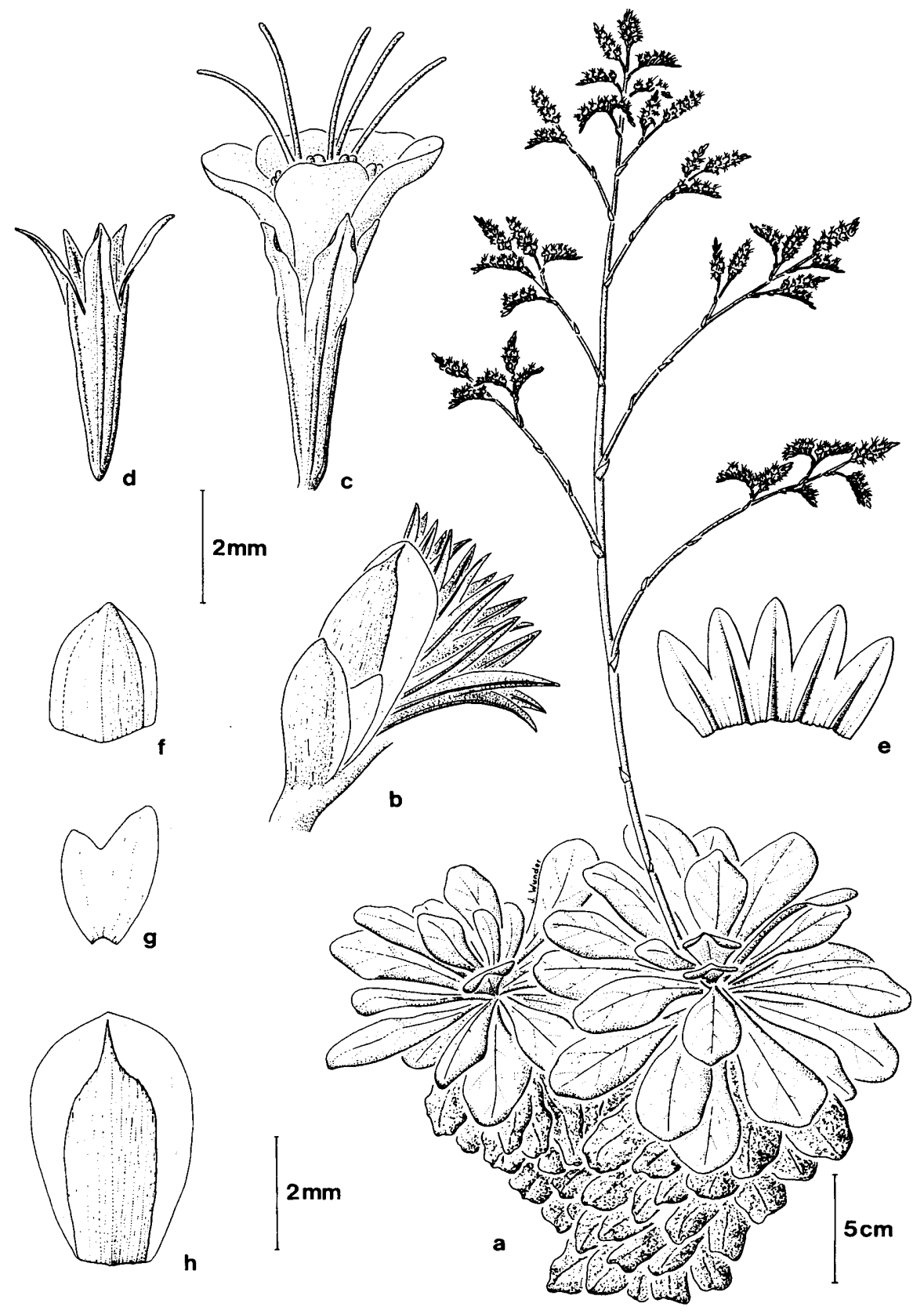

Fig. 150. Limonium jovi-barba. a. Habit; b. Spikelet with outer, middle, and inner bracts; c. Flower; d. Calyx at fruiting time; e. Calyx at anthesis; f. Outer bract; g. Middle bract; h. Inner bract. Drawn after cultivated and field-collected plants by J. Wunder. Reprinted from Lobin et al. (1995), Willdenowia 25 (with permission). 


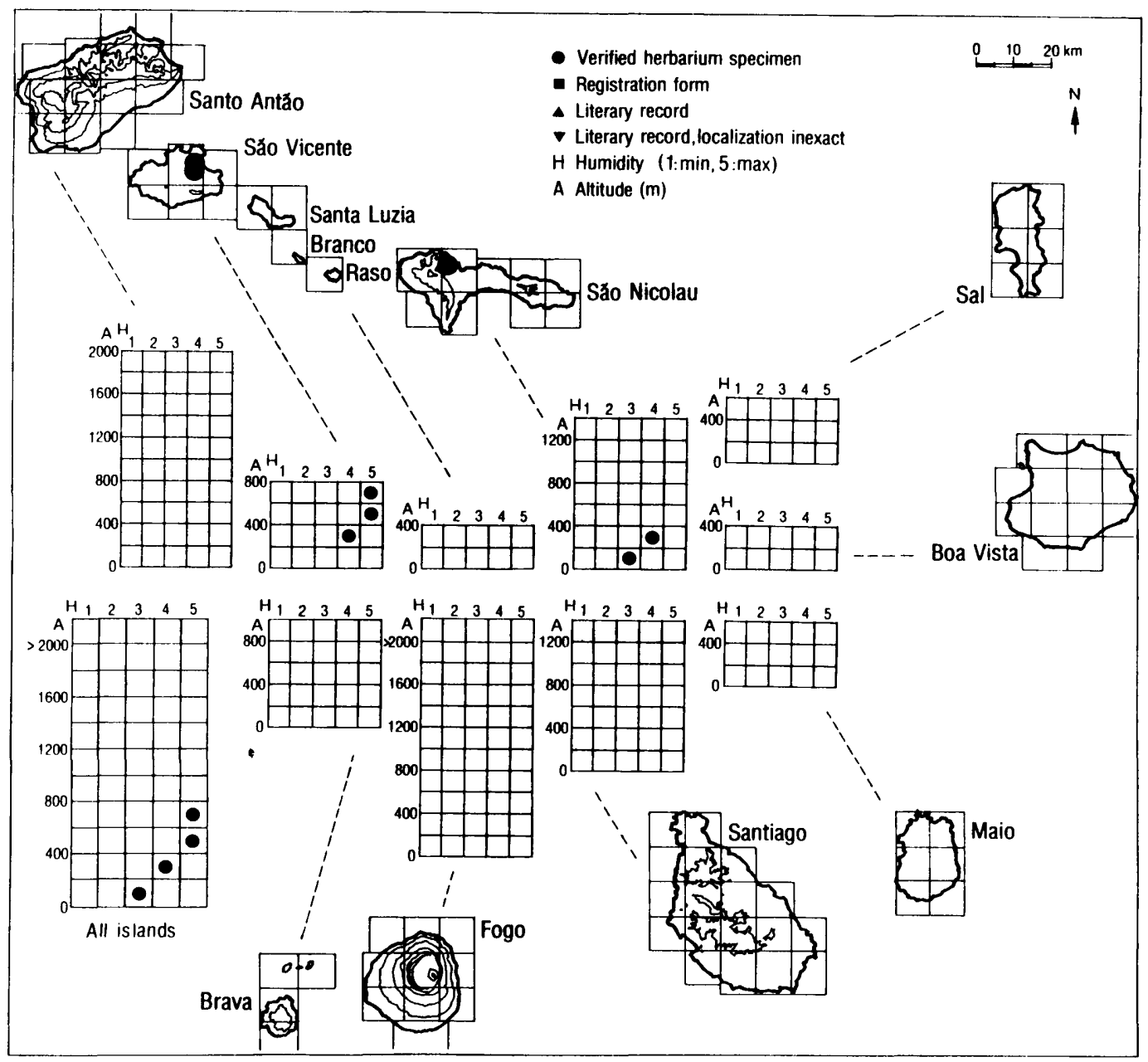

Fig. 151. Ecogeographic distribution of Limonium jovi-barba.

evolved from a single immigrant. Alternatively, the two herbaceous species, $L$. braunii and $L$. brunneri, may have evolved from one immigrant of the L. pectinatum group, and the rosette shrubs from a second immigrant of unknown origin.

Distribution and ecology. Limonium jovi-barba is a northern hygrophyte restricted to Monte Verde and the neighbouring Monte Antonio Gomes on São Vicente, and to the western mountain range on São Nicolau. The distribution area is mainly within the subhumid and humid zones, but the species also occurs in the semiarid zone, but then confined to locally moist habitats. The main altitudinal distribution is between 200 and $600 \mathrm{~m}$, but the species occasionally occurs down to $50 \mathrm{~m}$ (leg. Kilian \& Leyens) and up to $770 \mathrm{~m}$ (leg. Vogel). The plants grow in crevices of northwest- to northeast-facing, shaded, usually remote and inaccessible, steep cliffs. Limonium jovi-barba is frequently associated with Campanula 
jacobaea, Polycarpaea gayi, Launaea picridioides, Arthraxon lancifolius, Aeonium gorgoneum, Echium stenosiphon ssp. stenosiphon, Lobularia canariensis ssp. spathulata, and ferns.

Abundance. Only a few, small populations are known. Limonium jovi-barba is considered to be Rare (R).

\section{Limonium lobinii (Figs 152, 153)}

Limonium lobinii N. Kilian \& Leyens, Willdenowia 24: 59 (1994) - Type: Santiago, Serra da Malagueta, Chã de Figueiras, c. 800 m, NE-NW facing cliffs into Rib. Principal, 22.3.1994, Heckel (holotype: B!; isotypes: O!, herb. INIDA!, herb. Lobin!).

Illustrations: Kilian \& Leyens (1994: Fig. 1), Gomes et al. (1995b: p. 24)

Description. Small, cushion-like rosette shrub up to $0.4 \mathrm{~m}$ high, carrying up to 30 dense, cupshaped rosettes; caudex branches covered with a frill of marcescent foliage of slightly coiled rosette leaves. Rosette leaves obovate to broadly spathulate, up to $10 \mathrm{~cm}$ long and $4.2 \mathrm{~cm}$ wide, with a length to width ratio of (1.9-)2.1-2.9(-3.3). Inflorescence an erect panicle up to $45 \mathrm{~cm}$ long, main axis and branches distinctly 2 -winged. Spikes secund, compact, 7-13 mm long, with 6-7 spikelets per $0.5 \mathrm{~cm}$; each spikelet 2-4-flowered. Spikelets 3-bracteate; outer bract 2.5-3.6 mm long, 2/3 of the length of the inner bract; middle bract inconspicuous, $2 \mathrm{~mm}$ long, completely scarious; inner bract $4-5 \mathrm{~mm}$ long, often slightly hirsute. Calyx at anthesis 4.8-5.6 $\mathrm{mm}$ long; calyx fringe membranaceous, white, deeply 5-lobed, tightly folded, distinctly exceeding the calyx ribs; in fruiting state destitute of the membranaceous fringe and only $3.2-4 \mathrm{~mm}$ long, with the ribs forming 5 scarcely spreading teeth. Corolla bluish-purple, 6-8 $\mathrm{mm}$ long, radially spreading over the calyx; petals $6-8 \mathrm{~mm}$ long, with deeply emarginate apex. Styles free, $6 \mathrm{~mm}$ long. Fruit a circumscissile, one-seeded capsule enclosed by the calyx. Seeds smooth, brown.

Variation. The material is homogeneous.

Chromosome number: $2 \mathrm{n}=12[2 \mathrm{n}=18](2 \mathrm{n}=12,2 \mathrm{n}=18$, Santiago, Serra da Malagueta, $800 \mathrm{~m}$, Kilian \& Leyens 1994; $2 \mathrm{n}=12$, same locality, Lobin et al. 1995). The species is probably regularly diploid; only two occasional, triploid seedlings were observed among normal diploids (Kilian \& Leyens 1994).

Related taxa: See L. jovi-barba.

Distribution and ecology. Limonium lobinii is a southern hygrophyte restricted to the humid zone in Serra da Malagueta on Santiago, where it occurs between $550 \mathrm{~m}$ and $800 \mathrm{~m}$ in northeast- to northwest-facing cliffs and steep escarpments. The species is frequently associated with Echium hypertropicum, Campanula jacobaea, Verbascum capitis-viridis, Tornabenea annua, Diplotaxis varia, Polycarpaea gayi, and Lobularia canariensis ssp. fruticosa.

Abundance. The distribution area is very limited, and the few known populations are small. Limonium lobinii is considered to be Rare (R). 


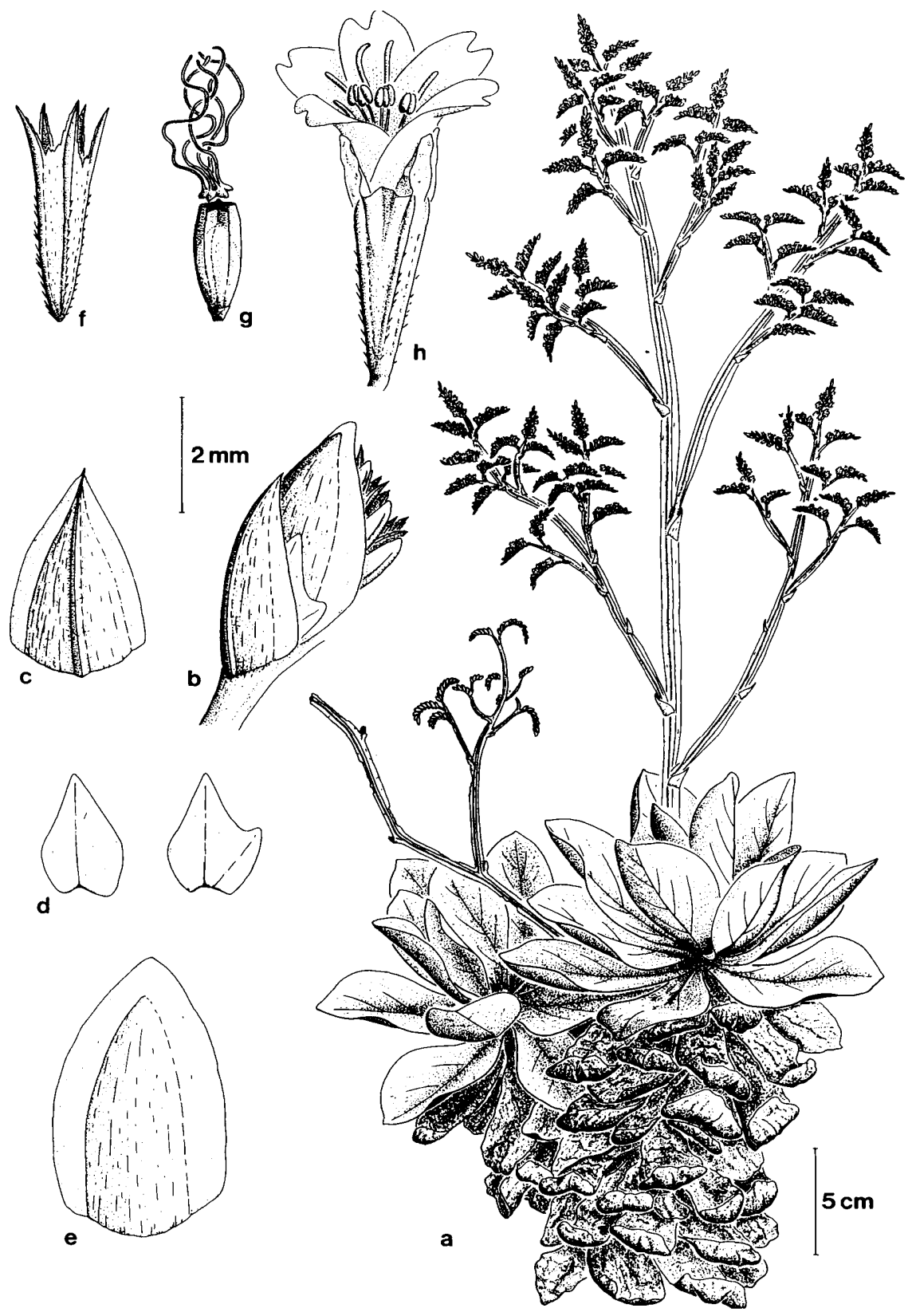

Fig. 152. Limonium lobinii. a. Habit; b. Spikelet with outer, middle, and inner bracts; c. Outer bract; d. Middle bracts of two different spikelets; e. Inner bract; f. Calyx at fruiting time; g. Capsule (calyx removed); h. Flower. Drawn by J. Wunder. Reprinted from Kilian \& Leyens (1994), Willdenowia 24 (with permission). 


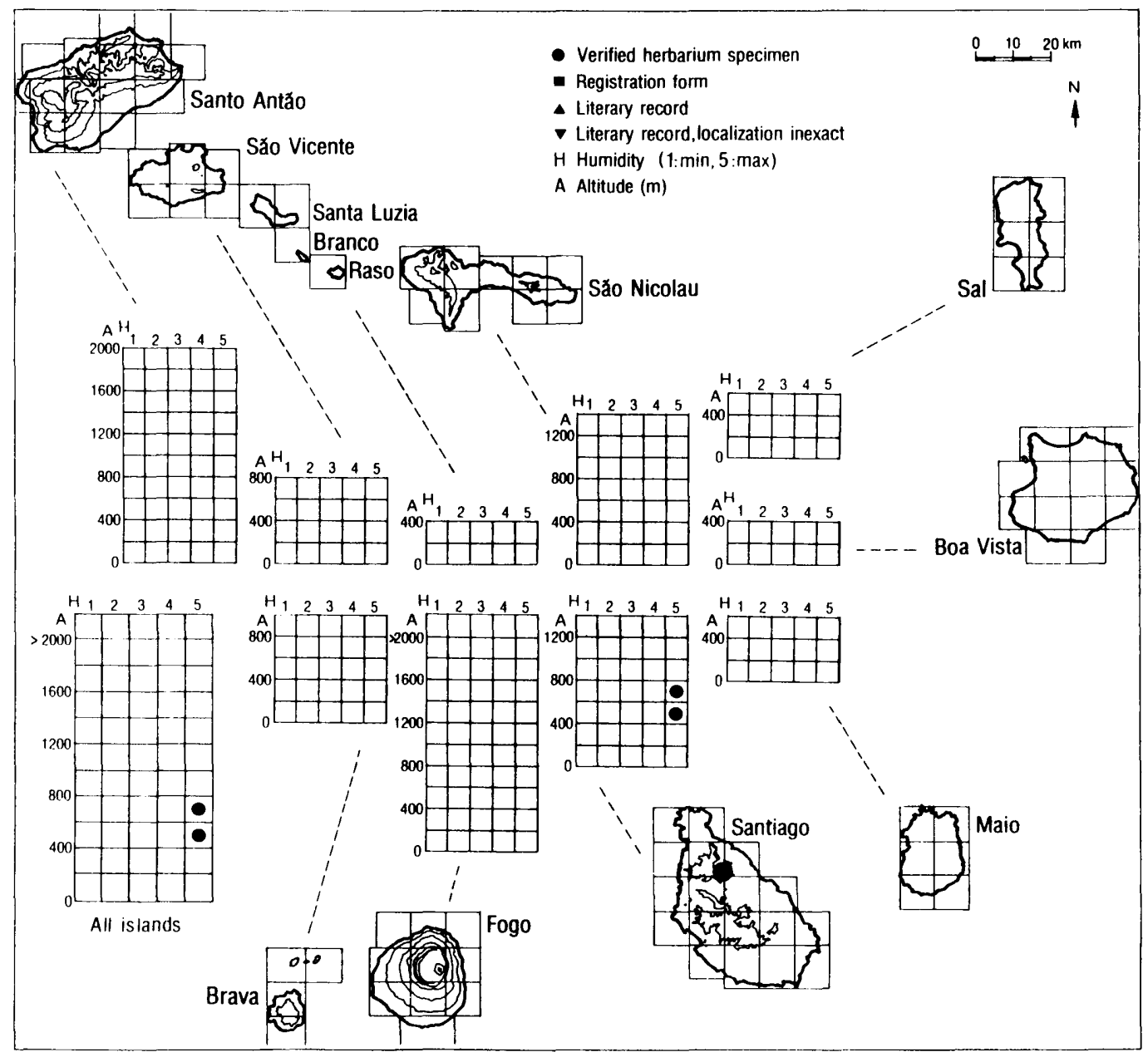

Fig. 153. Ecogeographic distribution of Limonium lobinii.

\section{Limonium sundingii (Figs 154, 155)}

Limonium sundingii Leyens, Lobin, N. Kilian \& Erben, Willdenowia 25: 208 (1995). — Type: S. Nicolau, Alto das Cabaças area, NE-NW facing, vertical escarpments to the coast, c. 550-650 m, 14.1.1994, Kilian 318t \& Leyens (holotype: B!; isotypes: M!, herb. INIDA!, herb. Kilian!, herb. Lobin!).

Illustration: Lobin et al. (1995: Fig. 5).

Description. Small rosette shrub with a branched woody caudex up to $0.7 \mathrm{~m}$ high. carrying 15-30 dense rosettes; caudex branches covered with a conspicuous frill of marcescent foliage: withering leaves revolving from their base. Rosette leaves obovate, up to $8 \mathrm{~cm}$ long and 2.6 $\mathrm{cm}$ wide with a length to width ratio of $2.5-3(-4.1)$. Inflorescence $10-30 \mathrm{~cm}$ long. Spikes secund, compact, with 5 spikelets per $0.5 \mathrm{~cm}$. Spikelets 3 -bracteate; outer bract 2.8-3.2 mm 

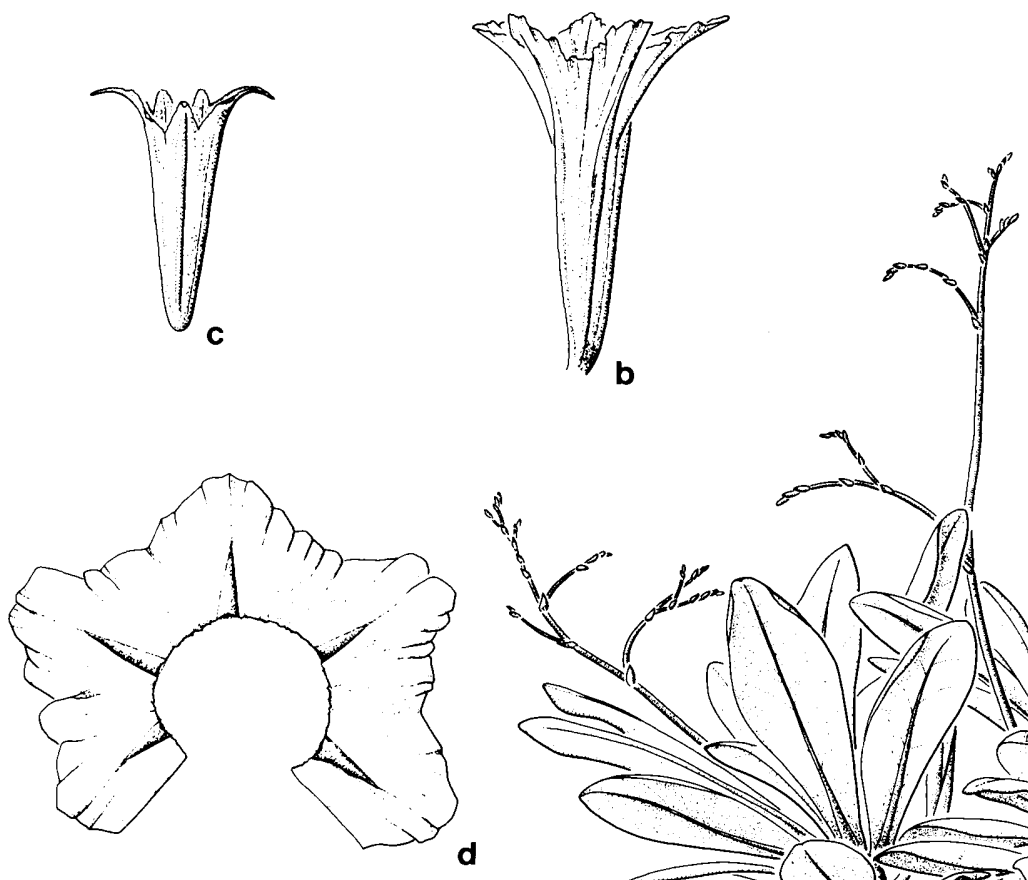<smiles>[14CH3]</smiles>
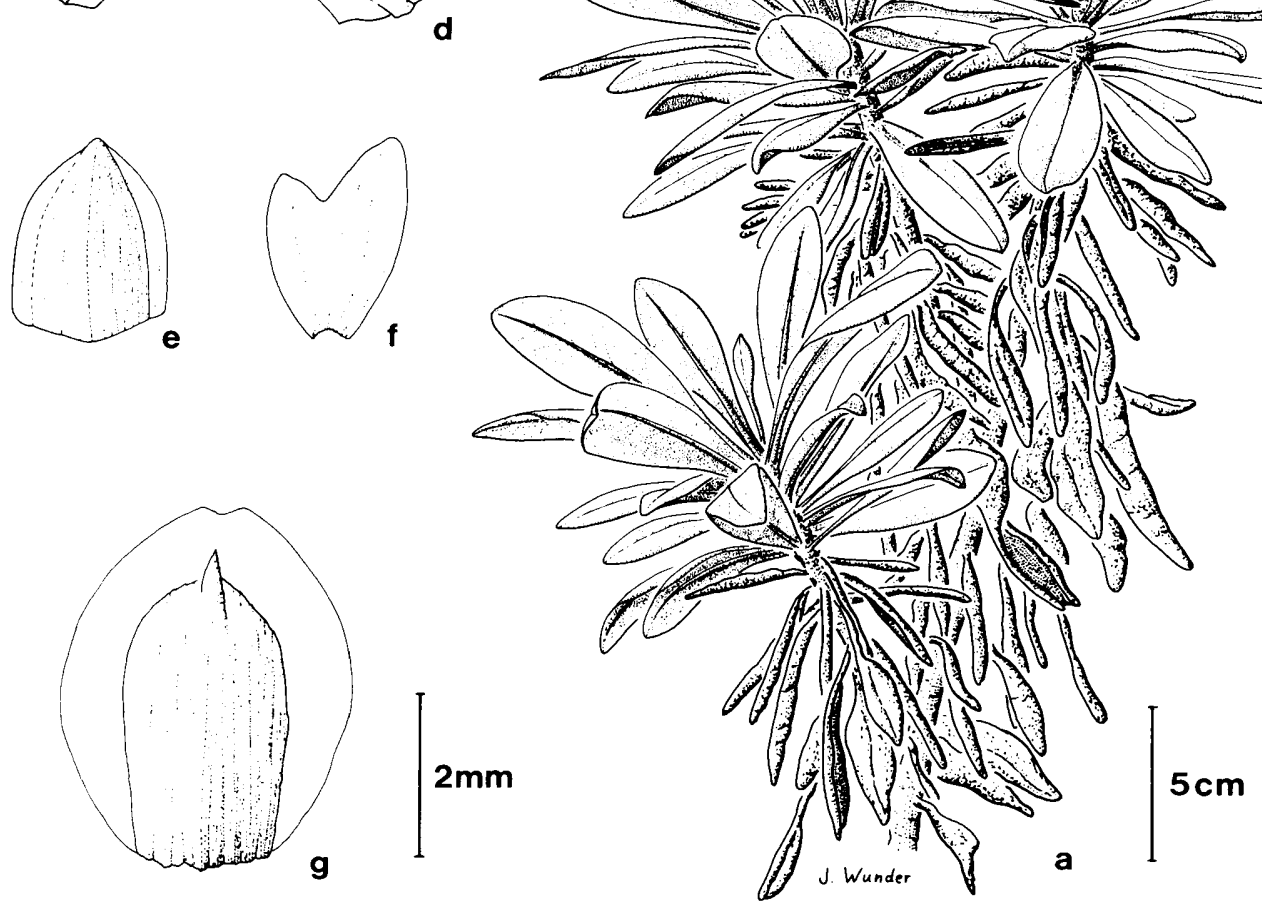

Fig. 154. Limonium sundingii. a. Habit (inflorescence immature); b. Calyx at anthesis; c. Calyx at fruiting time; d. Calyx lobes at anthesis; e. Outer bract; f. Middle bract; g. Inner bract. Drawn by J. Wunder. Reprinted from Lobin et al. (1995), Willdenowia 25 (with permission). 


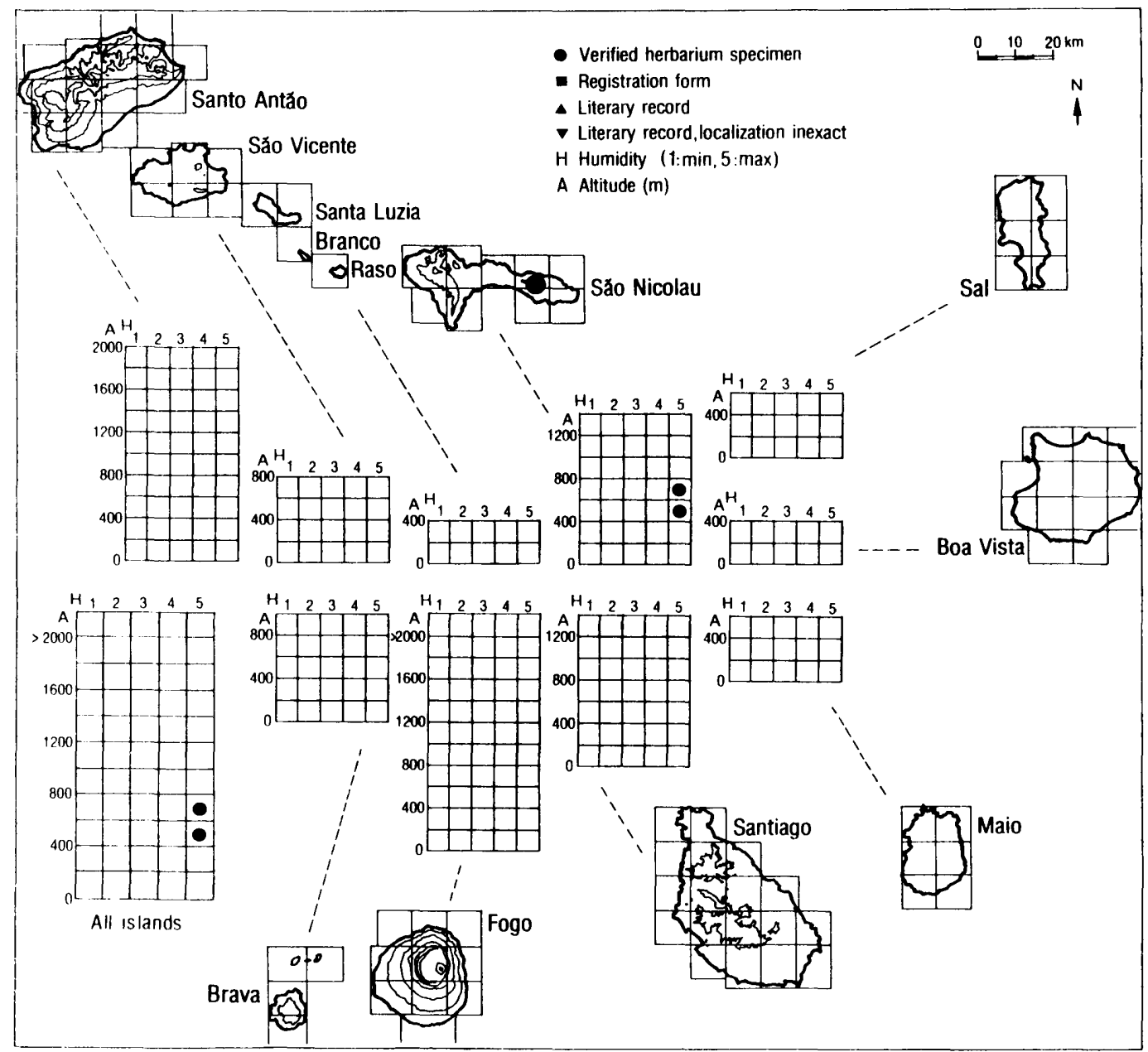

Fig. 155. Ecogeographic distribution of Limonium sundingii.

long and 2.2-2.5 mm wide, triangular-ovate in outline, obtuse, with a broad scarious margin: middle bract 1.9-2.1 long and 1.4-1.8 mm wide, completely scarious: inner bract 4.0-4.8 mm long and 3.3-3.8 mm wide, elliptical, obtuse to rounded, with a broad scarious margin, glabrous, tip of the fleshy middle part not reaching the margin. Calyx at anthesis 4.5-4.9 mm long, fringe almost entire to shallowly sinuate, calyx ribs not reaching the fringe margin, entirely glabrous; in fruiting state calyx destitute of the membranaceous fringe above the ribs, thus only 3.0-3.4 $\mathrm{mm}$ long, its 5 hardened prominent ribs forming 5 small, distinctly spreading teeth, not exceeding the inner bract and thus fruiting inflorescence not fluffy. Corolla purple, petals 5-6 mm long. Fruit a circumscissile, one-seeded capsule enclosed by the calyx. Seeds smooth, brown.

Variation. The material is fairly homogeneous. 

al. 1995).

Chromosome number: $2 \mathrm{n}=12$ (São Nicolau, Alto das Cabaças, 550-650 m, Lobin et

Related taxa: See L. jovi-barba.

Distribution and ecology. Limonium sundingii is a northern hygrophyte confined to the steep, north-facing escarpments of the Alto das Cabaças range on eastern São Nicolau. It grows on terraces in the coastal bluffs at elevations between $550 \mathrm{~m}$ and $700 \mathrm{~m}$. These bluffs are swept by trade wind clouds and situated within the subhumid to humid zones. The vegetation consists of L. sundingii, Euphorbia tuckeyana, Aeonium gorgoneum, Campanula jacobaea, Diplotaxis sundingii, Echium stenosiphon ssp. stenosiphon, Frankenia ericifolia ssp. montana, Lobularia canariensis ssp. spathulata, Nauplius daltonii ssp. vogelii, Tornabenea insularis, and Verbascum capitis-viridis.

Abundance. The distribution area of $L$. sundingii is restricted to a few square $\mathrm{km}$, but the populations are large, comprising several hundreds of individuals. Limonium sundingii is considered to be Rare (R).

\section{SAPOTACEAE}

It is phytogeographically remarkable that this pantropic family of trees is represented in NW Africa and the mid-Atlantic archipelagos by two genera. In the Cape Verde Islands, the Canary Islands, and Madeira, there are two species of Sideroxylon, of which one is endemic to the Cape Verde Islands and the only representative of its family in the archipelago. On the NW African mainland, the family is represented by the monotypic genus Argania, with $A$. spinosa (L.) Skeels.

\section{Sideroxylon L.}

This genus contains some 100 species, mainly trees, which are distributed in the old world tropics (Africa, Madagascar, and Mascarenes). Sideroxylon in the mid-Atlantic archipelagos has usually been treated as a single species with different varieties (e.g., Chevalier 1935, Press \& Short 1994). A current revision of Sideroxylon in the Cape Verde Islands, the Canary Islands, and Madeira (Lobin et al., unpubl. data), revealed, however, that variation in characters such as length of stamens, and size, colour, and shape of flowers and leaves, justifies separation of two species.

Sideroxylon marginata (Figs 156, 157)

Sideroxylon marginata (Decne.) Cout., Arq. Univ. Lisboa 2: 43 (1915) $\equiv$ Sapota marginata Decne. in Hooker, Icon. Pl. 8: ad tab. 761 (1848) ESideroxylon marmulano Lowe var. marginata (Decne.) A. Chev., Rev. Bot. Appl. Agric. Trop. 15: 925 (1935). - Type: In ins. S. Jacobi, ad apicem montis abruptis alt. circiter 2000 ped. vallis S. Dominici protecta, 11.1839, J. D. Hooker 114 (holotype: K!).

= Sideroxylon marmulano Lowe var. edulis A. Chev., Rev. Bot. Appl. Agric. Trop. 15: 926 (1935). --

Type: Fogo, Ferme de Pico Pires, $600 \mathrm{~m}$, Chevalier 45226 (holotype: P, not to be found; isotype: K!).

Illustrations: Decaisne (1848: Fig. 761), Webb (1849: Fig. 13), Gomes et al. (1995b: p. 30). 
Description. Small, evergreen tree, 1-5(-12) m high. Young branches usually with a dense indument of reddish brown hairs, often becoming glabrous with age. Leaves up to $11(-15) \mathrm{cm}$ long and $7 \mathrm{~cm}$ wide, leathery, broadly elliptical to almost roundish or obovate, rarely narrowly elliptical, upper surface dull green, glabrous, lower surface light green, reddish brown pubescent, often becoming glabrous with age; petioles $0.7-3.0 \mathrm{~cm}$ long. Flowers solitary or in clusters of up to 10-12; pedicels shorter than or equalling the petioles; sepals 5, roundish, 0.2$0.45 \mathrm{~cm}$ long, connate in basal third, with overlapping margins above; corolla cup-shaped, reddish to whitish, connate in basal third, 5-lobed above, $0.4 \mathrm{~mm}$ long; staminodes 5 , alternating with corolla lobes, petaloid, narrowly elliptical, whitish; stamens 5, like the staminodes inserted into the corolla tube, equal to or shorter than corolla; gynoecium $0.4 \mathrm{~cm}$ long. Fruit a one-seeded, globose to obovoid, dark brown to blackish berry, up to $1.5 \mathrm{~cm}$ long and $1.4 \mathrm{~cm}$ wide, with persistent style. Seeds $0.9 \mathrm{~cm}$ long and $0.7 \mathrm{~cm}$ wide, brown.

Variation. The species shows considerable variation in size and shape of the leaves. indument, and number of flowers per cluster.

Chromosome number: Unknown.

Related taxa. Sideroxylon marginata is closely related to $S$. marmulano from the Canary Islands and Madeira. Whereas $S$. marginata has anthers that do not exceed the corolla, reddish to whitish flowers, and leaves that usually are broadly elliptical to roundish or obovate (rarely narrowly elliptical), S. marmulano has anthers that exceed the corolla, invariably white flowers, and leaves that usually are narrowly lanceolate to narrowly elliptical (rarely broadly elliptical).

Distribution and ecology. Sideroxylon marginata is a ubiquitous mesophyte, but its extant distribution approaches that of the western hygrophytes. It has been reported from most of the major islands (Santo Antão, São Vicente, São Nicolau, Boa Vista, Santiago, Fogo, and Brava), and also as a subfossil from Sal (Pedra Lume, Chevalier 1935a), but never from Maio. From Boa Vista, it was only reported once in the previous century (Bowdich 1825). The species is mainly found in almost inaccessible, steep cliffs and escarpments between $500 \mathrm{~m}$ and $1200 \mathrm{~m}$ in the semiarid, subhumid, and humid zones, but quite a few trees are also known at lower altitudes. The lowermost records are from $150 \mathrm{~m}$ on northwestern Fogo (leg. Kilian \& Leyens, leg. Leyens), from $150 \mathrm{~m}$ on northern Brava (obs. Leyens, pers. comm.), and from $40 \mathrm{~m}$ at the eastern coast of Santiago (leg. Duarte \& Gomes). The uppermost records are from 1350-1400 m on Fogo (1350 m at Monte Velha, leg. Leyens; $1400 \mathrm{~m}$ SE of the caldeira, obs. Leyens, pers. comm.) and from $1100 \mathrm{~m}$ at Pico da Antonia on Santiago (leg. Lobin). The scattered, extant trees are probably relicts which have survived the extensive cutting of the species. Sideroxylon marginata was earlier much more frequent and widespread in the archipelago (Chevalier 1935a).

Abundance. Sideroxylon marginata is still widely distributed in the archipelago, but everywhere represented by only one or a few, scattered individuals. Although recent search has revealed several new trees, this slow-growing, widely used species is undoubtedly in urgent need of protection. The species is considered Extinct (EX) on Sal and Boa Vista. It is Critically Endangered (CR) on São Vicente, São Nicolau, and Brava, where the species only is known from a single or very few sites, and Endangered (EN) on Santo Antão, Santiago, and Fogo. Sideroxylon marginata is generally considered to be Endangered (EN). 

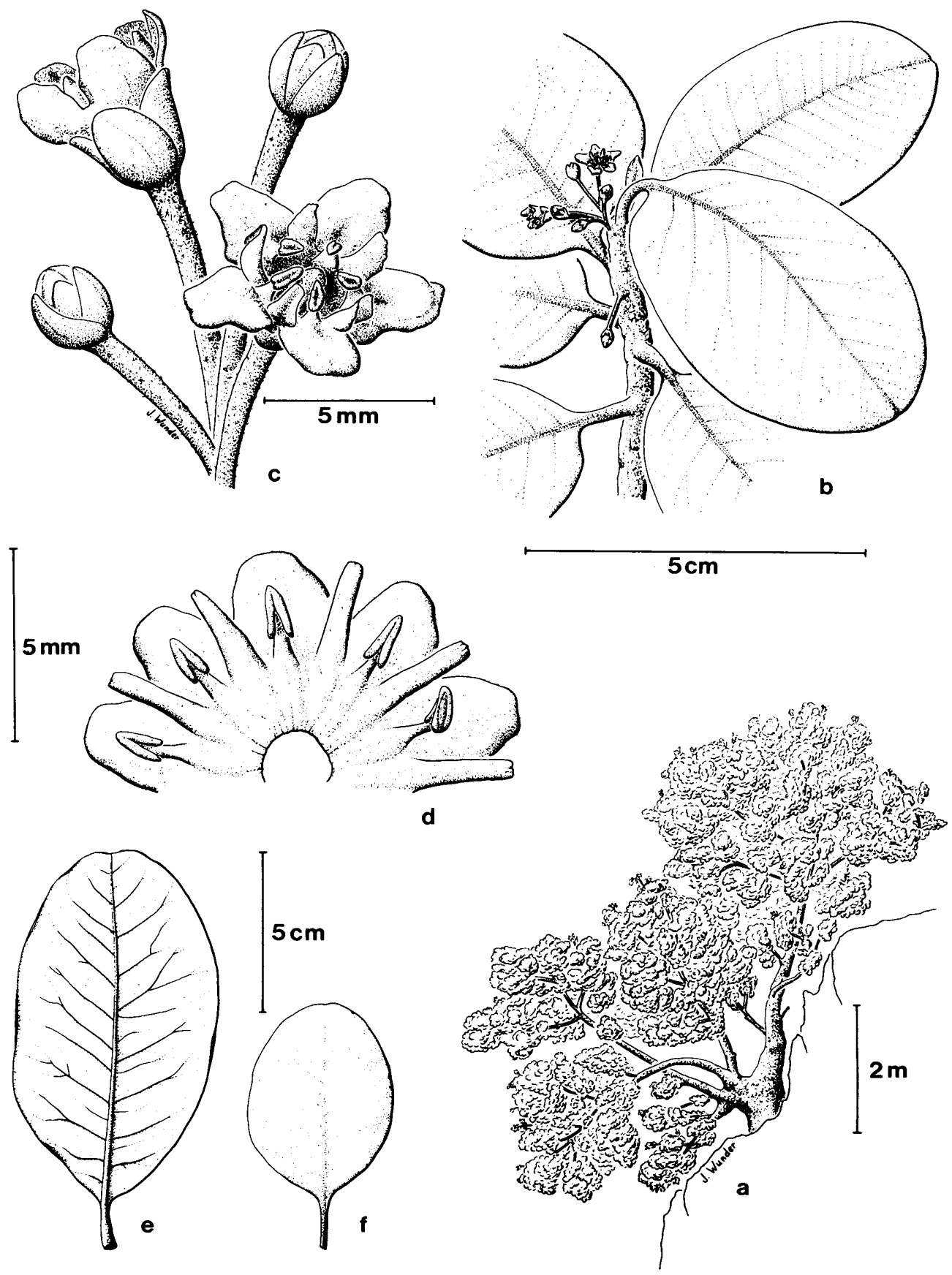

Fig. 156. Sideroxylon marginata. a. Habit; b. Part of stem with leaves and flowers; c. Flowers; d. Petals, stamens, and staminodes; e-f. Leaves. Drawn by J. Wunder. 


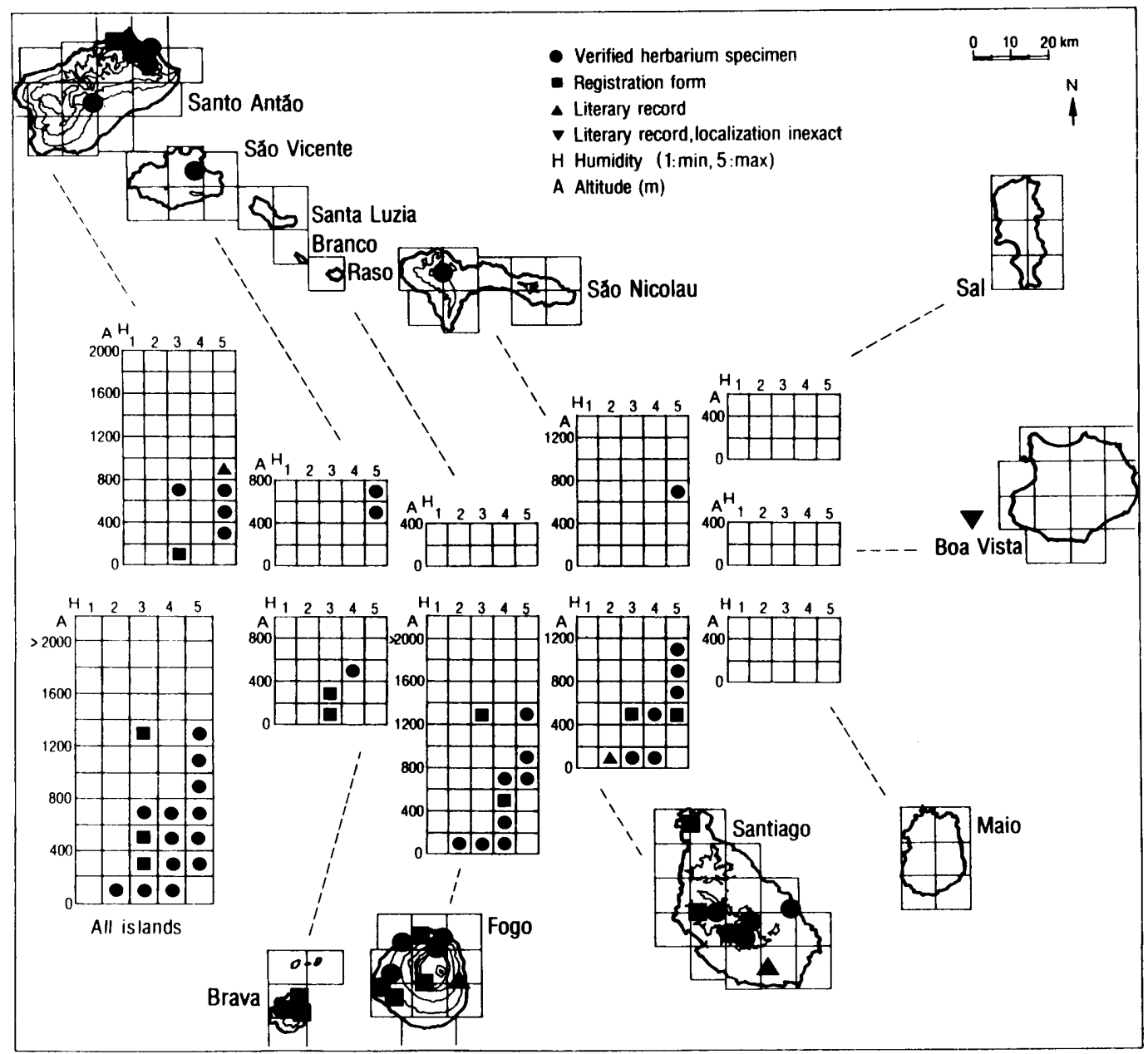

Fig. 157. Ecogeographic distribution of Sideroxylon marginata.

\section{SCROPHULARIACEAE}

This family is represented by 11 genera with 17 species and subspecies. Seven taxa belonging to three genera are endemic. 


\section{Campylanthus Roth}

The genus Campylanthus comprises about ten subshrubby or shrubby species. With the exception of one species endemic to the Canary Islands and one species (with two subspecies) endemic to the Cape Verde Islands, the genus is confined to the Horn of Africa including the Socotra Islands, S Arabia, and S Pakistan.

\section{Campylanthus glaber}

Campylanthus glaber Benth. in DC., Prodr. 10: 508 (1846) $\equiv$ Campylanthus benthamii Webb var. glaber (Benth.) Webb in Hooker, Icon. Pl. 8: ad tab. 776 (1848), nom. illeg. - Syntypes: S. Nicolau, in rupestribus totius montis Gourdo, 30.3.1822, Forbes 9 (FI-W!); ad apicem montis abruptis vallis S. Dominici, ins. S. Jacobi, ad alt. 1200 ad 2000 ped., 6.1839, J. D. Hooker [128] (FI-W!).

Literature: Miller (1980).

Note. The name Campylanthus benthamii Webb is nomenclaturally superfluous and thus illegitimate due to the inclusion of the earlier name $C$. glaber Benth. and its syntypes.

Description. Moderately branched, decumbent or ascending to erect, evergreen shrub up to 1 $\mathrm{m}$ high. Branches puberulent to hirsute, leafy, with persistent leaf bases in older parts. Leaves linear or narrowly oblong to spathulate, (1-)2-5 cm long and (0.05-)0.1-0.9 cm wide, more or less succulent, glabrous to hirsute, apex acute to obtuse, margin entire. Inflorescence a terminal raceme, simple or somewhat branched, puberulent to hirsute. Pedicels filiform. 3-10 $\mathrm{mm}$ long. Calyx lobes linear to triangular, 4-5(-6) $\mathrm{mm}$ long and $0.7-1.5 \mathrm{~mm}$ broad, glabrous to puberulent, margin sometimes ciliate. Corolla bluish pink, pink, or white, funnel-shaped to salveriform, glabrous; tube $6-10 \mathrm{~mm}$ long; lobes elliptical to broadly obovate, $3.5-6 \mathrm{~mm}$ long and 2.5-4 $\mathrm{mm}$ broad. Capsule dark brown to black, shiny, oblong to ovate, laterally compressed, 4-6 mm long and 3.5-4 mm broad, glabrous. Seeds reddish brown with a narrow hyaline wing, globose to subreniform, somewhat compressed, $0.8-1 \mathrm{~mm}$ in diameter.

Variation. Campylanthus glaber is a very variable species. The morphologically most different populations have frequently been recognized as separate species (C. glaber s. str., $C$. benthamii, and C. spathulatus), and several varieties have also been described (see below). Most of the variation is, however, complex and more or less continuous, probably caused by parallel ecoclinal evolution among different islands. In contrast to the situation in Kickxia, no reasonably distinct coastal and montane ecotypes have evolved in Campylanthus, except on Santo Antão. The only populations that can be fairly well distinguished morphologically and ecologically are situated at the northern coasts of this island. These coastal populations are here given subspecific rank as ssp. spathulatus.

Related taxa. Campylanthus glaber is closely related to the Canarian C. salsoloides (L. f.) Roth.

Key to the subspecies of Campylanthus glaber

1 Leaves linear to narrowly oblong, less than $3 \mathrm{~mm}$ wide ............................ ssp. glaber

1 Leaves spathulate, more than $5 \mathrm{~mm}$ wide ssp. spathulatus 

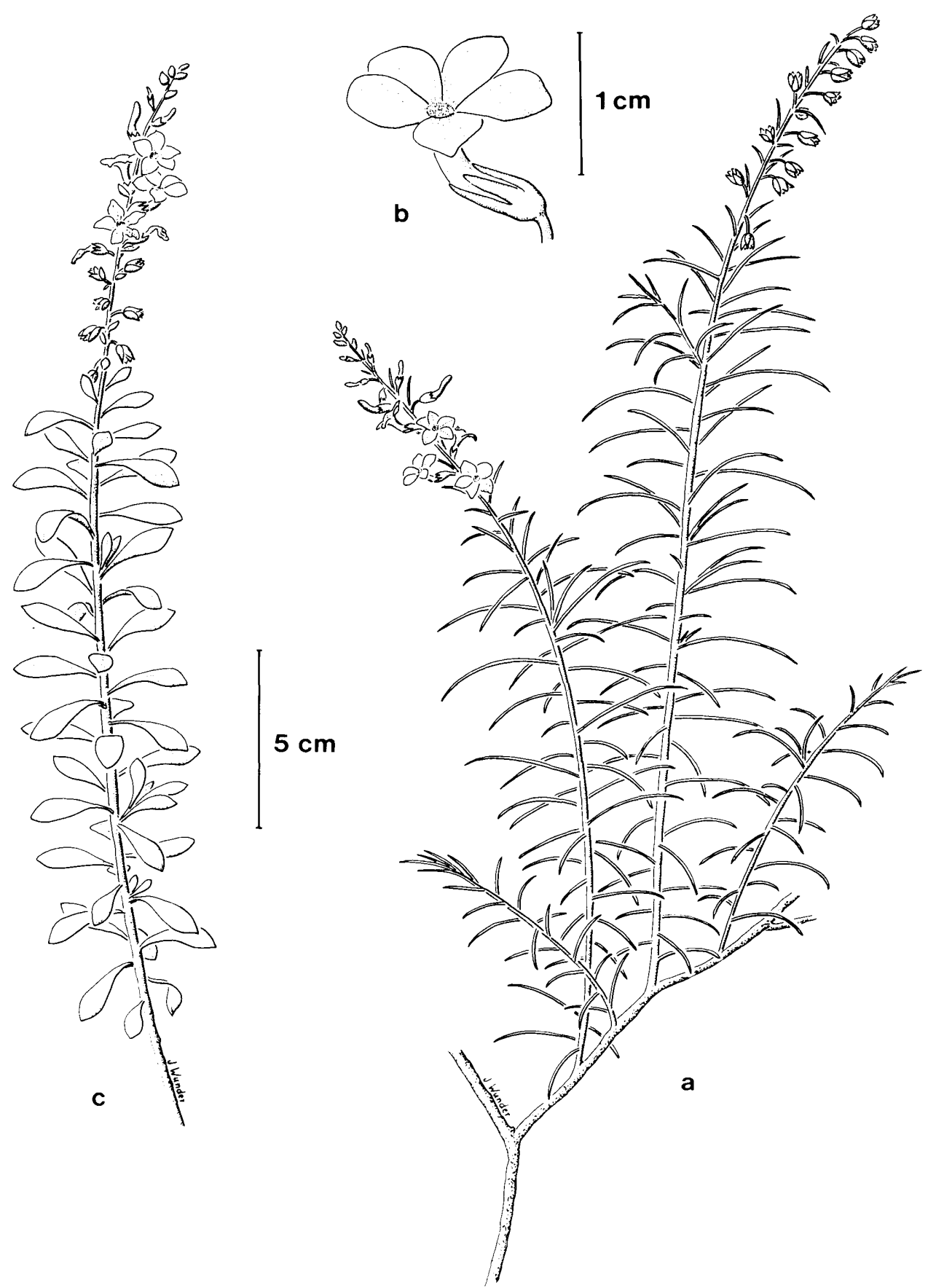

Fig. 158. Campylanthus glaber ssp. glaber and ssp. spathulatus. a-b. ssp. glaber: a. Habit; b. Flower. c. ssp. spathulatus, habit. Drawn by J. Wunder. 


\section{Campylanthus glaber ssp. glaber (Figs 158, 159)}

\section{Campylanthus glaber Benth. ssp. glaber}

= Campylanthus benthamii Webb var. hirsutus Webb in Hooker, Icon. Pl. 8: ad tab. 776 (1848). - Syntypes: S. Nicolau, in rupestribus totius montis Gourdo, 30.3.1822, Forbes 17; in ins. S. Antonii, Vogel 35; in montibus ins. S. Vicentii, ad alt. 800 ped., 6.1841, Vogel 72 (FI-W!) - Lectotype (designated by Lobin 1986b: 102): Vogel 72 (FI-W!).

= Campylanthus glaber Benth. var. pumilus Pett., Comm. Biol. Soc. Scient. Fenn. 22: 43 (1960). Type: S. Nicolau, Monte Gordo, 9.12.1953, H. Lindberg (holotype: H!).

Illustrations: Webb (1848: Fig. 776 sub C. benthamii, 1849: Fig. 16 sub C. benthamii), Lobin (1986b: Fig. 7), Gomes et al. (1995b: p. 25).

Note. When publishing the illegitimate name $C$. benthamii (see note for $C$. glaber) in 1848 , Webb included two varieties, var. glaber and var. hirsutus, under this name and quoted several specimens without explicitly indicating their reference to either of these varieties. In the Niger Flora, already quoted with page and table in the account of 1848 but published in 1849 , Webb referred all specimens to their respective variety, whereas for the binomial C. benthamii, no holotype or syntypes were cited (thus, both varietal names are valid). Recently, Lobin (1986b: 102) designated Vogel 72, which is a syntype of C. benthamii var. hirsutus, as lectotype of $C$. benthamii, but erroneously stated that $C$. benthamii var. hirsutus is homotypic with $C$. glaber.

Description. Decumbent to ascending-erect shrub up to $1 \mathrm{~m}$ high. Leaves linear to narrowly oblong, $0.05-0.2 \mathrm{~cm}$ wide, usually only moderately succulent, pubescence variable. Floral parts usually smaller than in ssp. spathulatus.

Variation. This subspecies is variable in habit, pubescence of all parts, as well as in size of the calyx and corolla. Even in large individuals, the branches are rarely entirely erect. Completely decumbent plants are typical of strongly wind-exposed habitats such as rocky ridges. The pubescence may vary conspicuously even within individual plants. Young shoots may be densely hirsute, but these shoots may later form new branches that are almost glabrous with almost glabrous leaves. On Santo Antão, there are scattered populations which are intermediate between the two subspecies in habit, succulence, leaf shape, leaf size, and flower size.

Chromosome number: $2 \mathrm{n}=14$ (São Nicolau, first foothill $\mathrm{E}$ of Monte Gordo, ridge, $1050 \mathrm{~m}$, Gomes et al. 1995a).

Distribution and ecology. Campylanthus glaber ssp. glaber is a western mesophyte occurring on all of the major western islands (Santo Antão, São Vicente, São Nicolau, Santiago, Fogo, and Brava). It is equally frequent in the semiarid and subhumid zones, less common in the humid zone, and it only occasionally occurs in the arid zone. The main altitudinal distribution is between $200 \mathrm{~m}$ and $1500 \mathrm{~m}$. The subspecies occurs down to sea-level on some islands and extends to $1550 \mathrm{~m}$ on Fogo (leg. Rustan \& Brochmann) and to $1500 \mathrm{~m}$ on Santo Antão (leg. Kilian). The plants usually grow in rocky or gravelly habitats. On Santo Antão, ssp. glaber is confined to montane, usually subhumid areas above $600 \mathrm{~m}$, and it is replaced by ssp. spathulatus in the semiarid coastal region. Morphologically intermediate populations (Fig. 161) are found between $200 \mathrm{~m}$ and $600 \mathrm{~m}$ at the transition between the semiarid and subhumid zones in the large valleys. In a few areas, e.g., the Morossos area on Santo Antão, C. glaber ssp. glaber still forms a dense scrub vegetation together with Nauplius daltonii ssp. vogelii, Conyza feae, Helianthemum gorgoneum, and Artemisia gorgonum, a vegetation type which is largely destroyed in other areas. 


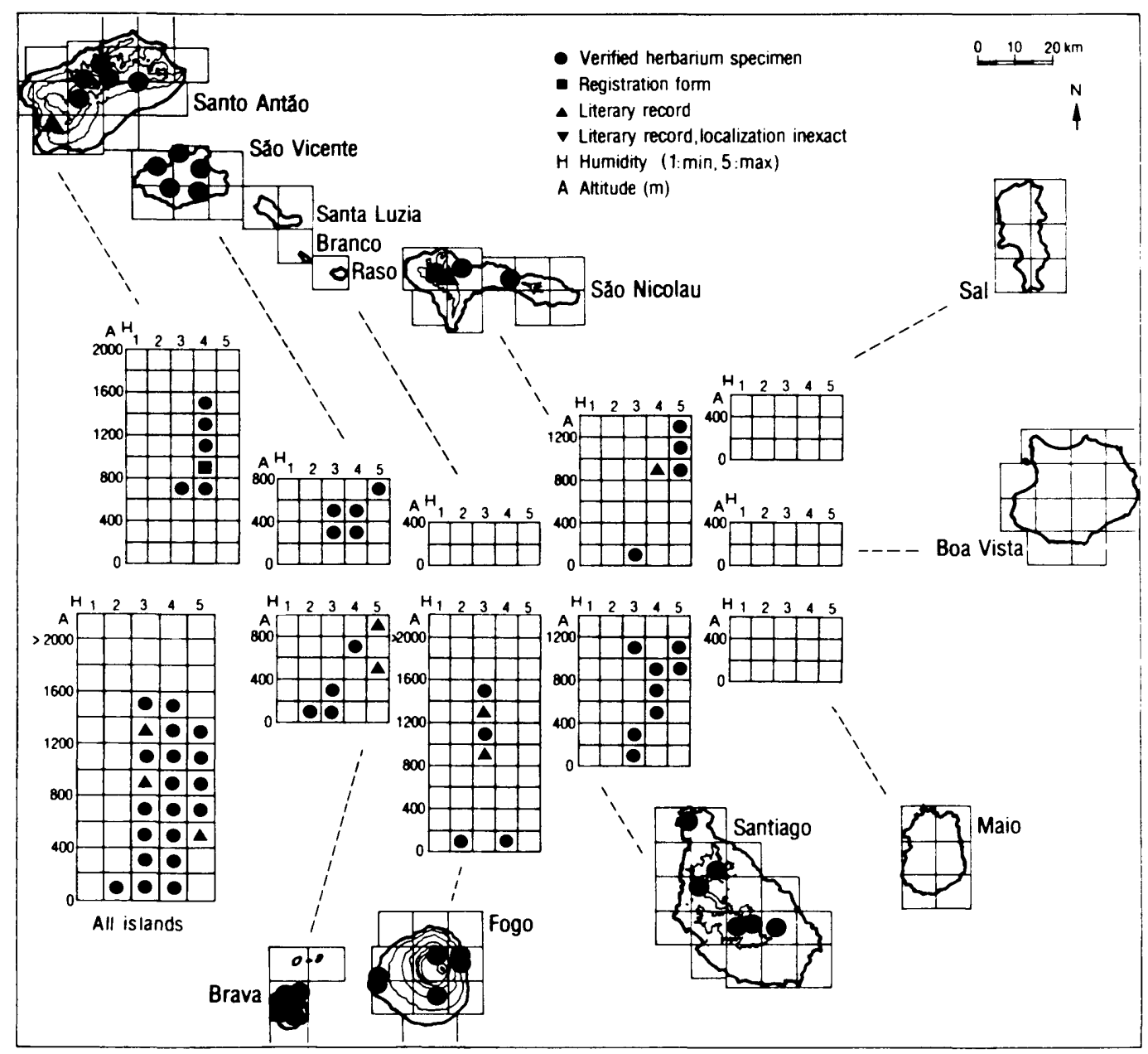

Fig. 159. Ecogeographic distribution of Campylanthus glaber ssp. glaber.

Abundance. Campylanthus glaber ssp. glaber was formerly widely distributed on several of the islands. Today, the subspecies has a scattered distribution, and many populations are small and probably continuously declining because of habitat destruction. It is therefore considered Endangered (EN) on São Vicente and Santiago, the most seriously destructed islands, and Vulnerable (VU) on the other islands. Campylanthus glaber ssp. glaber is generally considered to be Vulnerable (VU).

Note. A record from Ponta do Sol on Santo Antão (Sventenius 1971) is excluded because of apparent confusion with ssp. spathulatus. 


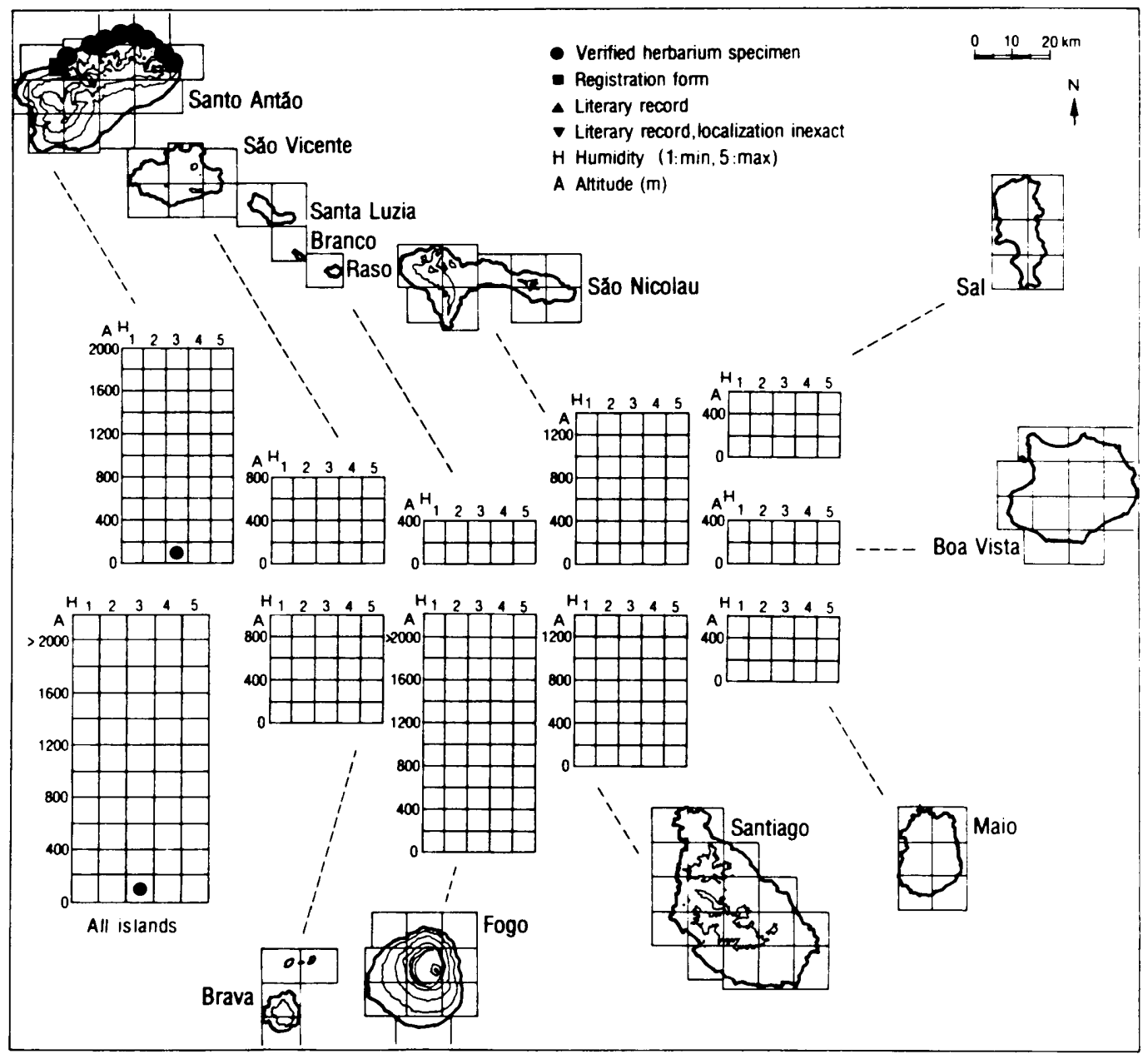

Fig. 160. Ecogeographic distribution of Campylanthus glaber ssp. spathulatus.

Campylanthus glaber ssp. spathulatus (Figs 158, 160)

Campylanthus glaber Benth. ssp. spathulatus (A. Chev.) Brochmann, N. Kilian, Lobin \& Rustan, comb. et stat. nov. $\equiv$ Campylanthus spathulatus A. Chev., Rev. Bot. Appl. Agric. Trop. 15: 897 (1935). - Type: Santo Antão, falaises suitantes et éboulis au bord de la mer, entre Pombas et Janela, 9.1934, Chevalier 45278 (holotype: P).

= Campylanthus glaber Benth. var. puberulus Cout., Arq. Univ. Lisboa 1: 310 (1914). - Type: Itha de Santo Antão, 4.-5.1894, Cardoso (holotype: LISU!).

Illustrations: Chevalier (1935a: Tab. 14 sub C. spathulatus), Lobin (1986b: Figs 6, 8 sub C. spathulatus), Gomes et al. (1995b: p. 25). 


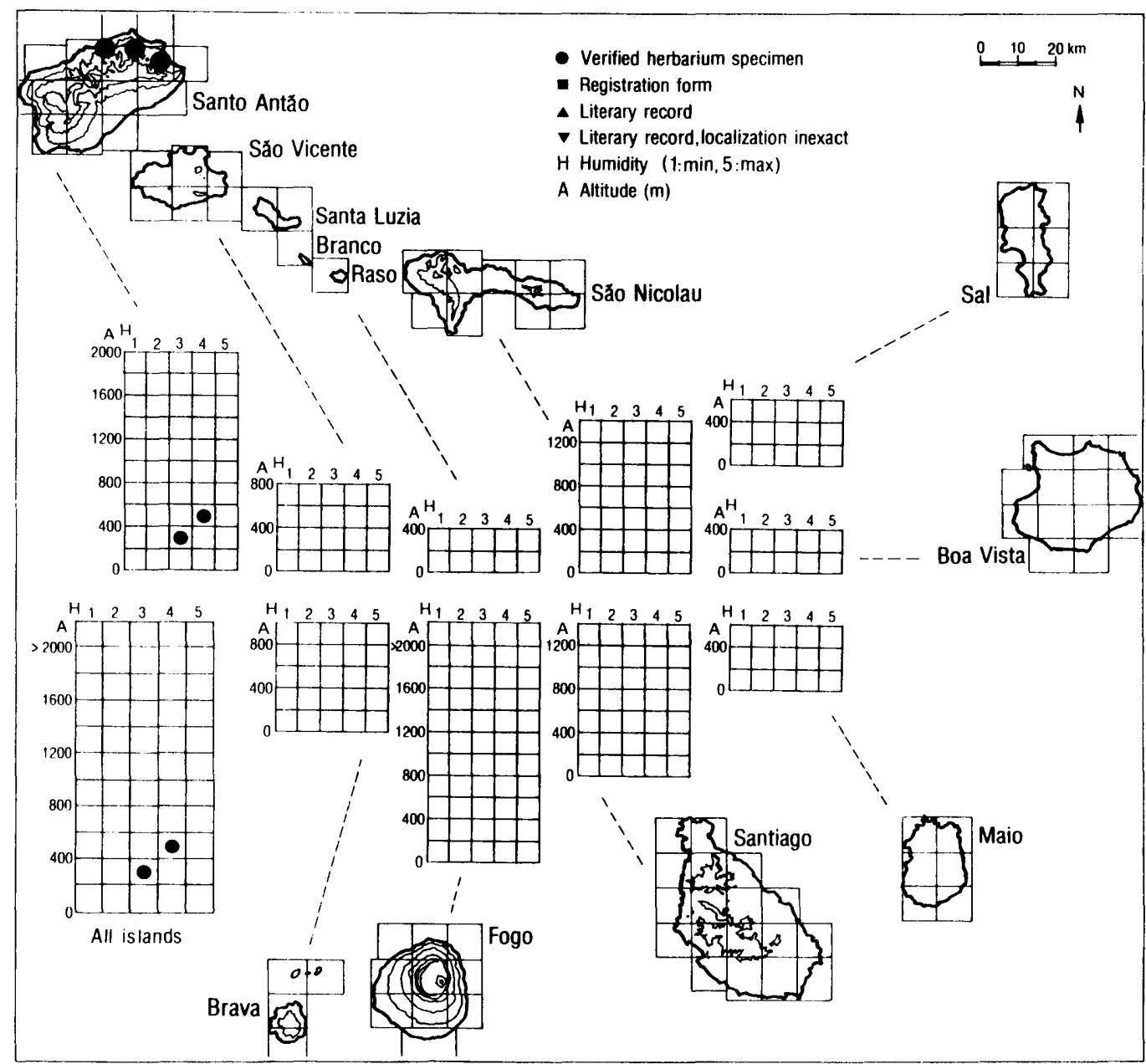

Fig. 161. Ecogeographic distribution of intermediates between Campylanthus glaber ssp. glaber and ssp. spathulatus.

Description. Shrub, usually decumbent to ascending. Leaves spathulate, $0.5-0.9 \mathrm{~cm}$ wide, strongly succulent, puberulent. Floral parts large; corolla tube $8-10 \mathrm{~mm}$ long, lobes up to 6 $\mathrm{mm}$ long.

Variation. In its most typical form, this subspecies appears conspicuously different from ssp. glaber because of its wider leaves. In addition, the leaves are more succulent and the flowers larger than in ssp. glaber, but this is valid only for the populations of ssp. glaber on Santo Antão. See also ssp. glaber.

Chromosome number: $2 \mathrm{n}=14$ (Santo Antão, E of Ribeira Grande, Bramwell \& Murray 1972, Bramwell et al. 1972). 
Distribution and ecology. Campylanthus glaber ssp. spathulatus is a northern mesophyte confined to the semiarid, steep, rocky northern coast of Santo Antão. The plants grow in maritime cliffs and gravelly slopes between $10 \mathrm{~m}$ and $130 \mathrm{~m}$ (see also ssp. glaher).

Abundance. The subspecies is fairly common within most of its small distribution area. We have observed several very large populations, e.g., between Cruzinhas and Janela. Campylanthus glaber ssp. spathulatus is considered to be Lower Risk (LR).

\section{Kickxia Dumort.}

The genus Kickxia comprises 46 species of annuals, perennial herbs, and dwarf shrubs distributed in the mid-Atlantic archipelagos, N Africa, Europe, and Asia. The genus is widely distributed in the Cape Verde Islands, and four endemic species were recognized in a recent revision of the entire genus (Sutton 1988). In a revision of the Capeverdean taxa. Rustan \& Brochmann (1988) suggested, however, that Kickxia in the Cape Verde Islands is more appropriately treated as a single species with three subspecies, and this treatment is followed here.

Literature: Rustan \& Brochmann (1988), Sutton (1988).

\section{Kickxia elegans}

Kickxia elegans (G. Forst.) D. A. Sutton, Rev. Antirrhineae: 211 (1988) झAntirrhinum elegans G. Forst., Comm. Soc. Regiae Sci. Gott. 9: 60 (1787). - Type (designated by Sutton 1988: 212): [Santiago], "ad portum, Praya dictum in Sti. Iacobi insula", 8.1772, Forster (holotype: K).

$=$ Linaria brunneri Benth. in DC., Prodr. 10: $270(1846) \equiv$ Linaria brunneri Benth. var. vera Webb in Hooker, Niger Fl.: 166 (1849), nom. illeg. 三 Elatinoides brunneri (Benth.) Wettst. in Engler \& Prantl, Nat. Pflanzenfam. 4(3b): 58 (1891) $\equiv$ Kickxia brunneri (Benth.) Janch., Österr. Bot. Z. 82: 152 (1933) $\equiv$ Nanorrhinum brunneri (Benth.) Betsche, Cour. Forsch.-Inst. Senckenberg 71: 132 (1984). - Syntypes: [vulgaris praesertim in rupibus ins. S. Jacobi, see Webb 1849: 166]. - Lectotype (designated by Sutton 1988: 214): "Senegambia, 1840", Brunner ex herb. Hooker (K).

Note. Sutton (1988) showed that the correct name of this Capeverdean species is $K$. elegans, not $K$. brunneri, which previously has been used (e.g., by Rustan \& Brochmann 1988). The confusion of names has been caused by mixing of herbarium labels of material from Madeira and the Cape Verde Islands (Sutton 1988).

Description. Moderately branched, procumbent subshrub up to $0.4 \mathrm{~m}$ long. Branches glabrous or with puberulent, pubescent, or whitish tomentose indument. Leaves very variable; reniform, elliptical, oblong, ovate-lanceolate, or rhomboid; glabrous, pubescent, or whitish tomentose; base subcordate to cordate; apex apiculate, acuminate to rounded; margin entire to irregularly dentate. Hairs usually eglandular, sometimes glandular. Flowers solitary, axillary, pedicellate. Calyx lobes linear-lanceolate to oblong-lanceolate. Corolla yellow, upper lobe sometimes violet or with violet margin. Capsule globose to ovate, as long as calyx or slightly longer. Seeds dark brown, oblong to globose, 0.2-0.5 mm long, tuberculate, 20-60 per capsule.

Variation. Kickxia elegans is a very variable species, and the variation is more or less continuous along complex and parallel ecogeographic gradients. The extremes of this morphological variation have frequently been regarded as separate species, which have been recognized based on sparse material. Based on the patterns of morphological and ecological variation, it is more reasonable to recognize three subspecies of a single, variable species, 
although populations that are morphologically intermediate between two of these subspecies occur on several islands. The subspecies represent ecotypes, which partly are bridged by ecoclinal variation: ssp. elegans is a coastal, xerophytic ecotype, ssp. dichondrifolia is a montane, hygrophytic ecotype, and ssp. webbiana is a mesophytic valley ecotype. Subspecies dichondrifolia has probably evolved independently on different islands from xerophytic elegans-like ancestors (see also Rustan \& Brochmann 1988).

The main difference between the revisions of Sutton (1988) and Rustan \& Brochmann (1988) is that Sutton divided our ssp. elegans (as ssp. brunneri in Rustan \& Brochmann 1988) into one southern species ( $K$. elegans) and one northern species ( $K$. glaberrima). Sutton (1988) did not, however, justify this by providing new distinguishing characters, and the characters provided in the key are not consistent with those given in the descriptions of the species.

Related taxa. The Capeverdean taxa belong to section Valvatae (Wettst.) Janchen, a complex section containing at least 36 species distributed from the mid-Atlantic archipelagos to the Indian subcontinent (Sutton 1988). Two groups of species were recognized within the section by Sutton (1988), which may suggest that there are no particularly close relationships between the Canarian and Capeverdean endemics in Kickxia: (1) species with short corolla tubes, including the Canarian endemics as well as S Arabian and E African species; and (2) species with longer corolla tubes, including the Capeverdean endemics as well as species from eastern NE Africa, E Africa, and Arabia.

Key to the subspecies of Kickxia elegans

1 Stem rigid; leaf indument whitish tomentose to pubescent, leaf margin usually with large. irregular teeth; seeds minutely tuberculate..............................................ssp. dichondrifolia

1 Stem thin and lax; leaves glabrous or with puberulent to pubescent indument, leaf margin usually entire; seeds strongly or minutely tuberculate ....................................................

2 (1) Seeds strongly tuberculate; petiole short; leaves oblong to ovate-lanceolate ssp. elegans

2 Seeds minutely tuberculate; petiole long; leaves reniform to ovate ssp. webbiana

Kickxia elegans ssp. elegans (Figs 162, 163)

Kickxia elegans (G. Forst.) D. A. Sutton ssp. elegans

$=$ Linaria brunneri Benth. var. glaberrima J. A. Schmidt, Beitr. Fl. Cap Verd. Ins.: 242 (1852) $\equiv$ Kickxia brunneri (Benth.) Janch. var. glaberrima (J. A. Schmidt) Sunding, Garcia de Orta, Sér. Bot. 2: 21 (1974) $\equiv$ Kickxia glaberrima (J. A. Schmidt) D. A. Sutton, Rev. Antirrhineae: 215 (1988). - Type: S. Vicente, 1851, J. A. Schmidt (holotype: HBG).

$=$ Linaria brunneri Benth. var. parietariffolia Webb in Hooker, Niger Fl.: 166 (1849) $\equiv$ Elatinoides

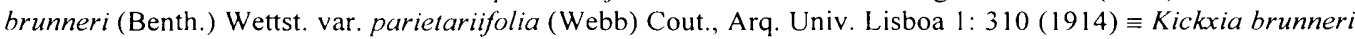
(Benth.) Janch. var. parietariffolia (Webb) A. Hansen \& Sunding, Fl. Macaronesia Checklist, ed. 2, 1: 92 (1979). - Type: Not designated (see also Lobin 1986b: 123 and Sutton 1988: microfiche p. 125).

Illustrations: Wawra (1866: Fig. 65 sub Linaria brunneri), Rustan \& Brochmann (1988: Fig. I sub $K$. brunneri ssp. brunneri), Sutton (1988: Figs 54.1-2 sub K. elegans, 54.5-6 sub $K$. glaberrima). 


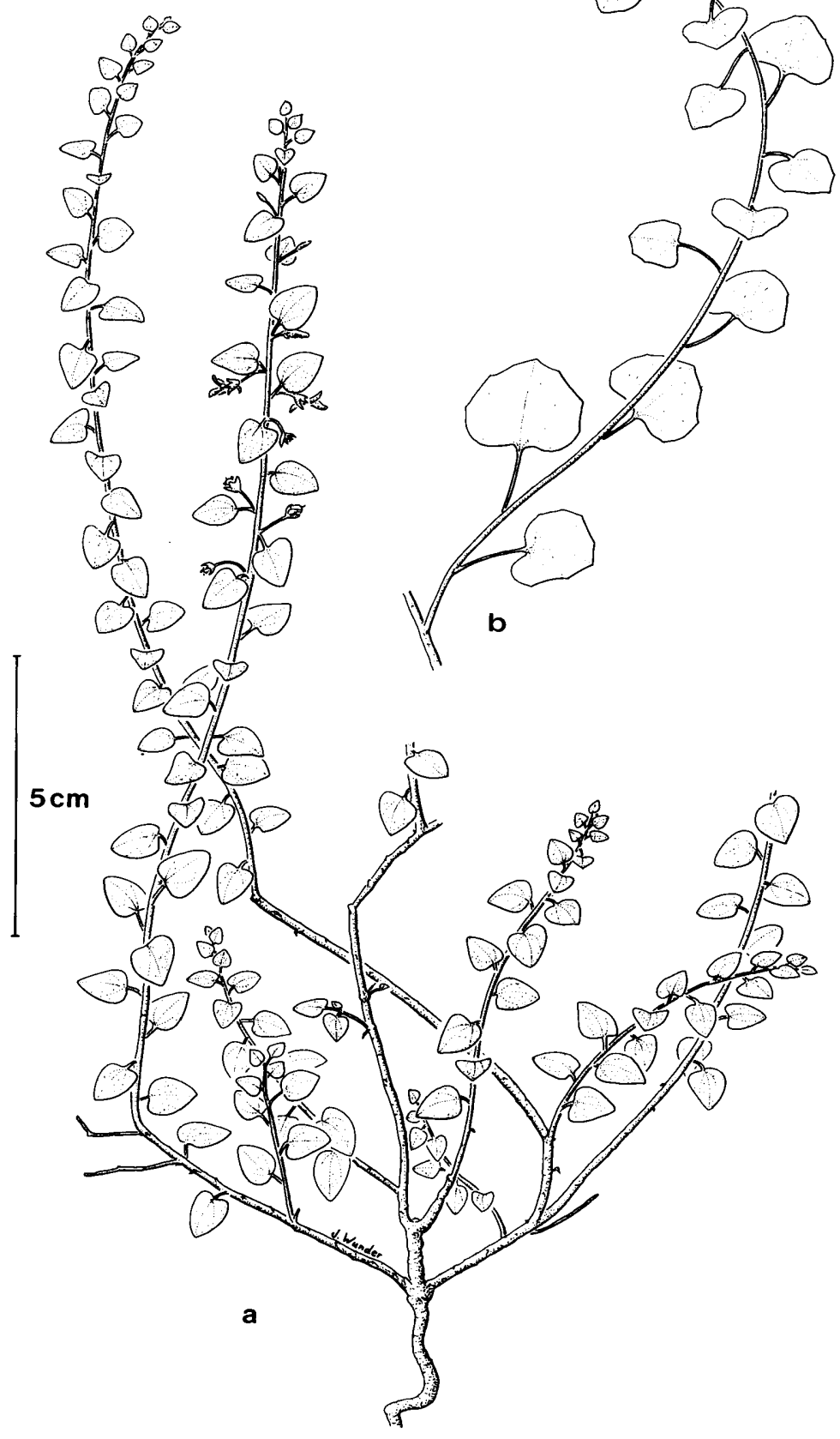

Fig. 162. Kickxia elegans ssp. elegans (a) and ssp. webbiana (b). Drawn by J. Wunder. 


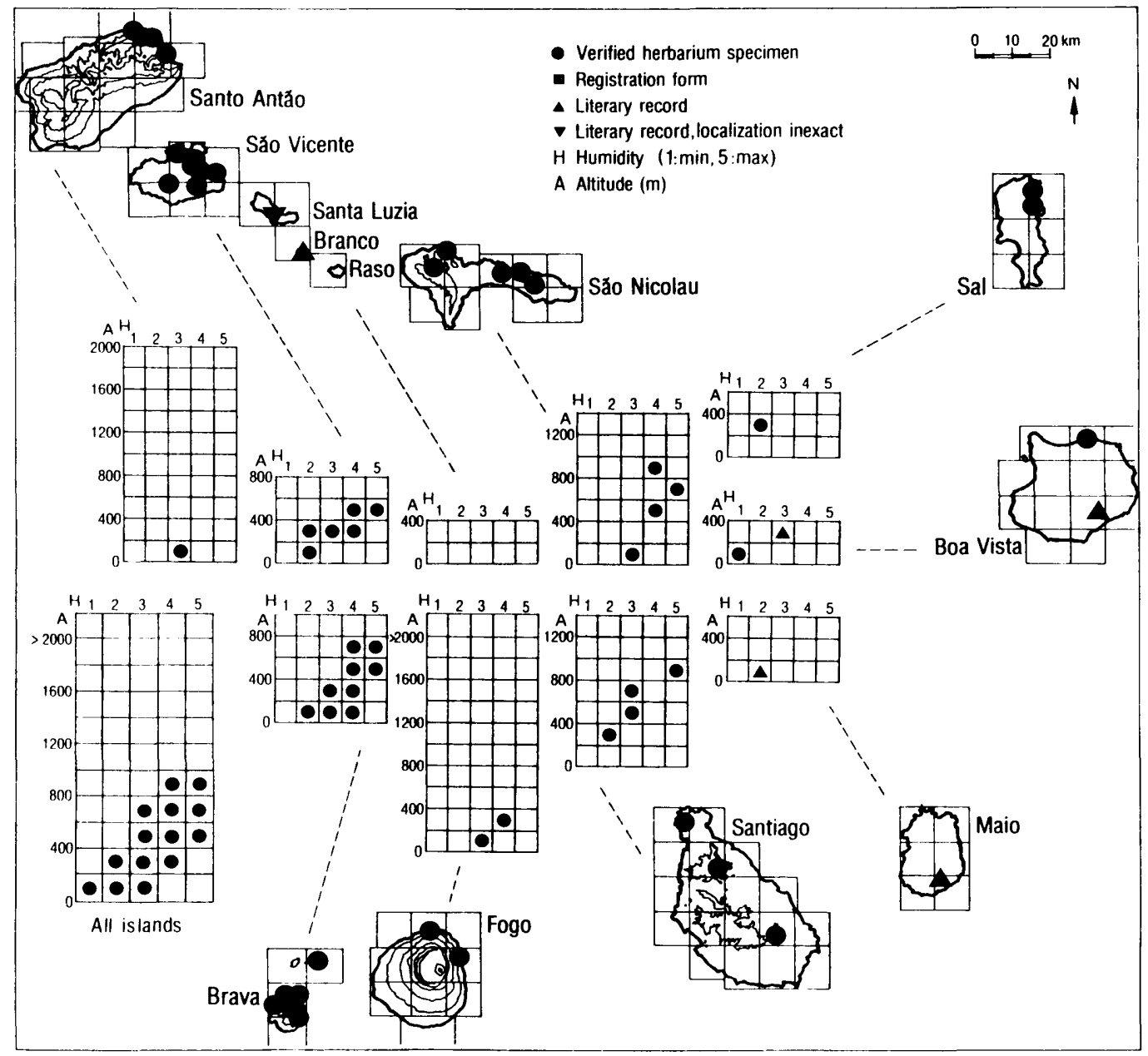

Fig. 163. Ecogeographic distribution of Kickxia elegans ssp. elegans.

Description. Stem thin and lax, glabrous or with puberulent to pubescent indument. Leaf petiole short; lamina usually dark green, oblong to ovate-lanceolate, small, glabrous to pubescent, sometimes succulent, margin usually entire. Seeds strongly tuberculate.

Variation. Material from all islands except Santa Luzia, Branco, Boa Vista, and Maio was examined. The subspecies is variable in leaf shape, indument, and size of all parts. The morphological variation within this subspecies is associated with local ecological factors such as exposition and humidity. Coastal, exposed populations have light green, succulent leaves, whereas populations in adjacent, non-exposed sites have dark green. non-succulent leaves. The populations that are morphologically and ecologically intermediate between ssp. elegans and ssp. dichondrifolia (Fig. 164) usually resemble ssp. dichondrifolia in habit, but the indument is less developed and the seeds are strongly tuberculate as in ssp. elegans. 


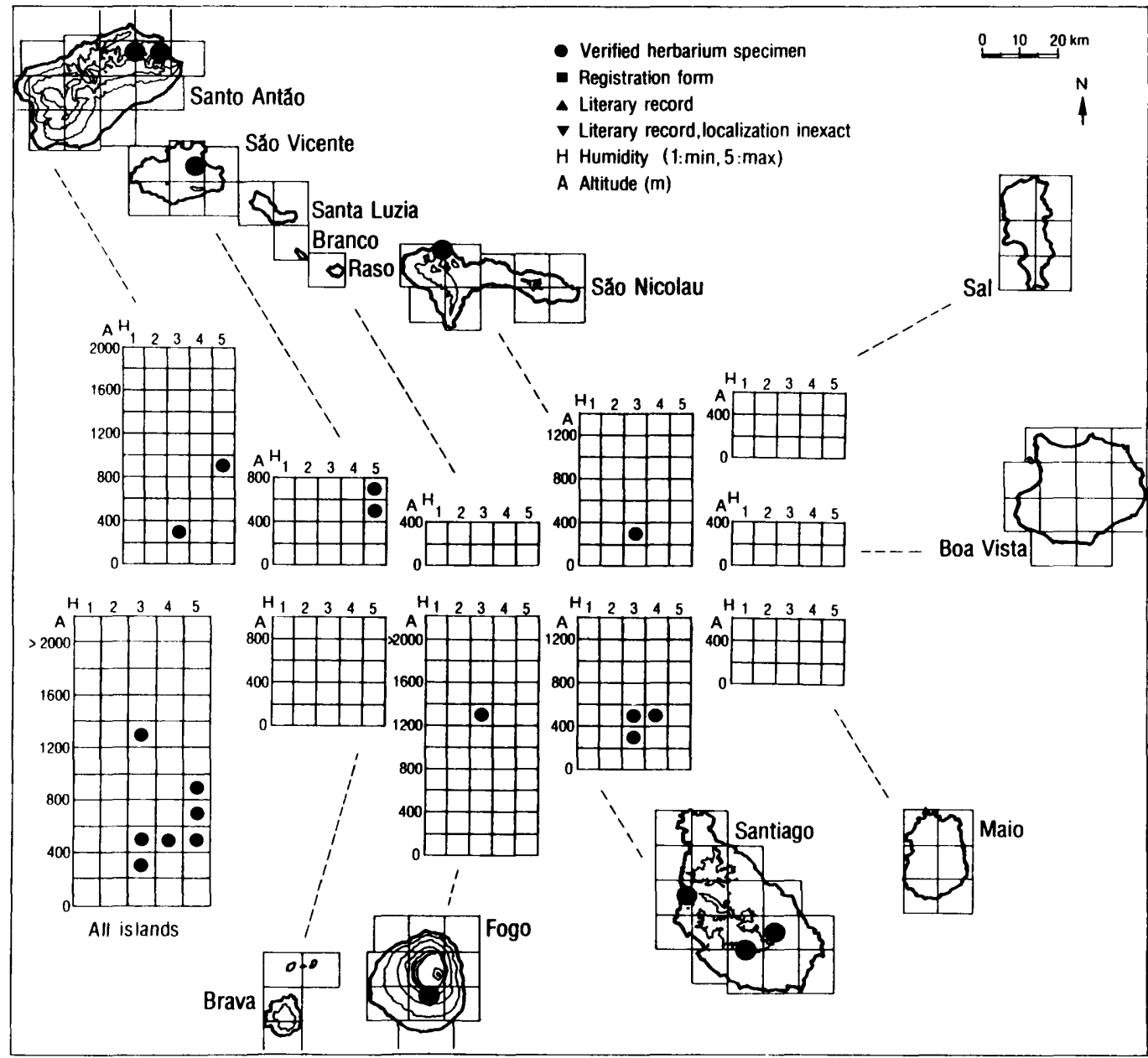

Fig. 164. Ecogeographic distribution of intermediates between Kickxia elegans ssp. elegans and ssp. dichondrifolia.

Chromosome number: $2 \mathrm{n}=18(2 \mathrm{n}=18$, São Vicente, Monte Verde, $200 \mathrm{~m}$, Borgen 1980 (as K. brunneri); 2n =18, Santo Antão, coast between Paul and Ribeira Janela, Zizka 1986 (as K. brunneri var. parietariifolia)).

Distribution and ecology. Kickxia elegans ssp. elegans is a ubiquitous xerophyte occurring on all of the main islands: Santo Antão, São Vicente, Santa Luzia (including the islet of Branco), São Nicolau, Sal, Boa Vista, Maio, Santiago, Fogo, and Brava (including the islet of Cima). It is mainly distributed in the arid and semiarid zones, but it also occurs in several sites in the subhumid and humid zones. The main altitudinal distribution is between sea-level and $600 \mathrm{~m}$, but the subspecies extends to $950 \mathrm{~m}$ on São Nicolau (Rustan \& Brochmann 1988). The plants grow in cliffs, crevices, and gravelly slopes. The populations 
that are transitional between ssp. elegans and ssp. dichondrifolia occur on most of the western islands at intermediate altitudes and humidity (see also ssp. dichondrifolia).

Abundance. The subspecies is common on several islands, but it is Vulnerable (VU) on the heavily grazed islands of Boa Vista and Maio. Kickxia elegans ssp. elegans is generally considered to be Lower Risk (LR).

Note. The maps are based on revised material except for Santa Luzia, Branco, and Maio. Béguinot's (1918) report of ssp. webbiana from Boa Vista probably refers to ssp. elegans.

Kickxia elegans ssp. dichondrifolia (Figs 165, 166)

Kickxia elegans (G. Forst.) D. A. Sutton ssp. dichondrifolia (Benth.) Rustan \& Brochmann, comb. nov. $\equiv$ Linaria dichondrifolia Benth. in DC., Prodr. 10: 270 (1846) E Elatinoides dichondrifolia (Benth.) Wettst. in Engler \& Prantl, Nat. Pflanzenfam. 4(3b): 58 (1891) 三 Kickxia dichondrifolia (Benth.) Janch., Österr. Bot. Z. 82: 152 (1933) $\equiv$ Nanorrhinum dichondrifolium (Benth.) Betsche, Cour. Forsch.-Inst. Senckenberg $71: 132(1984) \equiv$ Kickxia brunneri (Benth.) Janch. ssp. dichondrifolia (Benth.) Rustan \& Brochmann, Cour. Forsch.-Inst. Senckenberg 105: 70 (1988). — Type: Ins. S. Nicolau, in declivibus umbrosis, 27.3.1822, Forbes 16. Lectotype (designated by Sutton 1988: 214): S. Nicolau, Forbes, ex herb. Hooker (K).

Illustrations: Rustan \& Brochmann (1988: Fig. 2 sub K. brunneri ssp. dichondrifolia), Sutton (1988: Figs 54.3-4 sub $K$. dichondrifolia).

Description. Stem rigid, distinctly thicker than branches, densely puberulate to whitish tomentose. Leaf petiole short; lamina elliptical to rhomboid, size intermediate; whitish tomentose, becoming densely puberulate; margin usually with one to several large irregular teeth, rarely entire. Seeds minutely tuberculate.

Variation. This subspecies is variable in leaf shape, indument, and size of all parts. The colour of the upper corolla lobe varies from yellow to completely violet, also within populations (see also ssp. elegans).

Chromosome number: $2 \mathrm{n}=18(2 \mathrm{n}=18$, Santo Antão, Lombo Cebide Vila, $\mathrm{S}$ of Ribeira Grande, 920 m, Borgen 1975; n =9, without locality, Ortega \& Navarro 1977).

Distribution and ecology. Kickxia elegans ssp. dichondrifolia is a western hygrophyte occurring on Santo Antão, São Vicente, São Nicolau, and Santiago. It is equally frequent in the subhumid and humid zones, and it has been reported once from the semiarid zone (Santo Antão). The main altitudinal distribution is between $800 \mathrm{~m}$ and $1600 \mathrm{~m}$. The lowermost record is at $450 \mathrm{~m}$ on Santo Antão and the uppermost one at $1700 \mathrm{~m}$ on the same island (Rustan \& Brochmann 1988). Subspecies dichondrifolia replaces ssp. elegans in montane, humid parts of the islands.

Abundance. Kickxia elegans ssp. dichondrifolia is common or at least scattered on all recorded islands, and it is considered to be Lower Risk (LR).

Note. The map is based on revised material only. Chevalier's (1935a) reports from Fogo are omitted, because they may refer to transitions towards ssp. elegans. 


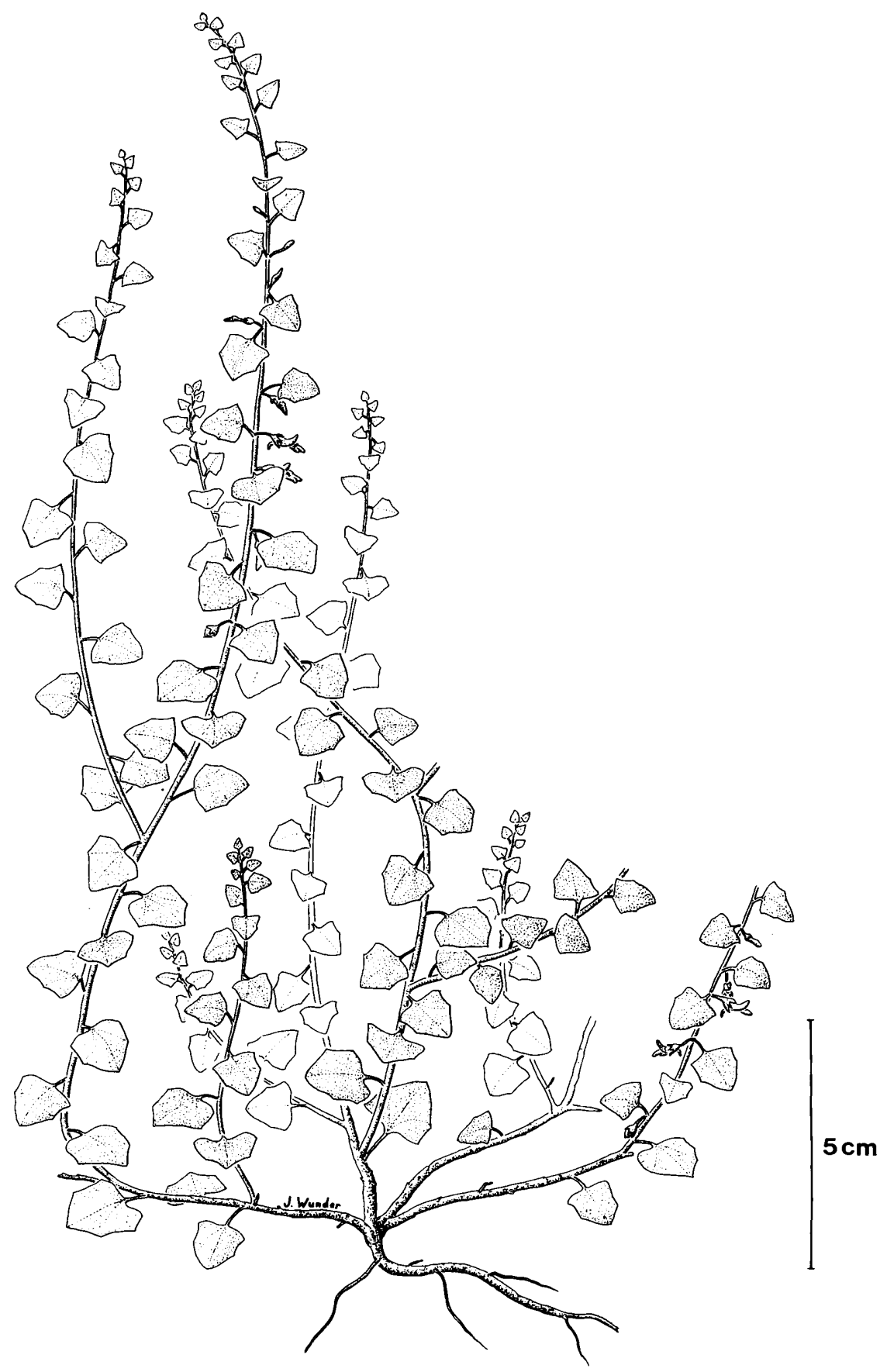

Fig. 165. Kickxia elegans ssp. dichondrifolia. Drawn by J. Wunder. 


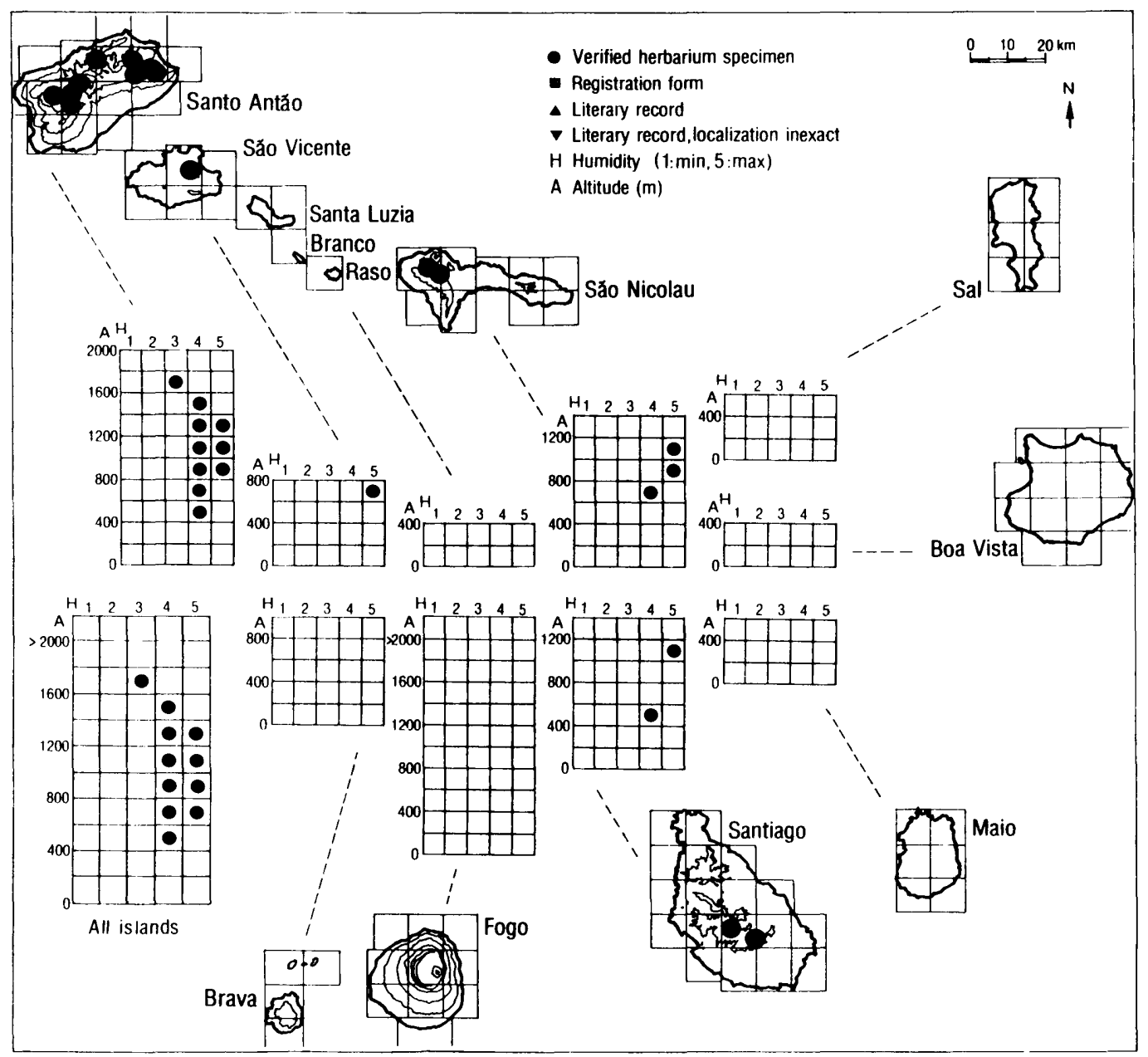

Fig. 166. Ecogeographic distribution of Kickxia elegans ssp. dichondrifolia.

Kickxia elegans ssp. webbiana (Figs 162, 167)

Kickxia elegans (G. Forst.) D. A. Sutton ssp. webbiana (Sunding) Rustan \& Brochmann, comb. nov. $\equiv$ Kickxia webbiana Sunding ["(J. A. Schmidt) Sunding"], Garcia de Orta, Sér. Bot. 2: 21 (1974) ELinaria webhiana J. A. Schmidt, Beitr. Fl. Cap Verd. Ins.: 240 (1852) non Vis. (1844), nom. illeg. E Kickxia schmidtii A. Hansen \& Sunding, Fl. Macaronesia Checklist, 2, ed. 2: iv (1979), nom. illeg. $\equiv$ Nanorrhinum webbianum (Sunding) Betsche ["(J. A. Schmidt) Betsche"], Cour. Forsch.-Inst. Senckenberg 71: 132 (1984) E Kickxia brunneri (Benth.) Janch. ssp. webbiana (Sunding) Rustan \& Brochmann ["(J. A. Schmidt) Rustan \& Brochmann"], Cour. Forsch.-Inst. Senckenberg 105: 71 (1988). - - Type: In rupibus basalticis et in locis lapidosis vallium ins. $\mathrm{S}$. Antonii, praecipue pr. Ribeir. grand., 3.1851, J. A. Schmidt (holotype: HBG).

Illustrations: Rustan \& Brochmann (1988: Fig. 3 sub K. brunneri ssp. webbiana), Sutton (1988: Figs 54.7-8 sub $K$. webbiana), Gomes et al. (1995b: p. 25 sub $K$. webbiana). 


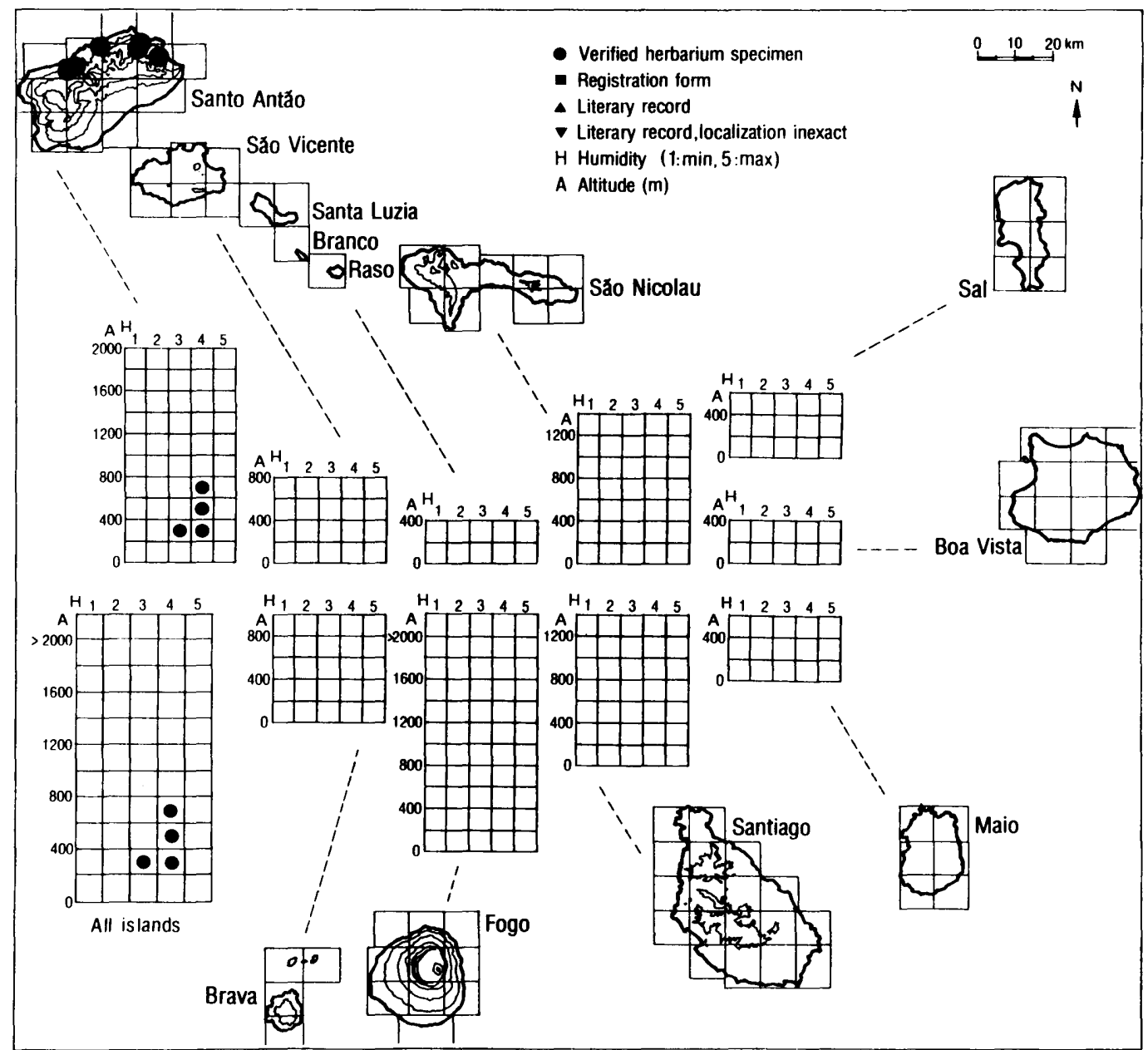

Fig. 167. Ecogeographic distribution of Kickxia elegans ssp. webbiana.

Note. Since Linaria webbiana J. A. Schmidt (as a later homonym of L. webbiana Vis.) and all combinations based on it are illegitimate, Hansen \& Sunding (1979) provided the nomen novum Kickxia schmidtii for the Capeverdean taxon. However, under Art. 58.3 of the Code (Greuter et al. 1994) the binominal Kickxia webbiana published by Sunding (1974) is legitimate as a nomen novum for Linaria webbiana J. A. Schmidt, and thus to be quoted as Kickxia webbiana Sunding (see also Greuter 1979: 43). Consequently, the later name Kickxia schmidtii for this taxon was superfluous when published and thus illegitimate. This was also stated by Sutton (1988: 215 , mf.: 128), who, however, erroneously quoted Nytt Mag. Bot. 17: 21 (1970) as the place of publication of Kickxia webbiana Sunding.

Description. Stem thin and lax, procumbent or sometimes ascending, glabrous. Leaf petiole usually long; lamina usually light green, reniform to ovate, often very large, glabrous, sometimes succulent, margin entire. Seeds minutely tuberculate. 
Variation. The leaves are variable in shape and size, also within individual plants. See also ssp. elegans.

Chromosome number: Unknown.

Distribution and ecology. Kickxia elegans ssp. webbiana is a northern mesophyte confined to Santo Antão. It occurs in the transition between the semiarid and subhumid zones in the major northern valleys, mainly between $200 \mathrm{~m}$ and $550 \mathrm{~m}$ (Rustan \& Brochmann 1988), but extending to $790 \mathrm{~m}$ (leg. Leyens). This subspecies is a valley ecotype, which in some respects is ecologically intermediate between the coastal xerophyte ssp. elegans and the montane hygrophyte ssp. dichondrifolia.

Abundance. Kickxia elegans ssp. webbiana is locally abundant and considered to be Lower Risk (LR).

Note. The map is based on revised material only.

\section{Verbascum L.}

The genus Verbascum contains about 360 species, most of which are biennial herbs. The genus is mainly distributed in Europe and SW Asia, with one centre of diversity in Turkey. Two endemic species occur in the Cape Verde Islands.

Literature: Murbeck (1921, 1925), Lobin \& Porembski (1994)

Key to the genus Verbascum

1 Annual to biennial(?) herb; basal leaves with soft lamina, at least 4 times longer than the petiole, lamina of lower cauline leaves usually more than $10 \mathrm{~cm}$ long; flowering stem with curved-erect branches V. capitis-viridis

1 Tuft-like, small rosette-(sub)shrub; basal leaves with leathery, more or less stiff lamina, usually at most 3 times longer than the petiole, lamina of lower cauline leaves less than 10 $\mathrm{cm}$ long; flowering branches stiffly spreading-erect V. cystolithicum

Verbascum capitis-viridis (Figs 168, 169)

Verbascum capitis-viridis Hub.-Mor., Bauhinia 5: 11 (1973) $\equiv$ Celsia insularis Murb., Acta Univ. Lund, ser. 2. 17: 12 (1921) [三Verbascum caboverdeanum Sunding, Check-list Vasc. Pl. Cape Verde Isl.: 26 (1973), nom. inval.]. - Type: S. Vicente, 1859-1860, Wawra \& Maly 69 (holotype: W).

- Celsia betonicaefolia Desf. f. glabra Bég., Ann. Mus. Civico Storia Nat. Giacomo Doria 48: 46 (1920). - Type: Boa Vista, 12.1897-1.1898, Fea (holotype: GDOR).

Illustrations: Murbeck (1921: Fig. 3 sub Celsia insularis), Barbosa (1961: Fig. 18 sub ('elsia insularis), Lobin \& Grasmück (1984: Figs 4, 7a-d), Lobin (1986b: Figs 11a-d, 12), Lobin \& Porembski (1994: Figs 2e-h. 3. 4, 7a, 8), Gomes et al. (1995b: p. 26).

Description. Annual to biennial(?), sparsely branched herb up to $1.2 \mathrm{~m}$ high, occasionally with somewhat lignified base. Leaves in a lax or prolonged basal rosette or distributed along the lower part of the flowering stem; basal leaves usually ovate to obovate, up to $18(-22.5) \mathrm{cm}$ long and $5(-6) \mathrm{cm}$ wide, more or less pubescent, glabrescent with age; petiole $2-3.5(-4) \mathrm{cm}$ long, lamina at least 4 times as long as petiole; cauline leaves shortly petiolated to sessile, smaller, otherwise similar. Flowers in terminal racemes, without scent. Calyx 5-lobed, lobes 


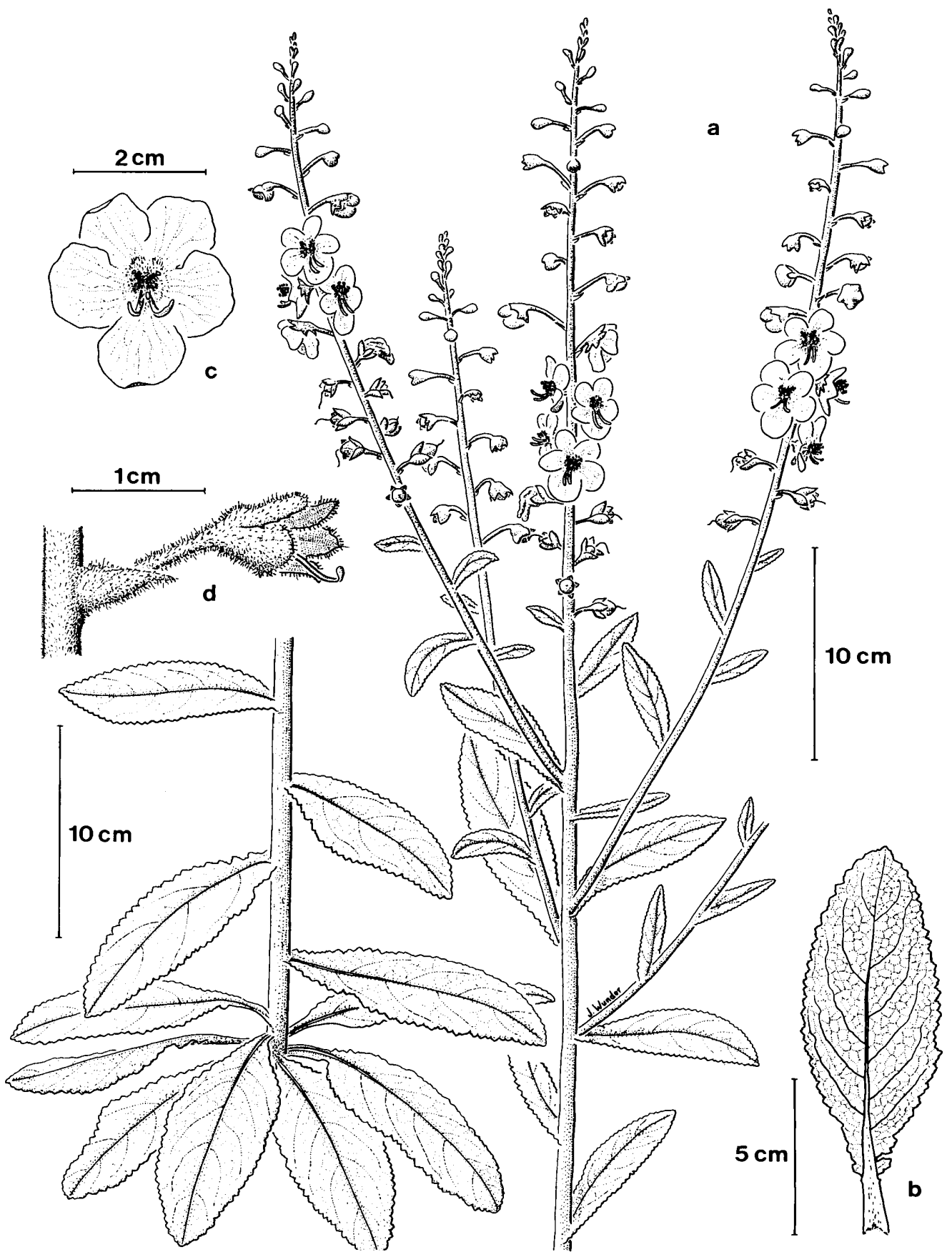

Fig. 168. Verbascum capitis-viridis. a. Habit; b. Leaf; c-d. Flowers. Drawn by J. Wunder. 


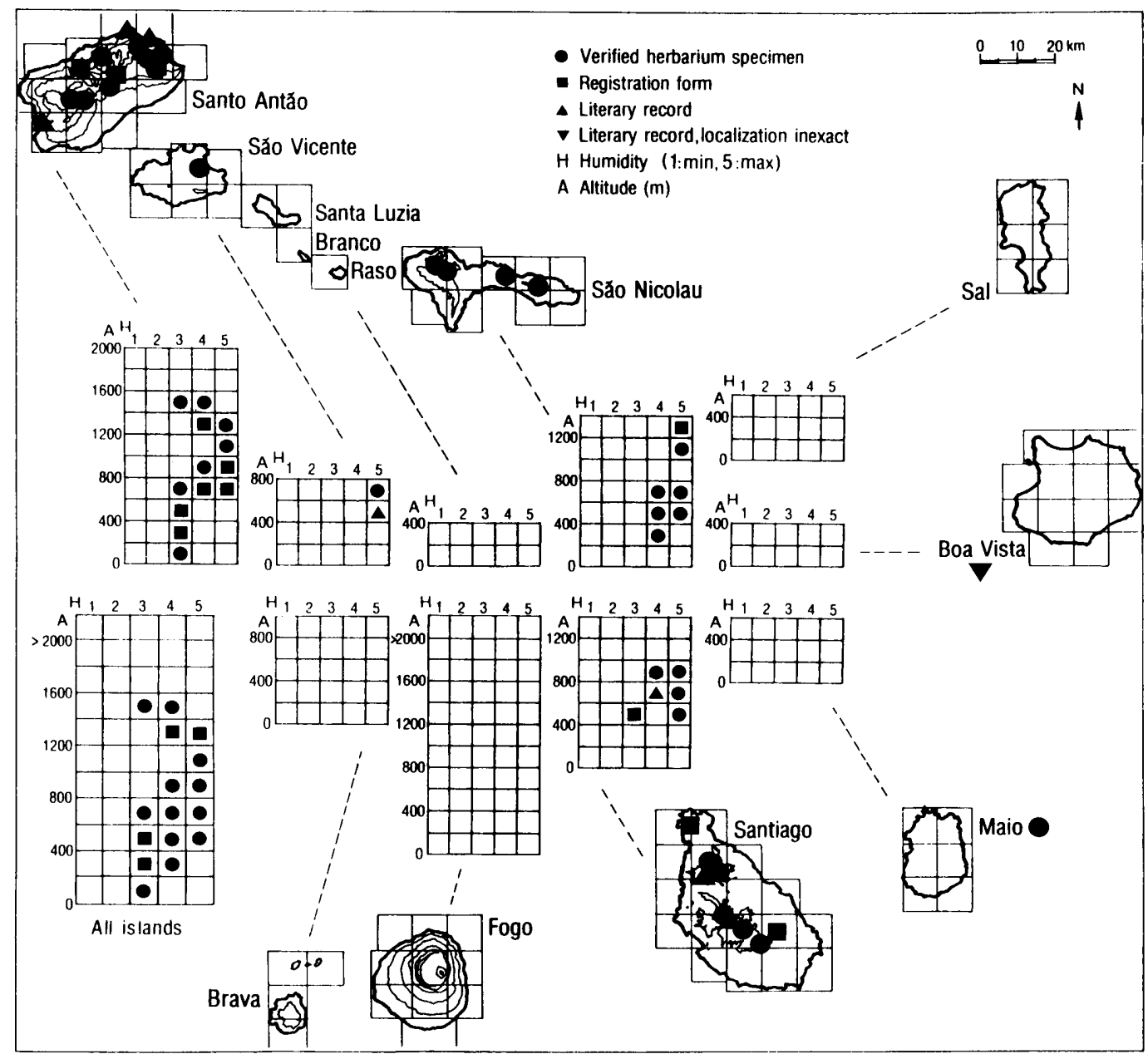

Fig. 169. Ecogeographic distribution of Verbascum capitis-viridis.

0.7-1.1 cm long. Corolla bright yellow, occasionally with basal violet mark, $2.3-3.2 \mathrm{~cm}$ in diameter, rotate, slightly irregular; tube $0.2-0.3 \mathrm{~cm}$ long, whitish; lobes 5 , oblong to orbicular, $0.8-1.5 \mathrm{~cm}$ long and $0.6-1.4 \mathrm{~cm}$ wide, the upper lobe slightly longer than the other lobes; corolla throat with a circle of white, clavate hairs, condensed at the upper corolla lobe to form a mark; stamens 4(-5). heteromorphic; posteriorly with long, white-hairy filaments and reniform anthers, anteriorly with short, only basally, white-hairy filaments and decurrent anthers; style $0.7-1.0 \mathrm{~cm}$ long, green, apically tinged with violet, stigma clavate. Capsule irregularly ovate, up to $1.1 \mathrm{~cm}$ long and $0.7 \mathrm{~cm}$ wide, glabrous to densely pubescent. septicidal, with $400-600$ seeds. Seeds $0.6 \mathrm{~mm}$ long.

Variation. The species is very variable, especially in branching pattern, pubescence, leaf shape, and leaf dentation, but most local populations are fairly homogeneous. No 
reasonable infraspecific taxa can be distinguished in spite of the considerable morphological variation.

Chromosome number: Unknown (but see $V$. cystolithicum).

Related taxa. Verbascum capitis-viridis is most closely related to V. cystolithicum. These Capeverdean species are probably most closely related to NW African species, in particular $V$. ballii (Batt.) Hub.-Mor., $V$. longirostre (Murb.) Hub.-Mor., and $V$. battandieri (Murb.) Hub.-Mor. This relationship is supported by similarities in leaf and seed morphology (Lobin \& Porembski 1994). The two Capeverdean species differ, however, conspicuously from these African species by their heteromorphic anthers (Murbeck 1921, 1925, Lobin \& Porembski 1994).

Distribution and ecology. Verbascum capitis-viridis is a ubiquitous mesophyte occurring on Santo Antão, São Vicente, São Nicolau, Boa Vista, Maio, and Santiago, but it is absent from Sal, Fogo, and Brava. It is equally frequent in the semiarid, subhumid, and humid zones, and it occurs mainly between $400 \mathrm{~m}$ and $1400 \mathrm{~m}$. The species has only occasionally been found down to sea-level (Santo Antão; Chevalier 1935a), and it extends to $1600 \mathrm{~m}$ on the same island (leg. Brochmann \& Rustan).

Abundance. Verbascum capitis-viridis is still fairly common on Santo Antão, but it is declining and considered Vulnerable (VU) on São Nicolau and Santiago. It has only been collected once on Maio (1851, leg. Schmidt), once on Boa Vista (1897-1898, leg. Fea), and three times on São Vicente (1841, leg. Vogel; 1851, leg. Schmidt; 1884-1889, leg. Krause), and it is thus considered Extinct (EX) on these three islands. Verbascum capitis-viridis is generally classified as Vulnerable (VU).

Note. The records from Fogo by Gilli (1976) and Ormonde (1980) are omitted because of probable confusion with $V$. cystolithicum.

Verbascum cystolithicum (Figs 170, 171)

Verbascum cystolithicum (Pett.) Hub.-Mor., Bauhinia 5: 12 (1973) $\equiv$ Celsia cystolithica Pett., Comm. Biol. Soc. Scient. Fenn. 22: 42 (1960). - Type: Fogo, S. Filipe, 12. 1954, H. Lindberg (holotype: H, not to be found). Lectotype (designated by Lobin \& Porembski 1994: 74): Photograph of the holotype in Comm. Biol. Soc. Scient. Fenn. 22: Tab. 3(4).

[= Verbascum sundingii Lobin \& Porembski, Sommerfeltia 17: 184 (1993), nom. nud.].

Illustrations: Pettersson (1960: Tab. 3(4)), Lobin \& Grasmück (1984: Fig. 7e-f), Lobin (1986b: Fig. $11 \mathrm{e}-\mathrm{g}$ ), Lobin \& Porembski (1994: Figs 2a-d, 6, 7b, 9), Gomes et al. (1995b: p. 26).

Description. Tuft-like, small rosette shrub or subshrub up to $0.8 \mathrm{~m}$ high, with branching, woody caudex and several, usually dense leaf rosettes, each with a single, stiffly erect flowering stem. Leaves narrowly elliptical, petiolate, lamina up to $10 \mathrm{~cm}$ long, leathery and more or less stiff, dark to brownish green with veins often tinged with violet, at most 3 times longer than petiole, petiole up to $3.4(-4.5) \mathrm{cm}$ long. Flowers in terminal racemes, sweetly scented. Calyx 5-lobed, lobes $0.5-0.8 \mathrm{~cm}$ long. Corolla yellow, always with basal violet mark, 2.2-3.1 cm in diameter, rotate; tube $0.2 \mathrm{~mm}$ long, whitish; lobes 5, oblong to orbicular, 1.0-1.4 $\mathrm{cm}$ long and $0.7-1.4 \mathrm{~cm}$ wide, the upper lobe slightly longer than the other lobes and basally with a mark of tufted, violet hairs, the other lobes basally with non-tufted, white hairs; stamens 4(-5), heteromorphic, posteriorly with long, white- and apically violet-hairy filaments and reniform anthers, anteriorly with short, only basally white-hairy filaments and decurrent anthers; style $0.8-1.2 \mathrm{~cm}$ long, green, stigma clavate, occasionally tripartite. Capsule 

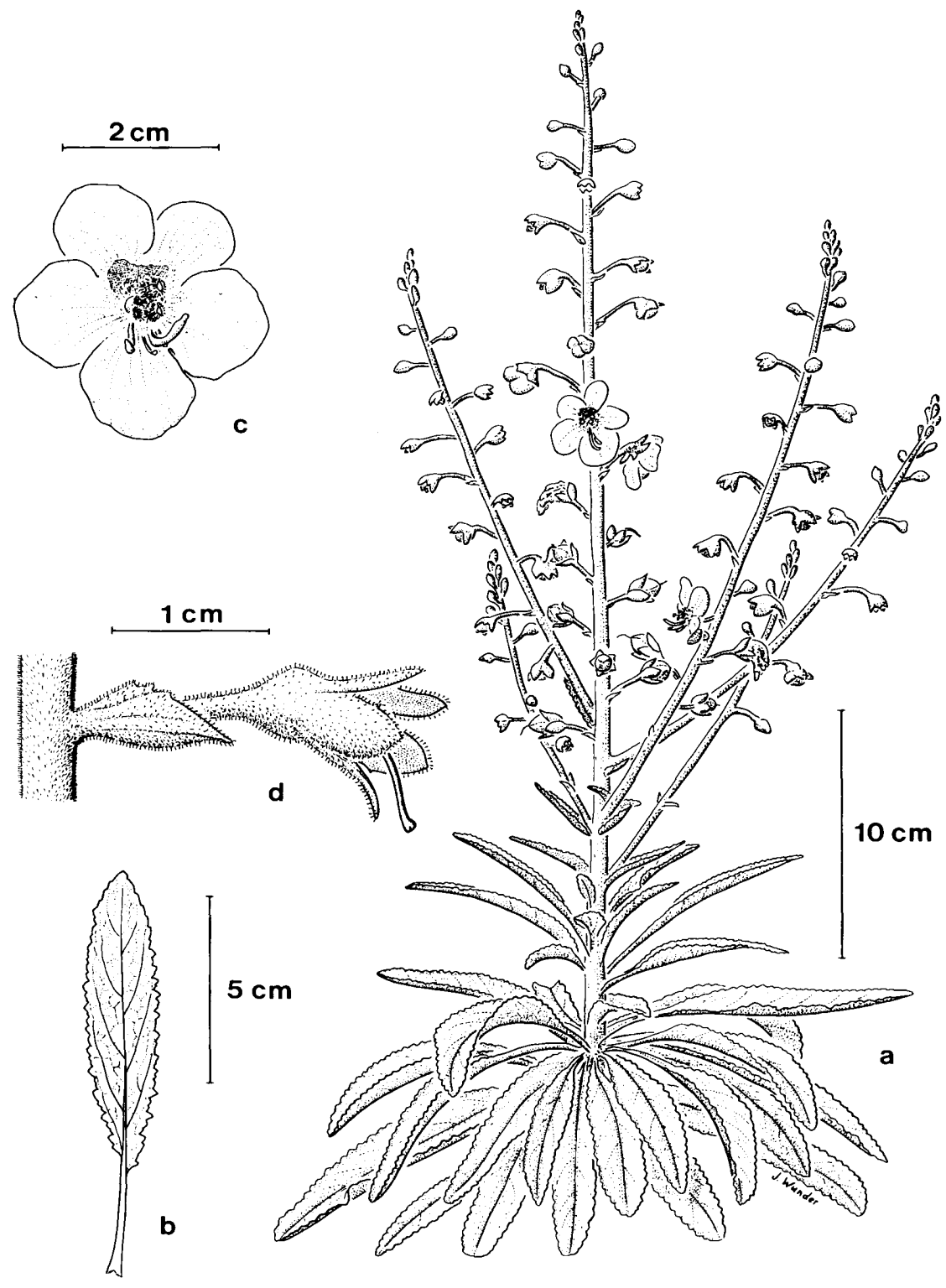

Fig. 170. Verbascum cystolithicum. a. Habit; b. Leaf; c-d. Flowers. Drawn by J. Wunder. 


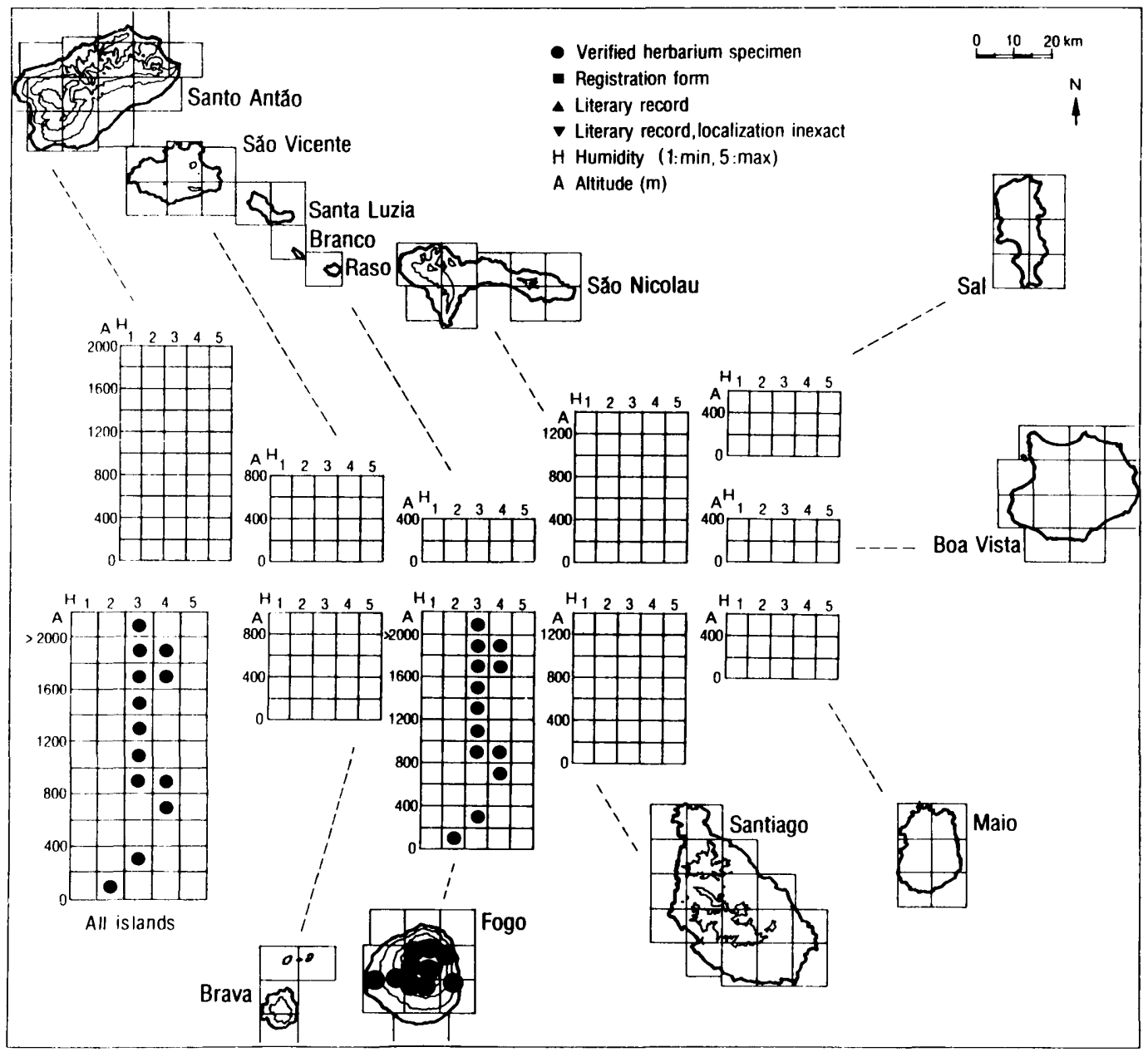

Fig. 171. Ecogeographic distribution of Verbascum cystolithicum.

irregularly ovate, up to $1 \mathrm{~cm}$ long and $0.8 \mathrm{~cm}$ wide, glandular-hairy, septicidal, with 400-800 seeds. Seeds $0.6 \mathrm{~mm}$ long.

Variation. This high-montane species is rather uniform. Single plants of ephemeral occurrence in the lowlands of Fogo are luxuriously branched, etiolated, and have larger leaves (Lobin \& Porembski 1994). These aberrant forms are modifications caused by the lowland conditions and thus without taxonomic significance. Unfortunately, Pettersson (1960) based the description of $V$. cystolithicum on such a lowland specimen, which have caused some trouble in recognizing this species, in particular because the original material cannot be found in Helsinki.

Chromosome number: $2 \mathrm{n}=$ ca. 54 (Fogo, Chã das Caldeiras, 1650 m, Borgen 1975). This chromosome number was published for V. capitis-viridis (Borgen 1975), but the voucher 
(Sunding 2791, cult. 73-1813, O!) represents V. cystolithicum. The species is possibly hexaploid based on $\mathrm{x}=9$ (Borgen 1975).

Related taxa. See $V$. capitis-viridis.

Distribution and ecology. Verbascum cystolithicum is a southern mesophyte mainly confined to the subhumid and semiarid high mountain area of Fogo. It has its main occurrence in the central caldeira, on the outer escarpments of the caldeira rim, and on Pico Novo, usually above $1300 \mathrm{~m}$ and up to $2800 \mathrm{~m}$ (leg. Kilian \& Leyens). The plants typically grow on black lapilli, associated with the local endemics Echium vulcanorum and Erysimum caboverdeanum as well as Artemisia gorgonum and Globularia amygdalifolia. The species is one of the first colonizers of new lava fields. Several records also exist from lower altitudes and even from the arid lowlands (e.g., the holotype), but most of these records represent ephemeral plants dispersed from source populations in the mountains.

Abundance. The species is common in the high mountain area, and the populations are large. Verbascum cystolithicum is considered to be Lower Risk (LR).

Note. A record from Santiago (Ormonde 1980) is omitted because of probable confusion with $V$. capitis-viridis.

\section{URTICACEAE}

This family is represented by three genera with five species, of which one is endemic.

\section{Forsskaolea L.}

The genus Forsskaolea comprises six species, of which one is endemic to the Canary Islands, one is endemic to the Cape Verde Islands, two are endemic to Namibia, and two species are widely distributed in S Spain, Africa, and SW Asia. One of the latter species, F. viridis, also occurs in the Cape Verde Islands (Fogo and Brava).

Key to the genus Forsskaolea

1 Herb; leaves with pronounced, narrowly triangular apical tip and obtusely dentate to crenate margin, lower surface at most slightly tomentose, usually green; subtending bracts of partial inflorescence 3-4, not more than 2 times as long as wide $[F$. viridis $]$

1 Subshrub or shrub; leaves without pronounced apical tip and with sharply dentate margin, lower surface usually distinctly whitish tomentose; subtending bracts of partial inflorescence 4-8 (or occasionally more), 4-5 times as long as wide F. procridifolia 
aridis vallium, 27.3.1822, Forbes 19; ibid., 29.3.1822, Forbes 39; ins. St. Jago, cool valleys, Porto Praya, 1839. J. D. Hooker 1/3 (K). - Lectotype (designated by Lobin \& Roessler 1985: 378): Vogel 7 I (K!).

= Forsskaolea procridifolia Webb var. microphylla J. A. Schmidt, Beitr. Fl. Cap Verd. Ins.: 169 (1852).

- Type: St. Vicent, J. A. Schmidt (holotype: HBG!; isotype: GOET!).

= Forsskaolea procridifolia Webb var. rigida Weddell, Arch. Mus. Hist. Nat. Paris 9 [Monogr. Fam. Urtic.]: 535 (1857). - Type: Not designated.

$=$ Forsskaolea procridifolia Webb var. umbrosa Weddell in DC., Prodr. 16(1): $235^{56}$ (1869). Lectotype (designated by Friis \& Wilmot-Dear 1988: 35): St. Vincent, Palha-Carza, 4.1853, Bolle (P).

Illustrations: Weddell (1856: Fig. 19B1-4), Lobin \& Roessler (1985: Figs 1B, 2, 3), Lobin (1986b: Fig. 20), Gomes et al. (1995b: p. 26).

Literature: Lobin \& Roessler (1985), Friis \& Wilmot-Dear (1988).

Description. Moderately branched, procumbent to more or less erect shrub or subshrub. usually $0.2-0.5 \mathrm{~m}$ high, occasionally much higher. Leaves broadly elliptical to ovate-elliptical. very variable in size, up to $10 \mathrm{~cm}$ long and $5 \mathrm{~cm}$ wide, whitish tomentose below, apex acute, margin sharply dentate. Inflorescences axillary, with 4-8(-12) bracts; 5-12 male flowers and 3-5 female flowers per inflorescence. Flowers greenish, small.

Variation. The species is very variable in habit, size, and leaf characters, but the variation seems to be continuous.

Chromosome number: $2 \mathrm{n}=14,2 \mathrm{n}=44(2 \mathrm{n}=14$, Santiago, Pico da Antonia, Bramwell \& Murray 1972, Bramwell et al. 1972; $2 n=44$, São Vicente, Monte Verde, $540 \mathrm{~m}$, Borgen 1975; $2 n=44$, Santo Antão, Ribeira do Barbasco, Borgen 1975). The chromosome number $2 n=14$ may be diploid based on $x=7$, and the number $2 n=44$ may be tetraploid based on $\mathrm{x}=11$ (Borgen 1975).

Related taxa. Forsskaolea procridifolia is most closely related to $F$. angustifolia Retz. $(2 \mathrm{n}=22$; Ardévol Gonzales et al. 1993), which occurs in the Canary Islands, and $F$. tenacissima L., which occurs from S Spain through N Africa, the Arabian peninsula, Iran, Afghanistan to Pakistan and India.

Distribution and ecology. Forsskaolea procridifolia is a ubiquitous xerophyte widely distributed on most of the islands: Santo Antão, São Vicente, Santa Luzia (including the islets of Branco and Raso), São Nicolau, Sal, Maio, Santiago, Fogo, and Brava. It has so far not been reported from Boa Vista. It grows in a wide range of habitats in all zones of humidity and at all altitudinal levels, mainly between sea-level and $1700 \mathrm{~m}$, but it only rarely occurs in the extremely arid zone. On Fogo, the species extends to $2700 \mathrm{~m}$ at the central volcanic cone (leg. Kilian \& Leyens). The plants typically grow among rocks, often at the edges of dry ribeiras, and in cliffs.

Abundance. The species is common in most recorded areas and has been collected on all major islands after 1970. Forsskaolea procridifolia is considered to be Lower Risk (LR).

Note. The map is based on specimens from various herbaria revised by Lobin \& Roessler (1985), more recent collections, registration form data, and one recent literary record (Branco; Basto 1987a). 


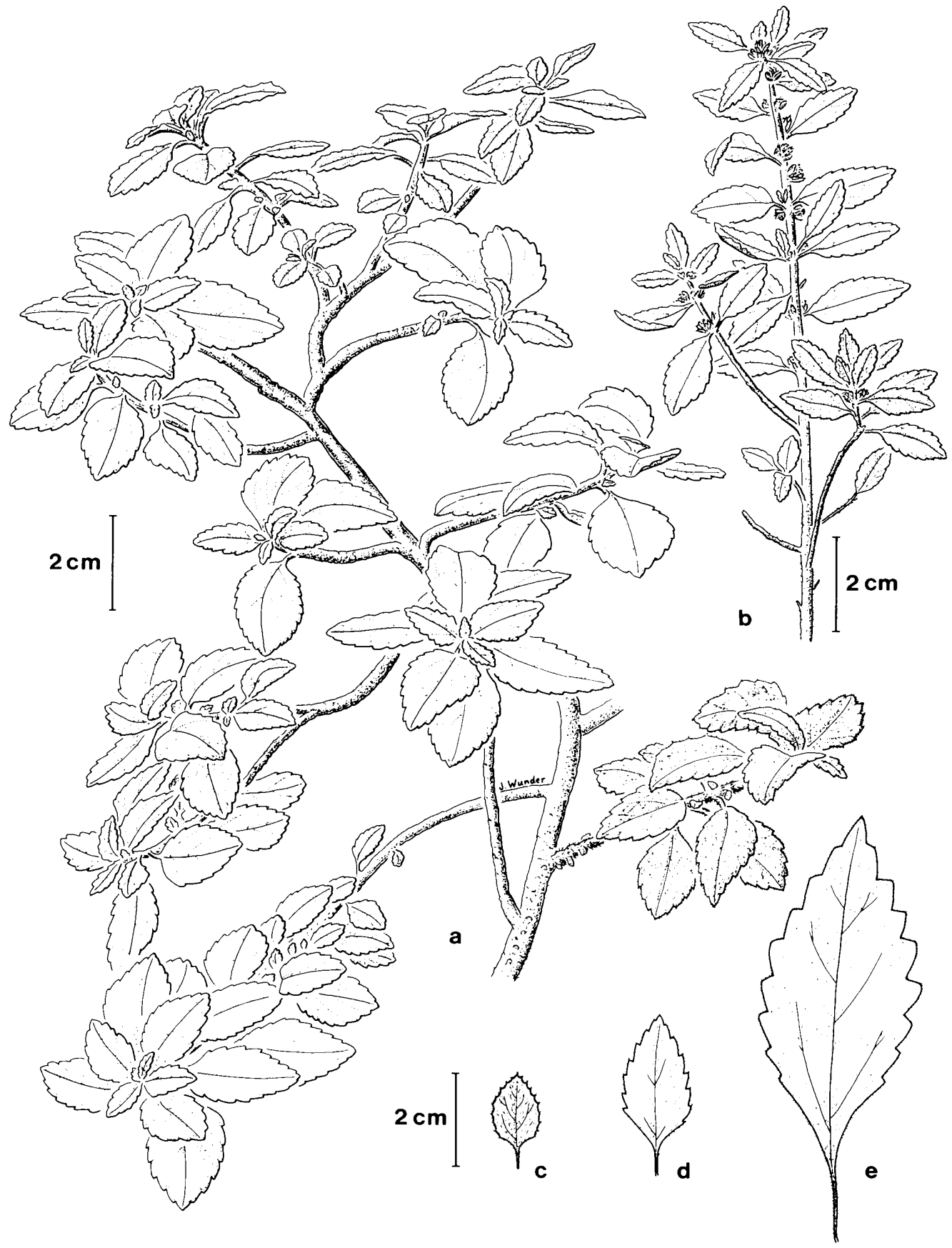

Fig. 172. Forsskaolea procridifolia. a. Habit; b. Part of stem with flowers; c-e. Leaves. Drawn by J. Wunder. 


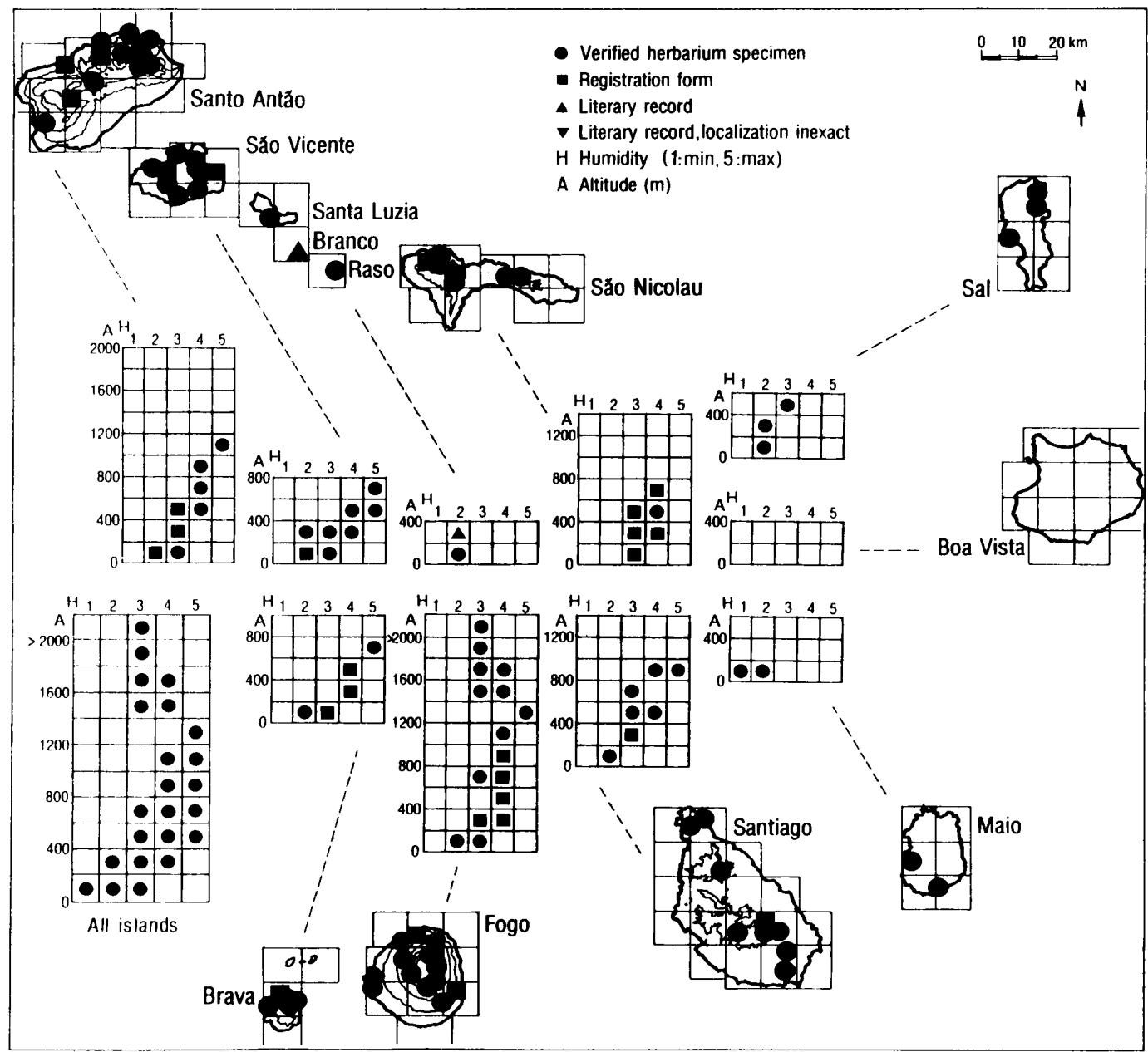

Fig. 173. Ecogeographic distribution of Forsskaolea procridifolia. 


\section{MONOCOTYLEDONEAE}

\section{ARECACEAE}

This family is represented by four genera with six species, of which one has been described as endemic.

\section{Phoenix L.}

The date palm genus, Phoenix, comprises some 15 species native to (sub)tropical Africa, Asia, and S Europe (Crete), but several species are cultivated worldwide for ornament and for their edible fruits. The genus is recognized by its pinnate leaves of which the lowermost leaflets are transformed into green spines and the other leaflets are folded onto the rachis with edges turned upwards. The male flowers and the fruits provide the most useful characters for species identification, which is difficult, however, because all species freely cross with each other and frequently form hybrids in sympatric situations. In the Cape Verde Islands, this genus is represented by three species, Phoenix dactylifera, $P$. canariensis, and $P$. atlantidis. The latter species has been described as endemic, but its taxonomic significance is questionable and needs further investigation. The other species have been introduced by man.

Provisional key to the genus Phoenix

1 Plant not soboliferous, always with a single, stout trunk; inner perianth segments of female flowers only slightly longer than the outer segments. $[P$. canariensis $]$

1 Plant soboliferous, in undisturbed growth with several, basally united, slender trunks; inner 3 perianth segments of female flowers almost twice as long as the outer 3 segments

2 (1) Petals of male flowers apically rounded; fruits more than $2.5 \mathrm{~cm}$ long

[P. dactylifera $]$

2 Petals of male flowers apically acuminate and sometimes hooked; fruits less than $2 \mathrm{~cm}$ long P. atlantidis

Phoenix atlantidis (Figs 174, 175)

Phoenix atlantidis A. Chev., Compt. Rend. Hebd. Séances Acad. Sci. 199: 1154 (1934) = Phoenix atlantica A. Chev., Bull. Mus. Nat. Hist. Natur., sér. 2, 7: 137 (1935). — Syntypes: Sal, Palha Verde, 1934, Chevalier 45840 (P); ibid., Palmeira, Algodoeiro, 1934, Chevalier 45839 (P); Santiago, environs de Praia, 1934, Chevalier 45858 (P).

Illustrations: Chevalier (1935a: Fig. 1, 1935b: Fig. 13).

Literature: Chevalier (1935b, 1952).

Note. Although this species is commonly known as Phoenix atlantica, it was first published by Chevalier as $P$. atlantidis. The change of name to $P$. atlantica, later explained with the statement that "atlantidis" 
was a printing error (Chevalier 1952: 217), is not sanctioned by the Code (Greuter et al. 1994) since the original epithet is grammatically fully correct. The name $P$. atlantica must therefore be rejected.

Description (after Chevalier 1935a, 1935b). Soboliferous, tuft-like-growing, dioecious tree with 5-10 trunks, each $5-10 \mathrm{~m}$ high and $30-60 \mathrm{~cm}$ in diameter. The trunks in their basal $50-70$ $\mathrm{cm}$ united with each other to some sort of pedestal by the frill of leaf fragments in whose axils adventive roots develop. Up to 100 leaves rosetted at the apex of the trunk, 2-3 m long, dark green (not glaucous); petioles short, yellowish green, basally distinctly enlarged and with 1015 pairs of straight, $5-8 \mathrm{~cm}$ long, strongly acute spines; rachis with 100-150 pairs of acuminate and pungent, $40-60 \mathrm{~cm}$ long and $2.0-2.5 \mathrm{~cm}$ wide leaflets. Inflorescences several, spreading-erect, male inflorescences somewhat shorter than female inflorescences. Male inflorescences $30 \mathrm{~cm}$ long, always partly enclosed by the spathe. Male flowers with calyx 3 $\mathrm{mm}$ long, scarcely lobed, each lobe mucronate and with white scarious margin; petals ovateoblong, coriaceous, $6 \mathrm{~mm}$ long and basally $3 \mathrm{~mm}$ wide, with acuminate and sometimes hooked apex, pale yellowish and strongly longitudinally striate abaxially, brownish adaxially; stamens 6 , much shorter than the petals and with very short filaments. Female inflorescences 40-60 cm long, at fruiting time with pendant branches, with slender, yellowish-orange main axis $20-40 \mathrm{~cm}$ long, simple or bifurcate. Fruit ovoid, $16 \mathrm{~mm}$ long and up to $12 \mathrm{~mm}$ in diameter, sometimes subglobose, yellow when ripe, with thin pericarp, only slightly sweet. Seeds ovoid, $10-14 \mathrm{~mm}$ long and $5-8 \mathrm{~mm}$ in diameter. Fruiting perianth $10-12 \mathrm{~mm}$ in diameter, with 3 inner, entire lobes, $3 \mathrm{~mm}$ long and $3 \mathrm{~mm}$ wide, with scarious margin, and 3 outer lobes, 5-6 mm long and up to $2.5-3 \mathrm{~mm}$ wide, basally with a subcarnose swelling.

Variation. According to Chevalier (1935b), Phoenix atlantidis forms hybrids with $P$. dactylifera.

Chromosome number: Unknown.

Related taxa. The taxonomy of Phoenix is known to be difficult because the differences between the species are rather subtle, and because the species are fully interfertile (Greuter 1967). In addition, the last monograph of Phoenix dates back to 1890 (Beccari 1890). Phoenix atlantidis was described by Chevalier as endemic to the Cape Verde Islands, but he did not provide precise diagnostic characters. Phoenix atlantidis seems to differ from $P$. dactylifera $\mathrm{L}$. by its acuminate (versus rounded) petals of the male flowers (see amended description by Chevalier 1935b), which is characteristic for the African species group of Phoenix (Greuter 1967: 249). The Capeverdean taxon is clearly distinguished from $P$. canariensis Chab. by the development of numerous basal innovations leading to a severalstemmed, tuft-like growth. This growth form is also characteristic of $P$. dactylifera, if not suppressed in cultivated trees of the latter species by repeated cutting of the innovations. In a later account of Phoenix in Africa, Chevalier (1952: 217) stated that P. atlantidis also is distributed in SW Morocco as well as in the Canary Islands, but this statement has never been confirmed (see e.g., Maire 1957 for NW Africa). Further complicating the situation in the Cape Verde Islands is the fact that $P$. dactylifera has been extensively planted on all islands where $P$. atlantidis has been recorded, and that hybrids between these species have been reported (Chevalier 1935a).

Distribution and ecology. The spontaneous distribution of Phoenix atlantidis is poorly known, both because of the taxonomic problems and because the species frequently has been planted. According to Chevalier (1935a), P. atlantidis is native only on the eastern islands of 


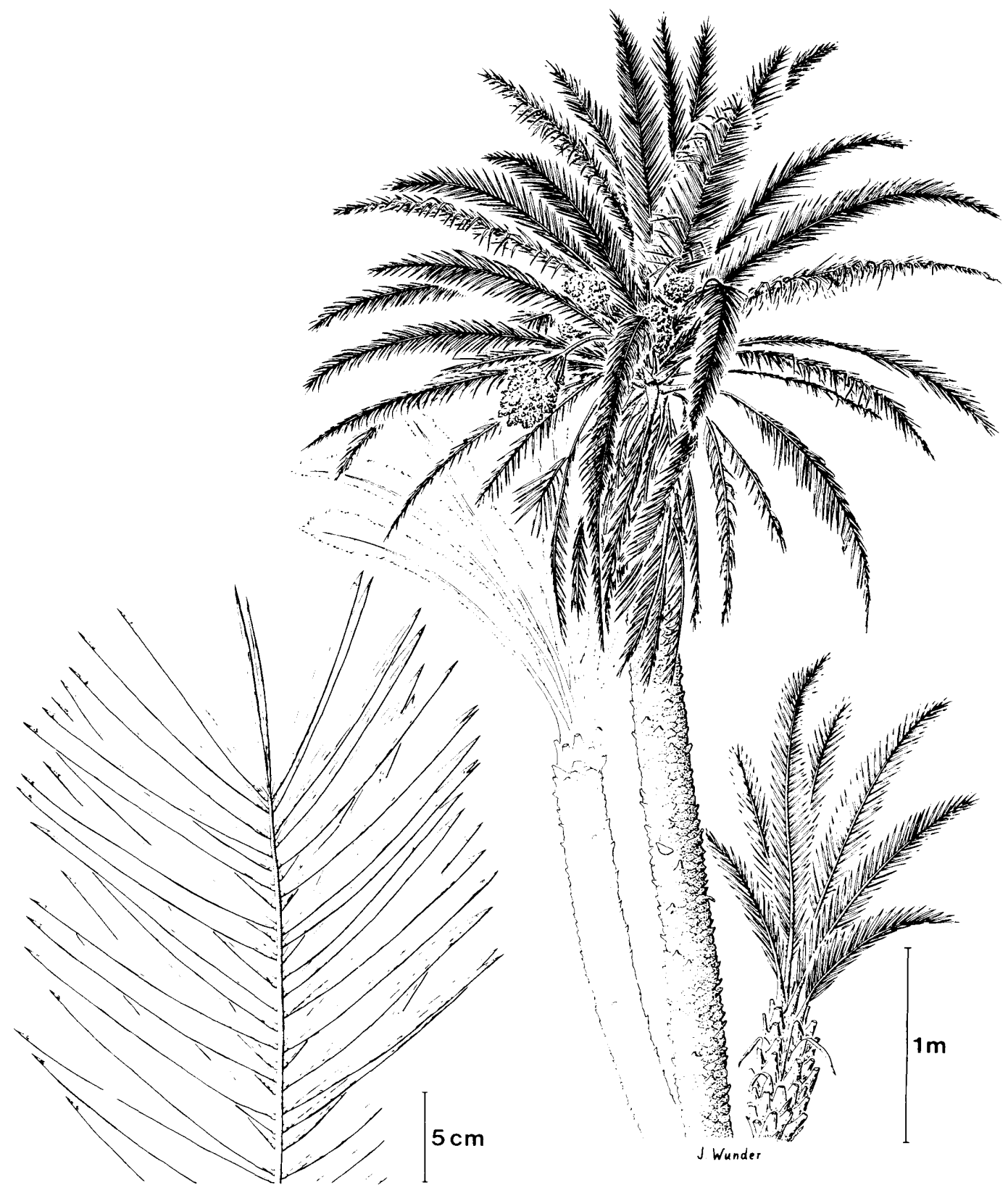

Fig. 174. Phoenix atlantidis. Habit and leaf of male plant. Drawn by J. Wunder. 


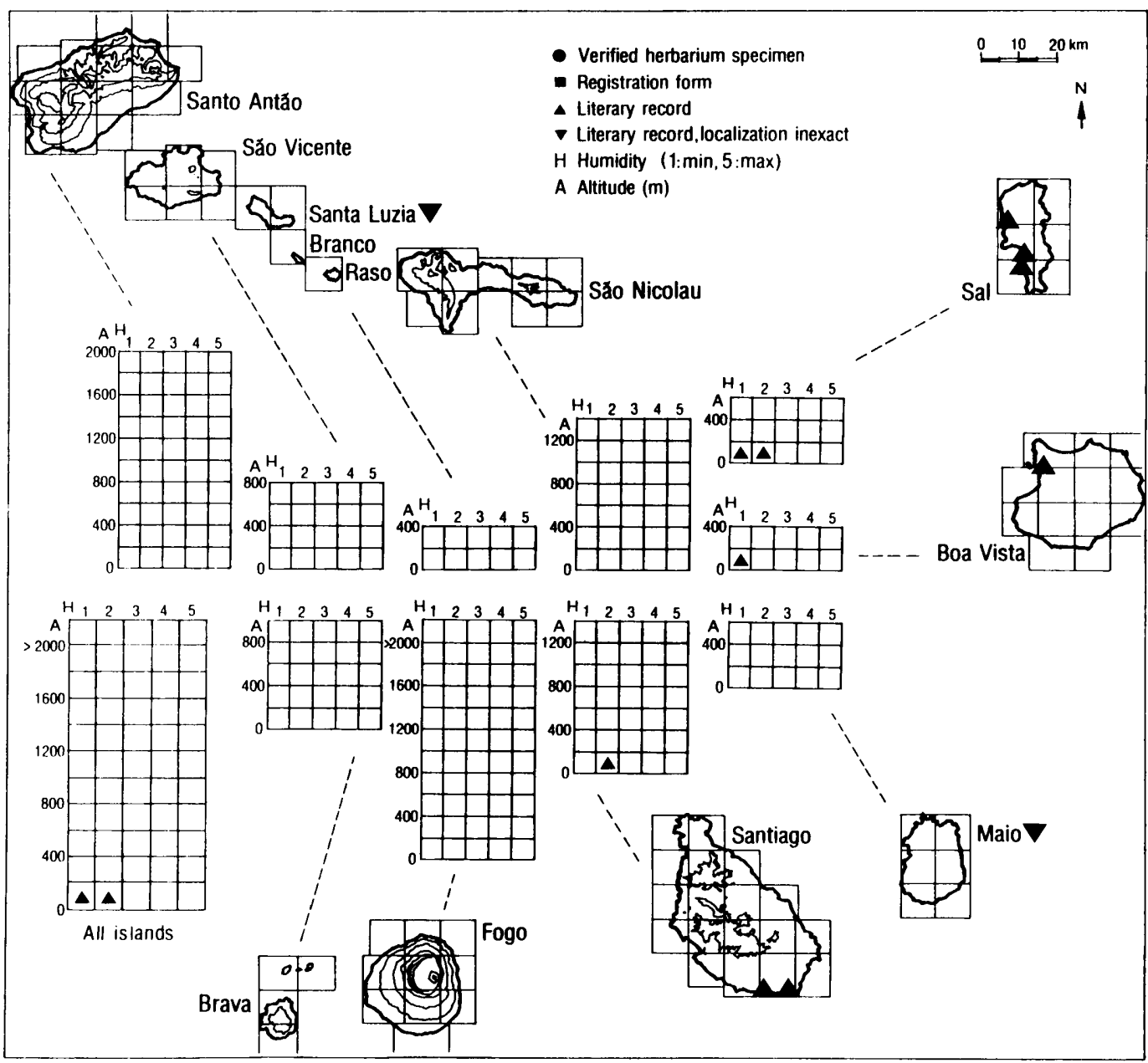

Fig. 175. Ecogeographic distribution of Phoenix atlantidis.

Sal, Boa Vista, and Maio, and on the southern island of Santiago. Nogueira (1979) also reported the species from the uninhabited islet of Santa Luzia. We therefore refer $P$. atlantidis to the ubiquitous xerophytic element, but it only deviates from the eastern xerophytes by also occurring on Santa Luzia and Santiago. It has only been recorded from the extremely arid and arid zones between sea-level and 200-300 m. The trees grow in coastal valleys on sand or gravel, often in dense stands.

Abundance. Reliable data on the abundance of Phoenix atlantidis are not available, and the species is classified as Data Deficient (DD). 


\section{ASPARAGACEAE}

This family is represented by a single genus with two species, of which one is endemic.

\section{Asparagus L.}

The genus Asparagus comprises about 100 species occurring in the warm temperate. subtropical, and tropical parts of the Old World. Many species are characterized by rhizomes and photosynthetic inflorescences, and some species, particularly in the mid-Atlantic archipelagos, have woody, thorny stems. The genus is represented in the mid-Atlantic archipelagos by seven endemic species. In the Cape Verde Islands, two species are known: the endemic A. squarrosus, and A. scoparius Lowe, which also occurs in Madeira and the Canary Islands.

Literature: Valdés (1979).

Key to the genus Asparagus

1 Subtending bract-like, scarious leaves with the basal spiny spur patent from the branches: cladodes canaliculate with distinct ribs A. squarrosiss

1 Subtending bract-like, scarious leaves with the basal spiny spur appressed to the branches; cladodes more or less terete. [A. scoparius]

Asparagus squarrosus (Figs 176, 177)

Asparagus squarrosus J. A. Schmidt, Beitr. Fl. Cap Verd. Ins.: 165 (1852). - Type: In rupestribus ins. S. Antonii, pr. Ribeiram grandem, 3.1851, J. A. Schmidt. — Lectotype (designated by Valdés 1979: 98): "In rupestribus ins. S. Antonii, März 1851", J. A. Schmidt (GOET).

= Asparagus vincentinus Welw. ex Cout., Arq. Univ. Lisboa 1: 277 (1914). — Type: S. Vicente, Monte Verde, 8.1853, Welwitsch 3880 (holotype: LISU; isotype: COI).

Illustrations: Valdés (1979: Fig. 8), Lobin (1986b: Fig. 4), Gomes et al. (1995b: p. 10).

Description. Strongly branched, procumbent or rarely ascending shrub, branches up to $2.5 \mathrm{~m}$ long. Needle-like cladodes in fascicles, in axils of reduced, scarious leaves with a spiny, patent basal spur. Cladodes 4.5-12(-20) mm long, up to 22 per fascicle. Pedicels up to $12 \mathrm{~mm}$ long. Flowers yellowish green, campanulate, up to $4 \mathrm{~mm}$ long, tepals connate at the base. Fruit a reddish, globose berry up to $6 \mathrm{~mm}$ in diameter, with 1-3 seeds.

Variation. The species is variable in habit, but homogeneous in leaf, cladode, and floral characters.

Chromosome number: Unknown.

Related taxa. The species is closely related to A. scoparius Lowe, which occurs on Santiago and Fogo.

Distribution and ecology. Asparagus squarrosus belongs to the ubiquitous-xerophytic element, but it only occurs on Santo Antão, São Vicente, the islet of Raso, São Nicolau, Sal, Boa Vista, and Maio. Thus, it deviates from most other ubiquitous species by its absence from the three southern islands. On Santiago and Fogo, it is replaced by A. scoparius. Most 


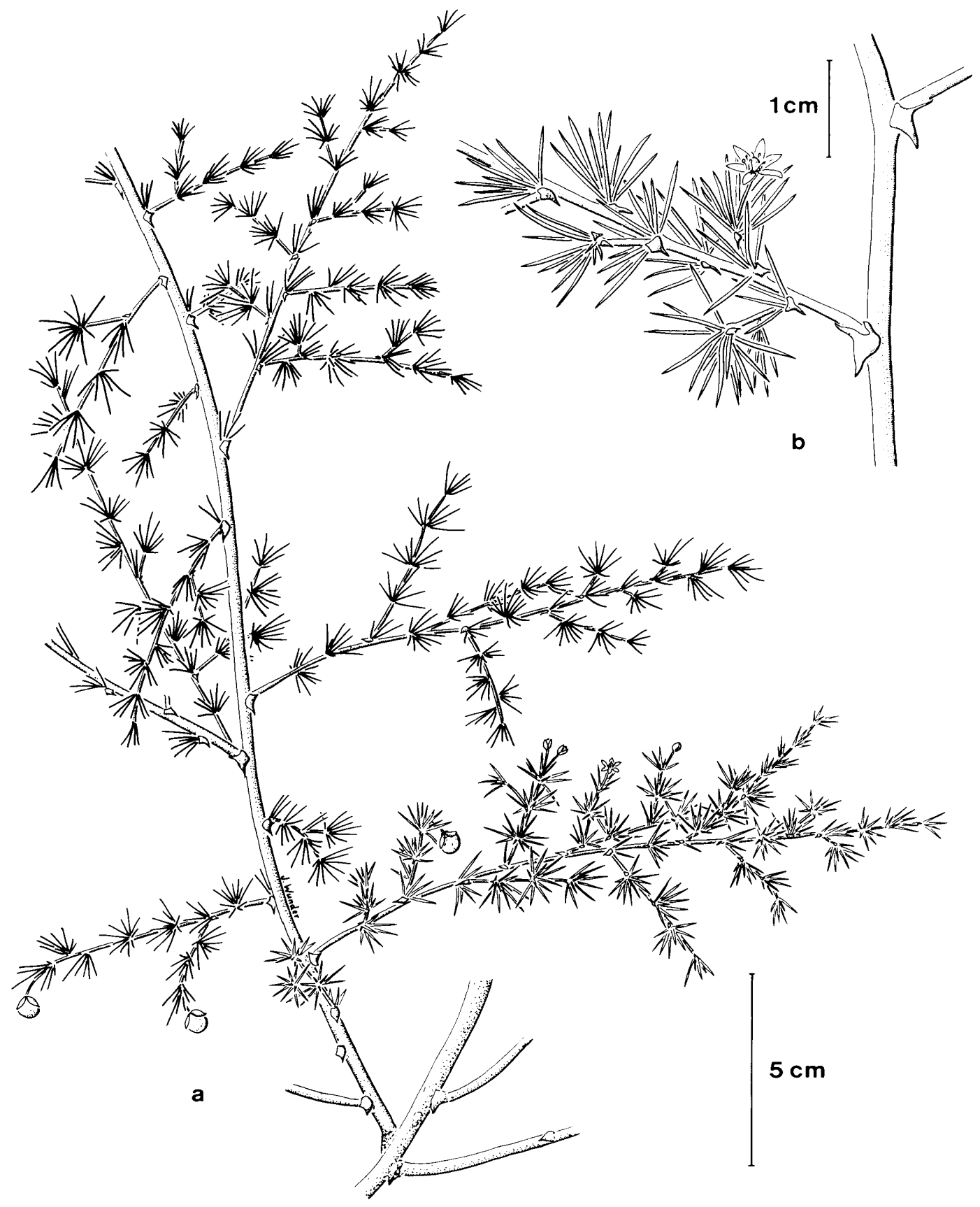

Fig. 176. Asparagus squarrosus. a. Habit; b. Branch with cladodes and flower. Drawn by J. Wunder. 


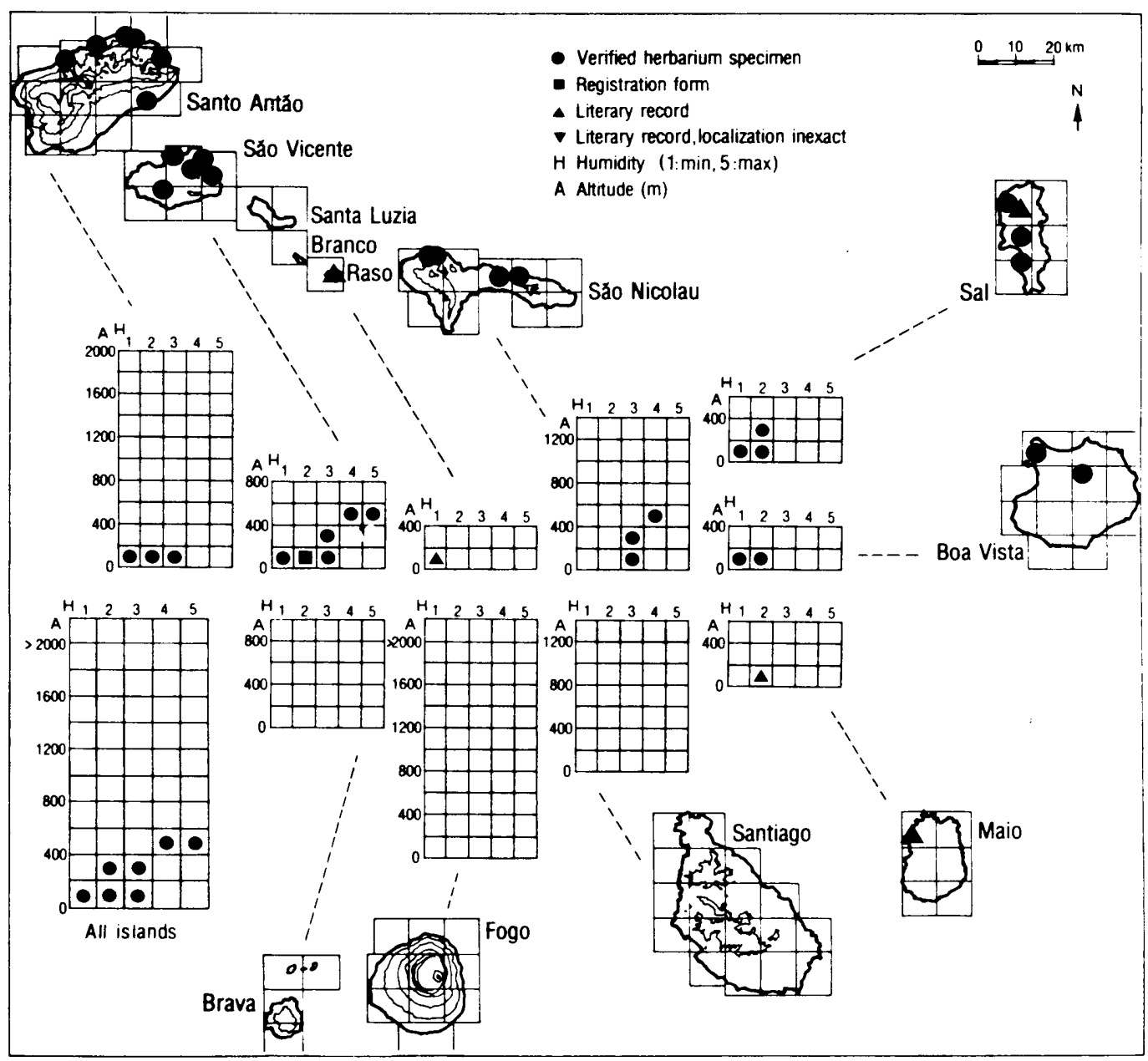

Fig. 177. Ecogeographic distribution of Asparagus squarrosus.

localities are situated in the extremely arid and arid zones from sea-level to $200 \mathrm{~m}$. The species occasionally extends to more elevated, humid areas on São Vicente and São Nicolau. The uppermost record is at $600 \mathrm{~m}$ on São Nicolau (leg. Rustan). The plants grow in coastal gravelly slopes and plains with Aizoon canariense, Corchorus depressus, Frankenia ericifolia ssp. ericifolia, Kickxia elegans ssp. elegans, Beta procumbens, and Sclerocephalus arabicus.

Abundance. The species is common on most islands, and it has been reported from all islands after 1970. It is Vulnerable (VU) on Sal, and probably also on Maio, where it only has been recorded a single time (Basto 1987a). Asparagus squarrosus is generally considered to be Lower Risk (LR).

Note. Two records from Santiago (Hansen \& Sunding 1985, Basto 1988) are omitted because of possible confusion with $A$. scoparius. 


\section{CYPERACEAE}

This family is represented by 11 genera with 31 species and subspecies. One species and one subspecies of a non-endemic species of the genus Carex are endemic.

\section{Carex L.}

The genus Carex comprises some 1000 species mainly distributed in moist habitats in temperate and cold regions of the world.

Key to the genus Carex

1 Lowermost spike male, remaining spikes female; subtending bracts of lower spikes much longer than the entire inflorescence.

C. antoniensis

1 All spikes with male and female flowers; subtending bracts of all spikes much shorter than spikes C. paniculata ssp. hansenii

Carex antoniensis (Figs 178, 179)

Carex antoniensis A. Chev., Rev. Bot. Appl. Agric. Trop. 15: 1032 (1935). - Type: Sto. Antão, [Rib. Paul], Covão, pied des cascades et bord des ruisseaux permanents à $800 \mathrm{~m}$ d'alt., 16.-17.9.1934, Chevalier 45396 (holotype: P!).

Illustrations: Lobin (1986b: Figs 9, 10), Lewejohann \& Lobin (1987: Fig. 3a-b), Rivas-Cembellin \& León Arenciba (1993: Fig. 1, I-II), Gomes et al. (1995b: p. 32).

Literature: Rivas-Cembellin \& León Arenciba (1993).

Description. Cespitose perennial up to $0.7 \mathrm{~m}$ high. Culms erect, triangular, leafy. Leaves mainly basal, up to $79 \mathrm{~cm}$ long and $1.7 \mathrm{~cm}$ wide, scabrous. Subtending bracts of lower spikes much longer than the entire inflorescence. Male spike solitary, narrowly cylindrical, up to 5 $\mathrm{cm}$ long. Female spikes (4-)6-8(-10), the upper ones grouped together, sessile or subsessile, surrounding the male spike, the lower spikes 1-2 pedunculate, pendant, broadly cylindrical, up to $6 \mathrm{~cm}$ long. Stigmas 3. Utricles ovoid-ellipsoid, narrowing into a bifid beak, up to $6 \mathrm{~mm}$ long and $1.5 \mathrm{~mm}$ broad, glabrous; veins distinct, prominent. variation.

Variation. Material from two populations was examined, showing no essential

Chromosome number: Unknown.

Related taxa. The species is closely related to the widely distributed C. pseudocyperus L. Rivas-Cembellin \& León Arenciba (1993) compared these species and kept them separate, mainly based on the morphology of the female spikes.

Distribution and ecology. Carex antoniensis is a northern hygrophyte confined to the Covão area in upper Ribeira do Paul, Santo Antão. The populations are situated in the humid zone between $620 \mathrm{~m}$ and $800 \mathrm{~m}$. The plants grow in permanently wet places, in or close to running water.

Abundance. A few, small populations within an area of a single square km are known, recorded in 1934, 1979, 1980,1982, 1994, and 1995. The area is strongly influenced by 


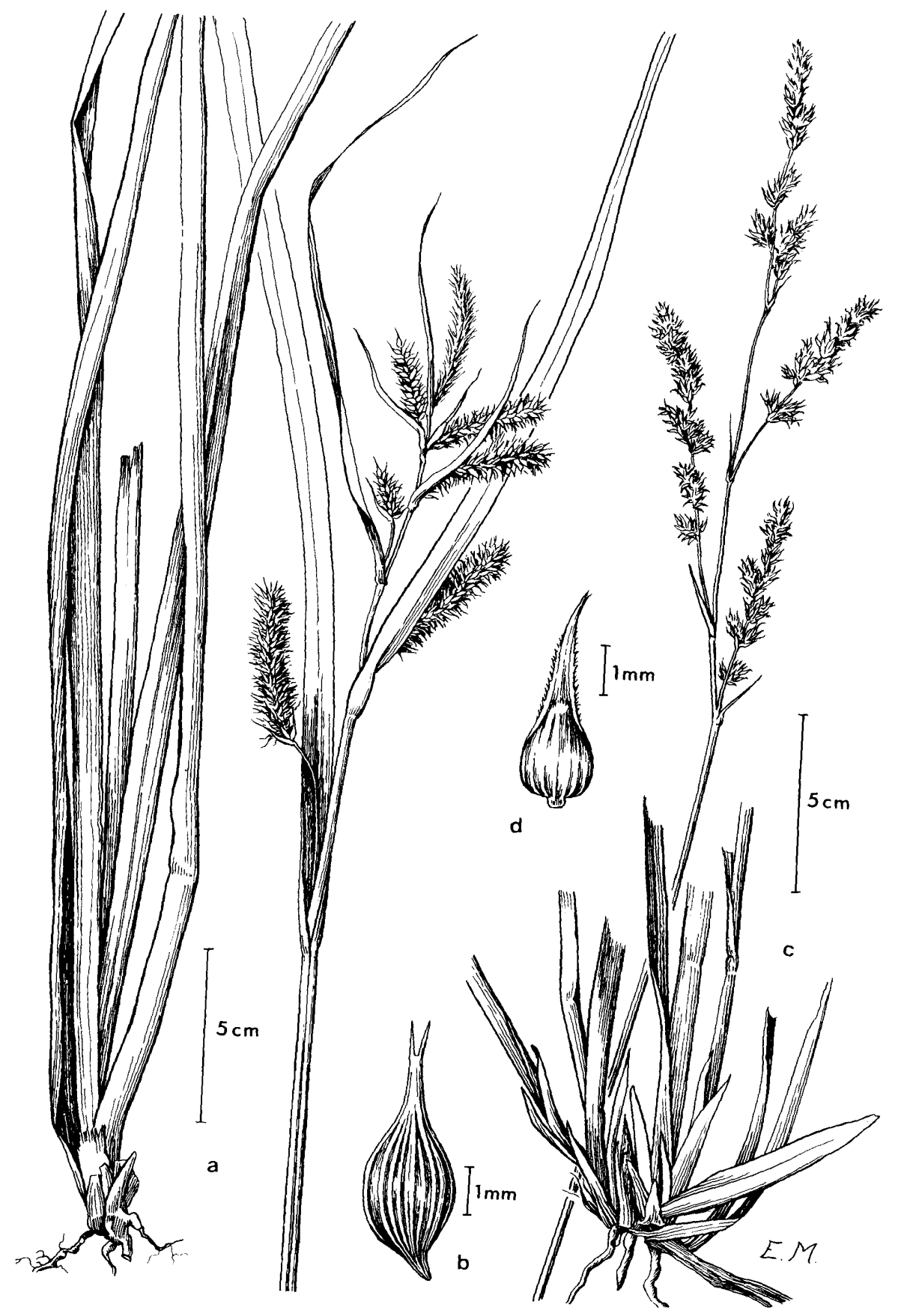

Fig. 178. Carex antoniensis and C. paniculata ssp. hansenii. a-b. C. antoniensis: a. Habit; b.
Utricle. c-d. C. paniculata Utricle. c-d. C. paniculata ssp. hansenii: c. Habit; d. Utricle. Drawn by E. Michels. Reprinted
from Lewejohann \& Lobin (1987), Senckenberg. Biol. 67 (with permission). 


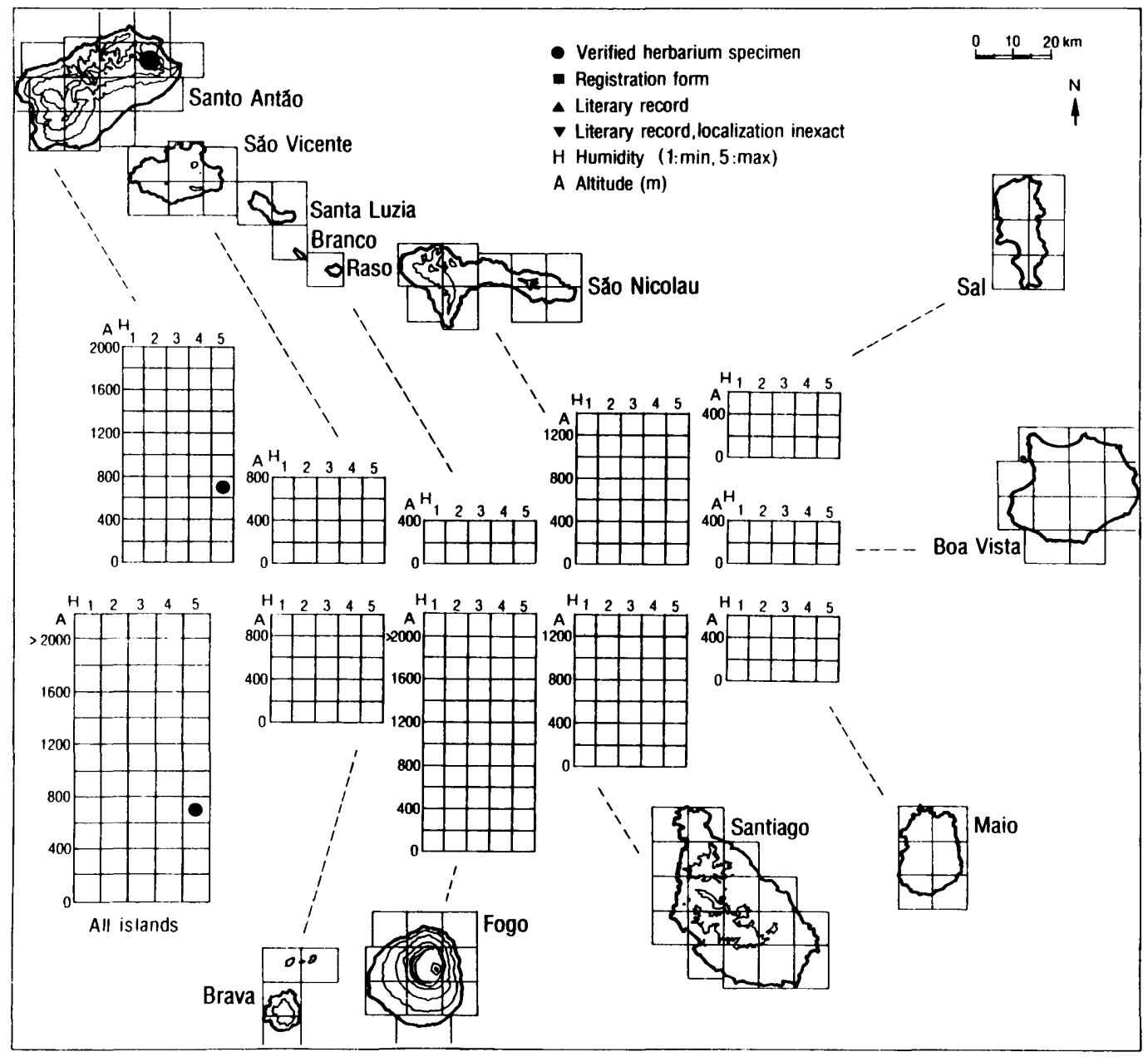

Fig. 179. Ecogeographic distribution of Carex antoniensis.

agriculture, and the species will most likely become extinct if its water supply changes as a result of increasing irrigation of cultivated land. Carex antoniensis is considered to be Critically Endangered (CR).

\section{Carex paniculata}

Carex paniculata Jusl. ex L., Cent. Pl. 1: 32 (1755). - Type: "Habitat in Europae australibus uliginosus" (holotype: LINN 1100/36).

Description. Densely cespitose, tussock-forming perennial up to $1.5 \mathrm{~m}$ high. Culm base entire, pale or blackish brown. Inflorescence lax, interrupted, $5-20 \mathrm{~cm}$ long. Spikes usually 
similar, the lowest ones sometimes female. Utricles $2.5-3(-4) \mathrm{mm}$ long, weakly to distinctly veined, beak winged.

Note. Five subspecies have been described of the mainly holarctic species Carex paniculata, differing in several utricle characters. Carex paniculata ssp. hansenii differs from the other subspecies by its larger utricles with long wings and distinct nerves (Lewejohann \& Lobin 1987). Subspecies paniculata is widely distributed in Europe, whereas the other four subspecies all have narrow distributions around this area: ssp. szovitsii (V. Kreczetovicz) Nilsson occurs in Krim, Caucasus, and NE Turkey; ssp. lusitanica (Schkuhr) Maire occurs in the Iberian Peninsula; ssp. calderae (Hansen) Lewej. \& Lobin occurs in the Canary Islands; and ssp. hansenii occurs in the Cape Verde Islands.

Carex paniculata ssp. hansenii (Figs 178, 180)

Carex paniculata Jusl. ex L. ssp. hansenii Lewej. \& Lobin, Senckenberg. Biol. 67: 440 (1987). - Type: Sto. Antão, oberer Teil der Ribeira da Torre, ca. $800 \mathrm{~m}$, in einer durchnässten Felswand, 20.4.1984, Heintze (holotype: FR!; isotypes: GOET!, herb. Lobin!).

Illustrations: Lewejohann \& Lobin (1987: Figs 1b, 2, 3c-d), Gomes et al. (1995b: p. 32).

Literature: Lewejohann \& Lobin (1987).

Description. Culms up to $1.2 \mathrm{~m}$ high, erect or overhanging, leafy, triangular. Leaves $3-4(-5)$ $\mathrm{mm}$ wide. Spikes all similar, with male and female flowers. Subtending bracts of all spikes much shorter than spikes. Lower bracts scabrous on the midrib, upper bracts pointed or aristate. Stigmas 3. Utricles (3.2-)3.8-4.2(-4.8) $\mathrm{mm}$ long and 1.4-1.8 $\mathrm{mm}$ broad, ovatelanceolate, ending in a long beak, winged in the upper part $(2 / 3$ of total length of utricle), veins prominent on dorsal side.

Variation. The material is homogeneous.

Chromosome number: Unknown.

Distribution and ecology. Carex paniculata ssp. hansenii is a northern hygrophyte with a very restricted distribution area. It is only known from a small area on northeastern montane Santo Antão (the upper parts of Ribeira da Torre, Ribeira do Paul (Covão), and the adjacent Cova area). The four known localities are situated in the humid zone between 800 and $1200 \mathrm{~m}$. The plants grow in northeast-facing, wet cliff walls.

Abundance. All populations have been recorded after 1980. The population in the upper part of Ribeira do Paul (Covão) was reported in 1934 (Chevalier 1935a) and rediscovered in 1995 (obs. Leyens, pers. comm.). The Ribeira da Torre population consists of a few plants covering an area of about $200 \times 100 \mathrm{~m}$. The subspecies is not directly influenced by agriculture because it inhabits inaccessible cliff walls, but it will probably become extinct if more water in this area is used for irrigation. Carex paniculata ssp. hansenii is considered to be Critically Endangered (CR). 


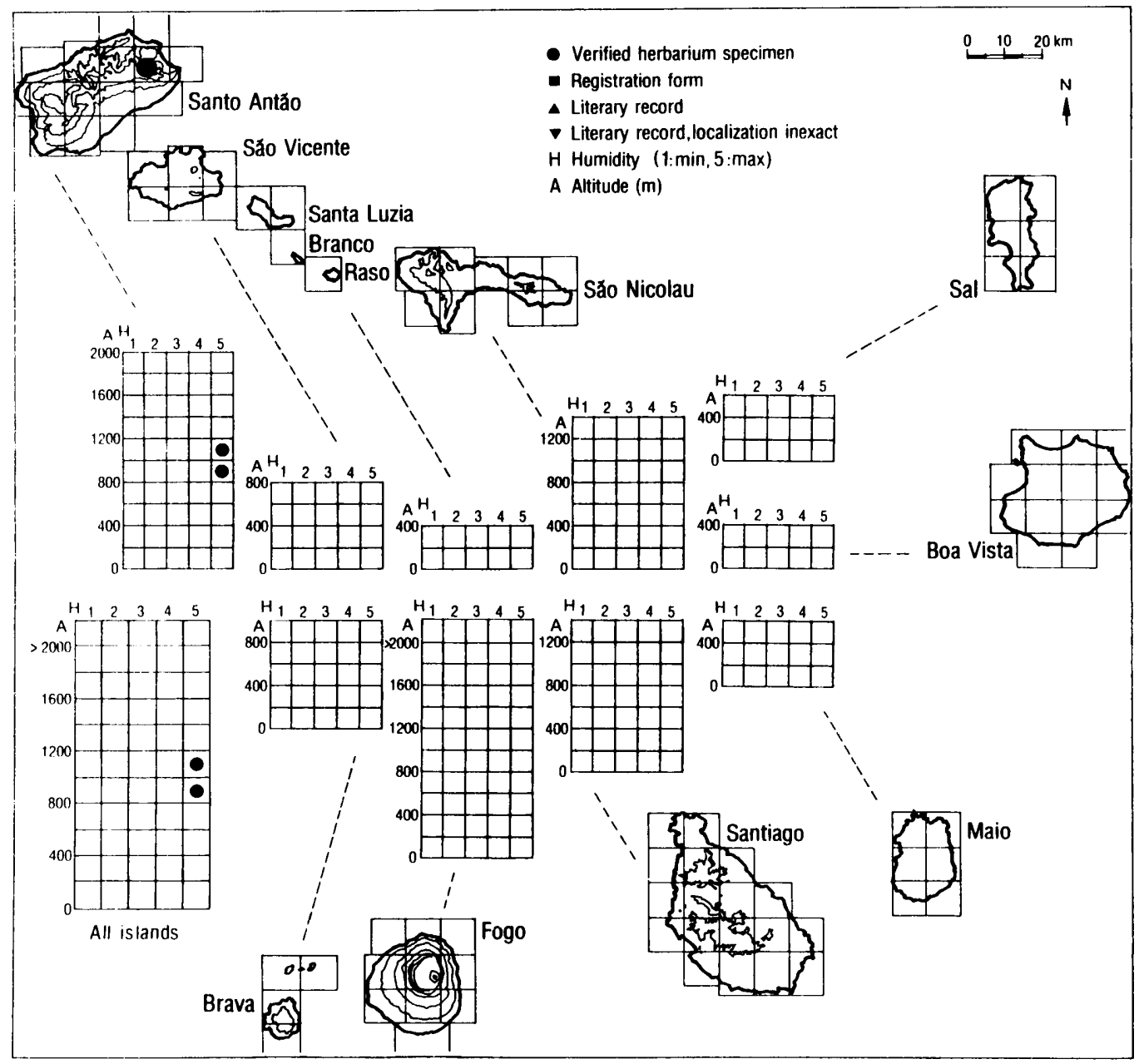

Fig. 180. Ecogeographic distribution of Carex paniculata ssp. hansenii.

\section{POACEAE}

This is the largest family in the archipelago with its 58 genera and 82 species and subspecies. Four species and subspecies are endemic (Köhler \& Lobin 1988). 


\section{Aristida L.}

The genus Aristida comprises about 250 annual and perennial species distributed in the tropics and subtropics. Some species, e.g., A. adscensionis L.. have a wide pantropical to pansubtropical distribution. The genus is represented by three species in the Cape Verde Islands, of which one is endemic.

Key to the genus Aristida

1 Awns long, more than $3 \mathrm{~cm}$, central and lateral awns almost equally long

1 Awns short, up to $2 \mathrm{~cm}$, central one longer than laterals [A. funiculata]

2 (1) Lemma with a nodule at the base of the awns, awns break off easily from the lemma A. cardosoi

2 Lemma without nodule, awns do not break off from the lemma [A. adscensionis]

Aristida cardosoi (Figs 181, 182)

Aristida cardosoi Cout., Arq. Univ. Lisboa 1: 273 (1914). - Syntypes: In ins. S. Antonii, 9.1893, Cardoso (LISU!); in ins. S. Nicolau, 11.1893, Cardoso (LISU [2 specimens]!). — Lectotype (designated by Lobin 1986b: 96): "Ilha de San Nicolau, Nov. ${ }^{\circ}, 1893$ ", Cardoso (LISU!).

Illustrations: Henrard (1926: Fig. on p. 88, 1929: Fig. 54 p.p.), Lobin (1986b: Fig. 3).

Literature: Henrard (1926, 1929).

Description. Cespitose, annual or perennial herb up to $0.5 \mathrm{~m}$ high. Stems ascending to erect. Leaves flat, up to $14 \mathrm{~cm}$ long and $0.2 \mathrm{~cm}$ wide, scabrous; ligule a ring of short hairs. Inflorescence a panicle with more or less appressed branches. up to $6 \mathrm{~cm}$ long. Spikelet 1-flowered, glumes almost equal. Lemma with a conspicuous, three-fid awn up to $23 \mathrm{~mm}$ long; awn with a distinct, basal nodule.

Variation. The awn length is variable, but the awns are always distinctly noduled.

Chromosome number: Unknown.

Related taxa. Aristida cardosoi is most closely related to the widely distributed $A$. adscensionis, which also is common in the Cape Verde Islands.

Distribution and ecology. Aristida cardosoi is a ubiquitous xerophyte occurring on all of the major islands: Santo Antão, São Vicente, Santa Luzia (including the islet of Raso). São Nicolau, Sal, Boa Vista, Maio, Santiago, Fogo, and Brava. It is most common in the arid, semiarid, and subhumid zones. The species is only known from a few localities in the extremely arid zone and the humid zone. It occurs from sea-level on most islands to $1780 \mathrm{~m}$ on Fogo (Gilli 1976). The plants grow in a wide array of habitats ranging from coastal sand dunes to montane plains. The species also occurs as a weed in cultivated areas.

Abundance. The species is common on most islands. The species was recently reported from Santa Luzia (Basto \& Diniz 1993) and Maio (Basto 1987a; Monte Penoso, leg. Kilian \& Leyens). Aristida cardosoi is generally considered to be Lower Risk (LR). 


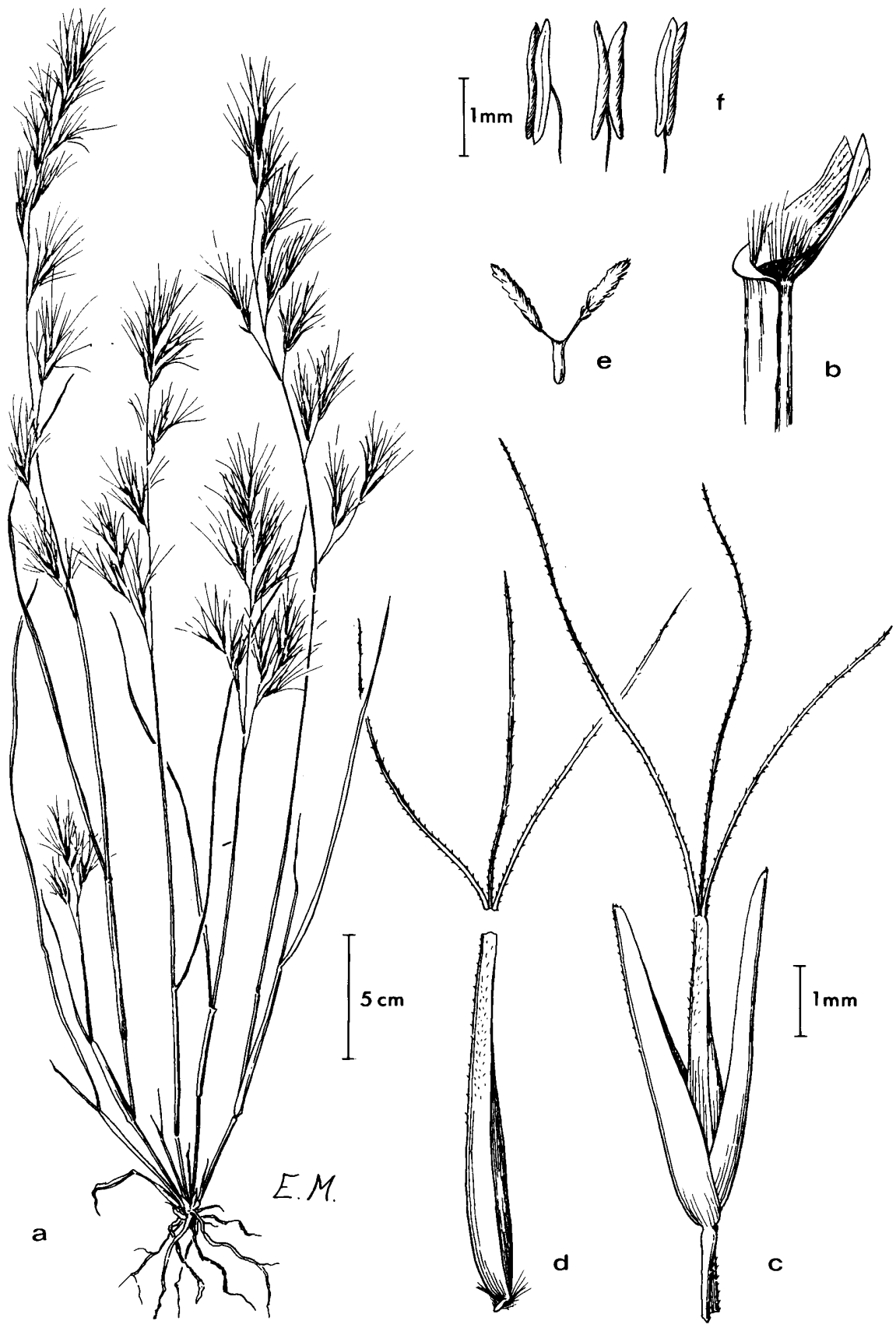

Fig. 181. Aristida cardosoi. a. Habit; b. Leaf showing ligula; c. Spikelet; d. Lemma; e. Stigma; f. Stamens. Drawn by E. Michels. 


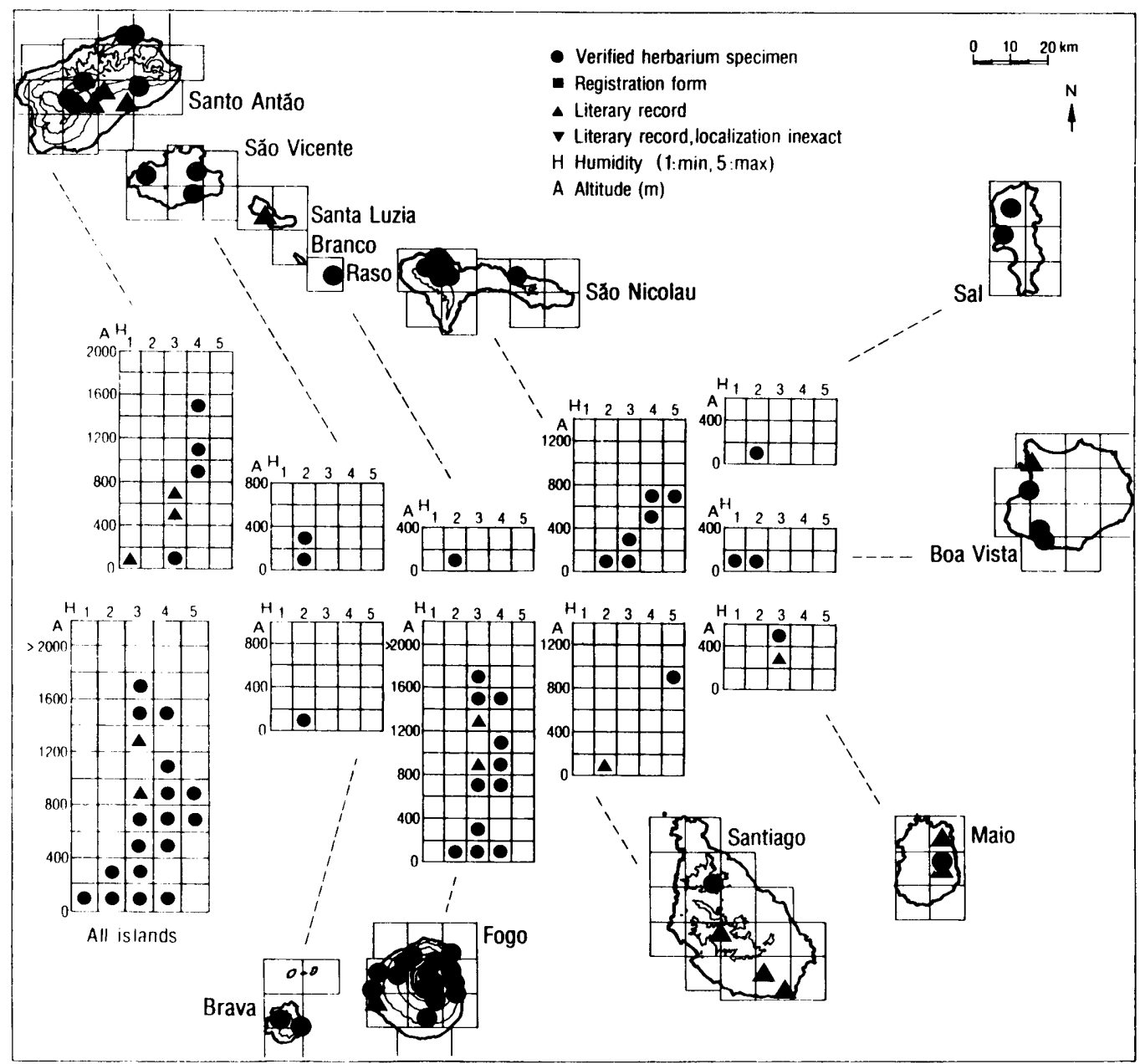

Fig. 182. Ecogeographic distribution of Aristida cardosoi.

Brachiaria (Trin.) Griseb.

The genus Brachiaria comprises about 80 tropical and subtropical species occurring in both hemispheres, but mainly in Africa. The species are annuals, some of them common ruderals, or perennials, often growing along streams, in muddy places, along forest margins, and only occasionally in grasslands. The genus is represented by five species in the archipelago, of which Brachiaria lata is represented with an endemic subspecies.

Literature: Köhler (1995). 
Key to the genus Brachiaria

1 Lamina and ligula densely silky hairy; spikelet $3.5-4.2 \mathrm{~mm}$ long, apically rostrate; basal, stalk-like part of lower glume $0.5-0.7 \mathrm{~mm}$ long..... [B. xantholeuca]

1 Lamina and ligula glabrous or scabrid or with long hairs on warty bases; spikelet usually ovate, apically not rostrate; basal, stalk-like part of lower glume up to $0.5 \mathrm{~mm}$ long or absent

2 (1) Lamina basally at the margin with long, stiff, erect hairs on warty bases or only with warts; peduncle of spikelet 0.3-0.8 mm long; spikelet always 3-flowered

B. lata ssp. caboverdiana

2 Lamina basally with glabrous or scabrid margin, never with warts or hairs with warty bases; spikelet always 2-flowered

3 (2) Spikelet 4.5-5 $\mathrm{mm}$ long, internode between glumes $0.5 \mathrm{~mm}$ long

[B. plantaginea]

3 Spikelet 2-3.4 $\mathrm{mm}$ long, internode between glumes $0.1 \mathrm{~mm}$ long .4

4 (3) Panicle lax, spreading, composed of racemes with spikelet pairs distantly arranged; peduncle of spikelet 6-10 mm long; spikelet 3-3.4 mm long; basal, stalk-like part of lower glume 0.2-0.4 mm long [B. deflexa]

4 Panicle condensed, composed of narrow racemes with spikelet pairs densely arranged; peduncle of spikelet 1-2(-3) mm long; spikelet 2.2-2.8(-3.2) $\mathrm{mm}$ long; basal, stalk-like part of lower glume $0.1-0.2 \mathrm{~mm}$ long [B. ramosa]

\section{Brachiaria lata}

Brachiaria lata (Schumach.) C. E. Hubb. in Hooker, Icon. Pl. 34: ad tab. 3363, p. 2 (1938) $\equiv$ Panicum latum Schumach., Beskr. Guin. Pl.: 6l (1827). - Type (see Hepper 1976: 144): "Guinea", Thonning 353 (C [2 sheets], S).

Description. Tufted annual, 0.3-0.6 $\mathrm{m}$ high, branched from near the base. Upper part of sheath and margin of leaf lamina ciliate with warty-based hairs towards the rounded base. Inflorescence of several racemes on a central axis. Spikelets 2-3-flowered, 2.5-3 mm long, mostly paired; pedicels $0.3-0.8 \mathrm{~mm}$ long, with long hairs.

Note. Brachiaria lata ssp. caboverdiana differs from ssp. lata $(2 \mathrm{n}=48$; Bolkhovskikh et al. 1969), which is distributed from W Africa to India, by its invariably three-flowered spikelets (Conert \& Köhler 1987). Subspecies caboverdiana represents a palaeotropic element in the Cape Verde Islands.

Brachiaria lata ssp. caboverdiana (Figs 183, 184)

Brachiaria lata (Schumach.) C. E. Hubb. ssp. caboverdiana Conert \& C. Köhler, Senckenberg. Biol. $67: 432$ (1987). - Type: Santiago, S. Jorge de Orgãos, entlang der Strasse von S. Jorge nach Picos, 8.9.1979, Lobin 351 (holotype: FR!; isotypes: B!, herb. Lobin!).

Illustration: Conert \& Köhler (1987: Fig. 1). 


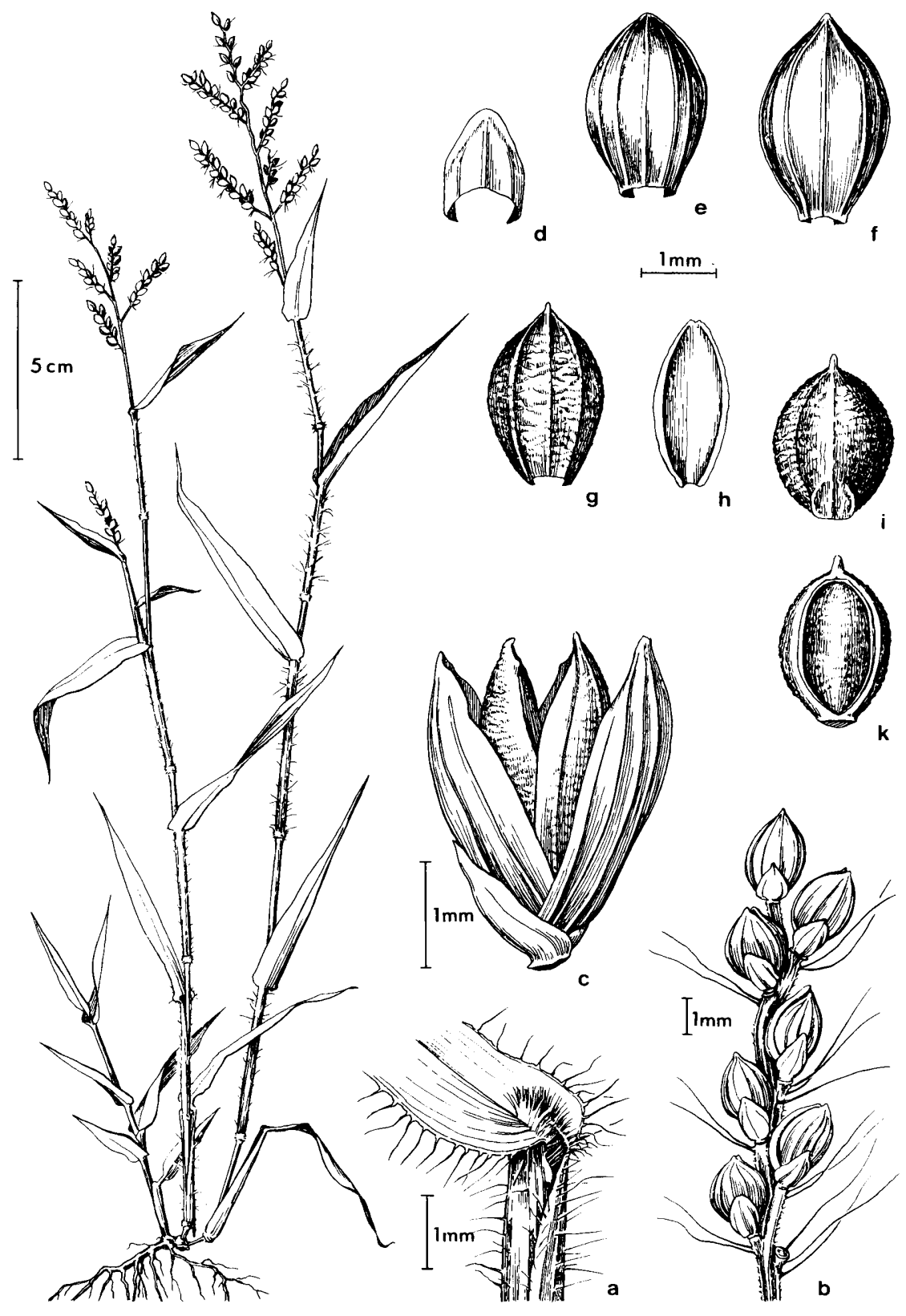

Fig. 183. Brachiaria lata ssp. caboverdiana. a. Part of leaf with ligula; b. Raceme; c. Spikelet. lateral view; d. Lower glume; e. Upper glume; f. Lemma of lowermost flower; g. Lemma of middle flower; h. Palea of middle flower; i. Uppermost flower, view from lemma; $\mathrm{k}$. Uppermost flower, view from palea. Drawn by E. Michels. Reprinted from Conert \& Köhler (1987), Senckenberg. Biol. 67 (with permission). 


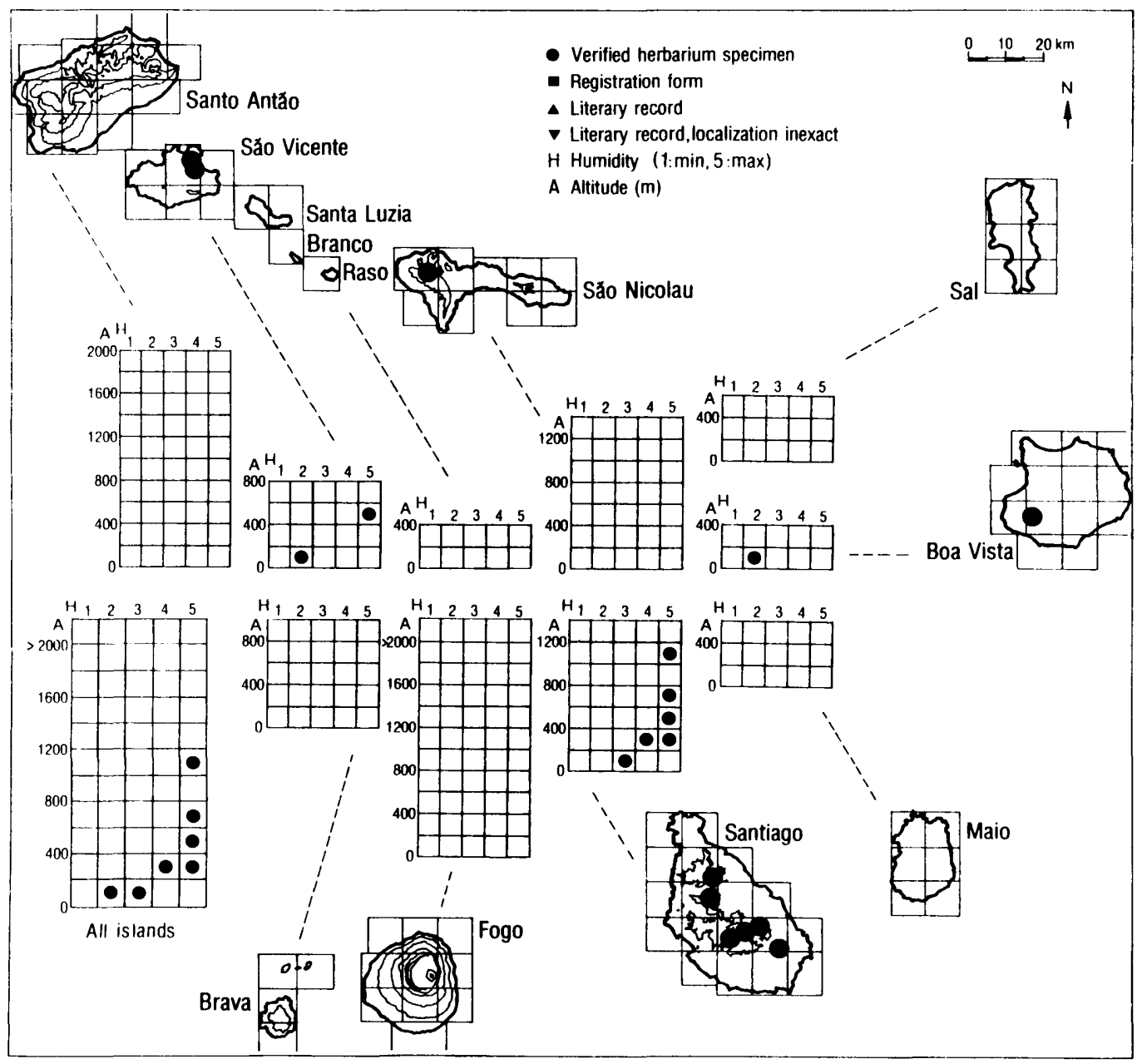

Fig. 184. Ecogeographic distribution of Brachiaria lata ssp. caboverdiana.

Description. Culms erect, glabrous to densely pubescent. Leaf lamina up to $16 \mathrm{~cm}$ long and 0.7-1.4 cm wide, margins basally with long hairs with warty bases, or only with warts; ligula hairy. Inflorescence a panicle with 4-10 spikes, peduncles with scattered, white, long hairs. Spikelets 3-flowered, glabrous. Glumes unequal, glabrous, herbaceous; lower glumes half the size of upper glumes, with 3 nerves; upper glumes with 7 nerves. Lemma as long as the upper glume, with 5 nerves. Upper flower sterile, middle flower male, lower flower hermaphrodite. Stamens 3.

Variation. The material shows no essential variation.

Chromosome number: $2 \mathrm{n}=48$ (Santiago, S. Domingos, Zizka 1986).

Distribution and ecology. Brachiaria lata ssp. caboverdiana is a ubiquitous xerophyte occurring on São Vicente, São Nicolau, Boa Vista, and Santiago. The distribution is probably 
insufficiently known because this taxon first was described in 1987. The subspecies has a wide ecological amplitude. It occurs in the arid, semiarid, subhumid, and humid zones, but most localities are situated in the humid zone. The main altitudinal distribution is between 200 $\mathrm{m}$ and $600 \mathrm{~m}$. It has been recorded at 50-100 m on São Vicente (leg. Köhler \& Lobin) and at Pico da Antonia on Santiago, probably above $1000 \mathrm{~m}$ (leg. Chevalier). The plants are often found as weeds in cultivated, usually irrigated fields, but they also grow in dry, gravelly slopes.

Abundance. The subspecies is still widespread on Santiago, and it has been collected on this island as well as São Vicente and Boa Vista after 1980. It is probably Extinct (EX) on São Nicolau; the only record from this island dates from 1891 (leg. Cardoso). The subspecies has only been recorded once on Boa Vista and three times in the Monte Verde area on São Vicente, and it is considered Vulnerable (VU) on these islands. Brachiaria lata ssp. caboverdiana is generally considered to be Vulnerable (VU).

\section{Eragrostis Wolf}

The genus Eragrostis comprises some 350 annual and perennial species distributed in tropical and subtropical regions throughout the world. Some species are economically important. The genus is represented by nine species in the Cape Verde Islands, of which one, E. conertii, is endemic to the archipelago.

Literature: Köhler (1988).

Key to the genus Eragrostis

1 Disarticulation of spikelet commencing at base ....................................................

1 Disarticulation of spikelet commencing at top ...................................................... 4

2 (1) Palea keels hirsute, without long cilia [E. japonica]

2 Palea keels ciliate, cilia 0.2-0.7 mm long. 3

3 (2) Stamens 2; palea with $0.4-0.7 \mathrm{~mm}$ long cilia...................................... [E. ciliaris]

3 Stamens 3; palea with $0.2-0.3 \mathrm{~mm}$ long cilia ............................................. [E. tenella]

4 (1) Palea falling off at same time as lemma .............................................. [E. pilosa

4 Lemma dehiscent together with fruit, palea retained on rachilla ................................5

5 (4) Plant annual; secondary axis always carrying panicles ....................................6

5 Plant perennial; sterile innovations usually present ................................................. 8

6 (5) Margin of lamina and keel of lemma without glands .............................. [E. barrelieri]

6 Margin of lamina and occasionally keel of lemma with small, cup-shaped glands .............7 
7 (6) Spikelet 3-4 mm broad; lemma 2.2-2.5 mm long; upper glume (2-)2.3-2.5(-2.7) mm long [E. cilianensis $]$

7 Spikelet 1.5-2.1 mm broad; lemma 2-2.2 mm long; upper glume (1.5-)1.8-2.1(-2.3) mm long

[E. minor]

8 (5) Stamens 2; spikelet 2-2.5 mm broad; lemma 2-2.2 mm long

8 Stamens 3; spikelet (1-)1.1-1.8 mm broad; lemma (1.2-)1.3-1.8(-1.9) $\mathrm{mm}$ long

[E. squamata]

..E. conertii

Eragrostis conertii (Figs 185, 186)

Eragrostis conertii Lobin, Willdenowia 16: 143 (1986). - Type: Sto. Antão, oberer Teil der Ribeira Janela, 900-1100 m, 19.11.1982, Lobin 2519 (holotype: FR!; isotypes: B!, GOET!, herb. Lobin!).

Illustrations: Lobin (1986a: Figs 1-3), Köhler (1988: Figs 9, 10).

Description. Cespitose, perennial herb. Stems procumbent, up to $0.5 \mathrm{~m}$ long. Leaves up to 30 $\mathrm{cm}$ long and $0.5 \mathrm{~cm}$ wide; ligule a ring of whitish hairs up to $4 \mathrm{~mm}$ long. Inflorescence a dense, greyish green panicle up to $26 \mathrm{~cm}$ long and $1.5 \mathrm{~cm}$ broad, lanceolate in outline. Spikelets 3-12-flowered, up to $12 \mathrm{~mm}$ long; glumes almost equal.

Variation. The species is fairly homogeneous. The number of flowers per spikelet is very variable, even within a single specimen.

Chromosome number: Unknown.

Related taxa. Eragrostis conertii is most closely related to E. braunii Schweinf., an afro-montane species occurring in NE Africa and the S Arabian peninsula at altitudes above $2000 \mathrm{~m}$. Eragrostis conertii differs from E. braunii by its procumbent habit, eglandular leaves, and almost equal glumes. Eragrostis conertii also resembles the Mediterranean $E$. barrelieri Daveau, which occurs in several of the Cape Verde Islands, but E. conertii is distinguished from this species by its almost equal glumes and perennial habit.

Distribution and ecology. Eragrostis conertii is a western hygrophyte distributed on the islands of Santo Antão, São Vicente, São Nicolau, Santiago, and Fogo, but it is absent from Brava. It occurs in the subhumid and humid zones in montane areas. The lowermost record is at $500 \mathrm{~m}$ on southeastern Fogo, and the uppermost one at $1250 \mathrm{~m}$ in the northern part of the same island (Lobin 1986a). The plants usually grow in northwest- to east-exposed, steep cliffs.

Abundance. The distribution and abundance may be insufficiently known on Santiago and Fogo, because the species first was described in 1986. Eragrostis conertii is, however, Rare (R) on Santo Antão, São Vicente, and São Nicolau, and it is generally considered to be Rare (R). 


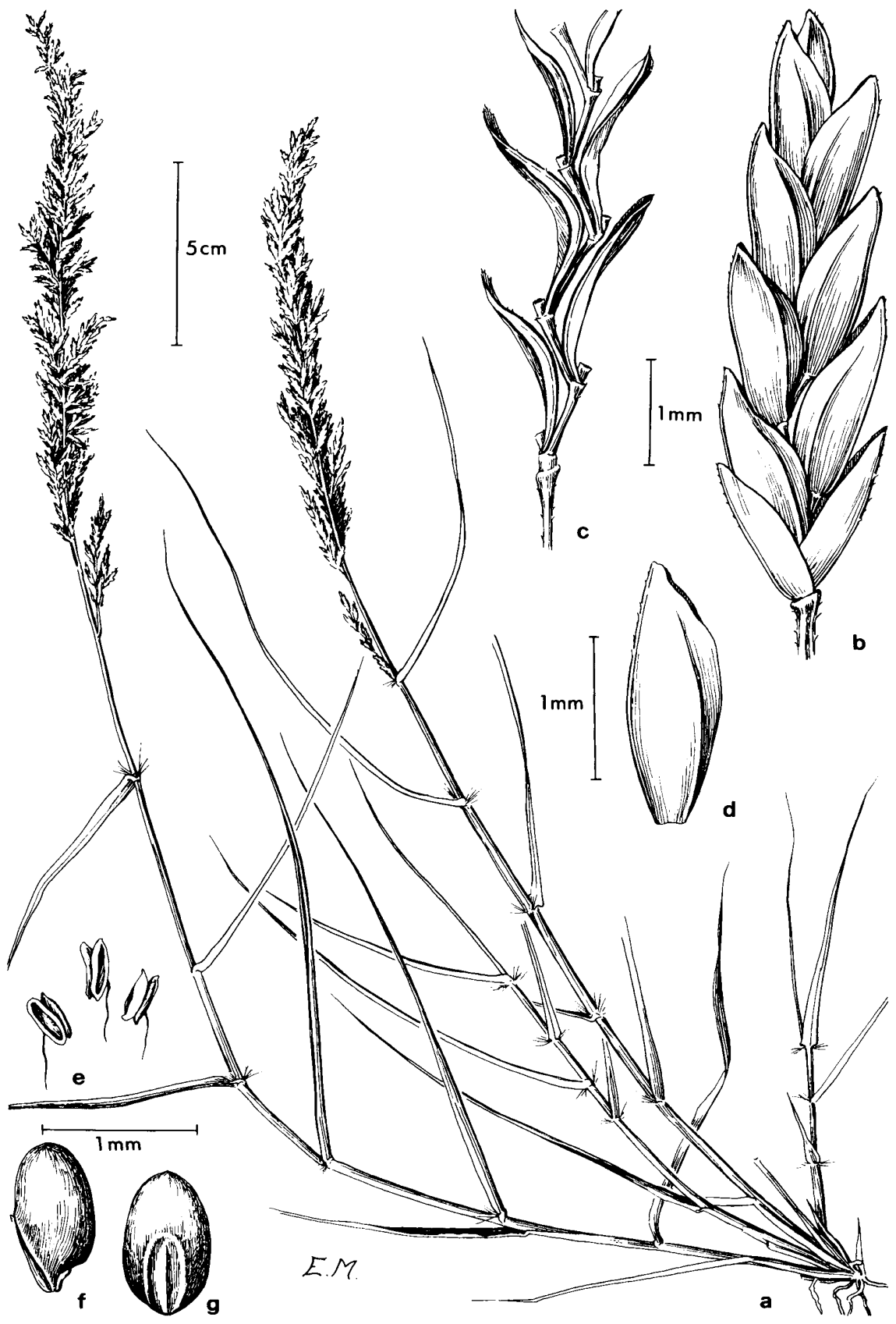

Fig. 185. Eragrostis conertii. a. Habit; b. Spikelet; c. Spikelet showing paleas; d. Lemma; e. Stamens; f. Fruit, lateral view; g. Fruit, viewed from the embryo side. Drawn by E. Michels. Reprinted from Lobin (1986a), Willdenowia 16 (with permission). 


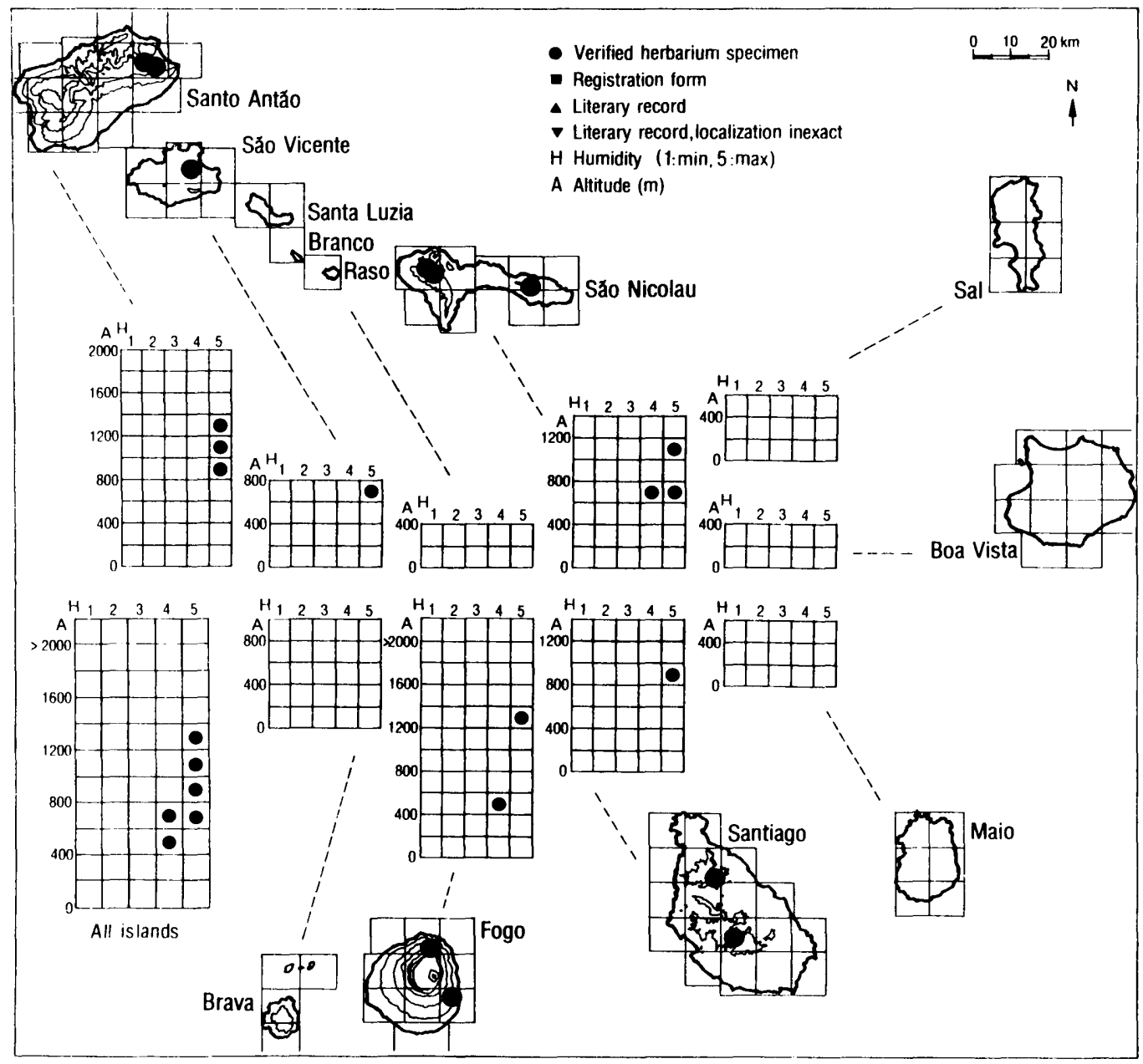

Fig. 186. Ecogeographic distribution of Eragrostis conertii.

Sporobolus R. Br.

The genus Sporobolus comprises about 160 annual and perennial species, mainly distributed in subtropical and tropical regions. In the Cape Verde Islands, the genus is represented by seven species. Sporobolus minutus is represented by two subspecies, of which one is endemic.

Literature: Conert \& Lobin (1985). 
Key to the genus Sporobolus

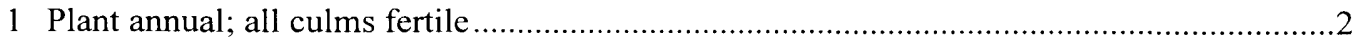

1 Plant perennial; with fertile culms and many leafy, sterile culms.....................................5

2 (1) Panicles with horizontal, distinctly spreading branches

.[S. minutus ssp. minutus]

2 Panicles contracted with branches appressed to the main axis or branches erectly spreading

3 (2) Lemma and glume narrow and subulate in upper half. [S. molleri $]$

3 Lemma and glume lanceolate to longish, acute ...4

4 (3) Spikelet 1.2-1.5 mm long; lower glume up to $0.5 \mathrm{~mm}$ long, ovate, often emarginate; upper glume $1.2 \mathrm{~mm}$ long

$S$. minutus ssp. confertus

4 Spikelet 2-2.4 mm long; lower glume $1.5 \mathrm{~mm}$ long, lanceolate, acuminate; upper glume 2 $\mathrm{mm}$ long.....

[S. piliferus]

5 (1) Plant with contracted, cylindrical panicles 6

5 Plant with loose panicles 7

6 (5) Culm only basally leafy; lamina convolute, pungent; spikelet 2.2-2.8 $\mathrm{mm}$ long

[S. spicatus]

6 Culm densely, distichously leafy upwards; lamina stiff, but not pungent; spikelet 1.6-2.2 $\mathrm{mm}$ long. [S. virginicus $]$

7 (5) Plant green; culm stout, basally $2-3 \mathrm{~mm}$ in diameter; glume lanceolate, acute

[S. robustus]

7 Plant greyish green; culm slender, basally $1 \mathrm{~mm}$ in diameter; glume linear-lanceolate, acuminate. [S. helvolus $]$

\section{Sporobolus minutus}

Sporobolus minutus Link, Hort. Berol. 1: 88 (1827). — Lectotype (designated by Lobin 1982c: 40): [Eritrea], Dhalac [island], 1829-26, C. G. Ehrenberg (B!; isolectotypes: B!, K!).

Illustration: Conert \& Lobin (1985: Fig. 3a-e, S. minutus ssp. minutus).

Description. Delicate, cespitose, short-living annual up to $0.15(-0.20) \mathrm{m}$ high; culms ascending to erect, glabrous, with 2-3 nodes. Leaves with glabrous sheath, ligula a corona of 0.3-0.5 mm long hairs, lamina glabrous, up to $4 \mathrm{~cm}$ long and up to $1.5 \mathrm{~mm}$ wide. Panicle up to $4 \mathrm{~cm}$ long, brownish, at least lower branches up to 4-8 at each node, with horizontally spreading or appressed erect branches; main axis, branches and peduncles of the spikelets glabrous and with narrowly elliptical, sunken glands. Spikelet up to $1.3 \mathrm{~mm}$ long, lanceolate, acute; glumes differing from each other, membranous, glabrous; lower glume 0.3-0.5 mm long, ovate, apically often emarginate; upper glume 1-veined, 0.7-0.9 mm long, broadly lanceolate, acute; lemma 1-veined, 1-1.2 mm long, ovate-lanceolate, acute, membranous, glabrous; palea somewhat shorter than lemma, broadly elliptical. Stamens 2(-3), anthers 0.2 


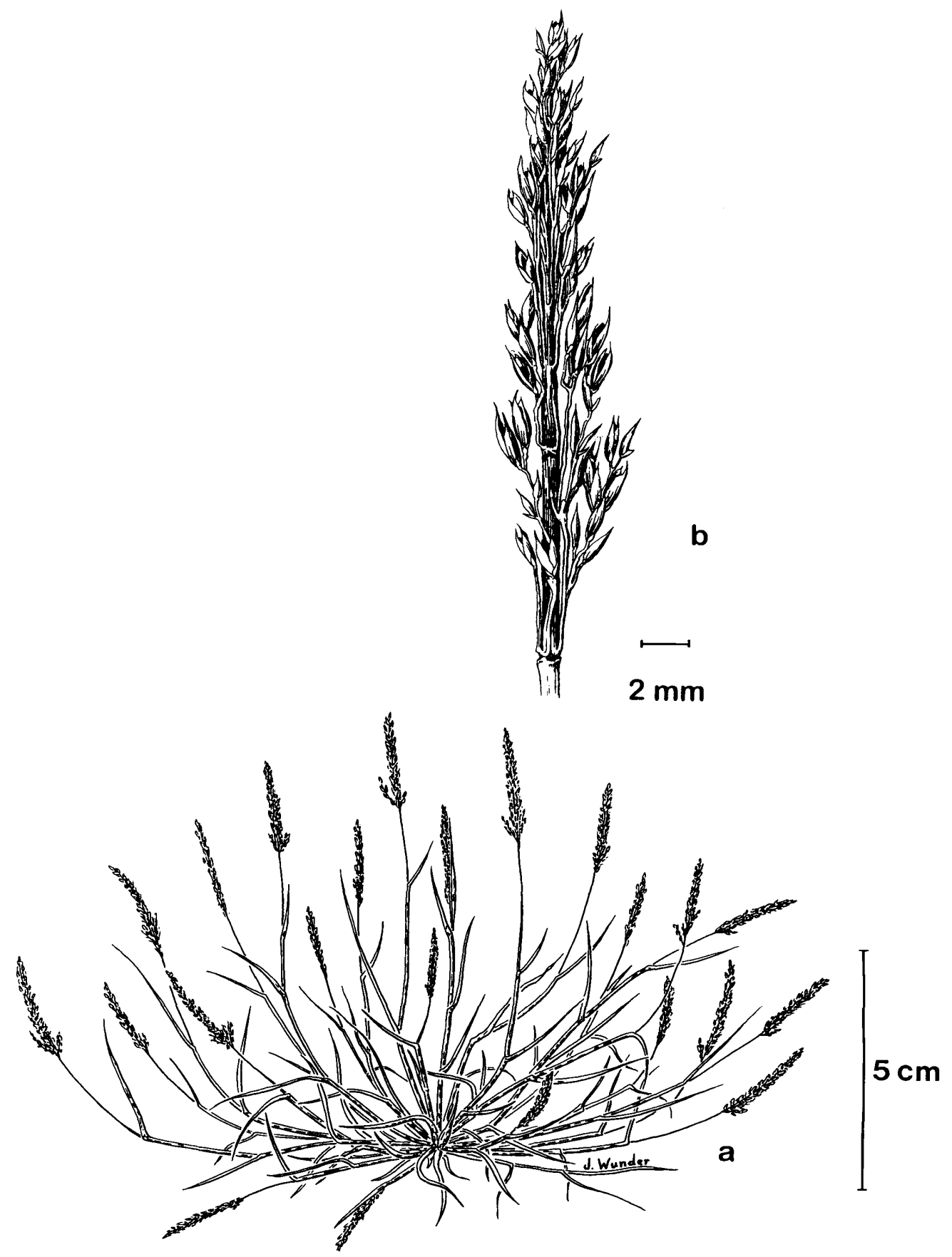

Fig. 187. Sporobolus minutus ssp. confertus. a. Habit; b. Panicle. Drawn by J. Wunder (a) and E. Michels (b). 


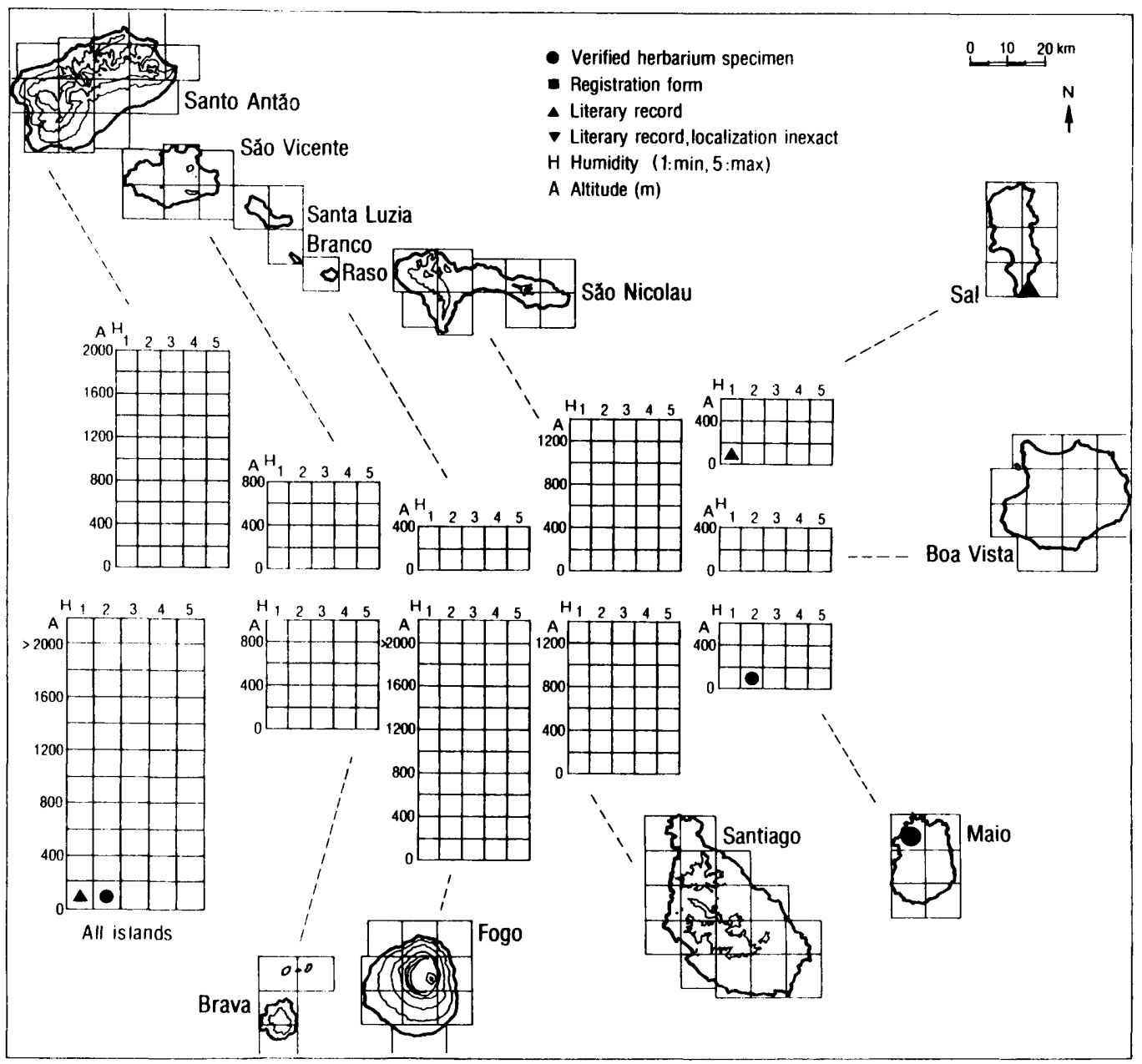

Fig. 188. Ecogeographic distribution of Sporobolus minutus ssp. confertus.

$\mathrm{mm}$ long. Caryopse 0.5-0.7 mm long, glabrous, elliptical in outline, laterally somewhat compressed.

Variation. Two forms are known of this species, recognized at the subspecific level: ssp. confertus with strongly contracted panicles, and ssp. minutus with distinctly horizontally spreading panicles. The subspecies may grow in the same sites in inundation areas. In ssp. confertus, the axils of the inflorescence branches are destitute of pulvini. No intermediates have been observed, and cultivated progeny of each subspecies remain constant in this character (Gomes et al. 1995a). The form with contracted panicles was described by Schmidt (1852) as a distinct species, Sporobolus confertus, but it was recently considered more appropriately classified as a subspecies of $S$. minutus (Gomes et al. 1995a). 
Note. Sporobolus minutus ssp. minutus has a remarkable, disjunct distribution, occurring mainly in coastal, saline habitats in E Africa (S Egypt, Sudan, Eritrea, and Somalia) and the Cape Verde Islands (Lobin 1982c). This subspecies is generally rare, also in the Cape Verde Islands. In this archipelago, it is known only from a few collections: Sal, at the salt-pit near Santa Maria, 1852, leg. Schmidt; Maio, Terras Salgadas Salinas near Morrinho. 1964, leg. Malato-Beliz and Guerra (Malato-Beliz 1970), 1979, leg. Lobin (Conert \& Lobin 1985), 1994, leg. Kilian \& Leyens (Gomes et al. 1995a). Subspecies confertus is only known from the Cape Verde Islands.

Sporobolus minutus ssp. confertus (Figs 187, 188)

Sporobolus minutus Link ssp. confertus (J. A. Schmidt) Lobin, N. Kilian \& Leyens, Willdenowia 25: 192 (1995) =Sporobolus confertus J. A. Schmidt, Beitr. Fl. Cap Verd. Ins.: 142 (1852). - Type: In locis humidiusculis ins. Salis, 2.1851, J. A. Schmidt (holotype: HBG!; isotypes: GOET!, MB!, O!, S!, W!).

Illustration: Conert \& Lobin (1985: Fig. 3f).

Literature: Conert \& Lobin (1985), Gomes et al. (1995a).

Description. Very similar to the typical subspecies except for the panicle, which is strongly contracted with branches appressed to the main axis.

Variation. The two known collections are morphologically very similar.

Chromosome number: Unknown.

Distribution and ecology. Sporobolus minutus ssp. confertus is an eastern xerophyte occurring on Sal and Maio. It is strictly limited to narrow belts with moderate salinity in inundation areas near the coast. Its life cycle is apparently very short, lasting only a few weeks, and its occurrence depends on irregular rain falls leading to inundations in arid areas. Thus, the subspecies may be absent for several years.

Abundance. Sporobolus minutus ssp. confertus was only known from the type collection from Sal made in 1851 until it was rediscovered on Maio in 1994 (Gomes et al. 1995a). It is considered Extinct (EX) on Sal and generally classified as Rare (R). 


\section{EXCLUDED TAXA}

The list comprises taxa that have been described on material from the Cape Verde Islands, but excluded from the taxonomic part because they were considered non-endemic or of doubtful taxonomic significance.

Adiantum capillus-gorgonis Webb in Hooker, Niger Fl.: $192(1849)=$ Adiantum incisum Forssk. (Lobin 1986b: 95).

Adiantum trifidum Willd. ex Bolle, Bonplandia 3(10): 121 (1855)= Adiantum capillus-veneris L. (Lobin 1986b: 95).

Antirrhinum orontium L. var. foliosum J. A. Schmidt, Beitr. Fl. Cap Verd. Ins.: 243 (1852) $\equiv$ Misopates orontium (L.) Raf. var. foliosum (J. A. Schmidt) Ormonde, Garcia de Orta, Sér. Bot. 4: $180(1980)=$ Misopates orontium (L.) Raf. (Lobin 1986b: 96).

Arenaria gorgonea J. A. Schmidt, Beitr. Fl. Cap Verd. Ins.: 278 (1852) = Arenaria leptoclados (Rchb.) Guss. (Hansen \& Sunding 1985: 107).

Aristida concinna Sonder ex J. A. Schmidt, Beitr. Fl. Cap Verd. Ins.: 140 (1852) = Stipagrostis uniplumis (Licht.) De Winter (Clayton 1972: 376).

Aristida paradoxa Steud. ex J. A. Schmidt, Beitr. Fl. Cap Verd. Ins.: $140(1852)=$ Aristida funiculata Trin. \& Rupr. (Lobin 1986b: 96).

Asplenium hemionitis L. var. productum Bolle, Z. Allg. Erdk, ser. 2. 17: $266(1864)=$ Asplenium hemionitis L. (Lobin 1986b: 98).

Asplenium polydactylon Webb in Hooker, Niger Fl.: 193 (1849) = Actiniopteris radiata (Sw.) Link (Pichi-Sermolli 1962: 15).

Borago tristis Forst. f., Comm. Soc. Regiae Sci. Gott. 9: 41 (1787) = Trichodesma africanum (L.) Lehm. (Lobin 1986b: 100).

Brassica oleracea L. var. glauca A. Chev., Rev. Bot. Appl. Agric. Trop. 15: 990 (1935) = Brassica oleracea L. (Lobin 1986b: 100).

Chloris cryptostachya J. A. Schmidt, Beitr. Fl. Cap Verd. Ins.: 148 (1852) = Chloris prieurii Kunth (Anderson 1974: 42).

Chloris nigra Hackel, Bol. Soc. Brot. 21: $179(1905)=$ Chloris pilosa Schum. (Anderson 1974: 58).

Cistanche lutea (Desf.) Hoffm. \& Link f. minor Bég., Ann. Mus. Civico Storia Nat. Giacomo Doria, Ser. 3, 8: $47(1920)=$ Cistanche phelypaea $($ L.) Cout. (Lobin 1986b: 135).

Conyza odontoptera Webb in Hooker, Niger Fl.: $135(1849)=$ Blumea pterodonta DC. (Heim 1984: 171).

Conyza pterocaulon Bolle, Bonplandia 7: 295 (1859) - nom. dubium (Heim 1984: 173).

Corchorus quadrangularis J. A. Schmidt, Beitr. Fl. Cap Verd. Ins.: 293 (1852) = Corchorus trilocularis L. (Chevalier 1935a: 943).

Cressa cretica L. var. salina J.A. Schmidt, Beitr. Fl. Cap Verd. Ins.: 243 (1852) = Cressa cretica L. (Lobin 1986c: 155).

Ctenium rupestre J. A. Schmidt. Beitr. Fl. Cap Verd. Ins.: $149(1852)=$ Enteropogon rupestre (J. A. Schmidt) A. Chev. (Lobin 1986b: 107).

Cuscuta notochlaena A. Chev., Rev. Bot. Appl. Agric. Trop. 15: 921 (1935) = Cuscuta planiflora Ten. (Hansen \& Sunding 1985: 117). 
Cyperus cadamostii Bolle, Bot. Jahrb. Syst. 14: 400 (1892) = Cyperus conglomeratus Rottb.. syn. nov.

C'yperus sonderi J. A. Schmidt, Beitr. Fl. Cap Verd. Ins.: 162 (1852) = Pycreus polystachyus (Rottb.) P. Beauv. (Chevalier 1935a: 1029).

Dalechampia senegalensis A. Juss. ex Webb in Hooker, Niger F1.: 174 (1849) = Dalechampia scandens L. var. cordofana Muell. Arg. (Carter et al. 1984: 434).

Dolichos daltonii Webb in Hooker, Niger Fl.: 125 (1849) = Macrotyloma daltonii (Webb) Verdc. (Verdcourt 1970: 401).

Dryopteris elongata (Aiton) A. Chev. var. simplex A. Chev., Rev. Bot. Appl. Agric. Trop. 15: $1060(1935)=$ Dryopteris oligodonta (Desv.) Pichi-Serm. (Fraser-Jenkins 1982: 252).

Elionurus grisebachii J. A. Schmidt, Beitr. Fl. Cap Verd. Ins.: $154(1852)=$ Elionurus royleanus Nees ex A. Rich. (Pettersson 1960: 62).

Epibaterium pendulum J. R. \& G. Forst., Char. Gen. Pl.: $108(1775)=$ Cocculus pendulus (J. R. \& G. Forst.) Diels (Lobin 1986b: 111).

Eragrostis insulatlantica A. Chev., Rev. Bot. Appl. Agric. Trop. 15: 1042 (1935) = Eragrostis barrelieri Daveau (Köhler 1984: 193).

Eragrostis pulchella Parl., Atti $8^{\mathrm{e}}$ Riun. Sci. Ital. Genova: $586(1847)=$ Eragrostis ciliaris (L.) R. Br. (Chevalier 1935a: 1042).

Euphorbia hypericifolia L. var. pusilla Webb in Hooker, Niger Fl.: 176 (1849)= Euphorhia glaucophylla Poir., syn. nov.

Evolvulus linifolius L. var. grandiflorus Bolle, Bonpandia 9(1): 55 (1861) = Evolvulus alsinoides L. var. linifolius (L.) Baker (Lobin 1986b: 113).

Fagonia albiflora A. Chev., Rev. Bot. Appl. Agric. Trop. 15: 961 (1935) - status doubtful.

Fagonia mayana Schltdl., Bot. Zeit. 9: 844 (1851) — status doubtful.

Fimbristylis ferruginea (L.) Vahl var. graminea Ridley, Trans. Linn. Soc., ser. 2, 2: 149 $(1884)=$ Fimbristylis ferruginea $(\mathrm{L}$.$) Vahl (Coutinho 1914: 276).$

Forsskaolea viridis Ehrenb. ex Webb in Hooker, Niger Fl.: 179 (1849) - (Lobin 1986b: 116).

Fumaria montana J. A. Schmidt, Beitr. Fl. Cap Verd. Ins.: 263 (1852) - (Lidén 1986: 72).

Gnaphalium luteo-fuscum Webb in Hooker, Niger Fl.: 143 (1849) ?= Pseudognaphalium luteo-album $\mathrm{L}$.

Gossypium barbosanum Clement \& Phillips, Bot. Mus. Leafl. 20: 214 (1963) = Gossypium anomalum Wawra ex Wawra \& Peyr. ssp. senarense (Wawra \& Peyr.) Vollesen (Vollesen 1987: 339; Gomes et al. 1995a: 189).

Gossypium capitis-viridis Mauer, Trudy Sredne Aziatsk. Gosud. Univ. Lenina ser. 2, 18: 19 $(1950)=$ Gossypium anomalum Wawra ex Wawra \& Peyr. ssp. senarense (Wawra \& Peyr.) Vollesen (Vollesen 1987: 339; Gomes et al. 1995a: 189).

Gymnanthemum bolleanum Steetz in Peters, Naturw. Reise Mossambique, Bot. 2: 336 [in footnote] $(1864)=$ Vernonia colorata $($ Willd.) Drake (Gomes et al. 1995a: 184).

Habenaria petromedusa Webb in Hooker, Niger Fl.: 180 (1849) - nom. dubium.

Indigofera anil L. var. canescens J. A. Schmidt, Beitr. Fl. Cap Verd. Ins.: 326 (1852) $\equiv$ Indigofera suffruticosa Mill. var. canescens (J. A. Schmidt) Lobin, Cour. Forsch.-Inst. Senckenberg 81: 118 (1986) = Indigofera suffruticosa Mill., syn. nov.

Indigofera tinctoria L. var. microcarpa A. Chev., Rev. Bot. Appl. Agric. Trop. 15: 969 (1935) = Indigofera tinctoria L., syn. nov. 
Inula leptoclada Webb in Hooker, Niger F1.: 137 (1849) = Vicoa leptoclada (Webb) Dandy (Lobin 1986b: 118).

Ipomoea dubia Cout., Arq. Univ. Lisboa 2: $45(1915)=$ Ipomoea acanthocarpa (Choisy) Asch. \& Schweinf. (Lobin 1986b: 120).

Ipomoea pes-caprae (L.) Sw. var. lamarckii Bolle, Bonplandia 9(1): 53 (1861) = Ipomoea asarifolia (Desr.) Roem. \& Schult. (Chevalier 1935a: 917; Lobin 1986c).

Ipomoea sancti-nicolai Bolle, Bonplandia 9(1): 53 (1861) - nom. dubium.

Ipomoea sessiliflora Roth var. angustifolia Bolle. Bonplandia 9(1): 53 (1861) = Ipomoea eriocarpa R. Br. (Lobin 1986b: 120).

Ipomoea sessiliflora Roth var. latifolia Bolle, Bonplandia 9(1): 53 (1861) = Ipomoea eriocarpa $\mathrm{R}$. Br. (Lobin 1986b: 120).

Ipomoea webbii Cout., Arq. Univ. Lisboa 1: 304 (1914) = Ipomoea triloba L. (Berhaut 1975: $163)$.

Lactuca nudicaulis (L.) Murray var. major Bolle, Bonplandia 8(7): $136(1860)=$ Launaea intybacea (Jacq.) P. Beauv. (Kilian 1988: 144).

Launaea melanostigma Pett., Comm. Biol. Soc. Scient. Fenn. 22(9): $60(1960)=$ Launaea arborescens (Batt.) Murb. (Brochmann \& Rustan 1988: 31; Kilian 1988: 122).

Lavandula dentata L. var. candicans Batt. \& Trabut. Fl. Alg. 2: $666(1888)=$ Lavandula dentata L., syn. nov.

Lavandula dentata L. var. rendalliana Bolle, Bonplandia 8(17/18): $280(1860)=$ Lavandula dentata L., syn. nov.

Lycopodium cernuum L. var. caboverdeanum Gilli, Verh. Zool.-Bot. Ges. Wien 115: 39 $(1976)=$ Lycopodium cernuum L. $($ Lobin 1986b: 126).

Malva velutina J. A. Schmidt, Beitr. Fl. Cap Verd. Ins.: $282(1852)=$ Malva parviflora L. (Lobin et al. 1988b: 69).

Malvastrum spicatum (L.) A. Gray var. mollissima A. Chev., Rev. Bot. Appl. Agric. Trop. 15: $944(1935)=$ Malvastrum americanum (L.) Torr. (Lobin 1986b: 126).

Manoelia pallida S. \& T. E. Bowdich, Exc. Mad. Port. Sant.: 381 (1826) = Withania somnifera (L.) Dunal (Chevalier 1935a: 902).

Monachyron Parl. in Hooker, Niger Fl.: $191(1849)=$ Rhynchelytrum Nees (Lobin 1986b: 127).

Monachyron villosum Parl. in Hooker, Niger Fl.: 191 (1849) = Rhynchelytrum villosum (Parl.) Chiov. (Lobin 1986b: 127).

Panicum daltonii Parl., Atti $8^{\mathrm{e}}$ Riun. Sci. Ital. Genova: $185(1847)=$ Echinochloa colonum (L.) Link (Clayton 1972: 439).

Panicum hookeri Parl., Atti $8^{\mathfrak{C}}$ Riun. Sci. Ital. Genova: $586(1847)=$ Echinochloa colonum (L.) Link (Clayton 1972: 439).

Pappophorum vincentinum J. A. Schmidt. Beitr. Fl. Cap Verd. Ins.: $144(1852)=$ Enneapogon desvauxii P. Beauv. (Clayton 1972: 383).

Pegolettia senegalensis Cass. f. pygmaea J. A. Schmidt, Beitr. Fl. Cap Verd. Ins.: 192 (1852) = Pegolettia senegalensis Cass. (Lobin 1986b: 131).

Pennisetum ciliatum Parl. in Hooker, Niger Fl.: $184(1849)=$ Pennisetum polystachion (L.) Schult. (Chase \& Niles 1962: 51).

Pennisetum intertextum Schltdl., Bot. Zeit. 9(50): 878 (1851) = Pennisetum pedicellatum Trin. (Chase \& Niles 1962: 50). 
Pennisetum myurus Parl. in Hooker, Niger Fl.: 184 (1849) = Pennisetum polystachion (L.) Schult. (Chase \& Niles 1962: 51).

Phaca vogelii Webb in Hooker, Icon. Pl. 8: ad tab. $763(1848)=$ Astragalus vogelii (Webb) Bornm.

Phelypaea brunneri Webb in Hooker, Niger Fl.: 167 (1849) = Cistanche phelypaea (L.) Cout. (Chevalier 1935a: 895).

Phyllanthus scabrellus Webb in Hooker, Niger Fl.: $175(1849)=$ Phyllanthus rotundifolizs Klein ex Willd. (Carter et al. 1984: 447).

Pleuroplitis ciliata J. A. Schmidt, Beitr. Fl. Cap Verd. Ins.: 152 (1852) = Arthraxon lancifolius (Trin.) Hochst. (Welzen 1981: 290).

Pluchea bravae Bolle, Bonplandia 8: $130(1860)=$ Pluchea ovalis (Pers.) DC. (Heim 1984: 173).

Pogonia bollei Rchb. f., Xenia Orch. 2: 88 (1874) = Nervilia crociformis (Zoll. \& Moritzi) Seidenf. (Pettersson 1990: 494, 1991: 36, 45).

Potamogeton antaicus Hagstr., Kungl. Svenska Vetenskapsakad. Handl. 55(5): 105 (1916)= Potamogeton pusillus L. s. 1. (Gomes et al. 1995a: 193).

Schmidtia Steud. in J. A. Schmidt, Beitr. Fl. Cap Verd. Ins.: 144 (1852) - (Lobin 1986b: 139).

Schmidtia pappophoroides Steud. in J. A. Schmidt, Beitr. Fl. Cap Verd. Ins.: 145 (1852) (Lobin 1986b: 139).

Sida affinis J. A. Schmidt, Beitr. Fl. Cap Verd. Ins.: 285 (1852) = Sida alba L. (Chevalier 1935a: 947).

Sida cordifolia L. var. angustifolia Cout., Arq. Univ. Lisboa 1: $298(1914)=$ Sida salviifolia C. Presl (Fuertes 1995: 86).

Sida coutinhoi J. Paiva \& I. Nogueira, Garcia de Orta, Sér. Bot. 2: 67 (1974) = Sida salviifolia C. Presl (Fuertes 1995: 86).

Sida pannosa Forst. f., Comm. Soc. Regiae Sci. Gott. 9: 62 (1787) = Abutilon pannosum (Forst. f.) Schltdl. (Lobin 1986b: 141).

Sida urens L. var. prostrata A. Chev., Rev. Bot. Appl. Agric. Trop. 15: $946(1935)=$ Sida urens L. (Lobin et al. 1988b: 77).

Sporobolus insulanus Parl., Atti $8^{\mathrm{e}}$ Riun. Sci. Ital. Genova: $586(1847)=$ Sporobolus robustus Kunth (Clayton 1966: 296).

Tephrosia gorgonea Cout., Arq. Univ. Lisboa 2: 37 (1915) = Tephrosia pedicellata Baker (Nogueira \& Ormonde 1985: 168).

Vernonia caboverdeana Lobin, Cour. Forsch.-Inst. Senckenberg 81: 117 (1986) = Vernonia colorata (Willd.) Drake (Gomes et al. 1995a: 184).

Vernonia cinerea Less. var. antoniensis Bolle, Bonplandia 7: $130(1860)=$ Vernonia cinerea Less. (Gomes et al. 1995a: 183). 


\section{ACKNOWLEDGEMENTS}

This work summarizes the present knowledge of the endemic plants in the Cape Verde Islands based on the published contributions from many other botanists and our own studies since 1979 . We are indebted to a number of persons and institutions for support. First of all we acknowledge the persons who initiated and always have stimulated our interest in the Macaronesian flora, in particular L. Borgen and P. Sunding at the University of Oslo and H. J. Conert at the Forschungs-Institut Senckenberg in Frankfurt a.M.

A special thank to $T$. Leyens, Bonn, for her interest and various important contributions: cooperation in the field, information on ecology, distribution, and conservation, and detailed comments on the manuscript. Most drawings of the taxa were prepared by J. Wunder, Bonn, who is thanked for his valuable contribution. We also thank C. Dervin, Berlin, G. Eder, Frankfurt a.M., E. Fischer, Bonn, E. Michels, Frankfurt a.M. for drawings; C. Köhler, Frankfurt a.M., for providing the key to Brachiaria; K. H. Schmidt, Bonn, for co-authoring the treatment of Tornabenea; I. Gomes, S. Gomes, and M. T. Veracruz, the Cape Verde Islands, for cooperation in the field and for providing information; $O$. Stabbetorp, Oslo, for discussions and advice on statistics; and L. Borgen, Oslo, J. Francisco-Ortega, Tenerife, P. Sunding, Oslo, and R. H. Økland, Oslo, for critical reading of the manuscript.

We also thank the authorities of the Republic of Cabo Verde, in particular the staff at Ministério dos Pescas, Agricultura e Animacão Rural (MPAAR, formerly MDR) on the various islands, for their indispensable help with information, transport, and practical matters during the many periods of field work. Financial support for parts of this study was obtained from the Botanical Garden and Museum. University of Oslo, and the World Wildlife Fund. Norway (C. Brochmann and $\varnothing$. H. Rustan); from the German Research Council (DFG) and the ForschungsInstitut Senckenberg, Frankfurt a.M. (W. Lobin); and from the German Technical Cooperation (GTZ) in cooperation with the National Institute of Agrarian Research (INIDA), the Cape Verde Islands (W. Lobin and N. Kilian). 


\section{REFERENCES}

Aldridge, A. E. 1976a. A critical reappraisal of the Macaronesian Sonchus subgenus Dendrosonchus s. 1. (Compositae-Lactuceae). - Bot. Macar. 2: 25-57.

Aldridge, A. E. 1976b. Macaronesian Sonchus subgenus Dendrosonchus s. 1. (Compositae Lactuceae), including a reappraisal of the species concept and new combinations. - Bot. Macar. 2: 81-93.

Aldridge, A. E. 1977. Anatomy and evolution in the Macaronesian Sonchus subgenus Dendrosonchus (Compositae - Lactuceae). Nodal and petiolar vascular patterns. - Bot. Macar. 3: 41-59.

Aldridge, A. E. 1979. Evolution within a single genus: Sonchus in Macaronesia. - In: Bramwell, D. (ed.), Plants and islands, Academic Press, London, pp. 279-291.

Aldridge, A. E. \& Ortega, J. 1976. Estudios en la flora de Macaronesia: Algunos numeros de chromosomas II. - Bot. Macar. 2: 9-18.

Amin, A. 1972. In: IOPB chromosome number reports XXXVIII. - Taxon 21: 679-684.

Andersen, B. G. \& Borns, H. W. jr. 1994. The ice age world. - Scandinavian University Press, Oslo.

Anderson, D. E. 1974. Taxonomy of the genus Chloris (Gramineae). - Brigham Young Univ. Sci. Bull., Biol. Ser. 19(2): 1-133.

Anderson, J. K. \& Warwick, S. I. 1995. Systematic implications of isozyme number variation in tribe Brassiceae (Cruciferae). - Abstract, VI International Symposium IOPB, "Variation and Evolution in Arctic and Alpine Plants", Tromsø, Norway.

Ardévol González, J. F., Borgen, L. \& Pérez de Paz, P. L. 1993. Checklist of chromosome numbers counted in Canarian vascular plants. - Sommerfeltia 18: 1-59.

Barbosa, L. A. Grandvaux 1961. Subsídios para um dicionário utilitário e glossário dos nomes vernáculos das plantas do arquipélago de Cabo Verde. - Garcia de Orta 9: 37-91.

Basto, M. F. P. 1987a. Aditamentos à flora vascular de Cabo Verde. - Garcia de Orta, Sér. Bot. 9: 1-15.

Basto, M. F. P. 1987b. Anotacôes à flora de Cabo Verde. - Bol. Soc. Brot., sér. 2, 60: 179-186.

Basto, M. F. P. 1988. Plantas vasculares endémicas do arquipélago de Cabo Verde. - Garcia de Orta, Sér. Bot. 10: 11-15.

Basto, M. F. P. 1995a. Cistaceae. - Flora de Cabo Verde, Plantas Vasculares 27: 1-9.

Basto, M. F. P. 1995b. Globulariaceae. - Flora de Cabo Verde, Plantas Vasculares 80: 1-8.

Basto, M. F. P. \& Diniz, M. A. 1993. Aditamentos à flora vascular do arquipélago de Cabo Verde - II. - Garcia de Orta, Sér. Bot. 11: 75-82.

Beccari, O. 1890. Rivista monografica delle specie del genere Phoenix Linn. - Malesia 3: 345416.

Béguinot, A. 1918. Viaggio di Leonardo Fea nell'Africa occidentale. Contributo alla flora delle isole del Capo Verde e notizie sulla sua affinità ed origine. - Ann. Mus. Civ. St. Nat. Genova, Ser. 3, 8: 9-73.

Benabid, A. \& Cuzin, F. 1997. Dragon tree (Dracaena draco subsp. ajgal Benabid et Cuzin) populations in Morocco: taxonomical, biogeographical and phytosociological values. - 
Comptes Rendus de l'Academie des Sciences Paris, Serie III, Sciences de la Vie 320: 267-277.

Berhaut, J. 1975. Flore illustrée du Sénégal. Dicotylédones. III. Connaracées à Euphorbiacées. - Gouvernement du Sénégal, Dakar.

Berhaut, J. 1976. Flore illustrée du Sénégal. Dicotylédones. V. Légumineuses à Papilionacees. - Gouvernement du Sénégal, Dakar.

Betsche, I. 1984. Taxonomische Untersuchungen an Kickxia Dumortier (s. 1.). Die neuen Gattungen Pogonorrhinum n. gen. und Nanorrhinum n. gen. (Phanerogamae: Scrophulariaceae). - Cour. Forsch.-Inst. Senckenberg 71: 125-142.

Boekschoten, G. J. \& Manuputty, J. A. 1993. The age of the Cape Verde Islands. - Cour. Forsch.-Inst. Senckenberg 159: 3-5.

Böhle, U.-R., Hilger, H., Cerff, R. \& Martin, W. F. 1994. Non-coding chloroplast DNA for plant molecular systematics at the infrageneric level. - In: Schierwater, B., Streit. B.. Wagner, G. P. \& DeSalle, R. (eds), Molecular ecology and evolution: approaches and applications, Birkhäuser Verlag, Basel, pp. 391-403.

Bolkhovskikh, Z., Grif, V., Matvejeva, T. \& Zakharyeva, O. 1969. Chromosome numbers of flowering plants. - Nauka, Leningrad. (In Russian).

Bolle, C. 1952. Notes on the botany of the Cape de Verd Islands, extracted from a letter of Dr. C. Bolle to William Willson Saunders, Esq. - Hook. J. Bot. 4: 59-62.

Bolle, C. 1855. Novitiae florae caboverdicae. Canariarum stirpium ratione habita. Bonplandia 3: 121-124.

Bolle, C. 1859a. Addenda ad floram Atlantidis, praecipue insularum Canariensium Gorgadumque. I. - Bonplandia 7: 238-246.

Bolle, C. 1859b. Addenda ad floram Atlantidis, praecipue insularum Canariensium Gorgadumque. II. - Bonplandia 7: 293-298.

Bolle, C. 1860a. Addenda ad floram Atlantidis, praecipue insularum Canariensium Gorgadumque. III. - Bonplandia 8: 130-136.

Bolle, C. 1860b. Addenda ad floram Atlantidis, praecipue insularum Canariensium Gorgadumque. IV. - Bonplandia 8: 279-287.

Bolle, C. 1861. Addenda ad floram Atlantidis, praecipue insularum Canariensium Gorgadumque. V. - Bonplandia 9: 50-55.

Borgen, L. 1974. Chromosome numbers of Macaronesian flowering plants II. - Norw. J. Bot. 21: 195-210.

Borgen, L. 1975. Chromosome numbers of vascular plants from Macaronesia. - Norw. J. Bot. 22: $71-76$.

Borgen, L. 1977. Check-list of chromosome numbers counted in Macaronesian vascular plants. - Botanical Garden and Museum, Univ. of Oslo.

Borgen, L. 1979. Karyology of the Canarian flora. - In: Bramwell, D. (ed.), Plants and Islands, Academic Press, London, pp. 329-346.

Borgen, L. 1980. Chromosome numbers of Macaronesian flowering plants III. - Bot. Macar. 7: 67-76.

Borgen, L. 1984. Chromosome numbers and fertility relationships in Lobularia. Cruciferae. A preliminary report. - Webbia 38: 645-653.

Borgen, L. 1987. Lobularia (Cruciferae). A biosystematic study with special reference to the Macaronesian region. - Opera Bot. 91: 1-96. 
Borgen, L. 1997. Genetic differentiation in endemic Lobularia (Brassicaceae) in the Canary Islands. - Nord. J. Bot. 16: 487-503.

Boulos, L. 1972. Révision systématique du genre Sonchus L. S. I. Introduction et classification. - Bot. Not. 125: 287-305.

Boulos, L. 1974. Révision systématique du genre Sonchus L. s. 1. V. Sous-genre 2. Dendrosonchus. - Bot. Not. 127: 7-37.

Bowdich, S. (ed.) 1825. Excursions in Madeira and Porto Santo, during the autumn of 1823, while on his third voyage to Africa. - London.

Bramwell, D. 1972. A revision of the genus Echium in Macaronesia. - Lagascalia 2: 37-115.

Bramwell, D. 1990. Conserving biodiversity in the Canary Islands. - Ann. Missouri Bot. Gard. 77: 28-37.

Bramwell, D. \& Murray, B. G. 1972. A preliminary report on the cytology of some Cape Verde Islands plants. - Cuad. Bot. Canaria 14/15: 27-29.

Bramwell, D., Humphries, C. J., Murray, B. G. \& Owens, S. J. 1972. Chromosome studies in the flora of Macaronesia. - Bot. Not. 125: 139-152.

Brand, A. 1898. Monographie der Gattung Lotus. - Bot. Jahrb. Syst. 25: 166-232.

Brochmann, C. 1987. Evaluation of some methods for hybrid analysis, exemplified by hybridization in Argyranthemum (Asteraceae). - Nord. J. Bot. 7: 609-630.

Brochmann, C. 1993. Clinal and parallel evolution in the vascular flora of the Cape Verde Islands, W Africa. - Cour. Forsch.-Inst. Senckenberg 159: 67-85.

Brochmann, C. \& Rustan, Ø. H. 1983. Large-scale plant preparing - presentation of a fan oven drier. - Blyttia 41: 128-131.

Brochmann, C. \& Rustan, Ø. H. 1987. Distributional and ecological patterns of the endemic vascular flora of the Cape Verde Islands. - Cour. Forsch.-Inst. Senckenberg 95: 155-173.

Brochmann, C. \& Rustan, Ø. H. 1988. Additions to the vascular flora of Cabo Verde - II. Garcia de Orta, Sér. Bot. 8 (1986): 9-37.

Brochmann, C., Lobin, W., Sunding, P. \& Stabbetorp, O. 1995. Parallel ecoclinal evolution and taxonomy of Frankenia (Frankeniaceae) in the Cape Verde Islands, W Africa. Nord. J. Bot. 15: 603-623.

Browicz, K. 1966. The genus Periploca L. A monograph. - Arbor. Kórnickie 11: 5-104.

Brunner, S. 1840. Botanische Ergebnisse einer Reise nach Senegambien und den Inseln des grünen Vorgebürges. - Flora 23, Beibl. 1: 1-96, Beibl. 2: 1-57.

Carlquist, S. 1970. Hawaii: a natural history. - The Natural History Press, New York.

Carlquist, S. 1974. Island Biology. - Columbia Univ. Press, New York.

Carter, S., Lobin, W. \& Radcliffe-Smith, A. 1984. A collection of and notes on Euphorbiaceae from the Cape Verde Islands (Dicotyledonae). - Senckenberg. Biol. 64: 429-451.

Chase, A. \& Niles, C. D. 1962. Index to grass species 3. - Hall, Boston.

Chaudhri, M. N. 1968. A revision of the Paronychiinae. - Meded. Bot. Mus. Herb. Rijksuniv. Utrecht 285: 1-440.

Chaytor, D. A. 1937. A taxonomic study of the genus Lavandula. - Bot. J. Linn. Soc. 51: 153-204.

Chevalier, A. 1935a. Les îles du Cap Vert. Flore de l'Archipel. - Rev. Bot. Appl. Agric. Trop. 15: 733-1090.

Chevalier, A. 1935b. Plantes nouvelles de l'Archipel des îles du Cap Vert. - Bull. Mus. Nat. Hist. Natur., sér. 2, 7: 137-144. 
Chevalier, A. 1946. Additions à la flore des Iles du Cap Vert. - Mém. Soc. Biogéogr. 8: 349-356.

Chevalier, A. 1952. Recherches sur les Phoenix africains. - Rev. Int. Bot. Appl. Agric. Trop. 32: $205-225$.

Clayton, W. D. 1966. Studies in the Gramineae: VI. Sporobolus robustus and its allies. - Kew Bull. 19(2): 295-296.

Clayton, W. D. 1972. Gramineae. - In: Hutchinson, J. \& Dalziel. J. M. (eds). Flora of West Tropical Africa, 2. rev. ed., 3(2), pp. 349-512.

Commelin, J. \& Commelin, C. 1701. Horti medici amstelodamensis rariorum 2. - Amsterdam.

Conert, H. J. \& Köhler, C. 1987. Brachiaria lata subsp. caboverdiana n. subsp. (Poaceae: Panicoideae: Paniceae). - Senckenberg. Biol. 67 (1986): 431-435.

Conert, H. J. \& Lobin, W. 1985. Revision der kapverdischen Sporobolus-Arten (Poaceae). Garcia de Orta, Sér. Bot. 6: 51-68.

Coutinho, A. X. P. 1914. Herbarii Gorgonei Universitatis Olisiponensis Catalogus. - Arq. Univ. Lisboa 1: 265-334.

Coutinho, A. X. P. 1915. Catalogi Herbarii Gorgonei Universitatis Olisiponensis Supplementum. - Arq. Univ. Lisboa 2: 27-59.

Crawford, D. J., Stuessy, T. F. \& Silva, M. O. 1987a. Allozyme divergence and the evolution of Dendroseris (Compositae: Lactuceae) on the Juan Fernandez Islands. - Syst. Bot. 12: 435-443.

Crawford, D. J., Witkus, R. \& Stuessy, T. F. 1987b. Plant evolution and speciation on oceanic islands. - In: Urbanska, K. M. (ed.), Differentiation patterns in higher plants, Acad. Press, London, pp. 183-199.

Cronk, Q. C. B. 1992. Relict floras of Atlantic Islands: patterns assessed. - Biol. J. Linn. Soc. 46: 91-103.

Curtis, W. 1797. Lotus jacobaeus - black lotus. - Curtis's Bot. Mag. 3: Tab. 79.

Dalgaard, V. 1994. Checklist of chromosome numbers counted in Madeiran flowering plants. with notes on polyploidy, life form. endemism and evolution. - Nord. J. Bot. 14: 241-255.

Decaisne, J. 1848. Sapota marginata, Sarcostemma daltonii. - Hooker's Icon. Pl. 8: Tab. 761. 768.

Diniz, M. A. 1995. Caryophyllaceae. - Flora de Cabo Verde, Plantas Vasculares 19: 1-26.

Drude, O. 1898. Umbelliferae. - In: Engler, A. \& Prantl, K., Die natürlichen Pflanzenfamilien 3(8), Engelmann, Leipzig, pp. 63-205.

Erben, M. 1986. Bemerkungen zur Taxonomie der Gattung Limonium III. - Mitt. Bot. München 22: 203-220.

Eriksson, O., Hansen, A. \& Sunding, P. 1974. Flora of Macaronesia. Checklist of vascular plants 1974. - Dept. of Biology, Univ. of Umeå.

Eriksson, O., Hansen, A. \& Sunding, P. 1979a. Flora of Macaronesia. Checklist of vascular plants. 2. rev. ed. by Hansen, A. \& Sunding, P. Part I. - Botanical Garden and Museum, Univ. of Oslo.

Eriksson, O., Hansen, A. \& Sunding, P. 1979b. Flora of Macaronesia. Checklist of vascular plants. 2. rev. ed. by Hansen, A. \& Sunding, P. Part II. Synonym index. - Botanical Garden and Museum, Univ. of Oslo.

Favarger, C. \& Contandriopoulos, J. 1961. Essai sur l'endémisme. - Ber. Schweiz Bot. Ges. 71: $383-408$. 
Febles Hernandez, R. \& Ortega Garcia, J. 1982. Estudio citogenético del género Pulicaria Gaertn. (Compositae - Inuleae) en las Islas Canarias. - Bot. Macar. 10: 41-47.

Fernandes, R. 1959. Sobre a identificacão de Matthiola caboverdeana A. Chev. - Garcia de Orta 7: 755-756.

Figueiredo, E. 1995. Campanulaceae. - Flora de Cabo Verde, Plantas Vasculares 86: 1-11.

Figueiredo, E. 1996. Euphorbiaceae. - Flora de Cabo Verde, Plantas Vasculares 54: 1-54.

Forster, G. 1789. Plantae atlanticae ex insulis Madeira, Sti. Jacobi, Adscensionis, Stae. Helenae et Fayal reportatae. - Comm. Soc. Reg. Scient. Goetting. 9: 46-74.

Francisco-Ortega, J., Crawford, D. J., Santos-Guerra, A. \& Sa-Fontinha, S. 1995a. Genetic divergence among Mediterranean and Macaronesian genera of the subtribe Chrysantheminae (Asteraceae). - Amer. J. Bot. 82: 1321-1328.

Francisco-Ortega, J., Jansen, R. K., Crawford, D. J. \& Santos-Guerra, A. 1995b. Chloroplast DNA evidence for intergeneric relationships of the Macaronesian endemic genus Argyranthemum (Asteraceae). - Syst. Bot. 20: 413-422.

Francisco-Ortega, J., Crawford, D. J., Santos-Guerra, A. \& Carvalho, J. A. 1996a. Isozyme differentiation in the endemic genus Argyranthemum (Asteraceae: Anthemideae) in the Macaronesian islands. - Pl. Syst. Evol. 202: 137-152.

Francisco-Ortega, J., Jansen, R. K. \& Santos-Guerra, A. 1996b. Chloroplast DNA evidence of colonization, adaptive radiation, and hybridization in the evolution of the Macaronesian flora. - Proc. Natl. Acad. Sci. USA 93: 4085-4090.

Fraser-Jenkins, C. 1982. Dryopteris in Spain, Portugal and Macaronesia. - Bull. Soc. Bot. 55 : 175-336.

Friis, I. \& Wilmot-Dear, C. M. 1988. A revision of the tribe Forsskaoleae (Urticaceae). Nord. J. Bot. 8: 25-59.

Fuertes, J. 1995. Sida L. (Malvaceae). - Flora de Colombia 17.

Gamal-Eldin, E. 1981. Revision der Gattung Pulicaria (Compositae - Inuleae) für Afrika, Makaronesien und Arabien. - Phanerogam. Monogr. 14: 1-311.

García-Talavera, F., Sánchez-Pinto, L. \& Socorro-Hernández, S. 1995. Vegetales fosiles en el complejo traquitico-Sienitico de Gran Canaria. - Revista de la Academia Canaria de las Ciencias 7: 77-91.

García-Talavera, F., Sánchez-Pinto, L. \& Socorro-Hernández, S. 1996. Fossil plants in the thrachytic-syenitic complex of Gran Canaria. - In: Anonymous (ed.), 2nd symposium Fauna and flora of the Atlantic Islands, 12-16 February 1996, Universidad de Las Palmas de Gran Canaria, Gran Canaria, Canary Islands, Abstract, p. 233.

Gier, S. \& Dahms, P. 1987a. Die Entstehung des Archipels. - In: Lobin, W. \& Ohm, P. (eds), Forschungsreisen in ein Entwicklungsland - Biologen arbeiten auf den Kapverdischen Inseln, Natur \& Museum 117, pp. 305-306.

Gier, S. \& Dahms, P. 1987b. Das Klima. - In: Lobin, W. \& Ohm, P. (eds), Forschungsreisen in ein Entwicklungsland - Biologen arbeiten auf den Kapverdischen Inseln, Natur \& Museum 117, pp. 306-307.

Gill, L. S. 1990. The incidence of polyploidy in the Nigerian flora. - Feddes Repert. 101: 449452.

Gilli, A. 1976. Die Veränderung der Flora der Kapverdischen Inseln in den letzten 124 Jahren. - Verh. Zool.-Bot. Ges. Wien 115: 34-39.

Goldblatt, P. 1981. Index to plant chromosome numbers 1975-1978. - Monogr. Syst. Bot. Missouri Bot. Gard. 5: 1-553. 
Goldblatt, P. 1984. Index to plant chromosome numbers 1979-1981. - Monogr. Syst. Bot. Missouri Bot. Gard. 8: 1-427.

Goldblatt, P. 1985. Index to plant chromosome numbers 1982-1983. - Monogr. Syst. Bot. Missouri Bot. Gard. 13: 1-224.

Goldblatt, P. 1988. Index to plant chromosome numbers 1984-1985. - Monogr. Syst. Bot. Missouri Bot. Gard. 23: 1-264.

Goldblatt, P. \& Johnson, D. E. 1990. Index to plant chromosome numbers 1986-1987. Monogr. Syst. Bot. Missouri Bot. Gard. 30: 1-238.

Gomes, I. 1995. Gentianaceae. - Flora de Cabo Verde, Plantas Vasculares 68: 1-9.

Gomes, I., Gomes, S., Kilian, N., Leyens, T., Lobin, W., Vera-Cruz, M. T. 1995a. Notes on the flora of the Cape Verde Islands, W Africa. - Willdenowia 25: 177-196.

Gomes, I., Gomes, S., Vera-Cruz, M. T., Kilian, N., Leyens, T., Lobin, W. (text); Leyens, P. \& Rees-Davies, K. (plates) 1995b. Plantas endémicas e árvores indígenas de Cabo Verde. - Praia.

Gómez-Campo, C. 1978. Studies on Cruciferae: V. Chromosome numbers for twenty-five taxa. - Anales Jard. Bot. Madrid 35: 177-182.

Good, R. 1974. The geography of the flowering plants. - Longman, London.

Grant, W. F. 1995. A chromosome atlas and interspecific - intergeneric index for Lotus and Tetragonolobus (Fabaceae). - Can. J. Bot. 73: 1787-1809.

Greuter, W. 1967. Beiträge zur Flora der Südägäis 8-9. - Bauhinia 3: 243-254.

Greuter, W. 1979. Review of O. Eriksson, A. Hansen \& P. Sunding - "Flora of Macaronesia. Checklist of vascular plants". Second revised edition, by A. Hansen \& P. Sunding. Optima Newsletter 8/9: 42-43.

Greuter, W., Barrie, F. R., Burdet, H. M., Chaloner, W. G., Demoulin, V., Hawksworth, D. L., Jørgensen, P. M., Nicolson, D. H., Silva, P. C., Trhane, P., McNeill, J. 1994. International Code of Botanical Nomenclature (Tokyo Code). - Koeltz, Königstein.

Grosser, W. 1903. Cistaceae. - Das Pflanzenreich 14: 1-161.

Hagerup, O. 1931. Über Polyploidie in Beziehung zu Klima, Ökologie, und Phylogenie. Hereditas 16: 19-40.

Halvorsen, T. \& Borgen, L. 1986. The perennial Macaronesian species of Bubonium (Compositae - Inuleae). - Sommerfeltia 3: 1-103.

Hansen, A. \& Sunding, P. 1985. Flora of Macaronesia. Checklist of vascular plants. 3. rev. ed. - Sommerfeltia 1: 1-167.

Hansen, A. \& Sunding, P. 1988. A botanical bibliography of the Cape Verde Islands. Additions 1987 [to P. Sunding: A botanical bibliography of the Cape Verde Islands, Bol. Mus. Mun. Funchal, 31 (138): 100-109, 1977]. - Cour. Forsch.-Inst. Senckenberg 105: 139-143.

Hansen, A. \& Sunding, P. 1993. Flora of Macaronesia. Checklist of vascular plants. 4. rev. ed. - Sommerfeltia 17: 1-295.

Harberd, D. J. 1972. A contribution to the cyto-taxonomy of Brassica (Cruciferae) and its allies. - Bot. J. Linn. Soc. 65: 1-23.

Harberd, D. J. 1976. Cytotaxonomic studies of Brassica and related genera. - In: Vaughan, J. G., MacLeod, A. J., Jones, B. M. G. (eds), The Biology and Chemistry of the Cruciferae, Academic Press, London. 
Heim, G. 1984. Die Compositen-Gattungen Conyza, Blumea und Pluchea auf den Kapverdischen Inseln (Phanerogamae: Asteraceae). - Cour. Forsch.-Inst. Senckenberg 68: 143-178.

Henrard, J. T. 1926 [-1929]. A critical revision of the genus Aristida. - Meded. Rijks Herb. Leiden 54: 1-220, 54a: 221-464, 54b: 465-701.

Henrard, J. T. 1929 [-1933]. A monograph of the genus Aristida. - Meded. Rijks Herb. Leiden 58: 1-153, 58a: 155-325, 58b: i-xii.

Henriques, J. A. 1896. Enumeracão de plantas colhidas nas ilhas de Cabo Verde por J. A. Cardoso Junior. - Bol. Soc. Brot. 13: 130-150.

Hepper, F. N. 1976. The West African herbaria of Isert and Thonning. A taxonomic revision and an index to the IDC microfiche. - Royal Bot. Gard. Kew, London.

Hooghiemstra, H., Stalling, H., Agwu, C. O. C. \& Dupont, L. M. 1992. Vegetational and climatic changes at the norhern fringe of the Sahara 250,000-5000 years BP: evidence from 4 marine pollen records located between Portugal and the Canary Islands. - Rev. Palaeobot. Palynol. 74: 1-53.

Holmgren, P. K., Holmgren, H. N. \& Barnett, L. C. 1990. Index herbariorum 1. The herbaria of the world, ed. 8. - Regn. Veg. 120.

Hooker, J. D. 1883. Campanula jacobaea. Native of the Cape de Verd Islands. - Curtis's Bot. Mag. 109: Tab. 6703.

Humphries, C. J. 1979. Endemism and evolution in Macaronesia. - In: Bramwell, D. (ed.), Plants and Islands, Academic Press, London, pp. 171-199.

Jarvis, C. E. 1984. The genus Tolpis Adanson and its occurrence in the Cape Verde Islands (Phanerogamae: Asteraceae: Cichoreae). - Cour. Forsch.-Inst. Senckenberg 68: 179-184.

Kadereit, J. W. 1988. A revision of Papaver sect. Rhoeadium. - Notes Royal Bot. Gard. Edinb. 45: 225-286.

Kadereit, J. W. \& Lobin, W. 1990. The taxonomy and affinities of Papaver gorgoneum from the Cape Verde Islands. - Nord. J. Bot. 9: 643-648.

Kämmer, F. 1982. Beiträge zu einer kritischen Interpretation der rezenten und fossilen Gefässpflanzenflora und Wirbeltierfauna der Azoren, des Madeira-Archipels, der Ilhas Selvagens, der Kanarischen Inseln und der Kapverdischen Inseln, mit einem Ausblick auf Probleme des Artenschwundes in Makaronesien. - Selbstverlag. Freiburg im Breisgau.

Kilian, N. 1988. Die Lactuceae (Compositae) der Kapverdischen Inseln (W-Afrika). Willdenowia 18: 113-216

Kilian, N. \& Leyens, T. 1994. Limonium lobinii (Plumbaginaceae), a new species from the Cape Verde Islands, W Africa. - Willdenowia 24: 59-63.

Kilian, N., Brochmann, C. \& Rustan, Ø. H. 1987. Launaea thalassica (Asteraceae, Lactuceae), a new species from the Cape Verde Islands, W Africa. - Willdenowia 16: 491-496.

Kim, S.-C., Crawford, D. J., Francisco-Ortega, J. \& Santos-Guerra, A. 1996. A common origin for woody Sonchus and five related genera in the Macaronesian islands: molecular evidence for extensive radiation. - Proc. Natl. Acad. Sci. USA 93: 7743-7748.

Kirkbride, J. H. Jr. 1994. Taxonomic circumscription of the genus Lotus Linnaeus (Fabaceae, Loteae), its tribal position, and its species. - In: Beuselinck, P.R. \& Roberts, C. A. (eds), 
Proceedings of the 1st international Lotus symposium, Univ. of Missouri, Columbia, pp. 11-15.

Klerkx, J. \& De Paepe, P. 1971. Cape Verde Islands: evidence for a Mesozoic oceanic ridge. Nature 233: 117-118.

Knox, E. B. \& Palmer, J. D. 1995. The origin of Dendrosenecio within the Senecioneae (Asteraceae) based on chloroplast DNA evidence. - Amer. J. Bot. 82: 1567-1573.

Köhler, C. 1984. Über Eragrostis insulatlantica Chevalier (= E. barrelieri Daveau) von den Kapverdischen Inseln (Phanerogamae: Poaceae). - Cour. Forsch.-Inst. Senckenberg 68: 191-199.

Köhler, C. 1987. Die Arten der Gattung Brachiaria von den Kapverdischen Inseln (Phanerogamae: Poaceae). - Cour. Forsch.-Inst. Senckenberg 95: 211-213.

Köhler, C. 1988. Revision der Eragrostis-Arten (Poaceae) von den Kapverdischen Inseln. Cour. Forsch.-Inst. Senckenberg 105: 99-127.

Köhler, C. 1995. Über die Gattung Brachiaria auf den Kapverdischen Inseln (Phanerogamae: Poaceae, Panicoideae, Paniceae). - Cour. Forsch.-Inst. Senckenberg 186: 115-127.

Köhler, C. \& Lobin, W. 1988. Über eine Gräser-Sammlung von den Kapverdischen Inseln (Poaceae). - Cour. Forsch.-Inst. Senckenberg 105: 73-97.

Krause, E. H. L. 1892. Flora der Insel St. Vincent in der Capverdengruppe. - Bot. Jahrb. Syst. 14: 394-425.

Krejci-Graf, K. 1961. Vertikal-Bewegungen der Makaronesen. - Geol. Rundschau 51: 73-122.

Kunkel, G. 1970. Novedades en la flora Canaria. - Cuad. Bot. Canaria 8: 10-14.

La Serna Ramos, I., León Arenciba, M. C. \& Wildpret de la Torre, W. 1982. Contribución a la tipification de algunas especies del genero Limonium Mill., endémicas de la region Macaronesia. - Vieraea 11: 57-68.

Lewejohann, K. \& Lobin, W. 1981. Ergänzungen und Anmerkungen zu: O. Eriksson, A. Hansen \& P. Sunding - Flora of Macaronesia. Checklist of vascular plants, 2 nd revised edition. - Garcia de Orta, Sér. Bot. 5: 9-11.

Lewejohann, K. \& Lobin, W. 1987. Über Carex paniculata s. 1. und Beschreibung einer neuen Unterart von den Kapverdischen Inseln (Cyperaceae). - Senckenberg. Biol. 67: 437-447.

Leyens, T. 1994. Erfassung und Bewertung dringend zu schützender Gebiete auf den Kapverdischen Inseln. - Thesis, Univ. of Bonn.

Leyens, T. \& Lobin, W. 1995. Campanula (Campanulaceae) on the Cape Verde Islands - two species or only one? - Willdenowia 25: 215-228.

Leyens, T. \& Lobin, W. (eds) 1996. Primeira Lista Vermelha de Cabo Verde. - Cour. Forsch.-Inst. Senckenberg. 193: 1-140.

Lidén, M. 1986. Synopsis of Fumarioideae (Papaveraceae) with a monograph of the tribe Fumarieae. - Opera Bot. 88: 1-133.

Liede, S. \& Meve, U. 1993. Towards an understanding of the Sarcostemma viminale (Asclepiadaceae) complex. - Bot. J. Linn. Soc. 112: 1-15.

Liu, H.-Y. 1989. Systematics of Aeonium (Crassulaceae). - National Museum Nat. Science, Taiwan, Special Publication 3: 1-102.

Lobin, W. 1982a. Additions and corrections to: O. Eriksson, A. Hansen \& P. Sunding - Flora of Macaronesia. Checklist of vascular plants, 2nd revised edition - II. - Garcia de Orta, Sér. Bot. 5: 213-224.

Lobin, W. 1982b. Beitrag zur Kenntnis der Cyperaceae (Phanerogamae, Monocotyledoneae) der Kapverdischen Inseln. - Cour. Forsch.-Inst. Senckenberg 52: 265-276. 
Lobin, W. 1982c. Untersuchung über Flora, Vegetation und biogeographische Beziehungen der Kapverdischen Inseln. - Cour. Forsch.-Inst. Senckenberg 53: 1-112.

Lobin, W. 1986a. Eragrostis conertii (Poaceae) - eine neue Art von den Kapverdischen Inseln. - Willdenowia 16: 143-151.

Lobin, W. 1986b. Katalog der von den Kapverdischen Inseln beschriebenen Taxa höherer Pflanzen (Pteridophyta \& Phanerogamae). - Cour. Forsch.-Inst. Senckenberg 81: 93-164.

Lobin, W. 1986c. On a collection of Convolvulaceae from the Cape Verde Islands. Willdenowia 16: 153-168.

Lobin, W. 1986d. The family Asclepiadaceae on the Cape Verde Islands, West Africa. Asklepios 37: 73-79.

Lobin, W. 1986e. Zur Flora der Kapverdischen Inseln Branco und Razo. - Cour. Forsch.-Inst. Senckenberg 81: 179-180.

Lobin, W. 1988. Ergänzungen und Verbesserungen zu "Katalog der von den Kapverdischen Inseln beschriebenen Taxa höherer Pflanzen". - Cour. Forsch.-Inst. Senckenberg 105: 145-147.

Lobin, W. 1993. 2. Ergänzungen und Verbesserungen zu "Katalog der von den Kapverdischen Inseln beschriebenen Taxa höherer Pflanzen". - Cour. Forsch.-Inst. Senckenberg 159: 87-90.

Lobin, W. \& Grasmück, H. 1984. Eine Sammlung kapverdischer Pflanzen im Botanischen Garten Frankfurt. - Natur und Museum 114: 127-135.

Lobin, W. \& Groh, K. 1980. Die Kapverdischen Inseln - ein Reisebericht. II. - Natur und Museum 110: 289-304.

Lobin, W. \& Ohm, P. 1987. Forschungsreisen in ein Entwicklungsland. Biologen arbeiten auf den Kapverdischen Inseln. - Natur und Museum 117: 301-333.

Lobin, W. \& Porembski, S. 1994. The genus Verbascum (Scrophulariaceae) on the Cape Verde Islands, W Africa. - Willdenowia 24: 65-81.

Lobin, W. \& Roessler, H. 1985. Die Gattung Forsskaolea Linnaeus 1764 auf den Kanarischen und Kapverdischen Inseln (Phanerogamae: Urticaceae). - Senckenberg. Biol. 65(1984): 373-390.

Lobin, W. \& Zizka, G. 1990. The impact of man on the flora (Phanerogamae) of the Cape Verde Islands. - Mitt. Inst. Allg. Bot. Hamburg 23b: 739-743.

Lobin, W., Kilian, N. \& Hiemstra, P. B. 1988a. Ergänzungen zu "Hansen \& Sunding, Flora of Macaronesia, Checklist of Vascular Plants, 3rd rev. ed. 1985" - III. - Cour. Forsch.-Inst. Senckenberg 105: 149-154.

Lobin, W., Kriesten, O. \& Leyens, T. 1993. Die Kapverdische Glockenblume (Campanula jacobaea Webb) - eine für Botanische Gärten attraktive endemische Art von den Kapverdischen Inseln. - Palmengarten 1993: 120-121.

Lobin, W., Leyens, T., Kilian, N., Erben, M. \& Lewejohann, K. 1995. The genus Limonium (Plumbaginaceae) on the Cape Verde Islands, W Africa. - Willdenowia 25: 197-214.

Lobin, W., Nogueira, I. \& Redeker, H. 1988b. On a collection of Malvales and Tiliales from the Cape Verde Islands. - Mem. Soc. Brot. 28: 55-91.

Lösch, R., Beyhl, F. E., Mies, B. \& Schweihofen, B. 1990. Relative Standortkonstanz der Federbuschvegetation auf den mittelatlantischen Inseln und das Fehlen klimatischorographischer Voraussetzungen für eine Waldklimax auf den Kapverden. - Cour. Forsch.-Inst. Senckenberg 129: 75-82. 
Lowrey, T. K. \& Crawford, D. J. 1985. Allozyme divergence and evolution in Tetramolopium (Compositae: Astereae) on the Hawaiian Islands. - Syst. Bot. 10: 64-72.

Mace, G. M. \& Stuart, S. N. 1994. Draft IUCN Red List Categories, Version 2.2. - Species 21-22: 13-24.

Maire, R. 1933. Mission scientific du Hoggar. Études sur la flore et la vegetation du Sahara central. - Mem. Soc. Hist. Nat. Afrique N. 3: 1-292.

Maire, R. 1957. Flore de l'Afrique du Nord. 4. - Encyclopédie Biologique 53.

Malato-Beliz, J. 1970. Gramíneas da Ilha de Maio (Arquipélago de Cabo Verde). - Bol. Soc. Brot., sér. 2, 44: 251-277.

Malato-Beliz, J. 1971. Papilionáceas da Ilha de Maio (Arquipélago de Cabo Verde). - Junta Invest. Ultramar, Missão Estud. Agron. Ultramar (1971): 29-41.

Markgraf, F. 1972. Periploca L. - In: Tutin, T. G., Heywood, V. H., Burges, N. A., Moore. D. M., Valentine, D. H., Walters, S. M. \& Webb, A. A. (eds), Flora europaea 3, Cambridge University Press, Cambridge, p. 70.

Martins, E. S. 1995. Boraginaceae. - Flora de Cabo Verde, Plantas Vasculares 74: 1-22.

Mes, T. H. M. \& Hart, H. T. 1996. The evolution of growth-forms in the Macaronesian genus Aeonium (Crassulaceae) inferred from chloroplast DNA RFLPs and morphology. Molecular Ecology 5: 351-363.

Meusel, H. 1952. Über Wuchsformen, Verbreitung und Phylogenie einiger mediterranmitteleuropäischer Angiospermen-Gattungen. - Flora 139: 333-393.

Miller, A. G. 1980. A revision of Campylanthus. - Notes Royal Bot. Gard. Edinb. 38 : 373-385.

Mitchell-Thomé, R. C. 1976. Geology of the Middle Atlantic Islands. - Borntraeger, Berlin.

Mitchell-Thomé, R. C. 1985. Radiometric studies in Macaronesia. - Bol. Mus. Mun. Funchal 37: 52-85.

Moore, R. J. (ed.) 1973. Index to plant chromosome numbers 1967-1971. - Oosthoek, Utrecht.

Moore, R. J. (ed.) 1974. Index to plant chromosome numbers for 1972. - Oosthoek, Utrecht.

Moore, R. J. (ed.) 1977. Index to plant chromosome numbers for 1973/74. - IAPT, Utrecht.

Moore, R. J. 1982. Flora Europaea check-list and chromosome index. - Cambridge Univ. Press, Cambridge.

Morton, J. K. 1966. The role of polyploidy in the evolution of a tropical flora. - In: Darlington, C. D. \& Lewis, K. K. (eds), Chromosomes today, Vol. 1, pp. 73-76.

Murbeck, S. 1921. Sur quelques espèces nouvelles ou critiques des genres Celsia et Onopordon. - Acta Univ. Lund, ser. 2, 17: 1-18.

Murbeck, S. 1925. Monographie der Gattung Celsia. - Acta Univ. Lund, ser. 2, 22: 1-237.

Nogueira, I. 1975a. Plantas colhidas pelo Eng. ${ }^{\circ}$ L. A. Grandvaux Barbosa no arquipélago de

Cabo Verde. - I. Pteridophyta. - Garcia de Orta, Sér. Bot. 2: 79-84.

Nogueira, I. 1975b. Plantas colhidas pelo Eng. ${ }^{\circ}$ L. A. Grandvaux Barbosa no arquipélago de Cabo Verde. - II. Spermatophyta (Annonaceae - Moringaceae). - Garcia de Orta, Sér. Bot. 2: 89-106.

Nogueira, I. 1976. Plantas colhidas pelo Eng. ${ }^{\circ}$ L. A. Grandvaux Barbosa no arquipélago de Cabo Verde. - III. Spermatophyta (Rubiaceae - Gentianaceae). - Garcia de Orta, Sér. Bot. 3: 19-32.

Nogueira, I. 1977. Plantas colhidas pelo Eng. ${ }^{\circ}$ L. A. Grandvaux Barbosa no arquipélago de Cabo Verde. - VI. Spermatophyta (Nyctaginaceae - Casuarinaceae). - Garcia de Orta, Sér. Bot. 3: 85-98. 
Nogueira, I. 1979. Plantas colhidas pelo Eng. ${ }^{\circ}$ L. A. Grandvaux Barbosa no arquipélago de Cabo Verde. - VII. Spermatophyta (Cannaceae - Cyperaceae). - Garcia de Orta. Sér. Bot. 4: 1-6.

Nogueira, I. \& Ormonde, J. 1981. Plantas colhidas pelo Eng. ${ }^{\circ}$ L. A. Grandvaux Barbosa no arquipélago de Cabo Verde. - IX. Spermatophyta (Gramineae). - Garcia de Orta, Sér. Bot. 5: 13-29.

Nogueira, I. \& Ormonde, J. 1985. Plantas colhidas pelo Eng. ${ }^{\circ}$ L. A. Grandvaux Barbosa no arquipélago de Cabo Verde - X. Aditamentos e correccôes às partes I a VII. - Garcia de Orta, Sér. Bot. 6: 163-176.

Ormonde, J. 1976. Plantas colhidas pelo Eng. ${ }^{\circ}$ L. A. Grandvaux Barbosa no arquipélago de Cabo Verde. - IV. Spermatophyta (Leguminosae). - Garcia de Orta, Sér. Bot. 3: 33-48.

Ormonde, J. 1977. Plantas colhidas pelo Eng. ${ }^{\circ}$ L. A. Grandvaux Barbosa no arquipélago de Cabo Verde. - V. Spermatophyta (Rosaceae - Umbelliferae). - Garcia de Orta, Sér. Bot. 3: $73-80$.

Ormonde, J. 1980. Plantas colhidas pelo Eng. ${ }^{\circ}$ L. A. Grandvaux Barbosa no arquipélago de Cabo Verde. - VIII. Spermatophyta (Boraginaceae - Plantaginaceae). - Garcia de Orta, Sér. Bot. 4: 171-188.

Ormonde, J. \& Nogueira, I. 1985. Plantas colhidas pelo Eng. ${ }^{\circ}$ L. A. Grandvaux Barbosa no arquipélago de Cabo Verde. - XI. Aditamentos e correccôes à parte IX. - Garcia de Orta, Sér. Bot. 7: 15-18.

Ortega, J. 1980. Estudios en la flora de Macaronesica: Algunos numeros de cromosomas IV. Bot. Macar. 7: 43-51.

Ortega, J. \& Navarro, B. 1977. Estudios en la flora de Macaronesica: Algunos numeros de cromosomas IV. - Bot. Macar. 4: 69-76.

Ozenda, P. 1977. Flore du Sahara septentrional et central. - Centre Nacional de la Recherche Scientifique, Paris.

Paiva, J. A. R. \& Nogueira, I. 1974. O género Sida L. no arquipélago de Cabo Verde. - Garcia de Orta, Sér. Bot. 2: 63-70.

Pérez de Paz, P. L. 1978. Revisión del genero Micromeria Bentham (Lamiaceae Stachyoideae) en la region Macaronesica. - Instituto de Estudios Canarios en la Universidad de La Laguna, Monografías, Sección IV: Ciencias Naturales 16: I-XIII + 1-306 + I-XXXII.

Pettersson, B. 1960. Notes on a collection of vascular plants from the Cape Verde Islands. Comm. Biol. Soc. Scient. Fenn. 22: 1-68.

Pettersson, B. 1990. Studies in the genus Nervilia (Orchidaceae) in Africa. - Nord. J. Bot. 9: 487-497.

Pettersson, B. 1991. The genus Nervilia (Orchidaceae) in Africa and the Arabian Peninsula. Orchid Monogr. 5.

Pichi-Sermolli, R. 1962. On the fern genus "Actiniopteris" Link. - Webbia 17: 1-32.

Polatschek, A. 1976. Die Gattung Erysimum auf den Kapverden, Kanaren und Madeira. Ann. Naturhistor. Mus. Wien 80: 93-103.

Porter, D. M. 1986. Charles Darwin's plant specimens from the voyage of HMS Beagle. - Bot. J. Linn. Soc. 93: 1-172.

Praeger, R. L. 1932. An account of the Sempervivum group. - Royal Hort. Society, London.

Reese, G. 1957. Über die Polyploidiespektren in der nordsaharischen Wüstenflora. - Flora 144: 598-634. 
Rivas-Cembellin, M. M. \& Leon-Arenciba, M. C. 1993. Contribution to the study of Carex antoniensis A. Chev. (Cyperaceae), endemic in the Cape Verde Islands. - Cour. Forsch.-Inst. Senckenberg 159: 199-203.

Rohlf, F. J. 1990. NTSYS-pc. Numerical taxonomy and multivariate analysis system. Version 1.60. - Exeter Software, New York.

Rothe, P. 1982. Zur Geologie der Kapverdischen Inseln. - Cour. Forsch.-Inst. Senckenberg 52: $1-9$.

Rustan, Ø. Н. 1996. Revision of the genus Diplotaxis (Brassicaceae) in the Cape Verde Islands, W Africa. - Nord. J. Bot. 16: 19-50.

Rustan, Ø. H. \& Borgen, L. 1979. Endemic species of Diplotaxis (Brassicaceae) in the Cape Verde Islands. - Bocagiana 47: 1-5.

Rustan, Ø. H. \& Brochmann, С. 1981. Guide to the field-note registration form for The Republic of Cape Verde. - Botanical Garden and Museum, Univ. of Oslo.

Rustan, Ø. H. \& Brochmann, C. 1985. Additions to the vascular flora of Cabo Verde. - Garcia de Orta, Sér. Bot. 6 (1983-84): 89-106.

Rustan, Ø. H. \& Brochmann, C. 1988. The genus Kickxia Dumortier (Scrophulariaceae) in the Cape Verde Islands, W Africa. - Cour. Forsch.-Inst. Senckenberg 105: 67-72.

Rustan, Ø. H. \& Brochmann, C. 1993. Additions to the vascular flora of Cabo Verde - III. Garcia de Orta, Sér. Bot. 11: 31-62.

Schlechtendal, D. F. L. v. 1851. Ein Beitrag zur Flora der Inseln des grünen Vorgebirges. Bot. Zeit. 9: 825-831, 841-846, 857-864, 873-880.

Schleich, H.-H. \& Wuttke, M. 1983. Die kapverdischen Eilande Santa Luzia, Branco und Razo - ein Reisebericht. - Natur und Museum 113: 33-44.

Schmidt, J. A. 1852. Beiträge zur Flora der Cap Verdischen Inseln. - Akademische Buchhandlung, Heidelberg.

Schwarz, O. 1939. Die Gattung Globularia. - Bot. Jahrb. Syst. 69: 318-373.

Schwarz, O. 1963. Chromosomenzahlen, Lebensformen und Evolution der Gattung Globularia L. - Drudea 3: 5-16.

Schwarz, O. 1967. The genus Globularia. - Quart. Bull. Alpine Gard. Soc. 35: 305-316.

Soares, F. A. 1961. Notas sobre a agrostologia de Cabo Verde. - Garcia de Orta 9: 833-848.

Stearn, W. T. 1983. Botanical Latin. - David \& Charles, Newton Abbott.

Stebbins, G. L. 1985. Polyploidy, hybridization, and the invasion of new habitats. - Ann. Missouri Bot. Gard. 72: 824-832.

Sunding, P. 1973a. Check-list of the vascular plants of the Cape Verde Islands. - Botanical Garden, Univ. of Oslo.

Sunding, P. 1973b. Endemism in the flora of the Cape Verde Islands, with special emphasis on the Macaronesian flora element. - Monogr. Biol. Canar. 4: 112-117.

Sunding, P. 1974. Additions to the vascular flora of the Cape Verde Islands. - Garcia de Orta, Sér. Bot. 2: 5-30.

Sunding, P. 1977. A botanical bibliography of the Cape Verde Islands. - Bol. Mus. Mun. Funchal 31: 100-109.

Sunding, P. 1979. Origins of the Macaronesian flora. - In: Bramwell, D. (ed.), Plants and Islands, Academic Press, London, pp. 13-40.

Sunding, P. 1980. Christen Smith som botaniker på Kapp Verde-øyene. - Blyttia 38: 181-188.

Sunding, P. 1981. Additions to the vascular flora of the Cape Verde Islands - II. - Garcia de Orta, Sér. Bot. 5: 31-46. 
Sunding, P. 1982. Additions to the vascular flora of the Cape Verde Islands - III. - Garcia de Orta, Sér. Bot. 5: 125-138.

Sunding, P. 1985. Plantenavn oppkalt etter Christen Smith. - Blyttia 43: 58-62.

Susanna, A., García-Jacas, N., Soltis, D. E. \& Soltis, P. S. 1995. Phylogenetic relationships in tribe Cardueae (Asteraceae) based on ITS sequences. - Amer. J. Bot. 82: 1056-1068.

Sutton, D. A. 1988. A revision of the tribe Antirrhineae. - Oxford University Press, London.

Sventenius, E. R. S. 1971. Semina ac sporae plantarum spontanearum vel subspontanearum quae in Insulis Gorgoneaensibus etc. - In: Index Seminum Hortus Acclimatationis Plantarum Arautapae, Orotava, Tenerife, pp. 35-39.

Teixeira, A. J. da Silva \& Barbosa, L. A. Grandvaux 1958. A agricultura do Arquipélago de Cabo Verde. Cartas agrícolas. Problemas agrários. - Mem. Junta Invest. Ultramar, sér. 2, 2: 7-178.

Tischler, G. 1934. Die Bedeutung der Polyploidie für die Verbreitung der Angiospermen, erläutert an den Arten Schleswig-Holsteins, mit Ausblicken auf andere Florengebiete. Bot. Jahrb. 67: 1-36.

Tischler, G. \& Wulff, H. D. 1953-63. Angewandte Pflanzenkaryologie. - Gebrüder Borntraeger, Berlin.

Tuckey, J. K. 1818. Narrative of an Expedition to explore the River Zaire,....; to which is added, the Journal of Professor Smith;...etc. - London.

Valdés, B. 1979. Revision del genero Asparagus (Liliaceae) en Macaronesia. - Lagascalia 9 : 65-107.

Ventenat, É. P. 1804-1805. Jardin de la Malmaison 2. - Paris.

Verdcourt, B. 1970. Studies in the Leguminosae-Papilionoideae for the "Flora of Tropical East Africa": III. - Kew Bull. 24: 379-447.

Vollesen, K. 1987. The native species of Gossypium (Malvaceae) in Africa, Arabia and Pakistan. - Kew Bull. 42: 337-349.

Warwick, S. I. \& Black, L. D. 1993. Molecular relationships in subtribe Brassicinae (Cruciferae, tribe Brassiceae). - Canad. J. Bot. 71: 906-918.

Wawra, H. 1866. Botanische Ergebnisse der Reise seiner Majestät des Kaisers von Mexico Maximilian I. nach Brasilien (1859-60). - Wien.

Webb, P. B. 1848. Sinapidendron gracile, Sinapidendron vogelii, Lotus brunneri, Paronychia illecebroides, Lotus purpureus, Campanula jacobaea, Phagnalon melanoleucum, Sonchus daltonii, Rhabdotheca picridioides, Echium stenosiphon, Campylanthus benthamii. - Hooker's Icon. Pl. 8: Tabs. 751-752, 754, 756-756, 762, 764-766, 772, 776.

Webb, P. B. 1849. Spicilegia Gorgonea; or a catalogue of all the plants as yet discovered in the Cape de Verd Islands. From the collections of J. D. Hooker, Esq. M.D.R.N., Dr. T. Vogel, and other travellers. - In: Hooker, W. J. (ed.), Niger Flora, Hippolyte Baillière, London.

Weddell, H. A. 1856. Monographie de la famille des Urticacees. - Arch. Mus. Hist. Nat. Paris 9.

Welzen, P. C. van 1981. A taxonomic revision of the genus Arthraxon Beauv. (Gramineae). Blumea 27(1): 225-300.

Westermann, G. 1969. Lexikon der Geographie. Bd. 2. - Braunschweig.

Wickens, G. E. 1976. The flora of Jebel Marra (Sudan Republic) and its geographical affinities. - Kew Bull. Add. 5: 1-368.

Wijnands, D. O. 1983. The botany of the Commelins. - Rotterdam. 
Wiklund, A. 1987. The genus Nauplius (Asteraceae - Inuleae). - Nord. J. Bot. 7: 1-23.

Wild, H. 1969. The species of Conyza L. with ligulate or lobed ray florets in Africa. Madagascar and the Cape Verde Islands. - Bol. Soc. Brot., sér. 2, 43: 247-279.

Willkomm, M. 1856-62. Icones et descriptiones plantarum novarum criticarum et rariorum Europae austro-occidentalis praecipue Hispanicae. 2. Cistinearum orbis veteris descriptio monographica iconibus illustrata. - Lipsiae [Leipzig].

Zizka, G. 1986. Chromosomenzählungen bei einigen kapverdischen Pflanzen. - Cour. Forsch.-Inst. Senckenberg 81: 181-182. 


\section{INDEX}

The following fonts and types are used in the index:

APIACEAE

Aeonium Webb \& Berth

Tornabenea Parl.

Aristida cardosoi Cout.

Aeonium webbii Bolle

Argemone mexicana L.
Family

Non-endemic genus

Endemic genus

Endemic taxon (species or subspecies)

Synonyms based on material from the Cape Verde Islands

Other taxa mentioned, either non-endemic or not from the Cape Verde Islands

Abutilon pannosum (Forst. f.) Schltdl.

Actiniopteris radiata (Sw.) Link

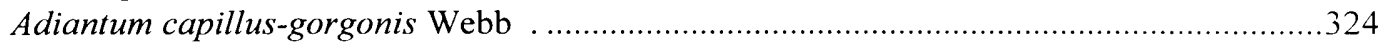

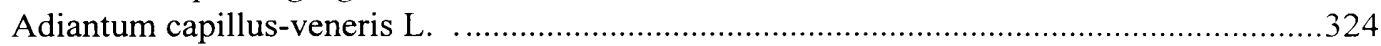

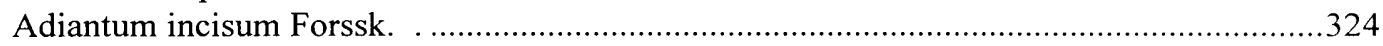

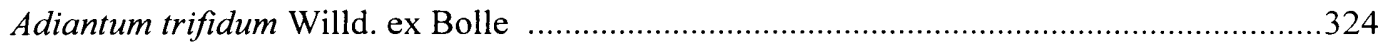

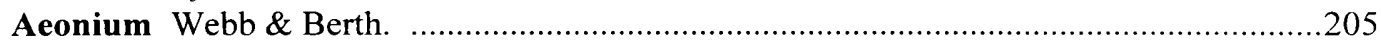

Aeonium arboreum (L.) Webb \& Berth. ........................................................................205

Aeonium glutinosum (Aiton) Webb \& Berth. . ............................................................205

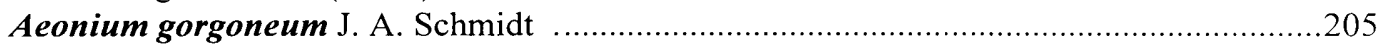

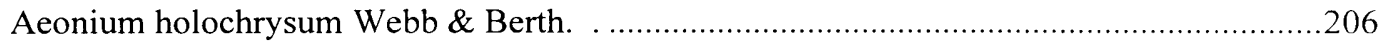

Aeonium leucoblepharum Webb ex A. Rich. . ............................................................206

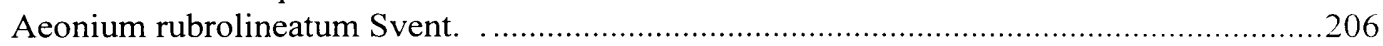

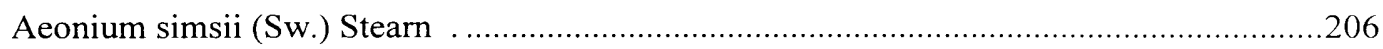

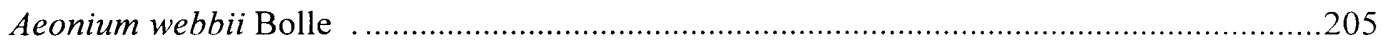

Alyssum maritimum (L.) Lam. var. canariense DC. ................................................ 186

Alyssum maritimum (L.) Lam. var. spathulatum (J. A. Schmidt) A. Chev. ......................191

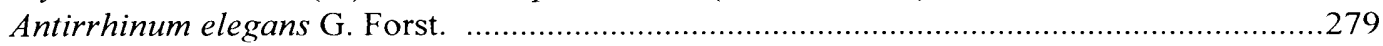

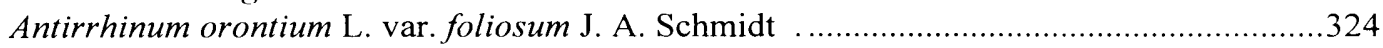

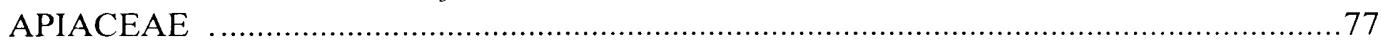

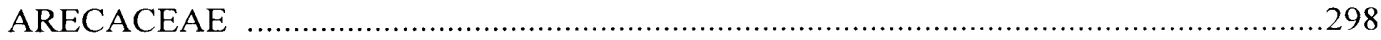

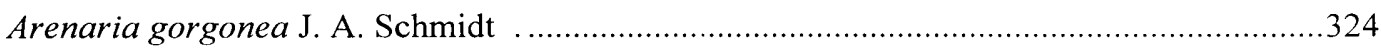

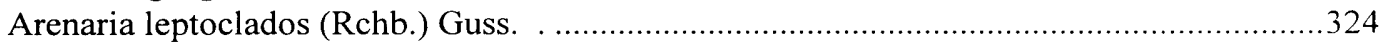

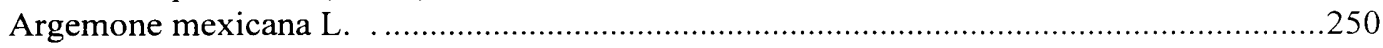

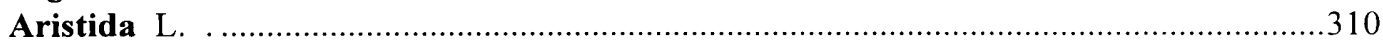

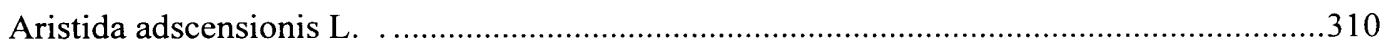

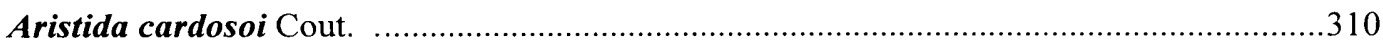

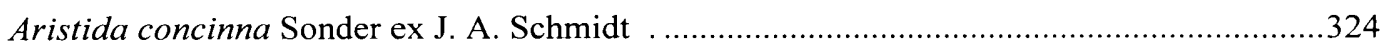

Aristida funiculata Trin. \& Rupr. ........................................................... $310 ; 324$

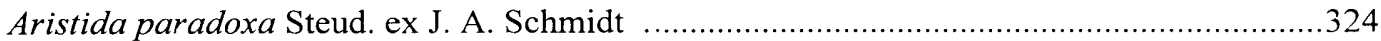

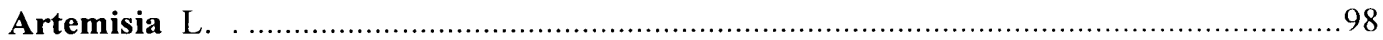




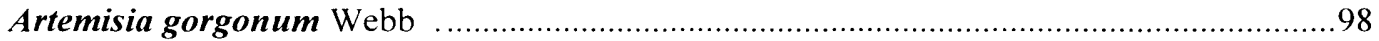

Artemisia thuscula Cav. ....................................................................................... 100

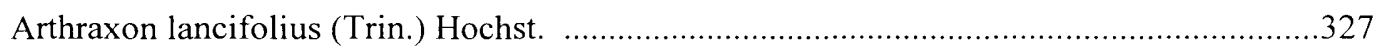

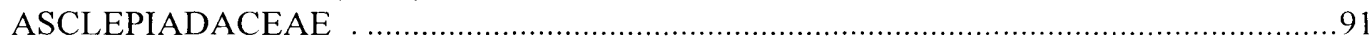

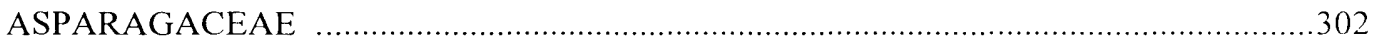

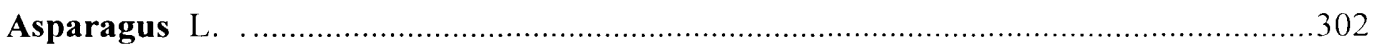

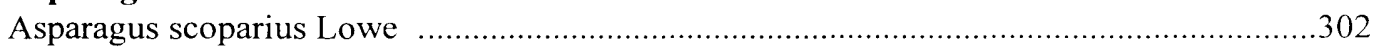

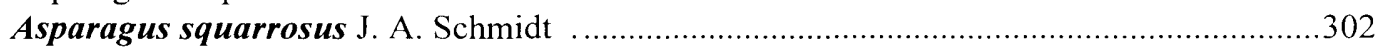

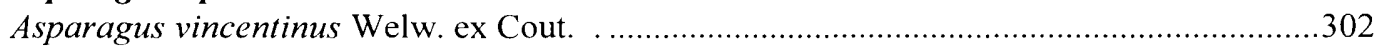

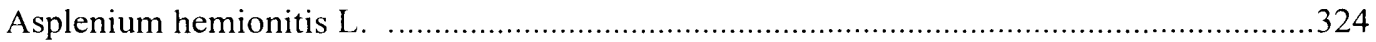

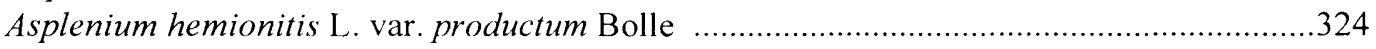

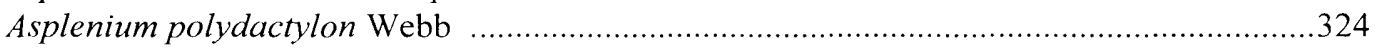

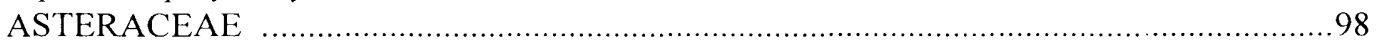

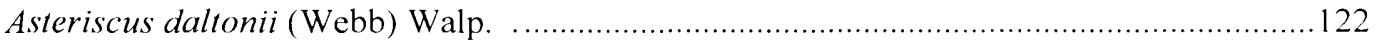

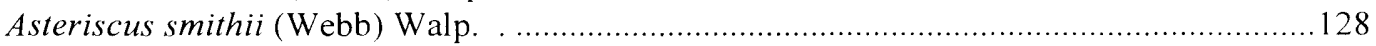

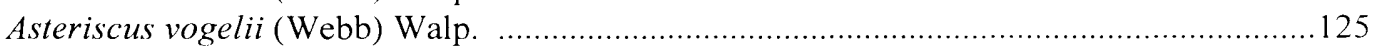

Asteriscus vogelii (Webb) Walp. var. darwinii (Webb) Walp. ..................................... 125

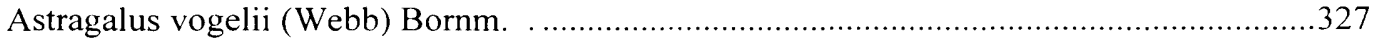

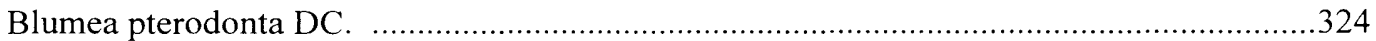

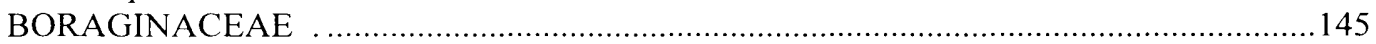

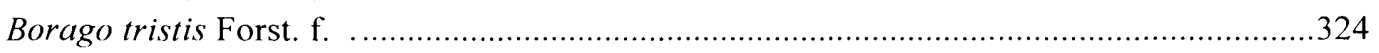

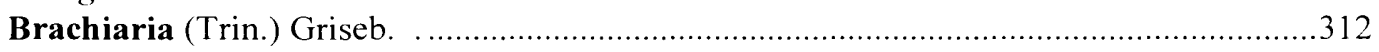

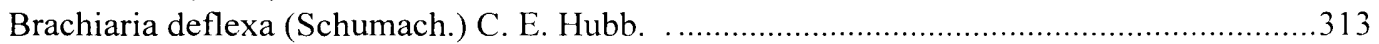

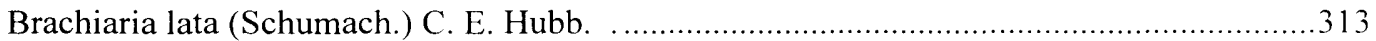

Brachiaria lata (Schumach.) C. E. Hubb. ssp. caboverdiana Conert \& C. Köhler .............313

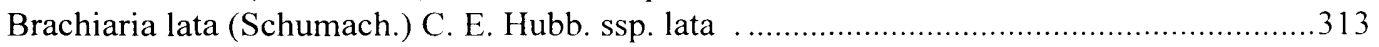

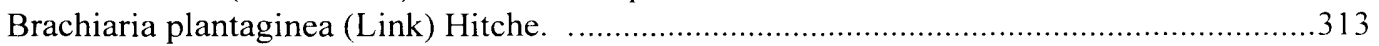

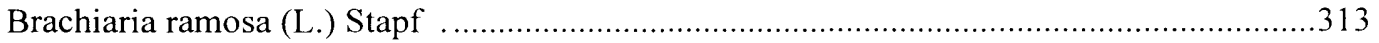

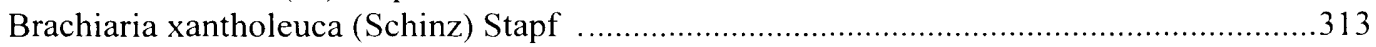

Brassica glauca (J. A. Schmidt) Kuntze ........................................................... 161; 167

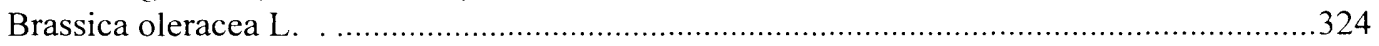

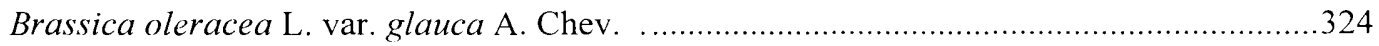

Brassica vogelii (Webb) Kuntze ....................................................................... 181

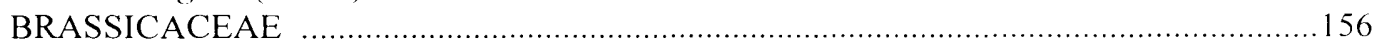

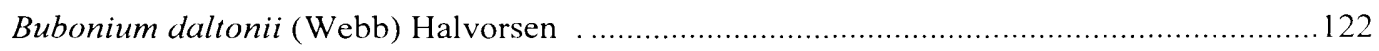

Bubonium daltonii (Webb) Halvorsen ssp. vogelii (Webb) Halvorsen ............................125

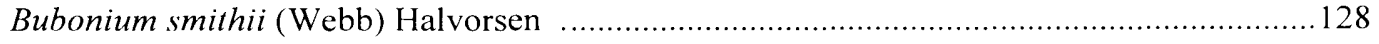

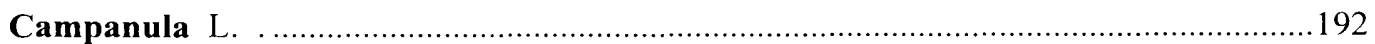

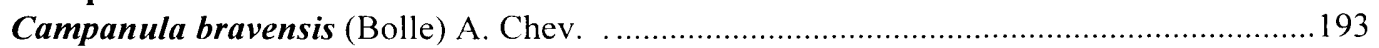

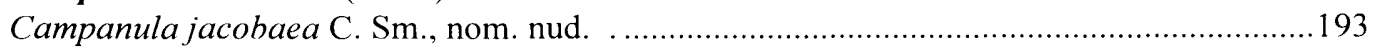

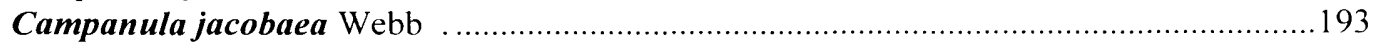

Campanula jacobaea Webb var. bravensis Bolle ................................................... 193

Campanula jacobaea Webb var. hispida Bolle ........................................................... 194

Campanula jacobaea Webb var. humilis Bolle .................................................. 194 


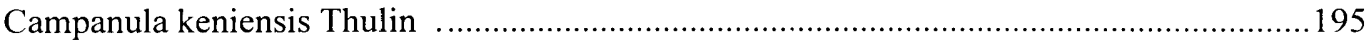

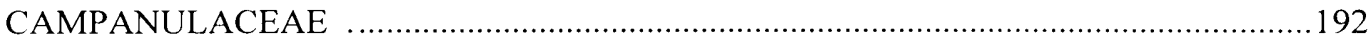

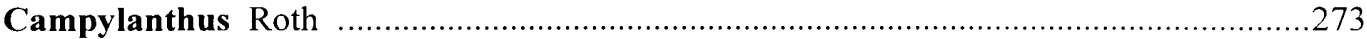

Campylanthus benthamii Webb var. glaber (Benth.) Webb, nom. illeg. .........................2273

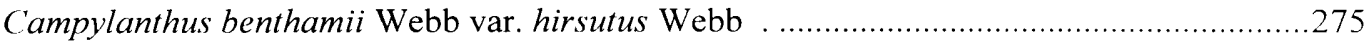

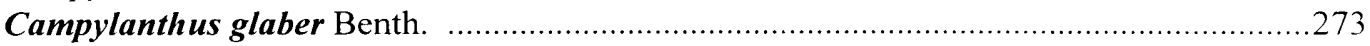

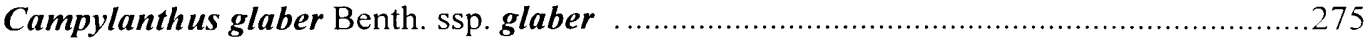

Campylanthus glaber Benth. ssp. spathulatus (A. Chev.) Brochmann. N. Kilian,

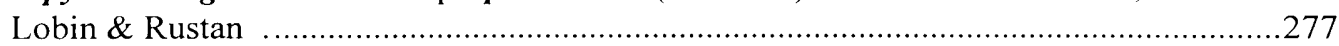

Campylanthus glaber Benth. var. puberulus Cout. .....................................................277

Campylanthus glaber Benth. var. pumilus Pett. ..........................................................2275

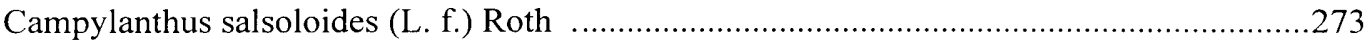

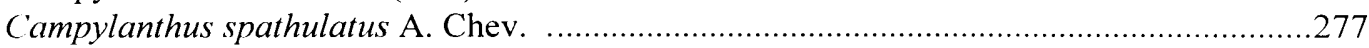

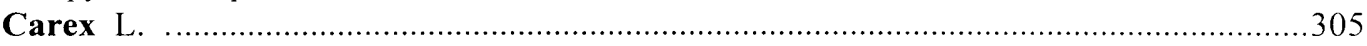

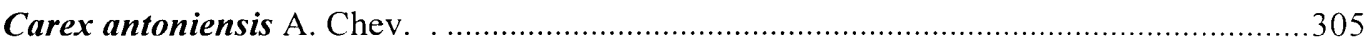

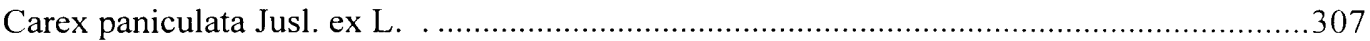

Carex paniculata Jusl. ex L. ssp. calderae (Hansen) Lewej. \& Lobin ........................................ 308

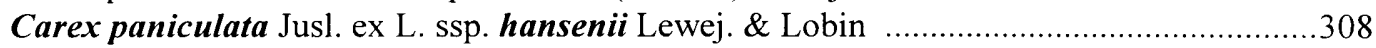

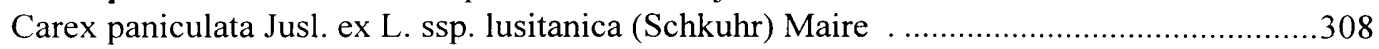

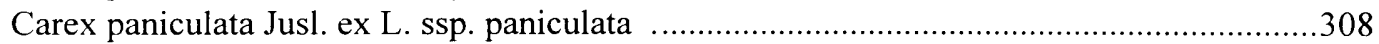

Carex paniculata Jusl. ex L. ssp. szovitsii (V. Kreczetovicz) Nilsson ................................308

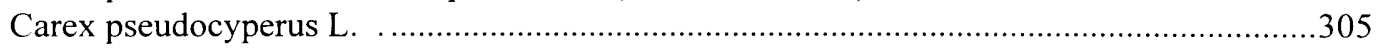

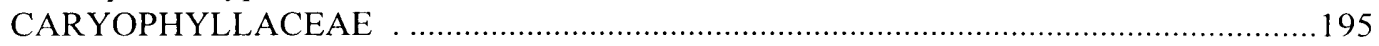

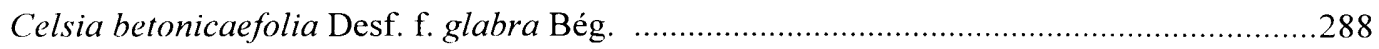

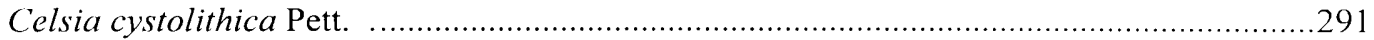

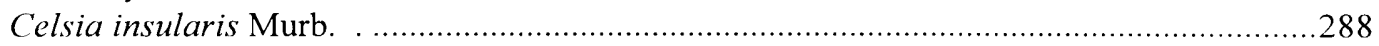

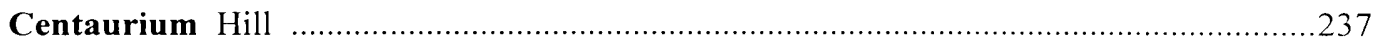

Centaurium pulchellum (Sw.) Druce ssp. viridense (Bolle) A. Chev. ................................237

Centaurium tenuiflorum (Hoffm. \& Link) Fritsch .......................................................2237

Centaurium tenuiflorum (Hoffm. \& Link) Fritsch ssp. viridense (Bolle) A. Hansen \&

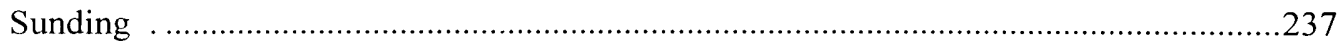

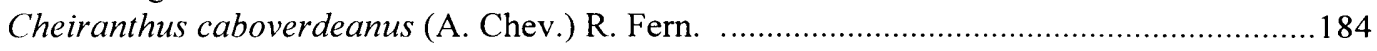

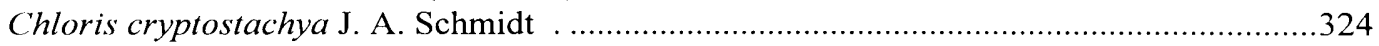

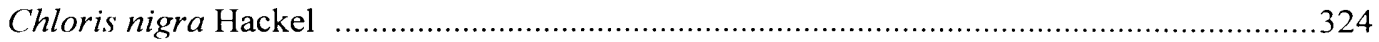

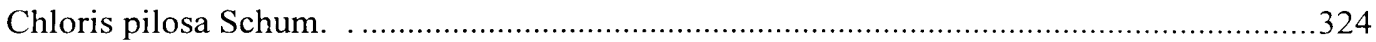

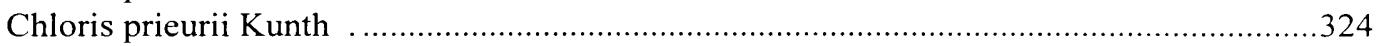

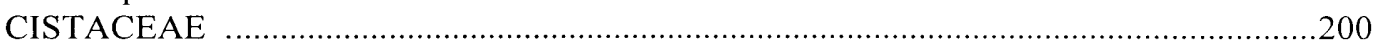

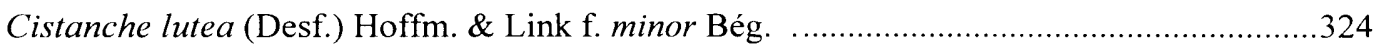

Cistanche phelypaea (L.) Cout. ...................................................................... 324; 327

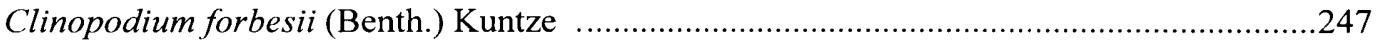

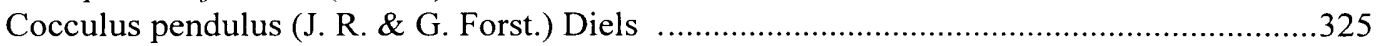

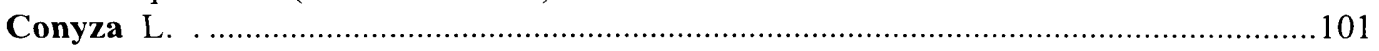

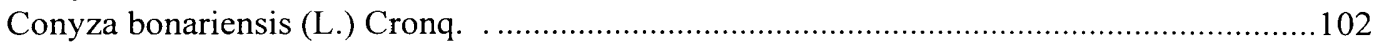

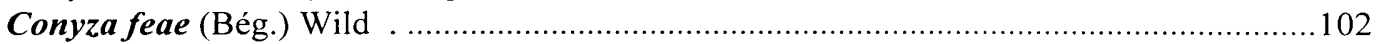

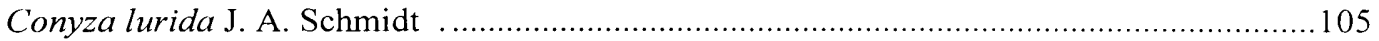

Conyza lurida J. A. Schmidt var. humilis Bolle . .................................................. 105 


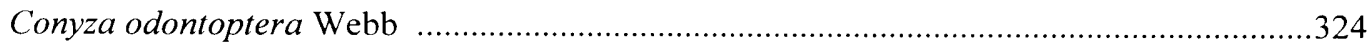

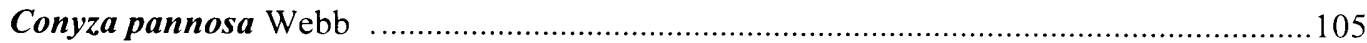

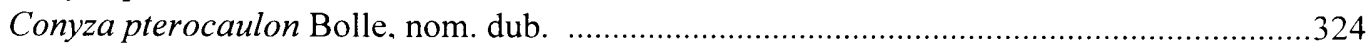

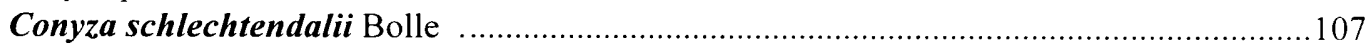

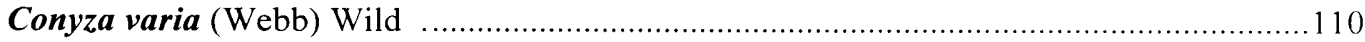

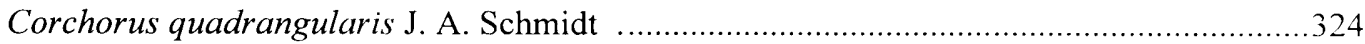

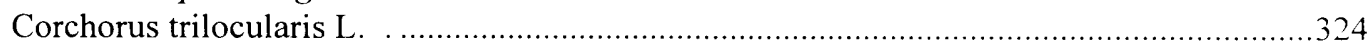

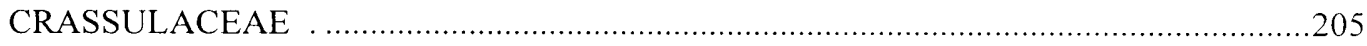

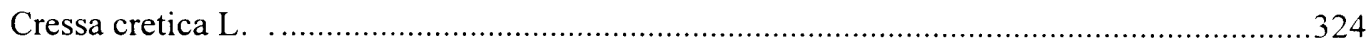

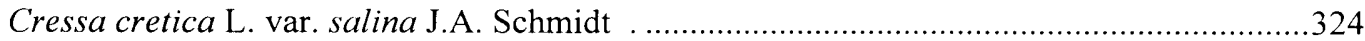

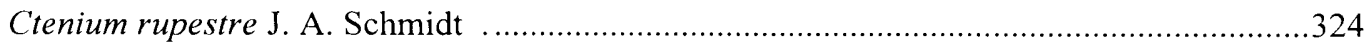

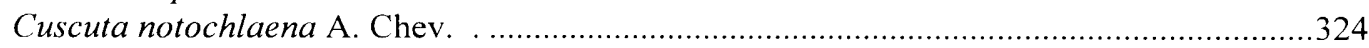

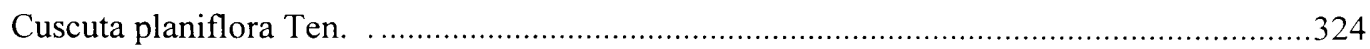

CYPERACEAE . .

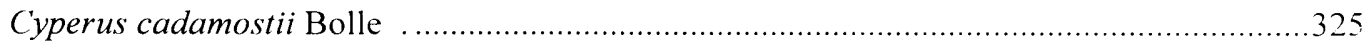

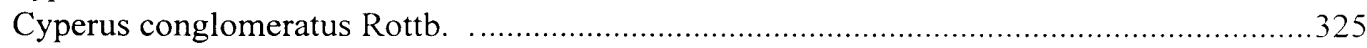

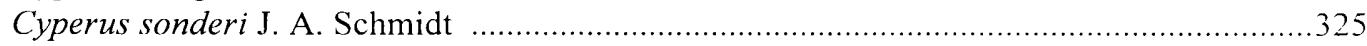

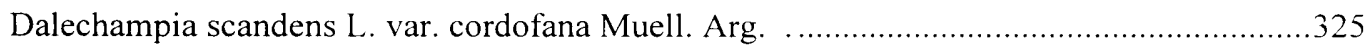

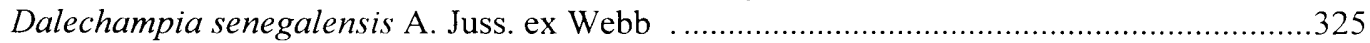

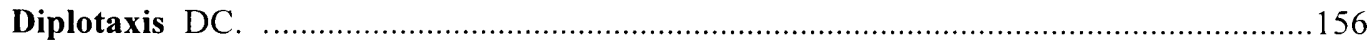

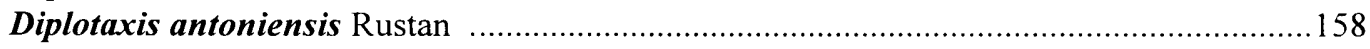

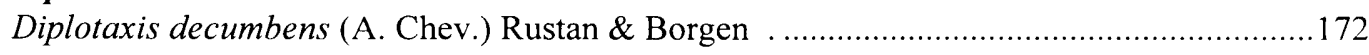

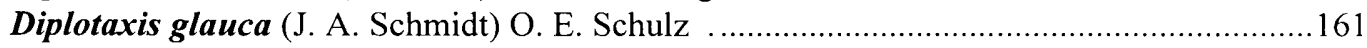

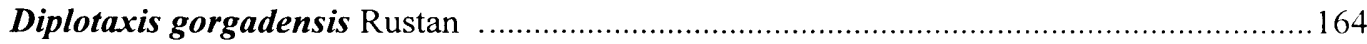

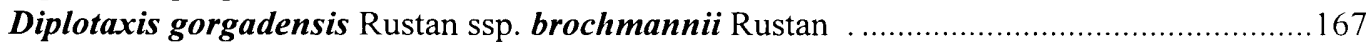

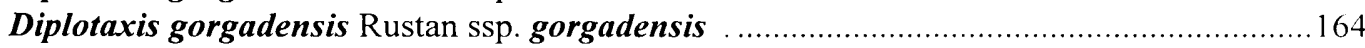

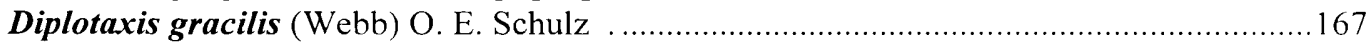

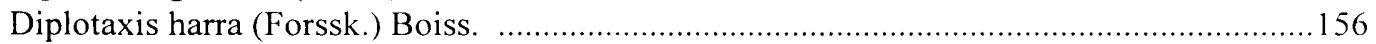

Diplotaxis harra (Forssk.) Boiss. ssp. glauca (J. A. Schmidt) Sobrino Vesperinas .............161

Diplotaxis harra (Forssk.) Boiss. ssp. hirta (A. Chev.) Sobrino Vesperinas .......................172

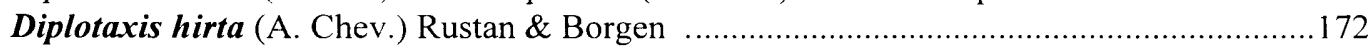

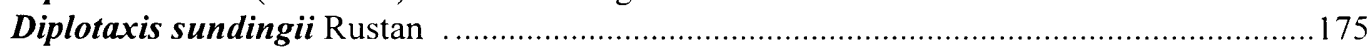

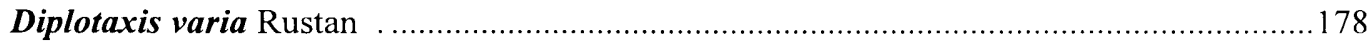

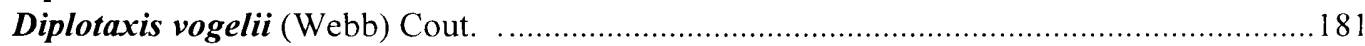

Diplotaxis vogelii (Webb) Cout. var. glauca (J. A. Schmidt) Cout. .....................................161

Diplotaxis vogelii (Webb) O. E. Schulz, nom. illeg. . ................................................181

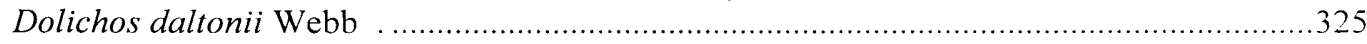

Dryopteris elongata (Aiton) A. Chev. var. simplex A. Chev. .............................................325

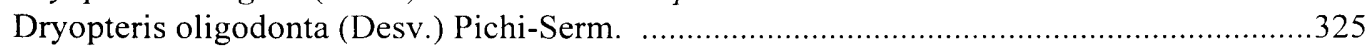

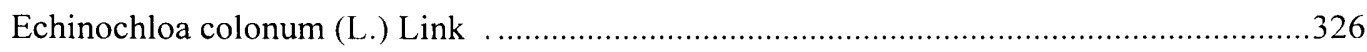

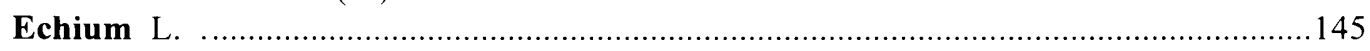

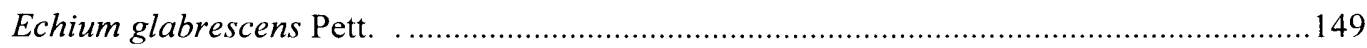

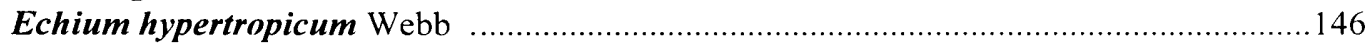

Echium hypertropicum Webb var. nudum Coincy ...................................................... 146 
Echium lindbergii Pett.

Echium nudum Lowe, nom. ined. ......................................................................... 146

Echium stenosiphon Webb ................................................................................. 146

Echium stenosiphon Webb ssp. lindbergii (Pett.) Bramwell .........................................149

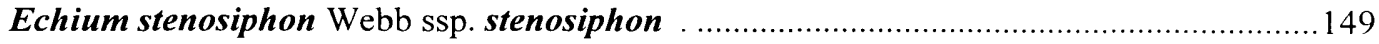

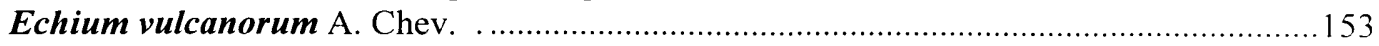

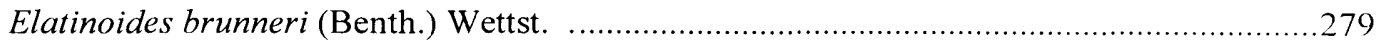

Elatinoides brunneri (Benth.) Wettst. var. parietariifolia (Webb) Cout. ..........................2280

Elatinoides dichondrifolia (Benth.) Wettst. ..................................................................28

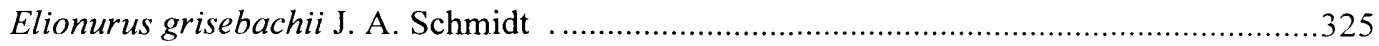

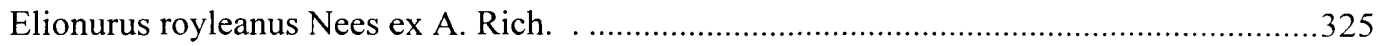

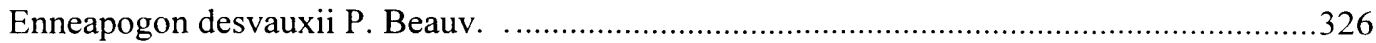

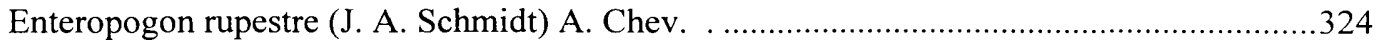

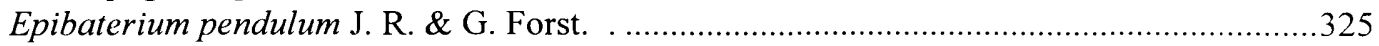

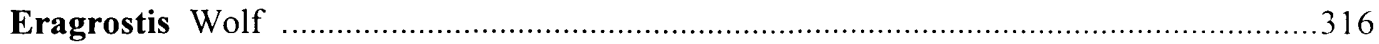

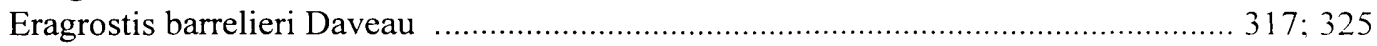

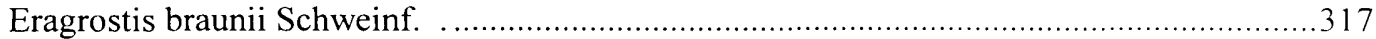

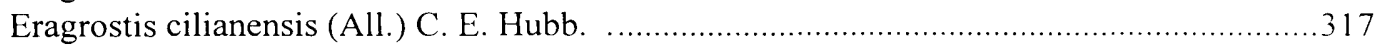

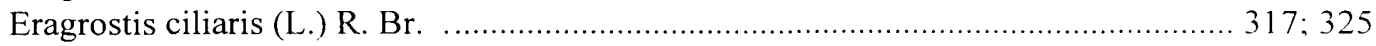

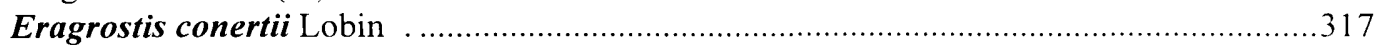

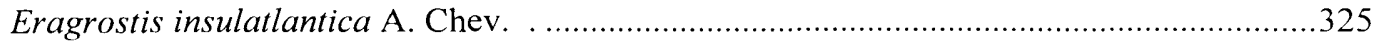

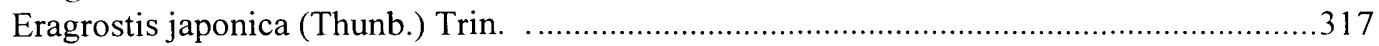

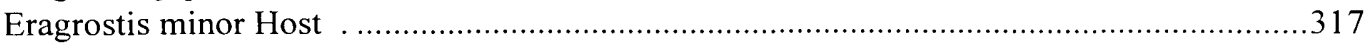

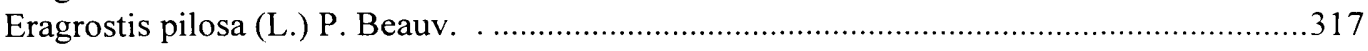

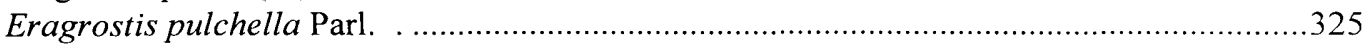

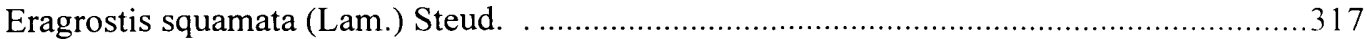

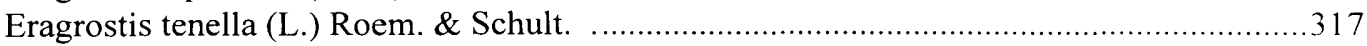

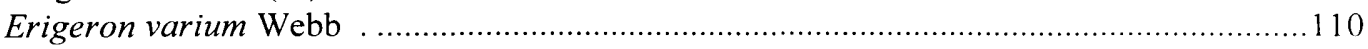

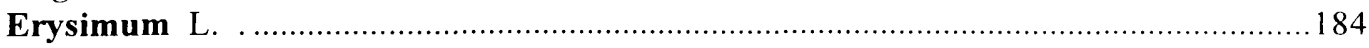

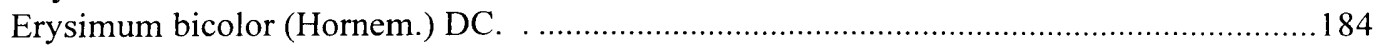

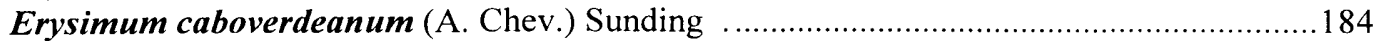

Erysimum scoparium (Brouss. ex Willd.) Wettst. ..................................................... 184

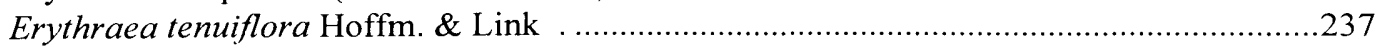

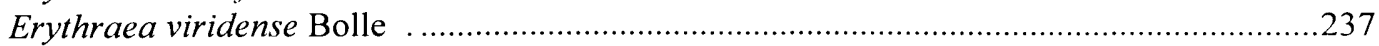

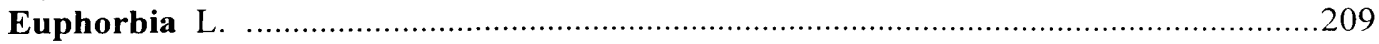

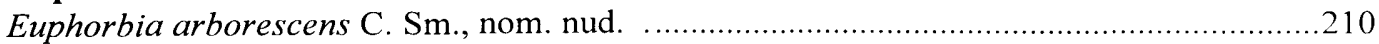

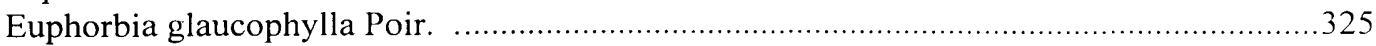

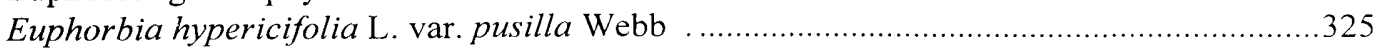

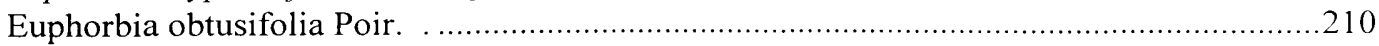

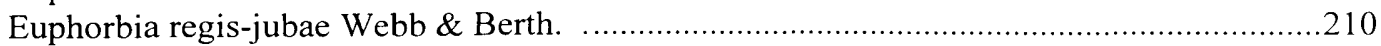

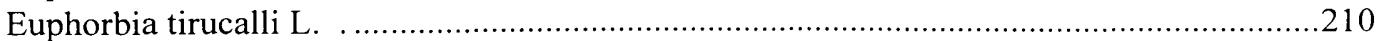

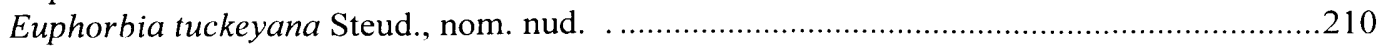

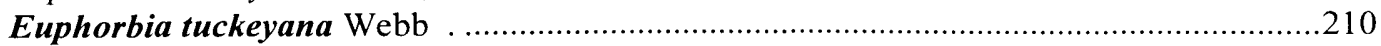

Euphorbia tuckeyana Webb var. mezereum A. Chev. .............................................210

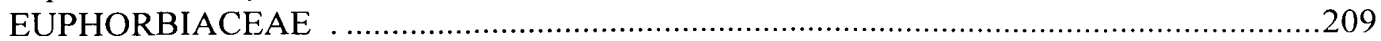

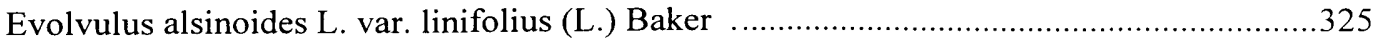


Evolvulus linifolius L. var. grandiflorus Bolle .325

FABACEAE .213

Fagonia albiflora A. Chev. .325

Fagonia mayana Schltdl. .325

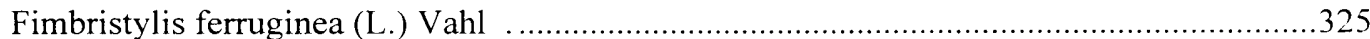

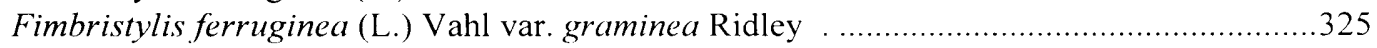

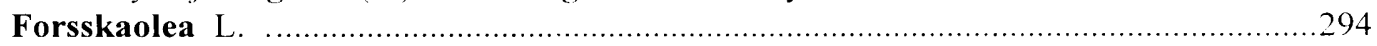

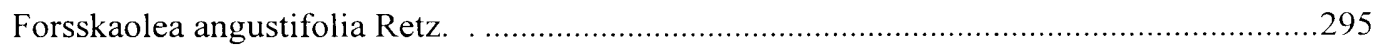

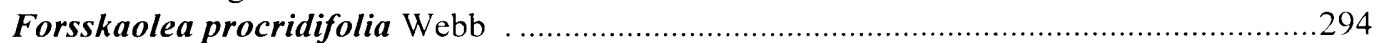

Forsskaolea procridifolia Webb var. microphylla J. A. Schmidt ....................................295

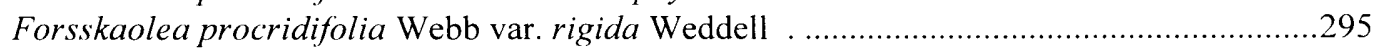

Forsskaolea procridifolia Webb var. umbrosa Weddell (1857), nom. inval. ....................294

Forsskaolea procridifolia Webb var. umbrosa Weddell (1869) ........................................295

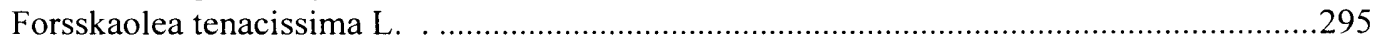

Forsskaolea viridis Ehrenb. ex Webb ............................................................... 294; 325

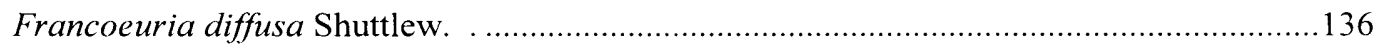

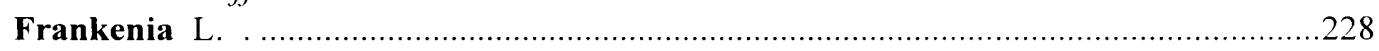

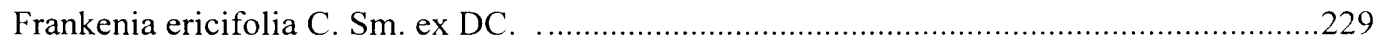

Frankenia ericifolia C. Sm. ex DC. ssp. caboverdeana Brochmann, Lobin \& Sunding ....230

Frankenia ericifolia C. Sm. ex DC. ssp. ericifolia ................................................229

Frankenia ericifolia C. Sm. ex DC. ssp. latifolia (Webb \& Berth.) Brochmann, Lobin \&

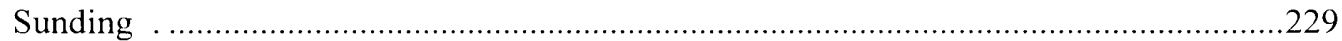

Frankenia ericifolia C. Sm. ex DC. ssp. montana Brochmann, Lobin \& Sunding ...........234

Frankenia ericifolia C. Sm. ex DC. var. latifolia sensu auct. ................................2230

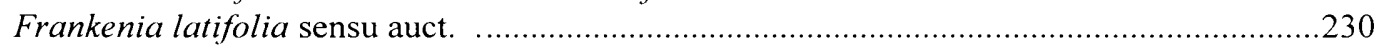

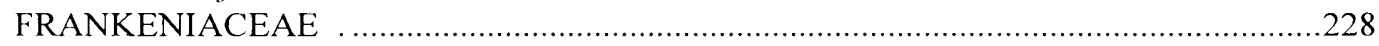

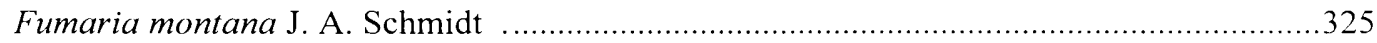

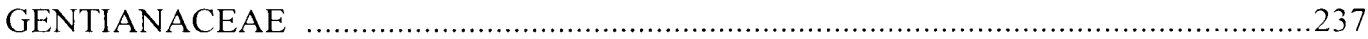

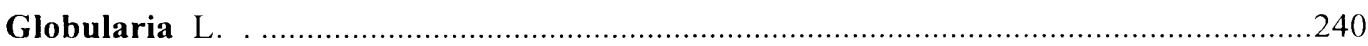

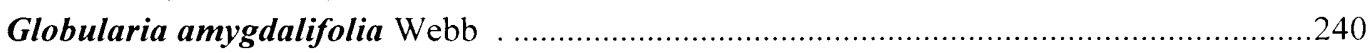

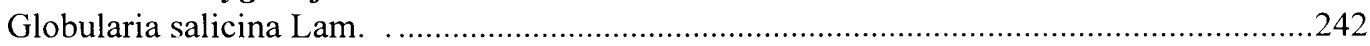

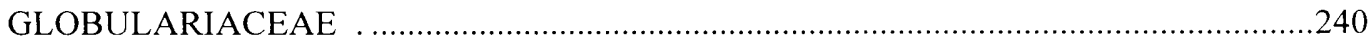

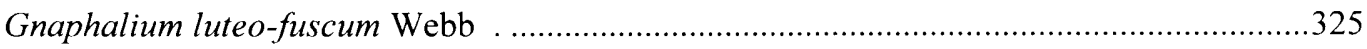

Gossypium anomalum Wawra ex Wawra \& Peyr. ssp. senarense (Wawra \& Peyr.)

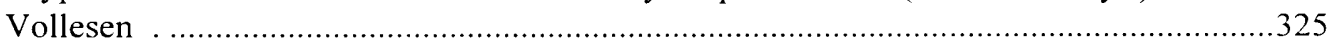

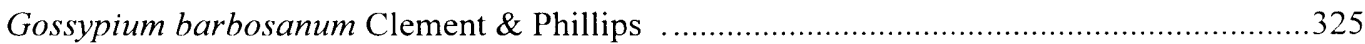

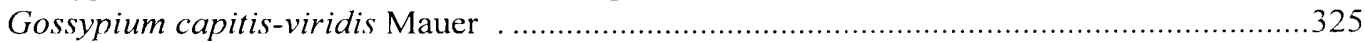

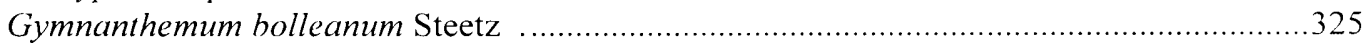

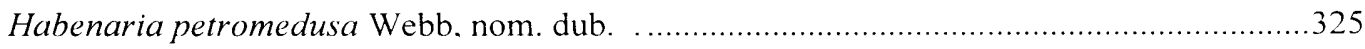

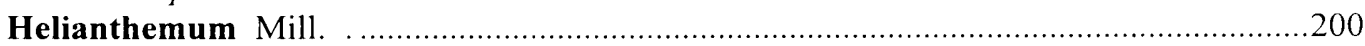

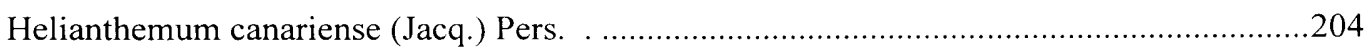

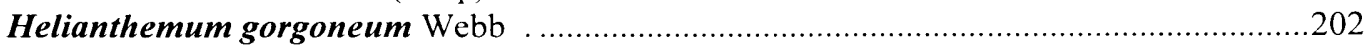

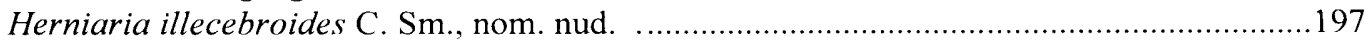




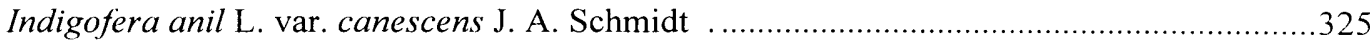

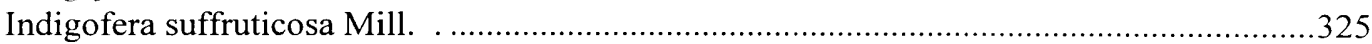

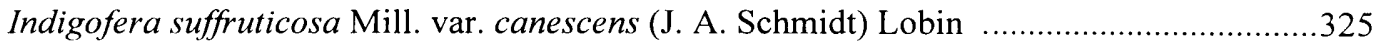

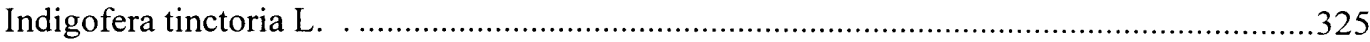

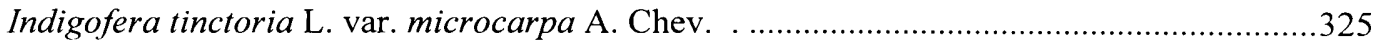

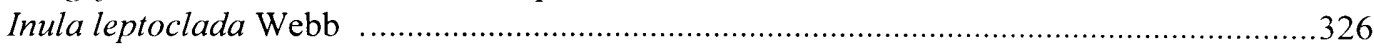

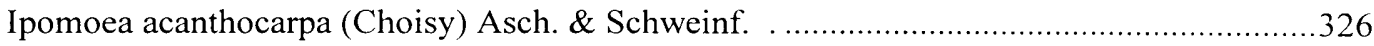

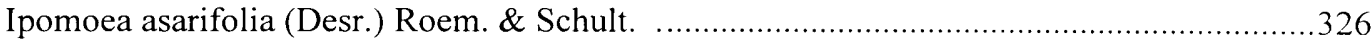

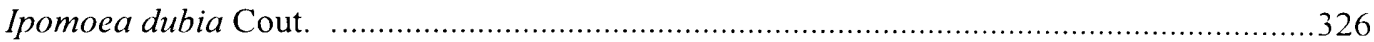

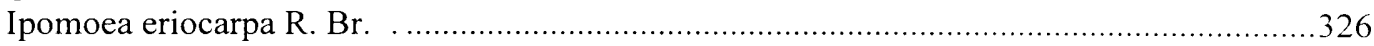

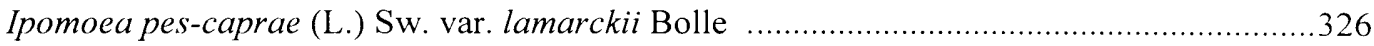

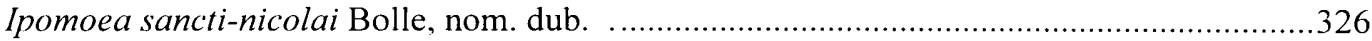

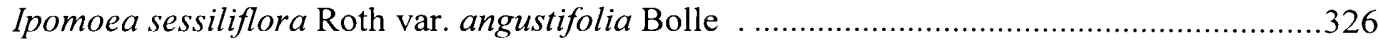

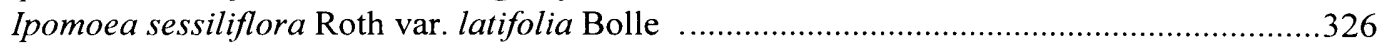

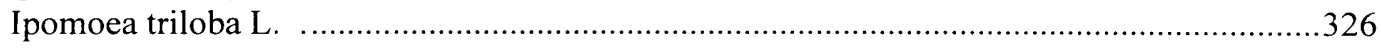

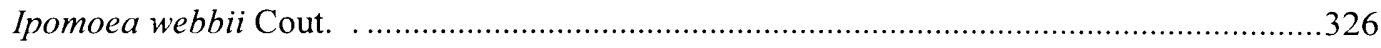

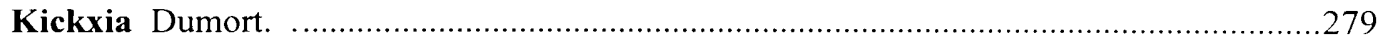

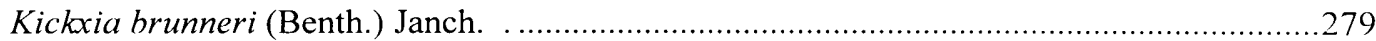

Kickxia brunneri (Benth.) Janch. ssp. dichondrifolia (Benth.) Rustan \& Brochmann .........284

Kickxia brunneri (Benth.) Janch. ssp. webbiana (Sunding) Rustan \& Brochmann .............286

Kickxia brunneri (Benth.) Janch. var. glaberrima (J. A. Schmidt) Sunding ......................280

Kickxia brunneri (Benth.) Janch. var. parietariifolia (Webb) A. Hansen \& Sunding .........280

Kickxia dichondrifolia (Benth.) Janch. ........................................................................28

Kickxia elegans (G. Forst.) D. A. Sutton ......................................................................2 279

Kickxia elegans (G. Forst.) D. A. Sutton ssp. dichondrifolia (Benth.) Rustan

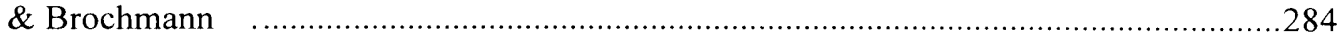

Kickxia elegans (G. Forst.) D. A. Sutton ssp. elegans ..................................................280

Kickxia elegans (G. Forst.) D. A. Sutton ssp. webbiana (Sunding) Rustan

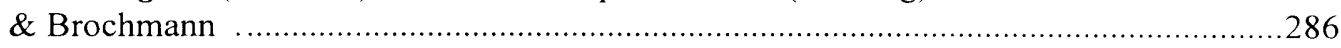

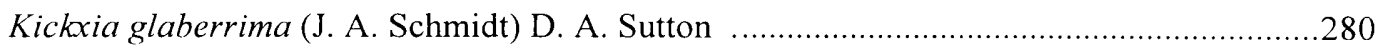

Kickxia schmidtii A. Hansen \& Sunding, nom. illeg. ............................................286

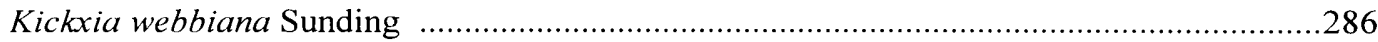

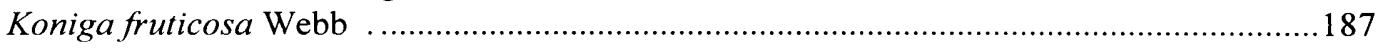

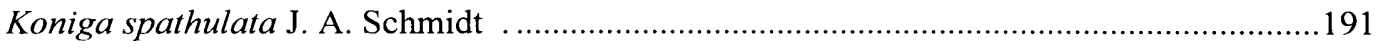

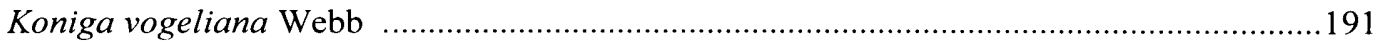

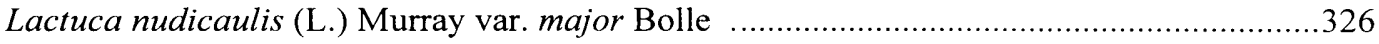

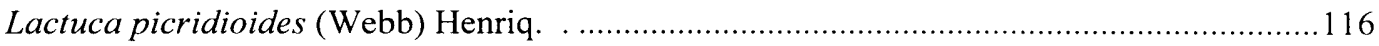

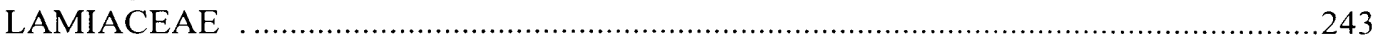

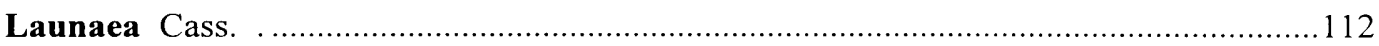

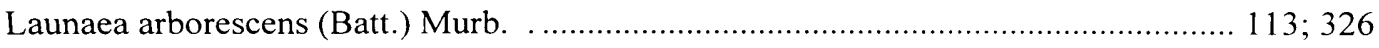

Launaea gorgadensis (Bolle) N. Kilian .......................................................... 113

Launaea intybacea (Jacq.) P. Beauv. ............................................................ 113; 326

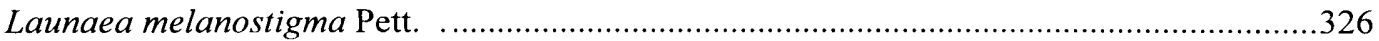




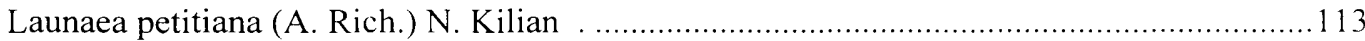

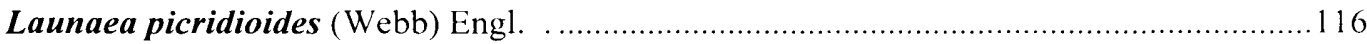

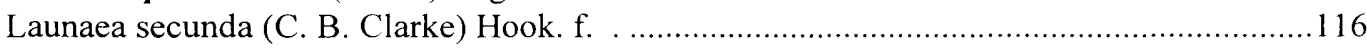

Launaea taraxacifolia (Willd.) Amin ex C. Jeffrey ..................................................119

Launaea thalassica N. Kilian, Brochmann \& Rustan .........................................................119

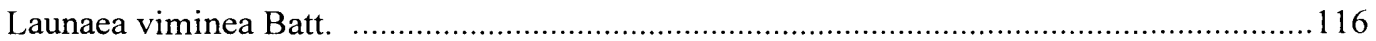

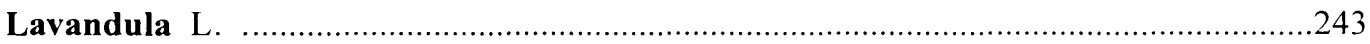

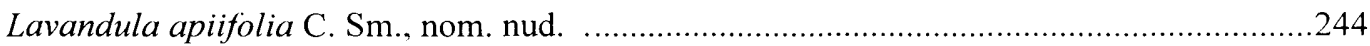

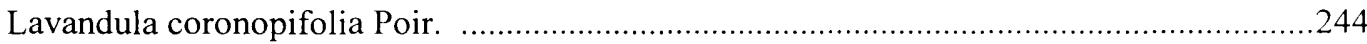

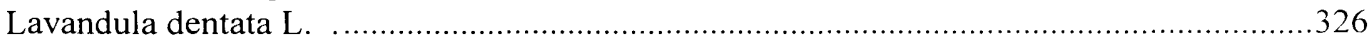

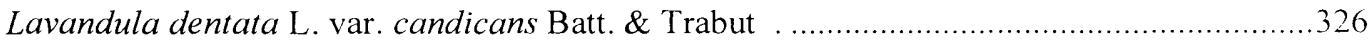

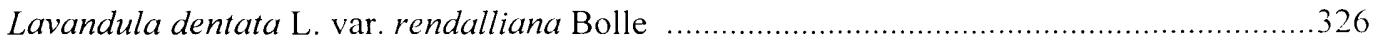

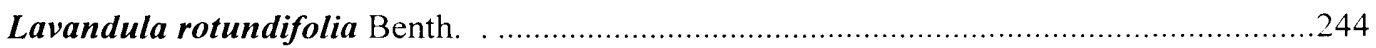

Lavandula rotundifolia Benth. var. crenata Lowe ex Chaytor, nom. inval. .....................244

Lavandula rotundifolia Benth. var. crenata Lowe ex Sunding \& M. C. León Arenciba ......244

Lavandula rotundifolia Benth. var. incisa Bolle . .......................................................24

Lavandula rotundifolia Benth. var. subpinnatifida Lowe ex A. Chev. . ...........................244

Lavandula rotundifolia Benth. var. subpinnatifida Lowe ex Chaytor, nom. inval. ............244

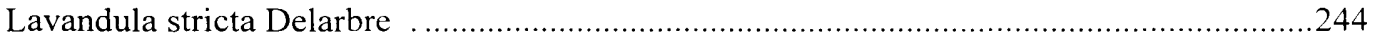

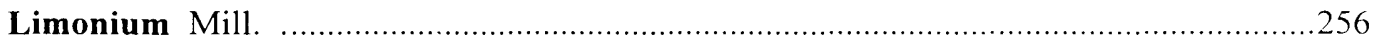

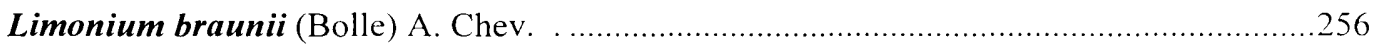

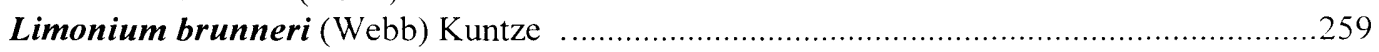

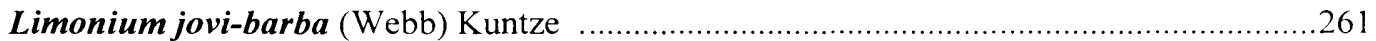

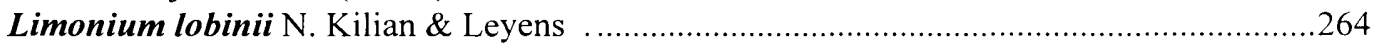

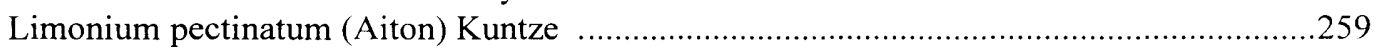

Limonium sundingii Leyens, Lobin, N. Kilian \& Erben ...........................................26

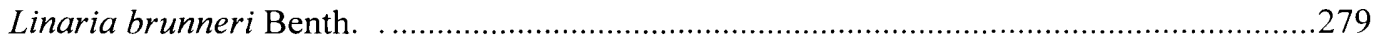

Linaria brunneri Benth. var. glaberrima J. A. Schmidt ..................................................28

Linaria brunneri Benth. var. parietariifolia Webb ........................................................28

Linaria brunneri Benth. var. vera Webb, nom. illeg. ...............................................279

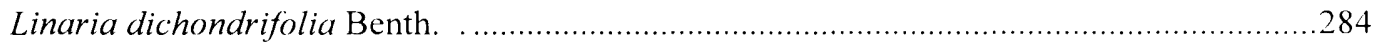

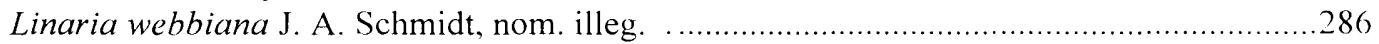

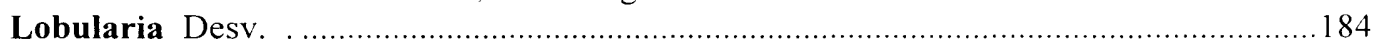

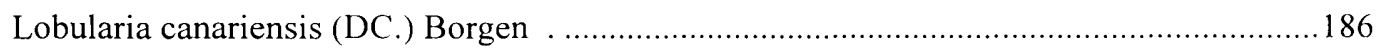

Lobularia canariensis (DC.) Borgen ssp. fruticosa (Webb) Borgen ..................................187

Lobularia canariensis (DC.) Borgen ssp. spathulata (J. A. Schmidt) Borgen ..................191

Lobularia intermedia Webb ssp. spathulata (J. A. Schmidt) Pett. ....................................191

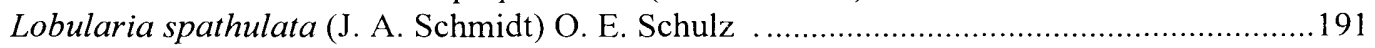

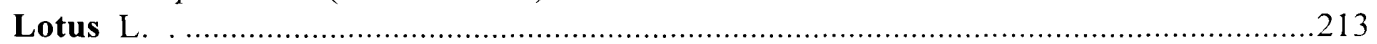

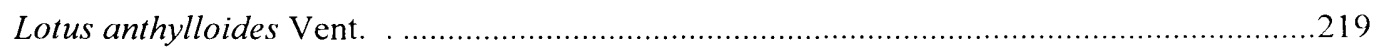

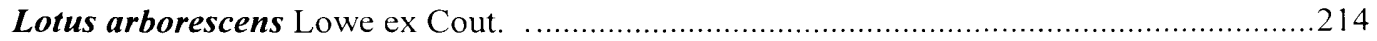

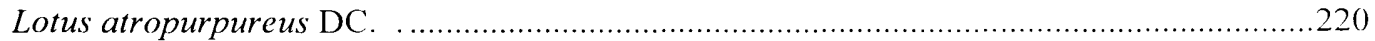

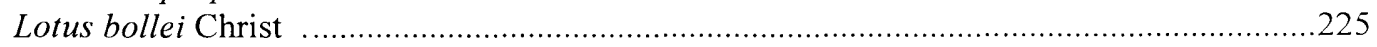

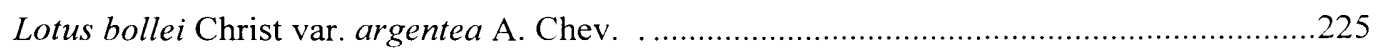

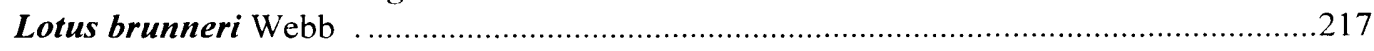

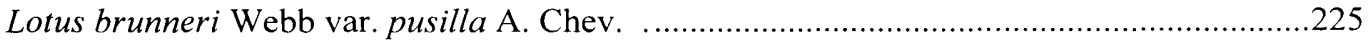




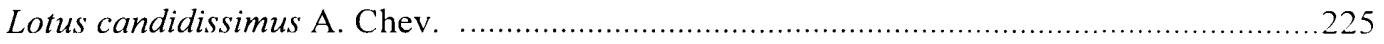

Lotus coronillaefolius Webb var. argenteus (A. Chev.) Sunding ................................225

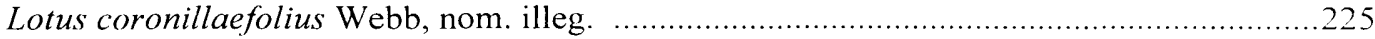

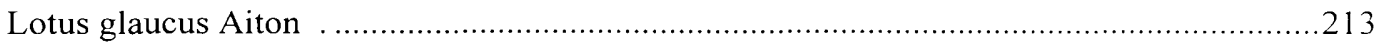

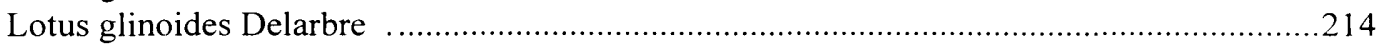

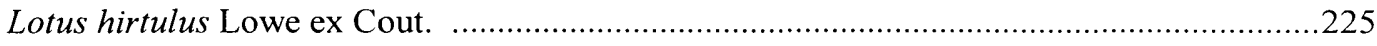

Lotus hirtulus Lowe ex Cout. var. laxifolius Lowe ex Cout. ..........................................225

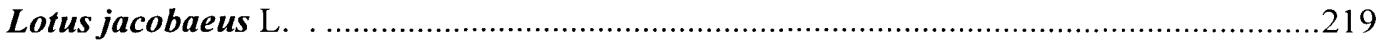

Lotus jacobaeus L. var. flaviflorus Brunner, nom. nud. . ............................................217

Lotus jacobaeus L. var. luteus A. Chev. ..................................................................219

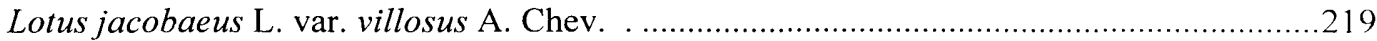

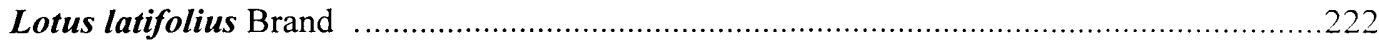

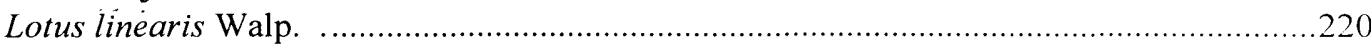

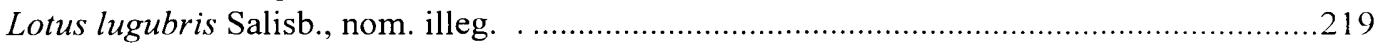

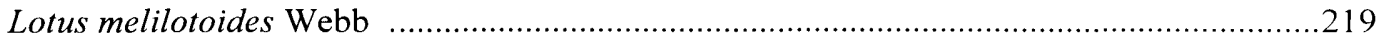

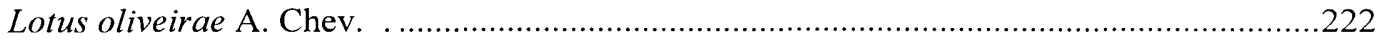

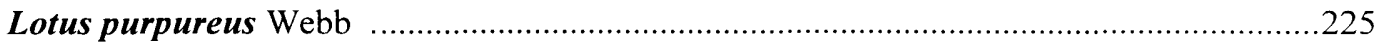

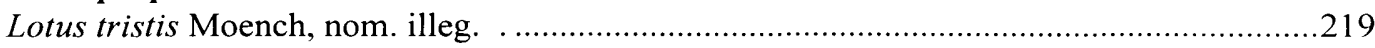

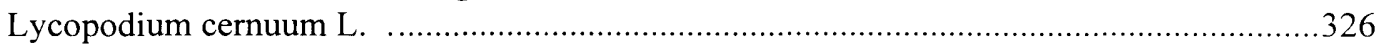

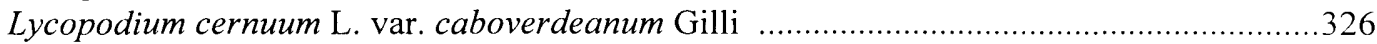

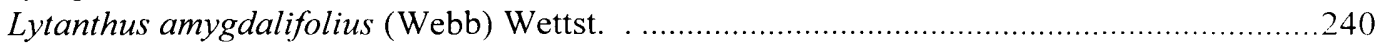

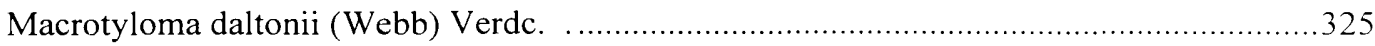

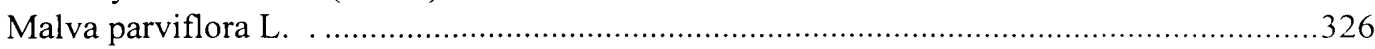

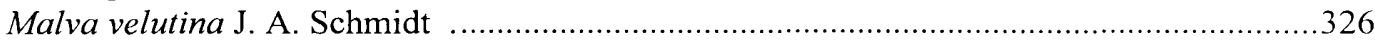

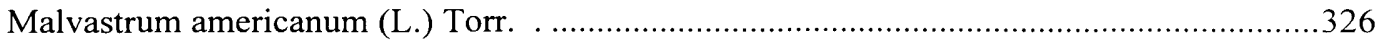

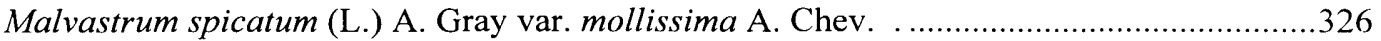

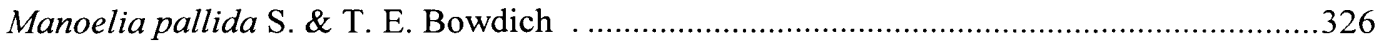

Matthiola caboverdeana A. Chev. ............................................................................ 184

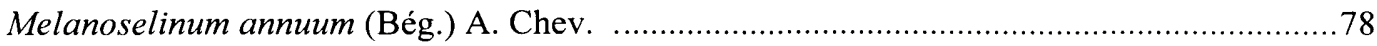

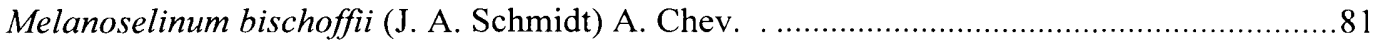

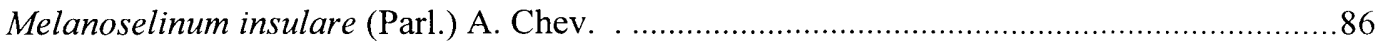

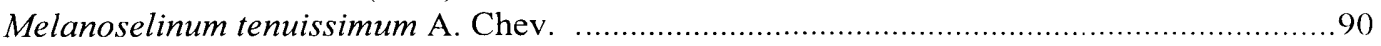

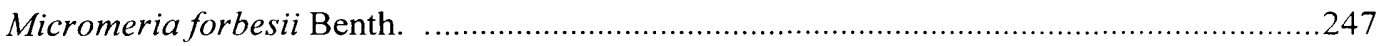

Micromeria forbesii Benth. var. altitudinum Bolle .................................................24

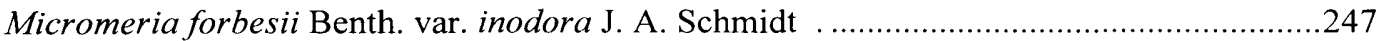

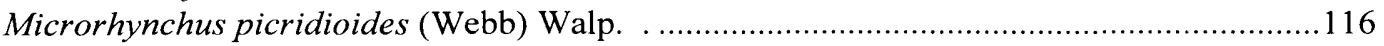

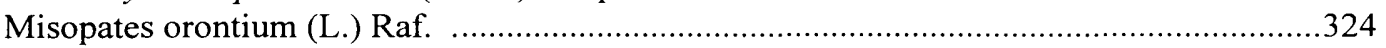

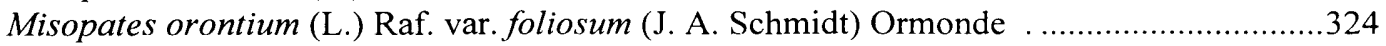

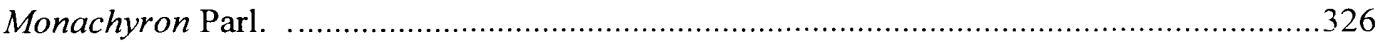

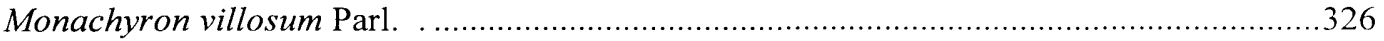

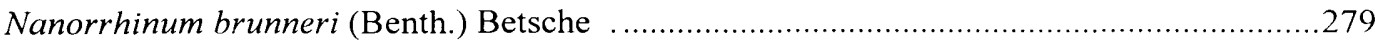

Nanorrhinum dichondrifolium (Benth.) Betsche ....................................................284

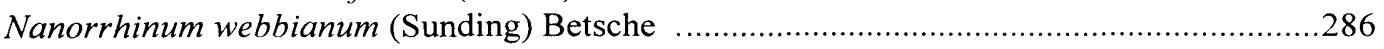

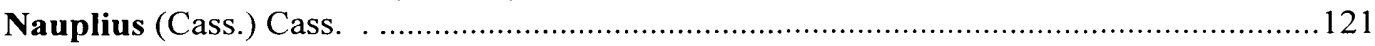




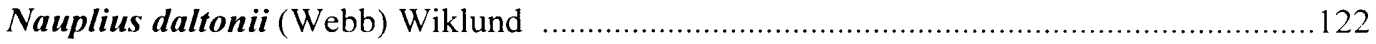

Nauplius daltonii (Webb) Wiklund ssp. daltonii .............................................. 122

Nauplius daltonii (Webb) Wiklund ssp. vogelii (Webb) Wiklund . ................................ 125

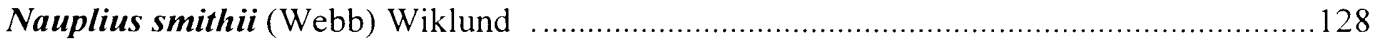

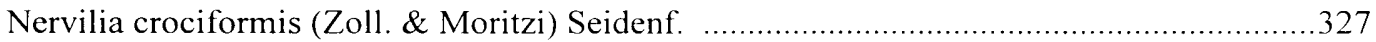

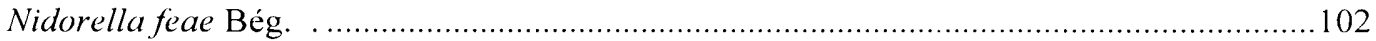

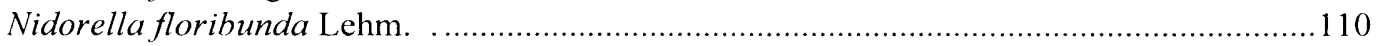

Nidorella forbesii Lowe ex Cout. ................................................................................. 110

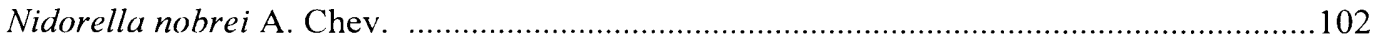

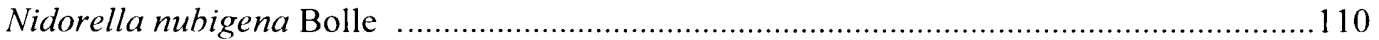

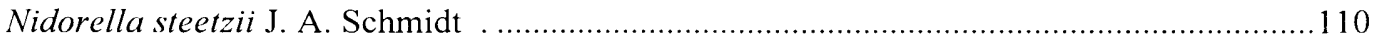

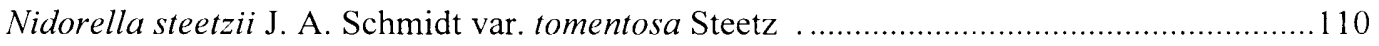

Nidorella varia (Webb) J. A. Schmidt ...........................................................110

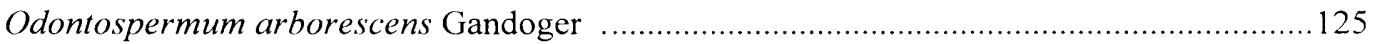

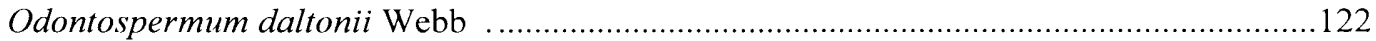

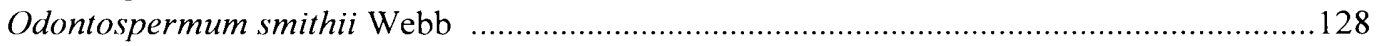

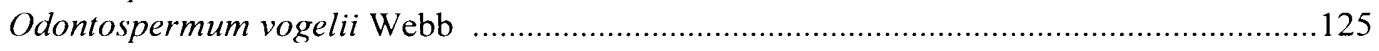

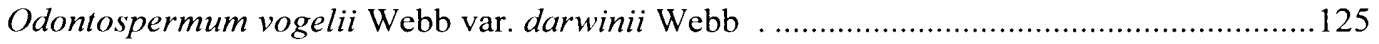

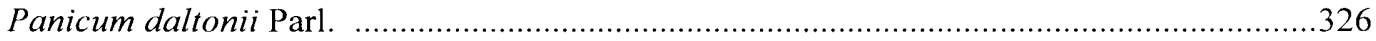

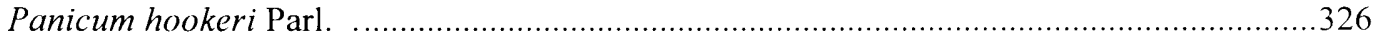

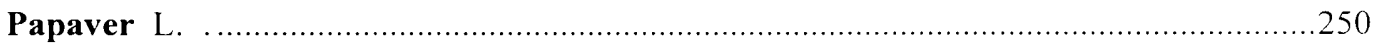

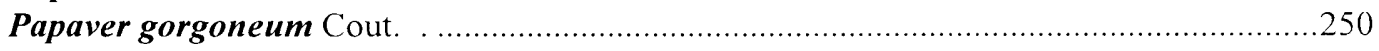

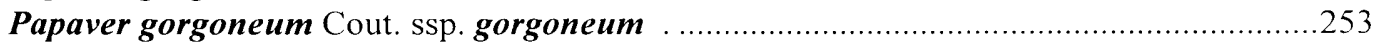

Papaver gorgoneum Cout. ssp. theresias Kadereit \& Lobin ......................................25

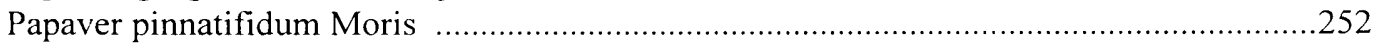

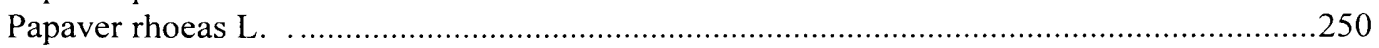

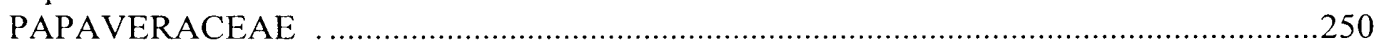

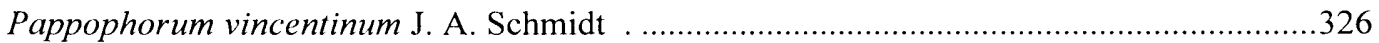

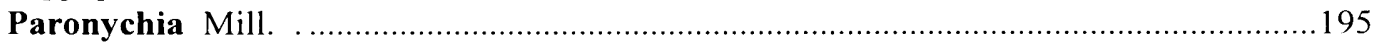

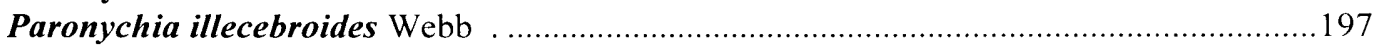

Paronychia illecebroides Webb var. nicolauensis Chaudhri ......................................... 197

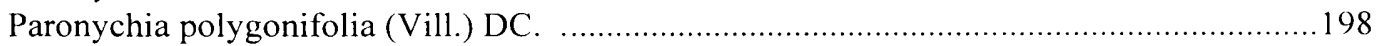

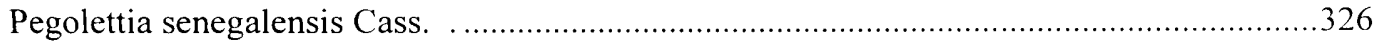

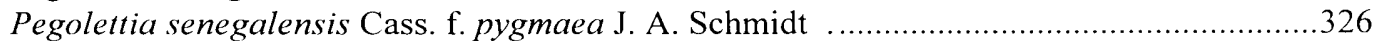

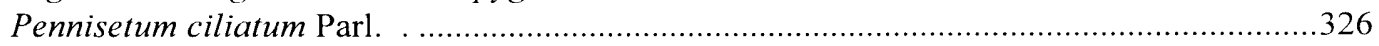

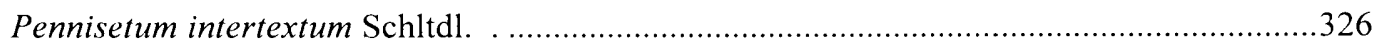

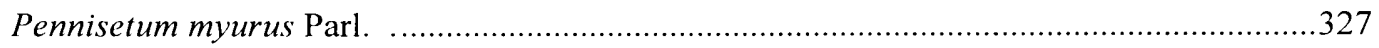

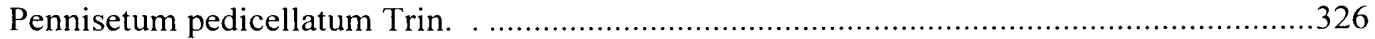

Pennisetum polystachion (L.) Schult. ........................................................... 326; 327

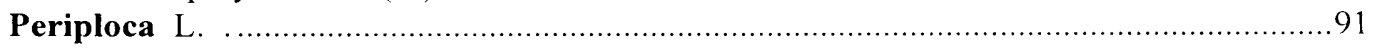

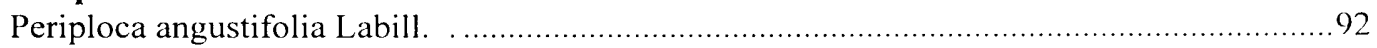

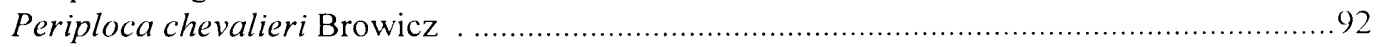

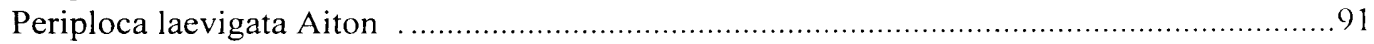

Periploca laevigata Aiton ssp. angustifolia (Labill.) Markgraf ....................................... 92 
Periploca laevigata Aiton ssp. chevalieri (Browicz) G. Kunkel ..................................992

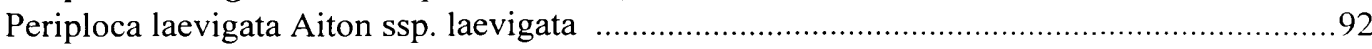

Periploca somaliensis Browicz . .

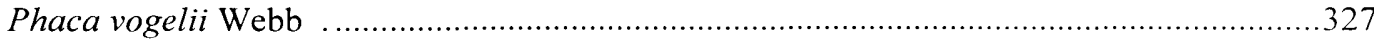

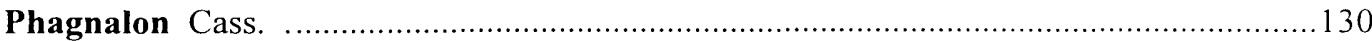

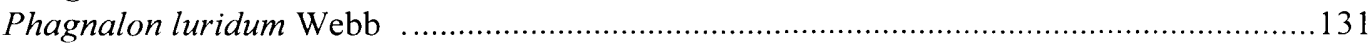

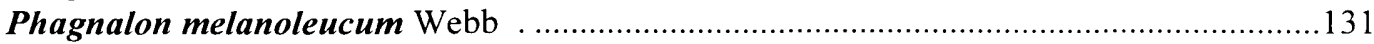

Phagnalon melanoleucum Webb var. luridum (Webb) A. Chev. ...................................131

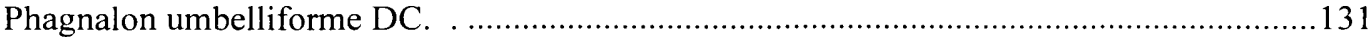

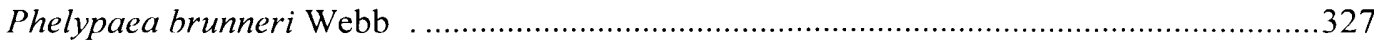

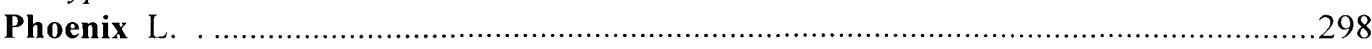

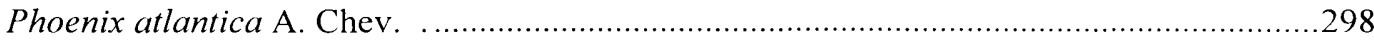

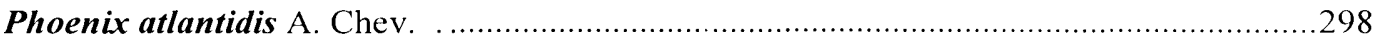

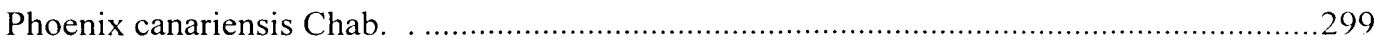

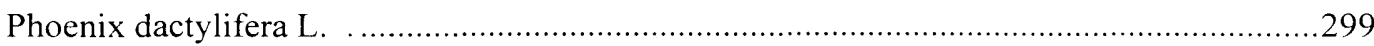

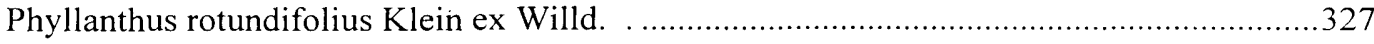

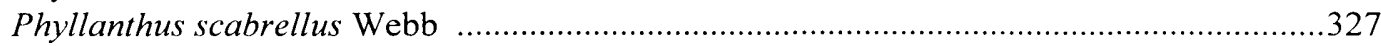

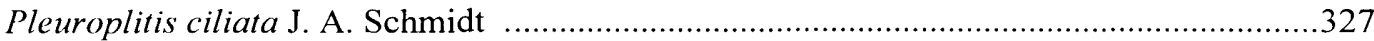

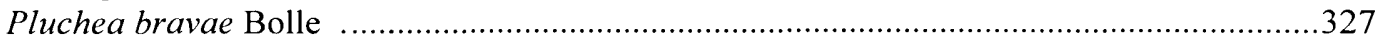

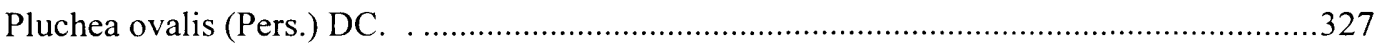

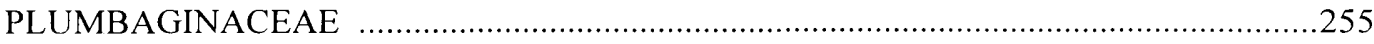

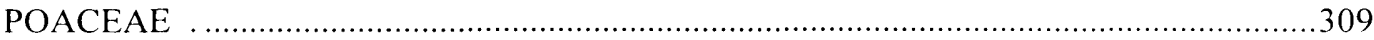

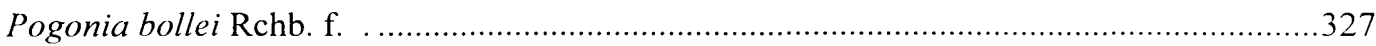

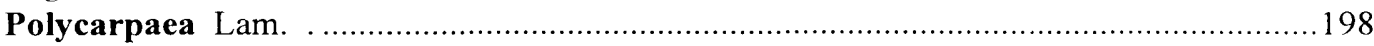

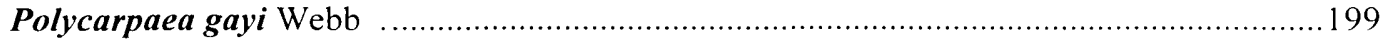

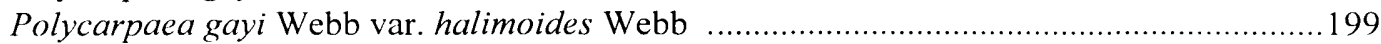

Polycarpaea gayi Webb var. helichrysoides Webb .......................................................199

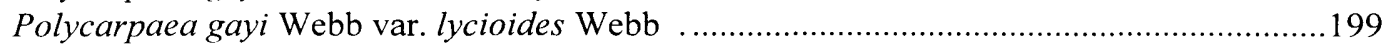

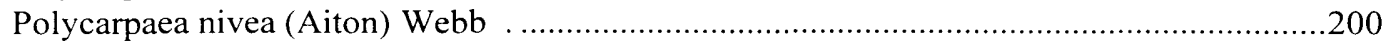

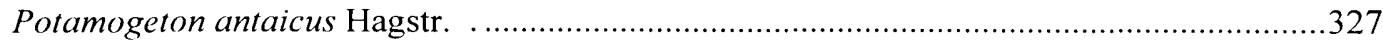

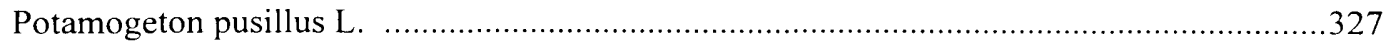

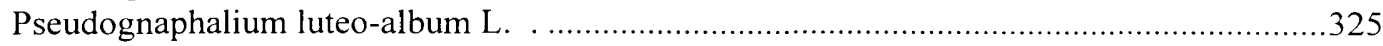

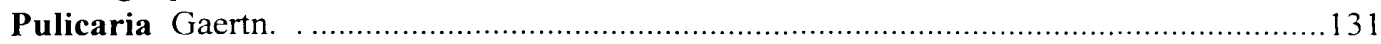

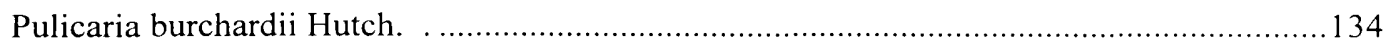

Pulicaria burchardii Hutch. ssp. Iongifolia Gamal-Eldin . .......................................... 134

Pulicaria crispa (Forssk.) Benth. ex Oliv. ....................................................................... 136

Pulicaria crispa (Forssk.) Benth. ex Oliv. ssp. argyrophylla Gamal-Eldin ........................136

Pulicaria crispa (Forssk.) Benth. ex Oliv. ssp. fogensis Gamal-Eldin ..............................136

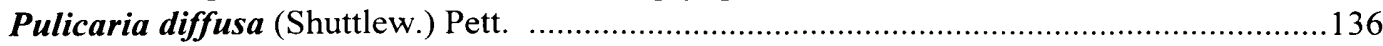

Pulicaria undulata L. .......................................................................................... 136

Pulicaria undulata L. ssp. fogensis (Gamal-Eldin) A. Hansen \& Sunding ........................136

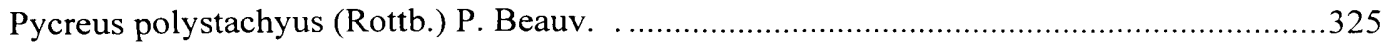

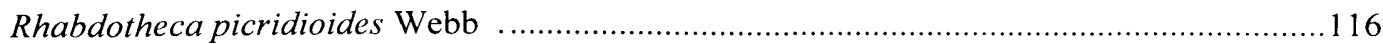

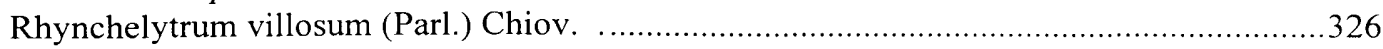




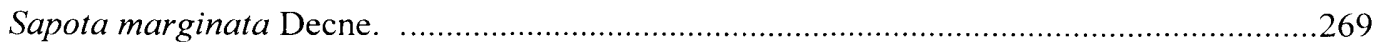

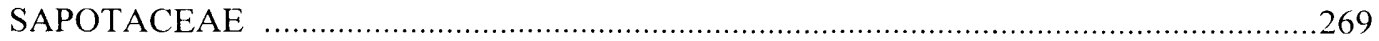

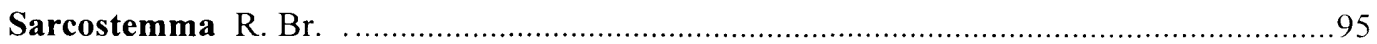

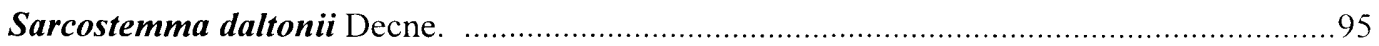

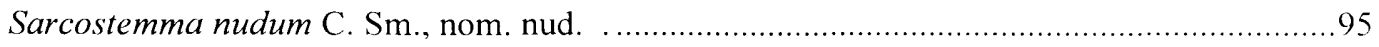

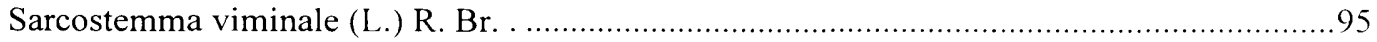

Sarcostemma viminale (L.) R. Br. ssp. thunbergii (Don) Liede \& Meve …………..............95

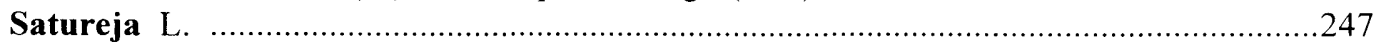

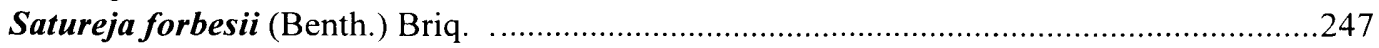

Satureja forbesii (Benth.) Briq. var. altitudinum (Bolle) R. H. Willemse …………...........247

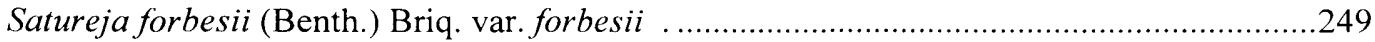

Satureja forbesii (Benth.) Briq. var. inodora (J. A. Schmidt) R. H. Willemse ..................2247

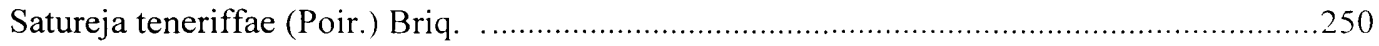

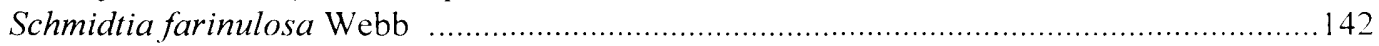

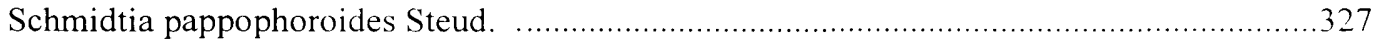

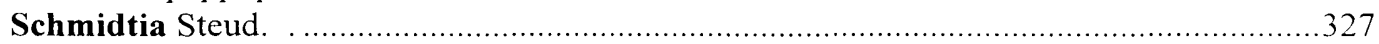

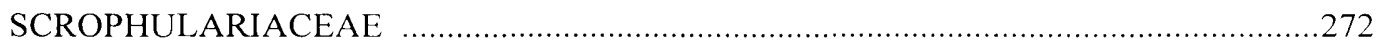

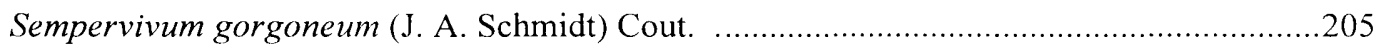

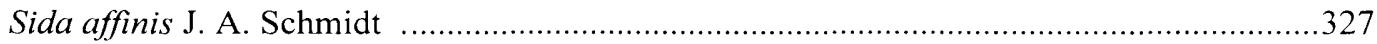

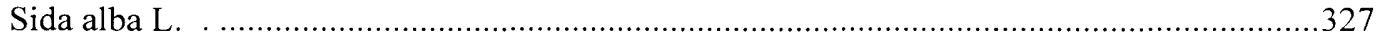

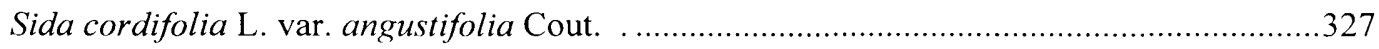

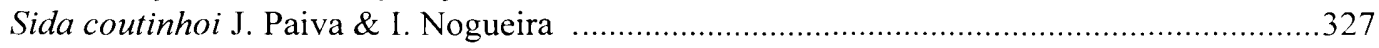

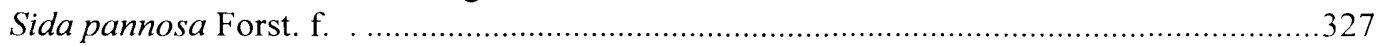

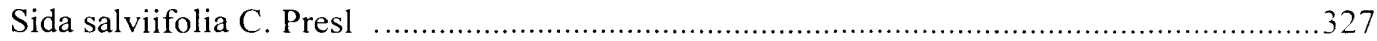

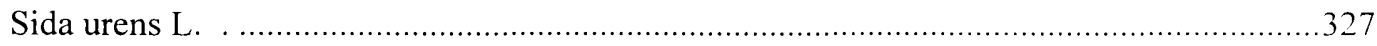

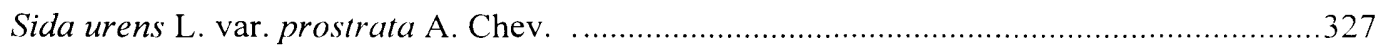

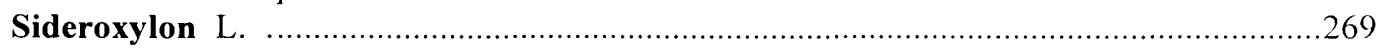

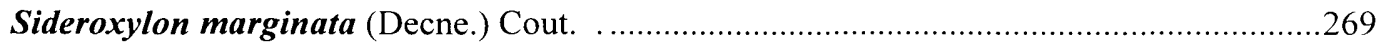

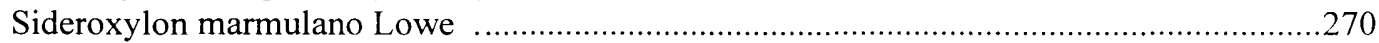

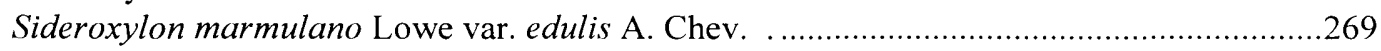

Sideroxylon marmulano Lowe var. marginata (Decne.) A. Chev. ......................................269

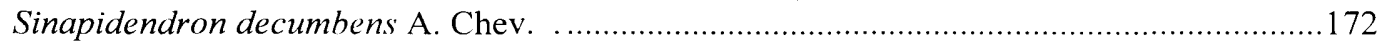

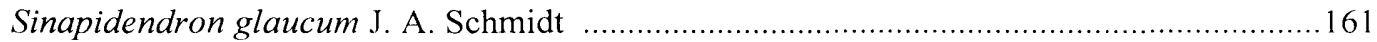

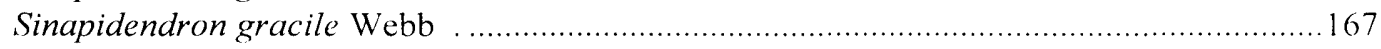

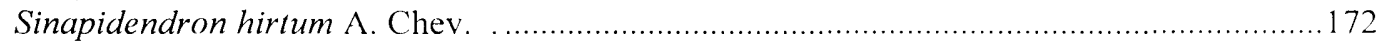

Sinapidendron hirtum A. Chev. var. paucipilosum A. Chev. …………............................172

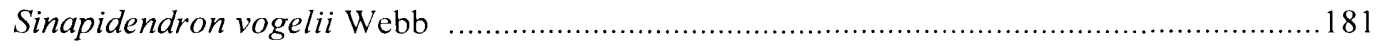

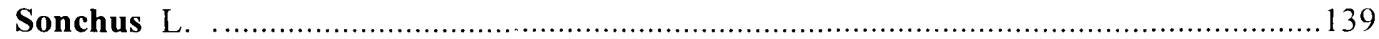

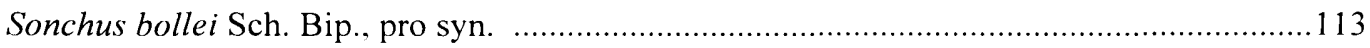

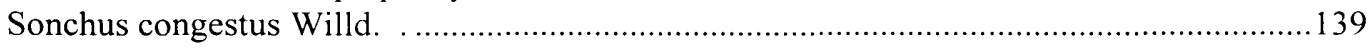

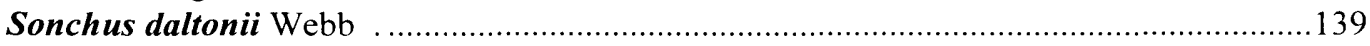

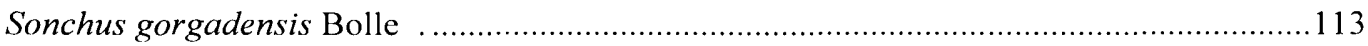

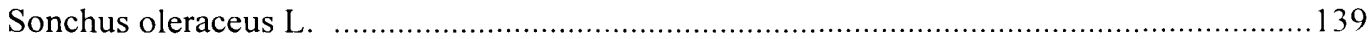

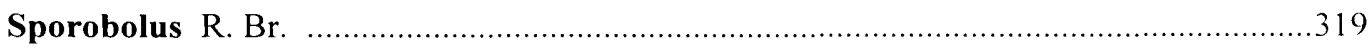

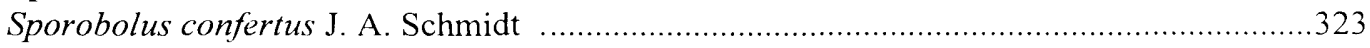

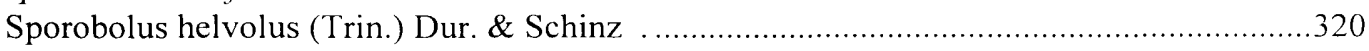


Sporobolus insulanus Parl. 327

Sporobolus minutus Link

Sporobolus minutus Link ssp. confertus (J. A. Schmidt) Lobin, N. Kilian \& Leyens ........323

Sporobolus minutus Link ssp. minutus

Sporobolus molleri Hack.

Sporobolus piliferus (Trin.) Kunth

Sporobolus robustus Kunth

Sporobolus spicatus (Vahl) Kunth

320

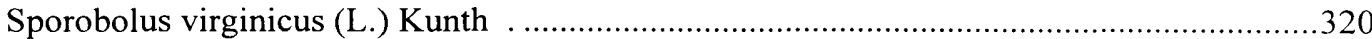

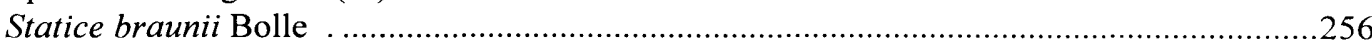

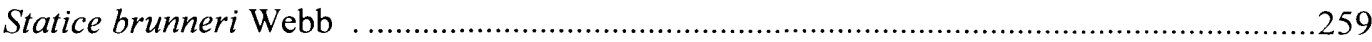

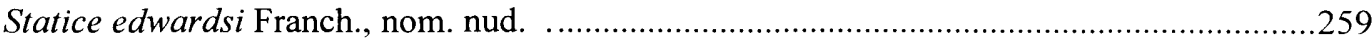

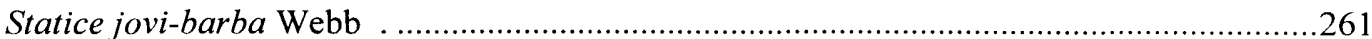

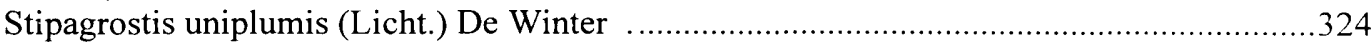

Stoechas rotundifolia (Benth.) Rchb. f. .......................................................................244

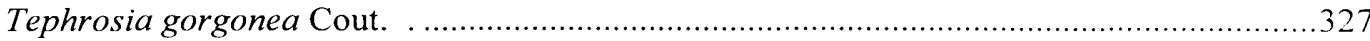

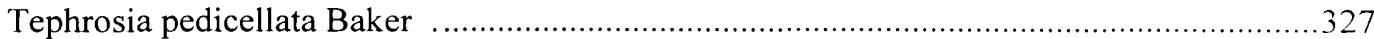

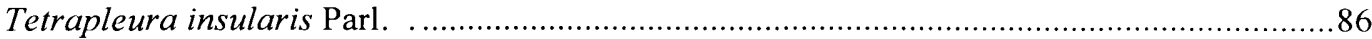

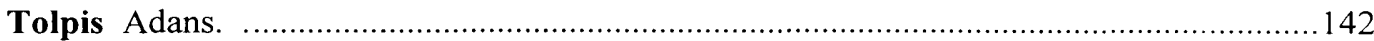

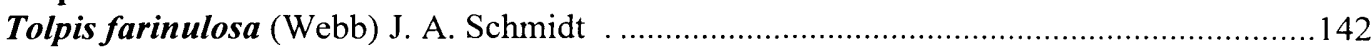

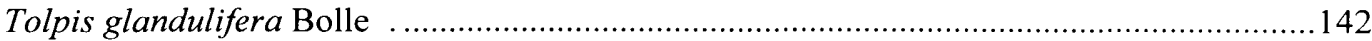

Tolpis laciniata (Sch. Bip. ex Webb \& Berth.) Webb ..................................................142

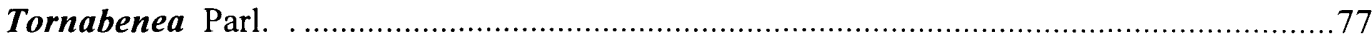

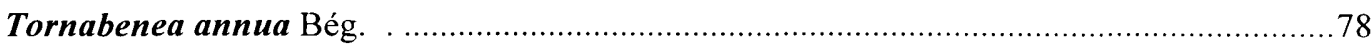

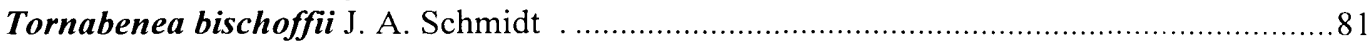

Tornabenea depressa I. Gomes, S. Gomes, M. T. Vera Cruz, N. Kilian, Leyens \& Lobin,

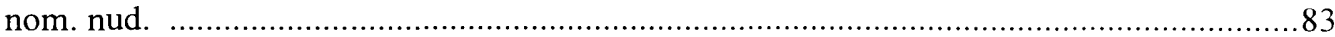

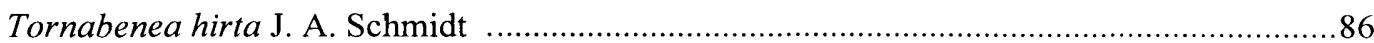

Tornabenea humilis Lobin \& K. H. Schmidt .............................................................. 83

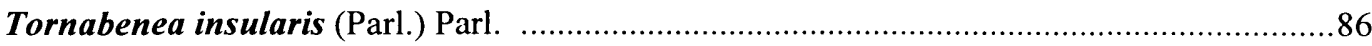

Tornabenea tenuissima (A. Chev.) A. Hansen \& Sunding ...............................................99

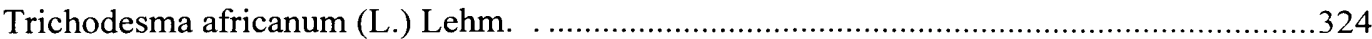

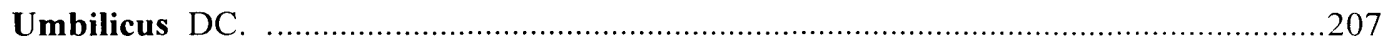

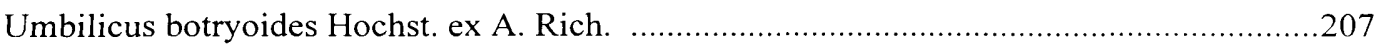

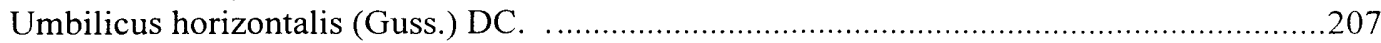

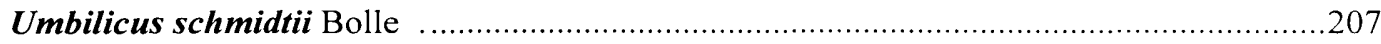

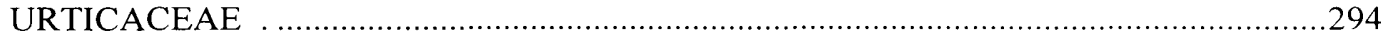

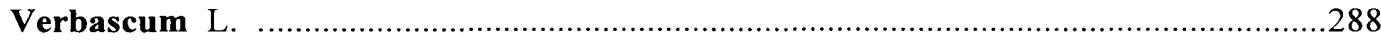

Verbascum ballii (Batt.) Hub.-Mor. ...........................................................................291

Verbascum battandieri (Murb.) Hub.-Mor. .....................................................................291

Verbascum caboverdeanum Sunding, nom. inval. ....................................................28

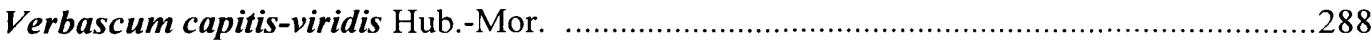

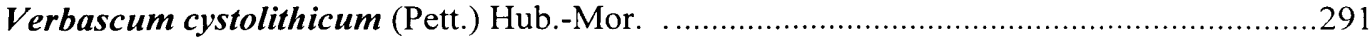


Verbascum longirostre (Murb.) Hub.-Mor.

Verbascum sundingii Lobin \& Porembski, nom. nud. ..............................................291

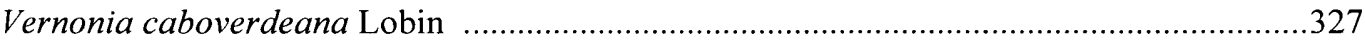

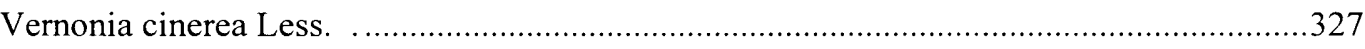

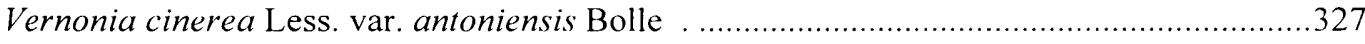

Vernonia colorata (Willd.) Drake .......................................................... 325; 327

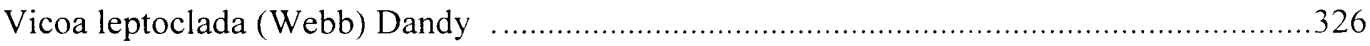

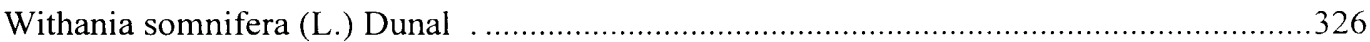




\section{SOMMERFELTIA AND SOMMERFELTIA SUPPLEMENT}

Vol. 1. A. Hansen \& P. Sunding: Flora of Macaronesia. Checklist of vascular plants. 3. revised edition. 167 pp. NOK 140. (Jan. 1985; out of stock).

Vol. 2. R.H. Økland \& E. Bendiksen: The vegetation of the forest-alpine transition in Grunningsdalen, S. Norway. 224 pp. NOK 17(). (Nov. 1985).

Vol. 3. T. Halvorsen \& L. Borgen: The perennial Macaronesian species of Bubonium (Compositae-Inuleae). 103 pp. NOK 90. (Feb. 1986).

Vol. 4. H.B. Gjærum \& P. Sunding: Flora of Macaronesia. Checklist of rust fungi (Uredinales). 42 pp. NOK 50. (Dec. 1986).

Vol. 5. J. Middelborg \& J. Mattsson: Crustaceous lichenized species of the Caliciales in Norway. 71 pp. NOK 70). (May 1987).

Vol. 6. L.N. Derrick, A.C. Jermy \& A.C. Paul: Checklist of European Pteridophytes. $x x+94$ pp. NOK 95. (Jun. 1987).

Vol. 7. L. Malme: Distribution of bryophytes on Fuerteventura and Lanzarote, the Canary Islands. 54 pp. NOK 60. (Mar. 1988).

Vol. 8. R.H. Økland: A phytoecological study of the mire Northern Kisselbergmosen, SE. Norway. I. Introduction, flora, vegetation, and ecological conditions. 172 pp. NOK 140. (Oct. 1989).

Vol. 9. G. Mathiassen: Some corticolous and lignicolous Pyrenomycetes s. lat. (Ascomycetes) on Salix in Troms, N Norway. 100 pp. NOK 85. (Oct. 1989).

Vol. 10. T. Økland: Vegetational and ecological monitoring of boreal forests in Norway. I. Rausjømarka in Akershus county, SE Norway. 52 pp. NOK 55. (June 1990).

Vol. 11. R.H. Økland (ed.): Evolution in higher plants: patterns and processes. Papers and posters presented on a symposium arranged on occasion of the 175th anniversary of the Botanical Garden in Oslo, June 5-8, 1989. 183 pp. NOK 150). (Dec. 1990).

Vol. 12. O. Eilertsen: Vegetation patterns and structuring processes in coastal shell-beds at Akerøya, Hvaler, SE Norway. 90 pp. NOK 85. (June 1991).

Vol. 13. G. Gulden \& E.W. Hanssen: Distribution and ecology of stipitate hydnaceous fungi in Norway, with special reference to the question of decline. 58 pp. NOK 110. (Feb. 1992).

Vol. 14. T. Tønsberg: The sorediate and isidiate, corticolous, crustose lichens in Norway. 300 pp. NOK 330. (May 1992). 
Vol. 15. J. Holtan-Hartwig: The lichen genus Peltigera, exclusive of the $P$. canina group, in Norway. 77 pp. NOK 90. (March 1993).

Vol. 16. R.H. Økland \& O. Eilertsen: Vegetation-environment relationships of boreal coniferous forests in the Solhomfjell area, Gjerstad, S Norway. 254 pp. NOK 170. (March 1993).

Vol. 17. A. Hansen \& P. Sunding: Flora of Macaronesia. Checklist of vascular plants. 4. revised edition. 295 pp. NOK 250. (May 1993).

Vol. 18. J.F. Ardévol Gonzáles, L. Borgen \& P.L. Péres de Paz: Checklist of chromosome numbers counted in Canarian vascular plants. 59 pp. NOK 80. (Sept. 1993).

Vol. 19. E. Bendiksen, K. Bendiksen \& T.E. Brandrud: Cortinarius subgenus Myxacium section Colliniti (Agaricales) in Fennoscandia, with special emphasis on the Arctic-alpine zones. 37 pp. NOK 5. (Nov. 1993).

Vol. 20. G. Mathiassen: Corticolous and lignicolous Pyrenomycetes s.lat. (Ascomycetes) on Salix along a mid-Scandinavian transect. 180 pp. NOK 180. (Nov. 1993).

Vol. 21. K. Rydgren: Low-alpine vegetation in Gutulia National Park, Engerdal, Hedmark, Norway, and its relation to the environment. 47 pp. NOK 65. (May 1994).

Vol. 22. T. Økland: Vegetation-environment relationships of boreal spruce forests in ten monitoring reference areas in Norway. 349 pp. NOK 230. (May 1996).

Vol. 23. T. Tønsberg, Y. Gauslaa, R. Haugan, H. Holien \& E. Timdal: The threatened macrolichens of Norway - 1995. 258 pp. NOK 220. (June 1996).

Vol. 24. C. Brochmann, Ø.H. Rustan, W. Lobin \& N. Kilian: The endemic vascular plants of the Cape Verde islands, W Africa. 356 pp. NOK 230. (Dec. 1997). 
Supplement Vol. 1. R.H. Økland: Vegetation ecology: theory, methods and applications with reference to Fennoscandia. 233 pp. NOK 180. (Mar. 1990).

Supplement Vol. 2. R.H. Økland: Studies in SE Fennoscandian mires, with special regard to the use of multivariate techniques and the scaling of ecological gradients. (Dissertation summary). 22 pp. NOK 35. (Dec. 1990).

Supplement Vol. 3. G. Hestmark: To sex, or not to sex... Structures and strategies of reproduction in the family Umbilicariaceae (Lecanorales, Ascomycetes). (Dissertation summary). 47 pp. NOK 55. (Dec. 1991).

Supplement Vol. 4. C. Brochmann: Polyploid evolution in arctic-alpine Draba (Brassicaceae). 37 pp. NOK 60. (Nov. 1992).

Supplement Vol. 5. A. Hansen \& P. Sunding: Botanical bibliography of the Canary Islands. 116 pp. NOK 130. (May 1994).

Supplement Vol. 6. R.H. Økland: Boreal coniferous forest vegetation in the Solhomfjell area, $S$ Norway: structure, dynamics and change, with particular reference to effects of long distance airborne pollution. 33 pp. NOK 43. (May 1995).

Supplement Vol. 7. K. Rydgren: Fine-scale disturbance in an old-growth boreal forest patterns and processes. 25 pp. NOK 40. (May 1997). 

SOMMERFELTIA accepts scientific papers of 32 printed pages or more, in English. The abstract must not exceed 300 words. The author is responsible for ensuring that the English is linguistically correct.

Manuscripts to SOMMERFELTIA must not have been published or accepted for publication elsewhere.

Manuscripts are subjected to peer reviewing by at least two reviewers, before acceptance or rejection is decided.

Authors of planned contributions to SOMMERFELTIA are recommended to contact the editor early in the writing process: manuscripts should, as far as possible, be prepared by the author to fit the layout of the series. Relevant WordPerfect codes on a discette, as well as further instructions, are obtained from the editor. The manuscript should be submitted in three copies; a discette copy will be asked for after acceptance.

Figures (incl. line drawings) should preferably be $16.0 \mathrm{~cm}$ broad and not higher than $23.6 \mathrm{~cm}$ the type area. They are reduced to $87 \%$ during the printing process. Narrower and broader figures may be accepted. Legends to figures should be included as a separate file. Tables (including headings) should be enclosed as separate WordPerfect files, using tabulator stops for vertical alignment of columns. One open line should be left between the table heading and the table proper. Tables placed at right angles to normal text should be $23.6 \mathrm{~cm}$ broad and not more than $16.0 \mathrm{~cm}$ high. Tables divided on more pages can be accepted; on the second and later pages the table heading should be Tab. x (continued).

Figures and tables should be numbered separately and consecutively with Arabic numerals. Black and white photographs can be accepted after agreement with the editor. Coloured illustrations are normally accepted only when paid for by the author. Taxonomic keys should have right margins and be based on dichotomies. References should be written according to current practice in SOMMERFELTIA. SOMMERFELTIA prefers abbreviations of titles in accordance with the World List of Scientific Periodicals. Recent issues of SOMMERFELTIA should be consulted for details of layout.

An author is supplied with ten copies free of charge. When there are more than one author, each receives eight copies free of charge. Additional copies may be ordered at subscription cost. 